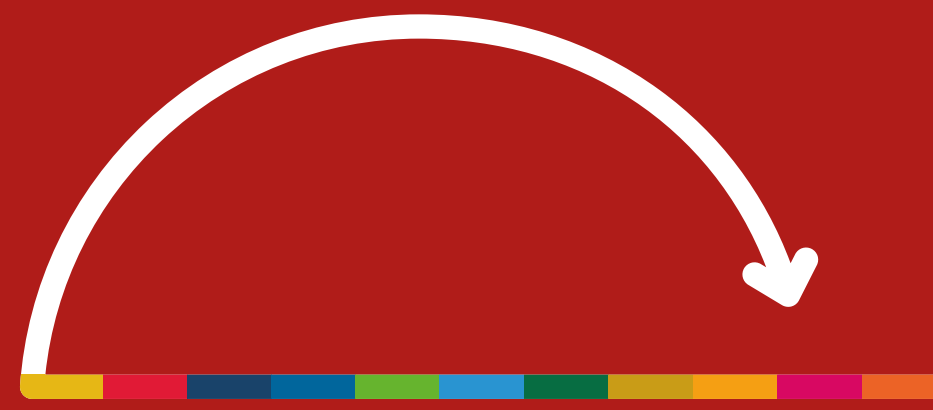

\title{
La ineficiencia \\ de la desigualdad
}
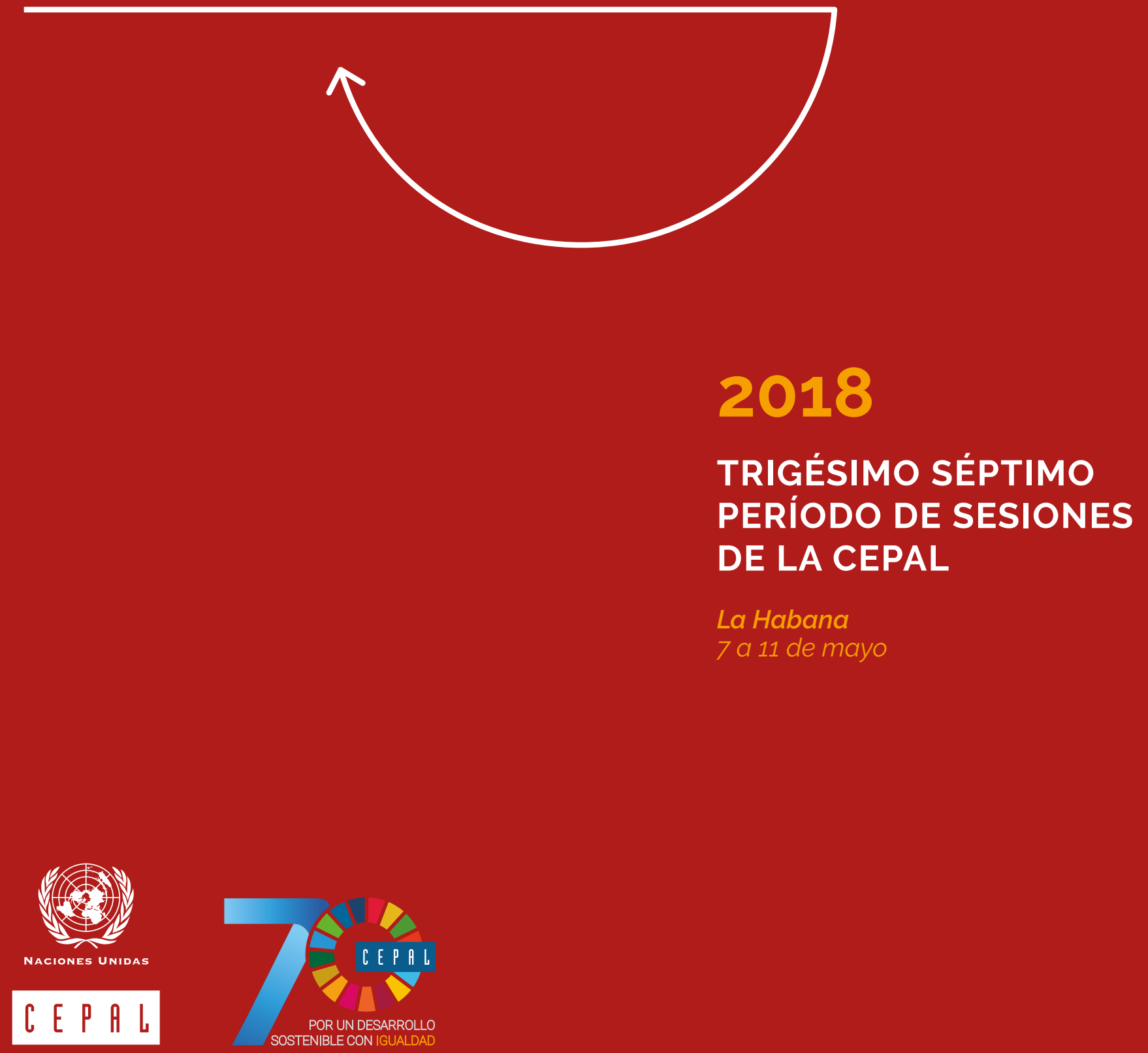


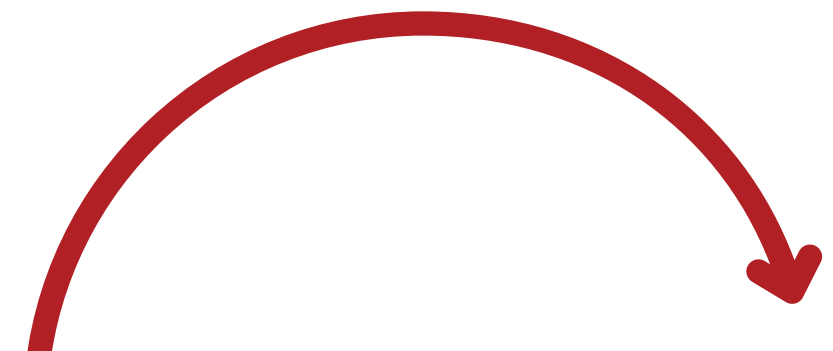

\section{La îneficiencia \\ de la desigualdad}

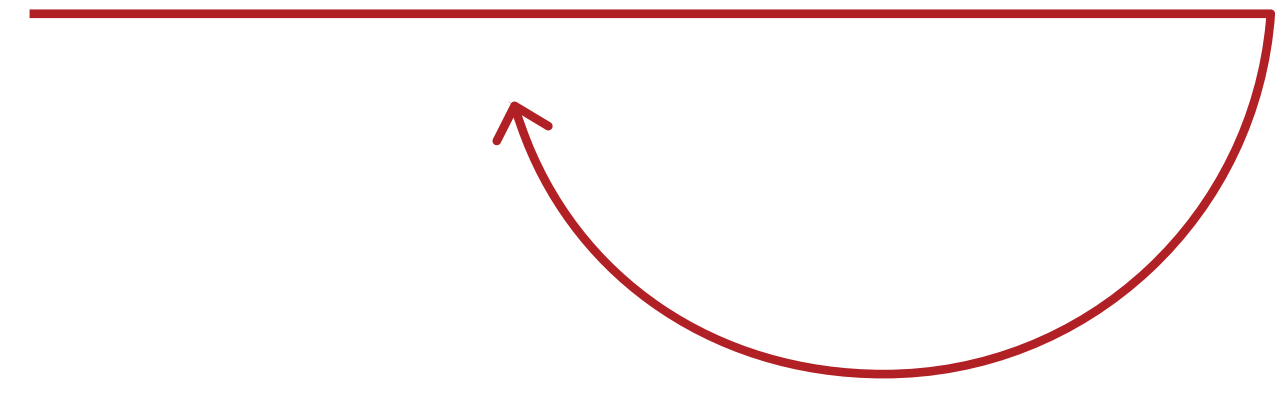

2018

TRIGÉSIMO SÉPTIMO PERÍODO DE SESIONES

DE LA CEPAL

La Habana

7 a 11 de mayo

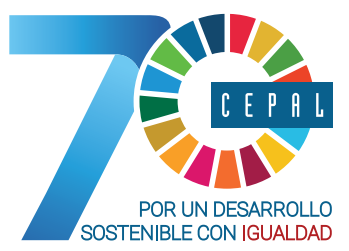




\section{Alicia Bárcena}

Secretaria Ejecutiva

Mario Cimoli

Secretario Ejecutivo Adjunto Interino

Raúl García-Buchaca

Secretario Ejecutivo Adjunto

para Administración y Análisis de Programas

Ricardo Pérez

Director de la División de Publicaciones y Servicios Web

Este documento fue coordinado por Alicia Bárcena, Secretaria Ejecutiva de la Comisión Económica para América Latina y el Caribe (CEPAL), con la colaboración de Mario Cimoli, Secretario Ejecutivo Adjunto Interino.

En el grupo de redacción participaron Martín Abeles, Verónica Amarante, Simone Cecchini, Wilson Peres, Esteban Pérez, Gabriel Porcile, Joseluis Samaniego y Pablo Yanes de la CEPAL, y Martín Hopenhayn, exfuncionario de la Comisión, quienes contaron con la colaboración de Cielo Morales, Jeannette Sánchez, Romain Zivy, Vianka Aliaga y Vera Kiss.

Colaboraron en la preparación de este documento los siguientes Directores de las Divisiones sustantivas, sedes subregionales y oficinas nacionales de la CEPAL: Daniel Titelman, Director de la División de Desarrollo Económico, Pascual Gerstenfeld, Director de la División de Estadísticas, Paulo Saad, Director del Centro Latinoamericano y Caribeño de Demografía (CELADE)-División de Población de la CEPAL, Cielo Morales, Directora del Instituto Latinoamericano y del Caribe de Planificación Económica y Social (ILPES), Laís Abramo, Directora de la División de Desarrollo Social, Joseluis Samaniego, Director de la División de Desarrollo Sostenible y Asentamientos Humanos, Jeannette Sánchez, Directora de la División de Recursos Naturales e Infraestructura, Nieves Rico, Directora de la División de Asuntos de Género, Osvaldo Sunkel, Presidente del Consejo Editorial de la Revista CEPAL, Hugo Beteta, Director de la sede subregional de la CEPAL en México, Diane Quarless, Directora de la sede subregional de la CEPAL para el Caribe, Juan Carlos Ramírez, Director de la oficina de la CEPAL en Bogotá, Carlos Mussi, Director de la oficina de la CEPAL en Brasilia, e Inés Bustillo, Directora de la oficina de la CEPAL en Washington, D.C.

En particular, se agradece la colaboración de los siguientes funcionarios de la CEPAL: José Eduardo Alatorre, Andrés Arroyo, David Barrio, Pablo Chauvet, Martín Cherkasky, Rodrigo Contreras, Felipe Correa, Manlio Coviello, Carlos de Miguel, Ernesto Espíndola, Jimy Ferrer, Tania García-Millán, Sebastián Herreros, Raúl Holz, Azhar Jaimurzina, Valeria Jordan, Andrei Jouravlev, Luiz Fernando Krieger Merico, Jeannette Lardé, Mauricio León, Karina Martínez, Antonio Martins, Luis Méndez, Beatriz Morales, Gabriel Pérez, Maria Cecilia Plottier, Verónica Quiroz, Luis Riffo, Adrián Rodríguez, Edwin Fernando Rojas, Miryam Saade, Ricardo Sánchez, Silvana Sánchez, Nunzia Saporito, Lucía Scuro, Valeria Torres, Daniela Trucco, Heidi Ullmann, Hugo Ventura y Soledad Villafañe.

Colaboraron asimismo los siguientes Consultores de la CEPAL: Hugo Altomonte, Rafael Aramendis, Bernardo Atuesta, Martín Brum, Fedora Carbajal, Maira Colacce, Nicole Favreau-Negront, Noemí Giosa Zuazúa, Pilar Manzi, Sebastián Valdecantos, Juan Pablo Valenzuela y Eduardo A. Vasconcellos.

Se agradece la colaboración de Cristóbal Budnevitch, Facundo Grimberg y Alicia Pita.

Se agradece también la colaboración de los Gobiernos de Alemania, España, Francia, Noruega y la República de Corea, así como de la Comisión Europea por su apoyo a diferentes trabajos sustantivos de la CEPAL, que han aportado análisis y propuestas para la preparación del presente documento.

Los límites y los nombres que figuran en los mapas de esta publicación no implican su apoyo o aceptación oficial por las Naciones Unidas.

Publicación de las Naciones Unidas ISBN: 978-92-1-121989-0 (versión impresa)

ISBN: 978-92-1-058627-6

(versión pdf)

ISBN: 978-92-1-358083-7

(versión ePub)

No de venta: S.18.II.G.11

LC/SES.37/3-P

Distr:. General

Copyright (c) Naciones Unidas, 2018

Todos los derechos reservados

Impreso en Naciones Unidas, Santiago S.18-00059
Notas explicativas

- Los tres puntos (...) indican que los datos faltan, no constan por separado o no están disponibles.

- La raya (-) indica que la cantidad es nula o despreciable.

- La coma (,) se usa para separar los decimales.

- La palabra "dólares" se refiere a dólares de los Estados Unidos, salvo cuando se indique lo contrario.

- La barra (/) puesta entre cifras que expresen años (por ejemplo, 2013/2014) indica que la información corresponde a un período de 12 meses que no necesariamente coincide con el año calendario.

- Debido a que a veces se redondean las cifras, los datos parciales y los porcentajes presentados en los cuadros no siempre suman el total correspondiente.

Esta publicación debe citarse como: Comisión Económica para América Latina y el Caribe (CEPAL), La ineficiencia de la desigualdad, 2018 (LC/SES.37/3-P), Santiago, 2018.

La autorización para reproducir total o parcialmente esta obra debe solicitarse a la Comisión Económica para América Latina y el Caribe (CEPAL), División de Publicaciones y Servicios Web, publicaciones@cepal.org. Los Estados Miembros de las Naciones Unidas y sus instituciones gubernamentales pueden reproducir esta obra sin autorización previa. Solo se les solicita que mencionen la fuente e informen a la CEPAL de tal reproducción. 


\section{Índice}

Prólogo.

\section{Capítulo I}

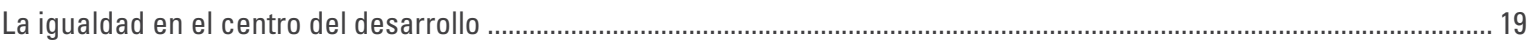

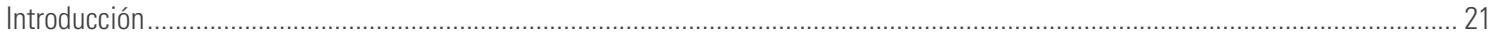

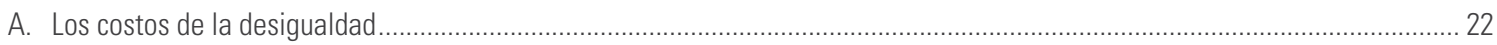

1. La desigualdad de acceso a las capacidades: una barrera al crecimiento de la productividad que el mercado no corrige ........ 25

2. La destrucción del medio ambiente: una forma de desigualdad entre generaciones y en la generación presente................ 26

B. La igualdad y la eficiencia requieren de más y mejores bienes públicos ................................................................................ 27

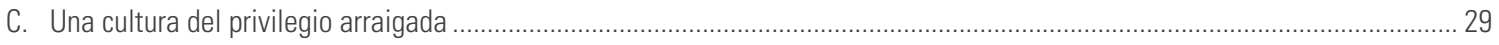

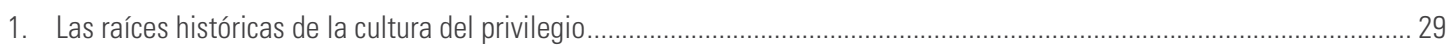

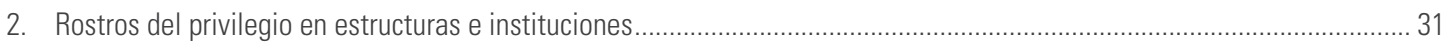

D. Construcción de una cultura de la eficiencia y la igualdad............................................................................................ 33

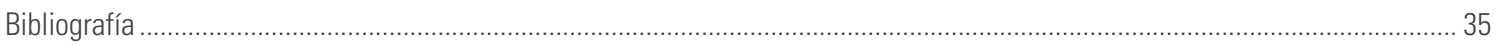

\section{Capítulo II}

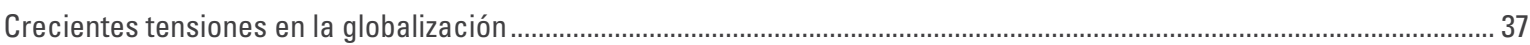

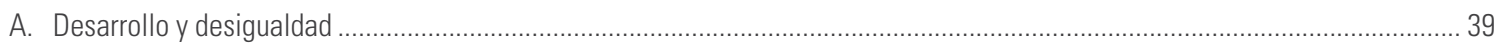

B. Un mundo más incierto en los ámbitos económico y tecnológico ..................................................................................... 43

1. La crisis de la interpretación macroeconómica dominante ...................................................................................... 43

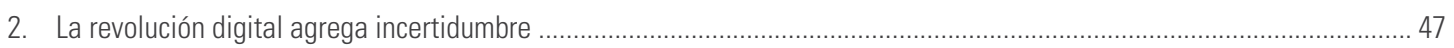

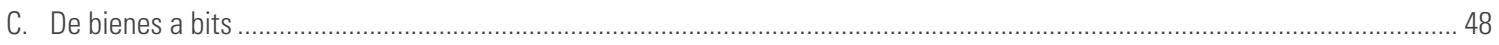

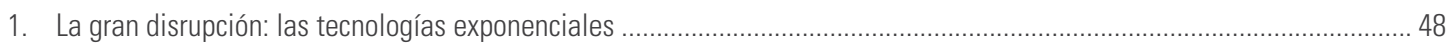

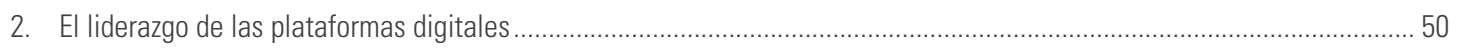

D. El comercio internacional no recupera su dinamismo previo a la crisis ....................................................................... 53

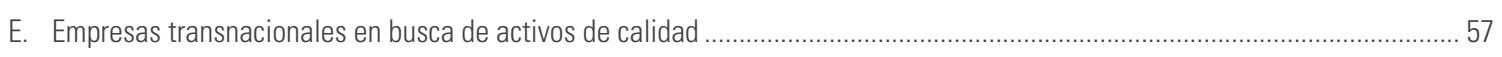

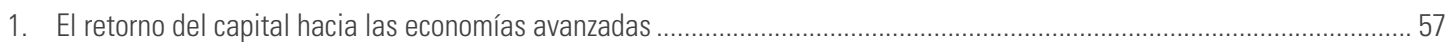

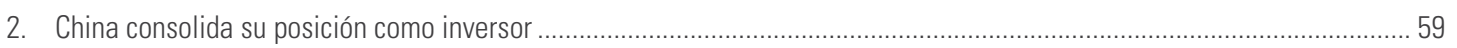

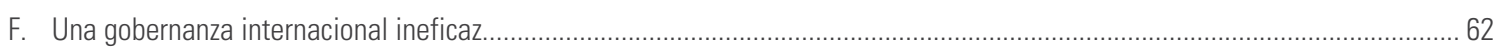

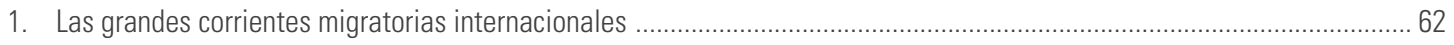

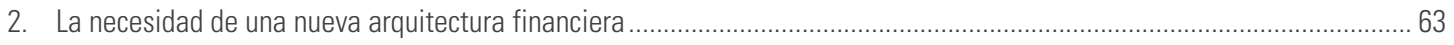

3. El debilitamiento del multilateralismo en el comercio internacional ........................................................................... 64

4. La solución de controversias entre inversionista y Estado ...................................................................................... 66

5. La difícil implementación de la gobernanza ambiental ............................................................................................ 67

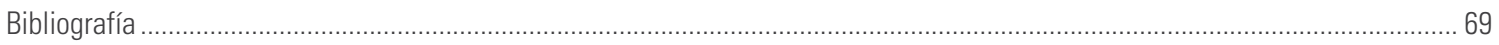




\section{Capítulo III}

La vulnerabilidad externa obstaculiza el desarrollo y aumenta la desigualdad ....................................................................... 73

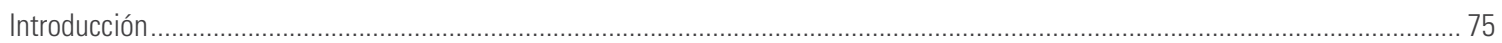

A. Los factores estructurales que limitan el crecimiento, la inversión y el empleo......................................................................75

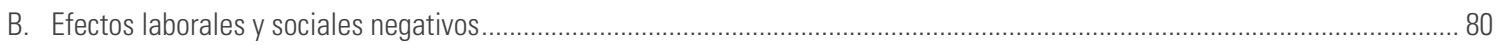

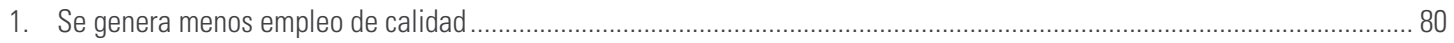

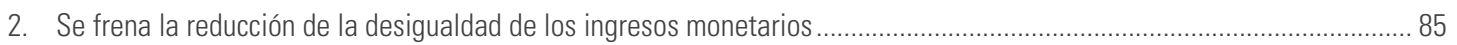

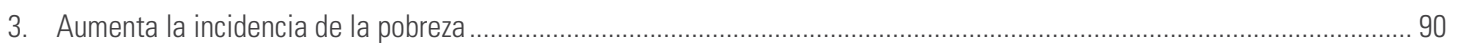

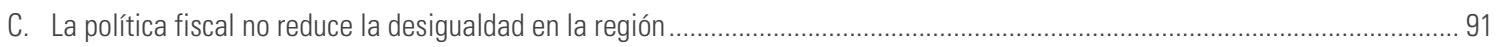

1. Ingresos tributarios sesgados contra la igualdad ..............................................................................................

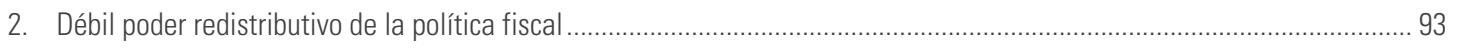

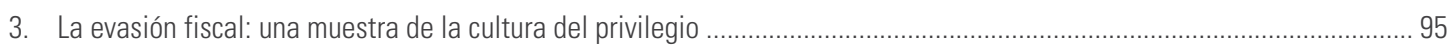

D. Interacciones positivas o negativas entre distribución, crecimiento e inversión ....................................................................... 98

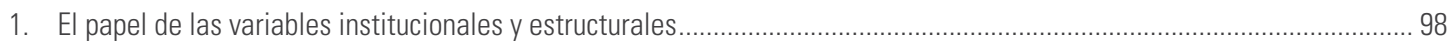

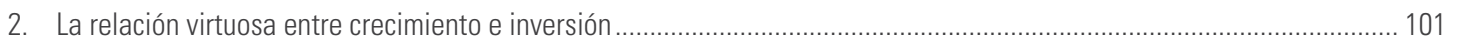

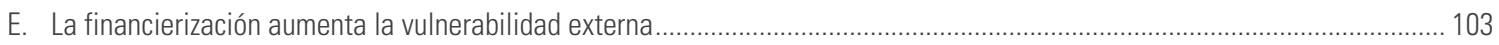

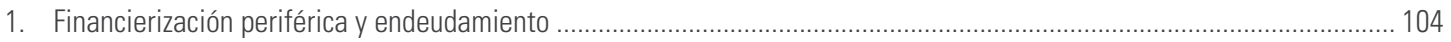

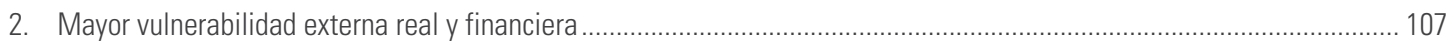

3. Obstáculos para el crecimiento, la inversión y la diversificación productiva en el largo plazo ........................................ 109

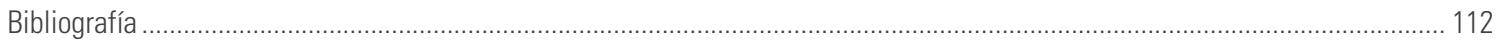

\section{Capítulo IV}

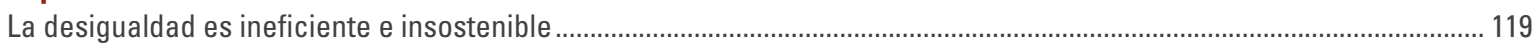

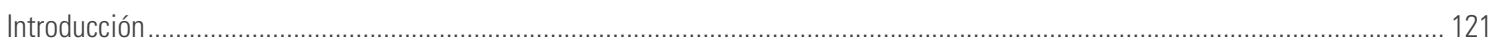

A. La desigualdad como obstáculo para el desarrollo ………………............................................................................. 123

1. El costo de las brechas en la educación y la salud ................................................................................................. 123

2. La desigualdad de ingresos impide la movilidad intergeneracional .................................................................... 128

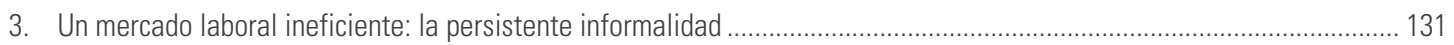

4. Discriminación y oportunidades en el mercado laboral: la desigualdad de género ............................................................ 136

5. Efectos positivos de la protección social y el cuidado en el crecimiento y el empleo ....................................................... 140

B. Desafíos futuros: los cambios demográficos y la revolución tecnológica ...................................................................... 144

1. Los efectos del envejecimiento, la participación laboral femenina y la educación .............................................................. 144

2. La disrupción tecnológica en el mercado de trabajo .................................................................................................. 148

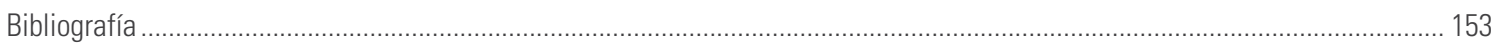

\section{Capítulo V}

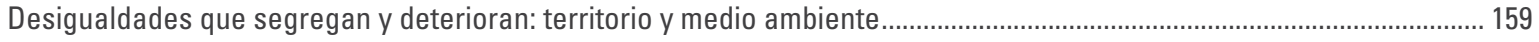

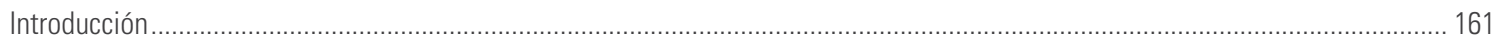

A. El territorio como expresión de los desequilibrios del modelo económico ............................................................... 161

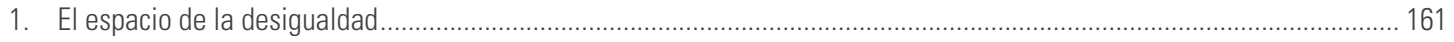

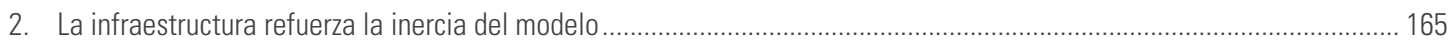

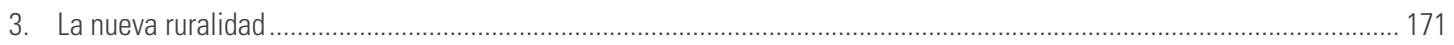

B. Las ciudades: centros dinámicos que reproducen la segmentación ............................................................................ 173

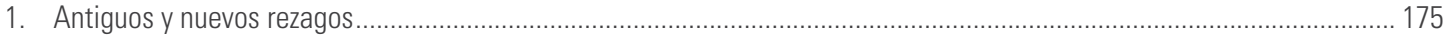

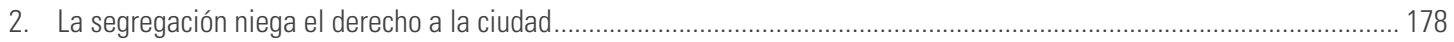

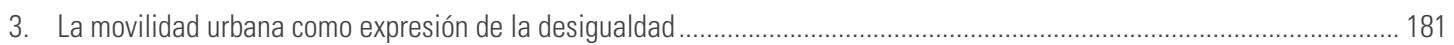


C. El estilo de desarrollo erosiona sus bases ambientales

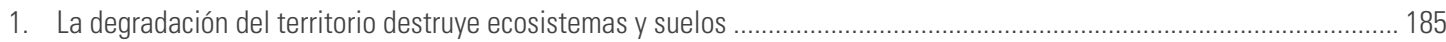

2. El cambio climático: contaminación global e impactos localizados ......................................................................... 187

3. La urgencia de aumentar la tasa de descarbonización....................................................................................... 191

D. Fuentes de energía renovables: un nuevo horizonte de inversiones.............................................................................. 195

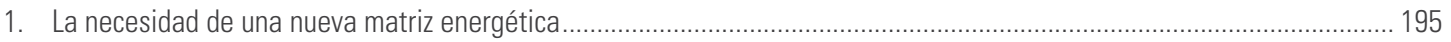

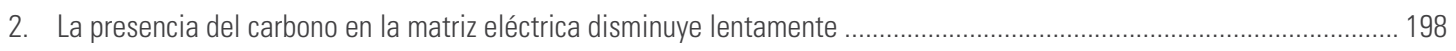

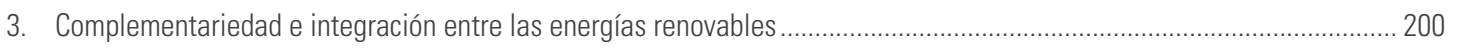

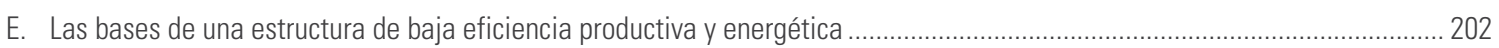

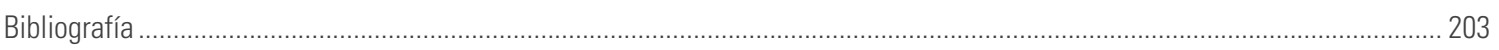

\section{Capítulo VI}

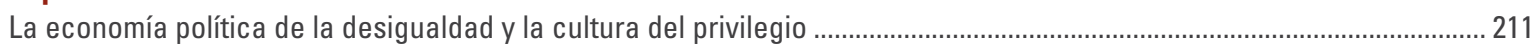

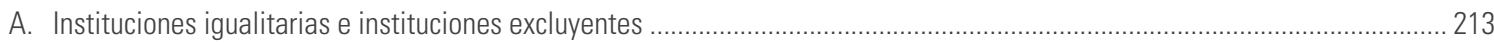

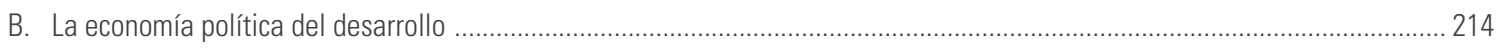

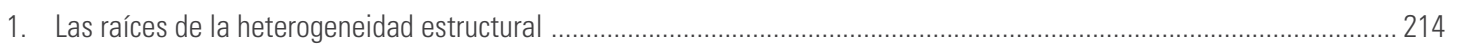

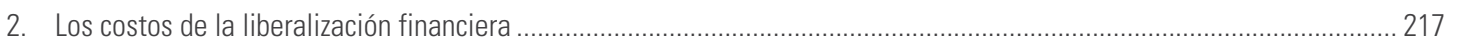

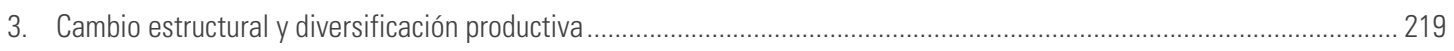

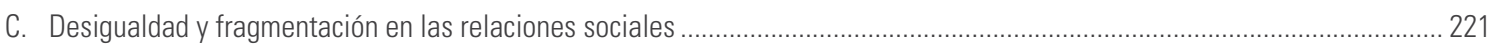

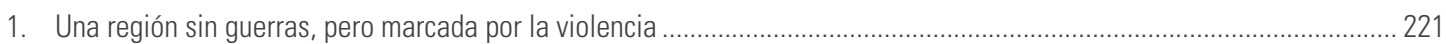

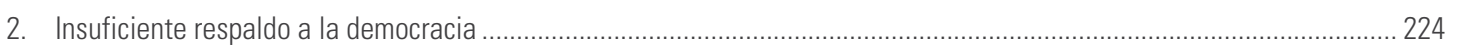

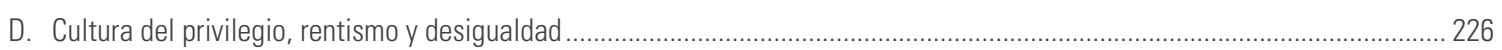

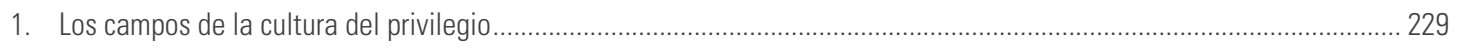

2. Fortalecer la cultura de la igualdad erosiona la cultura del privilegio ….............................................................. 231

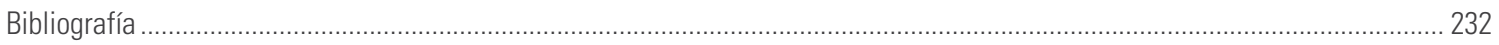

\section{Capítulo VII}

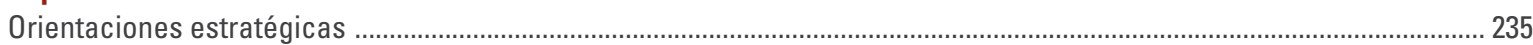

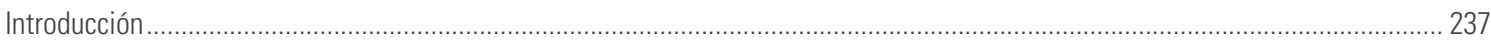

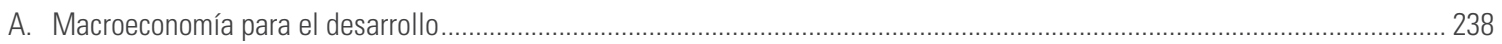

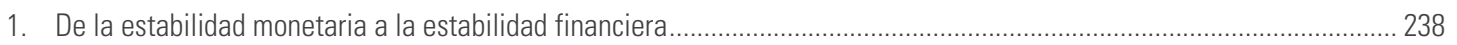

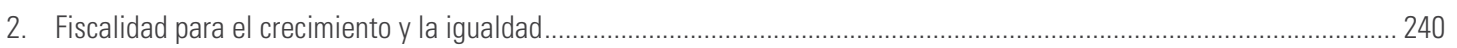

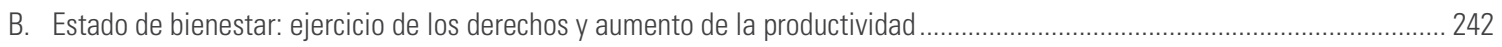

1. La protección del gasto público social mediante una tributación progresiva ................................................................... 242

2. Readecuación de la educación al nuevo contexto tecnológico ................................................................................... 244

3. Fortalecimiento de los sistemas de protección social y cuidado .......................................................................... 245

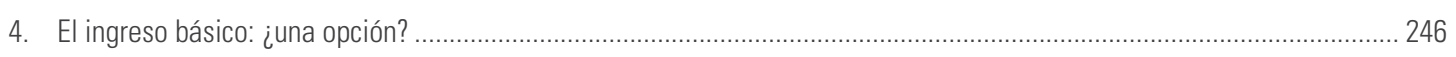

C. Tres ejes de la descarbonización: digitalización, ciudades sostenibles y energías renovables...............................................248

1. Un gran impulso ambiental para el cambio estructural progresivo........................................................................ 248

2. Políticas industriales y tecnológicas para la digitalización de la producción ............................................................ 249

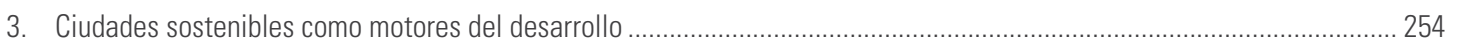

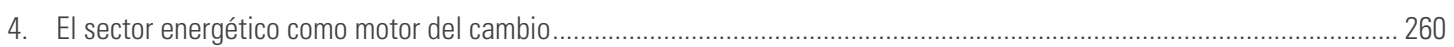

D. La transparencia y la confianza en las instituciones facilitan la implementación de políticas

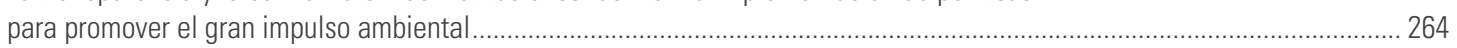

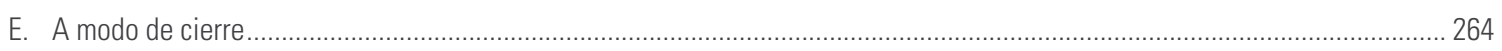

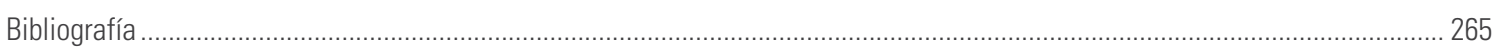




\section{Cuadros}

Cuadro III.1 América Latina (países seleccionados): relación de elasticidades del comercio exterior, 1999-2008 y 2007-2016............77

Cuadro III.2 América Latina (18 países): recaudación y participación relativa del impuesto a la renta de las empresas

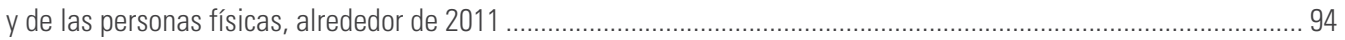

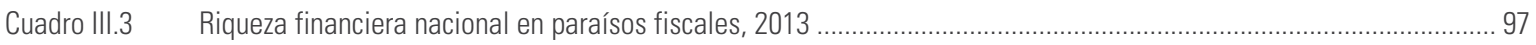

Cuadro III.4 América Latina: tasa de variación anual de la inversión y del PIB, 1990-2015 ................................................... 101

Cuadro IV.1 América Latina (9 países): nivel de productividad y aportes a la seguridad social, alrededor de 2016 ..................... 132

Cuadro IV.2 América Latina (9 países): diferencial salarial en relación con los trabajadores de baja productividad

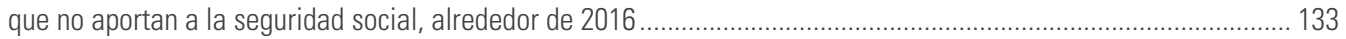

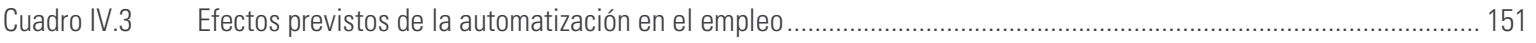

Cuadro V.1 América Latina y el Caribe: emisión de contaminantes por modo de transporte ................................................... 184

Cuadro VI.1 América Latina (18 países): frecuencia con que las personas piensan que pueden llegar

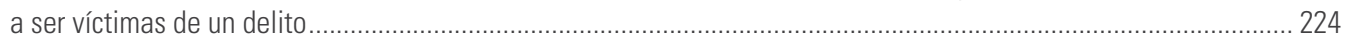

Cuadro VII.1 Medidas para apoyar la integración de las MIPYMES en la economía digital ....................................................... 253

\section{Gráficos}

Gráfico I.1

Productividad e índice de Gini, 2014

Gráfico I.2

América Latina (países seleccionados): ingresos laborales mensuales medios entre los ocupados de 15 años de edad y más, según sexo, condición étnico/racial y años de escolaridad, total nacional, alrededor de 2015......

Gráfico I.3

Anomalía de la temperatura superficial anual en el mundo, 1900-2100, respecto del promedio 1986-2005.

Gráfico II.1 Índice de Gini, promedios quinquenales.

Gráfico II.2 Crecimiento del ingreso real por adulto por percentil de ingresos en la distribución global, 1980-2016...................... 41

Gráfico II.3

Evolución de los ingresos del 1\% más rico de la población mundial, 1980-2015 .....

Gráfico II.4

Mundo, Estados Unidos, eurozona, Japón y países seleccionados: evolución de distintas variables económicas ........ 44

Gráfico II.5

Valor de mercado de las mayores empresas mundiales, 2006 y 2017

Gráfico II.6

Capitalización de mercado de las plataformas digitales por región, 2016

Gráfico II.7

Variación anual del volumen del comercio mundial de bienes y del PIB mundial y cociente entre ambas variaciones, 1981-2018.

Gráfico II.8

China: participación de las partes y componentes en las importaciones totales (excluido el petróleo)

desde el mundo y socios seleccionados, 2000-2016

Gráfico II.9

Corrientes mundiales de IED y participación por grupos de economías, 1990-2016

Gráfico II.10

Valor de las fusiones y adquisiciones transfronterizas netas globales, 2005-2016.

Gráfico Il.11

Participación en el valor de fusiones y adquisiciones transfronterizas netas, por país o región, 2016.

Gráfico Il.12

Estados Unidos y China: participación en los flujos mundiales de entrada y salida de IED, 2006-2016.

Gráfico II.13

El agotamiento del presupuesto de carbono.

Gráfico III.1

América Latina y el Caribe: crecimiento económico, 1965-2017.

Gráfico III.2 América Latina y el Caribe: crecimiento por subregión y determinantes externos, 2004-2017 ................................. 76

Gráfico III.3

América Latina y el Caribe: crecimiento y tasa de inversión, 1960-2017

Gráfico III.4 América Latina y el Caribe (en conjunto y por subregión): tasa de crecimiento efectiva y tasa de crecimiento compatible con un equilibrio de la tasa de empleo, 2000-2016.

Gráfico III.5 América Latina (14 países): relación entre crecimiento compatible con el equilibrio externo y crecimiento compatible con una tasa de empleo estable, 2000-2016

Gráfico III.6 América Latina y el Caribe (en conjunto y por subregión): tasa de empleo ajustada, 1991-2016 .

Gráfico III.7 América Latina y el Caribe (en conjunto y por subregión): contribución de los componentes de la tasa de empleo ajustada a la variación promedio anual de esta, 2000-2008 y 2012-2016 .

Gráfico III.8 América Latina y el Caribe: tasas y brecha en indicadores seleccionados según sexo, 2000-2016. 83

Gráfico III.9 América Latina y el Caribe: variación promedio anual de la tasa de empleo ajustada según sus componentes, por sexo, períodos seleccionados 
Gráfico III.10 América Latina y el Caribe (en conjunto y por subregión): participación del trabajo asalariado en el PIB, 1950-2014 .......

Gráfico III.11 América Latina y otras regiones: participación de las personas asalariadas en el ingreso total, alrededor de 2008.

Gráfico III.12 Países seleccionados: participación del 1\% más rico de la población en el ingreso, alrededor de 2014 ..................... 87

Gráfico III.13 Coeficiente de Gini, alrededor de 2012 ....................................................................................................... 88

Gráfico III.14 América Latina y el Caribe (15 países): desigualdad medida según el coeficiente de Gini del ingreso

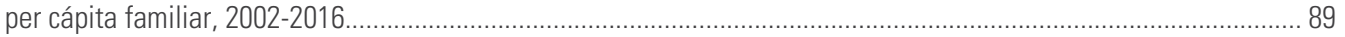

Gráfico III.15 América Latina y subregiones (15 países): incidencia de la pobreza en los hogares, 2002-2017.............................. 90

Gráfico III.16 América Latina (18 países): carga fiscal según tipo de ingreso y país, 2016 ....................................................... 91

Gráfico III.17 América Latina (19 países): carga tributaria y PIB per cápita, alrededor de 2013................................................... 92

Gráfico III.18 América Latina (18 países), OCDE (34 países) y Unión Europea (15 países): composición de los ingresos

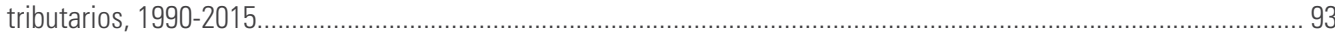

Gráfico III.19 América Latina y el Caribe (16 países): reducción de la desigualdad medida según el coeficiente de Gini

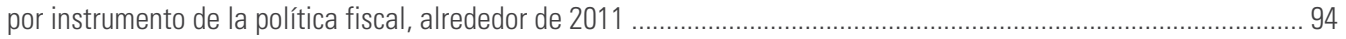

Gráfico III.20 América Latina (15 países): recaudación tributaria y evasión fiscal estimada, 2015................................................. 96

Gráfico III.21 América Latina y el Caribe: montos estimados de la manipulación de precios del comercio internacional

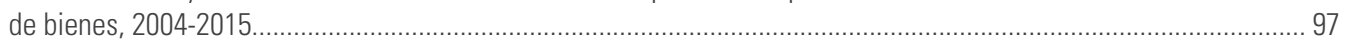

Gráfico III.22 América Latina y el Caribe: promedio de distribución y crecimiento por período, 1950-2014 …................................ 100

Gráfico III.23 América Latina: coeficiente de correlación móvil entre la tasa de variación de la formación bruta

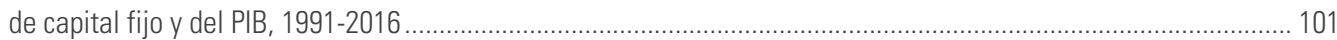

Gráfico III.24 Países desarrollados seleccionados: participación de los salarios en el ingreso y tasa de inversión promedio, 1970-2010

Gráfico III.25 América Latina (países seleccionados): flujos de deuda (bonos) y préstamos bancarios totales correspondientes al sector corporativo no financiero, 2001-2015

Gráfico III.26 Proporción de empresas en situación Ponzi, especulativa o cubierta en los mercados internacionales

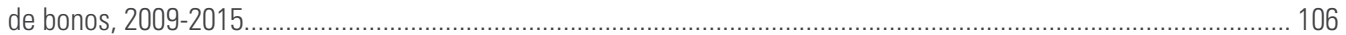

Gráfico III.27 América Latina (países seleccionados): deuda de los hogares, 2011-2016 ..................................................... 107

Gráfico III.28 América Latina y el Caribe: vulnerabilidad externa real y financiera, 2005-2007 y 2014-2016 ................................ 108

Gráfico III.29 América Latina (14 países): condiciones de crecimiento compatibles con el equilibrio externo

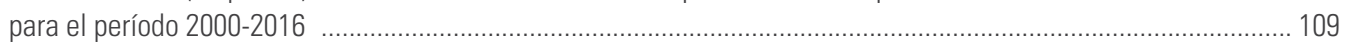

Gráfico III.30 América Latina y el Caribe: relación entre financierización y participación salarial en el ingreso, 1970-2014............ 110

Gráfico III.31 América Latina y el Caribe: relación entre financierización e inversión, 1970-2014................................................ 110

Gráfico III.32 América Latina y el Caribe (países seleccionados): reacciones de política macroeconómica en situaciones de recesiones o desaceleraciones para el período 2010-2016

Gráfico IV.1 América Latina (17 países): trayectorias salariales según años de estudio en asalariados de 20 años o más que trabajan 20 horas o más semanales, alrededor de 2015

Gráfico IV.2 América Latina(17 países): conclusión del primer ciclo de educación secundaria, mayores de 18 años, según quintil de ingresos, alrededor de 2016

Gráfico IV.3 América Latina (17 países): incremento del ingreso de los hogares si la población hubiese completado el primer ciclo de la enseñanza media, alrededor de 2016.

Gráfico IV.4 Niveles de desempeño de los estudiantes en las pruebas PISA por región y competencia

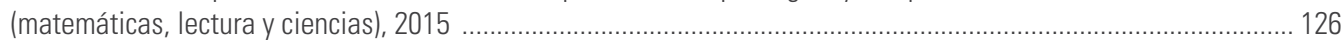

Gráfico IV.5 Contribución del cambio anual en la esperanza de vida al ingreso total por región, 1990-2000 y 2000-2011 ............ 127

Gráfico IV.6 América Latina (7 países): promedio de estudios de las mujeres de 25 a 35 años, según condición

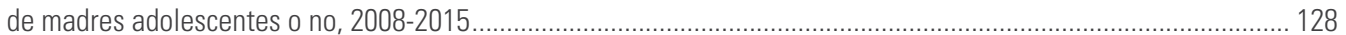

Gráfico IV.7 Movilidad intergeneracional y desigualdad de ingresos …....................................................................... 129

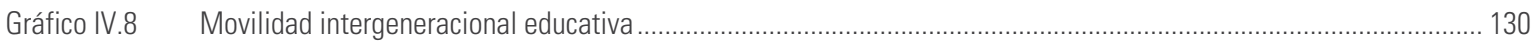

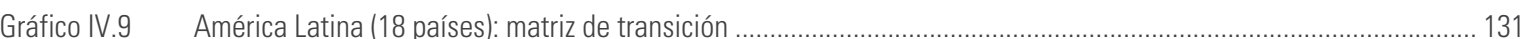

Gráfico IV.10 América Latina (16 países): desigualdad salarial (coeficiente de Gini) e informalidad, 1990-2014 ......................... 134 
Gráfico IV.11 América Latina (11 países): pérdida salarial debida a la informalidad, alrededor de 2008 y 2016 135

Gráfico IV.12 América Latina y el Caribe (15 países): cobertura y gasto de las pensiones no contributivas, 2015

Gráfico IV.13

América Latina (18 países): cambios en el ingreso promedio de los hogares en tres escenarios

de cierre de brechas de género (de participación, de ingresos y ambas), alrededor de 2012

Gráfico IV.14 América Latina (5 países): distribución del trabajo remunerado y no remunerado en hogares

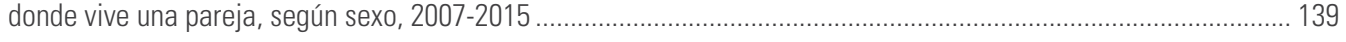

Gráfico IV.15 América Latina (5 países): ingreso de los hogares donde vive una pareja, escenarios 1 y 2 .................................... 139

Gráfico IV.16 América Latina (5 países): evolución de la tasa de actividad por países y escenarios, 2015-2050 ............................ 145

Gráfico IV.17 Evolución de la tasa de productividad por habitante, por países y escenarios, 2015-2050 ....................................... 147

Gráfico IV.18 Brasil y México: evolución del costo medio de un robot soldador y de la mano de obra manufacturera,

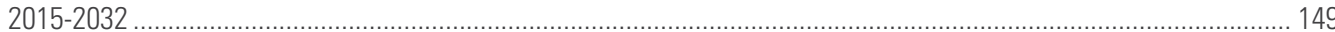

Gráfico V.1 Grado de dispersión del ingreso (evolución de las disparidades subnacionales del PIB por habitante), $1995-2015$

Gráfico V.2 América Latina (8 países): indicadores seleccionados del IDR 2015, según estratos de desarrollo......................... 164

Gráfico V.3 América del Sur (9 países): exportaciones, importaciones y balanza comercial física, 2002-2016 ........................... 166

Gráfico V.4 América del Sur: distribución modal del comercio intrarregional, 2013 ........................................................... 168

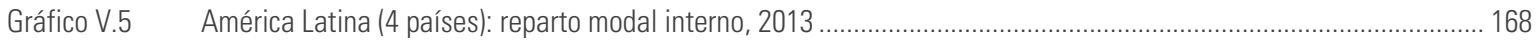

Gráfico V.6 América Latina (6 países): inversión en infraestructura por sector (público y privado), 1980-2015........................... 169

Gráfico V.7 Inversión per cápita en infraestructura de transporte: carreteras y ferrocarriles, 2008-2015 ................................... 170

Gráfico V.8 América Latina: inversión en infraestructura por modo de transporte, 2008-2015 ................................................ 170

Gráfico V.9 Inversión en infraestructura por modo de transporte, 2008-2015 ............................................................... 171

Gráfico V.10 Tendencias de la urbanización en el mundo: población urbana como porcentaje de la población total, 1950-2050

Gráfico V.11 Peso relativo de las ciudades de más de 1 millón de habitantes en la población urbana

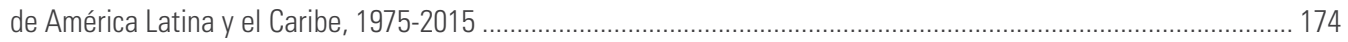

Gráfico V.12 América Latina y el Caribe (18 países): coeficiente de Gini por área geográfica, 2013 ............................................ 175

Gráfico V.13 Productividad laboral media de ciudades seleccionadas, 2010 .......................................................................... 175

Gráfico V.14 América Latina y el Caribe (17 países): diferencias en la cobertura de saneamiento entre los hogares urbanos del quintil de mayores ingresos y del quintil de menores ingresos .................................................................... 176

Gráfico V.15 América Latina y el Caribe (15 países): acceso a la energía eléctrica en los hogares urbanos del quintil de mayores ingresos y del quintil de menores ingresos ................................................................ 176

Gráfico V.16 América Latina (9 países): hogares con acceso a Internet por quintil de ingresos, alrededor de 2011 y $2015 \ldots \ldots \ldots \ldots \ldots . .177$

Gráfico V.17 América Latina (12 países): velocidades de conexión a Internet, cuarto trimestre de 2016 ....................................... 178

Gráfico V.18 América Latina: densidad urbana en ciudades seleccionadas, 1990-2014 ......................................................... 179

Gráfico V.19 América Latina y el Caribe: población urbana que vive en tugurios, 1990-2014 ................................................ 180

Gráfico V.20 América Latina (13 países): tasa de motorización, PIB per cápita y comparación con las tendencias

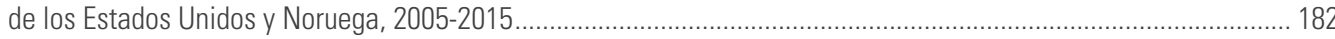

Gráfico V.21 América Latina (12 áreas metropolitanas): tiempo de viaje en automóviles privados y autobús, 2014 ..................... 183

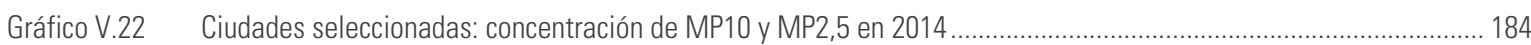

Gráfico V.23 América Latina y el Caribe: pérdida de superficie forestal y expansión del área agropecuaria, 1990-2014 ............... 186

Gráfico V.24 América Latina y el Caribe (11 países): territorios desertificados o en proceso de desertificación ........................... 186

Gráfico V.25 América Latina y el Caribe: costo de los eventos meteorológicos extremos, 1961-2015 ......................................... 187

Gráfico V.26 América Latina y el Caribe: impacto económico de un aumento de $2,5^{\circ} \mathrm{C}$ de la temperatura del planeta según diferentes estimaciones, segunda mitad del siglo XXI ......................................................................... 188

Gráfico V.27 América Latina y el Caribe: costo estimado anual de la adaptación al cambio climático, por sectores a 2050 ............... 189

Gráfico V.28 América Latina y el Caribe: emisiones per cápita de CO 2 equivalente, 1990-2014.............................................. 191

Gráfico V.29 Evolución de la relación entre el PIB per cápita y la intensidad carbónica de la economía, 1971-2014 .................... 192 
Gráfico V.30 Evolución de la relación entre el PIB per cápita y la intensidad energética de la economía, 1971-2014 193

Gráfico V.31 América Latina y el Caribe: proporción renovable de la oferta energética total, 1990-2015

Gráfico V.32 América del Sur: distribución de las inversiones en la matriz eléctrica según las fuentes de generación, 2016 y 2030.

Gráfico V.33 América del Sur: potencia instalada y generación efectiva de las energías renovables no convencionales como parte de la matriz eléctrica, 2015 y 2030

Gráfico V.34 América Latina y Caribe: inversiones en energías renovables, 2004-2016

Gráfico VI.

Tasa de homicidios en el mundo por cada 100.000 habitantes, por regiones y subregiones, 2010 y 2015.

Gráfico VI.2

América Latina (18 países): tasa de homicidios por cada 100.000 habitantes e índice de Gini (valores entre 0 y 1), 2014

Gráfico VI.3 América Latina (18 países): percepción de la seguridad en el país, 2007-2015................................................. 224

Gráfico VI.4 América Latina: apoyo a la democracia, 1995-2016 .................................................................................. 225

Gráfico VI.5 América Latina: percepción ciudadana del nivel de desarrollo de la democracia, 1997 y 2016 ................................ 226

Gráfico VII.1 América Latina (19 países): gasto social del sector público, por funciones, 2000-2015 ........................................ 243

Gráfico VII.2 América Latina y países de la Organización de Cooperación y Desarrollo Económicos (OCDE): gasto público social, carga tributaria y PIB per cápita, 1990-2015.

\section{Recuadros}

Recuadrol.1

Estimación del impacto de la desigualdad sobre la eficiencia dinámica de la economía .....

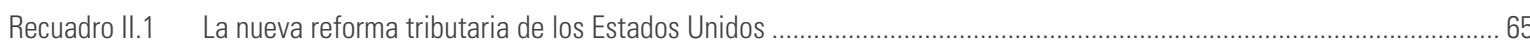

Recuadro IV.1 La desigualdad del ingreso restringe la reducción de la pobreza ............................................................... 121

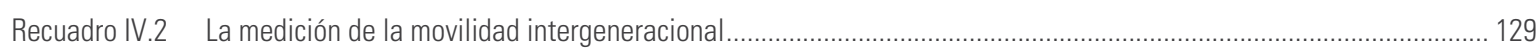

Recuadro IV.3 Efectos de la protección social no contributiva en los indicadores finales de capacidades humanas ....................... 140

Recuadro IV.4 Cambio tecnológico y mercado de trabajo en el Uruguay y la Argentina .............................................................. 150

Recuadro V.1 El umbral mínimo necesario de crecimiento y las emisiones de gases de efecto invernadero ................................. 194

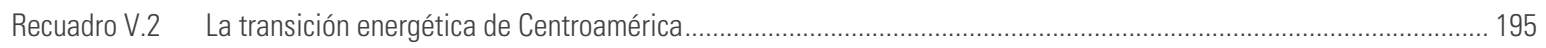

Recuadro VII.1 Regulación ambiental urbana y desarrollo tecnológico .................................................................................... 256

Recuadro VII.2 Articulación de políticas para impulsar las energías renovables en el Brasil ...................................................... 262

\section{Diagramas}

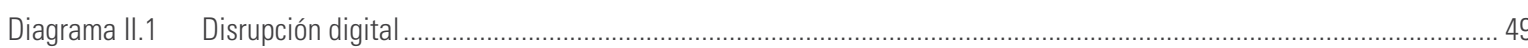

Diagrama IV.1 La disrupción tecnológica y el nuevo contexto laboral ........................................................................................ 149

Diagrama V.1 América Latina y el Caribe: focos de reproducción del efecto cerrojo (lock-in) de un equilibrio de bajo dinamismo ..........203

\section{Mapas}

Mapa V.1 América Latina (8 países): índice de desarrollo regional (IDR) 2015. 


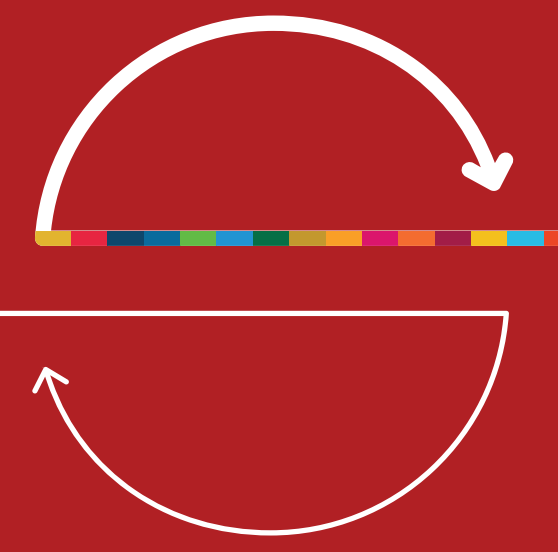

Prólogo 

La región de América Latina y el Caribe enfrenta un escenario de oportunidades, pero también de incertidumbres globales en un momento en que sus economías requieren transformaciones profundas y urgentes. Avanzar por un camino de mayor igualdad no es solo un imperativo ético en una región con brechas sociales que se expresan en diversos ámbitos; es también condición necesaria para acelerar el crecimiento de la productividad, internalizar y difundir la revolución digital, transitar hacia la sostenibilidad ambiental y proveer un marco institucional que permita actuar en un mundo en el que se conjugan grandes desequilibrios con enormes posibilidades.

Aunque el crecimiento económico de gran parte de los países de la región se ha acelerado en el último año, su dinámica de largo plazo continúa limitada por una macroeconomía poco favorable a la inversión y la diversificación productiva, una insuficiente incorporación de tecnologías, grandes brechas sociales y crecientes costos ambientales. Urge revertir esa situación y explorar más plenamente las complementariedades que existen entre igualdad, eficiencia productiva y sostenibilidad ambiental. En consonancia con ello y con la Agenda 2030 y sus Objetivos de Desarrollo Sostenible, este documento se centra en tres ejes de acción y sus sinergias: una macroeconomía para el desarrollo, un estado de bienestar basado en derechos y aumentos de la productividad, y la descarbonización de la estructura productiva, las ciudades y las fuentes de energía.

Los riesgos globales mencionados hacen más urgente una inflexión en el estilo de desarrollo. Son parte de una crisis que, como toda crisis, tiene la doble cara de la amenaza y la oportunidad. El cambio climático es hoy el mayor riesgo global. Las estimaciones de los costos derivados de sus efectos muestran que no solo afectará al crecimiento económico, sino que golpeará intensamente a los sectores más vulnerables y tendrá grandes consecuencias sociales. Las futuras generaciones no podrán contar con los servicios ambientales que contribuyeron al desarrollo en las generaciones pasadas. La falta de una gobernanza global eficiente para controlar estos procesos y prevenir y mitigar sus efectos exacerba el riesgo de que el deterioro del medio ambiente se vuelva irreversible.

Para enfrentar el calentamiento global es necesario cambiar la matriz energética y de transporte, así como los patrones de producción y consumo, como explícitamente propone la Agenda 2030, que llama también a reflexionar sobre las distintas dimensiones del desarrollo y reclama una mirada integral. En esa línea, la CEPAL Ilamó, hace ya varias décadas a pensar en un nuevo estilo de desarrollo, es decir, en cómo se ordena y organiza una sociedad para la producción, la distribución y el consumo de bienes y servicios, cómo se habitan sus espacios y cómo se articula el crecimiento económico con la calidad de vida. En el presente documento se resalta que la problemática ambiental se entrecruza de distintas maneras con los temas de territorio, infraestructura y ordenamiento urbano, y se reitera la idea de que es preciso un gran impulso ambiental como eje estratégico de la política industrial y tecnológica, la creación de bienes y servicios públicos, la transición hacia territorios y ciudades menos segregados, el avance hacia la economía digital y el cambio en la matriz energética.

La región debe superar un estilo de desarrollo que se expresa en ineficiencias ambientales, como la destrucción y pérdida de productividad de los recursos naturales, una matriz energética basada en combustibles fósiles, un modelo de transporte altamente contaminante e ineficiente, la pérdida de tiempo de trabajo y bienestar en las grandes ciudades, los costos del cambio climático y las dificultades que presenta el manejo de residuos.

La baja diversificación productiva, la dependencia de los recursos naturales y la especialización en actividades de bajo valor agregado, así como la vulnerabilidad a los choques externos repercuten negativamente en la igualdad, en la medida en que inhiben el dinamismo del mercado del trabajo, restringen la difusión de capacidades y distribuyen desigualmente los beneficios del crecimiento y los costos de la volatilidad económica. Al mismo tiempo, las brechas en materia de educación, así como las desigualdades territoriales, étnicas y de género, obstaculizan la innovación y difusión del progreso técnico en la estructura productiva. 
En materia ambiental, si no se desacoplan las emisiones y el crecimiento del producto, la propia sostenibilidad del crecimiento y el empleo se verá amenazada por externalidades negativas. La segregación en las ciudades, con una escasa dotación de bienes y servicios públicos de calidad (transporte, educación, seguridad, ambientes saludables) en amplias zonas, ocasiona pérdidas de productividad por tiempos de desplazamiento, falta de atención oportuna de la salud, morbimortalidad derivada de la violencia, y ambientes poco propicios para el aprendizaje y el desarrollo de capacidades. Por último, las desigualdades en el consumo, en el desplazamiento y en los asentamientos afectan las decisiones de dónde invertir y en qué modalidades de infraestructura hacerlo, lo que lleva a ineficiencias energéticas, ambientales y productivas. Todas estas son interdependencias negativas propias del estilo de desarrollo prevaleciente.

El gran impulso ambiental implica un giro copernicano. La interdependencia entre apropiación del progreso técnico, densificación del tejido productivo, calidad de vida y sostenibilidad ambiental es hoy más fuerte que nunca. Se abren campos en que la innovación tecnológica puede propiciar nuevas sinergias, como la gestión de ciudades sostenibles y digitalizadas, la expansión del transporte masivo, el manejo de la biodiversidad, el desarrollo de los biomateriales y la producción de energías renovables. Se trata de ámbitos en que puede abrirse un abanico de actividades productivas, generando nuevas condiciones materiales para la inclusión y la igualdad social y reorientando inversiones hacia una trayectoria de crecimiento bajo en carbono.

La crisis de 2008 alertó sobre el peligro de una economía financiera que no solo se autonomiza respecto del mundo productivo, sino que además se impone a él y lo distorsiona. Consagró un consenso en torno al carácter de riesgo global que entraña esta hipertrofia de la economía financiera. La economía mundial padece los desequilibrios provocados por burbujas financieras que transitan entre sectores, países y actividades, como las relacionadas con los bienes raíces, la inversión en materias primas o las criptomonedas. Como se plantea más adelante, la región se encuentra especialmente expuesta a un proceso de financierización con poder de veto sobre las alternativas de política económica ${ }^{1}$. Prevalece una visión cortoplacista y procíclica, poco auspiciosa para la inversión productiva y que refuerza los obstáculos seculares del desarrollo productivo en la región. Por lo mismo, este documento plantea, como una de sus propuestas centrales, que salir al paso del proceso de financierización es, a la vez, una urgencia y un desafío estratégico de cara a este riesgo global.

Los desequilibrios globales provocados por un sistema financiero cada vez más complejo e insuficientemente regulado exacerban los problemas en una región donde la volatilidad y el bajo nivel de maniobra endógena incrementan la exposición al riesgo y a la poca transparencia en la calificación del mismo por las entidades calificadoras internacionales. América Latina y el Caribe enfrenta una fase de financierización periférica, vale decir, un conjunto de prácticas económicas caracterizadas por relaciones de subordinación con respecto al ciclo financiero global - y a los actores internos y externos que determinan su dinámica- que llevan a cambios en el comportamiento de los actores económicos y políticos locales, lo que refuerza el patrón de especialización y aumenta la vulnerabilidad externa.

Por lo tanto, es urgente asumir una postura más proactiva y menos sujeta a la discrecionalidad de los grandes actores del poder financiero, internos e internacionales. Esto supone implementar una política macroeconómica que vaya más allá de las metas de control de la inflación, con un mayor manejo de la cuenta de capital de la balanza de pagos, que combine políticas anticíclicas con una estrategia de diversificación productiva y buenas políticas fiscales para la generación de bienes y servicios públicos y el fomento de las capacidades.

Un tercer riesgo global se asocia a los conflictos y desequilibrios provocados por la concentración de la riqueza, tanto a nivel nacional como mundial. La tendencia a la concentración de la riqueza, en un mundo cada vez más interconectado, genera desequilibrios que pueden volverse explosivos, y sus expresiones más elocuentes son las dinámicas migratorias y las crisis de gobernabilidad; el llamado "conflicto identitario" o "choque de civilizaciones", con sus amenazas a la seguridad y sus expresiones violentas, también se ve exacerbado

Se entiende por "financierización" la creciente importancia de los mercados financieros, las instituciones financieras y las élites financieras en el funcionamiento de las economías y sus instituciones de gobernanza a nivel nacional e internacional (véase G. Epstein, Financialization and the World Economy, Northampton, Edward Elgar, 2006) 
por la concentración de la riqueza y las asimetrías crecientes entre países y regiones. La imposibilidad de entendimiento entre pueblos o credos suele tener, como uno de sus sustratos, la profunda disimilitud en las oportunidades y condiciones de vida.

Aunque la distribución del ingreso en América Latina y el Caribe mejoró durante el último decenio, esta tendencia se estancó hace ya un trienio y la región sigue exhibiendo una de las peores distribuciones del ingreso en el mundo. Todo esto refleja el estigma de la desigualdad que la CEPAL ha descrito en sus más diversos matices: ingresos, activos físicos y financieros, capacidades, oportunidades, productividad, habitabilidad, poder, acceso al bienestar, redes de relaciones y goce de derechos.

La CEPAL ha planteado en documentos precedentes que no solo en lo social se juega lo social, señalando con ello que las brechas sociales tienen determinantes en los ámbitos macroeconómico, productivo, institucional, territorial, cultural y de relaciones de género. La CEPAL ha enfatizado anteriormente que la igualdad es un compromiso ético ineludible y que la igualdad de derechos, al constituir un valor intrínseco de la ciudadanía y del humanismo moderno, debe cuajar en instituciones, estructuras y políticas que permitan avanzar hacia el cierre de brechas.

En este documento se muestra la otra cara de la medalla: las brechas y rezagos sociales tienen un impacto negativo en la productividad, la fiscalidad, la sostenibilidad ambiental y la mayor o menor penetración de la sociedad del conocimiento. Dicho de otra manera, la desigualdad es ineficiente, es un obstáculo al crecimiento, el desarrollo y la sostenibilidad.

Los rezagos en materia de capacidades, determinados por brechas de aprendizajes en las trayectorias formativas y por una educación desfasada de las destrezas requeridas para acompañar los cambios del mundo productivo, son un obstáculo a la innovación y difusión del progreso técnico. La desnutrición tiene enormes costos para la productividad y repercute en los gastos en salud a lo largo de la vida, sean financiados privadamente o por el sistema público. Los déficits en la protección social también afectan las capacidades y suelen, a la vez, diferir los costos y aumentarlos, vale decir, son una mala inversión en el mediano plazo. La informalidad laboral plantea serias restricciones al financiamiento de los sistemas de pensiones, en particular ante el envejecimiento de las sociedades. La carga femenina del cuidado no solo restringe la autonomía de las mujeres, sino que limita sus contribuciones provenientes de ingresos laborales al bienestar de los hogares y a la economía en su conjunto. La desigualdad implica un enorme desaprovechamiento de talentos y capacidades humanas. Además, afecta y corroe la legitimidad política, la deliberación democrática y la convivencia pacífica, exacerbando la violencia y la violación de derechos.

Es, pues, indispensable una nueva articulación entre estructura productiva y régimen de bienestar. En consonancia con el aumento del producto por habitante, los países de la región deben expandir su gasto social y su capacidad de financiamiento de las políticas sociales para construir y fortalecer el estado de bienestar en el contexto de las profundas transformaciones del mundo del trabajo, la transición demográfica y la intensificación de las migraciones. Ello requiere reformar los sistemas tributarios para hacerlos progresivos, enfrentar la evasión y la elusión fiscales, limitar los incentivos tributarios y mejorar la efectividad del gasto social.

Especial mención merece el impacto de las nuevas tecnologías en la dinámica y calidad del empleo, sobre todo de la robótica y la inteligencia artificial. Esta creciente imbricación entre nuevas tecnologías y reordenamiento del mundo del trabajo encuentra a la región con altos niveles endémicos de precariedad e informalidad laborales. Sumada al aumento de flujos migratorios y el envejecimiento de la población, la reestructuración de las ocupaciones plantea desafíos a la protección social y su financiamiento. Es indispensable avanzar en la complementariedad entre la protección social contributiva, basada en el empleo formal, y la no contributiva, analizar alternativas de ingreso básico y considerar a los sistemas de cuidado como un eje de los sistemas de protección social. 
Como se señala en este documento, existe una marcada interdependencia entre fiscalidad, provisión de bienes públicos, solidaridad social y sostenibilidad ambiental. Una fiscalidad robusta y asociada a la provisión de bienes públicos de calidad promueve y hace posible un mayor uso común del transporte público, el aprovechamiento de una educación y salud públicas idóneas, y una mayor convergencia del conjunto de la sociedad en espacios públicos compartidos. Esto mejora la cohesión social, la solidaridad y el reconocimiento recíproco mediante un sentido más amplio de pertenencia a una sociedad, y previene (o revierte) la segregación residencial, el refugio de sectores privilegiados en servicios privados y excluyentes, y la fragmentación y jerarquización de la sociedad con enormes brechas de calidad y oportunidad en materia de servicios. Además, la confluencia de la sociedad en la infraestructura y el transporte públicos tiene efectos ambientales positivos y facilita el cambio en la matriz energética. La evidencia que aportan, por ejemplo, los países escandinavos, es la de círculos virtuosos que vinculan positivamente la fiscalidad, el estado de bienestar, la provisión de bienes y servicios públicos de calidad, y la cohesión social en torno al uso universal de esos bienes y servicios. Son, además, sociedades con una democracia de alta calidad, con una mayor sostenibilidad ambiental, una mejor matriz energética y niveles muy bajos de violencia e inseguridad.

En América Latina y el Caribe la convergencia en torno a los servicios públicos y las prácticas ambientalmente sostenibles tiende a ser escasa debido, sobre todo, a una cultura del privilegio que refuerza el patrón de consumo de las élites. Ejemplo de ello son el transporte público, cada vez más desplazado por los automóviles privados, la sustitución del espacio público abierto por centros comerciales cerrados y el incremento de servicios privados de seguridad y de barrios autosegregados. En este documento se busca mostrar que la economía política de sociedades altamente desiguales y la cultura del privilegio son obstáculos para avanzar en un desarrollo con igualdad.

En la región existen, por una parte, instituciones arraigadas en que se reproducen comportamientos de agentes con mayor poder económico y político, que hacen difícil impulsar políticas industriales y de innovación tecnológica, así como políticas de robustecimiento de la fiscalidad y políticas con vocación de igualdad. Existe una propensión rentista que se nutre originariamente del acceso privilegiado a la propiedad de los recursos naturales y que hoy se nutre también de la economía financiera y de posiciones oligopólicas en mercados poco expuestos a la competencia.

Asimismo, la región ha heredado los vestigios coloniales de una cultura del privilegio que naturaliza las jerarquías sociales y las enormes asimetrías de acceso a los frutos del progreso, la deliberación política y los activos productivos. Esa cultura del privilegio constituye el sustrato simbólico en que se cimenta la segregación territorial, la débil fiscalidad y la apropiación de las rentas por los grupos de poder.

Inversamente, la mayor democracia política, las políticas redistributivas y la ampliación de la sociedad del conocimiento tienden a consolidar una cultura de igualdad de derechos que está en las antípodas de la cultura del privilegio. En este sentido, se deben resaltar los avances logrados en la región en la primera década del siglo XXI, que implicaron una mayor conciencia sobre los derechos civiles, políticos y sociales, aunque también se han agudizado tensiones y conflictos en que unos actores exigen mayor acceso a los frutos del progreso, mientras que otros se repliegan sobre sí mismos, se aíslan del resto de la sociedad y procuran blindar sus privilegios. Entre la cultura de derechos y la cultura de privilegios, la política se ve atravesada por crisis y demandas de legitimidad.

Comenzamos afirmando que los riesgos globales nos hacen más vulnerables si no transitamos con urgencia de círculos viciosos a círculos virtuosos del desarrollo. Esto adquiere especial relevancia no solo para enfrentar riesgos, sino también para sintonizarnos, como región, con las posibilidades que ofrece el tránsito de una era analógica a una era digital. La dinámica exponencial del cambio tecnológico y de su difusión en todos los sectores productivos y esferas de la vida imprimen a la revolución industrial en curso un alto nivel de radicalidad e incertidumbre. Ante ello solo cabe apostar por activar las interdependencias positivas del gran impulso ambiental como motor impulsor de un nuevo estilo de desarrollo con la sostenibilidad y la igualdad en el centro. 
Se han mencionado los riesgos que enfrentan el mundo y la región; esos cambios tectónicos obligan a transformaciones de análoga magnitud en la política y en las políticas públicas. En este contexto, la región necesita acelerar y profundizar su adaptación al ritmo de cambio que vive el mundo.

La CEPAL ha advertido de manera enfática y recurrente respecto de la tendencia de la región a perder peso y relevancia en la economía mundial. Para revertir esa tendencia, se requiere un gran impulso político y de políticas. La inflexión es tanto más urgente cuanto mayor es la velocidad con que cambia el mundo en relación con la dinámica de la región.

Para impulsar las políticas propuestas en este documento se requiere, por cierto, movilizar recursos significativos y emprender esfuerzos en los que deben concurrir todos los agentes. Pero, tal como también se plantea en este documento, mayor sería el costo si eso no se hiciera. Persistir en el actual estilo de desarrollo tiene costos aún más altos para el crecimiento económico, la sostenibilidad ambiental, las capacidades y los talentos humanos y la calidad de vida de las personas. Además, erosiona la convivencia social y de los sistemas políticos. No hacer cuesta mucho más que hacer e hipoteca el futuro.

La Agenda 2030 ofrece un marco adecuado y oportuno para poner en marcha una nueva generación de políticas como las que aquí se proponen y avanzar hacia un nuevo estilo de desarrollo que permita alcanzar un círculo virtuoso de crecimiento, igualdad y sostenibilidad para las generaciones presentes y futuras. América Latina y el Caribe cuenta con una base de recursos y capacidades que le permiten estar a la altura de los retos de escala planetaria que enfrenta. En este documento se examinan esos desafíos y se proponen orientaciones estratégicas para superarlos.

\author{
Alicia Bárcena \\ Secretaria Ejecutiva \\ Comisión Económica para \\ América Latina y el Caribe (CEPAL)
}




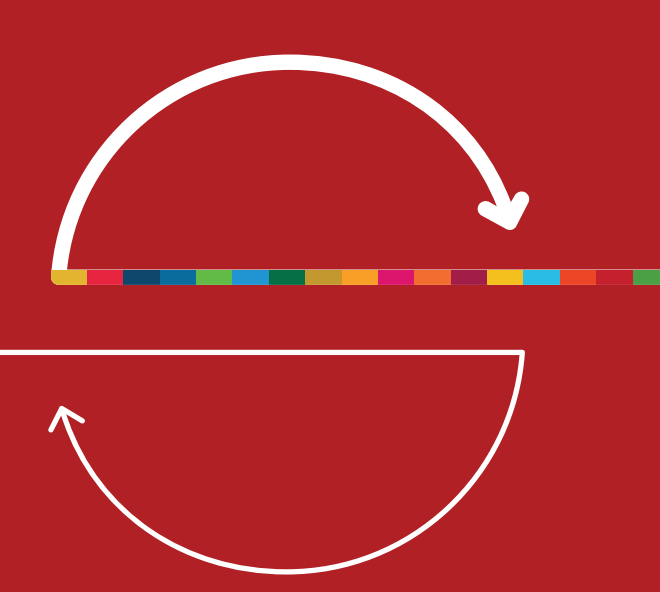

\section{CAPITULO} I

\section{La igualdad en el centro del desarrollo}

Introducción

A. Los costos de la desigualdad

1. La desigualdad de acceso a las capacidades: una barrera al crecimiento de la productividad que el mercado no corrige

2. La destrucción del medio ambiente: una forma de desigualdad entre generaciones y en la generación presente

B. La igualdad y la eficiencia requieren de más y mejores bienes públicos

C. Una cultura del privilegio arraigada

1. Las raíces históricas de la cultura del privilegio

2. Rostros del privilegio en estructuras e instituciones

D. Construcción de una cultura de la eficiencia y la igualdad

Bibliografía 



\section{Introducción}

Durante sus siete décadas de historia institucional, la Comisión Económica para América Latina y el Caribe (CEPAL) ha propuesto horizontes estratégicos de desarrollo. A partir de 2010, este compromiso adquirió un énfasis especial en la igualdad, que se expresa en los principales documentos sometidos a consideración de los países de la región en los últimos cuatro períodos de sesiones. Así, por casi una década, la CEPAL ha posicionado a la igualdad como un valor fundamental del desarrollo y como un principio ético irreductible, en sincronía con la creciente relevancia del tema en las demandas ciudadanas y el debate de políticas.

La igualdad está en el centro del desarrollo por dos razones. Primero, porque provee a las políticas de un fundamento último centrado en un enfoque de derechos y una vocación humanista que recoge la herencia más preciada de la modernidad. Segundo, porque la igualdad es también una condición propicia para avanzar hacia un modelo de desarrollo centrado en el cierre de brechas estructurales y en la convergencia hacia mayores niveles de productividad, la sostenibilidad económica y ambiental de cara a las futuras generaciones, la difusión de la sociedad del conocimiento y el fortalecimiento de la democracia y la ciudadanía plena.

La igualdad es también una construcción histórica. Implica, como hito fundacional, la abolición de privilegios y la instauración de un orden de iguales en derechos que incluye a todos los miembros de la sociedad. Sin embargo, la igualdad de derechos requiere como contrapartida la construcción de un orden sustantivo de mayor igualdad, es decir, de cierre de brechas de ingresos, capacidades, oportunidades y acceso al bienestar. Los derechos civiles, políticos y culturales se plasman en una institucionalidad que promueve las libertades, la participación política, el civismo, la igualdad de trato y de justicia, y el reconocimiento de las diferencias por sexo, género, etnia, lugar de origen, cultura y filiación socioeconómica, entre otras. Los derechos sociales y económicos se vuelven reales mediante prestaciones accesibles a todas las personas y políticas que promueven en todos los estratos el desarrollo de capacidades y la inserción en el mundo productivo a través de la innovación, la educación y el trabajo. Igualdad de derechos, justicia social y reconocimiento de la diversidad o igualdad en la diferencia son pilares de una misma plataforma para la igualdad.

El avance en materia de igualdad tiene, pues, dos caras: la de la igualdad de derechos y la de la igualdad sustantiva. El sentido último de los modernos estados de bienestar radica en que los individuos construyen su sentido de pertenencia a la sociedad y su adhesión a la vida democrática sobre la base de estas dos caras de la igualdad. Los círculos virtuosos entre la igualdad y esos sentidos de pertenencia y adhesión, a su vez, son la clave para enfrentar un mundo de complejidad creciente y en el que se hace cada vez más difícil articular en las sociedades nacionales determinantes exógenos y fuerzas endógenas.

La igualdad se refiere a igualdad de medios, de oportunidades, de capacidades y de reconocimiento (CEPAL, 2014). La igualdad de medios se traduce en una distribución más justa del ingreso y la riqueza, y una mayor participación de la masa salarial en el producto; la de oportunidades, en la ausencia de discriminación de cualquier tipo en el acceso a posiciones sociales, económicas o políticas. La igualdad en materia de acceso a capacidades hace referencia a habilidades, conocimientos y destrezas que los individuos logran adquirir y que les permiten emprender proyectos de vida que estiman valiosos. Implica igualdad en los ámbitos de la educación de calidad, la salud, el acceso al mundo digital, la nutrición y las condiciones de vida, reflejadas en un menor hacinamiento y un mayor acceso a bienes duraderos. Por otro lado, la igualdad como reconocimiento recíproco se expresa en la participación de distintos actores en el cuidado, el trabajo y el poder, en la distribución de costos y beneficios entre las generaciones presentes y las futuras, y en la visibilidad y afirmación de identidades colectivas. Entendida como igualdad relacional, hace referencia a cómo las personas perciben el orden colectivo en que viven en términos de igualdad y desigualdad, así como a diversos campos de intercambio social, como la convivencia urbana o en las escuelas. En este sentido, según se verá más adelante, la cultura del privilegio opera como un obstáculo a la igualdad en todas sus dimensiones ${ }^{1}$.

Un ejemplo de ello es la autosegregación territorial de los sectores de altos ingresos en las ciudades latinoamericanas, así como su opción de no recurrir al transporte público para evitar la proximidad de los distantes, o de enviar a sus hijos a escuelas donde solo se encuentran con hijos de familias que son parte de sus propios círculos sociales. Las élites cerradas entienden el privilegio no solo como ventaja, sino también como exclusividad: se es a la vez exclusivo y excluyente. 
En este documento se toma como punto de partida esta definición de igualdad y desde allí se avanza en una perspectiva complementaria, a saber, la de analizar la igualdad como una fuerza impulsora de la eficiencia -es decir, del pleno aprovechamiento de capacidades y recursos- y la sostenibilidad del sistema económico. La desigualdad no es solo el resultado del funcionamiento de la economía, sino también un determinante clave de ese funcionamiento, porque define el acceso de los agentes económicos a capacidades y oportunidades, y modela las reglas de juego que rigen sus decisiones. Su mensaje central es que la desigualdad conlleva grandes costos de eficiencia, lo que redunda en que su superación sea una condición necesaria para el desarrollo. En los capítulos siguientes, se analizará en detalle cada uno de los ámbitos en los que la desigualdad inhibe o limita la eficiencia económica y los mecanismos mediante los cuales ello ocurre. Se ofrece así una base empírica para el estudio de los efectos de la desigualdad sobre la eficiencia económica de las economías latinoamericanas y caribeñas. Las políticas en favor de la igualdad no solo producen efectos positivos en términos de bienestar social, sino que también contribuyen a generar un sistema económico más favorable para el aprendizaje, la innovación y el aumento de la productividad.

\section{A. Los costos de la desigualdad}

El historiador Alfred Cobban (1965) resumió con precisión la razón que llevó a los Gobiernos de Francia, en la década de 1950 y principios de la década de 1960, a adoptar planes de desarrollo económico que transformaron sustancialmente su economía: la pobreza es ineficiente. Sin embargo, durante mucho tiempo la visión predominante entre los economistas fue la opuesta, la de que eficiencia e igualdad se contraponían, a tal punto que Okun (1975) se refirió a la relación entre estas variables denominándola "la gran disyuntiva" (the big tradeoff). Se entendía que la pérdida de dinamismo económico era el costo que la sociedad debía pagar para reducir las asimetrías y desigualdades que surgían de la competencia en los mercados. Esta idea ha sido cuestionada de manera creciente en la literatura económica, de tal modo que está emergiendo un nuevo consenso en el que la desigualdad se percibe como una barrera al desarrollo. La nueva mirada se distingue de la anterior por lo menos en dos sentidos. Por un lado, esta visión se extiende para abarcar el largo plazo: busca explicar el desempeño de las economías a lo largo de décadas más que de años. Por otro, incluye entre los determinantes de la innovación y la productividad — junto a las habituales variables económicas_ - variables sociales, culturales y políticas, que tienen un papel destacado en la "nueva economía de la desigualdad y la redistribución" (Bowles, 2012).

En los modelos tradicionales, se consideraba que la desigualdad favorecía el crecimiento porque la concentración de los recursos en manos de un pequeño grupo elevaría su capacidad de ahorro y, por lo tanto, su capacidad de inversión. Inversamente, se consideraba que corregir la desigualdad comprometía el crecimiento, por cuanto reducía los estímulos al esfuerzo individual (cuyos frutos podrían ser capturados y redistribuidos por el gobierno) y generaba pérdidas de ingreso al transferir los recursos de un titular a otro en el proceso redistributivo. Esta visión ha sido puesta en jaque no solo por la evidencia empírica (Acemoglu y otros, 2013; Ostry, Berg y Tsangarides, 2014), sino también por la nueva economía de la igualdad. Esta reconoce los efectos favorables de la igualdad sobre la demanda efectiva y destaca sus efectos positivos sobre la oferta. La igualdad puede aumentar la eficiencia del sistema económico, definida en términos dinámicos como la velocidad con que se puede innovar, absorber las innovaciones generadas en otras partes del mundo y reducir la brecha tecnológica, difundir las innovaciones en el tejido productivo y, a través de ellas, elevar la productividad y abrir nuevos espacios de inversión.

En el gráfico I.1 se presenta la asociación negativa entre desigualdad y productividad en una muestra amplia de países. Esa asociación no supone una dirección única de causalidad entre las dos variables; por el contrario, se admite que la causalidad proviene tanto de la desigualdad como de la productividad en una 
interacción compleja, como se argumenta a lo largo de este y otros capítulos. Para obtener una estimación más precisa del impacto de la desigualdad sobre la eficiencia dinámica del sistema económico, se realizó un ejercicio econométrico simple que se presenta en el recuadro I.1. Se toma el crecimiento de la productividad en el tiempo como una aproximación a dicha eficiencia. El ejercicio se circunscribe a los países de América Latina y el Caribe y abarca el período comprendido entre 1980 y 2014. Los resultados indican que la desigualdad afecta negativamente el aumento de la productividad. Una diferencia de un punto en el índice de Gini entre dos países de la muestra estuvo asociada a una reducción de dos puntos porcentuales en la tasa de crecimiento de la productividad a favor del país menos desigual en el período mencionado.

La igualdad es una condición necesaria para maximizar la eficiencia dinámica de la economía al crear un ambiente institucional, de políticas y de esfuerzos que prioriza la innovación y la construcción de capacidades. Desde esta perspectiva, la igualdad es más relevante en la actualidad que en el pasado, debido al impacto de la revolución tecnológica, que torna a la construcción de capacidades y el cierre de brechas en una tarea más urgente y necesaria. Esa premura se acentúa por la insostenibilidad del actual patrón de crecimiento, que obliga a aprovechar la revolución tecnológica en favor de la transformación de la matriz energética y dirigir los procesos productivos hacia sendas bajas en carbono, preservando el medio ambiente y sus servicios productivos para las próximas generaciones.

Esta mirada al papel de la igualdad desde el lado de la oferta contribuye a viabilizar sus efectos positivos sobre la demanda efectiva. Como se examina en el capítulo III, es más probable que la distribución del ingreso ayude a la expansión de la demanda en un país cuya estructura productiva es más diversificada y competitiva. La igualdad, al favorecer la difusión de tecnologías y el aumento de la productividad, contribuye a esa diversificación. Así, se complementa la tradicional visión keynesiana sobre distribución y demanda efectiva con la mirada schumpeteriana sobre igualdad, innovación y capacidades.

Gráfico l.1

Productividad e índice de Gini, 2014

(En dólares de paridad de poder adquisitivo (PPA) y en términos porcentuales)

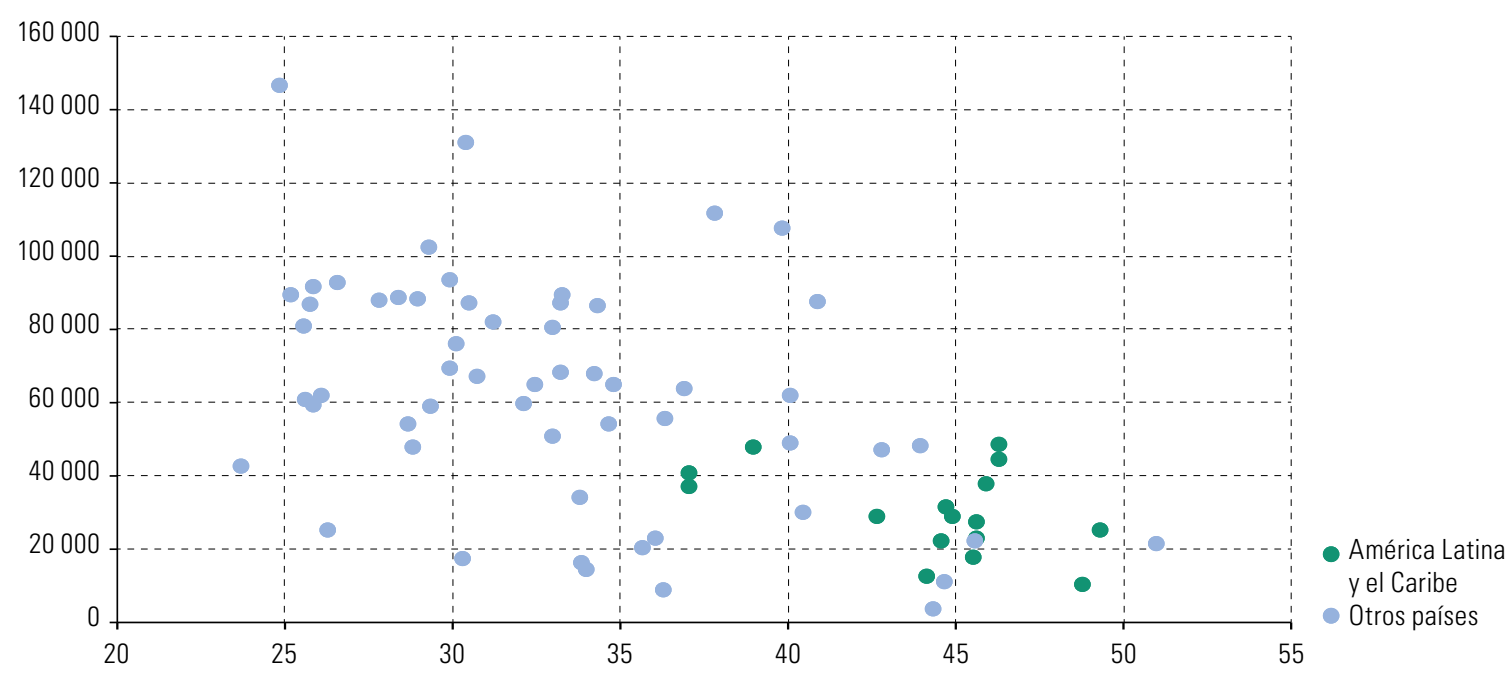

Fuente: Comisión Económica para América Latina y el Caribe (CEPAL), sobre la base de Universidad de Groningen, Penn World Table [base de datos en línea] https://www. rug.nl/ggdc/productivity/pwt/, y Universidad de Harvard, Standardized World Income Inequality Database (SWIID) [base de datos en línea] https://dataverse. harvard.edu/dataset.xhtml?persistentld=hdl:1902.1/11992.

Nota: El índice de Gini se expresa en términos porcentuales. La productividad se expresa en producto por empleado en dólares PPA de 2011. 


\section{Recuadro I.1}

\section{Estimación del impacto de la desigualdad sobre la eficiencia dinámica de la economía}

La variable que se busca explicar es la eficiencia dinámica de la economía medida por la tasa de crecimiento anual de la productividad entre 1980 y 2014. Como variables explicativas se incluyen del lado derecho de la ecuación, además del coeficiente de Gini (que representa a la desigualdad), variables que la teoría económica considera determinantes del crecimiento de la productividad, como la tasa de inversión y los niveles de capital humano (este constituye una parte de lo que la CEPAL denomina "capacidades humanas"). La inclusión del coeficiente de Gini en la regresión buscar captar los efectos de la desigualdad sobre el aprendizaje y la innovación; se espera que el coeficiente de esta variable tenga signo negativo (a mayor desigualdad, menor crecimiento de la productividad). Las variables de control buscan capturar aquellos efectos que devienen tanto del progreso técnico incorporado (capital físico) como del desincorporado (capital humano), además de los efectos de "aprender haciendo" asociados a la expansión de la inversión. Se espera en ambos casos obtener coeficientes positivos.

Como en todo ejercicio econométrico en que las variables son parte de un sistema de ecuaciones simultáneas, los resultados son preliminares y deben interpretarse con las debidas precauciones. Para corregir los problemas de endogeneidad en la estimación del modelo, se utilizó el método generalizado de los momentos (eligiendo el número de desfasajes de las variables de acuerdo con el test de Hansen). Los resultados se presentan en el cuadro 1.

\section{Cuadro 1}

Panel dinámico: crecimiento de la productividad y coeficiente de Gini, método generalizado de los momentos

\begin{tabular}{|l|r|}
\hline & Crecimiento de la productividad \\
\hline Productividad ${ }_{\mathrm{t}-1}$ & $-0,51^{* * *}$ \\
\hline Coeficiente de Gini ${ }_{\mathrm{t}-1}$ & $(0,0603)$ \\
\hline Capital humano ${ }_{\mathrm{t}-1}$ & $-0,02^{* * *}$ \\
\hline Inversión/PIB ${ }_{\mathrm{t}-1}$ & $(0,00566)$ \\
\hline Observaciones & $0,30^{* * *}$ \\
\hline Número de países & $(0,0976)$ \\
\hline Número de instrumentos & $0,27^{* *}$ \\
\hline AR(2) & $(0,122)$ \\
\hline Correlación de segundo orden & 620 \\
\hline Hansen & 23 \\
\hline Sobreidentificación & 30 \\
\hline
\end{tabular}

Fuente: Comisión Económica para América Latina y el Caribe (CEPAL), sobre la base de Universidad de Groningen, Penn World Table [base de datos en línea] https://www.rug.nl/ggdc/productivity/pwt/ (para datos de inversión, capital humano, PIB y paridad de poder adquisitivo), y Universidad de Harvard, Standardized World Income Inequality Database (SWIID) [base de datos en línea] https://dataverse.harvard.edu/dataset.xhtml?persistentld= hdl:1902.1/11992 (para el coeficiente de Gini).

Nota: El capital humano se mide mediante un índice basado en Barro-Lee Educational Attainment Dataset [base de datos en línea] http://www.barrolee.com/ y G. Psacharopoulos, "Returns to investment in education: a global update", World Development, vol. 22, № 9, 1994. La productividad se mide como el producto real en paridad de poder adquisitivo en dólares de 2011 / número de empleados (Penn Tables). Inversión / PIB corresponde a la inversión bruta en capital fijo como porcentaje del PIB (Penn Tables). Entre paréntesis se muestran los valores de la desviación estándar.

Todos los coeficientes de las variables explicativas muestran los signos esperados. El ejercicio pasó adecuadamente las pruebas de especificación indicadas en el cuadro 1.

Fuente: Comisión Económica para América Latina y el Caribe (CEPAL). 


\section{La desigualdad de acceso a las capacidades: una barrera al crecimiento de la productividad que el mercado no corrige}

Las desigualdades de acceso a la educación y la salud, al reducir las capacidades y las oportunidades, comprometen la innovación y los aumentos de productividad. Cuando una persona abandona sus estudios antes de terminar la educación primaria o secundaria, su potencial productivo se resiente por el resto de su vida activa. El menor salario que recibirá, ceteris paribus, respecto a trabajadores con más años de educación formal es un indicador de la pérdida de productividad y bienestar que conlleva ese abandono. La magnitud de esta pérdida es muy elevada a lo largo del tiempo. El costo para la sociedad no se agota en la pérdida futura de ingresos de la persona que no continúa sus estudios, ya que hay externalidades positivas asociadas a la interacción entre personas con alto nivel de educación²; en otras palabras, el beneficio social de la inversión en educación va más allá del beneficio privado. Cuando la desigualdad impide el acceso a la educación, sus efectos no son localizados, sino que además se difunden, afectando el conjunto del sistema económico.

En sociedades muy desiguales, la decisión de abandonar en forma temprana los estudios no refleja únicamente diferencias de talento o esfuerzo, sino también menores oportunidades de acceso a la educación - por ejemplo, la falta de financiamiento, la escasa oferta de centros de enseñanza de calidad en el barrio o región geográfica o la necesidad de ingresar tempranamente en el mercado laboral—. La correlación entre el nivel educativo alcanzado por padres e hijos a lo largo de varias generaciones es una expresión de esa desigualdad: es mucho más alta en economías desiguales, como las de América Latina y el Caribe, que en sociedades más igualitarias (véase el capítulo IV). Si la sociedad ofreciera las mismas oportunidades de acceso a la educación en el punto de partida, no habría motivos para esta correlación. La desigualdad en materia de educación es una correa de transmisión intergeneracional de la desigualdad de capacidades y oportunidades, y un mecanismo clave que perpetúa la baja productividad ${ }^{3}$.

Pero no son solo las asimetrías de acceso las que cuentan. Aun cuando todas las personas tuvieran igualdad de acceso a las capacidades al comienzo de la vida, la discriminación afectaría sus expectativas de oportunidades laborales. En sociedades marcadas por la discriminación por sexo o condición étnico-racial, las personas discriminadas saben que enfrentarán un techo en su carrera o que, por lo menos, estarán en desventaja frente a sus pares de otro sexo o condición étnico-racial. En el gráfico I.2, se muestra que las personas afrodescendientes e indígenas alcanzan menos años de escolaridad promedio y tienen ingresos del trabajo sensiblemente menores que las no afrodescendientes ni indígenas ${ }^{4}$. Esto representa un desincentivo para las mujeres, afrodescendientes e indígenas, quienes a pesar de sus logros educativos no tienen mejores perspectivas en el mercado de trabajo. Todo desincentivo al aprendizaje es una barrera a la innovación y la productividad, que se suma a la pérdida más directa e inmediata que significa la postergación de una persona talentosa.

En suma, corregir la desigualdad no es un beneficio que solo pueden permitirse los países que cuentan con elevados niveles de ingreso, sino una condición necesaria para que los países rezagados se aproximen a los niveles de productividad de los primeros.

2 Por esta razón, los investigadores y científicos se ven atraídos por las instituciones de excelencia y se concentran en ellas, en lugar de dispersarse en otras que no cuentan con las capacidades complementarias que demanda su trabajo.

3 En el capítulo IV se analiza cómo la desigualdad en materia de capacidades y oportunidades afecta la productividad y la eficiencia del sistema, fenómeno especialmente grave en el caso del acceso a la salud. Por su parte, los mecanismos vinculados a la desigualdad de acceso a la infraestructura y a la conformación de sistemas centro-periferia en las economías nacionales se estudian en el capítulo V.

4 El término "afrodescendiente" es aceptado en algunos países, pero rechazado en otros. La CEPAL reconoce ese debate y el hecho de que se trata de un concepto que no cuenta con aceptación general. 


\section{Gráfico 1.2}

América Latina (países seleccionados): ingresos laborales mensuales medios entre los ocupados de 15 años de edad y más, según sexo, condición étnico-racial y años de escolaridad, total nacional, alrededor de 2015 (En dólares de 2010 de paridad de poder adquisitivo)

A. Nueve países, según origen étnico (indígena o no indígena)

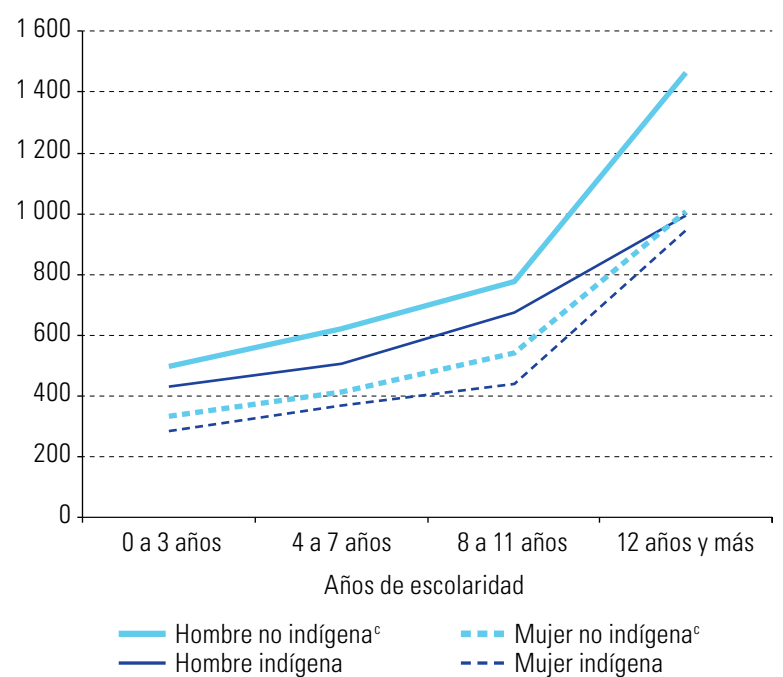

B. Cuatro países, según origen racial (afrodescendiente o no afrodescendiente) ${ }^{\mathrm{b}}$

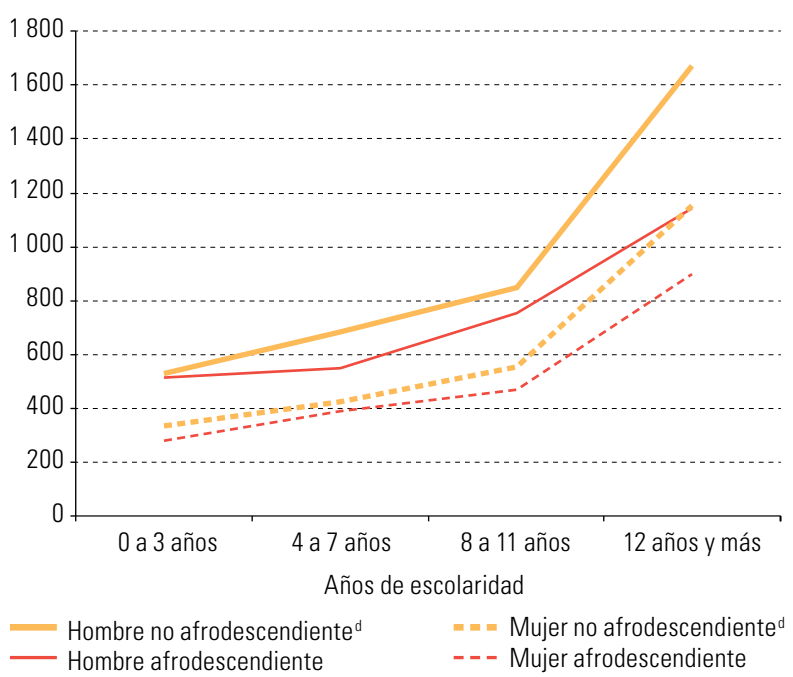

Fuente: Comisión Económica para América Latina y el Caribe (CEPAL), sobre la base de Banco de Datos de Encuestas de Hogares (BADEHOG).

a Incluye: Bolivia (Estado Plurinacional de) (2015), Brasil (2015), Chile (2015), Ecuador (2016), Guatemala (2014), México (2016), Nicaragua (2014), Perú (2016) y Uruguay (2016).

b Incluye: Brasil (2015), Ecuador (2016), Perú (2016) y Uruguay (2016).

${ }^{\mathrm{c}}$ No incluye población afrodescendiente.

d No incluye población indígena.

\section{La destrucción del medio ambiente: una forma de desigualdad entre generaciones y en la generación presente}

La sostenibilidad ambiental debe ser analizada como un problema de justicia intergeneracional que no se reduce a encontrar una apropiada tasa de descuento del consumo presente frente al consumo futuro (Beltratti, Chichilnisky y Heal, 1993). Abarca también una trayectoria de crecimiento que otorgue a las futuras generaciones el derecho de gozar del mismo nivel de bienestar que las generaciones presentes, derecho que se compromete en la medida en que se destruye el ecosistema. En un contexto en que esa destrucción y el aumento de la temperatura media mundial ocurren a tasas más altas que lo esperado (véase el gráfico I.3), el imperativo de la igualdad intergeneracional es impostergable.

En la perspectiva de este documento, la desigualdad entre generaciones conlleva un costo de productividad futura en la medida en que disminuyen los servicios productivos del ecosistema. Mientras tanto, también en las actuales generaciones la desigualdad afecta el medio ambiente y la productividad.

Un ejemplo de ello es la emisión de contaminantes en las ciudades según el medio de transporte que se utilice, con marcados efectos en la salud ${ }^{5}$. Las políticas de infraestructura urbana y de uso del suelo en la región penalizan fuertemente el transporte colectivo del que dependen los sectores de ingresos más bajos. Esta penalización es resultado de la desigualdad y la segregación en las políticas de infraestructura urbana. Al favorecer el transporte individual, la desigualdad tiene consecuencias ambientales negativas, pero además refuerza sus efectos negativos sobre la productividad de las personas, ya que los sectores de menores ingresos deben realizar viajes más largos y frecuentemente viven en barrios más expuestos a la contaminación. A la ausencia de justicia intergeneracional en materia ambiental (con sus correspondientes costos de bienestar y productividad), se suma la forma desproporcionada en que cada segmento de ingreso contribuye a la contaminación y está expuesto a sus efectos en cada generación.

En el capítulo V se examinan en detalle los costos que supone para la productividad la destrucción del medio ambiente. 


\section{Gráfico l.3}

Anomalia de la temperatura superficial anual en el mundo, 1900-2100, respecto del promedio 1986-2005

(En grados Celsius)

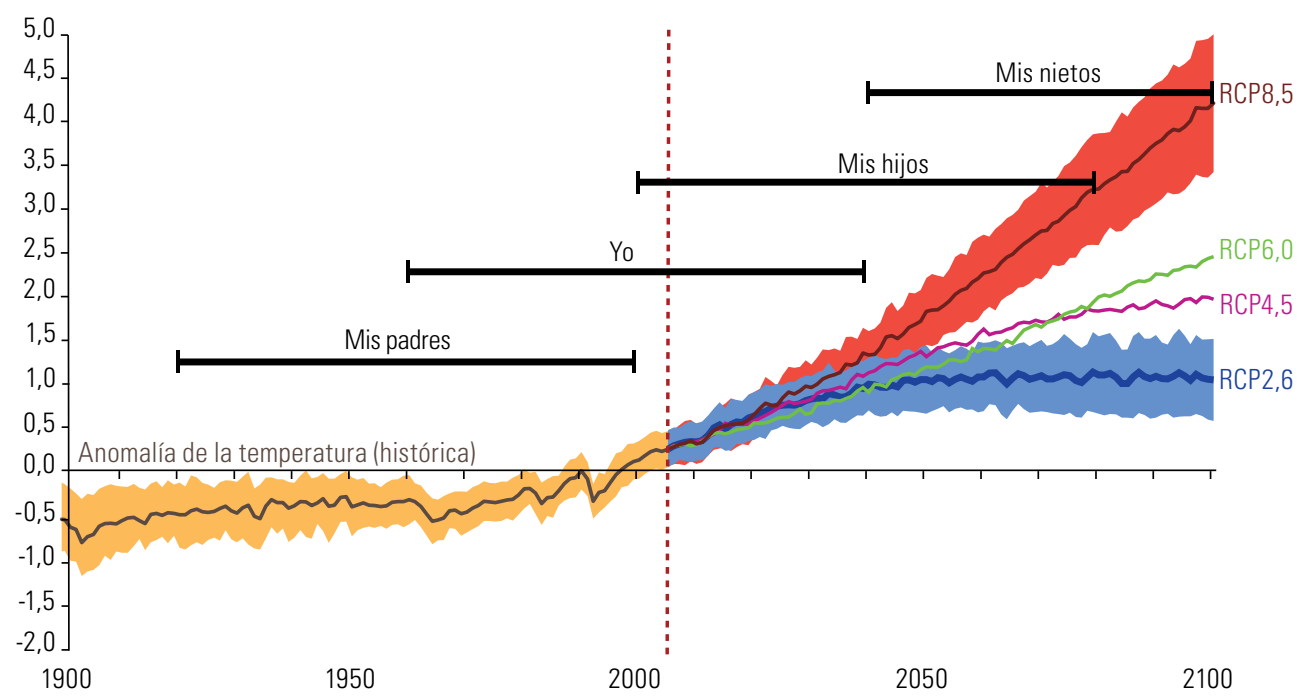

Fuente: Comisión Económica para América Latina y el Caribe (CEPAL), sobre la base de Grupo Intergubernamental de Expertos sobre el Cambio Climático (IPCC), Climate Change 2014: Impacts, Adaptation, and Vulnerability. Part B: Regional Aspects. Contribution of Working Group II to the Fifth Assessment Report of the Intergovernmental Panel on Climate Change, V. R. Barros y otros (eds.), Cambridge, Cambridge University Press, 2014, y D. Weston, "State of the planet, Kyoto and technical fixes", The Political Economy of Global Warming: The Terminal Crisis, Londres, Routledge, 2013.

Nota: RCP: trayectoria de concentración representativa; RCP2,6: escenario de mitigación conducente a un nivel de forzamiento radiativo muy bajo; RCP4,5 y RCP6,0: escenario de estabilización; RCP8,5: escenario con un nivel muy alto de emisiones de gases de efecto invernadero.

\section{B. La igualdad y la eficiencia requieren de más y mejores bienes públicos}

Un determinante común de los problemas causados por la desigualdad es la ausencia o la baja calidad de bienes públicos como la seguridad, la educación, la salud y el medio ambiente, al igual que la carencia de sistemas de reglas que garanticen la igualdad de oportunidades.

Tal vez el principal bien público que el Estado ofreció en sus orígenes —y que aún hoy es un poderoso motor en la construcción de sus capacidades- fue la defensa. Buena parte de las innovaciones que han aplicado empresas líderes en sus mercados tienen su origen en investigaciones con fines de defensa o fueron muy influidas por ellas. Mientras tanto, los Gobiernos de las naciones desarrolladas se volcaron cada vez más a producir los bienes públicos que demandaba el estado de bienestar, sin que ello significara alejarse de la frontera tecnológica (evaluada por sus niveles de productividad) ${ }^{6}$. El tipo de régimen político imperante es un fuerte determinante de la producción de bienes públicos: existe una relación positiva y estadísticamente robusta entre democracia y oferta de bienes públicos, si se controla por el efecto del nivel de ingreso de los países (Deacon, 2009) ${ }^{7}$.

De manera similar a lo que sucede a nivel nacional, la desigualdad de ingreso y poder en el sistema internacional dificulta la transición hacia un nuevo modelo con mayor provisión de bienes públicos globales. En este sentido, la hiperglobalización —la plena liberalización comercial y financiera sin más reglas que las necesarias para reducir al mínimo los costos de transacción entre países- es incompatible con la existencia

6 Incluso en el caso de una tecnología de gran impacto, como Internet, que en sus orígenes dependió de la investigación militar —el proyecto ARPANET, del Departamento de Defensa de los Estados Unidos-, otros actores (en particular, las universidades y posteriormente las empresas) influyeron en su trayectoria. La diversidad, la flexibilidad y la descentralización de los esfuerzos de investigación contribuyeron decisivamente a su éxito y difusión (Abbate, 1999).

7 Alesina, Reich y Ribboni (2017) argumentan que la expansión en gran escala de la provisión de bienes públicos al conjunto de la población fue la manera que los Estados encontraron para lograr su participación efectiva en los esfuerzos bélicos. Una discusión desde la óptica de la justicia distributiva y la filosofía política se encuentra en Kallhoff (2011). Véase también Acemoglu y otros (2013). 
simultánea de Estados nacionales y democracia (Rodrik, 2011). Esto es así porque la hiperglobalización reduce los temas abiertos a la decisión de los habitantes de un país. En un contexto de hiperglobalización, los Estados nacionales ven reducidas sus atribuciones solamente a legitimar las reglas impuestas por los mercados. En particular, por su capacidad de transferir recursos de forma rápida y flexible entre países, los mercados financieros pueden arbitrar no solo entre las tasas de ganancia y los rendimientos de los bonos en distintas monedas, sino también entre las políticas. Los efectos de estos movimientos (sin un vínculo evidente con las variables fundamentales de la economía) sobre el valor de la moneda, la capacidad de endeudamiento y la expansión o contracción del crédito condicionan fuertemente las decisiones que pueden tomar e incluso los anuncios que pueden realizar las autoridades nacionales. Se trata, parafraseando a un ministro de De Gaulle, de un "privilegio exorbitante" en el plano de las políticas que el sistema internacional confiere a un pequeño grupo de inversores financieros. Esta movilidad, lo que no es menos importante, reduce la capacidad de los Estados de cobrar impuestos, que son sistemáticamente evadidos mediante paraísos fiscales ubicados tanto en países en desarrollo como en países desarrollados ${ }^{8}$. En ese sentido, la cultura del privilegio también se expresa plenamente en las reglas del juego del sistema internacional.

En el presente documento se ofrecen ejemplos de la insuficiente oferta de bienes públicos en las sociedades de América Latina y el Caribe, que ilustran (aunque no agotan) la existencia generalizada de la exclusión. Una característica que distingue a los países desarrollados de los países en desarrollo es la variedad y el grado de difusión que han alcanzado en el tejido social las redes y organizaciones públicas y privadas que proveen bienes públicos y generan externalidades (North, Wallis y Weingast, 2009), lo que necesariamente conduce a la pregunta: ¿por qué las economías periféricas no producen los bienes públicos requeridos para el desarrollo?

Para responder a esta pregunta es necesario mirar más allá de los determinantes inmediatos de la productividad o el crecimiento, a fin de abarcar las interrelaciones entre la economía política, las instituciones y la cultura en sociedades desiguales. La producción de bienes públicos tiene un costo y un impacto distributivo. Si bien la provisión de bienes públicos permite que el sistema económico se desplace hacia una nueva configuración con mayores niveles de eficiencia y bienestar, la transición al nuevo equilibrio supone un proceso político complejo y altamente conflictivo que tiene como correlato una redistribución de ingresos y poder entre los agentes. Aquellos que se encuentran en una posición más favorable en la actual configuración tenderán a invertir recursos y esfuerzos para obstaculizar o evitar esa transición. Esto se debe a dos razones: en primer lugar, a que los bienes públicos favorecerán sobre todo a los grupos de menores ingresos y esto se financiaría con impuestos que recaerían sobre los grupos de mayores ingresos; en segundo lugar, a que al ampliar las oportunidades de acceso a los mercados y potenciar la innovación y los cambios en los sectores productivos, la transición abre las puertas a la competencia de nuevos actores sociales y empresariales que amenazan las ganancias de los ya establecidos.

En todos estos casos, los actores que se encuentran en posiciones ventajosas -en términos simples, aquellos ubicados en la cima de la distribución — tendrán motivos para oponerse al nuevo equilibrio. Cuanto más elevada sea la desigualdad inicial en lo económico y lo político, mayores serán el poder y los incentivos de dichos actores para resistir la transición. Es por ello que la democracia y la igualdad política son necesarias para el desarrollo: abren espacios para formar coaliciones favorables a un equilibrio con mayor oferta de bienes públicos. Son condiciones necesarias, pero no suficientes porque la reacción de los actores no se deriva automáticamente de la posición que lograrían en el nuevo equilibrio. La dinámica política, la cultura y el legado histórico de cada sociedad desempeñan un papel en el proceso de facilitar o retardar esa transición, como se discute en el capítulo VI.

Lo anterior permite analizar las relaciones entre el Estado, el mercado y la sociedad desde un ángulo distinto (CEPAL, 2014). Un Estado eficaz en la producción de bienes públicos va de la mano de una sociedad civil altamente organizada y diversa, y de un mercado en que la cooperación se complementa con la innovación y la competencia. En la literatura económica tradicional frecuentemente se asume que la única institución que importa es el respeto de los derechos de propiedad, y por lo general se subentiende que ello implica una reducción de la presencia y del peso del Estado en la economía (Chang, 2006). Sin embargo, los países

Los casos recientes de filtraciones de documentos sobre cuentas en paraísos fiscales, como los denominados "papeles de Panamá" y "papeles del paraíso", revelan la extensión de estos privilegios. 
que cuentan con mejores indicadores de respeto a los contratos privados son los que aplican impuestos más altos (Besley y Persson, 2010). La razón de ello es que los impuestos son clave para financiar la construcción de las capacidades del Estado y, como consecuencia, la producción de bienes públicos. Sin esa capacidad, el dinamismo del mercado se vería mermado o sujeto a expansiones intermitentes, limitadas por la inexistencia de bienes públicos o la intensidad de los conflictos sociales generados por la desigualdad, que se pueden agudizar por la ausencia de regímenes regulatorios eficaces. Ya a comienzos del siglo XIX, un observador agudo de su época resaltó el papel de la desigualdad en la generación de instituciones ineficientes desde el punto de vista económico. En 1835, Alexis de Tocqueville describió las consecuencias de la desigualdad (en una de sus formas más brutales, la esclavitud) al comparar las economías de las dos riberas del río Ohio: la ribera derecha, donde la esclavitud había sido abolida, y la ribera izquierda, donde persistía.

"El viajero que, situado en medio del Ohio, se deje llevar por la corriente hasta la desembocadura del río en el Misisipi, navega, por así decirlo, entre la libertad y la servidumbre, y no tiene más que echar una mirada a su alrededor para juzgar en un instante cuál de ellas es la más favorable a la Humanidad.

En la orilla izquierda del río, la población está diseminada. De vez en cuando se percibe una tropa de esclavos recorriendo con aire despreocupado los campos medio desiertos. El bosque primitivo reaparece sin cesar. Se diría que la sociedad está adormecida. El hombre parece ocioso, la naturaleza ofrece la imagen de la actividad y la vida.

En la orilla derecha se eleva, por el contrario, un rumor confuso que proclama desde lejos la presencia de la industria. Ricas cosechas cubren los campos; moradas elegantes anuncian el gusto y los cuidados del labrador. Por todas partes se revela el bienestar. El hombre parece rico y contento: trabaja." (Tocqueville, 2007, págs. 413-414).

La relación entre desigualdad e instituciones es persistente. La transmisión intergeneracional de la pobreza refleja y refuerza la transmisión intergeneracional de instituciones excluyentes. Un factor explicativo de esa persistencia es que la desigualdad se incorpora a la cultura de la sociedad, que percibe como natural que ciertos grupos disfruten de los derechos que se niegan a otros. Como se verá más adelante, se conforma así una cultura del privilegio que es implícitamente aceptada tanto por los grupos privilegiados como por los excluidos.

En suma, al efecto directo de la desigualdad sobre el aprendizaje y las capacidades se agrega un efecto quizás menos visible, pero no menos poderoso y ubicuo: el debilitamiento de las capacidades del Estado y de la eficacia de las políticas públicas. La economía política de la desigualdad y su estrecha relación con las instituciones y la cultura que gobiernan las relaciones sociales son una barrera al aumento de la productividad y al crecimiento, por cuanto limitan la oferta de bienes públicos imprescindibles para la existencia de mercados competitivos y agentes innovadores. Pensar en la lucha contra la desigualdad y la pobreza como un sacrificio en términos de eficiencia implica desconocer que son determinantes centrales de los altos niveles de ineficiencia incorporados en las relaciones sociales y las estructuras productivas de las economías desiguales. Por el contrario, en una sociedad democrática los bienes públicos son una materialización de la igualdad y el sentido de pertenencia9.

\section{Una cultura del privilegio arraigada}

\section{Las raíces históricas de la cultura del privilegio}

La cultura del privilegio opera como un sustrato profundo en que se cimenta y reproduce la desigualdad en América Latina y el Caribe. Su génesis es indiscernible de la conquista y la colonización, por medio de las cuales se sometió a poblaciones indígenas a trabajos forzados y a personas afrodescendientes a la esclavitud, se expropiaron los bienes y riquezas de los pueblos originarios, se prohibieron sus creencias y valores, se

9 La provisión de bienes públicos — como bienes a los que el público puede acceder- no solo es un signo visible de solidaridad, sino también un compromiso conjunto de poner los logros colectivos a disposición de cada ciudadano. Los regímenes de bienes públicos resumen esencialmente el progreso de la sociedad (Kallhoff, 2014). 
les aplicó un maltrato sistemático y se les negó todo estatuto de ciudadanía. Esta cultura de la negación del otro fue concomitante con privilegios económicos, políticos y sociales vinculados a diferencias adscriptivas y semiadscriptivas: condición étnico-racial, género, origen, cultura, lengua y religión (Calderón, Hopenhayn y Ottone, 1994 y 1996). Constituye, a su vez, la base histórica de la cultura del privilegio que, con distintas expresiones y rangos, se perpetúa hasta hoy.

La negación del otro no solo se aplicó a personas indígenas y afrodescendientes durante la época de la colonia, sino también a mestizos, zambos y mujeres y, cuando ya se habían creado las repúblicas, se extendió a inmigrantes, campesinos, analfabetos, habitantes de tugurios y trabajadores domésticos. La colonización estableció esta marca de dominio mediante la cual el que impone la diferencia se yergue, al mismo tiempo, en juez que jerarquiza la diferencia: conquistador, colonizador, criollo, hacendado, figura conspicua, aristócrata, político.

La cultura del privilegio puede entenderse a partir de tres rasgos básicos que se remontan a la lógica colonial y que en la historia republicana se transfiguran y a la vez se preservan. El primero es la naturalización de la diferencia como desigualdad. Condiciones adscriptivas o semiadscriptivas operan como factores que justifican la desigualdad en derechos de propiedad, poder, nivel de vida, acceso a activos, redes de influencia y condición de ciudadanía. Esta homologación jerárquica entre distintos y desiguales se instaura en el sentido común de las élites y grupos dominantes, vale decir, pasa a considerarse como condición natural. El carácter hegemónico de esta forma de dominación radica, precisamente, en que una construcción histórica (la jerarquía de razas, géneros, pueblos o poblaciones) se internaliza como una realidad casi natural.

El segundo rasgo presente en la cultura del privilegio es que quien establece esta jerarquía no es un juez imparcial, sino un actor entre otros que procura apropiarse de beneficios, para lo cual se constituye a la vez en juez y parte. Este sujeto obtiene esa posición de privilegio por su origen de clase o de sangre, su posición socioeconómica, su adscripción racial o de género, su cuna, su cultura o su pertenencia a élites de poder, o una combinación de las anteriores.

El tercer rasgo propio de la cultura del privilegio es que, para operar y perpetuarse, la jerarquía tiene que difundirse a través de actores, instituciones, reglas y prácticas. De esta manera, se establece una dialéctica entre, por una parte, la naturalización de la diferencia como desigualdad y, por otra, la reproducción de las desigualdades por medio de estructuras e instituciones sociales. En esta dialéctica, la cultura del privilegio garantiza asimetrías en múltiples ámbitos de la vida colectiva, como el acceso a posiciones privilegiadas en los negocios y las finanzas; el poder decisorio o deliberativo; la mayor o menor presencia en medios que imponen ideas, ideologías y agendas políticas; la captura de recursos públicos para beneficios privados; condiciones especiales de justicia y fiscalidad; contactos para acceder a mejores empleos y servicios, y facilidad para dotarse de los mejores lugares para vivir, circular, educarse, abastecerse y cuidarse.

Por medio de la cultura del privilegio, las desigualdades pasadas se transmiten y reproducen en el presente. Así, por ejemplo, la población afrodescendiente, cuyos antepasados fueron esclavizados y sometidos a trabajos forzosos, sigue padeciendo mayores niveles de pobreza, menores niveles de educación, mayor exposición a los efectos negativos de la segregación territorial y una inserción ocupacional en los nichos más precarios del mercado laboral. Las tasas de pobreza de las poblaciones indígena y afrodescendiente son claramente mayores que las del resto de la población, al mismo tiempo que la mala distribución del ingreso ilustra la asociación entre etnicidad y desigualdad social, siendo mucho mayor el porcentaje de afrodescendientes e indígenas ubicados en el quintil más pobre (CEPAL, 2016b).

La sobrerrepresentación de la población afrodescendiente en las cárceles es otro ejemplo de la diferencia como desigualdad y es una realidad en países cuya población carcelaria se encuentra entre las más altas del mundo, como los Estados Unidos y el Brasil. En este último país, el número de personas encarceladas aumentó un 74\% entre 2005 y 2012, y el número de afrodescendientes arrestados fue equivalente a 1,5 veces el número de blancos arrestados ${ }^{10}$.

10 Véase Brasil, Secretaría General de la Presidencia de la República (2014). 


\section{Rostros del privilegio en estructuras e instituciones}

En la perspectiva del desarrollo con igualdad, la cultura del privilegio es clave por cuanto naturaliza la relación entre el lugar que se ocupa en la escala social y el mayor o menor acceso a educación, salud, trabajo, seguridad y habitabilidad del lugar en que se vive. Esta dinámica se disemina en múltiples ámbitos en los que factores estructurales e institucionales concurren para perpetuar o recrear un orden de desiguales: la fiscalidad, la apropiación de rentas de los recursos naturales o la financierización, el bloqueo de poderes fácticos a regulaciones políticas y de política, la segregación territorial y la dotación de infraestructura, la segmentación de la calidad de la vida urbana, los costos que las poblaciones pagan por la degradación ambiental y el cambio climático, las rigideces de la movilidad social intergeneracional, o la segregación de capacidades y acceso al bienestar según factores adscriptivos o de origen.

Cuanto más se correlacionan el nivel de educación, el acceso a buenos servicios de salud, la estabilidad y la movilidad ocupacional, la seguridad física y la calidad de vida que ofrece el entorno con los ingresos monetarios y el patrimonio de las familias de origen, más asumen todas esas características el rango de privilegio. Inversamente, cuanto más pueden disociarse el bienestar, la protección, la calidad de vida y la formación de capacidades de las condiciones socioeconómicas de las familias de origen, más se socava la cultura del privilegio. Esta es la lógica que subyace al estado de bienestar en sociedades desarrolladas ${ }^{11}$.

La cultura del privilegio se relaciona con el carácter estructural de la reproducción de las desigualdades. La heterogeneidad estructural de los sistemas productivos de la región constituye una verdadera fábrica social en que las brechas de productividad, incorporación de progreso técnico y acceso a mercados ampliados se vinculan a la desigualdad en materia de educación y conocimiento, ingresos y trayectorias laborales, inserción en la sociedad del conocimiento y acceso a sistemas de protección social. Dicho de otro modo, hay un refuerzo sistémico entre las trayectorias de la desigualdad y la reproducción de brechas, cuyo núcleo es la heterogeneidad estructural (CEPAL, 2010, 2012 y 2014).

Como se señala en el capítulo VI, la heterogeneidad estructural, que hunde sus raíces en la cultura del privilegio, emerge de una combinación de accesos privilegiados a los recursos naturales y captura de rentas públicas o de cuasirrentas por parte de los agentes con mayor poder económico y político, y la conjunción de estructuras poco diversificadas y de baja intensidad en conocimientos con instituciones poco eficientes. La orientación de inversiones hacia esta estructura tradicional se sustenta en incentivos de precios relativos, estructuras de gasto, subsidios, políticas de infraestructura y acceso al financiamiento que refuerzan la desigual distribución primaria de recursos. Posteriormente, la fiscalidad no logra corregir esta desigualdad porque la propia cultura del privilegio sostiene un sistema con altas exenciones tributarias y bajo impuesto a la renta.

Las instituciones pueden reforzar la heterogeneidad estructural como fábrica de la desigualdad o bien revertirla mediante políticas industriales, tecnológicas, fiscales, sociales y de mercado de trabajo. Cuanto más fuerte es la cultura del privilegio, menor espacio existe para innovar en la dialéctica entre instituciones y estructuras. La capacidad de veto de los sectores privilegiados para inhibir políticas de innovación y de redistribución de recursos es parte de esta restricción del espacio. Por otra parte, en una cultura del privilegio se compenetran intereses de élites económicas y políticas que tornan muy difícil avanzar en reformas favorables a la igualdad. Esto es claro en economías intensivas en extracción de materias primas, donde los privilegios derivados de la obtención de grandes ganancias sobre la base de bajos salarios y la sobreexplotación de recursos naturales redundan en el predominio de una cultura rentista tanto en el sector público como en el privado.

Otro aspecto clave en que se plasma la cultura del privilegio en América Latina y el Caribe es la profunda desigualdad de ingresos monetarios y la concentración de la riqueza. Por ejemplo, en el Brasil, Chile, Colombia y México el $1 \%$ más rico de la población se apropia de más del $20 \%$ del ingreso total. Como promedio regional,

11 Cuanto más se desfamiliariza y desmercantiliza el acceso a los sistemas de bienestar y protección social, más carácter universal, igualitario y ciudadano adquieren (Esping-Andersen y otros, 2003). 
el coeficiente de Gini es mucho más alto que el de otras regiones del mundo, y el país menos desigual de la región es más desigual que cualquier país no latinoamericano integrante de la Organización de Cooperación y Desarrollo Económicos (OCDE). Un pilar institucional clave en que se plasma la cultura del privilegio, que se aborda en el capítulo III, es el bajo efecto redistributivo de la fiscalidad.

En América Latina y el Caribe persisten privilegios tributarios que se concretan en exenciones, evasión y bajo impuesto a la renta. Gran parte de la carga tributaria es indirecta y recae sobre el consumo, mientras que el impuesto a la renta es inferior al que existe, en promedio, en los países de la OCDE. La carga tributaria promedio de la región es la mitad del promedio de un conjunto de 15 países de la Unión Europea, y esta diferencia se concentra en el impuesto a la renta personal. En la región, mientras que el grueso de la carga tributaria proviene de impuestos al consumo y tiene un efecto regresivo, la tasa efectiva de carga tributaria en los ingresos del decil X alcanzó un 4,8\% en 2014, en contraste con un promedio del 21,3\% en los países de la Unión Europea.

El magro efecto redistributivo de la fiscalidad, ya sea por la composición y la carga tributarias, por la falta de fiscalización efectiva o por las regalías vigentes, forma parte de un sistema de privilegios en el que quienes tienen más no perciben el compromiso social de aportar al bien común por la vía fiscal. Esto refuerza la cultura del privilegio. Por el contrario, la responsabilidad fiscal ejercida desde la política y las instituciones públicas debería ir de la mano de un mayor sentido de responsabilidad social de los sectores de mayores ingresos de la sociedad. Un claro efecto redistributivo logrado mediante la fiscalidad, que pueda ser percibido como norma de la sociedad, no solo es indispensable para promover más igualdad: es también una señal comunicativa y de formación de conciencia sobre la igualdad de derechos.

Otro aspecto en que la cultura del privilegio cristaliza en las relaciones sociales son las rigideces de la movilidad social intergeneracional. Como se ha mencionado, en América Latina y el Caribe, los logros educacionales de los hijos todavía están mucho más determinados por los de sus padres que en los países europeos. La reproducción intergeneracional de la desigualdad sigue marcada por las brechas en materia de logros educacionales que, a su vez, se traducen en brechas en trayectorias ocupacionales y acceso a la protección social. Además, opera la segregación educativa como mecanismo de aislamiento social y diferenciación en redes de relaciones. Esto último refuerza la endogamia de clase en los sectores altos, lo que a su vez preserva y reproduce un sistema de patrimonios y privilegios que funciona cuando un grupo cautela sus filiaciones de origen.

El privilegio tiene en la región dos rostros territoriales inequívocos. Uno es un mapa de las desigualdades en cuanto a capacidades, productividad y acceso a infraestructura, servicios y mercados entre regiones de un país. Otro es la segregación territorial en los grandes conglomerados urbanos, que se acentúa con las nuevas dinámicas inmobiliarias y traza con claridad el mapa de los privilegios. En esas metrópolis, hay zonas urbanas donde las vulnerabilidades se refuerzan entre sí: fracaso escolar, precariedad laboral y maternidad precoz. El lugar está marcado por una línea divisoria, de tal modo que la distribución de oportunidades condiciona en extremo las trayectorias de vida. Además, como se verá en el capítulo $\mathrm{V}$, la matriz de infraestructura, transporte, servicios básicos y costos ambientales responde a un patrón de inclusiones y exclusiones que frecuentemente se remonta a las economías de enclave.

Si bien en este documento se enfatiza el carácter arraigado de la cultura del privilegio en América Latina y el Caribe, ello no significa que los privilegios no se ejerzan a escala global. La falta de solidaridad intergeneracional en lo referente a la huella de carbono ostenta tristemente el don de la ubicuidad. La cultura del privilegio también se ejerce, o se reconstruye, en la concentración de la riqueza en el mundo, que registra una intensidad y una velocidad de aumento sin precedentes. Lo mismo puede decirse de la relación entre el ejercicio de privilegios y el reordenamiento de poderes, que refuerza asimetrías a escala global en materia de avance tecnológico, poder financiero y flujo de capitales. 


\section{Construcción de una cultura de la eficiencia y la igualdad}

La primera década del siglo XXI en América Latina y el Caribe estuvo marcada por señales positivas en lo social, como la reducción de la pobreza, algunas reformas a los sistemas de protección social que aumentaron su carácter solidario, la expansión del consumo y una leve inflexión favorable de la distribución del ingreso. Lo anterior fue de la mano de un cambio en la cultura ciudadana, en el sentido de afirmar la dignidad y asociarla a derechos efectivos y a la reciprocidad en el trato. Sin embargo, estos avances no son irreversibles. En la segunda década del siglo XXI han surgido mayores resistencias al avance en términos de igualdad de derechos y profundización de las reformas sociales. En algunos países, el péndulo empieza a moverse regresivamente mediante recortes del gasto social o retracción de derechos laborales y reformas fiscales.

Por otro lado, los avances logrados en los derechos sociales, sumados a una mayor penetración de la sociedad de la información y nuevas dinámicas de movilidad ascendente, también producen cambios culturales a través de los cuales se difunden la conciencia ciudadana y las expectativas de igualdad. La ciudadanía somete la cultura del privilegio a un escrutinio más severo. En buena medida, la crisis de legitimidad de los sistemas políticos y de los Gobiernos de la región responde a una percepción crítica respecto de privilegios enraizados en sectores de la sociedad, así como en las relaciones entre el poder y el dinero.

El fortalecimiento de la democracia pone en tensión la cultura del privilegio. Pero, al mismo tiempo, plantea un interrogante respecto de la consistencia entre el avance simbólico y el avance material de la democracia hacia una cultura de igualdad de derechos. El avance simbólico hace referencia a una institucionalidad democrática y una apertura de espacios deliberativos que inscriben en el imaginario colectivo la idea de una comunidad de iguales en derechos ciudadanos. El avance material se refiere a instrumentos efectivos que traducen esa conciencia en acciones para promover la igualdad y sancionar los privilegios.

En este campo de conflicto entre la cultura de igualdad de derechos y la cultura del privilegio, es necesario fortalecer los tres pilares sobre los que se construye la igualdad. En primer lugar, las instituciones y las políticas en favor de igualdad deben tener como complemento el avance en materia de instituciones y políticas de reconocimiento de la diferencia. De este modo, se desnaturaliza la jerarquía que pone desigualdad y diferencia como dos caras de la moneda. En su visión de la igualdad como valor fundamental del desarrollo, la CEPAL planteó esta bisagra que articula la igualdad material y la igualdad simbólica —-derechos sociales y derechos culturales- (CEPAL, 2010 y 2014). Las políticas del reconocimiento tienen, a su vez, un fundamento igualitario y democrático. El privilegio, cuando se asocia al género, la cultura, la condición étnico-racial o el lugar de origen, es cada vez más impugnado y resistido desde la lógica del reconocimiento. La mayor visibilidad pública y política de grupos tradicionalmente invisibilizados, junto a sus demandas y derechos, afirma la cultura de la igualdad.

En segundo lugar, las democracias deben combatir las prácticas características de la cultura del privilegio en las que un actor se constituye, a la vez, en juez y parte. Para ello es necesario contar con un sistema de justicia independiente y con acceso igualitario, a fin de que las prácticas de abuso se sancionen oportunamente y se den señales claras ante los delitos propios del ejercicio del privilegio - la evasión fiscal, la apropiación ilícita de rentas o el trato abusivo en la relación laboral- Complementariamente, la justicia debe empoderar a quienes requieren de la institucionalidad judicial para hacer respetar sus derechos políticos, sociales, laborales y culturales. Las políticas de no discriminación deben plasmarse en instituciones consagradas por el Estado y ser capaces de revertir la cultura del privilegio en campos y acciones concretos.

El tercer elemento es introducir cambios institucionales que reviertan la cultura del privilegio mediante pactos sociales para la igualdad, como propuso la CEPAL a los países miembros en el documento de posición presentado en el trigésimo quinto período de sesiones (CEPAL, 2014). La construcción de pactos, que se plasmen en leyes y políticas de Estado, en materias que han sido secularmente sometidas a la cultura del 
privilegio puede ejercer su efecto en el imaginario colectivo y revertir marcas culturales largamente afincadas. Los pactos son a la vez fin y medio: en cuanto frutos de un proceso deliberativo en favor de la igualdad y de aprendizaje democrático son fines en sí mismos y en cuanto instrumentos de política pública son medios para proveer de continuidad y progresividad a las políticas en favor de la igualdad. Tanto en el proceso de construcción de pactos como en su consagración institucional, se produce un aprendizaje colectivo en que la cultura de la igualdad de derechos se abre paso en el imaginario colectivo y, consecuentemente, el espacio de la cultura del privilegio se restringe. Se desarrollan así los hitos fundacionales con los que la democracia crea instituciones que favorecen la igualdad.

Promover una cultura de la igualdad requiere de instituciones que permeen las estructuras y modifiquen los hábitos. Un pacto fiscal que procure la reorientación de patrones de consumo, a fin de mejorar la provisión de servicios públicos y llevar a distintos sectores a converger en su uso, es necesario tanto para impulsar la cultura de la igualdad como para favorecer la sostenibilidad ambiental, un ámbito en que el privilegio se manifiesta como indolencia ante las externalidades ambientales negativas. La falta de preocupación por el conjunto de la sociedad y por las generaciones que vienen se expresa en patrones de consumo y de habitabilidad que priorizan la gratificación, la exclusividad y la distinción en los circuitos privilegiados. Esto se extiende más allá de las fronteras de la región y constituye una negligencia global arraigada en el ejercicio del privilegio.

La cultura de la igualdad es alentada cuando el bienestar de la sociedad se aborda de manera conjunta, con provisión de servicios y bienes públicos que todos usan y consumen. Cuando el Estado consigue proveer buenos servicios con alcance universal en materia de salud, educación, transporte, seguridad, servicios básicos y medio ambiente, ello redunda en una mayor predisposición a compromisos recíprocos. Este es uno de los logros más valiosos de los estados de bienestar avanzados. En contraste, el atrincheramiento en el consumo privado de algunos en el sector privado alimenta la cultura del privilegio. Cuando los grupos más privilegiados se encapsulan en un consumo distintivo, de alto costo monetario y que cierra filas en el mundo privado, la igualdad "relacional" es gravemente afectada (CEPAL, 2014), por cuanto se restringen las relaciones transversales entre grupos y se consolidan brechas de bienestar que, a su vez, refuerzan la cultura del privilegio.

La cultura de la igualdad es clave para avanzar en acuerdos colectivos, lo que es imperativo ante la complejidad de los desafíos, que obligan a armonizar estratégicamente los condicionantes externos y los márgenes de maniobra internos. En este documento se reitera la propuesta de un gran impulso ambiental que la CEPAL planteó en su trigésimo sexto período de sesiones (CEPAL, 2016a), vale decir, una mirada estratégica hacia el futuro que, desde la urgencia de la sostenibilidad ambiental, articule políticas industriales, macroeconómicas y sociales. Para ello se requieren amplias coaliciones sociales y políticas. Por lo mismo, es clave transitar de una cultura del privilegio a una cultura de la igualdad, pues la igualdad de derechos difunde en el tejido social un mayor sentido de pertenencia y compromiso con grandes desafíos hacia el futuro.

La mirada desde la perspectiva de la igualdad converge con las demandas de construcción de capacidades en un mundo en que se ha acelerado el cambio tecnológico, pero va más allá de esto. También converge con el énfasis que la Agenda 2030 para el Desarrollo Sostenible y los Objetivos de Desarrollo Sostenible otorgan al tema. La creciente preocupación por los elevados niveles de desigualdad que se expresa en las políticas internas de los países tiene su correlato externo en ese consenso que la comunidad internacional alcanzó en 2015. Se reconoce así que la igualdad es un factor clave de la estabilidad internacional y de la reducción de conflictos. El propósito de asegurar "que nadie se quede atrás" expresado en la Agenda 2030 refleja con claridad esa vocación universalista e incluyente.

El consenso de la comunidad internacional surge no solo de análisis técnicos, sino también del diálogo de los gobiernos y los organismos internacionales con la sociedad civil. Un ejemplo de ese diálogo fue la Primera Reunión del Foro de los Países de América Latina y el Caribe sobre el Desarrollo Sostenible, realizada en Ciudad de México en abril de 2017. En ella, autoridades de gobierno, organismos internacionales, académicos y organizaciones de la sociedad civil examinaron y constataron los avances alcanzados por la región en materia de igualdad e implementación de la Agenda 2030. Se previó entonces que estos objetivos se abordaran también en la Segunda Reunión del Foro, que se celebraría en abril de 2018 en Santiago. 
Este documento contribuye a esos diálogos y debates. Al analizar los elevados costos de la desigualdad, las pérdidas de eficiencia que implica y sus efectos en las instituciones y la cultura, se muestra que los objetivos de igualdad y reconocimiento de derechos no son parte de una mirada nostálgica a la estabilidad y, en general, al mundo anterior a la hiperglobalización. Por el contrario, son la puerta de entrada a la revolución tecnológica y la difusión de conocimientos y capacidades que sustenten la expansión de la producción, el empleo y el comercio. Al hacerlo, también se contribuye a prevenir la agudización de los conflictos políticos internacionales y el deterioro ambiental mediante la cooperación entre naciones para alcanzar el desarrollo sostenible al que se han comprometido los países en la Agenda 2030 para el Desarrollo Sostenible.

\section{Bibliografía}

Acemoglu, D. y otros (2013), "Democracy, redistribution and inequality", National Bureau of Economic Research (NBER) Working Paper, № 19746, Cambridge, Massachusetts, diciembre [en línea] http://www.nber.org/papers/w19746.

Abbate, J. (1999), Inventing the Internet, MIT Press, Cambridge, Massachussetts.

Alesina, A., B. Reich y A. Ribboni (2017), "Nation-building, nationalism and wars", Working Paper, № 23435, Cambridge, Massachusetts, National Bureau of Economic Research, mayo [en línea] http://www.nber.org/papers/w23435.

Beltratti, A., G. Chichilnisky y G. Heal (1993), "Sustainable growth and the green golden rule”, NBER Working Paper, № 4430, National Bureau of Economic Research, agosto [en línea] http://www.nber.org/papers/w4430.

Besley, T. y T. Persson (2010), "State capacity, conflict and development", Econometrica, vol. 78, № 1, The Econometric Society, enero.

Bowles, S. (2012), The New Economics of Inequality and Redistribution, Cambridge University Press, Nueva York.

Brasil, Secretaría General de la Presidencia de la República (2014), Mapa do encarceramento: os jovens do Brasil, Brasilia.

Calderón, F., M. Hopenhayn y E. Ottone (1996), Esa esquiva modernidad: desarrollo, ciudadanía y cultura en América Latina y el Caribe, Caracas, Nueva Sociedad/Organización de las Naciones Unidas para la Educación, la Ciencia y la Cultura (UNESCO).

(1994), “Una perspectiva cultural de las propuestas de la CEPAL", Revista de la CEPAL, № 52, (LC/G.1824-P), Santiago, abril.

CEPAL (Comisión Económica para América Latina y el Caribe) (2016a), Horizontes 2030: la igualdad en el centro del desarrollo sostenible (LC/G.2660/Rev.1), Santiago, julio.

(2016b), La matriz de la desigualdad social en América Latina (LC/G.2690(MDS.1/2)), Santiago, octubre.

(2014), Pactos para la igualdad: hacia un futuro sostenible (LC/G.2586(SES.35/3)), Santiago, abril.

(2012), Cambio estructural para la igualdad: una visión integrada del desarrollo (LC/G.2524(SES.34/3)), Santiago, julio. (2010), La hora de la igualdad: brechas por cerrar, caminos por abrir (LC/G.2432(SES.33/3)), Santiago, mayo.

Chang, H. J. (2006), "Understanding the relationship between institutions and economic development: some key theoretical issues", Discussion Paper, № 2006/05, Instituto Mundial de Investigaciones de Economía del Desarrollo (UNU-WIDER), julio.

Cobban, A. (1965), A History of Modern France. Volume 3: 1871-1962, Harmondsworth Penguin Books, enero.

Deacon, R. (2009), "Public good provision under dictatorship and democracy", Public Choice, vol. 139, № 1-2, abril [en línea] https://link.springer.com/article/10.1007/s11127-008-9391-x.

Esping-Andersen, G. y otros (2003), Why We Need a New Welfare State, Oxford, Oxford University Press, noviembre [en línea] http://www.oxfordscholarship.com/view/10.1093/0199256438.001.0001/acprof-9780199256433.

Kallhoff, A. (2014), "Why societies need public goods", Critical Review of International Social and Political Philosophy, vol. $17, \mathrm{~N}^{\circ} 6$, abril.

(2011), Why Democracy Needs Public Goods, Plymouth, Lexington Books.

North, D., J. J. Wallis y B. Weingast (2009), Violence and Social Orders: A Conceptual Framework for Interpreting Recorded Human History, Nueva York, Cambridge University Press, febrero.

Okun, A. (1975), Equality and Efficiency: The Big Tradeoff, Washington, D.C., Brookings Institution Press.

Ostry, J., A. Berg y C. Tsangarides (2014), "Redistribution, inequality, and growth", IMF Staff Discussion Note, № SDN/14/02, Fondo Monetario Internacional (FMI), abril.

Rodrik, D. (2011), The Globalization Paradox: Democracy and the Future of the World Economy, Nueva York, W.W. Norton \& Company, febrero.

Tocqueville, A. (2007), La democracia en América, Madrid, Ediciones Akal. 


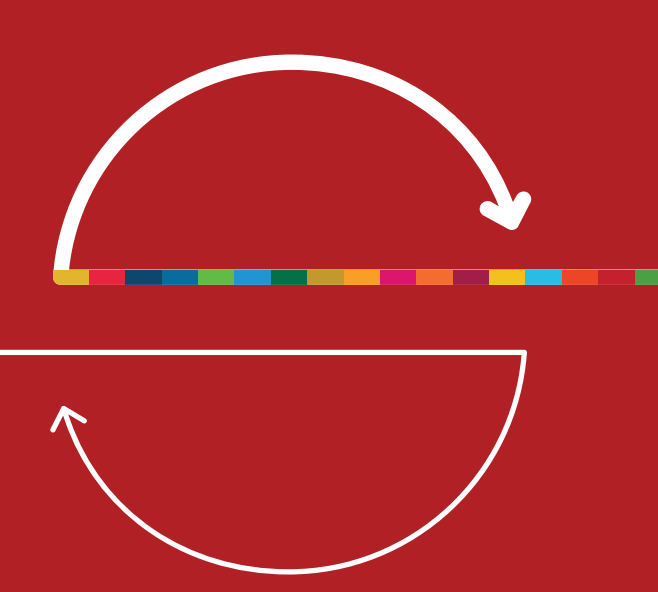

\section{CAPITULO II}

\section{Crecientes tensiones en la globalización}

A. Desarrollo y desigualdad

B. Un mundo más incierto en los ámbitos económico y tecnológico

1. La crisis de la interpretación macroeconómica dominante

2. La revolución digital agrega incertidumbre

C. De bienes a bits

1. La gran disrupción: Las tecnologías exponenciales

2. El liderazgo de las plataformas digitales

D. El comercio internacional no recupera su dinamismo previo a la crisis

E. Empresas transnacionales en busca de activos de calidad

1. El retorno del capital hacia las economías avanzadas

2. China consolida su posición como inversor

F. Una gobernanza internacional ineficaz

1. Las grandes corrientes migratorias internacionales

2. La necesidad de una nueva arquitectura financiera

3. El debilitamiento del multilateralismo en el comercio internacional

4. La solución de controversias entre inversionista y Estado

5. La dificil implementación de la gobernanza ambiental

Bibliografía 



\section{A. Desarrollo y desigualdad}

El último bienio ha sido testigo de profundos cambios económicos, tecnológicos y geopolíticos en el escenario mundial. Luego de casi un decenio de iniciada la crisis financiera global, por primera vez los tres grandes bloques económicos (Estados Unidos, Europa y Asia Oriental) están creciendo simultáneamente, aunque a ritmos muy disímiles, al tiempo que los países en desarrollo estarían aumentando su crecimiento sobre la base de la recuperación de los precios de los recursos naturales. Por su parte, la revolución digital se está acelerando, impulsada por el avance de las plataformas digitales globales y los efectos de escala y de red derivados de la difusión del acceso a los servicios digitales a casi dos tercios de la población mundial y su creciente importancia en los sectores económicos. La combinación de diferentes ritmos de reacción a la crisis, el sostenido crecimiento de China y la lucha por el control de los puntos neurálgicos de la economía digital han dado lugar a tensiones geopolíticas de intensidad inesperada.

Todos los países, en particular las economías en transición, han estado expuestos a los efectos de la globalización a través de la competencia en los mercados mundiales, como resultado de políticas de liberalización del comercio internacional y de los flujos de inversión extranjera directa (IED), acentuados por el progreso tecnológico, sobre todo en las tecnologías digitales, que contribuyó a reducir los costos de transacción y desarrollar cadenas productivas globales. La apertura de los mercados internacionales a los flujos de bienes, servicios e inversiones, y la difusión tecnológica han favorecido la aceleración del crecimiento económico y el empleo en todas las regiones, permitiendo a cientos de millones de personas salir de la pobreza. Por otro lado, el creciente nivel de interdependencia a nivel global ha aumentado la incertidumbre acerca del funcionamiento de la economía y de los factores que influyen en las principales variables económicas, expandiendo también el impacto de eventuales crisis.

La globalización y el gran crecimiento de algunas economías en desarrollo (especialmente China y Asia Oriental) han impulsado una significativa reducción de la brecha de ingresos entre países. Sin embargo, no todos se han beneficiado igualmente de la globalización. Pese al crecimiento económico, en muchos países la desigualdad en la distribución del ingreso aumentó desde comienzos de la década de 1980 hasta mediados de la década de 2010 (véase el gráfico II.1). Esa desigualdad y sus posibles causas e impactos han generado una creciente preocupación por la concentración de ingresos y de la riqueza, por lo que el tema ocupa un lugar destacado en el debate internacional ${ }^{1}$. Es particularmente importante el diagnóstico de Oxfam Internacional de enero de 2017 de que tan solo ocho hombres tienen la misma riqueza acumulada que los 3.600 millones de personas más pobres, es decir que la mitad de la humanidad².

A pesar de la disminución de la desigualdad entre naciones, en las regiones más desarrolladas la desigualdad interna se encuentra hoy en su nivel más alto en décadas y el índice de Gini (la medida de desigualdad más utilizada) aumenta en casi todas las regiones del mundo. En los países de la Organización de Cooperación y Desarrollo Económicos (OCDE), ese índice llegó a 32 en 2014, su mayor valor desde la década de 1980; en China aumentó de 28,6 en los años ochenta a 48 en 2012 (último dato disponible). La única excepción a esta tendencia es América Latina que, en la última década, alcanzó su mínimo histórico en términos de concentración del ingreso, aunque manteniéndose en los mayores niveles de desigualdad del mundo.

El número de publicaciones anuales sobre el tema de inequidad y justicia social en ciencias sociales y económicas pasó de ser poco menos de 1.000 en 1991 a 6.000 en 2014. Los investigadores en ciencias económicas publican el mayor número de artículos sobre la desigualdad. El crecimiento del número de artículos se aceleró a partir de 2007/2008 (ISSC/IDS/UNESCO, 2016).

Véase [en línea] https://www.oxfam.org/en/pressroom/pressreleases/2017-01-16/just-8-men-own-same-wealth-half-world. 


\section{Gráfico Il.1}

İndice de Gini, promedios quinquenales
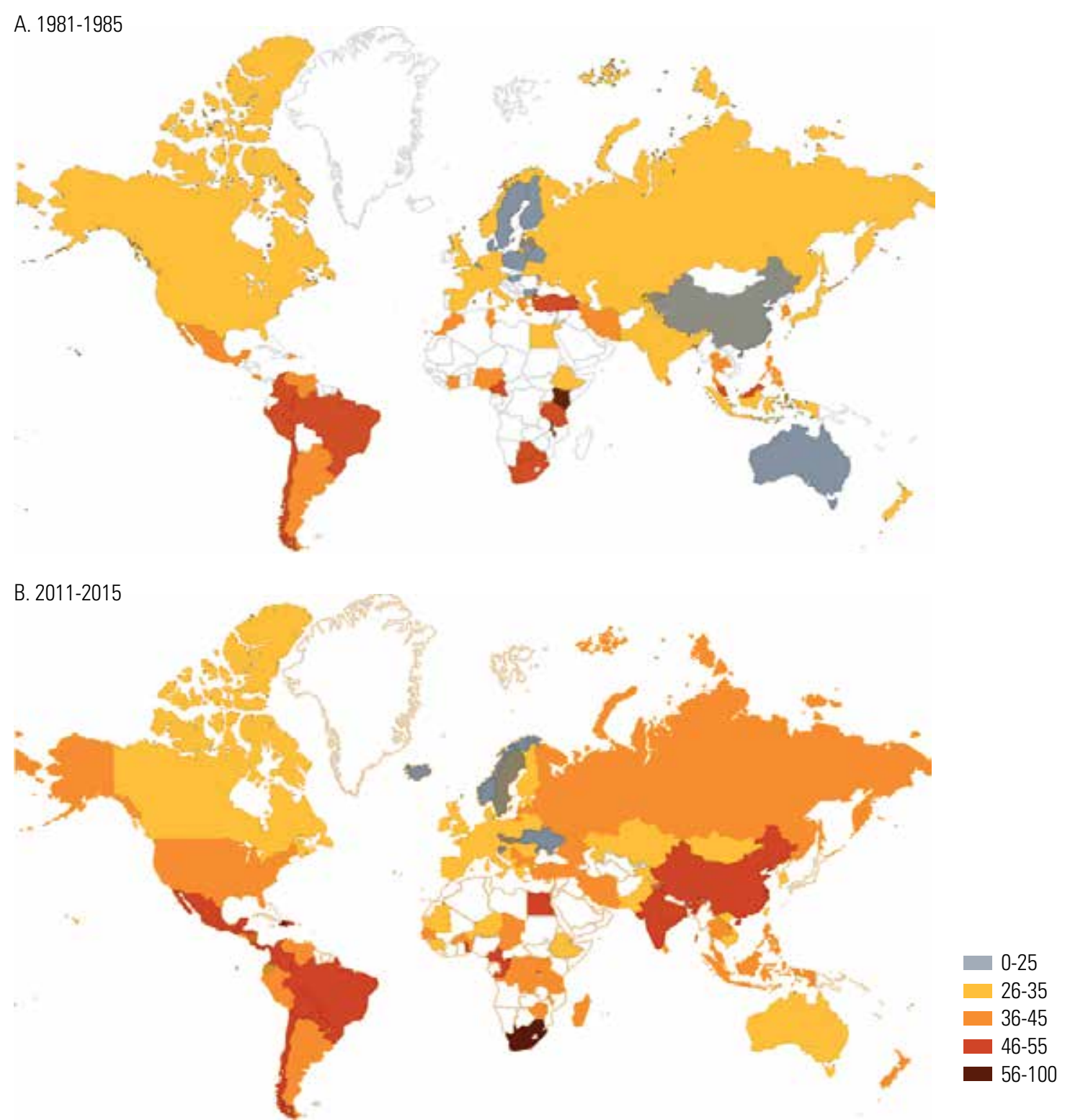

Fuente: Instituto Mundial de Investigaciones de Economía del Desarrollo (UNU-WIDER), "World Income Inequality Database (WIID 3.4)" [base de datos en línea] https://www.wider.unu.edu/database/world-income-inequality-database-wiid34.

Dada la multiplicidad de variables que inciden en la determinación del ingreso de los individuos y la distribución de los recursos entre países, es imposible desentrañar cuánto de la creciente desigualdad se debe a la globalización económica y cuánto a la apertura del comercio internacional. Sin embargo, un análisis de la distribución global de los ingresos puede facilitar la identificación de los efectos de la globalización en distintas partes del mundo y grupos de ingreso.

A partir de los datos de World Inequality Report 2018 (Alvaredo y otros, 2018), en el gráfico II.2 se muestra el crecimiento acumulado del ingreso medio en cada uno de los percentiles de la distribución global del 
ingreso en el período 1980-2016³ . Se observa que la globalización y la apertura de los mercados impulsaron en todos los países un aumento significativo del ingreso real per cápita. Sin embargo, el gráfico confirma que los ingresos globales crecieron a velocidades distintas, generando ganadores y perdedores. Se podrían definir como ganadores en términos de crecimiento del ingreso real per cápita a los individuos con un ingreso medio alrededor de los percentiles 20 y 60 —en su mayor parte personas de China o India, economías que en los últimos 30 años crecieron a tasas sin precedentes- y a los que tienen un ingreso medio alrededor del percentil 99 - que corresponde al $1 \%$ más rico del mundo-. Los que se rezagaron relativamente fueron aquellos con un ingreso medio per cápita entre el percentil 70 y el percentil 90 de la distribución global, en su mayor parte individuos que pertenecen a las (viejas) clases medias de los países más avanzados.

\section{Gráfico II.2}

Crecimiento del ingreso real por adulto por percentil de ingresos en la distribución global, 1980-2016 (En porcentajes)

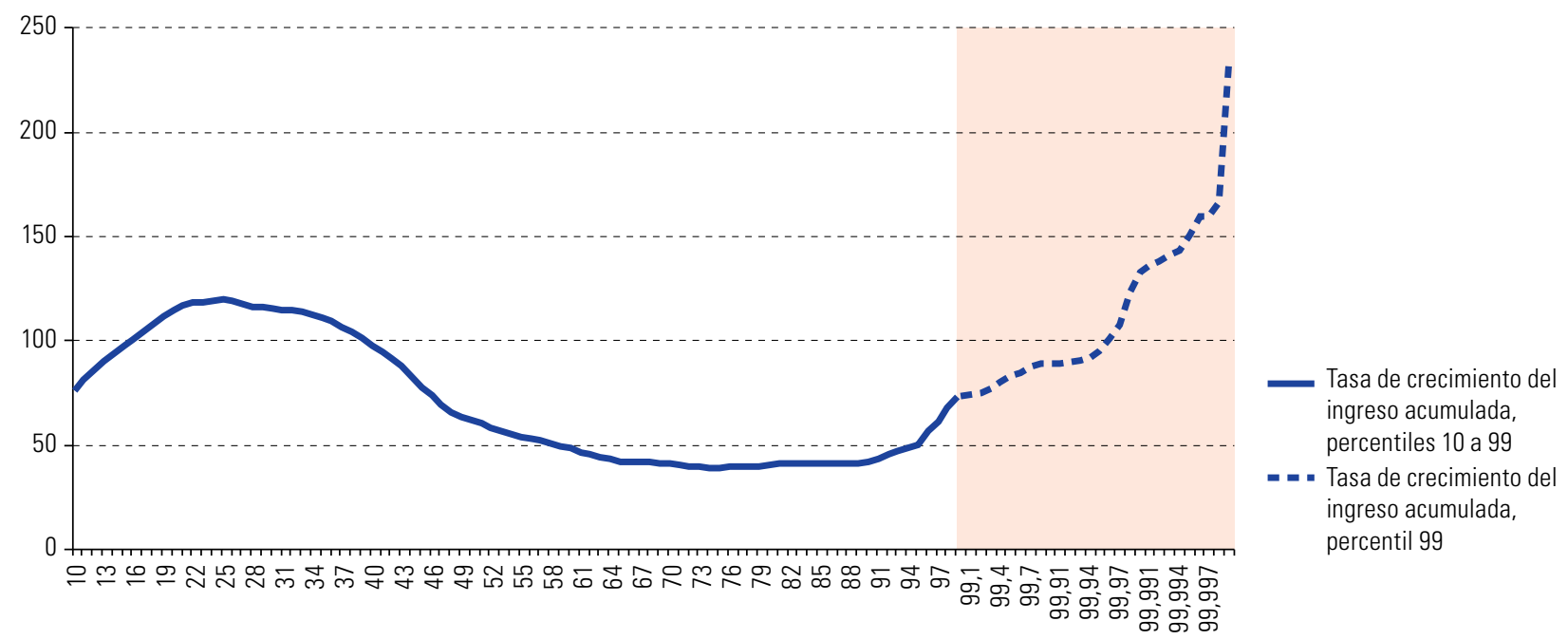

Fuente: Comisión Económica para América Latina y el Caribe (CEPAL), sobre la base de F. Alvaredo y otros, World Inequality Report 2018, World Inequality Lab, 2018 [en línea] http://wir2018.wid.world/files/download/wir2018-full-report-english.pdf.

Del análisis surge una marcada evidencia de la polarización de los beneficios de la globalización a favor de los más ricos. El $1 \%$ más rico del mundo capturó el $27 \%$ del monto total acumulado del crecimiento de los ingresos entre 1980 y 2016 , mientras que el $50 \%$ de la distribución capturó solo el 12\% (Alvaredo y otros, 2018). Esta tendencia se confirma en el gráfico II.3, que muestra que el $1 \%$ más rico de la población incrementa sus ingresos a un ritmo sostenido en la mayoría de los países.

Aunque muchos factores han contribuido al aumento de la desigualdad, gran parte de la polarización de los ingresos responde a los cambios en la distribución de los salarios (OCDE, 2011). En la mayoría de las economías desarrolladas y en muchas de las economías en transición, los salarios de nivel alto crecieron más que el resto. Distintos factores explican el deterioro de los salarios de los trabajadores menos calificados, incluidos la globalización de la producción, la movilidad transfronteriza del capital, el cambio tecnológico y la automatización. Estos procesos fueron reforzados por factores políticos, como la pérdida de poder de los sindicatos y el debilitamiento de las normas referentes a los salarios mínimos (Autor, 2014). El aumento de la desigualdad de los salarios contribuyó a la crisis financiera de 2008-2009 y a la lenta recuperación, primero en los Estados Unidos y después a nivel mundial (Setterfield, 2013).

3 El ingreso por adulto se informa a partir de la distribución del ingreso total nacional por adulto (Alvaredo y otros, 2018). 


\section{Gráfico Il.3}

Evolución de los ingresos del 1\% más rico de la población mundial, 1980-2015

(En porcentajes del ingreso total)
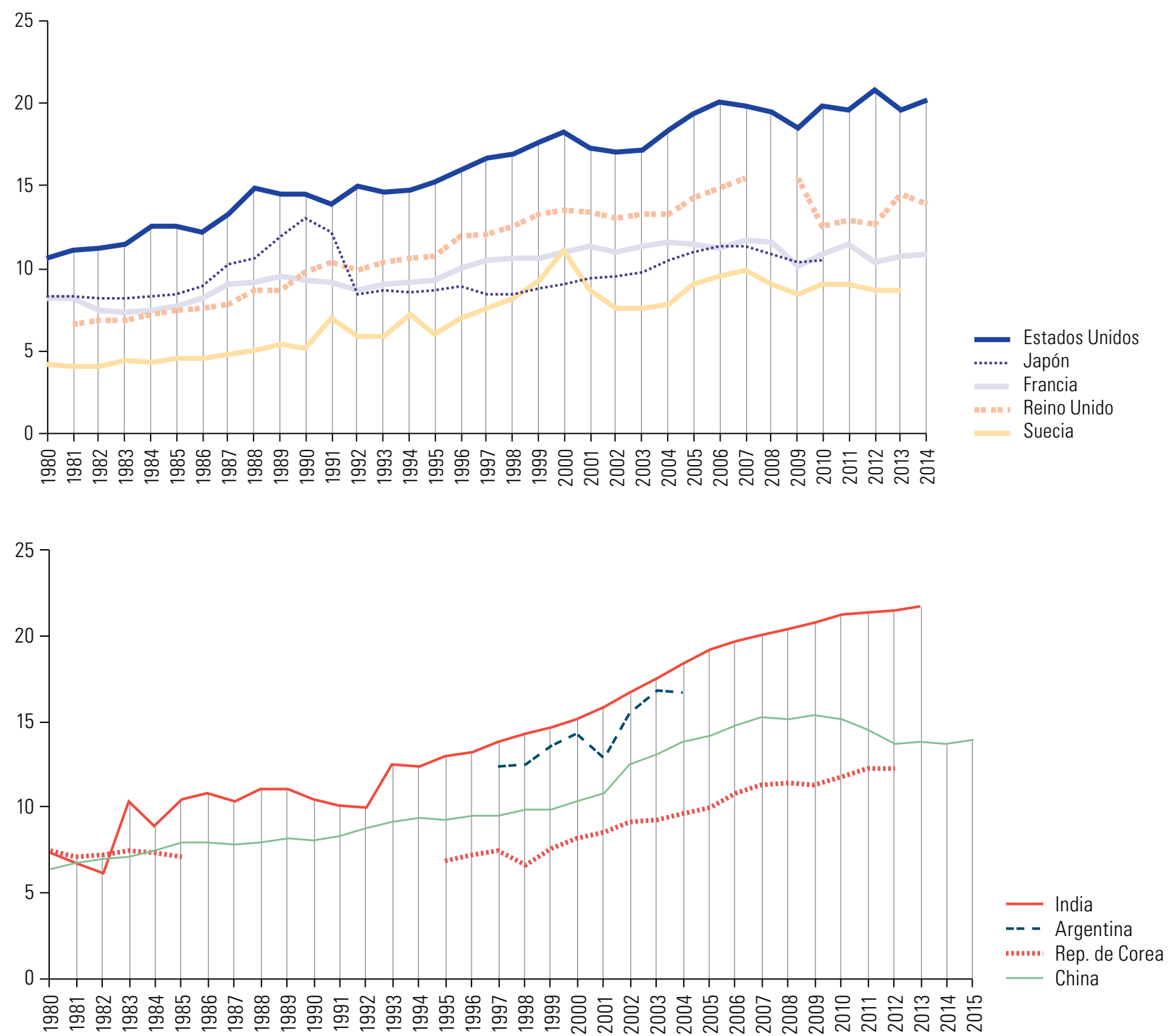

Fuente: World Wealth and Income Database (WID) [base de datos en línea] http://wid.world/es/pagina-de-inicio/.

Aunque es difícil separar empíricamente el efecto de las distintas fuerzas que interactúan en el sistema económico, las conclusiones del análisis de Alvaredo y otros (2018), Milanovic (2016), y el análisis presentando más arriba sobre la evolución de los ingresos por decil, ayudan a entender el cuestionamiento que se hace a la globalización en los países avanzados. La polarización de los ingresos disminuyó los salarios de la clase media, lo que llevó a las familias a recurrir al endeudamiento para mantener sus niveles de bienestar. Al mismo tiempo, los que se beneficiaron del crecimiento de sus ingresos aumentaron sus inversiones en activos financieros más que en las actividades productivas. El creciente endeudamiento de la clase media, junto con el aumento desproporcionado de los activos financieros, provocaron el desplome de los títulos hipotecarios de alto riesgo, que fue un factor decisivo en la crisis de 2008. El alto nivel de desigualdad y la incapacidad de estimular el crecimiento de los salarios deprimieron la demanda de consumo y dificultaron la recuperación de la economía global. 


\section{B. Un mundo más incierto en los ámbitos económico y tecnológico}

\section{La crisis de la interpretación macroeconómica dominante}

Pese al reciente repunte del crecimiento, persiste la incertidumbre sobre la consolidación de la recuperación 4 . El crecimiento del producto interno bruto (PIB) per cápita en las mayores economías exhibe una importante desaceleración respecto de su pauta histórica. Por otra parte, en las principales economías desarrolladas la inversión como porcentaje del PIB todavía es menor que los niveles previos a la crisis. El capital productivo sigue aumentando lentamente y el crecimiento de la productividad no recupera sus niveles históricos. Las tasas de inflación siguen siendo demasiado bajas y, aunque el desempleo registra niveles históricamente bajos (especialmente en los Estados Unidos y el Japón), los salarios nominales se mantienen estancados (véase el gráfico II.4).

Los programas de estímulo monetario adoptados por las economías avanzadas después de la crisis buscaban recuperar el crecimiento mediante una expansión de la base monetaria y una aceleración de la inflación ${ }^{5}$. Se esperaba que la reducción de las tasas de interés de largo plazo estimulara la demanda agregada. Sin embargo, pese a las políticas monetarias expansivas, el sesgo recesivo de la economía mundial se prolongó más de lo anticipado, intensificando las tensiones sociales y aumentando los cuestionamientos a la globalización y al modelo económico tradicional (CEPAL, 2016a).

Además de los riesgos y los costos que implica un sector financiero global desligado de la economía real, altamente concentrado en grandes instituciones financieras interconectadas (CEPAL, 2016a), la economía mundial experimenta intermitentemente los efectos de burbujas que se desplazan entre sectores, países y actividades, como las que caracterizaron a los bienes raíces, la inversión en productos básicos o las criptomonedas. Ante esta situación, diferentes organismos han prevenido sobre la posibilidad de una nueva crisis financiera derivada del crecimiento de burbujas especulativas y de factores de riesgo, como la deuda china, los desequilibrios en cuenta corriente o el exceso de liquidez internacional.

La falta de reacción de la inflación a los bajos niveles de desempleo y a la expansión económica, sobre todo en los Estados Unidos y el Japón, apunta a un debilitamiento de la relación entre esas variables y cuestiona la validez de algunos modelos económicos tradicionales. El hecho de que algunas variables cruciales no respondan de acuerdo con lo esperado pone en duda que la economía mundial esté saliendo definitivamente de la trampa de bajo crecimiento. Asimismo, queda en evidencia que la relación entre crecimiento económico, empleo e inflación es más compleja y menos predecible de lo que se creía.

En los Estados Unidos, el Sistema de la Reserva Federal comunicó que empezará un proceso de reducción de su balance y que ajustará las tasas de interés gradualmente, con la perspectiva de una posible intervención en la eventualidad de un cambio de trayectoria del crecimiento (Banco de la Reserva Federal de Nueva York, 2017; Yellen, 2017a). Su expresidenta se ha manifestado optimista frente a la futura respuesta de la inflación al crecimiento económico y al bajo desempleo, pero ha admitido en varias ocasiones que los bancos centrales han malinterpretado la fuerza del mercado laboral, el grado de consistencia entre las expectativas de inflación de largo plazo y las metas de inflación, e incluso los determinantes de la inflación (Yellen, 2017b). Por otro lado, el Banco Central Europeo confía en la estabilidad del crecimiento y el resurgimiento de las dinámicas inflacionarias (Banco Central Europeo, 2017). En el Japón, el banco central ha declarado que la situación económica y las expectativas de inflación no justifican una interrupción de las políticas de flexibilización cuantitativa (Banco Central del Japón, 2017).

En 2017, la tasa de crecimiento del PIB mundial aumentó al 3,4\% en comparación con el 3\% del año anterior y se espera que en 2018 alcance el 3,7\%. Pese a esta aceleración, el crecimiento se mantendría en niveles inferiores al promedio del quinquenio previo a la crisis. En un contexto de aumento de la producción industrial, las inversiones y el consumo privado, el comercio internacional reafirmaría su recuperación iniciada a finales de 2016.

5 La expansión cuantitativa es una política monetaria no convencional adoptada ante la ineficacia de la política monetaria tradicional para estimular el crecimiento económico. Un aumento de la base monetaria —-mediante la compra de títulos de deuda pública y otros instrumentos financieros—implica una mayor cantidad de moneda en circulación. Esto reduciría su valor y estimularía el alza de los precios. La expansión cuantitativa fue adoptada en los años noventa en el Japón, a finales de 2008 en los Estados Unidos, en 2009 en el Reino Unido y en 2011 y en varias etapas hasta hoy en la eurozona. 


\section{Gráfico II.4}

Mundo, Estados Unidos, eurozona, Japón y países seleccionados: evolución de distintas variables económicas

\section{A. Tasas de variación del PIB real mundial, 2000-2017} (en porcentajes)

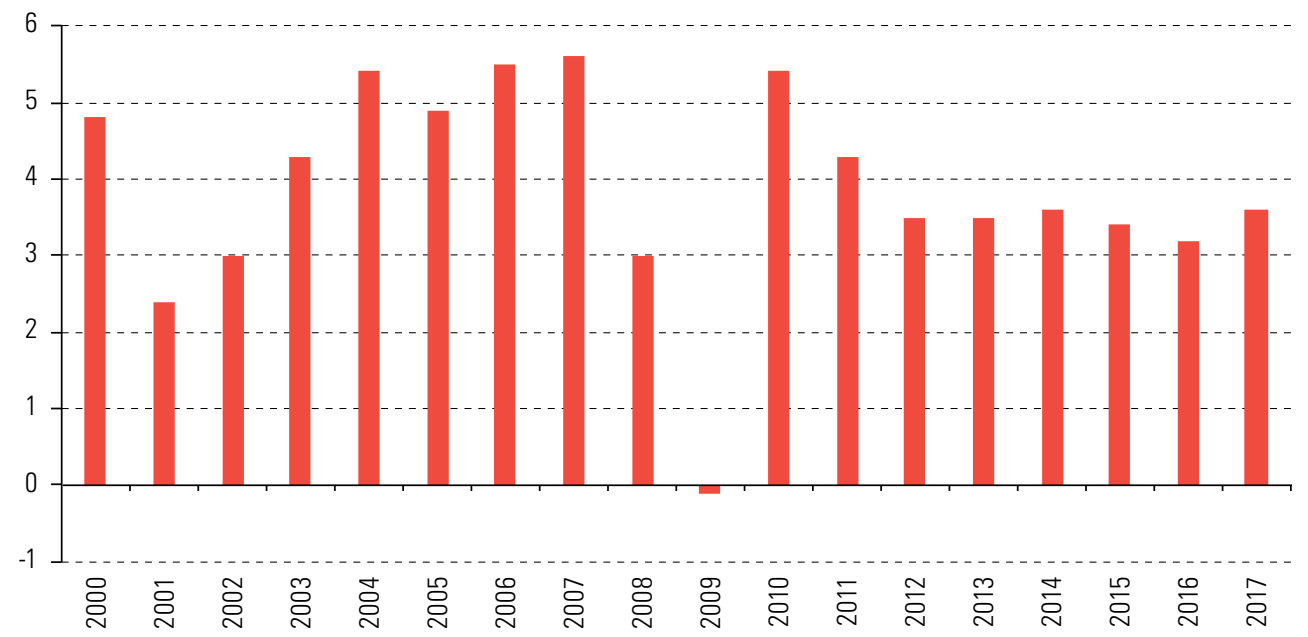

Fuente: Comisión Económica para América Latina y el Caribe (CEPAL), sobre la base de Fondo Monetario Internacional (FMI), World Economic Outlook, 2017 [base de datos en línea] https://www.imf.org/external/pubs/ft/weo/2017/02/weodata/index.aspx.

\section{B. Países seleccionados: participación de la inversión en el PIB, 1990-2018a} (en porcentajes)
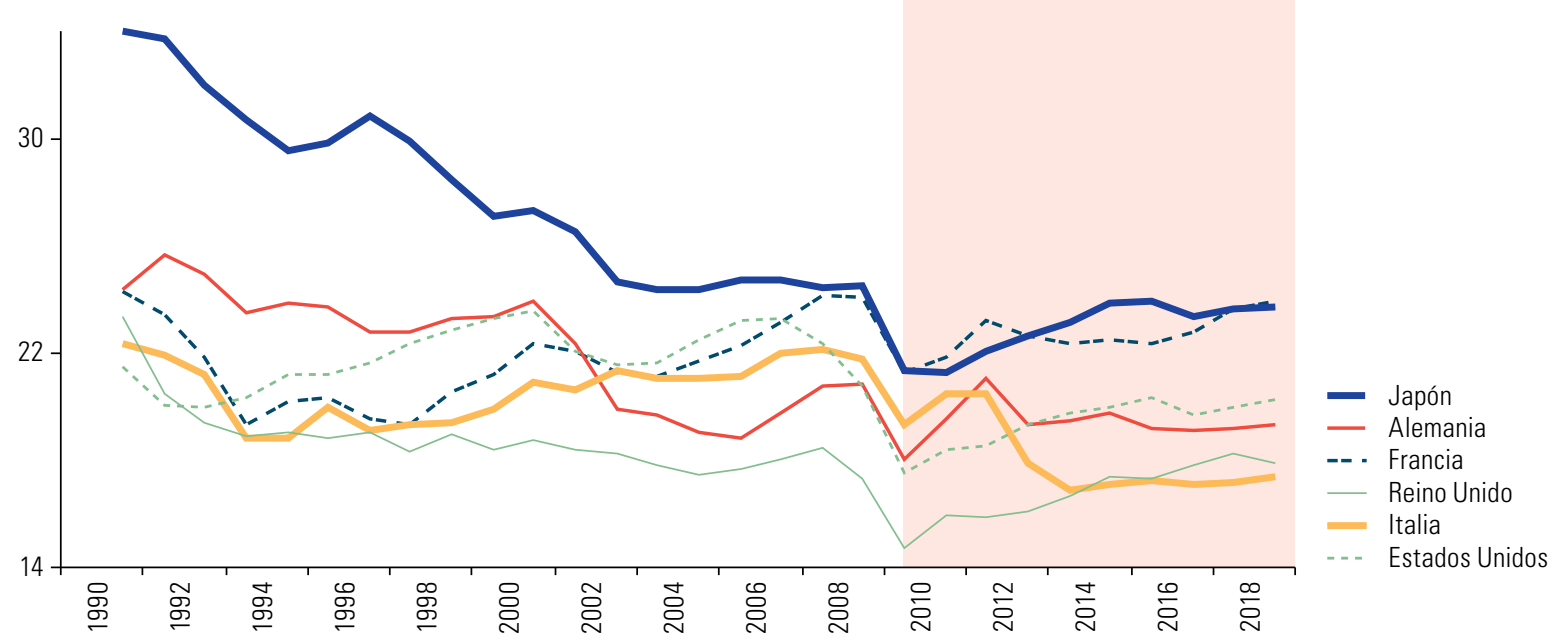

Fuente: Comisión Económica para América Latina y el Caribe (CEPAL), sobre la base de Fondo Monetario Internacional (FMI), Perspectivas de la economía mundial: ¿está cobrando impulso?, abril de 2017.

a Los datos de 2017 y 2018 son proyecciones. 


\section{Gráfico Il.4 (continuación)}

\section{Estados Unidos, eurozona y el Japón: tasa de desempleo} (en porcentajes)

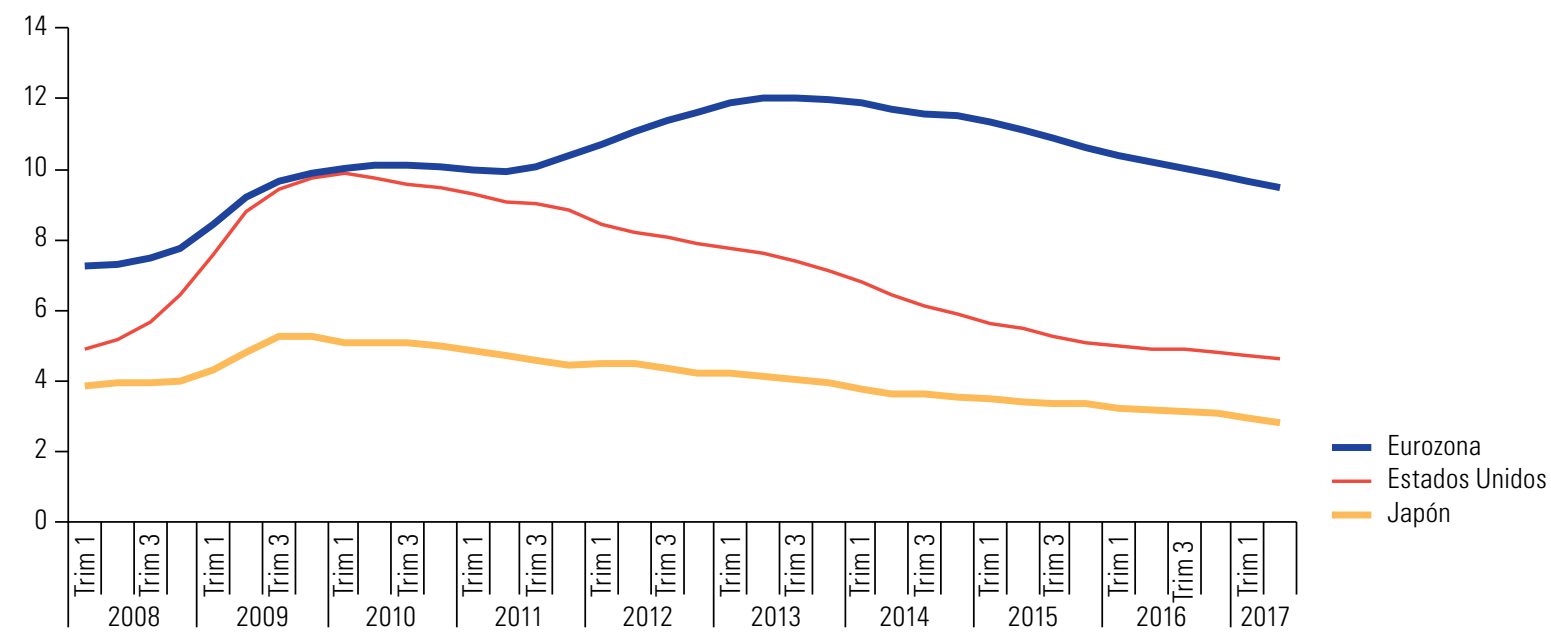

Fuente: Comisión Económica para América Latina y el Caribe (CEPAL), sobre la base de cifras de la Organización de Cooperación y Desarrollo Económicos (OCDE).

\section{Estados Unidos y el Japón: variación de los salarios nominales} (en porcentajes)

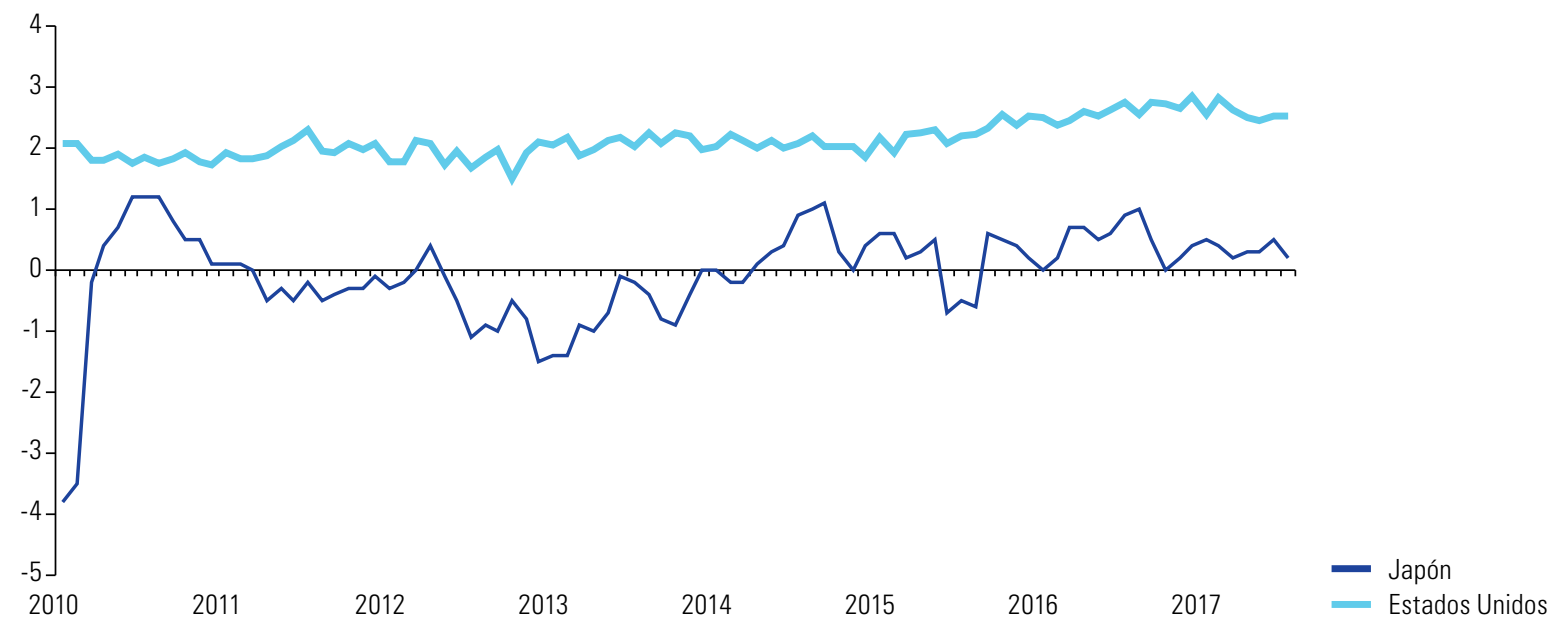

Fuente: Comisión Económica para América Latina y el Caribe (CEPAL) sobre la base de Oficina de Estadísticas Laborales de los Estados Unidos, "Current Employment Statistics" [en línea] https://www.bls.gov/ces/ y Ministerio de Salud, Trabajo y Bienestar del Japón. 
Gráfico Il.4 (conclusión)

E. Estados Unidos, eurozona y el Japón: inflación subyacente, 2010-2017 (cambios respecto del período previo, en porcentajes)

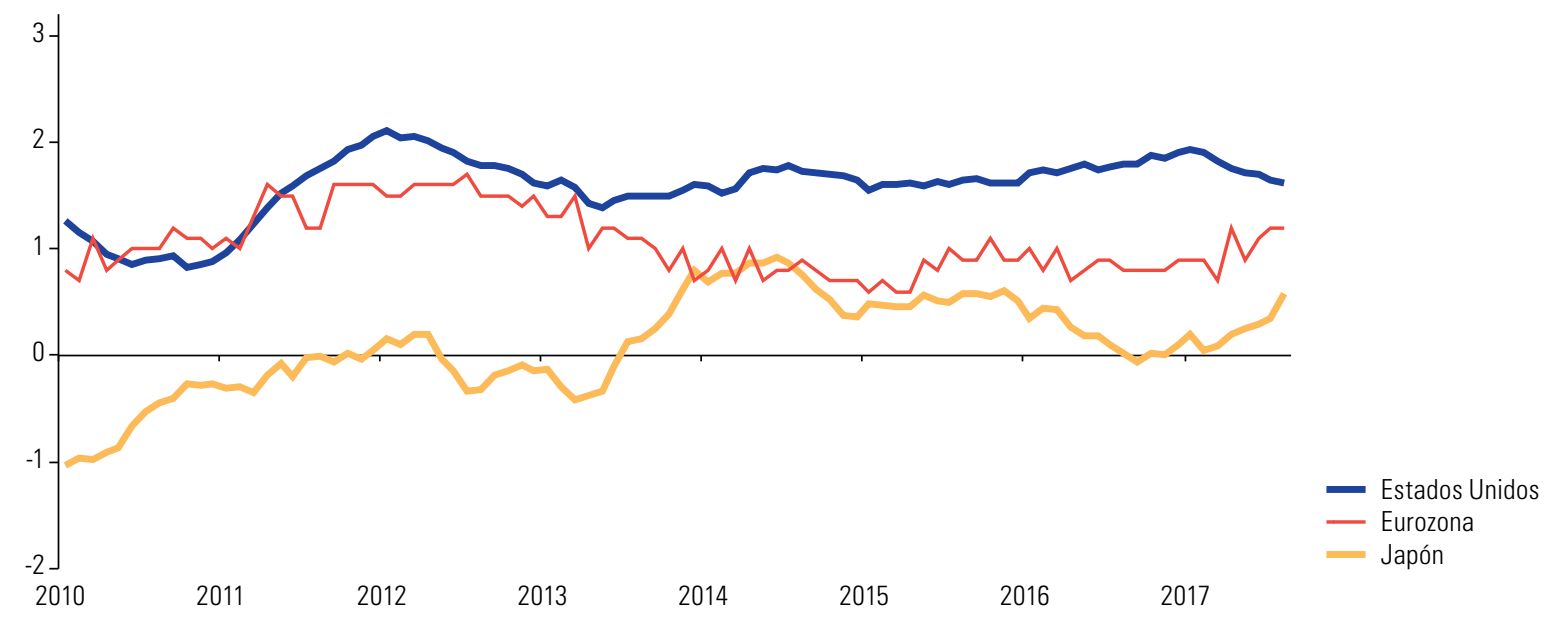

Fuente: Comisión Económica para América Latina y el Caribe (CEPAL), sobre la base del Banco de la Reserva Federal de St. Louis, Federal Reserve Economic Data (FRED), "Trimmed Mean PCE Inflation Rate" [en línea] https://fred.stlouisfed.org/series/PCETRIM1M158SFRBDAL; Eurostat, Harmonised Indices of Consumer Prices (HICP) [en línea] http://ec.europa.eu/eurostat/web/hicp/methodology/euro-area Japan Macro Advisors "Trimmed Mean CPI Inflation Rate" [en línea] https://www.japanmacroadvisors.com/page/category/economic-indicators/inflation-and-prices/10per-trimmed-cpi .

Nota: El cálculo de la inflación subyacente no incluye energía, alimentos, alcohol y tabaco.

Dada esta incertidumbre, los encargados de formular de políticas enfrentan dos escenarios. Por un lado, en un contexto de débil relación entre inflación y desempleo, podrían implementar políticas fiscales expansivas sin generar tasas de inflación insostenibles. Por otro lado, si la debilidad de la relación fuera solo temporal y como consecuencia de las políticas fiscales expansivas la inflación se acelerara, podría ser necesario un período sostenido de alto desempleo para estabilizarla. Por ello, entender las fuerzas que afectan la inflación y el desempleo y la relación entre ambas variables es más fundamental que nunca.

Las autoridades macroeconómicas de las economías más desarrolladas interpretan la baja respuesta de la inflación a la dinámica del mercado del trabajo y al crecimiento económico como un fenómeno temporal y esperan que la relación vuelva a la normalidad. Se sostiene que operarían factores temporales que comprimen las presiones inflacionarias y que en algún momento se atenuarán, reactivando el crecimiento de la inversión productiva. Volver a los niveles previos a la crisis podría tomar entre 15 y 20 años. Este es el plazo que demandaría el desapalancamiento de los balances de los bancos centrales, especialmente dado que no existe certeza sobre su estructura y tamaño deseables. Por ello, los dos mayores bancos centrales, la Reserva Federal y el Banco Central Europeo, han dado considerable flexibilidad a las políticas que seguirían en el corto y mediano plazos.

Según otro punto de vista, las fuerzas en juego tendrían un carácter más estructural y de largo plazo y los instrumentos de política económica y monetaria deberían incorporar estas fuerzas y sus efectos para recuperar poder predictivo (Auer, Borio y Filardo, 2017). Se argumenta que las fuerzas seculares que operan en el sistema económico y que se manifiestan como choques de oferta positivos tendrían efectos permanentes en la determinación de las variables macroeconómicas. Desde esta perspectiva, sería ingenuo esperar que la globalización y la revolución tecnológica no hayan afectado la determinación de los salarios y los precios. La globalización frena las presiones inflacionarias, manteniendo bajos los precios de los bienes y servicios importados desde China y otros mercados emergentes. Asimismo, la entrada de un número creciente de trabajadores en el mercado mundial y el debilitamiento de la sindicalización han reducido el poder de negociación de los trabajadores. Así, pese al bajo nivel de desempleo estructural, se mantiene la compresión salarial. La revolución tecnológica y la posibilidad de automatización del empleo refuerzan estos procesos. La expansión de Internet y el comercio en línea contribuyen a comprimir las presiones inflacionarias, bajando los precios de los bienes de consumo y permitiendo a los consumidores comparar precios más fácilmente, además de reducir los costos de intermediación. 
Más aún, en un contexto de elevado endeudamiento, la política monetaria expansiva pierde eficacia e incluso podría tener efectos negativos ${ }^{6}$. Para evitar que las acciones de política monetaria tengan tales efectos es clave considerar el grado de vulnerabilidad de los balances públicos antes de modificar las tasas de interés. Por otra parte, en un contexto incierto, mantener bajo el costo del endeudamiento del sector público podría facilitar la implementación de políticas fiscales expansivas y estimular las inversiones y el consumo privados.

En una economía mundial que se recupera lentamente, es fundamental tener seguridad de que el crecimiento será suficientemente estable y dejará de depender del estímulo monetario derivado de las políticas de expansión cuantitativa. Diagnosticar las causas de la baja respuesta de la inflación al crecimiento económico, la lenta dinámica de la productividad y el estancamiento de los salarios es crucial para evitar que un cambio de tendencia en las políticas de los bancos centrales desacelere el crecimiento o genere nuevas fuerzas recesivas.

\section{La revolución digital agrega incertidumbre}

El universo tecnológico también presenta fuertes grados de incertidumbre tanto en su propia dinámica como en sus efectos sobre las actividades analógicas. Pero a diferencia de la realidad macroeconómica, donde la incertidumbre es resultado de una década de lento crecimiento y de dudas sobre la validez del modelo interpretativo en el que se basan las políticas, en el ámbito digital la incertidumbre es resultado de su éxito. El desarrollo de las nuevas tecnologías se ha acelerado y sus efectos se han expandido transversalmente en la economía y la sociedad.

La aceleración del cambio tecnológico es manifiesta cuando se considera el flujo de datos medido por la capacidad instalada de ancho de banda transfronterizo. Esta siguió una dinámica exponencial a partir de 2007, en un contexto en que las corrientes internacionales de comercio de bienes y servicios, de inversión extranjera directa y de financiamiento registraron fuertes fluctuaciones, en particular luego de la crisis financiera global (Manyika y otros, 2016). La expansión digital, basada en el aumento de las capacidades de procesamiento, transmisión y almacenamiento, no fue afectada por los problemas que incidieron en la formación de capital, el crecimiento y el empleo a nivel agregado.

La velocidad del cambio se observa también en múltiples indicadores, entre los que destacan los vinculados al acceso a Internet y el uso de las tecnologías móviles. En 2017, la difusión mundial de estas tecnologías alcanza a más de 5.000 millones de suscriptores únicos de telefonía móvil, a 3.580 millones de usuarios de Internet (48\% de la población mundial) y a más de 5.100 millones de suscriptores de banda ancha fija y móvil, lo que produce más de 100 exabytes de tráfico IP por mes y ha llevado a la descarga de alrededor de 180.000 millones de descargas de aplicaciones, es decir, cerca de 26 por habitante del planeta. El ritmo de expansión del uso de aplicaciones se ha acelerado y el tiempo para alcanzar los 50 millones de usuarios se ha reducido de años a menos de un mes en los casos más dinámicos. En este sentido, es cada vez más incierto prever qué tipo de aplicaciones se usará en el mediano plazo (por ejemplo, un quinquenio) y, por lo tanto, cuáles serán los equipos y las habilidades necesarios para manejarlas eficientemente (UIT, 2017).

Entre las tecnologías más avanzadas, el dinamismo también es notable. En menos de una década, se introdujeron paquetes tecnológicos vinculados a la computación en la nube y la analítica de grandes datos que se masificaron rápidamente entre los consumidores y las empresas, sobre todo las de tamaño medio y grande. Más aun, en menos de dos años, se han abierto nuevos campos de acción en materia de robótica e inteligencia artificial que, si bien fueron desarrollados a lo largo de decenios, se han vuelto habituales en las discusiones de política por sus potenciales impactos.

A la incertidumbre derivada de estos nuevos avances tecnológicos se agrega una radical reconfiguración de la estructura empresarial. Se consolidan plataformas digitales globales cuyas actividades dominan el universo en línea y también ejercen un creciente impacto en el universo analógico. Esas plataformas, que se gestaron en los últimos 15 años, tienen un amplio alcance a nivel global, pero pertenecen mayoritariamente a empresas de los Estados Unidos (Apple, Google, Facebook, Amazon, Microsoft) y China (Baidu, Alibaba, Tencent). Aún es temprano para prever la dinámica de esta nueva estructura empresarial y la respuesta que recibirá de los

La deuda total en la economía mundial aumentó del 180\% del PIB en 2007 al 220\% en marzo de 2017 (BPI, 2017). 
gobiernos en temas regulatorios (seguridad, privacidad) y fiscales. Esto aumenta también la incertidumbre global, en la medida en que esas plataformas son los agentes más dinámicos en materia de inversión y oferta de bienes y servicios digitales, y que su accionar puede ser contradictorio con las normativas nacionales.

Los efectos del avance de la economía y la sociedad digitales son múltiples, pero tres son de particular interés para la formulación de políticas. En primer lugar, debido a la expansión de las tecnologías digitales, se han desdibujado los límites entre los sectores productivos de bienes y los de servicios. Dada la generalización de los "productos inteligentes conectados", es cada vez más difícil separar los costos y los beneficios de la producción y utilización física y los correspondientes a las dimensiones digitales. Las ventajas competitivas tradicionales de costos se han vuelto más difíciles de identificar y utilizar en la medida en que el uso de los bienes físicos depende cada vez más de su conexión a "la nube del producto". Un fenómeno similar se observa en el creciente número de empresas que usan estrategias de comercialización $\mathrm{O} 2 \mathrm{O}$ (online to offline) para, por ejemplo, manejar la capacidad ociosa en la prestación de servicios. En segundo término, ha revivido la discusión sobre la paradoja de Solow ("se ven computadoras en todos lados, excepto en las estadísticas de productividad"). La discusión sobre los efectos de la economía de plataformas en la productividad se ha agudizado y dista de llegar a una conclusión. En particular, se señalan problemas derivados de los errores de medición y los rezagos de implementación y generación de complementariedades (McAfee y Brynjolfsson, 2017).

El tercer efecto es por lejos el más relevante para las decisiones de política y es posiblemente el más incierto. El impacto de las nuevas tecnologías, en particular la robótica y la inteligencia artificial, en el nivel y la calidad del empleo se observará en áreas que van desde los mecanismos compensatorios para los sectores perjudicados hasta el diseño de los nuevos planes de enseñanza. Las estimaciones realizadas a partir de 2013 llegan a resultados muy diferentes; sin embargo, en todos los casos los efectos son importantes, sobre todo en contextos con lento crecimiento del empleo o fuerte crecimiento de la población en edad de trabajar, como se analiza en el capítulo IV.

\section{De bienes a bits}

\section{La gran disrupción: las tecnologías exponenciales}

La digitalización transforma los flujos económicos reduciendo los costos de transacción y los costos marginales de producción y distribución mediante la creación de bienes y servicios digitales, la agregación de valor, al incorporar lo digital en bienes y servicios en principio no digitales, y el desarrollo de plataformas de producción, intercambio y consumo (CEPAL, 2016b).

La inserción de las tecnologías digitales en la economía no es reciente; data de la década de 1960 con el avance de la electrónica y la automatización de los procesos productivos. Se acelera entre los años ochenta y noventa con la difusión de las computadoras personales y la transmisión de datos, y logra una mayor preponderancia con el desarrollo de Internet, la telefonía móvil y sistemas de información que facilitaron el despliegue de cadenas globales de valor. En ese contexto, el uso de estas tecnologías apuntaba a generar ganancias de productividad, mediante la reducción de los costos de transacción y de la mano de obra, lo que llevó a trasladar plantas productivas a localidades con menores costos laborales. Estos avances impulsaron la globalización y estrecharon los vínculos entre los países más desarrollados al facilitar los flujos comerciales y financieros y hacer más eficientes los procesos de gestión, producción y comercialización.

El mundo está ad portas de una disrupción aún mayor, pasando de una era analógica a una era digital, dando origen a la denominada cuarta revolución industrial, que no se define por un conjunto de tecnologías emergentes en sí mismas, sino por la transición hacia nuevos sistemas construidos sobre la infraestructura de la revolución digital. Hay tres razones por las que esas transformaciones representan la llegada de un nuevo modelo: su velocidad, debido a la naturaleza exponencial de los avances tecnológicos; su alcance, en la medida en que impactan a todos los sectores e industrias, y su profundidad, pues transforman sistemas completos de producción, gestión y gobernanza (Schwab, 2016; CEPAL, 2017).

La convergencia de las capacidades de transmisión, cómputo y almacenamiento, el aumento exponencial de su potencia, la continua disminución de sus costos y la permeabilidad de las tecnologías digitales en la 
economía están dando lugar a una fase disruptiva basada en la inteligencia de las máquinas y los objetos, y la analítica de datos, e impulsada por plataformas digitales de alcance global que sustentan las actividades sectoriales (véase el diagrama II.1).

\section{Diagrama ll.1}

Disrupción digital
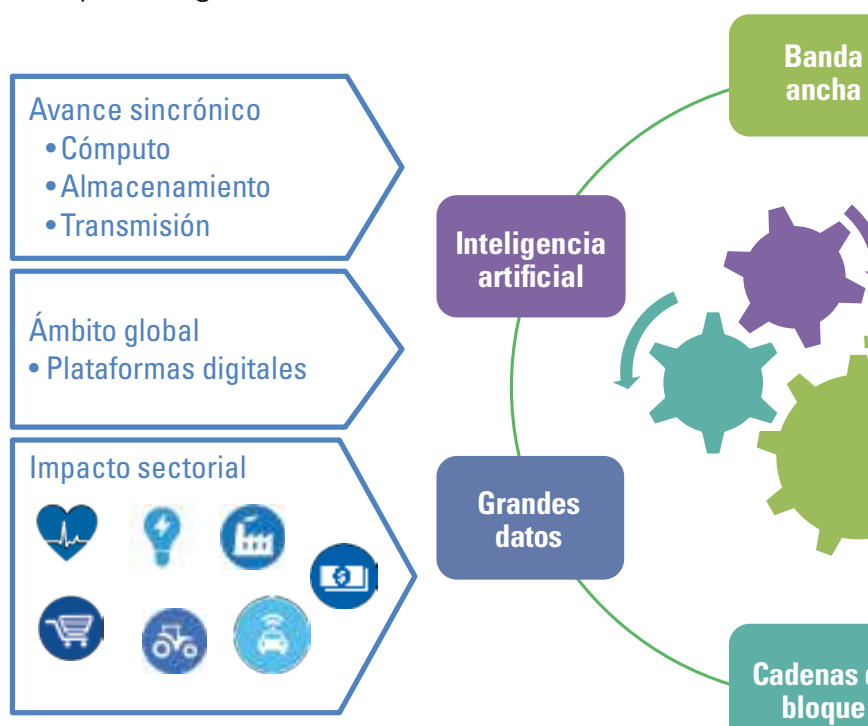

ancha

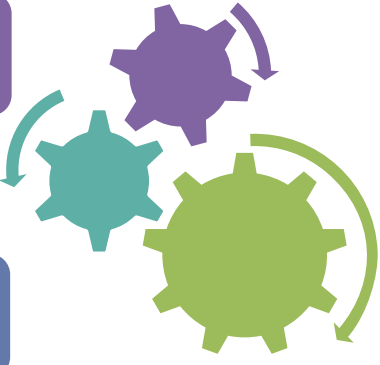

Computación en la nube

Modelos de negocios

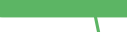

Modelos de consumo

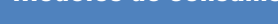

Internet de las cosas

Modelos de producción

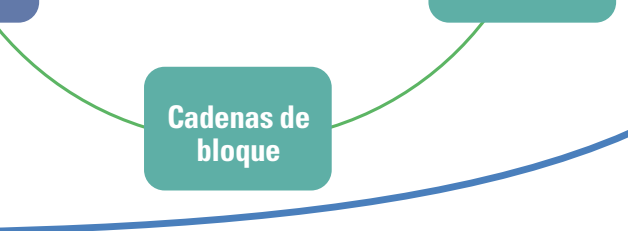

Ecosistemas sectoriales

Fuente: Comisión Económica para América Latina y el Caribe (CEPAL).

Consideradas aisladamente, las redes de Internet de banda ancha de alta velocidad, la ubicuidad del acceso con múltiples dispositivos, el cómputo en la nube, la Internet de las cosas, la analítica de los grandes datos y los avances en inteligencia artificial abren oportunidades de innovación en la prestación de servicios y generación de modelos de negocio. Sin embargo, su utilización combinada es la que produce cambios disruptivos que se concretan en la generación de productos inteligentes conectados en ecosistemas digitales de producción y en nuevos modelos de consumo y negocios. Más recientemente, la tecnología de las cadenas de bloque (blockchain) da forma a nuevas industrias y modifica los sistemas productivos de bienes y servicios ${ }^{7}$. Tal es el caso del sistema financiero, en el que permite disminuir el número de intermediarios, bajar los costos de transacción y democratizar la validación de las operaciones, reduciendo el riesgo sistémico (Casey y Wong, 2017). En un par de años, las tecnologías digitales que apoyan o posibilitan la prestación de servicios bancarios y financieros (financial technologies o fintech) han ocupado un lugar importante en el desarrollo del sector y la atención de las autoridades monetarias ${ }^{9}$. Así, el rápido crecimiento de las redes, las plataformas digitales y los modelos de negocio de datos son los cambios más recientes en las fuerzas que determinan la globalización ${ }^{10}$.

Así como la revolución digital transforma los estilos de vida de los consumidores y los modelos de negocios, las ciudades inteligentes y conectadas mejorarán la prestación de los servicios públicos, como la educación, la atención médica, el transporte y la generación y distribución de energía, apoyando una urbanización sostenible. Una mejor gestión de las ciudades aumentará la eficiencia con la consiguiente reducción de costos, lo que impulsaría el crecimiento económico y generaría nuevas oportunidades de empleo e ingresos. Esta visión

\footnotetext{
Una cadena de bloque es un protocolo criptográfico que permite a usuarios diferentes (computadoras) la validación y la actualización de transacciones de objetos digitales. La tecnología blockchain es un conjunto de algoritmos que permite que los denominados criptoconductos —incluido el bitcoin — sean comercializados y verificados electrónicamente por una red de computadoras sin un libro mayor central.

8 Seis de los mayores grupos bancarios analizan la oportunidad de desarrollar una criptomoneda que les permitiría hacer transacciones de manera más rápida y segura que con la moneda tradicional (Arnold, 2017).

9 El término fintech se refiere a actividades y empresas que utilizan las tecnologías digitales para ofrecer servicios financieros más accesibles, a menor costo y más rápidamente, tanto a personas como a entidades financieras. Incluye pagos electrónicos nacionales e internacionales, préstamos mediante financiamiento colectivo, asesoría financiera e inversiones usando criptomonedas.

10 Véase la Iniciativa sobre Economía Digital del Instituto Tecnológico de Massachusetts (MIT) [en línea] http://ide.mit.edu/.
} 
sugiere que el mundo puede transitar hacia un nuevo estilo de desarrollo e industrialización que maneje de manera sostenible los recursos sociales, económicos y ambientales, es decir hacia un gran impulso ambiental.

\section{El liderazgo de las plataformas digitales}

Los agentes de la disrupción digital son las plataformas globales, como Apple, Google, Microsoft, Amazon, Facebook, Tencent y Alibaba, y más recientemente Uber, Airbnb y Netflix. Se trata de empresas cuyo modelo de negocio, digitalmente habilitado, crea valor al facilitar el encuentro entre dos o más grupos de usuarios interdependientes, generando mercados multilaterales con importantes efectos de red, y al utilizar los datos que se producen e intercambian en la plataforma como activos del negocio. Su desarrollo puede ser acelerado por terceros mediante la provisión de interfaces para la programación de aplicaciones (API) que permiten a los participantes compartir datos para agregar nuevos servicios.

Las empresas plataforma son disruptivas pues alteran los modelos de negocios, consumo y producción no solo en la industria en la que emergen, sino que, al combinarse con otras innovaciones, transforman también otros sectores de la economía, modificando su organización industrial. Hacia fines de los años noventa y comienzos de 2000, las industrias de la fotografía, la música y los libros fueron las primeras en sentir los efectos de la digitalización y el posterior surgimiento de los nuevos modelos de negocios. En no más de 15 años, se han sucedido olas de disrupción digital, como Skype en las comunicaciones de voz, Amazon y Alibaba en el comercio minorista, iTunes y Spotify en música, Netflix y YouTube en contenido de audio y video, Expedia y Airbnb en viajes y alojamiento, Uber y Cabify en el servicio de taxi. Actualmente, las actividades en mayor proceso de transformación son la industria automotriz, con productos cada vez más digitalizados y procesos productivos más automatizados (autotech), y el sector financiero, con el desarrollo de las fintech. Hacia 2020, los sectores de la salud, la manufactura, la agricultura, el transporte y la energía (ciudades inteligentes) serían los más afectados por las siguientes etapas de la digitalización. Estas olas disruptivas desafían a los actores tradicionales y suponen un reto mayor a los modelos normativos y de gobernanza, con efectos profundos en la organización industrial y el mercado laboral.

La caída de Kodak no solo ejemplifica la rapidez con la que un titular puede salir del mercado ${ }^{11}$, sino que también refleja una transformación del modelo de negocio, que se hace mucho menos intensivo en mano de obra, y una estrategia empresarial basada en una fuerte dinámica de fusiones y adquisiciones en busca de escala e innovaciones que sumen valor a la red existente ${ }^{12}$. Estas operaciones, si bien en un principio se circunscribían al sector de las tecnologías digitales, han trascendido a otros, dando origen a industrias híbridas, que representan la creciente convergencia de las actividades tradicionales con subsectores tecnológicos como el de la Internet de las cosas, la inteligencia artificial y las cadenas de bloque (Baker McKenzie, 2017b). Esta diversificación, que origina ecosistemas digitales verticales, hace de estas plataformas sistemas complejos de innovación, en los que se desdibujan las fronteras entre industrias, como lo ejemplifica la industria automotriz, o transforma las cadenas de producción y la gestión en sectores tradicionales, como el agrícola. Más aún, el modelo de negocios de estas plataformas se adopta en otros sectores pues permite un eficiente manejo de la intersección de los mundos físico y digital.

Debido a su modelo de negocios basado en tecnologías digitales y economías de escala, las empresas plataforma tienen la capacidad de expandirse rápidamente, pues dependen poco de la instalación de capacidad física, como tiendas de distribución, o del desarrollo de cadenas de producción. Las grandes plataformas tecnológicas son las mayores empresas mundiales en términos de valor de mercado, desplazando a las compañías de los sectores tradicionalmente preponderantes, como los de energía, manufactura y finanzas (véase el gráfico II.5).

11 Fundada en 1888, en 1996 Kodak era líder del mercado fotográfico, con un valor de capitalización de 28.000 millones de dólares, y empleaba a 140.000 trabajadores. Con la digitalización de las cámaras fotográficas, los primeros impactos se sintieron en la venta de rollos fotográficos y revelado, efecto que se profundizó con el desarrollo y difusión de los teléfonos inteligentes, que reemplazaron la función de la tradicional cámara de fotos y permitieron compartir las imágenes en streaming vía redes sociales como Facebook o la aplicación Instagram. Así, en 2012, mientras que Kodak se declaraba en quiebra, Instagram, una pequeña empresa de 13 empleados creada en 2010, fue comprada por Facebook en aproximadamente 1.000 millones de dólares (Leslie, 2014).

12 Según Statista, entre 2013 y 2017, Google realizó alrededor de 98 fusiones y adquisiciones, seguida por Microsoft con 56 y Apple con 50, mientras que General Electric totalizó 18. En tanto, las plataformas chinas Tencent, Alibaba y Baidu mostraron un comportamiento similar con 75, 72 y 27 operaciones de este tipo desde 2012, respectivamente. 
Gráfico Il.5

Valor de mercado de las mayores empresas mundiales, 2006 y 2017

(En miles de millones de dólares)

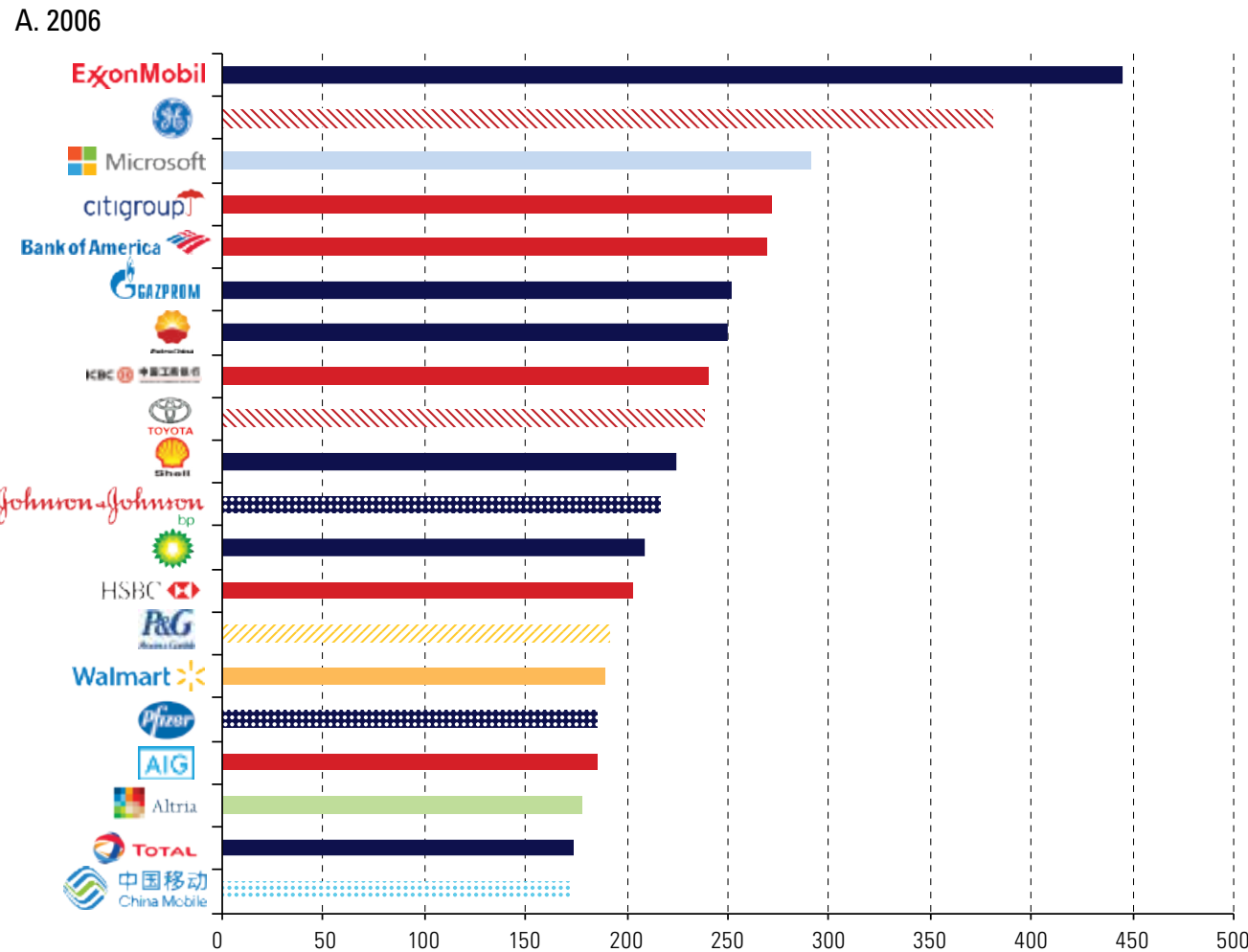

B. 2017

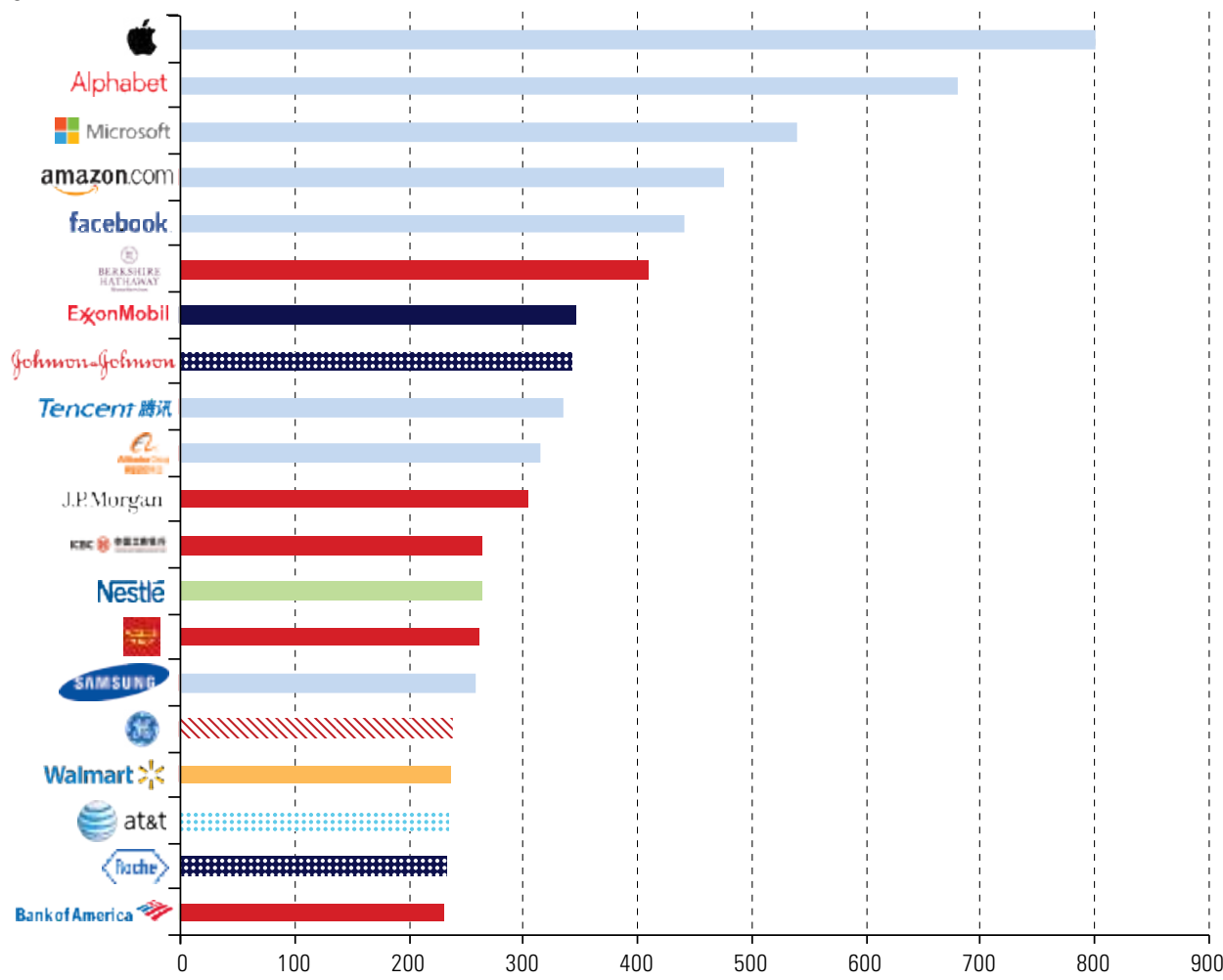

Energía

IIII Industrial

Tecnología de la información

Financiero

Salud

Bienes de consumo

Comercio minorista

Alimentos y tabaco

::::: Telecomunicaciones

Fuente: Comisión Económica para América Latina y el Caribe (CEPAL), sobre la base de datos de Bloomberg a mayo de 2017. 
Además, en el universo de las 100 empresas más grandes a nivel mundial en términos de ingresos y utilidades, sobresalen las empresas tecnológicas (Forbes, 2017). En particular, los montos de sus utilidades se asemejan a los de las grandes compañías financieras y superan a los de las grandes empresas de energía y petróleo, aunque estas últimas han visto afectados sus resultados por los menores precios de los recursos naturales.

Las plataformas digitales se originan localmente; sin embargo, a medida que se expanden y diversifican, se desarrollan en el mercado internacional, con lo cual los límites territoriales pierden relevancia en términos de transacciones y utilización. El mayor número de plataformas digitales es propiedad de empresas estadounidenses, entre las que destacan Apple, Alphabet, Facebook, Amazon, Uber y Microsoft, con un valor de capitalización de mercado de 3,2 billones de dólares. Asia tiene la segunda mayor concentración, con plataformas que se valoran en 854.700 millones de dólares, entre las que destacan las chinas Alibaba y Tencent. Europa cuenta con plataformas digitales por un valor de 128.000 millones de dólares, lideradas por SAP, empresa alemana de diseño de productos informáticos para la gestión empresarial. Los montos correspondientes a otras regiones son muy inferiores (véase el gráfico II.6) ${ }^{13}$. No obstante, el modelo de plataformas ofrece mayores oportunidades de participación a empresas de América Latina en comparación con los paradigmas anteriores. En 2017, la región contaba con más de 5.000 empresas denominadas tecnolatinas, de las cuales las 123 mayores tienen un valor conjunto superior a los 37.000 millones de dólares ${ }^{14}$. Entre estas, hay nueve empresas unicornio (nuevas empresas con un valor superior a los 1.000 millones de dólares cada una), que fueron creadas como pequeñas empresas alrededor de la crisis de la industria digital de 2001.

\section{Gráfico II.6}

Capitalización de mercado de las plataformas digitales por región, 2016

(En dólares)

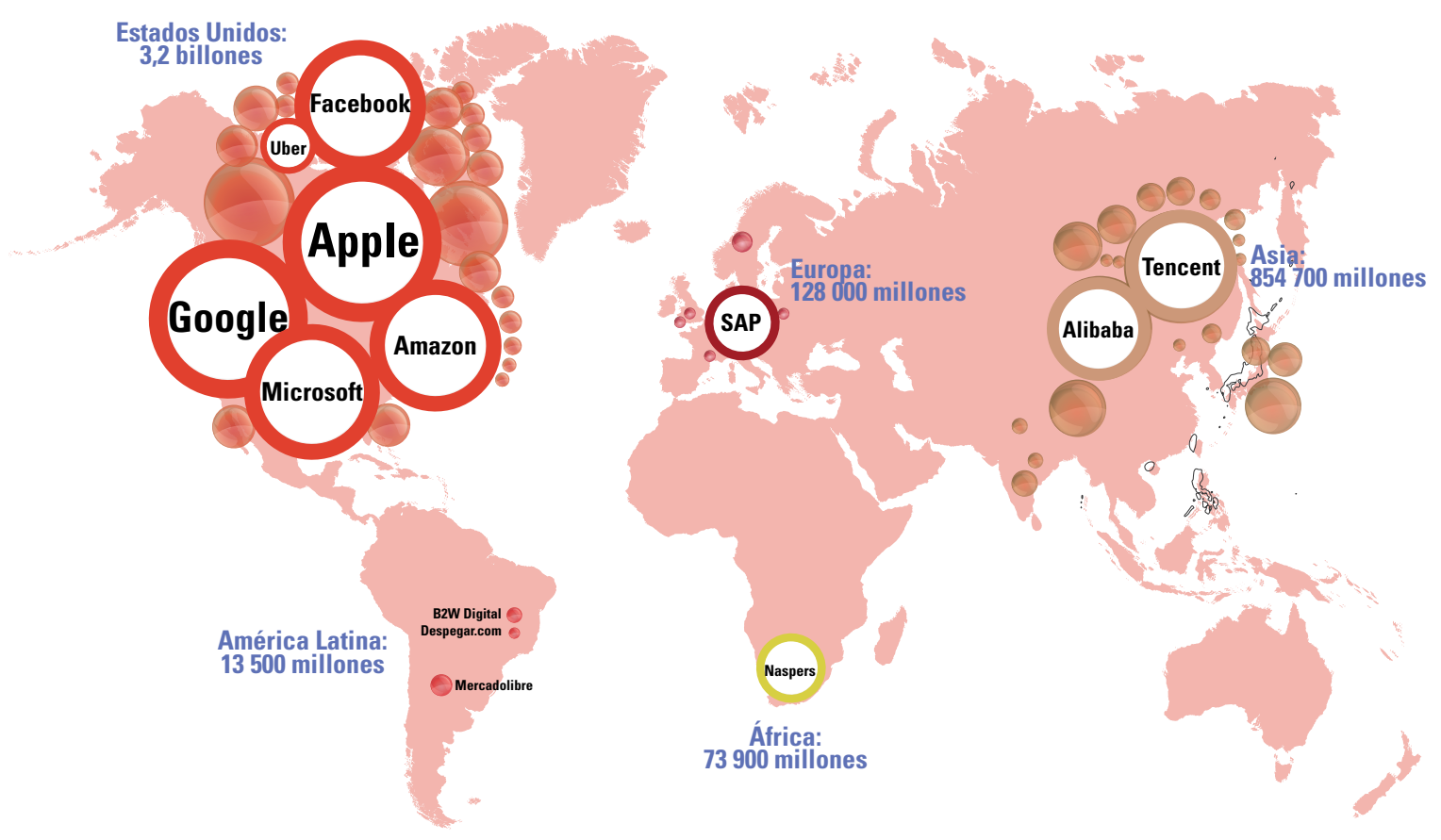

Fuente: Comisión Económica para América Latina y el Caribe (CEPAL), sobre la base de datos no oficiales de fuentes especializadas.

13 En África, destaca la sudafricana Nasper, que ofrece servicios de entretenimiento e Internet, cuyo valor es de casi 74.000 millones de dólares. Finalmente, América Latina concentra un valor de apenas 13.500 millones de dólares con Mercado Libre, empresa argentina de intermediación de compra y venta online, B2W Global, compañía brasileña de comercio minorista en línea, y Despegar.com, agencia de viajes en línea, fundada en la Argentina.

14 Se definen como tecnolatinas las empresas (startups) de base tecnológica de propiedad privada que han nacido y están basadas en la región. En las 123 empresas mencionadas, se consideran solo las valuadas en más de 25 millones de dólares (Arrieta y otros, 2017). 
Los ingresos de los cinco gigantes tecnológicos con mayor valor de mercado (Apple, Alphabet, Microsoft, Amazon y Facebook) provienen de los mercados del hardware, el comercio electrónico y la publicidad en línea (sustento de la oferta de servicios gratuitos en línea), que generaron el $76 \%$ del total de sus ingresos en 2016, a los que se agregan el software y los servicios de cómputo en la nube (Visual Capitalist, 2017). Las plataformas digitales globales son los mayores actores de los principales mercados en los que operan ${ }^{15}$. Más allá de ese poder de mercado, en el futuro lo más importante es su dominio en materia de innovaciones ligadas al cómputo en la nube, el manejo de grandes datos y la inteligencia artificial, por lo que implica en cuanto a servicios de datos en múltiples industrias.

Las características de la nueva economía están cambiando las reglas y los límites del mercado, afectando la competencia y desafiando los modelos regulatorios. No hay una clara comprensión del valor de los datos ni por parte de los consumidores, que están dispuestos a entregar información por recibir gratuitamente un servicio en línea, ni por parte de muchas empresas, que no saben cuál es su importancia y menos cómo gestionarlos. En tanto, existen firmas que se especializan en ese manejo, en extraer información y sobre todo en generar inteligencia artificial. En estas actividades, el uso de datos no tiene rendimientos decrecientes, ya que, a mayor información, mayor precisión de los algoritmos predictivos y de aprendizaje. Esto plantea desafíos de política no solo en materia de competencia, sino también de privacidad, seguridad y equidad en lo que se refiere al acceso a estos recursos clave de la nueva economía.

Al respecto, en los Estados Unidos han surgido voces de alerta sobre la concentración de poder en manos de los gigantes tecnológicos. También se evalúa modificar los criterios de autorización de adquisiciones y fusiones, yendo más allá del tamaño y participación de mercado hacia una evaluación del tipo de activos de las compañías involucradas y un análisis del impacto de su operación. Además, se analizan mecanismos para otorgar mayor control sobre los datos a los oferentes, impulsando regímenes de localización de datos y restricciones de flujos según el tipo de información.

En Europa, los reguladores ya han tomado algunas medidas. Durante el discurso del estado de la Unión se anunció que, a fines de 2018, se presentará una propuesta para establecer normas comunes en materia de fiscalidad de la economía digital (Comisión Europea, 2017). Paralelamente, los ministros de finanzas de varias economías de la Unión Europea pidieron una reforma fiscal que considere un impuesto sobre el volumen de negocios para reformar las reglas impositivas en todo el bloque, de forma que las plataformas tecnológicas impongan donde generan ingresos y no donde registren sus ganancias (Europost, 2017) ${ }^{16}$.

Estas acciones muestran que se inicia un debate en el tema regulatorio que abarcará ámbitos que van desde las leyes de competencia hasta la fiscalidad, pasando por temas de privacidad y seguridad, además de estándares tecnológicos. A lo complejo del tema debe agregarse la necesidad de coordinación internacional para lograr una mínima consistencia al tratarse de asuntos que trascienden los límites geográficos.

\section{El comercio internacional no recupera su dinamismo previo a la crisis}

El comercio mundial de bienes — que desde 1990 representa el $80 \%$ del comercio mundial de bienes y servicios, medido en valores brutos_- perdió drásticamente su dinamismo tras la crisis económica mundial de 2008-2009. Mientras que entre 2000 y 2007 su volumen creció un 6,3\% anual, entre 2012 y 2016 solo aumentó un 2,2\%

15 En el comercio en línea a nivel global en 2016, destacaban Alibaba (27\% de participación) y Amazon (13\%), ambas dominantes en sus países de origen. Facebook y Google recaudaban cerca del $60 \%$ de los ingresos globales por publicidad digital. En cómputo en la nube, Amazon ostentaba el liderazgo mundial, con una participación mayor del 30\%, seguida de Microsoft, IBM y Google. En lo que se refiere a sistemas operativos, en febrero de 2017, Windows tenía una cuota de mercado del 38,6\%, seguida de Android de Google, con un 37,4\%. Finalmente, en cuanto a motores de búsqueda destaca el predominio de Google en los Estados Unidos y Europa, con tasas de participación superiores al 85\%, en tanto que Baidu lidera en China.

16 En junio de 2017, los reguladores antimonopolio sancionaron a Google con una multa de 2.700 millones de dólares por abuso de posición dominante como motor de búsqueda. 
anual, y en ese último año se expandió apenas un 1,3\% ${ }^{17}$. Como correlato, mientras en el primer período la expansión del comercio fue 1,7 veces la del PIB mundial, entre 2012 y 2015 ambas variables crecieron al mismo ritmo y en 2016 la tasa de crecimiento del comercio fue inferior a la del PIB (véase el gráfico II.7).

\section{Gráfico Il.7}

Variación anual del volumen del comercio mundial de bienes y del PIB mundial y cociente entre ambas variaciones, 1981-2018

(En porcentajes y número de veces)

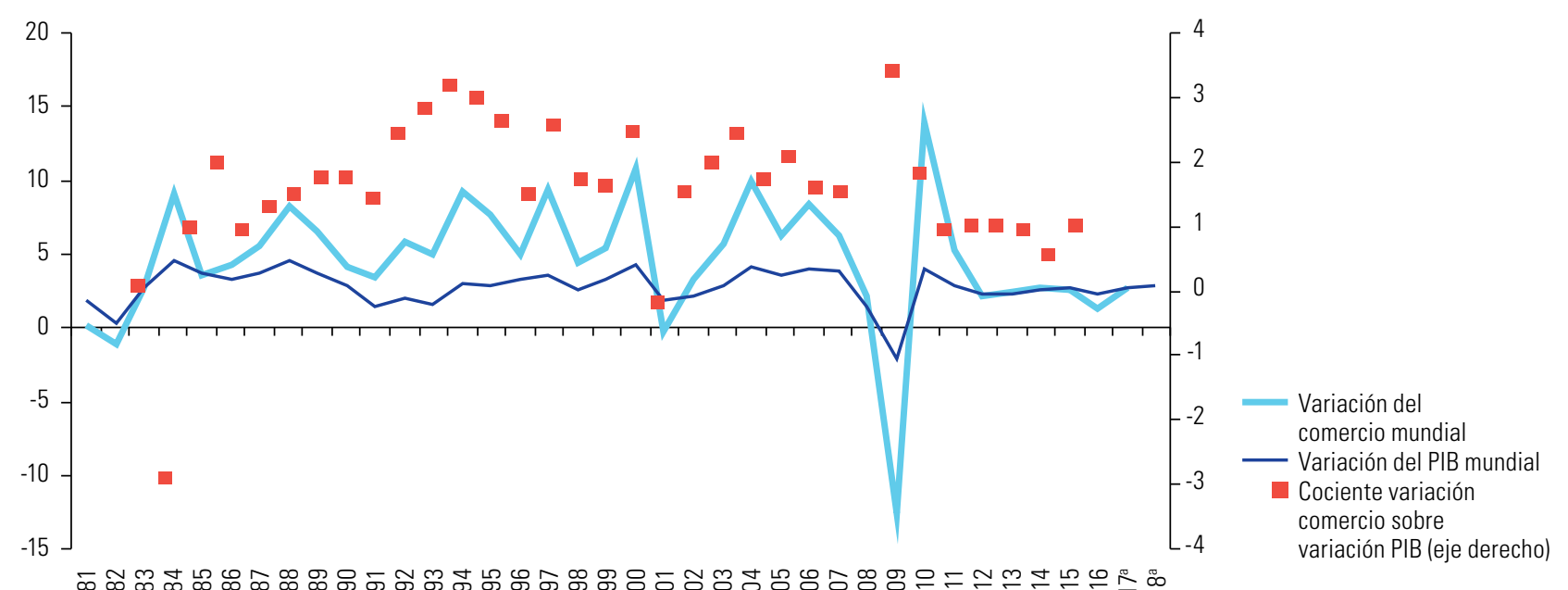

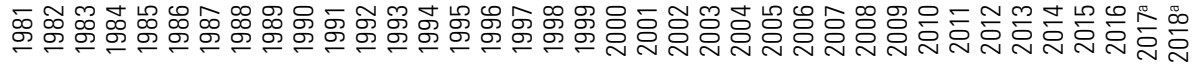

Fuente: Organización Mundial del Comercio (OMC), World Trade Statistical Review 2017[en línea] https://www.wto.org/english/res_e/statis_e/wts2017_e/wts17_toc_e. htm; y "WTO Upgrades Forecast for 2017 as Trade Rebounds Strongly", Nota de Prensa, 21 de septiembre de 2017 [en línea] https://www.wto.org/english/ news_e/pres17_e/pr800_e.htm.

a El comercio mundial corresponde al promedio de las exportaciones e importaciones. Las cifras de 2017 y 2018 son proyecciones.

Según proyecciones recientes, el comercio mundial registraría una recuperación más robusta que la prevista a comienzos de 2017. En efecto, el comercio crecería un 3,6\% tras expandirse un 4,2\% en el primer semestre del año, impulsado por un mayor crecimiento del producto $-\mathrm{y}$, por ende, de la demanda de importaciones- en los Estados Unidos, la eurozona y China. Para 2018, se proyecta una expansión algo menor $(3,2 \%)$, debido a una base de comparación más alta que en 2017 y al endurecimiento previsto de la política monetaria en los Estados Unidos, la eurozona y China, que en este último país estaría acompañada de una menor expansión fiscal. En el mediano plazo, se prevé una moderación de la demanda china de importaciones a medida que aumente el peso de los servicios en su economía (que creció de un $43 \%$ en 2008 a un 54\% en 2017) y disminuya el de las manufacturas, dado que los servicios suelen generar una menor demanda de importaciones que el sector manufacturero (OMC, 2017).

Sin perjuicio de la incipiente recuperación en curso, el comercio mundial sigue sin mostrar el dinamismo que tuvo entre fines de la década de 1980 y mediados de la de 2000, período que Auboin y Borino (2017) denominan "Ios años noventa largos." Los factores mencionados con mayor frecuencia para explicar esa debilidad en la poscrisis son el escaso dinamismo de la demanda global, el cambio en la composición del producto, un menor ritmo de expansión de las cadenas globales de valor y una menor liberalización comercial, o incluso un aumento del proteccionismo (Banco Central Europeo, 2016; Banco Mundial, 2016; Constantinescu, Matto y Ruta, 2015; FMI, 2016; OCDE, 2016).

17 Se excluyen del análisis los años 2008 y 2009 (crisis) y 2010 y 2011 (recuperación de corto plazo). 
En general, la literatura coincide en que la persistente debilidad de la actividad económica global es el principal factor detrás de la desaceleración del comercio. Este impacto se ve magnificado por el hecho de que los componentes más intensivos en importaciones de la demanda agregada —en particular, la inversión— son los que han mostrado un menor dinamismo en la poscrisis. En este contexto, se ha argumentado que alrededor del 75\% de la caída del crecimiento de las importaciones mundiales de bienes entre los períodos 2003-2007 y 2012-2015 obedecería a la debilidad de la actividad económica (FMI, 2016). Del mismo modo, Auboin y Borino (2017) concluyen que un 80\% de la reducción del dinamismo del comercio mundial en el período 2012 a 2015 responde a la debilidad de la demanda agregada, ajustada por la intensidad en importaciones de sus componentes. Ambos fenómenos se retroalimentan, ya que la debilidad del comercio refuerza el escaso dinamismo de la demanda agregada en cada país, al reducir las oportunidades de acceder a mercados más amplios y disminuir costos, con impactos negativos sobre las decisiones de inversión y consumo.

La literatura también coincide en que la pérdida de dinamismo del comercio mundial en la poscrisis es atribuible, en parte, a un menor ritmo de expansión de las cadenas globales y regionales de valor (por ejemplo, Auboin y Borino, 2017; Banco Central Europeo, 2016; Constantinescu, Matto y Ruta, 2015; OCDE, 2016$)^{18}$. Este fenómeno tiene varias causas. Una sería la maduración de esas cadenas, en el sentido de que ya se habrían agotado gran parte de las ganancias de eficiencia asociadas a la fragmentación geográfica de los procesos productivos que tuvo lugar desde los años noventa. Un segundo factor es el acortamiento de las cadenas globales de suministro en algunas economías clave, especialmente China. Este país hoy produce muchos insumos que previamente debía importar, lo que se refleja en la caída de 9 puntos porcentuales (de un $57 \%$ a un $48 \%$ ) de la participación de las partes y componentes en sus importaciones no petroleras desde 2000 (véase el gráfico II.8). Un tercer factor sería el menor ritmo de liberalización comercial. Por ejemplo, la aplicación en los últimos años de requisitos de contenido local en varios países desarrollados y en desarrollo induciría a las firmas a producir y abastecerse localmente en vez de importar (Banco Central Europeo, 2016).

\section{Gráfico II.8}

China: participación de las partes y componentes en las importaciones totales (excluido el petróleo) desde el mundo y socios seleccionados, 2000-2016

(En porcentajes)

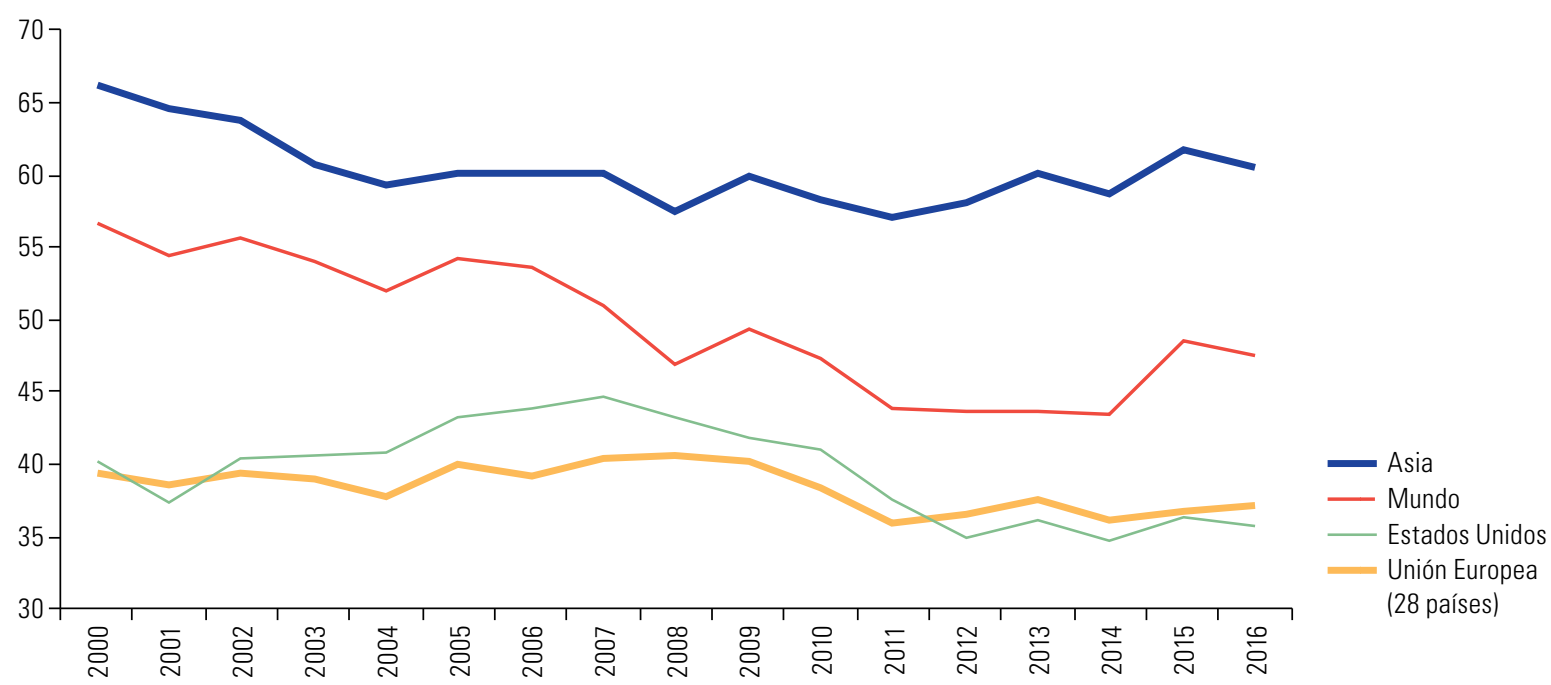

Fuente: Comisión Económica para América Latina y el Caribe (CEPAL), sobre la base de información de la Base de Datos Estadísticos de las Naciones Unidas sobre el Comercio de Productos Básicos (COMTRADE).

18 La participación hacia atrás en cadenas globales de valor, aproximada mediante la relación a precios constantes entre las importaciones de bienes intermedios y la demanda final interna, se habría reducido en promedio un 1,7\% al año desde 2011, después de crecer a un promedio de un 4\% anual entre 1991 y 2011 (OCDE, 2016 ). 
A diferencia del período previo a la crisis, cuando la liberalización comercial y la expansión de las cadenas globales de valor impulsaron fuertemente el comercio, en los últimos años estos factores habrían contribuido a frenar su crecimiento. El período de "los años noventa largos" fue de intensa liberalización del comercio y de la inversión extranjera directa a nivel mundial. Entre sus hitos se cuentan la entrada en vigor del Mercado Único Europeo en 1993, del Tratado de Libre Comercio de América del Norte (TLCAN) en 1994 y de los acuerdos de la Organización Mundial del Comercio (OMC) en 1995, así como el ingreso de China a esa organización en 2001. Fueron importantes también las sucesivas ampliaciones de la Unión Europea (especialmente en 2004, al incorporar a 10 países de Europa Central y Oriental) y los procesos de apertura emprendidos desde los años noventa por muchos países en desarrollo, incluidos varios de la región. Esto contribuyó a la expansión de las redes internacionales de producción y, en general, al fuerte dinamismo del comercio mundial en las dos décadas previas a la crisis.

El ritmo de la apertura comercial se ha reducido desde la irrupción de la crisis. Dos de las principales negociaciones comerciales iniciadas en la presente década, el Acuerdo de Asociación Transpacífico (TPP) y la Asociación Transatlántica de Comercio e Inversión (TTIP), se vieron negativamente impactadas por el drástico giro de la política comercial de los Estados Unidos bajo la actual administración. Por una parte, las negociaciones del TTIP se encuentran suspendidas desde octubre de 2016. Por otra parte, y tras el retiro de los Estados Unidos del TPP en enero de 2017, los otros 11 países suscriptores continuaron negociando una versión ligeramente modificada de dicho acuerdo. El resultado es el denominado Tratado Integral y Progresista de Asociación Transpacífico, suscrito en Santiago en marzo de $2018^{19}$. El acuerdo alcanzado en torno a este tratado es digno de destacarse, dada la compleja coyuntura por la que atraviesa el comercio mundial. No obstante, la ausencia de los Estados Unidos implica que se trata de un acuerdo de un peso económico y geopolítico mucho menor que el del TPP original. Por lo tanto, el impacto que puede tener como generador de nuevos estándares globales resulta también más limitado.

A este complejo cuadro se suman las dificultades por las que atraviesa la Organización Mundial del Comercio $(\mathrm{OMC})$ y la incertidumbre que generan la futura salida del Reino Unido de la Unión Europea (brexit) y la renegociación del TLCAN. Sin embargo, no existe consenso sobre el impacto de la menor liberalización comercial (o del aumento del proteccionismo) en el desempeño del comercio mundial en los últimos años. Ello se debe, en gran medida, a la dificultad de establecer métricas precisas y cuantificables. Mientras que la OCDE (2016) concluye que el menor ritmo de liberalización comercial explicaría alrededor del $25 \%$ del menor crecimiento del comercio en el período 2011-2015 respecto de 1991-2007, Auboin y Borino (2017) sostienen que la contribución de un eventual aumento del proteccionismo es pequeña y estadísticamente no significativa.

En el ámbito tecnológico, los continuos avances en materia de automatización, especialmente en los países avanzados, restarían dinamismo al comercio mundial en los próximos años. En la medida en que se reduzcan los incentivos a localizar producción en países en desarrollo en búsqueda de menores costos laborales, se frenaría la expansión de las cadenas globales de valor y el comercio vinculado con estas.

Por último, cabe destacar que, en una economía mundial crecientemente digitalizada, las estadísticas disponibles para medir el comercio presentan evidentes limitaciones. La irrupción de las plataformas digitales permite la comercialización (incluso transfronteriza) de una creciente gama de servicios considerados previamente no transables, así como también de los llamados bienes digitales, como libros electrónicos, videojuegos y descargas de música y películas. En algunas categorías, los bienes digitales prácticamente han sacado del mercado a sus equivalentes físicos. En estos casos, el comercio observable (es decir, que atraviesa físicamente las fronteras) puede estar cayendo, pero esto podría reflejar, al menos en parte, un aumento del comercio digital, que no es captado con precisión por las estadísticas disponibles. En este contexto, es evidente la necesidad de desarrollar nuevas metodologías para medir el comercio digital de bienes y servicios.

9 La principal diferencia entre los textos del TPP y de este tratado es que este último suspende la aplicación de 22 disposiciones del primero. Estas corresponden principalmente a demandas de los Estados Unidos en materia de propiedad intelectual e inversiones que habían sido resistidas por los demás participantes. 


\section{E. Empresas transnacionales en busca de activos de calidad}

Los cambios en la globalización también se reflejan en la dinámica de los flujos de inversión extranjera directa (IED). Durante la crisis financiera, el movimiento de capitales transfronterizos se redujo de forma sustantiva. Luego del máximo alcanzado en 2007, las corrientes globales de capitales transfronterizos —IED, compra internacional de acciones y títulos de deuda, préstamos y otras inversiones-cayeron un 65\%, llegando a 4,3 billones de dólares; en términos relativos pasaron de un $23 \%$ a un $7 \%$ del producto interno bruto (PIB) mundial. Esta disminución se explica por la fuerte reducción de los préstamos de corto plazo en el sistema bancario, que llevó a una reconversión de los componentes de los flujos. De esta forma, la IED y las compras de acciones se transformaron en el principal componente, aumentando del $36 \%$ al $69 \%$ de los flujos globales entre 2000-2007 y 2008-2016 (McKinsey Global Institute, 2017).

Pese a esta disminución, la globalización financiera sigue vigente: los sistemas bancarios se mantienen estrechamente interconectados y las operaciones de las empresas transnacionales continúan activas. Así, la razón entre el acervo de capitales transfronterizos y el PIB global se mantiene en un nivel similar al de antes de la crisis (pasó de 185 a 183 entre 2007 y 2016), que fue el período de mayor expansión de los capitales transnacionales.

La dinámica de los flujos de IED en este nuevo escenario se caracteriza por dos elementos: i) el crecimiento de las fusiones y adquisiciones de firmas que buscan incorporar capacidades tecnológicas o avanzar hacia la convergencia de las actividades tradicionales con subsectores tecnológicos y ii) el avance de las inversiones transnacionales de empresas chinas en su actual etapa de expansión. Ambas dinámicas reducen los flujos de IED hacia las economías en desarrollo y aumentan las inversiones en las economías avanzadas.

\section{El retorno del capital hacia las economías avanzadas}

Un elemento distintivo de la IED frente a otros flujos transnacionales es su menor volatilidad, ya que refleja decisiones empresariales de inversión de largo plazo orientadas a la explotación de recursos naturales, el acceso a mercados, el aumento de eficiencia operativa o la búsqueda de activos estratégicos (Dunning, 1998).

La inversión en busca de recursos naturales tiene una fuerte presencia en las economías en desarrollo y su evolución está vinculada al ciclo de precios de las materias primas. Las inversiones en búsqueda de mercados y de eficiencia operativa se incrementaron por la creación de mercados comunes mediante acuerdos de integración regional y los menores costos de transporte y de transacción derivados del avance tecnológico. La deslocalización de la producción hacia mercados con menores costos, que comenzó en los años setenta y se profundizó en los noventa, se intensificó aún más durante la década de 2000 producto del impacto de las tecnologías digitales y de un sistema global de financiamiento y comercialización que permitió que las principales empresas transnacionales crearan complejas cadenas de valor globales, en las que la localización de los eslabones no obedecía únicamente a ventajas de costos, sino también a la disponibilidad de activos estratégicos. Así, se crearon cadenas de valor no solo en los sectores que tradicionalmente localizaban las actividades de ensamblaje según ventajas competitivas en costos de mano de obra, como la textil o la electrónica, sino también en industrias de mayor complejidad.

En los últimos años, la aceleración de la revolución tecnológica aumentó la presión por innovar y por acceder a activos estratégicos, lo que incrementó la IED que busca activos de calidad, como patentes y recursos humanos altamente calificados, los que se encuentran en mayor grado en las economías desarrolladas, principalmente en los Estados Unidos, Europa Occidental y Asia Oriental, y en los que América Latina y el Caribe muestra un rezago significativo (CEPAL, 2017). 
Estas dinámicas se ven reflejadas en la evolución de las corrientes globales de IED en el último cuarto de siglo. El primer gran impulso se registró en la década de 1990, con un marcado predominio de las inversiones en las economías desarrolladas (68\% del total), y creció de forma sustantiva nuevamente en la década de 2000, ya con una participación de las economías desarrolladas un poco menor, pero igualmente dominante (64\%). El crecimiento de ingresos en los países en desarrollo y la fase ascendente del ciclo de precios de las materias primas aumentaron el interés de las transnacionales por invertir en los mercados emergentes. Además, la crisis financiera internacional de 2008 afectó más los flujos de IED hacia las economías desarrolladas, con lo cual los países en desarrollo aumentaron su participación como mercados receptores e incluso, en 2014, por primera vez recibieron más capitales, lo que se interpretó en su momento como un cambio de tendencia. Sin embargo, en los últimos dos años las economías avanzadas recuperaron el liderazgo y en 2016 recibieron el $59 \%$ del total de los flujos mundiales de IED, mientras que un $37 \%$ se dirigió hacia economías en desarrollo (véase el gráfico II.9).

\section{Gráfico Il.9}

Corrientes mundiales de IED y participación por grupos de economías, 1990-2016

(En billones de dólares y porcentajes de las corrientes totales)

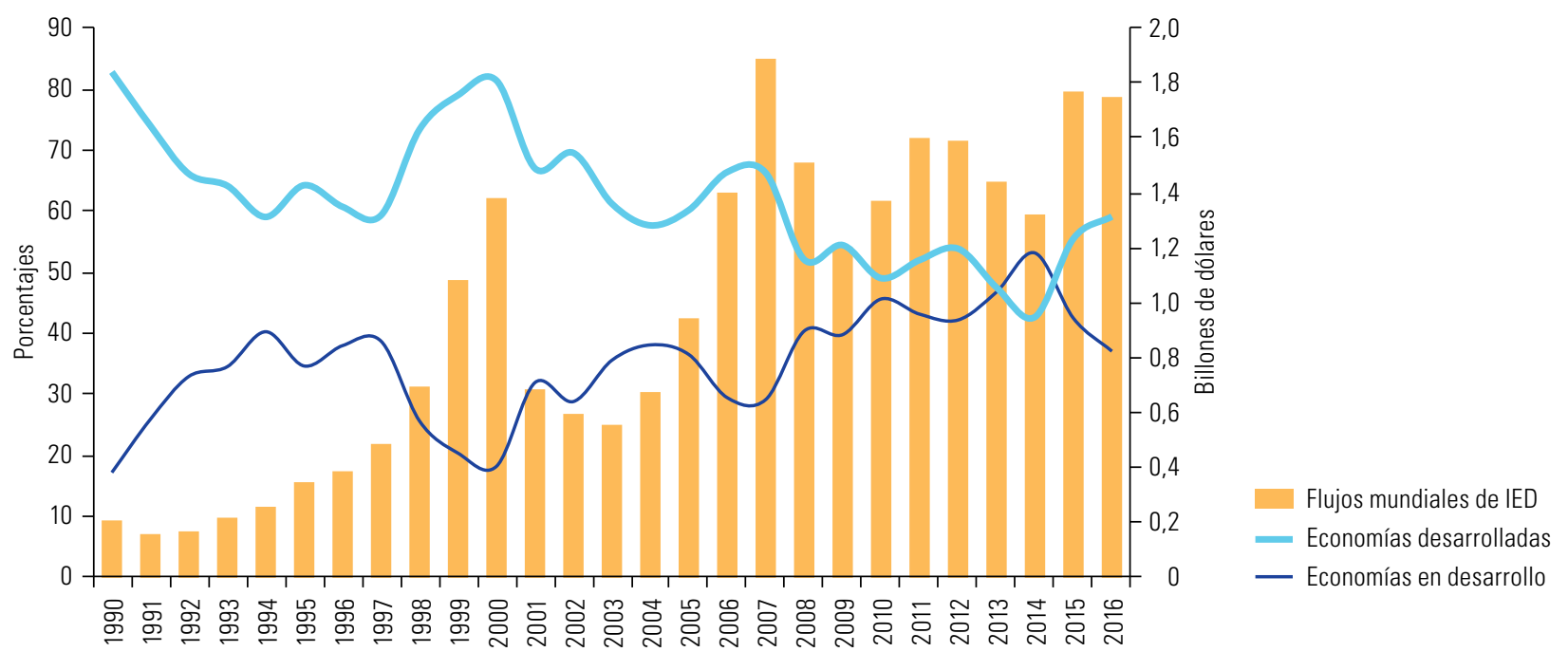

Fuente: Comisión Económica para América Latina y el Caribe (CEPAL), sobre la base de Conferencia de las Naciones Unidas sobre Comercio y Desarrollo (UNCTAD), World Investment Report 2017: Investment and the Digital Economy (UNCTAD/WIR/2017), Ginebra, 2017.

En 2016, las corrientes globales de IED totalizaron 1,75 billones de dólares; este monto, pese a implicar una caída del $2 \%$ con respecto a 2015 , sigue siendo elevado en términos históricos y es solamente un $8 \%$ inferior al máximo alcanzado en 2007. Así, es claro que las operaciones de las empresas transnacionales siguen siendo un fenómeno crucial de la globalización financiera.

En 2016, la IED hacia las economías desarrolladas creció un 5\%, mientras que hacia las economías en desarrollo cayó un 14\%. La mayor caída se registró en los países de Asia en desarrollo (15\%) y en segundo lugar se ubicó América Latina y el Caribe, con una disminución del 8\%; la menor caída se registró en África (3\%). Las principales razones de estas disminuciones fueron el bajo crecimiento de la economía mundial (incluso recesión en algunos países de América Latina), la lenta recuperación del precio de las materias primas, la creciente sofisticación tecnológica y la expansión de la economía digital. En este escenario, las inversiones de las empresas transnacionales tienden a dirigirse hacia los países desarrollados en búsqueda de activos estratégicos. Así, la Unión Europea (UE) y los Estados Unidos lideraron la recepción de inversiones. En 2016, los ingresos en los Estados Unidos, principal receptor e inversor del mundo, crecieron un $12 \%$ y registraron 
un récord histórico, mientras que los ingresos en la UE aumentaron un 17\%, al tiempo que el crecimiento en la UE se explica fundamentalmente por operaciones de fusiones y adquisiciones de gran magnitud que se registraron en el Reino Unido y el aumento de los flujos hacia los Países Bajos, Bélgica e Italia.

La dinámica de la IED en los últimos dos años puede interpretarse como un cambio en las estrategias de los inversionistas y un reflejo del avance de la globalización digital. Los flujos de capitales ya no se mueven en búsqueda de una mayor eficiencia hacia los países con menores costos relativos, sino que son impulsados por empresas con elevada liquidez y que buscan activos estratégicos, lo que es clave en un período de fuertes transformaciones tecnológicas. El mercado de fusiones y adquisiciones con objetivos de alta tecnología ha crecido de forma sustantiva: en 2015 y 2016 un $20 \%$ del valor de operaciones tuvo una empresa objetivo de alta tecnología, cifra que en 2013-2014 era un 14\%. Además, el porcentaje de empresas no tecnológicas que adquiere empresas de alta tecnología aumentó de un $61 \%$ a un $70 \%$ entre 2012 y 2016, lo que obedece a la necesidad de las empresas en sectores tradicionales de incorporar capacidades para la economía digital (Kengelbach y otros, 2017). La convergencia, la elevada liquidez de las plataformas digitales y su diversificación hacia otros sectores y la captación de talentos han impulsado las fusiones y adquisiciones transfronterizas en sectores de alta tecnología. Los sectores objetivo más dinámicos son los de la inteligencia artificial, la computación en la nube, la ciberseguridad y los grandes datos, mientras que las finanzas y la salud son considerados como los de mayor potencial para promover la convergencia, que ya estaría consolidada en la industria automotriz o en el consumo (Baker McKenzie, 2017a).

\section{China consolida su posición como inversor}

Las corrientes de IED se concretan en tres tipos de operaciones. En primer lugar, los ingresos de capitales para el desarrollo de nuevos proyectos, que tendrían un mayor impacto en la creación de capacidad productiva. En segundo, los fondos para la adquisición o fusión con empresas establecidas, cuyos efectos están más asociados a cambios en las capacidades de las firmas, los modelos de negocios y las tecnologías. Un tercer grupo corresponde a los flujos que ingresan a los países para luego ser reinvertidos en terceros mercados, lo que es particularmente relevante en centros financieros que otorgan ventajas fiscales ${ }^{20}$. Esta inversión se destina luego a otras economías, lo que dificulta el análisis de los flujos transfronterizos según países de origen reales.

Desde el punto de vista de la empresa compradora, las fusiones y adquisiciones permiten adquirir rápidamente conocimientos, capacidades tecnológicas, marcas, bases de clientes y acceso a mercados. Debido a estas características, este tipo de operaciones se realiza fundamentalmente con empresas objetivo en las economías avanzadas, donde hay mayores oportunidades para avanzar hacia la frontera tecnológica mediante la participación en empresas en operación. Así, mientras la participación de América Latina y el Caribe, África y China como receptoras de inversiones se ubica en torno al $10 \%$ del monto global cada una, en fusiones y adquisiciones transfronterizas representan porcentajes menores, que van desde el 3,7\% en China al 1,8\% en África (UNCTAD, 2017). Los flujos globales vinculados a fusiones y adquisiciones transfronterizas crecieron de manera sostenida en los últimos años (véase el gráfico II.10). En 2016, su valor aumentó un $18 \%$, sobre todo por las operaciones en economías desarrolladas, que concentraron el $91 \%$ de las ventas.

Aunque las economías avanzadas son el principal origen de estas fusiones y adquisiciones (81\% del total en 2016), en los últimos años las empresas chinas irrumpieron como fuertes compradoras en el contexto global y concentraron el $11 \%$ del valor total de compras, duplicando su participación de 2010 (6\%) (véase el gráfico II.11).

20 En Luxemburgo, los Países Bajos, Hong Kong (Región Administrativa Especial de China) e Irlanda en 2016, los acervos de IED alcanzaron al 8,231\%, 576\%, 574\% y 447\% del PIB, respectivamente (McKinsey Global Institute, 2017). 


\section{Gráfico Il.10}

Valor de las fusiones y adquisiciones transfronterizas netas globales, 2005-2016

(En billones de dólares)

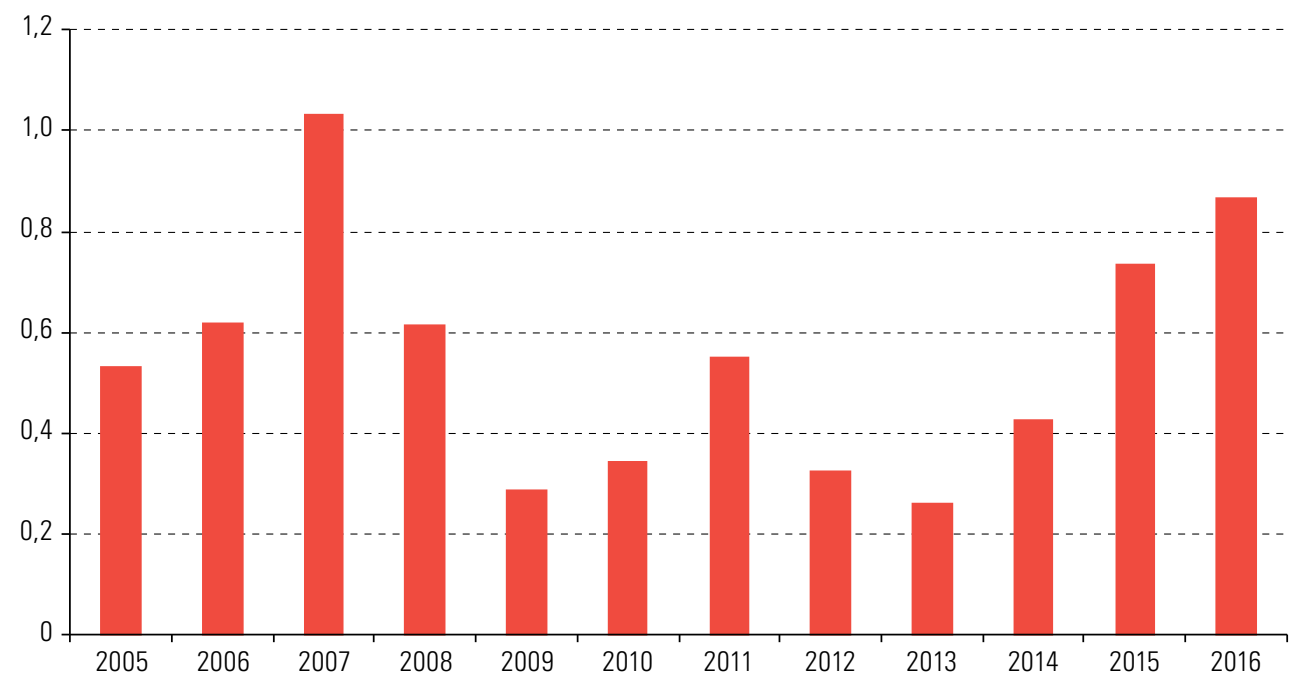

Fuente: Comisión Económica para América Latina y el Caribe (CEPAL), sobre la base de Conferencia de las Naciones Unidas sobre Comercio y Desarrollo (UNCTAD), World Investment Report, 2017: Investment and the Digital Economy (UNCTAD/WIR/2017), Ginebra, 2017.

\section{Gráfico Il.11}

Participación en el valor de fusiones y adquisiciones transfronterizas netas, por país o región, 2016 (En porcentajes)

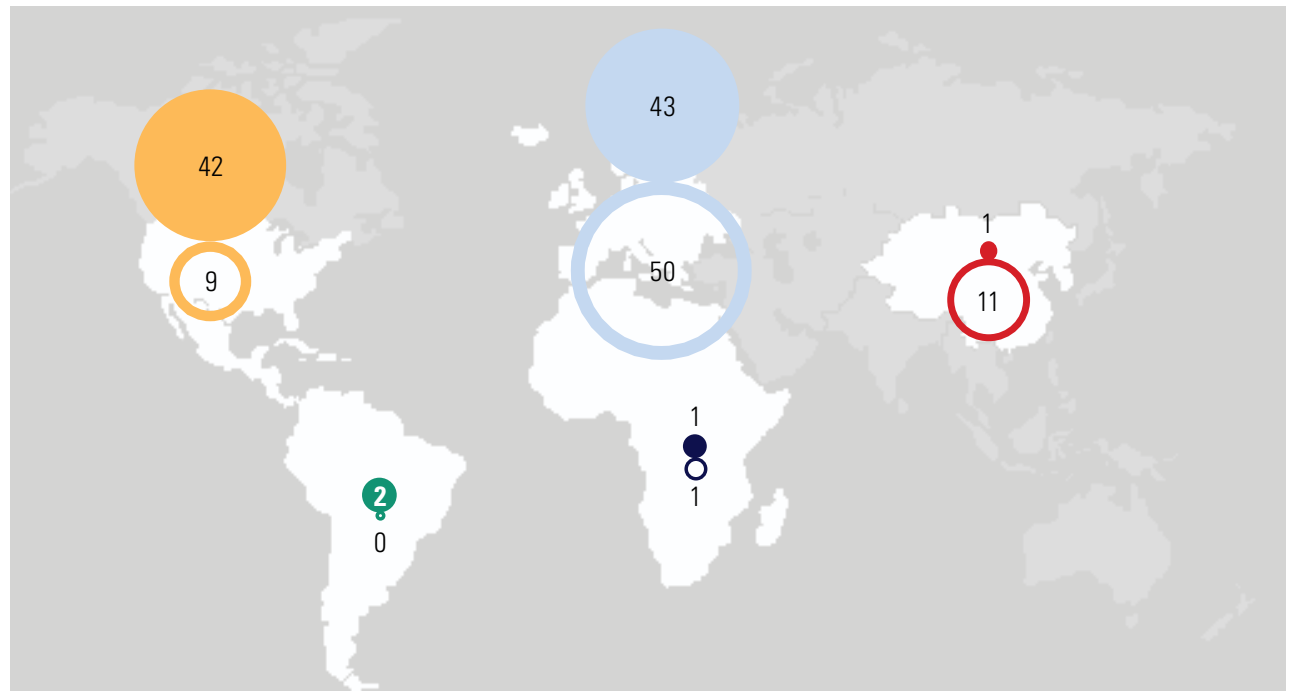

- Estados Unidos ingresos

- Estados Unidos egresos

- Europa ingresos

- Europa egresos

- América Latina y el Caribe ingresos

- América Latina y el Caribe egresos

- África ingresos

○ África egresos

- China ingresos

o China egresos

Fuente: Comisión Económica para América Latina y el Caribe (CEPAL), sobre la base de Conferencia de las Naciones Unidas sobre Comercio y Desarrollo (UNCTAD), World Investment Report, 2017: Investment and the Digital Economy (UNCTAD/WIR/2017), Ginebra, 2017.

La evolución reciente de las inversiones en el exterior de empresas transnacionales de China es una fuerza adicional que impulsa el posicionamiento del país entre los actores líderes en el contexto económico y geopolítico global. Su participación en los flujos de salida de IED ha crecido de forma sostenida desde mediados de la década de 2000, ya que pasó de representar el 1,3\% de las salidas globales en 2006 al 12,6\% en 2016. 
Esta participación, que correspondió a un máximo histórico de 183.100 millones de dólares, ubicó a China como el segundo país con más inversiones en el exterior luego de los Estados Unidos (véase el gráfico II.12).

\section{Gráfico Il.12}

Estados Unidos y China: participación en los flujos mundiales de entrada y salida de IED, 2006-2016

(En porcentajes)

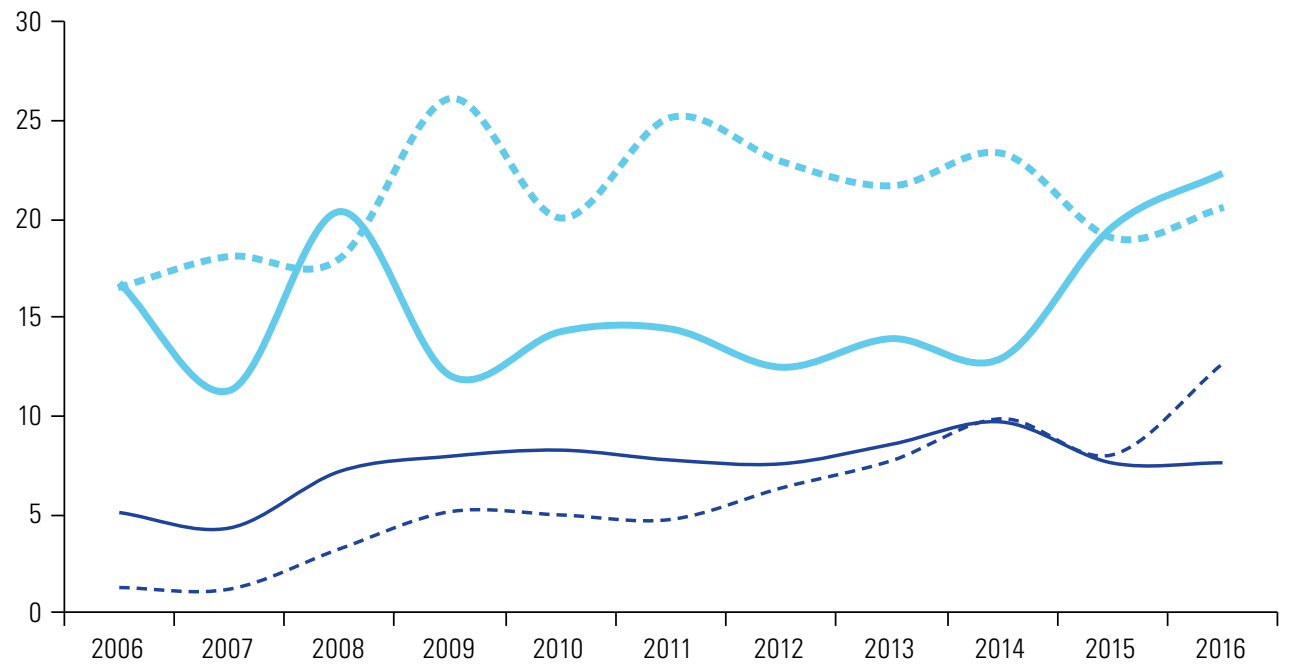

$=-$ Estados Unidos: salidas de IED

Estados Unidos: entradas de IED

- - - China: salidas de IED

- China: entradas de IED

Fuente: Comisión Económica para América Latina y el Caribe (CEPAL), sobre la base de Conferencia de las Naciones Unidas sobre Comercio y Desarrollo (UNCTAD), World Investment Report, 2017: Investment and the Digital Economy (UNCTAD/WIR/2017), 2017, Ginebra.

Esta expansión puede atribuirse a tres factores. En primer lugar, un gran superávit comercial, que permite la provisión de créditos a bajas tasas, otorgados en gran parte por bancos públicos. En segundo lugar, las dificultades que enfrentan las empresas para mantener ganancias elevadas en el mercado interno impulsan sus operaciones transfronterizas. En tercer lugar, la intención de China de alcanzar un papel protagónico en las nuevas dinámicas industriales y tecnológicas.

La mayoría de los flujos de salida de IED de China se materializó en fusiones y adquisiciones, con empresas objetivo de los Estados Unidos y Europa; si bien las operaciones están diversificadas sectorialmente, las industrias de mayor avance tecnológico tienen una elevada participación. En los Estados Unidos, el mayor interés de las transnacionales de China se ha concentrado en hardware y electrónica de consumo, bienes raíces y la industria del espectáculo. Por su parte, sus intereses en Europa se dirigieron hacia tecnologías de la información y de las comunicaciones, transporte, energía e infraestructura, y maquinaria industrial. Mediante estas adquisiciones, China se consolida en la economía mundial insertándose con éxito en las dinámicas de sectores cada vez más sofisticados, lo que le permite ser un importante protagonista en la revolución digital.

Este ritmo de expansión puede no ser sostenible en el futuro cercano. Por un lado, las autoridades monetarias han aumentado los controles a la salida de capitales, buscando evitar el impacto negativo sobre la balanza de pagos, las presiones sobre la moneda nacional y el elevado endeudamiento de algunas transnacionales chinas. Por otra parte, pero en la misma dirección, las adquisiciones de las empresas chinas, que en muchos casos han sido apoyadas por bancos o empresas estatales, generaron preocupación en Europa y los Estados Unidos. En septiembre de 2017, la Comisión Europea propuso un marco regulatorio para hacer una revisión (screening) de la IED en su territorio a fin de defender sus intereses estratégicos si se ven amenazados ${ }^{21}$; por su parte, en los Estados Unidos el control por parte del Comité de Inversión Extranjera (CFIUS) ha focalizado muchas de sus investigaciones en operaciones de empresas chinas.

21 Véase Comisión Europea (2017) y el discurso sobre el estado de la Unión pronunciado por el Presidente de la Comisión en 2017 [en línea] http://europa.eu/rapid/ press-release_SPEECH-17-3165_es.htm. La propuesta requiere la aprobación del Parlamento Europeo y los Estados miembros del Consejo. La Unión Europea busca enfrentar las críticas a los mecanismos tradicionales de solución de controversias entre inversionistas y Estado mediante una propuesta de pasar del actual sistema de arbitrajes ad hoc, sin instancia de apelación, a un sistema de tribunales permanentes con apelación. 
Una visión de conjunto muestra que se consolida el mayor interés de los capitales extranjeros en la tríada de las áreas avanzadas (Estados Unidos, Europa Occidental y Asia Oriental). Los flujos de IED se mantienen en niveles superiores a los del período previo a la crisis y en los dos últimos años crecen en los países desarrollados, principalmente por las operaciones de fusiones y adquisiciones que buscan activos estratégicos para incorporarse en la dinámica del acelerado cambio tecnológico que impulsa el desarrollo de la economía digital. Entre las economías emergentes, China afianza su posición y despliega una estrategia de fusiones y adquisiciones en sectores de tecnología avanzada en países como los Estados Unidos y Alemania, que le permita estar en la frontera de las capacidades requeridas para el avance de la economía digital.

\section{F. Una gobernanza internacional ineficaz}

En la última década, un conjunto de factores ha puesto presión sobre los actores, la gobernanza y las instituciones que impulsaron la globalización, en particular los que inciden sobre las migraciones internacionales, la dinámica macroeconómica global, la revolución tecnológica, el comercio internacional, la inversión extranjera directa y la crisis ambiental. Afianzar la gobernanza internacional no resulta de la sumatoria de acciones nacionales aisladas, sino de la construcción de pactos globales. Estos fortalecerían el proceso de implementación de la Agenda 2030 mediante un renovado multilateralismo con la participación de todos los actores involucrados.

\section{Las grandes corrientes migratorias internacionales}

En 2015, los migrantes internacionales representaban un 3,3\% de la población mundial, unos 244 millones de personas $^{22}$. Un tercio de ellos se encontraba en Europa, otro tercio en Asia y el tercio restante se distribuía entre América del Norte, África, América Latina y el Caribe (9 millones) y Oceanía. En términos relativos, tenían un peso más significativo en Oceanía, América del Norte y Europa que en Asia, África y América Latina y el Caribe (1,5\%). Entre 1990 y 2015, el acervo de migrantes en el mundo aumentó un 60\%. Después de un crecimiento particularmente intenso en la década de 2000, con 4,9 millones de migrantes anuales, comparado con 2 millones anuales entre 1990 y 2000, el aumento se desaceleró ligeramente, pasando a 4,4 millones anuales entre 2010 y 2015 (Naciones Unidas, 2016).

A partir de 2000, Asia fue la región que recibió más migrantes. En 2015, el flujo de migración Asia-Asia fue el mayor del mundo (59 millones de personas). El segundo corredor más importante fue el de Europa-Europa (40 millones). El tercero fue el de América Latina y el Caribe a América del Norte (casi 25 millones). Sin embargo, el promedio anual de migrantes añadidos a través de este corredor ha disminuido de manera significativa, pasando de 0,8 millones entre 1990 y 2000 a 0,3 millones entre 2010 y 2015.

Los migrantes internacionales se concentran en pocos países: Estados Unidos, Alemania, Federación de Rusia, Arabia Saudita, Reino Unido, Emiratos Árabes Unidos, Canadá, Francia, Australia y España, donde vivía el $51 \%$ de ellos en 2015. Entre 1990 y 2015 los mayores incrementos se observaron en los Estados Unidos, los Emiratos Árabes Unidos, Alemania, Arabia Saudita y España. Cinco de los diez principales corredores de migración bilateral tenían un país desarrollado como destino, siendo el de México a los Estados Unidos el más utilizado, con alrededor de 240.000 migrantes adicionales por año en promedio. Otros corredores importantes tenían países productores de petróleo de Asia Occidental como destino y países del Sur de Asia como origen. En el quinquenio 2010-2015, los patrones de migración cambiaron radicalmente: solo uno de los corredores de migración más grandes del mundo tenía un país de las regiones desarrolladas como destino: el de México a los Estados Unidos. Los otros nueve tenían como destino un país en desarrollo. Varios de los destinos que registraron el mayor aumento del número de migrantes fueron los productores de petróleo de Asia occidental. Además, el conflicto en Siria provocó un gran aumento de la cantidad de refugiados en países vecinos, como Jordania, el Líbano y Turquía, así como en países europeos, sobre todo Alemania y Serbia.

22 Se considera migrante internacional a las personas nacidas en el exterior o que se identificaron como ciudadanos extranjeros. 
En la década de 1990, la migración neta superó el aumento natural como el principal impulsor del crecimiento poblacional en las regiones desarrolladas y se espera que sea el único motor de crecimiento a partir de la década de 2020. Para la década de 2040, se proyecta que el crecimiento de la población en esas regiones será negativo y la migración neta positiva ya no podrá compensar el mayor número de defunciones con relación a los nacimientos. En las regiones en desarrollo, se espera que el crecimiento demográfico disminuya entre 2000 a 2050, debido principalmente a una desaceleración del aumento natural causado por la caída de la tasa de fecundidad. Si bien, de una manera general, el efecto de la migración sobre el tamaño de la población en estas regiones será relativamente pequeño, sería bastante significativo en algunos países, en especial aquellos con poblaciones menos numerosas.

Dado que los migrantes internacionales tienden a concentrarse en las edades laborales, la migración neta positiva puede reducir la relación de dependencia de las personas mayores (personas de 65 años o más por cada 100 personas de 15 a 64 años), que es comúnmente utilizada para evaluar los posibles costos sociales y económicos asociados al envejecimiento poblacional. Según las proyecciones de las Naciones Unidas, esa relación aumentará un $71 \%$ en las regiones desarrolladas entre 2015 y 2050. En ausencia de la migración, el aumento sería del $87 \%$. Si bien la migración internacional podría tener un impacto importante en las tasas de dependencia en determinadas situaciones y períodos, es improbable que revierta la tendencia a largo plazo hacia el envejecimiento.

El marco normativo sobre migración internacional incluye instrumentos relacionados con los derechos humanos de las personas migrantes, los derechos de los trabajadores migrantes y la protección de los refugiados, así como instrumentos diseñados para combatir el tráfico de migrantes y la trata de personas. En general, en todas las regiones estos instrumentos muestran tasas de ratificación más bajas en comparación con los demás instrumentos. En América Latina y el Caribe se encuentra el mayor porcentaje de países que han ratificado al menos un instrumento de derechos de los migrantes, mientras que los países de América del Norte no han ratificado ninguno (Naciones Unidas, 2016).

\section{La necesidad de una nueva arquitectura financiera}

La Agenda 2030 para el Desarrollo Sostenible, la Agenda de Acción de Addis Abeba sobre el financiamiento para el desarrollo, el Marco de Sendái para la Reducción del Riesgo de Desastres y el Acuerdo de París sobre el cambio climático implican una transformación profunda del estilo de desarrollo, cuya implementación requiere una gran movilización de recursos, acompañada de cambios en su financiación, organización y asignación.

Para ello es preciso profundizar la reforma a la gobernanza global iniciada por los organismos multilaterales, que aumenta el reconocimiento del peso y el poder de voto de las economías en desarrollo. En septiembre de 2016, el FMI incluyó el yuan en la canasta de monedas que conforman los derechos especiales de giro (DEG). A esto hay que añadir que el Gobierno de los Estados Unidos aprobó la reforma al sistema de cuotas del FMI planteada en 2010. Esta reforma dispone el aumento de las cuotas para sus 188 países miembros, que se duplicaron, en un aumento sin precedentes, y la reasignación de un 6\% de ellas desde los países desarrollados a las economías emergentes y en desarrollo. Asimismo, otorga un mayor poder de decisión y voto a algunas de las mayores economías emergentes y en desarrollo: Brasil, China, India y Rusia, que pasan a situarse entre los diez principales miembros del FMI. Además, se mantuvieron las cuotas y los derechos de voto de los países miembros con menores ingresos (con un PIB per cápita inferior a 1.135 dólares en 2008). Por último, esa reforma planteó aumentar los cupos para países emergentes y países en desarrollo.

En 2008, el Banco Mundial inició una reforma para ampliar la representación de los países en desarrollo, reconociendo que "la distribución de la participación es importante para la legitimidad de la institución". En 2010, aumentó la participación de los países en desarrollo al 47,19\%, de un 44,06\% en 2009. En septiembre de 2015, se reconoció la participación creciente de los países en desarrollo y en transición en la economía mundial y, en consecuencia, se plantea que la participación con derecho a voto de los países en desarrollo ascienda al 52,76\%. 
Pese a su importancia, estos avances son insuficientes y es cada vez más necesario cambiar el sistema financiero internacional para hacerlo compatible con la movilización de recursos requeridos por la Agenda 2030. Por ello, en CEPAL (2016a) se resaltó que el aumento de la representación y el poder de decisión de los países en desarrollo en las instituciones financieras internacionales (en función de su mayor peso en la economía mundial) tendría el carácter de bien público global. En este esfuerzo debe combinarse la creación de otros bienes públicos como la coordinación de políticas fiscales, cambiarias y financieras y, en particular, la acción internacional para reducir la evasión y elusión fiscales, temas que se analizan en el capítulo III.

\section{El debilitamiento del multilateralismo en el comercio internacional}

La revolución digital plantea desafíos sin precedentes a la regulación del comercio mundial. Los acuerdos de los años noventa resultan hoy inadecuados para gobernar los flujos digitales transfronterizos, que crecen de manera exponencial. Las plataformas digitales y las infraestructuras asociadas, los sistemas de innovación y las instituciones acordes al nuevo paradigma son determinantes de las ventajas competitivas en esta nueva era industrial y, por ende, de la hegemonía global en los próximos años.

Mientras el espacio para desarrollar políticas industriales tradicionales se ha reducido marcadamente producto de los acuerdos de la OMC y de los acuerdos comerciales y de inversión Norte-Sur, la economía digital permanece menos regulada. Ello deja espacios a los gobiernos para implementar medidas como el bloqueo de ciertos sitios de Internet, requisitos de localización de servidores o exigencias a los proveedores extranjeros de revelar el código fuente de sus programas. En este contexto, actores como China, los Estados Unidos y la Unión Europea compiten por influir en la regulación del comercio digital mundial, con visiones y modelos muy heterogéneos.

En parte como respuesta a la irrupción de la economía y el comercio digitales, en la primera mitad de la presente década se iniciaron varios acuerdos comerciales a los que, dada su gran magnitud, se denominó megarregionales. Entre ellos están el Acuerdo de Asociación Transpacífico (TPP), la Asociación Transatlántica de Comercio e Inversión (TTIP) y la Asociación Económica Integral Regional (RCEP). Estos tres procesos, si bien diferentes en varios aspectos, tenían en común su carácter plurilateral, su gran peso económico y demográfico y su amplia cobertura temática (CEPAL, 2016a). En particular, representaban la primera generación de acuerdos comerciales que, además de abordar la liberalización de los flujos tradicionales de comercio e inversión, buscaban (con diversos énfasis) la liberalización y regulación de los flujos digitales. Dada su gran escala y la participación de los principales actores de la economía digital, las negociaciones megarregionales ofrecían el potencial de generar estándares globales de facto para el comercio electrónico, particularmente en vista del estancamiento de las negociaciones de la Ronda de Doha de la OMC. En efecto, uno de los aspectos más destacados del TPP —y de su sucesor, el Tratado Integral y Progresista de Asociación Transpacífico- es su énfasis en la regulación de la economía digital. Ello respondía originalmente al interés de los Estados Unidos en preservar su posición de liderazgo frente a competidores emergentes, en particular China, país que en los últimos años ha desplegado una agresiva política industrial digital (Azmeh y Foster, 2016) y adquirido un papel preponderante en la estructura de poder de la economía digital global, desafiando el liderazgo de los Estados Unidos.

La llegada al poder de una nueva administración en los Estados Unidos en enero de 2017 alteró sustancialmente los esfuerzos en curso para redefinir la gobernanza del comercio mundial. La nueva política comercial de ese país, conocida como America First (los Estados Unidos ante todo), se caracteriza por un discurso abiertamente proteccionista, un giro desde el multilateralismo al bilateralismo e incluso el unilateralismo, un enfoque que prioriza la reducción de los déficits comerciales por sobre cualquier otro objetivo, y variados esfuerzos por lograr una relocalización (reshoring) de industrias y empleos mediante la renegociación de acuerdos comerciales, la desregulación ambiental y la reforma fiscal que entró en vigencia en diciembre de 2017 (véase el recuadro II.1). 


\section{Recuadro II.1}

La nueva reforma tributaria de los Estados Unidos

El 1 de enero de 2018 entró en vigor la Ley de Empleo y Reducción Tributaria, la reforma impositiva federal más amplia y completa desde 1986. En este nuevo contexto tributario se disponen cambios significativos en la estructura tributaria corporativa y se reduce la tasa del impuesto corporativo del $35 \%$ al $21 \%$. Además, permite la aplicación única de una tasa corporativa de repatriación (del $8 \%$ para activos no líquidos y el 15\% para activos líquidos) para alentar a las empresas a repatriar casi 3 billones de dólares de activos corporativos que poseen en el extranjero, sobre todo en Europa, y lleva a los Estados Unidos a un sistema de impuestos territoriales. Se espera que la Ley de Empleo y Reducción Tributaria estimule significativamente a los sectores tecnológico, manufacturero, farmacéutico, automotor, financiero y de telecomunicaciones. De hecho, los objetivos principales del nuevo régimen tributario son relocalizar empresas, empleos y propiedad intelectual, fomentar la inversión extranjera y nacional y aumentar los ingresos fiscales. La ley también contiene una reforma a la estructura tributaria individual.

Las repercusiones macroeconómicas del nuevo régimen aún no están claras dado que el estímulo fiscal podria sumar más de 1 billón de dólares al déficit nacional en los próximos diez años y las estimaciones del incremento del PIB que podría compensar estos costos oscilan entre el 0,7\% y el 5\% (Comité Conjunto de Tributación, 2017, Comité de Consejeros Económicos de la Casa Blanca, 2017). La deuda nacional de los Estados Unidos, que ya se acerca a los 20 billones de dólares, podría aumentar significativamente, lo que también causa preocupación en cuanto a la sostenibilidad, ya que se alcanzarian los mayores niveles de deuda después de los existentes alrededor de la posguerra (Appelbaum, 2017). La Ley de Empleo y Reducción Tributaria es la primera de muchas reformas legislativas previstas en el corto plazo, o ya en curso, incluido un amplio plan de infraestructura, una revisión de los programas de seguridad social y la desregulación en varios sectores.

Fuente: Comisión Económica para América Latina y el Caribe (CEPAL), sobre la base de Comité Conjunto de Tributación, Macroeconomic Analysis of the Conference Agreement for H.R. 1, the Tax Cuts and Jobs Act, Washington, D.C., 22 de diciembre de 2017 [en línea] https://www.jct.gov/publications. html?func=startdown\&id=5055; Comité de Consejeros Económicos de la Casa Blanca, The Growth Effects of Corporate Tax Reform and Implications for Wages, Washington, D.C., octubre de 2017 [en línea] https://www.whitehouse.gov/sites/whitehouse.gov/files/images/Corporate\%20Tax\%20 Reform\%20and\%20Growth\%20Final.pdf y B. Appelbaum, "Debt concerns, once a core Republican tenet, take a back seat to tax cuts", New York Times, 1 de diciembre de 2017 [en línea] https://www.nytimes.com/2017/12/01/us/politics/tax-cuts-deficit-debt.html.

Otro cambio importante fue el referido a la neutralidad de Internet. En diciembre de 2017, la Comisión Federal de Comunicaciones acordó revocar la regulación sobre neutralidad de la red adoptada en 2015 que, en principio, prohibía cualquier tipo de bloqueo de contenido legítimo, degradación de tráfico y priorización pagada en Internet, reclasificando también los servicios de Internet como servicios de comunicación públicos. El argumento principal fue que esas regulaciones afectaban negativamente a la inversión, la innovación y el surgimiento de nuevos modelos de negocios. Sin embargo, dada la estructura del mercado de provisión de esos servicios, estos cambios podrían perjudicar también a los consumidores, quienes podrán ser sujetos de nuevos cargos por parte de los operadores según la calidad y la velocidad de la señal. Por otra parte, los proveedores de servicios en línea más pequeños (por ejemplo, empresas minoristas de comercio electrónico) pueden verse afectados al no poder acceder a un tratamiento preferencial de su contenido, como lo pueden hacer las empresas de mayor tamaño, incrementando aún más las asimetrías en Internet.

Producto del drástico giro de la política comercial de los Estados Unidos, la principal negociación megarregional que continúa en curso es la de la Asociación Económica Integral Regional (RCEP), con la participación de los diez países miembros de la Asociación de Naciones del Asia Sudoriental (ASEAN), Australia, China, la India, el Japón, Nueva Zelandia y la República de Corea. En caso de prosperar, ese proceso culminaría con la creación de un área de libre comercio cuyos miembros representan la mitad de la población del mundo, el 38\% de su PIB (medido en paridad de poder adquisitivo), el $31 \%$ de las exportaciones mundiales de bienes y el $26 \%$ de las importaciones. No obstante, la conclusión exitosa de esta Asociación Económica también enfrenta importantes dificultades que derivan, en gran medida, de la marcada heterogeneidad de sus participantes en términos de niveles de desarrollo y, por ende, de sus posiciones negociadoras (Cook y Basu Das, 2017).

La incertidumbre en torno a los acuerdos megarregionales tiene implicancias para la normativa y la estructura de la economía global. Primero, resalta la ausencia de un consenso entre los principales actores 
globales sobre cómo regular el comercio en bienes y servicios y los sectores emergentes del siglo XXI. Esto dificulta los procesos de convergencia regulatoria y la modernización del marco de la OMC. Además, se desaceleran los proyectos de integración económica de amplio alcance entre los Estados Unidos, América Latina y el Caribe y Asia y el Pacífico (TPP) y entre los Estados Unidos y la Unión Europea (TTIP). La mayor integración económica que podría ocurrir a mediano plazo es en Asia y el Pacífico mediante la Asociación Económica Integral Regional, si estas negociaciones superan las dificultades.

La ausencia de marcos regulatorios de carácter multilateral ha llevado a la creación de estándares fragmentados basados en prioridades nacionales, particularmente con respecto a comercio, inversión y tecnología. En suma, los Estados Unidos, que durante las primeras siete décadas de la posguerra fueron el principal promotor de la liberalización comercial, han tomado una dirección opuesta, con resultados que son aún difíciles de prever. Hasta ahora este giro no parece marcar un punto de inflexión en el proceso de apertura comercial que ha experimentado el mundo en las últimas tres décadas. En efecto, los otros grandes actores de la economía mundial, en particular la Unión Europea, China y el Japón, han reiterado públicamente su compromiso con la apertura y el multilateralismo. No obstante, es indudable que se ha configurado un panorama de fuerte incertidumbre en la gobernanza mundial, que requiere un multilateralismo reforzado y equitativo que responda a las urgencias del siglo XXI.

\section{La solución de controversias entre inversionista y Estado}

La inversión extranjera es otra dimensión fundamental de la globalización, cuya actual gobernanza presenta serias deficiencias. En efecto, en los últimos años surgieron crecientes cuestionamientos a los acuerdos internacionales sobre inversión, argumentándose que privilegian los derechos de los inversionistas extranjeros por sobre el derecho del Estado anfitrión a regular en la búsqueda del interés público y del desarrollo sostenible (UNCTAD, 2015). La percepción de la importancia de este tema ha aumentado producto de eventos como la crisis financiera global, que llevó a muchos gobiernos a asumir posturas más intervencionistas en la economía.

El impacto negativo sobre el espacio regulatorio de los Estados se ve magnificado por el hecho de que un gran número de acuerdos sobre inversión incluyen mecanismos de solución de controversias entre inversionistas y Estados, que permiten a un inversionista extranjero demandar directamente al Estado anfitrión en un proceso de arbitraje internacional si considera que no se han respetado sus derechos según el acuerdo respectivo. Desde mediados de los años noventa, los inversionistas extranjeros han utilizado cada vez más estos mecanismos: más del $80 \%$ de los casos en este período han sido iniciados por empresas transnacionales de países desarrollados.

Las principales críticas a los mecanismos de solución de controversias son: i) la posibilidad de que el Estado anfitrión se inhiba de regular en el interés público por temor a ser demandado (situación conocida como regulatory chill); ii) la falta de consistencia entre fallos sobre asuntos similares; iii) la imposibilidad de corregir eventuales decisiones erróneas de los tribunales al no existir una instancia de apelación; iv) la discriminación hacia los inversionistas locales, que no pueden recurrir al arbitraje internacional; v) los eventuales conflictos de interés de los árbitros; vi) la falta de transparencia de los procedimientos; vii) los elevados costos de la defensa para los Estados anfitriones, y viii) el otorgamiento de sumas excesivas como compensación a los inversionistas extranjeros (Herreros y García-Millán, 2017).

Numerosos países han reaccionado a los cuestionamientos a estos mecanismos mediante reformas a sus acuerdos sobre inversión. Algunos han introducido ajustes menores al mecanismo, manteniendo su estructura básica (este fue el enfoque seguido en el TPP y el Tratado Integral y Progresista de Asociación Transpacífico). Otros, como la India, establecieron el requisito de recurrir a los tribunales locales como condición previa al arbitraje internacional. Con un mayor grado de ambición se sitúa la propuesta de la Unión Europea de pasar del actual sistema de arbitrajes ad hoc, sin instancia de apelación, a un sistema de tribunales permanentes con apelación ${ }^{23}$. Por último, otros países, como el Brasil, optaron por eliminar estos mecanismos de sus nuevos acuerdos de inversión, recurriendo a mecanismos alternativos de solución de controversias.

23 Sus recientes acuerdos comerciales con el Canadá y Singapur incluyen este mecanismo, así como el compromiso de las partes de promover la creación de un tribunal multilateral de inversiones. Estos acuerdos contienen también disposiciones para garantizar el derecho del Estado anfitrión a regular en el interés público, como se indica en Comisión Europea (2015). 
La actual gobernanza del comercio y la inversión es cada vez más inadecuada para enfrentar fenómenos como la economía digital, las demandas ciudadanas por preservar el espacio regulatorio de los Estados y la necesidad de garantizar que el comercio y la inversión apoyen la Agenda 2030 para el Desarrollo Sostenible. Las señales recientes de debilitamiento del multilateralismo hacen aún más difícil revertir ese déficit.

\section{La difícil implementación de la gobernanza ambiental}

En las últimas décadas, se han ido acumulando presiones ambientales de escala global en áreas como la pérdida de biodiversidad, la contaminación por sustancias químicas de suelos y aguas, el agotamiento de la capa de ozono y el calentamiento global. El reconocimiento del creciente deterioro del patrimonio natural mundial llevó a la redefinición del concepto de desarrollo hacia el de desarrollo sostenible ${ }^{24}$. Este concepto fue central para la formulación de la estructura de gobernanza ambiental moderna, que se formalizó en los acuerdos alcanzados en la Cumbre para la Tierra de 1992, sumando al Convenio de Viena para la Protección de la Capa de Ozono, la Convención Marco de las Naciones Unidas sobre el Cambio Climático, la Convención de las Naciones Unidas de Lucha contra la Desertificación y el Convenio sobre la Diversidad Biológica (CDB), un plan de acción (el Programa 21) y una declaración con 27 principios de gobernanza, la Declaración de Río sobre el Medio Ambiente y el Desarrollo. Posteriormente se sumaron el Convenio de Minamata sobre el Mercurio, el Convenio de Estocolmo y el Convenio sobre la Diversidad Biológica. El esfuerzo de gobernanza ambiental global ha estado encaminado a proteger tanto a la sociedad como a las propias economías de la degradación de sus bases de sustentación. Por ello, los Objetivos de Desarrollo Sostenible (ODS) y la Agenda 2030 articulan los diferentes campos del desarrollo con una visión integrada y universal basada en dicho concepto.

En este camino los éxitos han sido lentos y escasos. Destaca el avance en la recuperación de la capa de ozono. El resto de los temas muestra poca mejora o abierto retroceso, como los colapsos de las pesquerías, la contaminación oceánica, la extinción masiva de especies, la degradación de los suelos y el imparable calentamiento global.

El cambio climático revela la urgencia de lograr una transformación productiva hacia una mayor sostenibilidad del desarrollo. La Convención Marco de las Naciones Unidas sobre el Cambio Climático ilustra el problema de la gobernanza ambiental global. Transitar hacia un círculo virtuoso depende, en gran medida, del Acuerdo de París aprobado en 2015, que reconoció como umbral para la seguridad climática evitar un calentamiento global de más $2^{\circ} \mathrm{C}$ sobre el nivel preindustrial, haciendo esfuerzos por limitar ese calentamiento a no más de $1,5^{\circ} \mathrm{C}$. Sin embargo, el calentamiento acumulado desde 2015 ya es mayor a $1,0^{\circ} \mathrm{C}$ y se está sobrepasando el presupuesto de carbono disponible para limitar el calentamiento a $1,5^{\circ} \mathrm{C}$. Más aún, al ritmo de emisión actual ${ }^{25}$ solo quedarían unos 20 años para evitar cruzar la barrera de los $2^{\circ} \mathrm{C}^{26}$. Suponiendo que se alcancen todas las contribuciones previstas determinadas a nivel nacional (CPDN), la brecha continúa siendo alarmante, pues solo cubren un tercio de las reducciones necesarias para lograr la meta de $2{ }^{\circ} \mathrm{C}$ (véanse el gráfico $1 \mathrm{l} .13$ y PNUMA, 2017) ${ }^{27}$.

24 Este concepto quedó plasmado en 1987, en el Informe de la Comisión Mundial sobre el Medio Ambiente y el Desarrollo: "Nuestro futuro común", conocido como Informe Brundtland, en que se determinó que el desarrollo duradero es el desarrollo que satisface las necesidades de la generación presente sin comprometer la capacidad de las generaciones futuras para satisfacer sus propias necesidades.

25 Actualmente, las emisiones de combustibles fósiles, cemento y procesos industriales representan el $70 \%$ de los gases emitidos ( $35,8 \mathrm{GtCO2} \mathrm{en} 2016$ y actualmente $40 \mathrm{GtCO2)} \mathrm{(PNUMA,} \mathrm{2017).} \mathrm{Para} \mathrm{un} \mathrm{sendero} \mathrm{seguro} \mathrm{hacia} \mathrm{el} \mathrm{futuro,} \mathrm{las} \mathrm{emisiones} \mathrm{totales,} \mathrm{incluidas} \mathrm{las} \mathrm{del} \mathrm{uso} \mathrm{del} \mathrm{suelo} \mathrm{y} \mathrm{cambio} \mathrm{del} \mathrm{uso} \mathrm{del} \mathrm{suelo,} \mathrm{fueron} \mathrm{estimadas}$ en 51,9 GtCO2 en 2016. Para alcanzar la meta de $2{ }^{\circ} \mathrm{C}$ con un 66\% de posibilidad, las emisiones totales no deben ser superiores a $42 \mathrm{GtCO} 2$ en 2030 . En la región, el cambio del uso del suelo es fuente del $49 \%$ de las emisiones de gases de efecto invernadero (CEPAL, 2015). Por eso, la mayor parte de las acciones previstas en las contribuciones previstas determinadas a nivel nacional (CPDN) de los países se orienta a la reducción de ese tipo de emisiones.

26 Véase Global Carbon Project [en línea] http://www.globalcarbonproject.org/.

27 La brecha de reducciones para lograr la meta de $2^{\circ} \mathrm{C}$ hacia 2030 es de entre 11 y $13,5 \mathrm{GtCO}_{2}$, dependiendo de si se trata de metas sobre la base del esfuerzo puramente nacional o de metas más ambiciosas que demandan transferencias de recursos y otros apoyos internacionales. Para la meta de $1,5^{\circ} \mathrm{C}$, la brecha es de entre 16 y $19 \mathrm{GtCO}_{2}$. Se estima que el potencial de reducciones de emisiones proviene básicamente de seis categorías: energía solar, eólica, eficiencia energética, transporte eficiente, forestación y cero deforestación, cuyo potencial de reducción de emisiones es del orden de $22 \mathrm{GtCO}_{2} /$ año. El Acuerdo de París prevé un fortalecimiento de las contribuciones cada cinco años. 


\section{Gráfico II.13}

El agotamiento del presupuesto de carbono

(Emisiones acumuladas de $\mathrm{CO}_{2}$ en gigatoneladas)

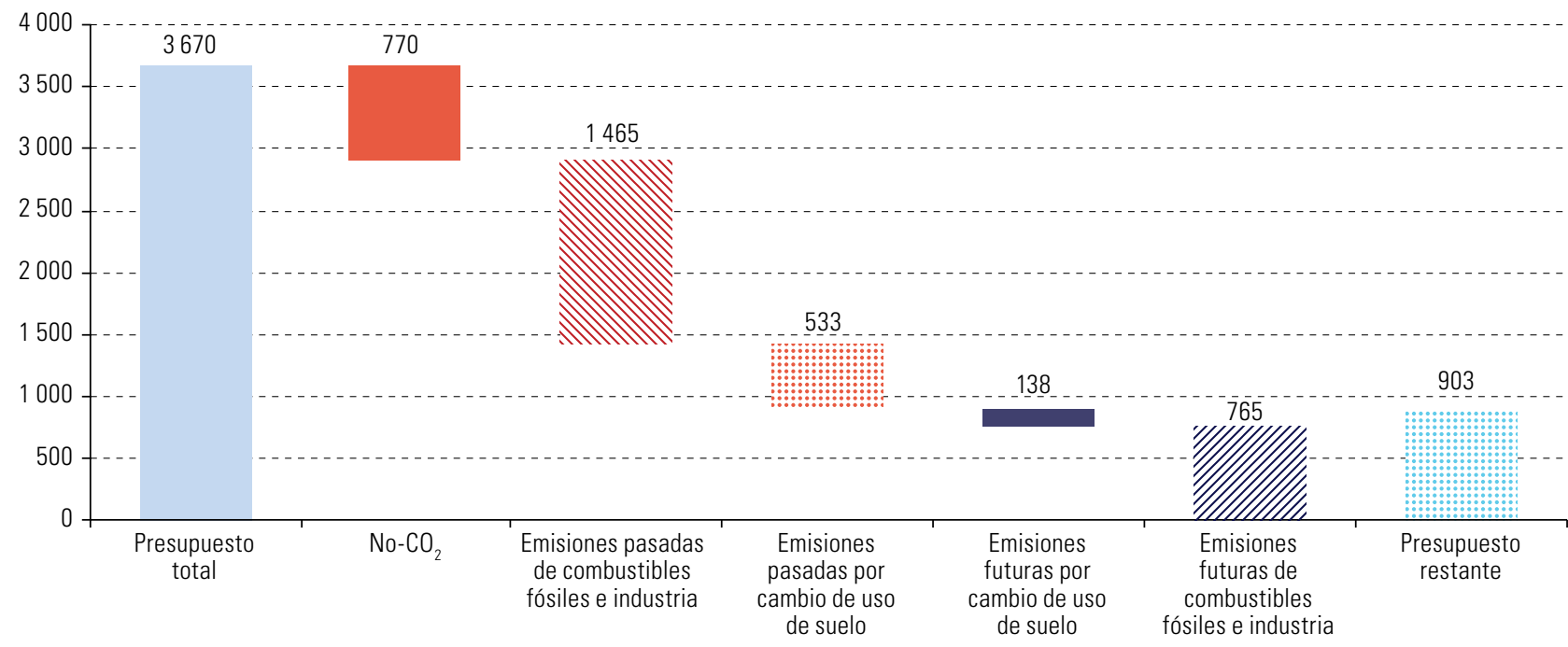

Fuente: Programa de las Naciones Unidas para el Medio Ambiente (PNUMA), The Emissions Gap Report 2017, Nairobi, noviembre de 2017.

La Convención Marco de las Naciones Unidas sobre el Cambio Climático es el espacio donde se busca regular el acceso a la atmósfera global y dosificar su uso como depósito de los desechos de la actividad industrial. La relación entre potencias y los recelos a aceptar límites y cambios a los estilos de desarrollo paralizan los procesos de cambio y cuestionan la efectividad y la eficiencia de una estructura de gobernanza desprovista de instrumentos para asegurar su cumplimiento. El agotamiento de los tiempos, el rezago tecnológico y las fuerzas del statu quo traban los esfuerzos para alcanzar, en el largo plazo, un cambio de régimen y de marco valorativo. Esto exige pasar de un multilateralismo ineficaz a uno que responda a los crecientes desafíos que surgen conforme el mundo se acerca a los límites críticos de su capacidad de absorción de los desechos del patrón productivo vigente. En la medida en que las contribuciones previstas determinadas a nivel nacional actuales implican un aumento de la temperatura de $3,2^{\circ} \mathrm{C}$ hacia 2100 , que podría tener impactos muy negativos para la humanidad, es imprescindible combinar una política climática comprehensiva con una política industrial orientada a un cambio estructural progresivo. En este contexto, adquiere aún más fuerza el planteo de la CEPAL (2016a) de considerar la seguridad climática y la implementación del Acuerdo de París de 2015 como un punto central de la gobernanza para crear bienes públicos globales.

La Agenda 2030 subraya el vínculo entre el bienestar humano, la calidad ambiental, los derechos humanos y la paz. Al postular que nadie se quede atrás, establece con claridad una perspectiva de derechos que supone el impulso de políticas públicas activas para disminuir la desigualdad en todas sus manifestaciones. La aplicación efectiva del Principio 10 de la Declaración de Río sobre el Medio Ambiente y el Desarrollo se convierte en un eje central de la Agenda 2030 para garantizar que las necesidades de las personas y los grupos vulnerables se tomen en cuenta en la gobernanza ambiental, de modo que puedan ejercer sus derechos en condiciones de igualdad y no discriminación. Por ello constituye un ejemplo mundial el Acuerdo Regional sobre el Acceso a la Información, la Participación Pública y el Acceso a la Justicia en Asuntos Ambientales en América Latina y el Caribe, acuerdo vinculante resultado de una exitosa negociación regional inspirada en el Principio 10.

En una visión de conjunto de este capítulo, resalta la fuerte incertidumbre en los ámbitos económico, tecnológico, ambiental y geopolítico, que aumenta las dificultades para evaluar si el crecimiento actual se sostendrá en el mediano plazo. En todo caso, sus efectos generales sobre las políticas de fomento a la inversión y la diversificación productiva son negativos. La incertidumbre dificulta el cálculo económico y, si todo lo demás se mantiene constante, reduce las tasas de retorno esperadas, con efectos negativos sobre 
la inversión. Las dificultades para formular políticas productivas de alcance sectorial se incrementan en la medida en que el dinamismo tecnológico pone en tela de juicio cuáles serán los patrones de especialización y de generación de empleos, incluso en el mediano plazo. Finalmente, la creciente contradicción entre las dinámicas de crecimiento del uso y del consumo digitales y el universo analógico plantea cuestiones sobre la estructura productiva que solo se dilucidarán con el tiempo. En esta dinámica, es cada vez más necesario, como se plantea en el capítulo VII, avanzar hacia un nuevo estilo de desarrollo sustentado en un gran impulso ambiental.

\section{Bibliografía}

Alvaredo, F. y otros (coords.) (2018), World Inequality Report 2018, World Inequality Lab [en línea] http://wir2018.wid.world/ files/download/wir2018-full-report-english.pdf.

Arnold, M. (2017), "Six global banks join forces to create digital currency", Financial Times, agosto [en línea] https://www. ft.com/content/20c10d58-8d9c-11e7-a352-e46f43c5825d.

Arrieta, A. y otros (2017), Tecnolatinas: Latin America Riding the Technology Tsunami, Banco Interamericano de Desarrollo (BID), mayo [en línea] https://publications.iadb.org/bitstream/handle/11319/8722/Tecnolatinas-Latin-America-Riding-theTechnology-Tsunami.pdf? sequence $=1$ \&isAllowed $=\mathrm{y}$.

Auboin, M. y F. Borino (2017), "The falling elasticity of global trade to economic activity: testing the demand channel", Working Paper, № ERSD-2017-09, Organización Mundial del Comercio (OMC), Ginebra, abril [en línea] https://www. wto.org/english/res_e/reser_e/ersd201709_e.pdf.

Auer, R., C. Borio y A. Filardo (2017), "The globalisation of inflation: the growing importance of global value chains", Working Paper, N 602, Banco de Pagos Internacionales (BPI), enero [en línea] https://www.bis.org/publ/work602.pdf.

Autor, D. (2014), "Skills, education and the rise of earnings inequality among the "other 99 percent", Science, vol. 344, № 6186, mayo [en línea] http://seii.mit.edu/wp-content/uploads/2014/05/Science-2014-Autor-843-51.pdf.

Azmeh, S. y C. Foster (2016), "The TPP and the digital trade agenda: digital industrial policy and Silicon Valley's influence on new trade agreements", Working Paper Series, № 175, Londres, enero [en línea] http://www.Ise.ac.uk/internationaldevelopment/Assets/Documents/PDFs/Working-Papers/WP175.pdf.

Baker McKenzie (2017a), "Convergence, cash, acqui-hires and super sectors drive record tech deals" [en línea] http:// crossbordermaindex.bakermckenzie.com/technology-q2-2017.

(2017b), "Blockchain and Financial Institutions: The Information Governance Challenge Ahead", junio [en línea] http:// www.bakerinform.com/home/2017/6/21/blockchain-and-financial-institutions-the-information-governance-challenge-ahead.

Banco Central del Japón (2017), "Statement on Monetary Policy", septiembre [en línea] https://www.boj.or.jp/en/ announcements/release_2017/k170921a.pdf.

Banco Central Europeo (2017), "Decisiones de política monetaria", Nota de Prensa, septiembre [en línea] https://www. ecb.europa.eu/press/pr/date/2017/html/ecb.mp170907.es.html.

(2016), Economic Bulletin, № 6 [en línea] https://www.ecb.europa.eu/pub/pdf/ecbu/eb201606.en.pdf?736d49e8295d 82ec1762c76d09812ef8.

Banco de la Reserva Federal de Nueva York (2017), "Statement regarding reinvestment in treasury securities and agency mortgage-backed securities", Nota de Prensa, septiembre [en línea] https://www.newyorkfed.org/markets/opolicy/ operating_policy_170920.

Banco Mundial (2016), Global Economic Prospects: Divergences and Risks, Washington, D.C, junio [en línea] http://pubdocs. worldbank.org/en/842861463605615468/Global-EconomicProspects-June-2016-Divergences-and-risks.pdf.

BPI (Banco de Pagos Internacionales) (2017), BIS Statistics Explorer [base de datos en línea] https://stats.bis.org/statx/ toc/LBS.html.

Casey, M. y P.Wong (2017), "Global chains are about to get better, thanks to blockchain", Hardvard Business Review, marzo [en línea] https://hbr.org/2017/03/global-supply-chains-are-about-to-get-better-thanks-to-blockchain.

CEPAL (Comisión Económica para América Latina y el Caribe) (2017), La Inversión Extranjera Directa en América Latina y el Caribe, 2017 (LC/PUB.2017/18-P), Santiago.

(2016a), Horizontes 2030: la igualdad en el centro del desarrollo sostenible (LC/G.2661/Rev.1), Santiago, julio.

(2016b), La nueva revolución digital: de la Internet del consumo a la Internet de la producción (LC/L.4029(CMSI.5/4)/

Rev.1), Santiago, agosto.

(2015), La economía del cambio climático en América Latina y el Caribe: paradojas y desafíos del desarrollo sostenible (LC/G.2624), Santiago, febrero. 
Comisión Europea (2017), Comunicación de la Comisión al Parlamento Europeo, el Consejo Europeo, el Consejo, el Comité Económico y Social Europeo y el Comité de las Regiones: recibir favorablemente la inversión extranjera directa al tiempo que se protegen los intereses esenciales (COM/2017/494), Bruselas, septiembre.

(2015), Comercio para todos: hacia una política de comercio e inversión más responsable, Luxemburgo, octubre [en línea] http://trade.ec.europa.eu/doclib/docs/2016/january/tradoc_154134.pdf.

Comité de Consejeros Económicos de la Casa Blanca (2017a), Corporate Tax Reform and Wages: Theory and Evidence, Washington, D.C., octubre, [en línea] https://www.whitehouse.gov/sites/whitehouse.gov/files/documents/Tax\%20 Reform\%20and\%20Wages.pdf.

(2017b), The Growth Effects of Corporate Tax Reform and Implications for Wages, Washington, D.C., octubre [online] https://www.whitehouse.gov/sites/whitehouse.gov/files/images/Corporate\%20Tax\%20Reform\%20and\%20Growth\%20 Final.pdf.

Constantinescu, C., A. Matto y M. Ruta (2015), "The global trade slowdown: cyclical or structural?", IMF Working Paper, $N^{\circ}$ WP/15/6, Washington, D.C., Fondo Monetario Internacional (FMI).

Cook, M. y S. Basu Das (2017), "RCEP's strategic opportunity", Perspective, No 76, Singapur, ISEAS-Yusof Ishak Institute, octubre [en línea] https://www.iseas.edu.sg/images/pdf/ISEAS_Perspective_2017_76.pdf.

Dunning, J. (1998), "Location and the multinational enterprise: a neglected factor?", Journal of International Business Studies, vol. $1, \mathrm{~N}^{\circ} 29$, marzo.

Europost (2017), "Turnover tax for digital giants sought", 16 de septiembre [en línea] http://www.europost.bg/article?id=20616.

FMI (Fondo Monetario Internacional) (2016), World Economic Outlook: Subdued Demand: Symptoms and remedies, Washington, D.C., octubre [en línea] http://www.imf.org/external/pubs/ft/weo/2016/02/pdf/text.pdf.

Forbes (2017), "The Global 2000" [en línea] https://www.forbes.com/global2000/\#2296fea2335d.

Herreros, S. yT. García-Millán (2017), "Opciones para la convergencia entre la Alianza del Pacífico y el Mercado Común del Sur (MERCOSUR): la regulación de la inversión extranjera directa", serie Comercio Internacional, № 135 (LC/TS.2017/81), Santiago, Comisión Económica para América Latina y el Caribe (CEPAL), septiembre.

ISSC/IDS/UNESCO (International Social Science Council/Institute of Development Studies/Organización de las Naciones Unidas para la Educación, la Ciencia y la Cultura) (2016), World Social Science Report 2016. Challenging inequalities: pathways to a just world, París.

Kengelbach, J. y otros (2017), "The 2017 M\&A Report: the technology takeover,"The Boston Consulting Group, septiembre [en línea] https://www.bcg.com/en-cl/publications/2017/corporate-development-finance-technology-digital-2017-m-anda-report-technology-takeover.aspx.

Leslie, I. (2014), "Kodak vs Instagram: this is why it's only going to get harder to make a good living", New Statesman, enero [en línea] https://www.newstatesman.com/politics/2014/01/kodak-vs-instagram-why-its-only-going-get-hardermake-good-living.

Manyika, J. y otros (2016), Digital Globalization: The New Era of Global Flows [en línea] http://www.mckinsey.com/businessfunctions/digital-mckinsey/our-insights/digital-globalization-the-new-era-of-global-flows.

McAfee, A. y E. Brynjolfsson (2017), Machine, Platform, Crowd: Harnessing our Digital Future, Nueva York, W.W. Norton \& Company, junio.

McKinsey Global Institute (2017), The New Dynamics of Financial Globalization, McKinsey and Company, agosto [en línea] https://www.mckinsey.com/ /media/McKinsey/Industries/Financial\%20Services/Our\%20Insights/The\%20new\%20 dynamics\%20of\%20financial\%20globalization/Financial\%20globalization_Full\%20Report_August_29_2017\%20(1).ashx.

Milanovic, B. (2016), Global Inequality: A New Approach for the Age of Globalization, Cambridge, Massachusetts, Harvard University Press, abril.

Naciones Unidas (2016), International Migration Report 2015 (ST/ESA/SER.A/384), Nueva York.

_(1987), Informe de la Comisión Mundial sobre el Medio Ambiente y el Desarrollo: "Nuestro futuro común" (A/42/427), Nueva York, 4 de agosto.

OCDE (Organización de Cooperación y Desarrollo Económicos) (2016), "Cardiac arrest or dizzy spell: why is world trade so weak and what policy do about it?", OECD Economic Policy Paper, № 18, París, septiembre [en línea] http://www. oecd-ilibrary.org/economics/cardiac-arrest-or-dizzy-spell_5jlr2h45q532-en. (2011), Divided We Stand: Why Inequality Keeps Rising, París, OECD Publishing.

OMC (Organización Mundial del Comercio) (2017b), World Trade Statistical Review 2017, Ginebra [en línea] https://www. wto.org/english/res_e/statis_e/wts2017_e/wts17_toc_e.htm.

Oxfam Internacional (2017), Una economía para el 99\%: es hora de construir una economía más humana y justa al servicio de las personas, enero [en línea] https://d1 tn3vj7xz9fdh.cloudfront.net/s3fs-public/file_attachments/bp-economy-for99-percent-160117-es.pdf.

PNUMA (Programa de las Naciones Unidas para el Medio Ambiente) (2017), The Emissions Gap Report 2017, Nairobi, noviembre. 
Schwab, K. (2016), "The Fourth Industrial Revolution: what it means, how to respond",World Economic Forum (WEF), enero [en línea] https://www.weforum.org/agenda/2016/01/the-fourth-industrial-revolution-what-it-means-and-how-to-respond/.

Setterfield, M. (2013), “Wages, demand and us macroeconomic travails: Diagnosis and prognosis", After the Great Recession: The Struggle for Economic Recovery and Growth, B. Z. Cynamon, S. Fazzari and M. Setterfield (eds.), New York, Cambridge University Press.

The New York Times (2017), "Debt concerns, once a core republican tenet, take a back seat to tax cuts", Nueva York, 1 de diciembre [en línea] https://www.nytimes.com/2017/12/01/us/politics/tax-cuts-deficit-debt.html.

UIT (Unión Internacional de Telecomunicaciones) (2017), The State of Broadband: Broadband catalyzing sustainable development [en línea] https://www.itu.int/dms_pub/itu-s/opb/pol/S-POL-BROADBAND.18-2017-PDF-E.pdf.

UNCTAD (Conferencia de las Naciones Unidas sobre Comercio y Desarrollo) (2017), World Investment Report 2017: Investment and The Digital Economy (UNCTADMIR/2017), Ginebra.

_ (2015), World Investment Report 2015: Reforming International Investment Governance, Ginebra.

Visual Capitalist (2017), "Chart: here's how 5 tech giants make their billions", mayo [en línea] http://www.visualcapitalist. com/chart-5-tech-giants-make-billions/.

Yellen, J. (2017a), Conferencia de prensa en la reunión del Comité Federal de Mercado Abierto (FOMC), 20 de septiembre [en línea] https://www.federalreserve.gov/mediacenter/files/FOMCpresconf20170920.

(2017b), "Inflation, uncertainty, and monetary policy", documento presentado en la 59a reunión de la Asociación Nacional de Economía Empresarial (NABE), Cleveland, septiembre [en línea] https://www.federalreserve.gov/newsevents/ speech/files/yellen20170926a.pdf. 


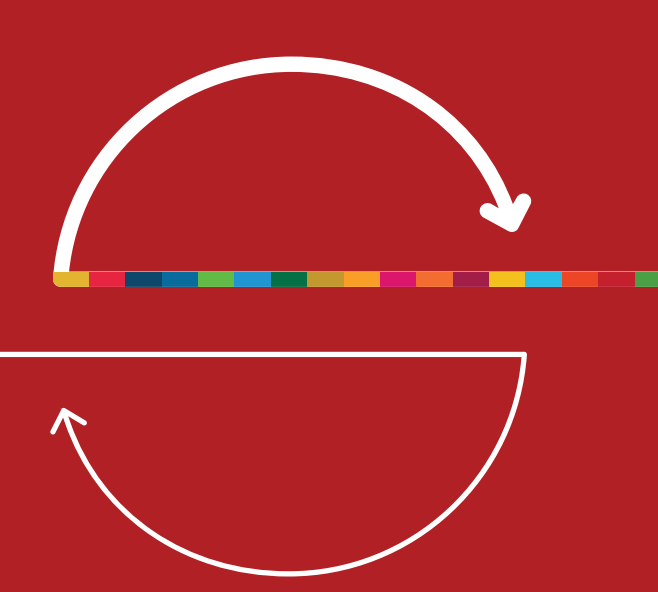

\section{CAPÍTULO}

III

\section{La vulnerabilidad externa obstaculiza el desarrollo}

\section{y aumenta la desigualdad}

Introducción

A. Los factores estructurales que limitan el crecimiento, la inversión y el empleo

B. Efectos laborales y sociales negativos

1. Se genera menos empleo de calidad

2. Se frena la reducción de la desigualdad de los ingresos monetarios

3. Aumenta la incidencia de la pobreza

C. La política fiscal no reduce la desigualdad en la región

1. Ingresos tributarios sesgados contra la igualdad

2. Débil poder redistributivo de la política fiscal

3. La evasión fiscal: una muestra de la cultura del privilegio

D. Interacciones positivas o negativas entre distribución, crecimiento e inversión

1. El papel de las variables institucionales y estructurales

2. La relación virtuosa entre crecimiento e inversión

E. La financierización aumenta la vulnerabilidad externa

1. Financierización periférica y endeudamiento

2. Mayor vulnerabilidad externa real y financiera

3. Obstáculos para el crecimiento, la inversión y la diversificación productiva en el largo plazo

Bibliografía 



\section{Introducción}

En el capítulo II se analizó el bajo dinamismo del comercio internacional y la persistencia de un sesgo recesivo global que afectan el desempeño económico de la región mediante dos canales: el comercial y el financiero. Por el primero se produce el efecto más directo, que se refleja en el dinamismo de las exportaciones. Por el segundo se transmiten las decisiones de cartera que determinan la intensidad de las entradas y las salidas de flujos transfronterizos de capital. Este canal cobró preponderancia en las últimas décadas, con la integración de los países de América Latina y el Caribe en los mercados globales de crédito, la desregulación de los sistemas financieros locales y el peso creciente de las empresas transnacionales, incluidas las translatinas, en las economías de la región.

En un contexto de lento crecimiento del comercio internacional y mayor exposición a los ciclos de liquidez global, las economías de la región se desaceleraron o experimentaron un menor ritmo de crecimiento luego de la recuperación que tuvo lugar en el bienio posterior a la crisis financiera internacional de 2009. La fase de desaceleración, que comenzó en 2012 y tocó su punto más bajo en 2016, se manifiesta desde una perspectiva histórica (al contrastar con el desempeño pasado de la región) y en comparación con otras regiones en desarrollo.

Aunque esta pérdida de dinamismo económico sea en gran medida consecuencia de factores externos, la intensidad con que estos inciden en la dinámica de la región es también el producto de condicionantes internos, que profundizan en diferente medida el impacto de los primeros. Los condicionantes internos dependen de las características estructurales y el marco institucional de cada país, y se relacionan, entre otros, con el perfil de especialización productiva, la estructura fiscal, la regulación ambiental y la gobernanza de los recursos naturales, el tipo de institucionalidad laboral, las políticas de salud y educación, las características del sistema de cuidados y el grado de apertura, la desregulación del sistema financiero y la orientación de la política económica. En este capítulo, se analiza el modo en que los condicionantes internos intermedian el impacto de los factores externos y dificultan la adopción de medidas destinadas a acelerar el crecimiento económico.

\section{A. Los factores estructurales que limitan el crecimiento, la inversión y el empleo}

El crecimiento de las economías de la región se desaceleró después de la recuperación de 2010 y 2011 que tuvo lugar a continuación de la crisis financiera internacional. El crecimiento promedio del 2,3\% entre 2012 y $2017^{1}$ fue inferior al del período de 2000 a 2008 (3,8\%) (véase el gráfico III.1). Este resultado estuvo muy por debajo del de regiones como Asia sudoriental (5,3\%), África septentrional $(3,1 \%)$ y las mayores economías emergentes de Europa (2,8\%) en el mismo período².

Al comparar la dinámica entre las subregiones, se observa que la desaceleración fue más acentuada en América del Sur, en buena medida por lo sucedido en la Argentina, el Brasil y la República Bolivariana de Venezuela, que decrecieron en 2016 (2,2\%, 3,6\% y 16,5\%, respectivamente). Aun si se excluyen estos países, el crecimiento conjunto de los restantes países de América del Sur se redujo a casi la tercera parte entre 2011 y 2016 (del 6,0\% al 2,3\%). La desaceleración fue menor en Centroamérica, México y el Caribe, economías más estrechamente vinculadas con el nivel de actividad en los Estados Unidos. Estos países crecieron un 3,8\% entre 2012 y 2016, con una tendencia apenas ascendente, en un período durante el cual, en los Estados Unidos, a diferencia de la Unión Europea o el Japón, se sostuvo una tasa de crecimiento anual promedio del 2,2\%. En 2017 hay una cierta reversión de la tendencia negativa, que se explica en lo fundamental por la dinámica de América del Sur, en particular de la Argentina y el Brasil, que volvieron a crecer. No obstante, si se excluyen esos casos (y el de la República Bolivariana de Venezuela, cuyo PIB volvió a caer en 2017), la tendencia a la desaceleración del crecimiento del resto de la región se revirtió solo marginalmente entre 2016 y 2017 , ya que este pasó del $2,3 \%$ al $2,5 \%$.

El dato de 2017 para los países de América Latina y el Caribe corresponde a las proyecciones de la CEPAL (2018).

El dato de 2017 para los países de Asia sudoriental, África septentrional y las mayores economías emergentes de Europa corresponde a proyecciones del Fondo

Monetario Internacional (FMI). 


\section{Gráfico III.1}

América Latina y el Caribe: crecimiento económico, 1965-2017

(Promedio móvil de 5 años, en porcentajes)

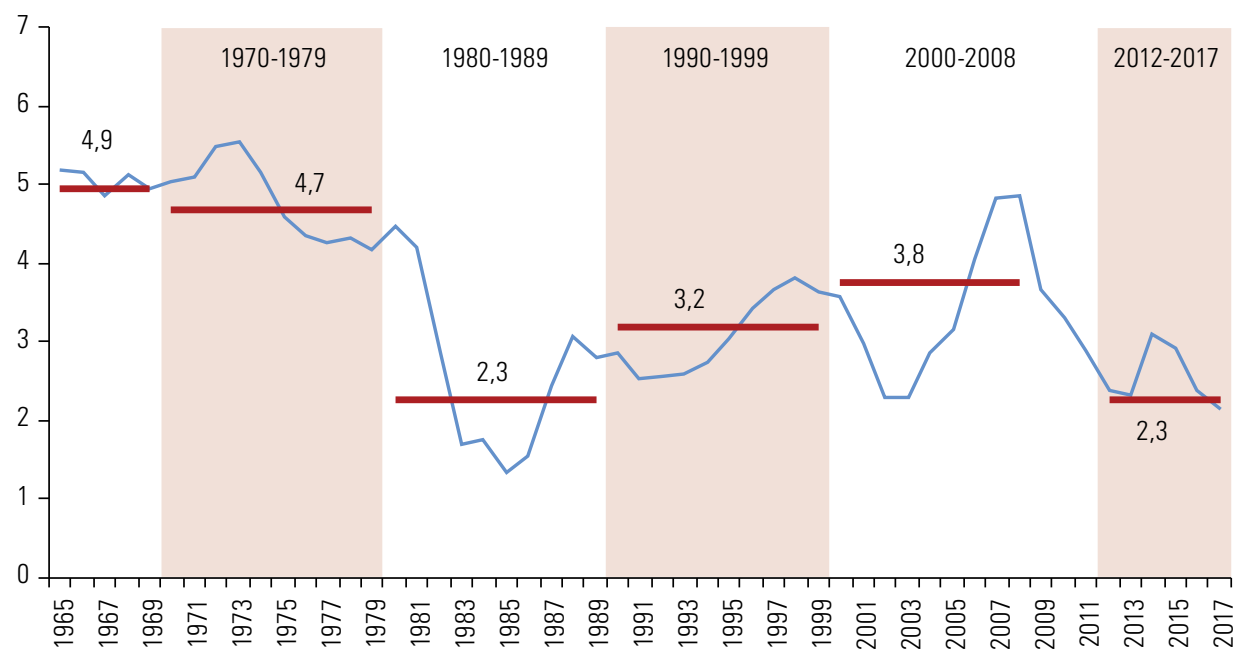

Fuente: Comisión Económica para América Latina y el Caribe (CEPAL), CEPALSTAT [base de datos en línea] http://estadisticas.cepal.org/cepalstat/Portada.html; CEPAL, Balance Preliminar de las Economías de América Latina y el Caribe, 2017(LC/PUB.2017/28-P), Santiago, 2018 (para datos de 2017); Banco Mundial, Data Bank [base de datos en línea] http://databank.worldbank.org/data/home.aspx, y Fondo Monetario Internacional (FMI), Perspectivas de la Economía Mundial. En busca del crecimiento sostenible: recuperación a corto plazo, desafíos a largo plazo, 2017 [en línea] https://www.imf.org/es/Publications/WE0/Issues/2017/09/19/ world-economic-outlook-october-2017.

a Los datos de 2017 son proyecciones.

En síntesis, como planteó Raúl Prebisch al referirse al vínculo de los países periféricos con el "movimiento cíclico universal", la dinámica reciente de la región está muy ligada al contexto global ${ }^{3}$. En América del Sur, se observa una estrecha correlación entre la tasa de crecimiento y la dinámica de los precios de las materias primas, mientras que, en Centroamérica, México y el Caribe, la evolución de la tasa de crecimiento está asociada al desempeño de los Estados Unidos (véase el gráfico III.2).

\section{Gráfico III.2}

América Latina y el Caribe: crecimiento por subregión y determinantes externos, 2004-2017

(En porcentajes)

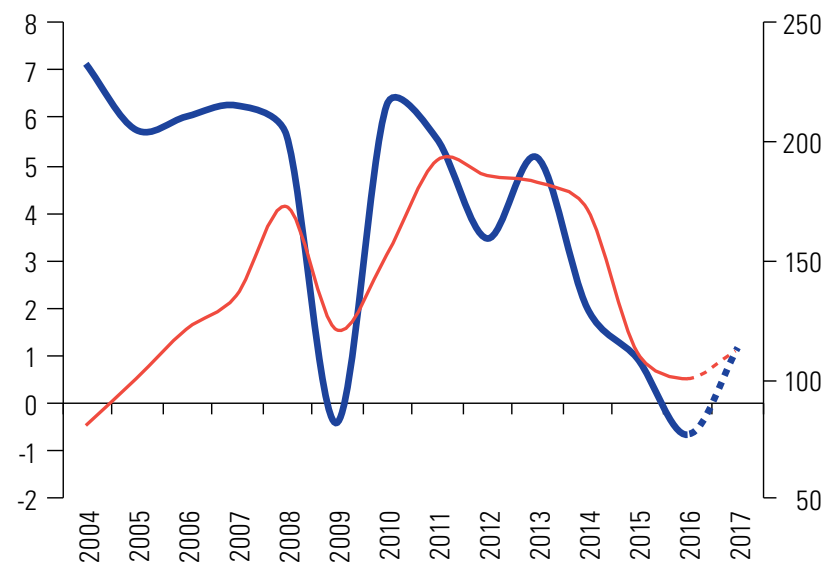

- PIB de América del Sur

— Índice de precios de las materias primas (eje derecho)

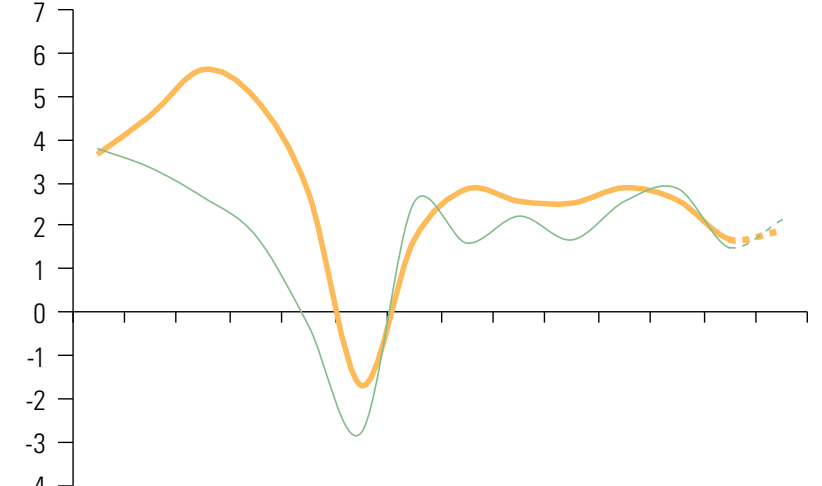

宆

PIB de Estados Unidos

—PIB de Centroamérica, México y el Caribe

Fuente: Comisión Económica para América Latina y el Caribe (CEPAL), sobre la base de CEPALSTAT [base de datos en línea] http://estadisticas.cepal.org/cepalstat/ Portada.html y Fondo Monetario Internacional (FMI), Perspectivas de la Economía Mundial. En busca del crecimiento sostenible: recuperación a corto plazo, desafíos a largo plazo, 2017 [en línea] https://www.imf.org/es/Publications/WEO/Issues/2017/09/19/world-economic-outlook-october-2017. 
La pérdida de dinamismo exportador no solo se explica por los factores externos que actúan a través del canal comercial, como el deterioro de los términos de intercambio o el menor ritmo de crecimiento de la demanda de exportaciones de los principales socios comerciales: también se debe al recrudecimiento de condicionantes internos asociados a la evolución del perfil productivo y comercial de cada país. Como se observa en el cuadro III.1, que muestra la tendencia a la disminución de la elasticidad ingreso mundial de las exportaciones en muchos países de la región, la capacidad de estos para aprovechar el impulso que emana del crecimiento del resto del mundo es cada vez menor.

Cuadro III.1

América Latina (países seleccionados): relación de elasticidades del comercio exterior, 1999-2008 y $2007-2016$

\begin{tabular}{|c|c|c|c|c|c|c|}
\hline & \multicolumn{2}{|c|}{$\begin{array}{l}\text { Elasticidad ingreso de las } \\
\text { exportaciones }(\varepsilon)\end{array}$} & \multicolumn{2}{|c|}{$\begin{array}{l}\text { Elasticidad ingreso de las } \\
\text { importaciones }(\pi)\end{array}$} & \multicolumn{2}{|c|}{ Relación de elasticidades $(\varepsilon / \pi)$} \\
\hline & 1999-2008 & $2007-2016$ & 1999-2008 & $2007-2016$ & 1999-2008 & $2007-2016$ \\
\hline Argentina & 1,5 & 0,4 & 2,5 & 2,9 & 0,6 & 0,2 \\
\hline Bolivia (Estado Plurinacional de) & 2,8 & 1,5 & 1,7 & 1,2 & 1,7 & 1,3 \\
\hline Brasil & 2,6 & 0,6 & 1,4 & 2,2 & 1,8 & 0,3 \\
\hline Chile & 0,9 & 0,4 & 2,2 & 1,1 & 0,4 & 0,3 \\
\hline Colombia & 1,7 & 1,5 & 2,2 & 1,6 & 0,8 & 0,9 \\
\hline Costa Rica & 1,7 & 0,8 & 1,2 & 0,7 & 1,4 & 1,1 \\
\hline Ecuador & 2,5 & 1,6 & 1,8 & 0,9 & 1,4 & 1,9 \\
\hline Guatemala & 1,0 & 1,3 & 0,6 & 1,1 & 1,5 & 1,1 \\
\hline Honduras & 1,9 & 2,2 & 1,5 & 1,1 & 1,3 & 2,1 \\
\hline México & 1,6 & 2,9 & 2,1 & 2,2 & 0,7 & 1,3 \\
\hline Nicaragua & 3,4 & 4,8 & 1,5 & 1,6 & 2,2 & 3,0 \\
\hline Paraguay & 2,1 & 2,3 & 2,2 & 0,8 & 1,0 & 2,8 \\
\hline Perú & 3,4 & 0,6 & 1,7 & 1,2 & 2,0 & 0,5 \\
\hline República Dominicana & 0,6 & 1,5 & 0,6 & 0,6 & 1,0 & 2,3 \\
\hline
\end{tabular}

Fuente: Comisión Económica para América Latina y el Caribe (CEPAL), sobre la base de CEPALSTAT [base de datos en línea] http://estadisticas.cepal.org/cepalstat/ Portada.html.

Para analizar de manera integral la sostenibilidad externa del crecimiento suelen estimarse la elasticidad ingreso mundial de las exportaciones y la elasticidad ingreso interno de las importaciones. En la ley de Thirlwall (1979) se afirma que, dado el ritmo de crecimiento de los socios comerciales, el crecimiento económico que es compatible con el equilibrio externo de un país en el largo plazo depende del cociente entre las elasticidades de exportación e importación. Un análisis por subregiones permite observar que, en América del Sur, el cociente de las elasticidades, o condición de Thirlwall, se deterioró significativamente en los últimos años, en general como consecuencia de la caída de la elasticidad ingreso de las exportaciones ${ }^{4}$. El volumen de exportaciones de América del Sur subió apenas el 0,6\% entre 2012 y 2016, en contraste con un ritmo de expansión del $5,7 \%$ entre 2000 y 2008. Así, la pérdida de dinamismo exportador no es producto solo de la desaceleración del comercio internacional, sino también el efecto de un retroceso estructural.

Por el contrario, en Centroamérica y México, la condición de Thirlwall mejoró en la mayoría de los casos, con base en el aumento de la elasticidad ingreso de las exportaciones (véase el cuadro III.1). Entre 2012 y 2016 , las exportaciones de estos países se incrementaron a un ritmo anual del $4,3 \%$, que supera el $4 \%$ observado entre 2000 y 2008 y está por encima del promedio de crecimiento del PIB.

La dinámica de las elasticidades del comercio exterior revela la persistencia de problemas estructurales vinculados con las brechas tecnológicas, el perfil de especialización y otras variables que inciden en la competitividad sistémica de los países de la región (CEPAL, 2007 y 2010). En las economías especializadas

4 La excepción fue el Paraguay, donde se observó una leve mejora asociada a la adopción de las nuevas tecnologías de producción de soja, que en la Argentina, el Brasil y el Uruguay se habían difundido y consolidado con anterioridad. 
en productos que tienen una demanda mundial más dinámica (eficiencia keynesiana) y una mayor capacidad de difusión del progreso técnico (eficiencia schumpeteriana), es esperable que la contribución al crecimiento del producto mundial, así como el crecimiento local que es compatible con el equilibrio en la cuenta corriente, sean mayores. El deterioro del cociente entre las elasticidades de exportación e importación —es decir, la caída de la tasa de crecimiento que es compatible con el equilibrio externo en el largo plazo— revela la permanencia o ampliación de las brechas de productividad de la región con respecto a los países avanzados ${ }^{5}$.

Este cuadro es característico de los países de América del Sur, cuyo perfil de especialización se profundizó al aumentar la participación de los bienes primarios en sus exportaciones. En Centroamérica y México, por el contrario, aumentó la participación de las exportaciones de tecnología media y tendió a diversificarse la canasta exportadora. En el Caribe, por su parte, se mantuvo una fuerte dependencia de las materias primas brutas y procesadas, pero se registró una mayor diversificación de los productos exportados ${ }^{6}$.

En un contexto de bajo dinamismo económico, también se observó una tendencia a la desaceleración de la inversión, lo que retroalimentó la situación de bajo crecimiento de los últimos años. Al igual que el nivel de actividad, luego de repuntar en 2010 y 2011, la tasa de variación de la inversión disminuyó al 4\% y al 2\% en 2012 y 2013, respectivamente, para situarse en terreno negativo en los tres años siguientes (con un promedio del -3,6\%). Su componente más afectado fue el de maquinaria y equipo, que es el más dinámico y con mayor contenido tecnológico, y también el más volátil en el ciclo económico. Este patrón de comportamiento se reprodujo sobre todo en los países de América del Sur.

El desempeño de la inversión de los últimos años es mediocre desde una perspectiva histórica, como se aprecia en el gráfico III.3, que permite comparar la tasa de inversión reciente con la de las décadas de 1960 y 1970 (cuando llegó a superar, en promedio, el 24\% del PIB) y también observar la retroalimentación que existe entre el crecimiento y la inversión, tema que se aborda en detalle más adelante.

\section{Gráfico III.3}

América Latina y el Caribe: crecimiento y tasa de inversión, 1960-2017

(En porcentajes)

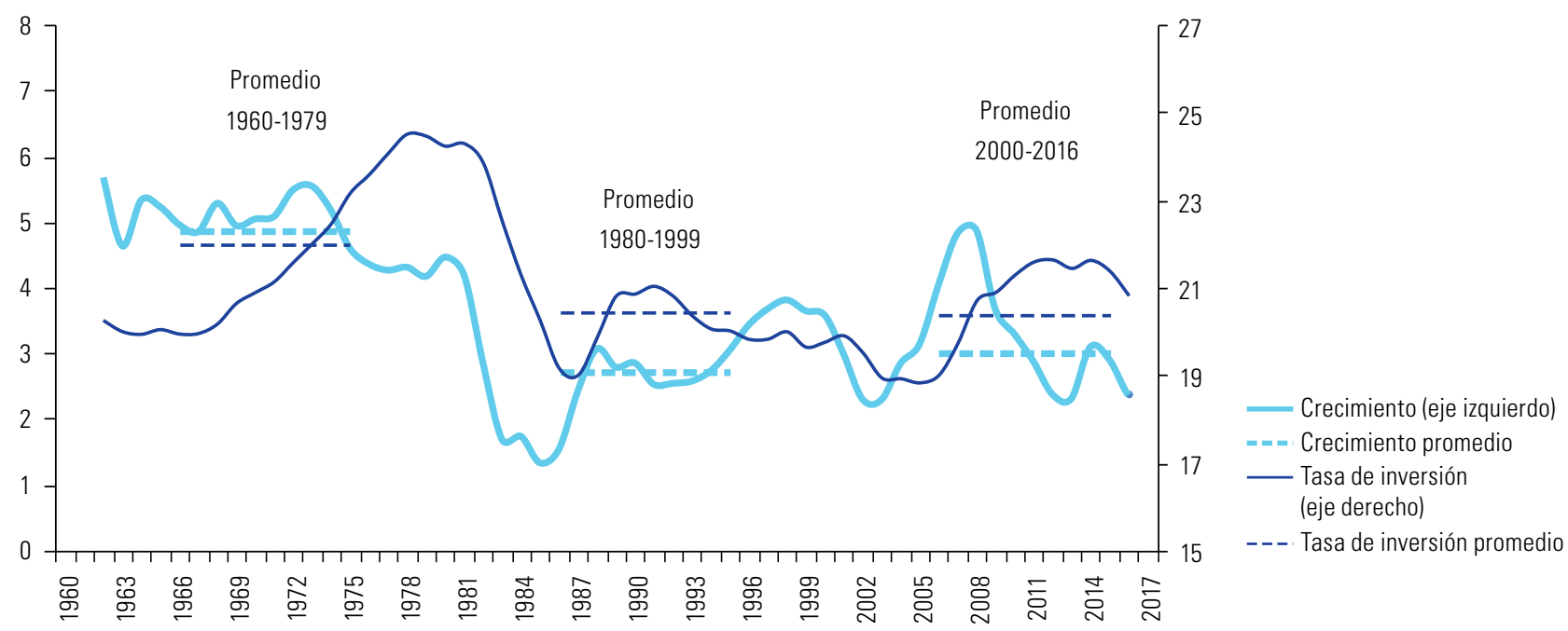

Fuente: Comisión Económica para América Latina y el Caribe (CEPAL), sobre la base de Banco Mundial, Data Bank [base de datos en línea] http://databank.worldbank. org/data/home.aspx; ; Fondo Monetario Internacional (FMI), Perspectivas de la Economía Mundial. En busca del crecimiento sostenible: recuperación a corto plazo, desafíos a largo plazo, 2017 [en línea] https://www.imf.org/es/Publications/WEO/Issues/2017/09/19/world-economic-outlook-october-2017, y CEPAL, Balance Preliminar de las Economías de América Latina y el Caribe, 2017 (LC/PUB.2017/28-P), Santiago, 2018 (para datos de 2017).

a Promedio móvil correspondiente a cinco años. El dato de 2017 corresponde a la proyección de la CEPAL incluida en el Balance Preliminar de las Economías de América Latina y el Caribe, 2017.

\footnotetext{
También refleja el contenido tecnológico relativamente bajo de las exportaciones de la región que, entre otras variables, se manifiesta en la caída de su participación en las exportaciones mundiales de las manufacturas de alta tecnología, que pasó del 8\% en 2000 al 5\% en 2015 (CEPAL, 2016e).

6 Según la Comisión Económica para América Latina y el Caribe (CEPAL), que estimó el índice de Herfindahl-Hirschman de las exportaciones de bienes al mundo por producto, la concentración de las exportaciones de Centroamérica, México y el Caribe se redujo entre 2000 y 2016.
} 
La desaceleración del crecimiento también afectó el mercado de trabajo. En los años de mayor dinamismo económico (antes de 2009), la creación de empleo fue intensiva, en parte como consecuencia del ritmo de crecimiento, pero también de una elasticidad empleo-producto inusitadamente alta (CEPAL, 2017a) ${ }^{7}$. Durante ese período, el crecimiento económico superó el umbral necesario para absorber el crecimiento poblacional, lo que explica la importante reducción de la desocupación ${ }^{8}$. Ese umbral se ubica en torno al 2,5\% en el conjunto de la

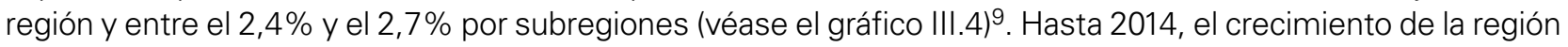
se mantuvo por encima del umbral mencionado, pero con un ritmo que apenas logró absorber el crecimiento de la población y sostener la tasa de empleo. Posteriormente, la región creció en promedio por debajo de ese límite.

\section{Gráfico III.4}

América Latina y el Caribe (en conjunto y por subregión): tasa de crecimiento efectiva y tasa de crecimiento compatible con un equilibrio de la tasa de empleo, 2000-2016

(En porcentajes)

\section{A. América Latina y el Caribe}

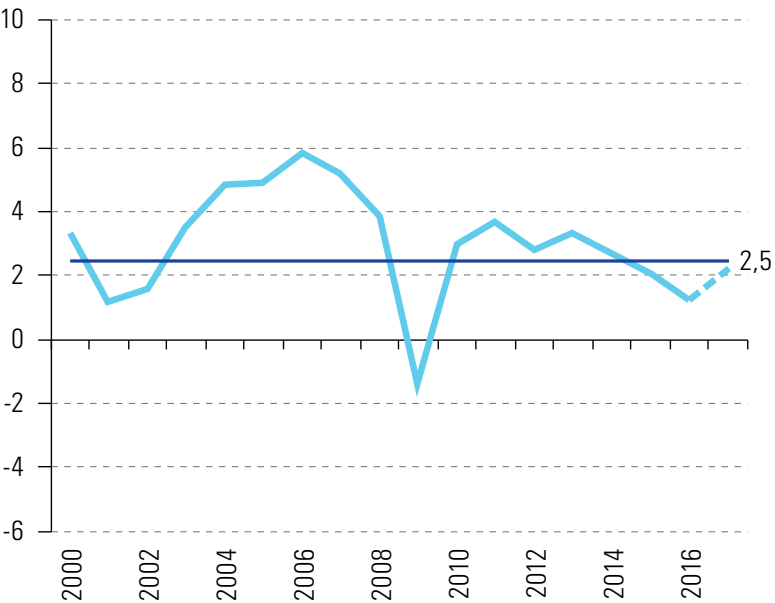

C. Centroamérica y México

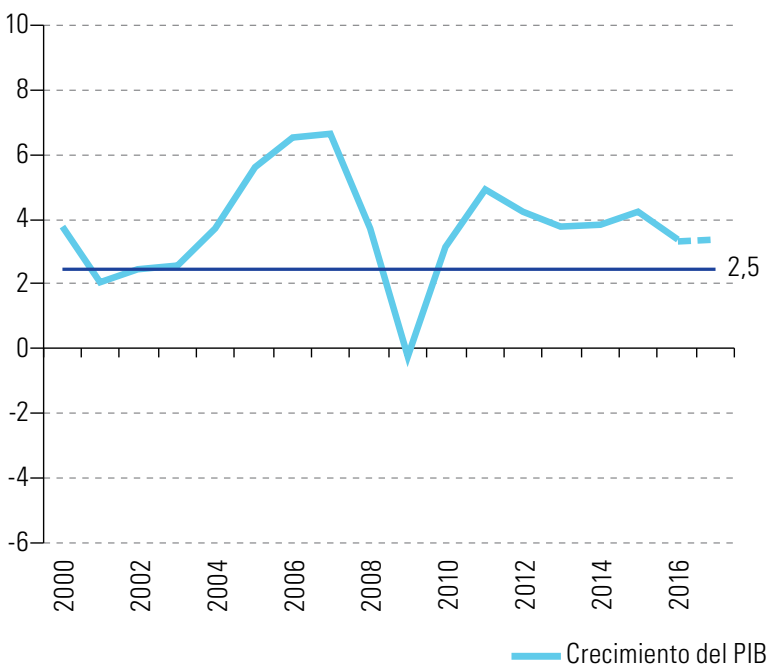

B. América del Sur

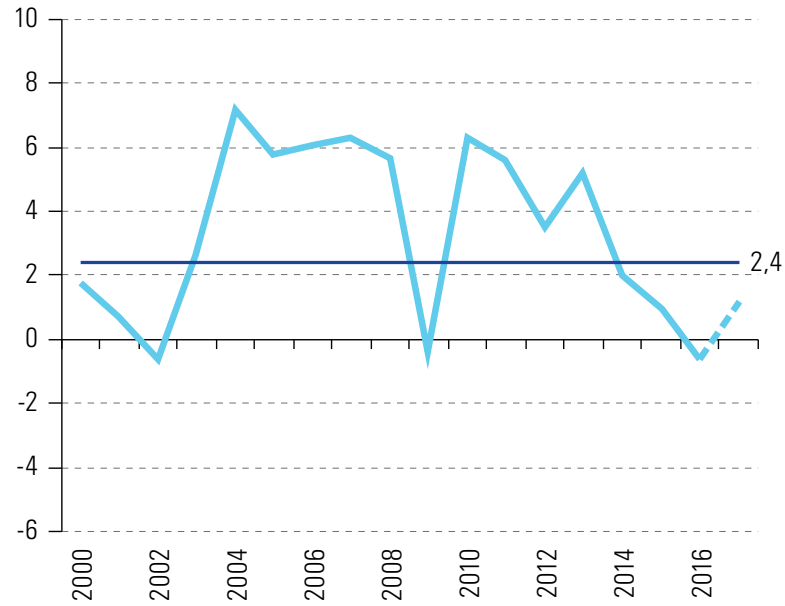

D. El Caribe

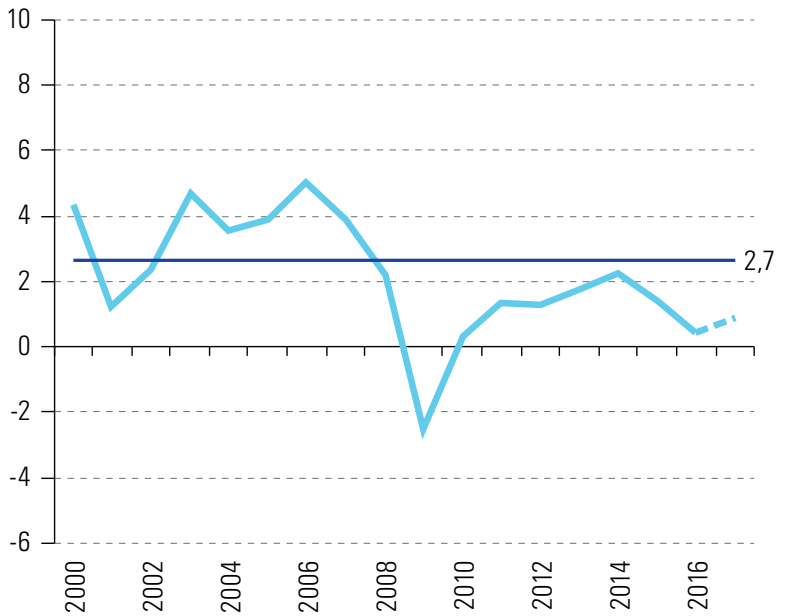

Fuente: Comisión Económica para América Latina y el Caribe (CEPAL), sobre la base de información de CEPALSTAT [base de datos en línea] http://estadisticas.cepal.org/cepalstat/ Portada.html, Banco Mundial, Data Bank [base de datos en línea] http://databank.worldbank.org/data/home.aspx) y Organización Internacional del Trabajo (OIT).

Nota: Se estima que la elasticidad empleo-ingreso de América del Sur es 0,53, la de Centroamérica y México, 0,57, y la del Caribe, 0,33. El crecimiento poblacional equivalente anual promedio de América del Sur es del 1,3\%, el de Centroamérica y México, del 1,4\%, y el del Caribe, del 0,9\%.

En el empleo se incluye el total de personas que pertenecen a las distintas categorías ocupacionales del mercado de trabajo: trabajadores asalariados, trabajadores por cuenta propia, patrones y trabajadores familiares sin remuneración.

8 El umbral de crecimiento se calcula como el cociente entre el crecimiento poblacional y la elasticidad empleo-producto. Permite estimar cuánto debe ser el crecimiento económico para que el número total de empleos aumente al mismo ritmo que la población y la tasa de empleo se mantenga estable.

9 En el umbral se considera un crecimiento vegetativo promedio del orden del 1,2\% y una elasticidad empleo-producto de 0,48 en los últimos 16 años. 
Esta dinámica comenzó a reflejarse en la tasa de desempleo, que en 2016 registró un incremento de 1,6 puntos porcentuales con respecto a 2015 y que acumula un aumento de dos puntos desde $2014^{10}$. También se observan diferencias entre los países y las subregiones, con un deterioro relativamente mayor de los indicadores en América del Sur ${ }^{11}$. Como se verá en la sección siguiente, el deterioro de los indicadores laborales tiene su correlato en la dinámica de la desigualdad y la pobreza.

La proximidad entre el umbral mínimo de crecimiento requerido para absorber el aumento de la población y el límite máximo de crecimiento que es compatible con el equilibrio externo en el largo plazo refleja la vigencia de la perspectiva estructuralista — toda vez que la generación de empleo se encuentra en última instancia limitada por la restricción externa al crecimiento-y, por ende, del perfil de especialización productiva. Como se aprecia en el gráfico III.5, en muchos países de la región (los ubicados por debajo de la recta de $45^{\circ}$ ), el umbral de crecimiento mínimo para absorber el aumento poblacional (eje horizontal) se encuentra por encima del límite máximo que la sostenibilidad externa de largo plazo impone al crecimiento (eje vertical).

\section{Gráfico III.5}

América Latina (14 paises): relación entre crecimiento compatible con el equilibrio externo y crecimiento compatible con una tasa de empleo estable, 2000-2016

(En porcentajes)

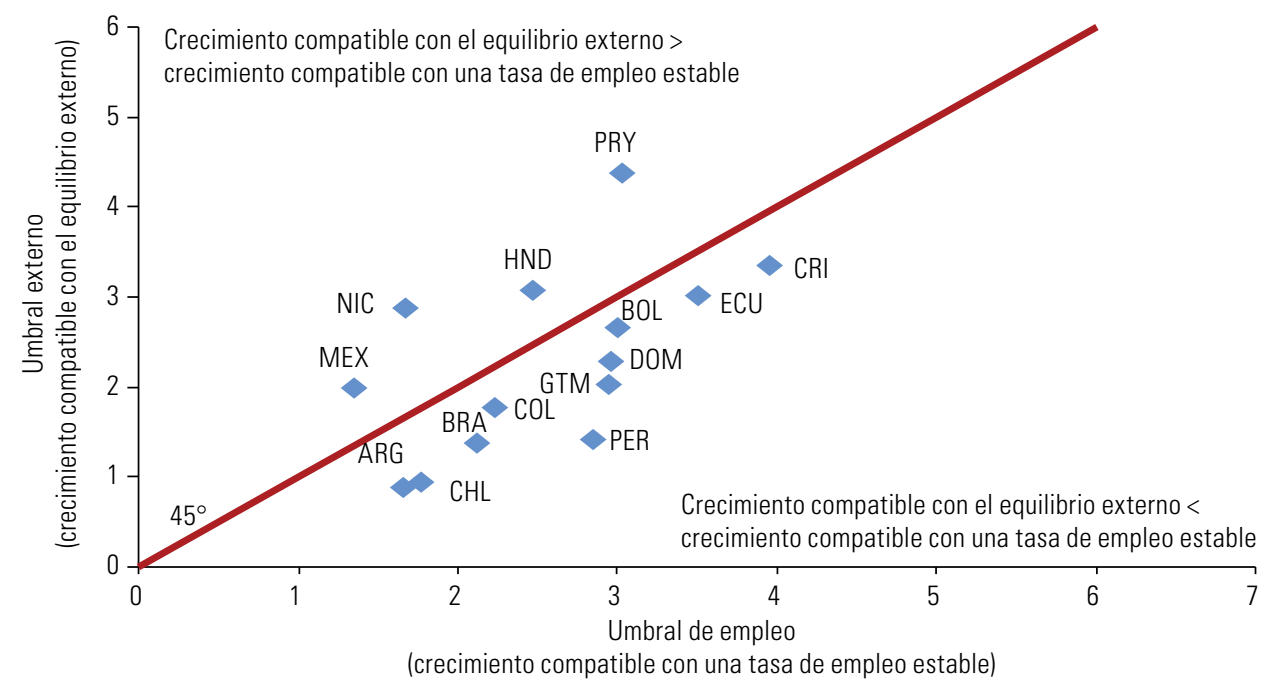

Fuente: Comisión Económica para América Latina y el Caribe (CEPAL).

Nota: La condición de Thirlwall se define como: $y^{*}=\frac{\phi_{1} \varepsilon . z}{\pi}$, en donde $\varepsilon$ es la elasticidad ingreso de las exportaciones, $\pi$ es la elasticidad ingreso de las importaciones, $z$ es el crecimiento de los socios comerciales, $\phi_{1}$ es la relación entre las exportaciones y las importaciones, e $y^{*}$ es el crecimiento de la economía interna compatible con el equilibrio de la cuenta corriente en el largo plazo. Se supone que el crecimiento de los socios comerciales es del $2 \%$.

\section{B. Efectos laborales y sociales negativos}

\section{Se genera menos empleo de calidad}

El menor ritmo de crecimiento económico de los últimos años no solo repercutió en el desempleo, sino que afectó la generación de empleo de calidad, uno de los factores clave para el cambio estructural progresivo. Para analizar la dinámica de este tipo de empleo, se estimó la tasa de empleo ajustada, una medida que se

La tasa de desempleo de 2014 fue la más baja de los últimos 20 años.

Nueve de los 13 países en los que se registró un incremento de la tasa de desempleo en 2016 son sudamericanos. 
usa para corregir la tasa de empleo en función de la tasa de asalarización ${ }^{12}$, por considerar que el indicador de empleo asalariado muestra una alta correlación con el grado de desarrollo económico ${ }^{13}$.

En una perspectiva histórica, el crecimiento de la tasa de empleo ajustada se aceleró a partir de 2002 y permaneció en un valor elevado hasta 2008 (véase el gráfico III.6). La desaceleración económica afectó esa tasa a partir de 2012, cuando su ritmo de crecimiento promedio anual pasó del 0,8\% (de 2000 a 2008) al 0,05\% (de 2012 a 2016) y comenzó a ganar peso el trabajo no asalariado por cuenta propia. Este amesetamiento en la tasa de empleo ajustada se manifiesta sobre todo en América del Sur y, en menor medida, en el Caribe. En Centroamérica y México, la tasa de empleo ajustada continuó expandiéndose, aunque a un ritmo menor.

\section{Gráfico III.6}

América Latina y el Caribe (en conjunto y por subregión): tasa de empleo ajustada, 1991-2016 (En porcentajes)

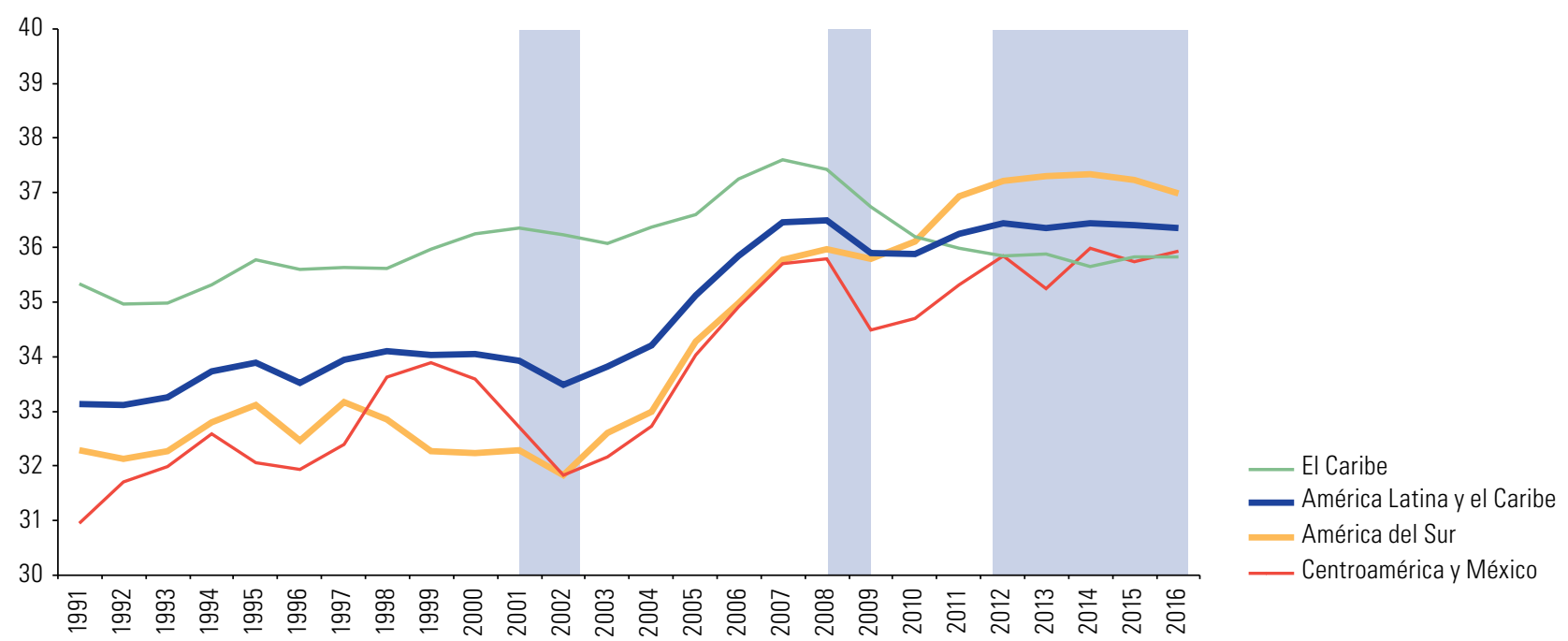

Fuente: Comisión Económica para América Latina y el Caribe (CEPAL), sobre la base de Organización Internacional del Trabajo (OIT), Base de datos ILOSTAT [en línea] http://www.lo.org/ilostat/faces/ilostat-home?locale=es.

Como se muestra en el gráfico III.7, la mejora de la tasa de empleo ajustada depende de la evolución de sus dos componentes: la tasa de empleo total y la tasa de asalarización. Durante la fase de crecimiento más alto (hasta 2008), una parte considerable (aproximadamente el 25\%) del aumento promedio anual de la tasa de empleo ajustada se debió al aumento de la tasa de asalarización. Por el contrario, entre 2012 y 2016 esa contribución pasó a ser negativa. Ello implica una diferencia cualitativa entre el período más dinámico y el período de desaceleración de la actividad económica. En esta fase, la expansión del trabajo por cuenta propia estuvo en general asociada a los trabajos más precarios, que surgieron de manera compensatoria ante la insuficiente generación de empleo de calidad (Weller, 2014; CEPAL, 2017a).

12 Esa corrección equivale a calcular el total de trabajadores asalariados sobre la población en edad de trabajar. Su principal ventaja es la comparabilidad entre países, a partir de la disponibilidad de información sobre la tasa de empleo (homogeneizada sobre la base de la población mayor de 15 años) y la de asalarización. Una limitación es que no todas las inserciones asalariadas son de calidad, por lo que resultarían más convenientes otros indicadores, como los de informalidad laboral y empleo no registrado. Como esos indicadores no están ampliamente disponibles ni son estrictamente comparables a escala internacional, en este capítulo se analizan las tendencias de todos los países de la región utilizando la tasa de empleo ajustada. En el capítulo IV, se profundiza en la situación de algunos países en particular mediante indicadores de alcance más específico.

13 El indicador de la tasa de empleo ajustada es una buena aproximación al grado de desarrollo relativo de los países: los más avanzados tienen tasas de asalarización elevadas. Por ejemplo, los Estados Unidos, Suecia, Alemania, el Japón, Francia, Austria, Suiza, Nueva Zelandia y el Reino Unido se encuentran entre los países con tasas superiores al $85 \%$. A pesar de los cambios tecnológicos y del surgimiento de nuevas formas de empleo en las últimas décadas, esa tasa se ha mantenido constante, e incluso, en algunos casos, ha mostrado una trayectoria creciente desde 1990. Solo en algunos casos, como Alemania, Reino Unido y Suiza, se registran caídas que, sin embargo, no superan el 1,2 punto porcentual. 


\section{Gráfico III.7}

América Latina y el Caribe (en conjunto y por subregión): contribución de los componentes de la tasa de empleo ajustada a la variación promedio anual de esta, 2000-2008 y 2012-2016

(En porcentajes)

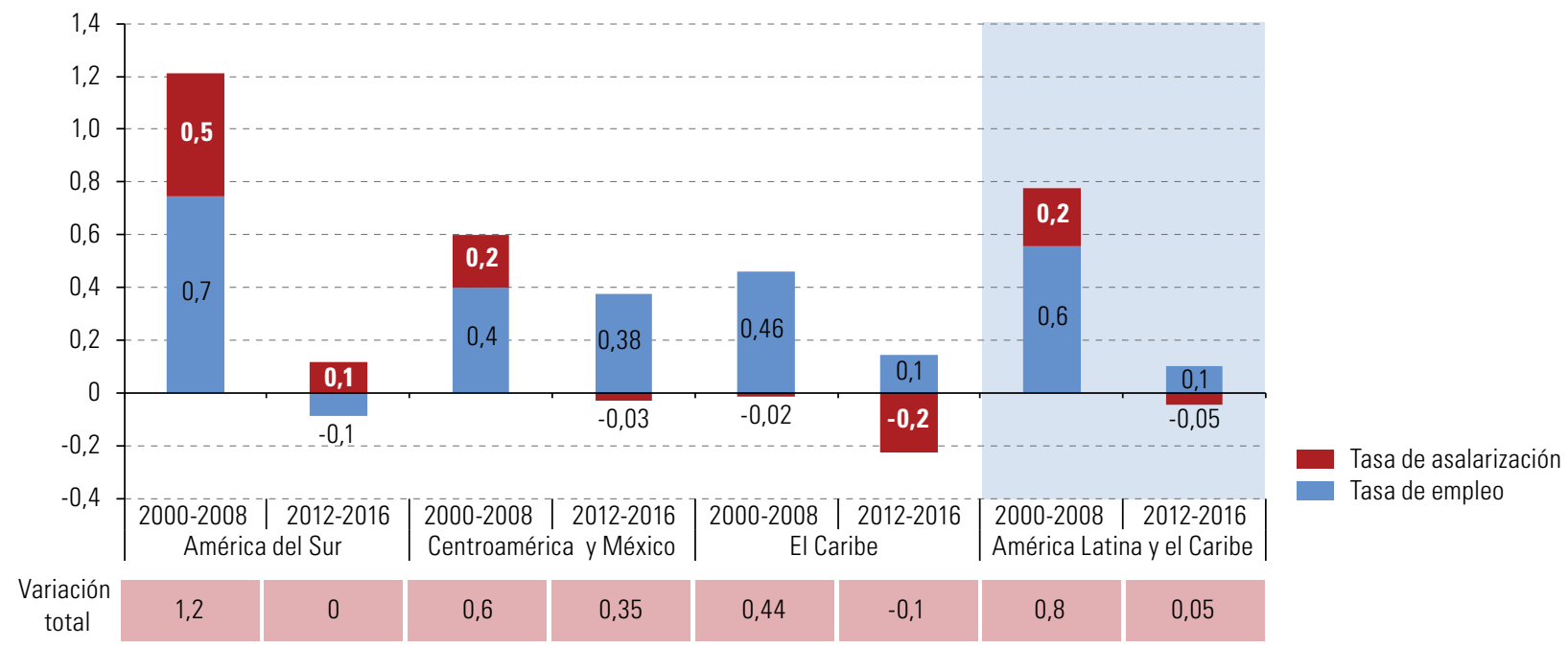

Fuente: Comisión Económica para América Latina y el Caribe (CEPAL), sobre la base de Organización Internacional del trabajo (OIT).

La desagregación por sexo permite apreciar tendencias diferentes en la evolución de las tasas de empleo ajustadas de mujeres y hombres, que parten de situaciones muy diferentes (en 2000, por ejemplo, esa tasa era del $42 \%$ en los hombres y de solo el $26 \%$ en las mujeres). En los años previos a la crisis financiera internacional, las tasas de empleo ajustadas crecieron más en el caso de las mujeres que de los hombres. Como se observa en el gráfico III.8C, esto permitió reducir la brecha entre los sexos, que de todos modos se mantuvo elevada. En la fase de amesetamiento, la dinámica también fue más favorable para las mujeres, aunque en este caso en un contexto de crecimiento negativo de la tasa de empleo ajustada de los hombres, cuyo ritmo de expansión se redujo del 3\% al -0,2\% anual entre ambos períodos, y de enlentecimiento de la de las mujeres, que pasó del 1,4\% al 0,4\% (véase el gráfico III.9). Esta dinámica se verificó también en las subregiones y permitió que la tendencia a la reducción de esta brecha se mantuviera en el tiempo.

Las diferentes trayectorias según el sexo responden a dinámicas laborales distintas pero articuladas, que reflejan inequidades y estereotipos que se manifiestan en el mercado laboral, así como la desigual división sexual del trabajo en los hogares. Las demandas de mayor autonomía económica de las mujeres para revertir esta desigualdad comienzan a reflejarse en la reducción de la brecha entre las tasas de participación de las mujeres y los hombres (véase el gráfico III.8A), aunque, como en el caso de las tasas de empleo, todavía se registra una diferencia importante a favor de los hombres (20 puntos porcentuales según el último dato disponible). Además, se reduce la brecha en las tasas de desempleo, aunque esta también sigue siendo muy significativa (véase el gráfico III.8B).

El efecto combinado de la mayor participación de las mujeres en el mercado laboral y la desaceleración del ritmo de expansión de su empleo ha dado lugar a un aumento más pronunciado de la tasa de desempleo en las mujeres que en los hombres a partir de $2012^{14}$. Así, paradójicamente, mientras se acortan las brechas de participación, actividad y empleo, aumentan las brechas vinculadas a la desocupación.

14 Salvo en 2016, año en que la tendencia se revierte parcialmente. 


\section{Gráfico III.8}

América Latina y el Caribe: tasas y brecha en indicadores seleccionados según sexo, 2000-2016

(En puntos porcentuales)

\section{A. Tasa de actividad}

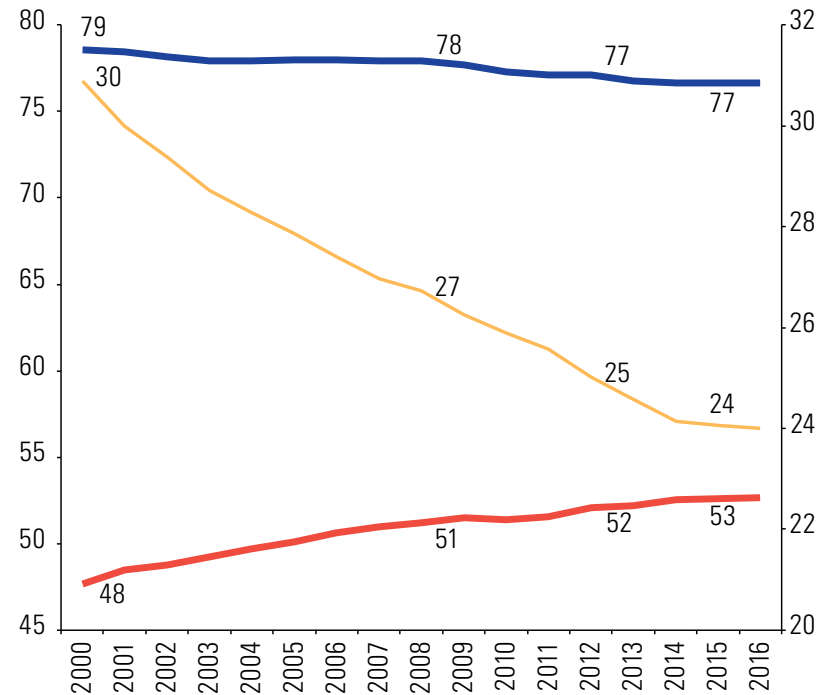

C. Tasa de empleo ajustada

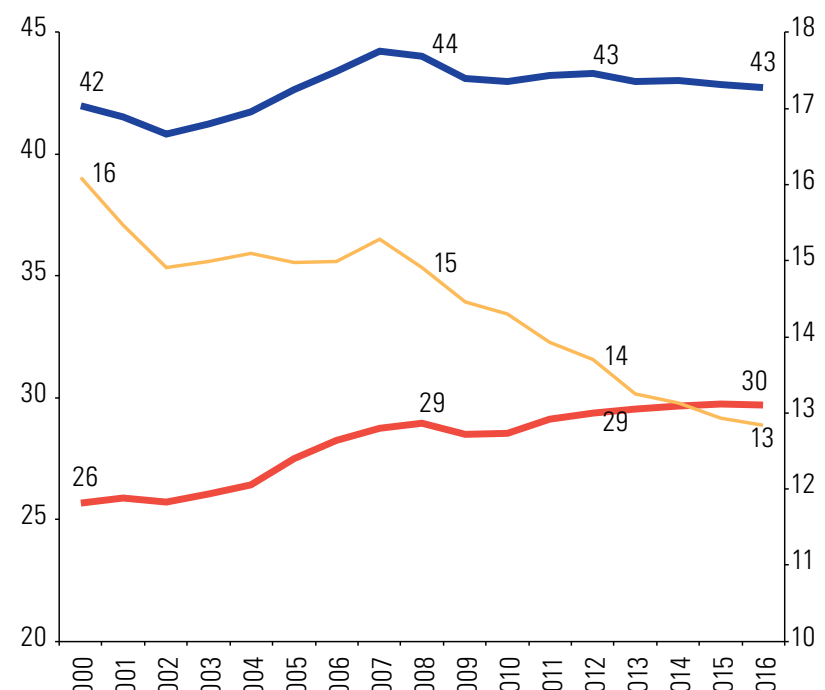

\section{B. Tasa de desempleo}

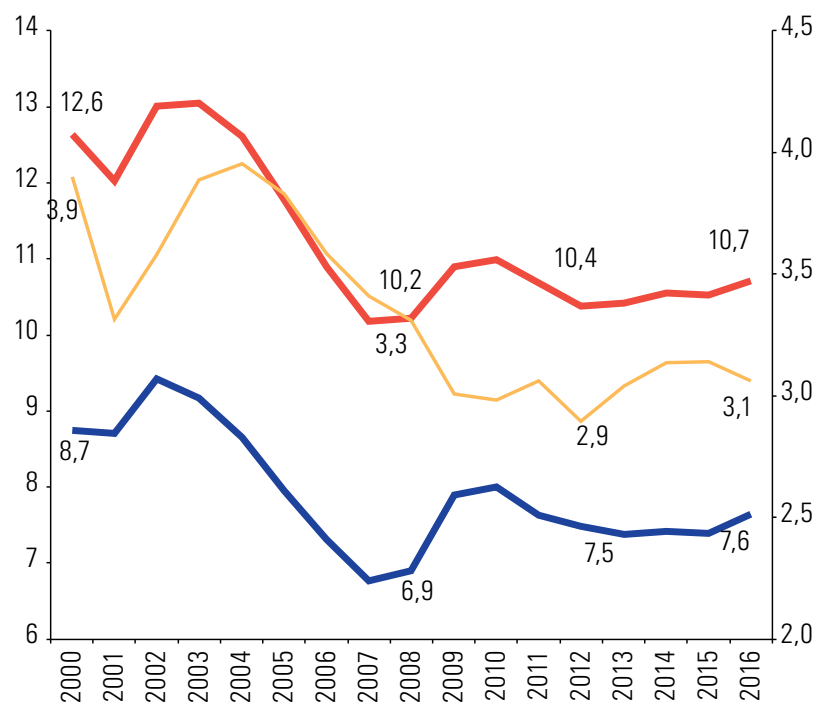

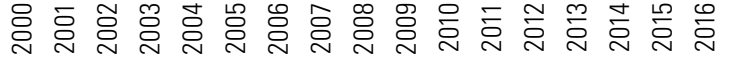

Hombre

Brecha (eje derecho)

- Mujer

Fuente: Comisión Económica para América Latina y el Caribe (CEPAL), sobre la base de datos de la Organización Internacional del trabajo (OIT). 
Otra de las manifestaciones de la desigualdad desde una perspectiva de género se relaciona con el perfil de los puestos de trabajo a los que acceden las mujeres y los hombres. La mayor calidad (en términos de derechos) de los puestos de trabajo de los hombres frente a los de las mujeres se aprecia al analizar las fuentes de su variación en el tiempo. El gráfico III.9 muestra cómo el aumento de la tasa ajustada de las mujeres se explica casi exclusivamente por efecto de la tasa de empleo, mientras que, en el caso de los hombres, se explica por la tasa de asalarización, tanto cuando la tasa de empleo crece como cuando se contrae. Es decir, la tasa de empleo ajustada de los hombres no solo sigue siendo más elevada que la de las mujeres, sino que sus movimientos son por lo general determinados por cambios en la tasa de asalarización.

\section{Gráfico III.9}

América Latina y el Caribe: variación promedio anual de la tasa de empleo ajustada según sus componentes, por sexo, períodos seleccionados

(En porcentajes)

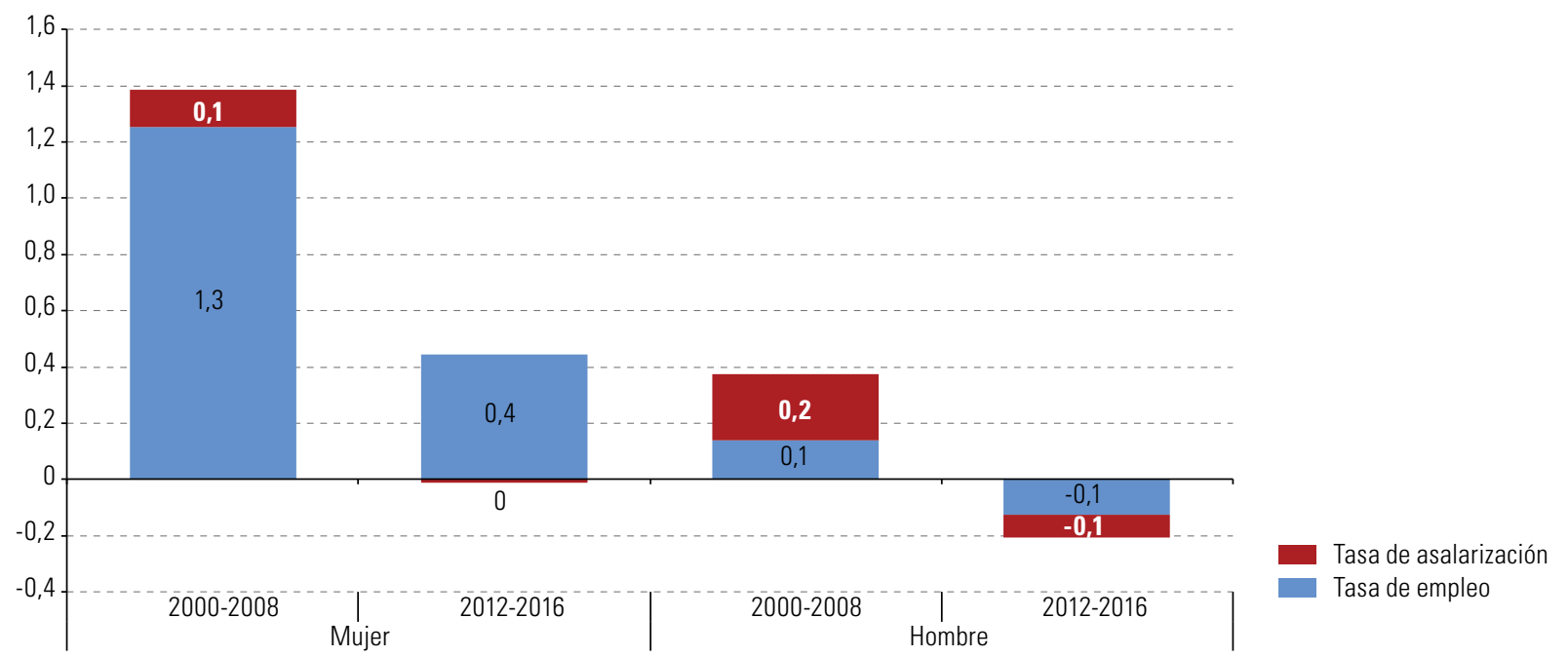

Fuente: Comisión Económica para América Latina y el Caribe (CEPAL), sobre la base de datos de la Organización Internacional del trabajo (OIT).

El cuadro general indica ciertos avances hacia una mayor autonomía económica de las mujeres (Vásconez, 2012; CEPAL, 2016a), aunque con limitaciones que se reflejan en la persistencia de brechas en la calidad del empleo y dinámicas diferentes en materia de desempleo. Por otra parte, no se han registrado grandes avances en la división sexual del trabajo en las actividades de cuidado. Las encuestas de uso del tiempo muestran que las mujeres dedican más del triple de tiempo al trabajo no remunerado que los hombres, así como más tiempo al trabajo total (remunerado y no remunerado) (CEPAL, 2016a). Estas diferencias, por lo general, se agudizan en el caso de las mujeres de menores recursos que no pueden adquirir servicios de cuidado en el mercado ${ }^{15}$.

En un contexto de menor dinamismo económico y generación de empleo, el crecimiento de la tasa de participación de las mujeres y del desempleo abre interrogantes respecto de la continuidad de algunas de las mejoras recientes en la situación laboral y de autonomía económica de las mujeres. La evidencia histórica muestra que, en fases de menor crecimiento económico, la desaceleración de la tasa de empleo presenta características diferentes entre las mujeres y los hombres, que dan como resultado un crecimiento relativo a favor de las mujeres. En paralelo al deterioro de la condición de empleo de los hombres y a la merma de los ingresos del hogar, aumenta la participación de las mujeres en edades centrales en el mercado

5 La liberación del tiempo desde la esfera reproductiva hacia el mercado de trabajo se verifica en mayor proporción en el segmento de mujeres que puede comprar servicios de cuidado. El resto se enfrenta a una doble jornada laboral (remunerada y no remunerada) generalmente en peores condiciones (sus hogares tienen un número mayor de miembros, están más alejadas de la oferta de servicios públicos de las ciudades y cuentan con peores medios de transporte para ejercer tareas relativas a la administración del hogar y el cuidado de los miembros dependientes). 
laboral —lo que reduce la brecha de la tasa de actividad—, pero como resultado de la discriminación en el mercado de trabajo, la inserción laboral de las mujeres es precaria, inestable y tiene una baja remuneración (Rodríguez Enríquez, 2012). Cabe preguntarse en qué medida la región se encuentra ante el inicio de otro ciclo de mayor participación económica de la mujer supeditado al objetivo de compensar la reducción del ingreso de los hogares por la pérdida del empleo de los hombres o si, por el contrario, se trata de un ciclo diferente en el que se profundizarán las mejoras de los últimos años.

\section{Se frena la reducción de la desigualdad de los ingresos monetarios}

Durante el último período de crecimiento económico, la reducción de la desigualdad de los ingresos en sus distintas dimensiones fue un fenómeno inédito en la región, que, aun después de esta mejora, continúa ubicada entre las más desiguales del planeta. La dinámica del mercado laboral, en primera instancia, y los efectos de las políticas de protección social, en forma complementaria, explican esa mejora. La disminución del ritmo de crecimiento que se advierte en los últimos años puede, por su impacto en el ámbito laboral, interrumpir ese sendero de mejoras o incluso revertirlo.

La desigualdad en la apropiación de los ingresos generados en el proceso productivo que se manifiesta en una baja participación de los salarios en el ingreso nacional ha sido una de las características de las economías latinoamericanas y caribeñas ${ }^{16}$. En los últimos años se han realizado esfuerzos importantes de recopilación y análisis de datos referidos a la distribución funcional del ingreso en la región. La dinámica histórica de la participación del salario en el ingreso se ha caracterizado por una caída persistente desde mediados de la década de 1970 (con la excepción de los primeros años de la década de 1990). Desde el período de 2004 a 2006 se registra una reversión de esa tendencia, con una mejora de la participación de los trabajadores asalariados en el ingreso total (véase el gráfico III.10), aunque con diferencias entre las subregiones y los países. Entre 2004 y 2014, del total de 16 países sobre los que había información, en ocho se registra un incremento de la participación de las personas asalariadas en el ingreso total (entre esos países se destacan la Argentina, el Uruguay, la República Bolivariana de Venezuela, el Brasil y Costa Rica), en tres prácticamente no se advierten cambios y, en los cinco restantes, se observa una caída.

No obstante estas mejoras, la participación asalariada en el ingreso sigue siendo, en la mayoría de los casos, inferior a sus máximos históricos (registrados en las décadas de 1960 y 1970) y mucho más baja que la de los países desarrollados. Aun con las limitaciones que se deben tener en cuenta al establecer comparaciones entre los países acerca del nivel de participación de los trabajadores en el ingreso ${ }^{17}$, en el gráfico 111.11 se muestra la baja posición relativa de la región y se advierte cómo el país latinoamericano donde la participación de los trabajadores asalariados en el ingreso es mayor se encuentra por debajo del país de la Organización de Cooperación y Desarrollo Económicos (OCDE) (con exclusión de Chile y México) en el que esa participación es menor, y muy lejos del país del Grupo de los Ocho (G8) que ocupa el peor lugar.

16 La noción de igualdad de la CEPAL no se limita a la igualdad económica o de medios. Como se expone en el capítulo IV, se refiere también a la igualdad en el ejercicio de los derechos y el desarrollo de las capacidades, al reconocimiento recíproco de los actores sociales que en ella intervienen y a la igualdad relacional de género, étnica y racial. Desde el punto de vista económico, se reconocen no solo las desigualdades entre los ingresos monetarios de que disponen las personas y los hogares como una manera de aproximarnos a su bienestar (distribución personal del ingreso), sino también la distribución primaria que se genera en el proceso económico en función de la capacidad de apropiación de los ingresos generados por los factores de producción o las clases sociales (distribución funcional del ingreso). Por otro lado, es cada vez más relevante considerar la distribución de la propiedad de los activos (financieros y no financieros). Las mediciones de estas dos últimas dimensiones de la desigualdad continúan siendo un reto importante para la región. En este capítulo, se incorporan datos sobre esta materia. Véanse CEPAL (2016b); Alarco Tosoni (2014); Abeles, Amarante y Vega (2014), y Abeles, Arakaki y Villafañe (2017).

17 Véase un análisis de los reparos que se deben tener al comparar este indicador entre países, habida cuenta no solo de las diferencias en la participación de la remuneración de los trabajadores en el ingreso per se, sino también de la diferente composición sectorial, véase Abeles, Arakaki y Villafañe (2017). 


\section{Gráfico IIl.10}

América Latina y el Caribe (en conjunto y por subregión): participación del trabajo asalariado en el PIB, 1950-2014 (En porcentajes)

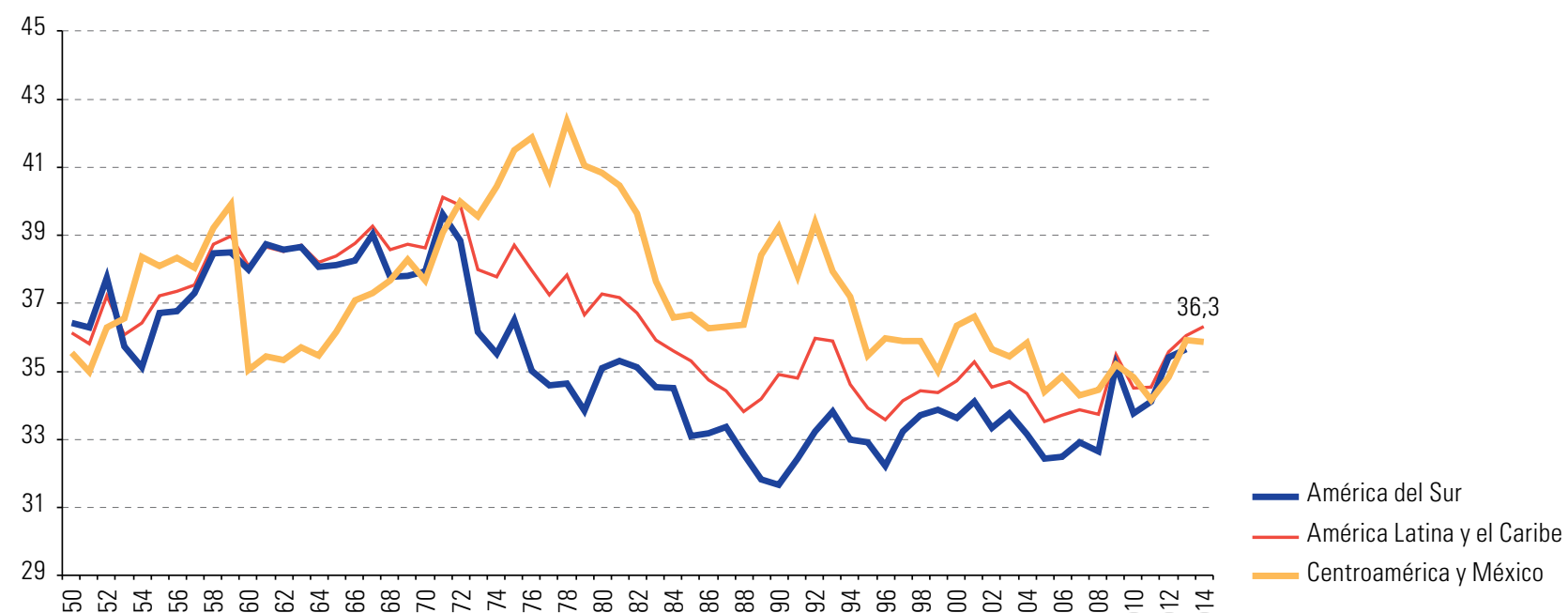

Fuente: Comisión Económica para América Latina y el Caribe (CEPAL), sobre la base de CEPALSTAT [base de datos en línea] http://estadisticas.cepal.org/cepalstat/ Portada.html; Naciones Unidas, Base de datos UNdata [en línea] http://data.un.org/; G. Alarco Tosoni, "Participación salarial y crecimiento económico en América Latina, 1950-2011", Revista CEPAL, № 113 (LC/G.2614-P), Santiago, Comisión Económica para América Latina y el Caribe (CEPAL), 2014; e institutos de estadística y bancos centrales de los países.

Nota: Promedio no ponderado de los países con disponibilidad de información: Argentina, Bolivia (Estado Plurinacional de), Brasil, Chile, Colombia, Costa Rica, Ecuador, El Salvador, Honduras, México, Nicaragua, Panamá, Paraguay, Perú, Uruguay y Venezuela (República Bolivariana de).

\section{Gráfico IIl.11}

América Latina y otras regiones: participación de las personas asalariadas en el ingreso total, alrededor de $2008^{a}$ (En porcentajes)

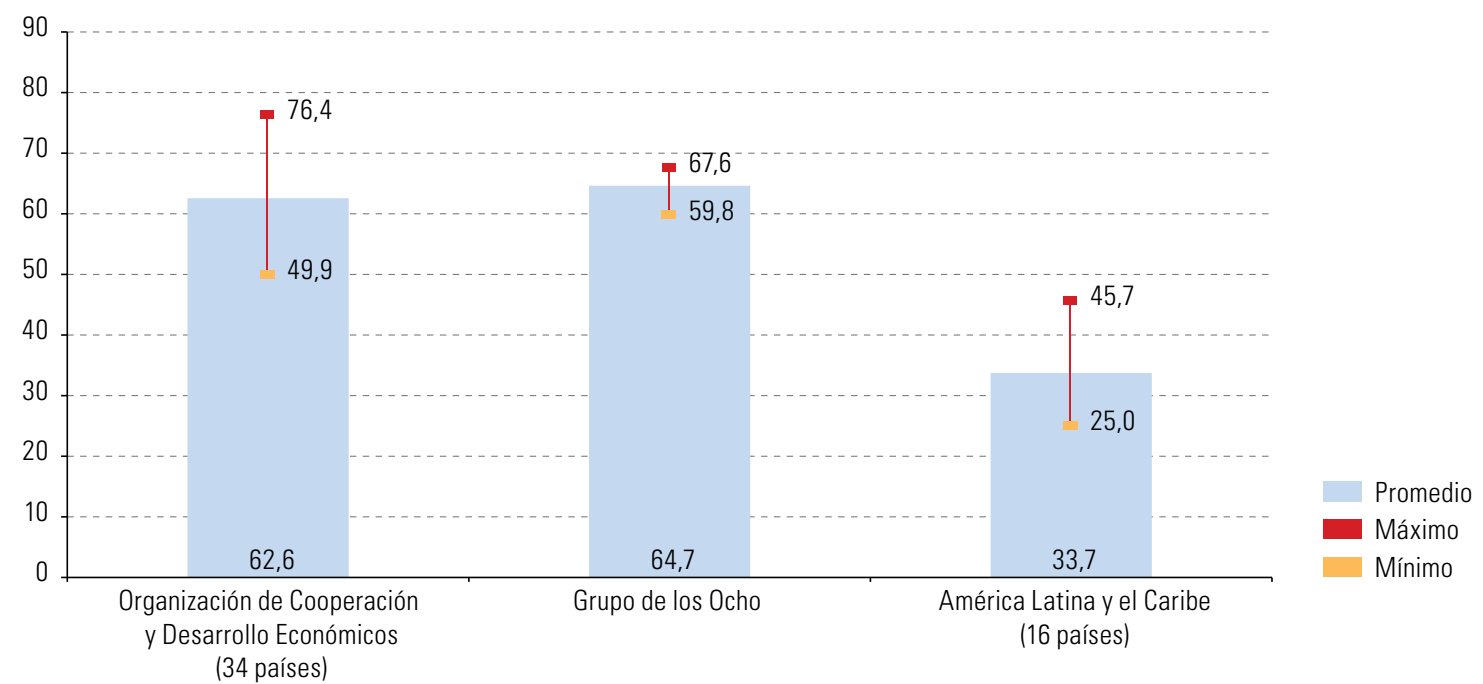

Fuente: Comisión Económica para América Latina y el Caribe (CEPAL), sobre la base de CEPALSTAT [base de datos en línea] http://estadisticas.cepal.org/cepalstat/ Portada.html; Organización de Cooperación y Desarrollo Económicos (OCDE), Base de datos OECDSTAT [en línea] http://stats.oecd.org/; Naciones Unidas, Base de datos UNdata [en línea] http://data.un.org/; G. Alarco Tosoni, "Participación salarial y crecimiento económico en América Latina, 1950-2011", Revista CEPAL, № 113 (LC/G.2614-P), Santiago, Comisión Económica para América Latina y el Caribe (CEPAL), 2014; e institutos de estadística y bancos centrales de los países.

Nota: En las estadísticas de la OCDE no se consideran ni México ni Chile.

a Los datos regionales corresponden a promedios simples. 
Por otro lado, es importante considerar que la retribución a los factores de producción se distribuye en forma muy heterogénea entre los hogares. Más adelante se analiza la distribución de los ingresos, principalmente los laborales y los provenientes de transferencias del Estado, que se captan en las encuestas de hogares. Pero antes es importante destacar que la evidencia disponible (todavía escasa y fragmentada) muestra que la desigualdad en la distribución de la riqueza en activos financieros o no financieros — que a la vez son los que generan los ingresos de capital o de la propiedad que se registran en las series de distribución funcional del ingreso- es considerablemente mayor que la desigualdad en la distribución de los ingresos disponibles. En un estudio de la CEPAL (Amarante y Jiménez, 2015), se muestra que en 26 países el coeficiente de Gini promedio asociado a la desigualdad de la riqueza alcanza un valor de 0,68 , mientras que el correspondiente a la desigualdad de los ingresos es de solo 0,36. En los pocos países latinoamericanos sobre los que hay información (la Argentina, el Brasil y México), el coeficiente de Gini relativo a la riqueza se encuentra entre los más altos (desiguales) de la muestra. Por consiguiente, también en lo que respecta a la distribución de la riqueza, los países de la región parecen ubicarse entre los más desiguales del mundo.

Una manera alternativa de medir la desigualdad y la concentración del ingreso y la riqueza que ha ganado importancia es la incorporación de los registros tributarios en el análisis ${ }^{18}$. Además de que permite evaluar el impacto que el sistema impositivo tiene en la distribución, permite analizar la apropiación de ingresos por parte de las élites, que tradicionalmente se subestima en los cálculos provenientes de las encuestas de hogares. Si bien esta línea de trabajo es incipiente, los datos confirman la alta concentración del ingreso en la región. Por ejemplo, el $1 \%$ más rico de la población del Brasil, Chile, Colombia y México se apropia de más del 20\% del ingreso total. En términos comparativos, en la mayoría de los países desarrollados (con excepción de los Estados Unidos), el ingreso del 1\% más rico no supera el 15\% del ingreso total (véase el gráfico III.12).

\section{Gráfico III.12}

Paises seleccionados: participación del 1\% más rico de la población en el ingreso, alrededor de 2014 (En porcentajes)

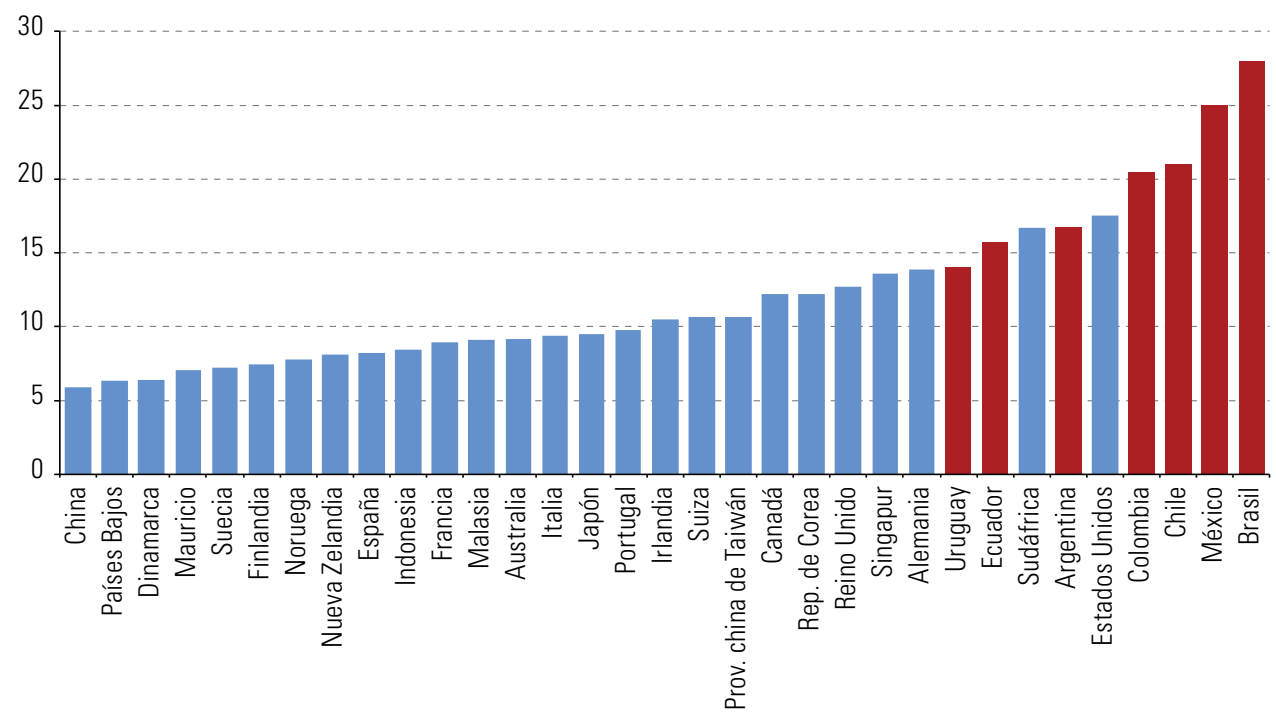

Fuente: Comisión Económica para América Latina y el Caribe (CEPAL), sobre la base de World Wealth and Income Database (WID. world), T. Fairfield y M. Jorratt, “Top income shares, business profits, and effective tax rates in contemporary Chile", The Review of Income and Wealth, vol. 62, No S1, Hoboken, Wiley, 2016; D. Rossignolo, N. Oliva y N. Villacreses, "Cálculo de la concentración de los altos ingresos sobre la base de los datos impositivos: un análisis para el Ecuador", serie Macroeconomía del Desarrollo, № 184 (LC/L.4278), Santiago, Comisión Económica para América Latina y el Caribe (CEPAL), 2016; R. Campos, E. Chávez y G. Esquivel, "Los ingresos altos, la tributación óptima y la recaudación posible", documento preparado para el Premio Nacional de Finanzas Públicas, Ciudad de México, Centro de Estudios de las Finanzas Públicas (CEFP), 2014; M. Morgan, "Extreme and persistent inequality: new evidence for Brazil combining national accounts, surveys and fiscal data, 2001-2015", WID.world Working Paper, № 2017/12, World Wealth and Income Database (WID.world), 2017.

18 En la literatura relacionada con los ingresos más altos (entre cuyos principales exponentes se encuentran Piketty, Atkinson, Sanz y Alvaredo) se ha revitalizado el debate sobre desigualdad, concentración y políticas públicas en la región. 
La elevada desigualdad en la distribución personal del ingreso es otra característica de la situación social en América Latina, donde el coeficiente de Gini del ingreso captado en las encuestas de hogares es sustancialmente más alto que en otras regiones. En la región, el país menos desigual es más desigual que cualquier país integrante de la OCDE (con exclusión de Chile y México que son miembros de esa organización). Además, todos los países de América Latina (salvo el Uruguay) tienen coeficientes de Gini superiores al promedio de cada una de las regiones, a excepción de África Subsahariana (véase el gráfico III.13).

\section{Gráfico III.13}

Coeficiente de Gini, alrededor de $2012^{a}$

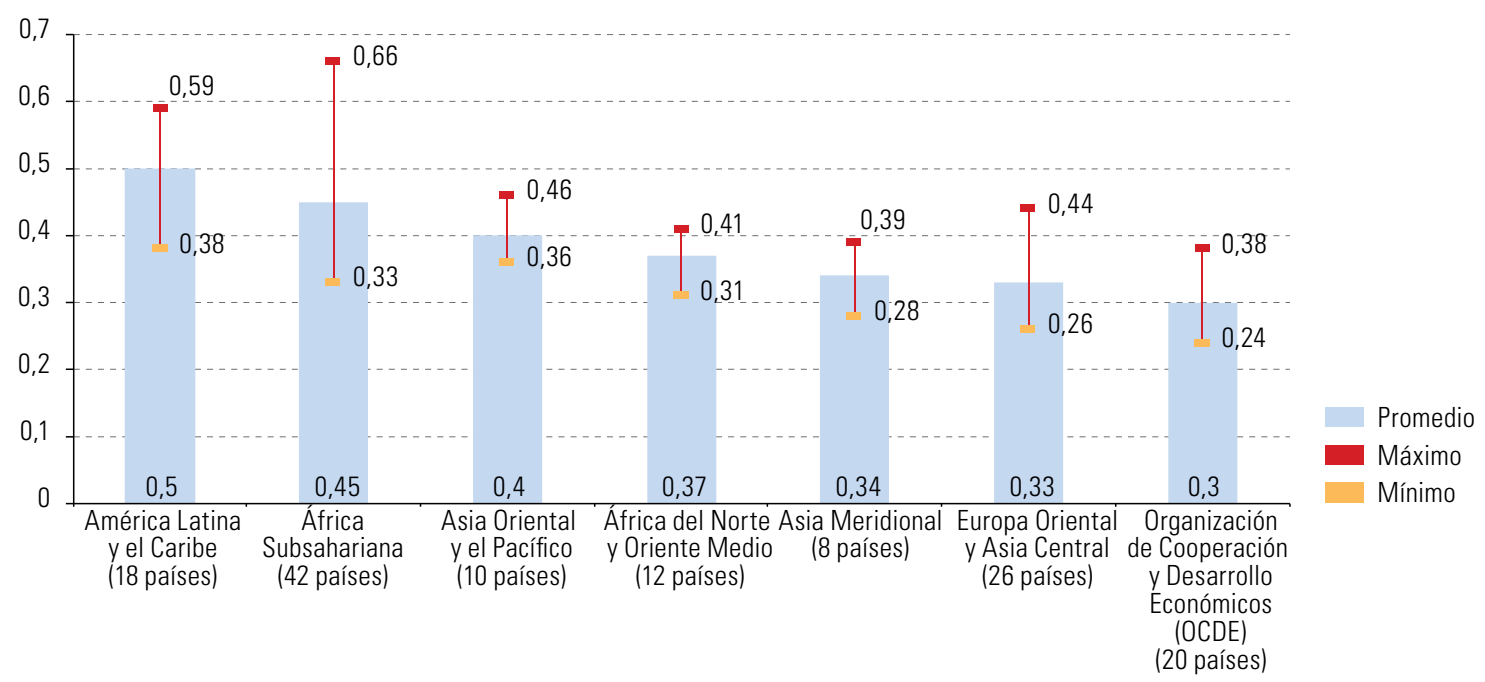

Fuente: Comisión Económica para América Latina y el Caribe (CEPAL), sobre la base de CEPALSTAT [base de datos en línea] http://estadisticas.cepal.org/cepalstat/ Portada.html; Organización de Cooperación y Desarrollo Económicos (OCDE), Base de datos OECDSTAT [en línea] http://stats.oecd.org/; Banco Mundial, World Development Indicators [base de datos en línea] http://databank.worldbank.org/data/reports.aspx? source=world-development-indicators.

a Los datos regionales corresponden a promedios simples. En el cálculo se consideró la última observación disponible en cada país correspondiente al período $2002-2012$.

Aunque los niveles de desigualdad de los países de la región continúan entre los más altos del mundo, a diferencia de lo ocurrido en otras regiones, en la década de 2000 se inicia un proceso sostenido de reducción de la desigualdad de ingresos entre los hogares. Entre 2002 y 2016, el coeficiente de Gini promedio disminuyó de 0,527 a 0,467. Desde 2012, con la desaceleración del crecimiento, se observa cierta moderación en el ritmo promedio de reducción de la concentración del ingreso, así como una mayor heterogeneidad entre los países. En el gráfico III.14 se muestra cómo, entre 2000 y 2008, la desigualdad se redujo, aunque con distinta intensidad, en todas las subregiones y en casi todos los países de los que se dispone de información. A partir de 2012, las tendencias comienzan a diversificarse, con países que empeoran, otros donde se detiene la mejora y un grupo en el que todavía se sostiene el ritmo de reducción del coeficiente.

Desde el cambio de siglo, la región ha avanzado mucho en materia sociolaboral, al fortalecer instituciones o introducir nuevos instrumentos que, con distinta intensidad y gravitación, explican la mejora en la dinámica distributiva. En el plano laboral, destaca el intenso ritmo de generación de empleo y la mejora de su calidad (en términos de formalidad y derechos), asociados al dinamismo de la actividad económica y a la recuperación de instituciones laborales clave como el salario mínimo, la negociación colectiva y las políticas de formación profesional. Entre las políticas sociales, que se analizan en el capítulo IV, destacan las mejoras en los sistemas de protección social, especialmente las transferencias de ingresos dirigidas al segmento más desprotegido de la población (Martínez, 2017). 


\section{Gráfico III.14}

América Latina y el Caribe (15 paises): desigualdad medida según el coeficiente de Gini del ingreso per cápita familiar, 2002-2016a

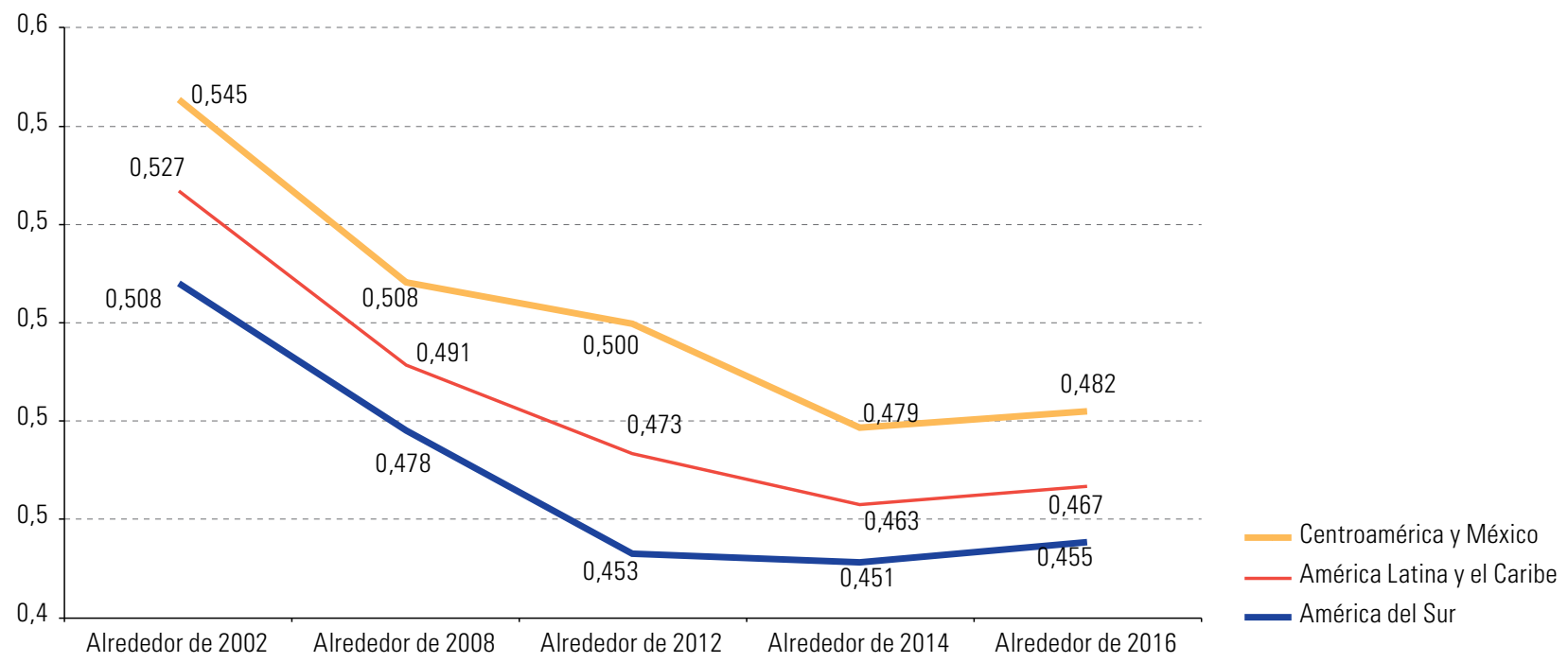

Fuente: Comisión Económica para América Latina y el Caribe (CEPAL).

Nota: Datos de: Argentina, Brasil, Chile, Colombia, Costa Rica, Ecuador, Guatemala, Honduras, México, Panamá, Paraguay, Perú, República Dominicana, Uruguay y Venezuela (República Bolivariana de).

a Promedios no ponderados.

Sin perjuicio de los avances en materia de protección social, las mejoras en el mercado de trabajo son el factor más relevante para explicar la reducción de la desigualdad en los años de mayor dinamismo económico ${ }^{19}$. Ello se debe, en primer lugar, al peso que los ingresos provenientes del trabajo tienen en los ingresos disponibles de los hogares frente al que tienen los ingresos que provienen de la protección social. También se debe a la debilidad de los sistemas fiscales de la región, que reproducen la distribución regresiva de los ingresos emanada del mercado. La preponderancia de la dinámica laboral en relación con la trayectoria de la desigualdad se constata en estudios ${ }^{20}$ en los que se muestra que la reducción de la desigualdad que se observó en la fase de mayor crecimiento económico estuvo asociada en más de un 60\% con la mejora de los ingresos laborales. En la Argentina, el Brasil y el Uruguay, la caída de la desigualdad se debió principalmente al ingreso laboral generado por los salarios de los trabajadores registrados (Bertranou y Maurizio, 2011; Amarante y Arim, 2015). Amarante y Jiménez (2015) muestran también que la trayectoria de la desigualdad en la región se explica sobre todo por la mejora en la distribución de los ingresos laborales, que en parte estuvo asociada a la disminución de las diferencias salariales entre los trabajadores de distinta calificación. Sin embargo, dichos autores destacan asimismo el fortalecimiento de las instituciones laborales y las políticas redistributivas.

En suma, las mejoras distributivas en la región han sido importantes respecto de comienzos de la década de 2000. No obstante, la región sigue siendo la más desigual del mundo en términos de relación entre el

19 De manera congruente con lo que se ha hallado en países desarrollados, en las mediciones basadas en encuestas de hogares se subestima el alcance de las transferencias no contributivas y se subestimaría el impacto de estas en la reducción de la pobreza y la desigualdad del ingreso. En particular, en relación con los programas de transferencias condicionadas que se llevaron a cabo en 13 países de la región entre 2011 y 2015, en las encuestas se subestima en un $13 \%$ la cantidad de perceptores. En el caso de las pensiones sociales, en las encuestas se subestima en un 21,1\% los ingresos totales con respecto a lo que surge de los registros administrativos (Villatoro y Cecchini, 2018).

20 Países y período analizado: Argentina (de 2003 a 2010), Brasil (de 2001 a 2009) y México (de 2000 a 2008). 
capital y el trabajo (distribución funcional), la distribución de los activos (riqueza) y la distribución de los ingresos entre los hogares y las personas, en gran medida producto de la desproporcionada apropiación de ingresos por parte de las élites. Dado que las mejoras han estado en gran medida asociadas a la dinámica laboral, la pérdida de dinamismo económico de los últimos años puede afectarlas. Una preocupación similar, aunque todavía con evidencia menos definida, se plantea en torno a la dinámica de la pobreza.

\section{Aumenta la incidencia de la pobreza}

La tendencia a la reducción de la pobreza y de la pobreza extrema en la región antes de la crisis internacional se estanca entre 2012 y 2014, y luego se revierte (véase el gráfico III.15). La incidencia de la pobreza en el conjunto de la región, que se había reducido a un ritmo promedio anual del 4,8\% entre 2002 y 2008 , se incrementa a un ritmo promedio anual del 1,8\% entre 2012 y 2016, sobre todo entre 2014 y 2016 . En Centroamérica y México, donde la reducción antes de la crisis no había sido tan grande como en América del Sur, la tendencia se estanca a partir de entonces.

\section{Gráfico III.15}

América Latina y subregiones (15 paises): incidencia de la pobreza en los hogares, 2002-2017ª

(En porcentajes)

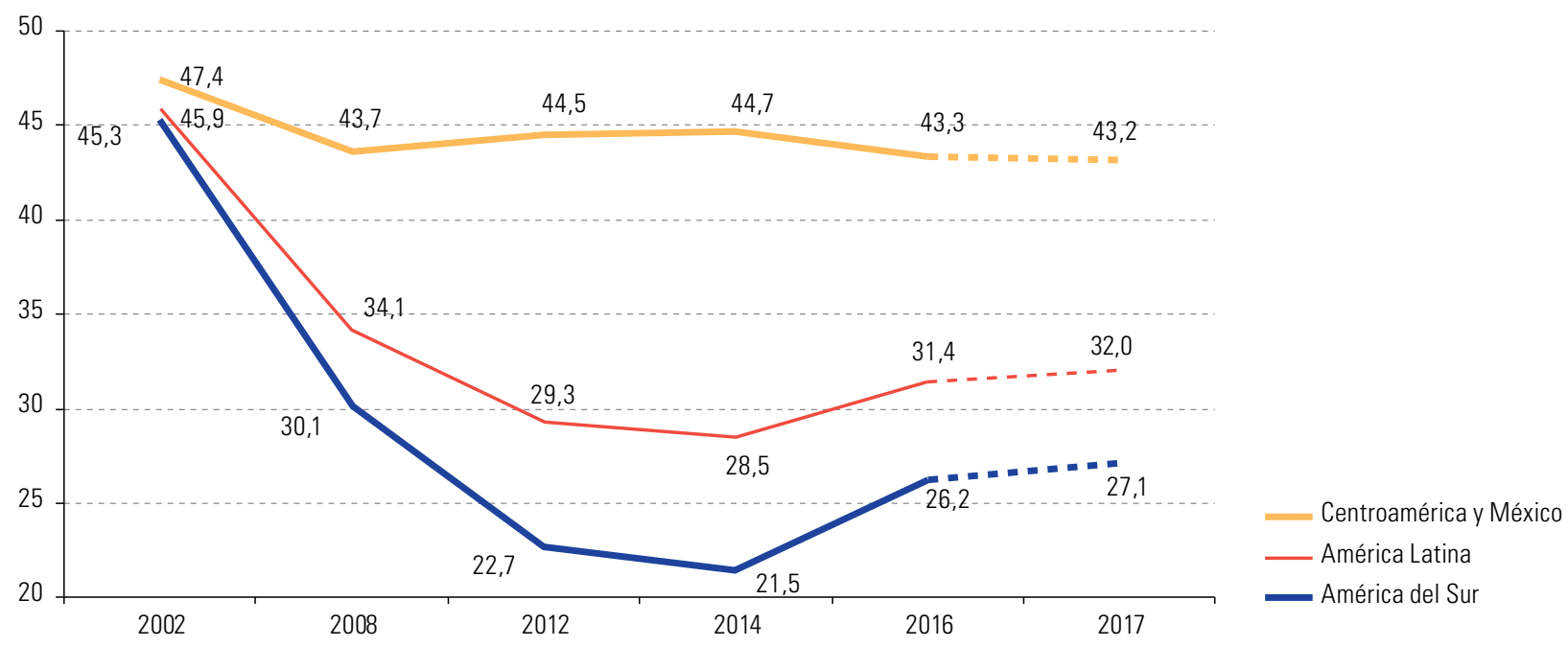

Fuente: Comisión Económica para América Latina y el Caribe (CEPAL).

Nota: Datos de: Argentina, Brasil, Chile, Colombia, Costa Rica, Ecuador, Guatemala, Honduras, México, Panamá, Paraguay, Perú, República Dominicana, Uruguay y Venezuela (República Bolivariana de).

a Promedio ponderado.

Como en el caso de la dinámica distributiva, la evolución de la pobreza también estuvo estrechamente asociada con la dinámica laboral. En un conjunto de países de la región, la mejora en la situación laboral fue el factor más relevante para explicar la salida de la pobreza en la fase previa a la crisis (Beccaria y otros, 2013) ${ }^{21}$. Si bien hay disparidades entre los países, entre un $30 \%$ y un $70 \%$ de la salida de la pobreza se asoció a eventos exclusivamente laborales (creación de nuevos empleos o incremento de los ingresos laborales). La segunda causa fue la combinación de eventos laborales con eventos no laborales (asociados a la protección social), que en conjunto dieron cuenta de entre un $60 \%$ y un $80 \%$ de la salida de la pobreza.

La reducción de la pobreza y la pobreza extrema durante los años de mayor dinamismo económico afectó de manera distinta a las mujeres y los hombres. En CEPAL (2016a), se mostró la sobrerrepresentación de las

21 Países y período analizado: Argentina (de 2003 a 2006), Brasil (de 2003 a 2006), Costa Rica (de 2006 a 2008), Ecuador (de 2004 a 2008) y Perú (de 2002 a 2006). Metodología: análisis a nivel hogar con paneles de encuestas de hogares. 
mujeres en la pobreza. Incluso en países en los que hubo una reducción importante del nivel general de pobreza y pobreza extrema, aunque la situación de las mujeres mejoró en términos absolutos, empeoró en términos relativos a la de sus pares hombres. Un fenómeno adicional que subyace a esta dinámica es la proporción de mujeres sin ingresos propios, que, aunque se ha reducido considerablemente (10 puntos porcentuales), en 2014 todavía era tal que una de cada tres mujeres mayores de 15 años que no estudiaban de manera exclusiva no tenía ingresos propios. En los hombres, esta relación era de uno de cada diez.

A pesar de lo que se ha avanzado con respecto a la mayor autonomía económica de las mujeres, persiste una fuerte discriminación en el mercado laboral (CEPAL, 2016a), que se manifiesta en la mayor ocupación relativa de estas en actividades de autoempleo y microempresas familiares, o en actividades de menor calificación, por las que perciben una remuneración menor o en las que no cuentan con la protección de la seguridad social (Vásconez, 2012).

\section{La política fiscal no reduce la desigualdad en la región}

\section{Ingresos tributarios sesgados contra la igualdad}

La capacidad de la política tributaria para reducir la inequidad distributiva depende del nivel y la composición de los ingresos fiscales. En los países de la región, la carga tributaria es mucho menor que en los países desarrollados, y la participación de los impuestos directos sobre la propiedad y la renta, especialmente sobre la renta personal, también es menor.

El nivel y la composición de los ingresos fiscales de los que dispone cada país son bastante heterogéneos. En algunos países, cerca del 90\% o más de los ingresos públicos provienen de la recaudación tributaria, mientras que, en otros, también son importantes los ingresos que se obtienen de fuentes no tributarias, como los derivados del petróleo o la minería (véase el gráfico III.16). Los ingresos de esas fuentes son más volátiles, lo que expone el espacio fiscal a las oscilaciones de los precios internacionales de las materias primas.

\section{Gráfico III.16}

América Latina (18 paises): carga fiscal según tipo de ingreso y país, 2016

(En porcentajes del PIB)

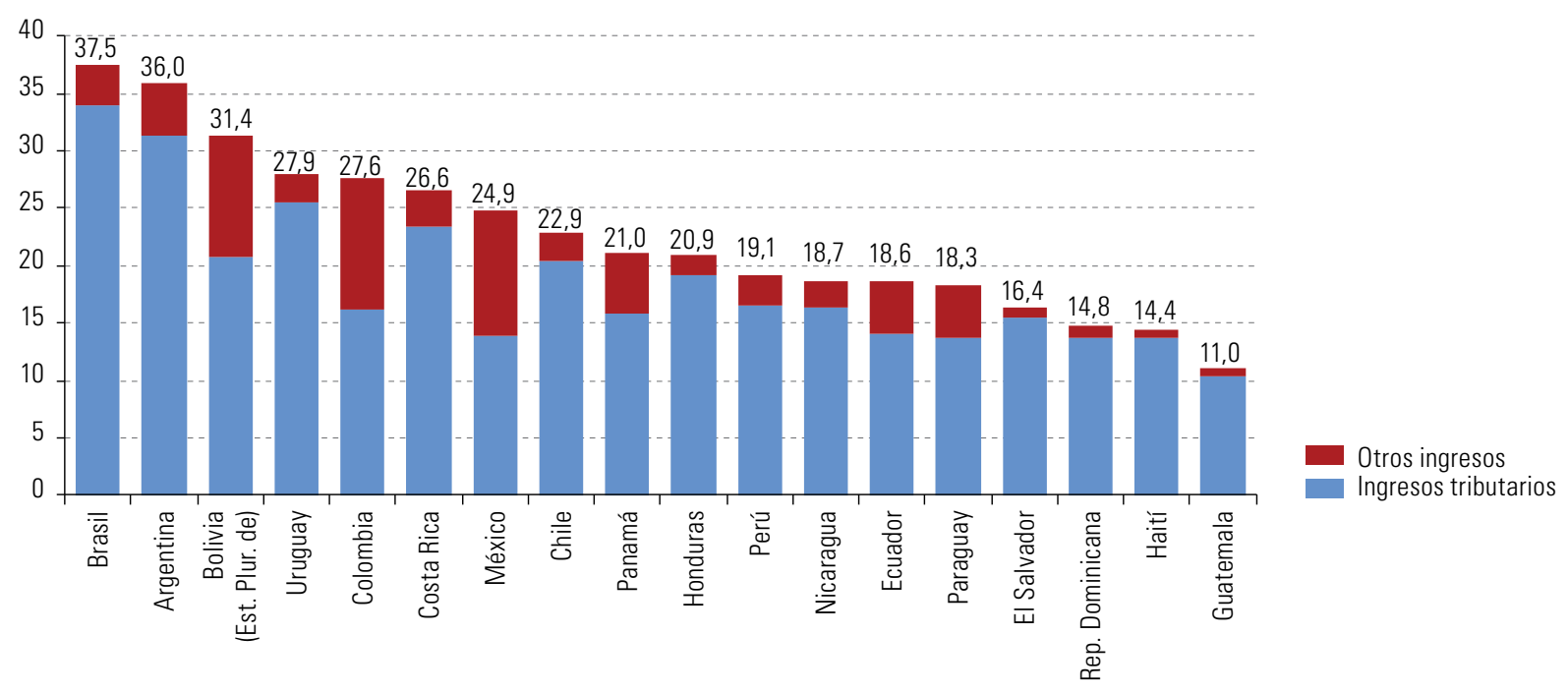

Fuente: Comisión Económica para América Latina y el Caribe (CEPAL), sobre la base de cifras oficiales.

Nota: La cobertura corresponde al gobierno central, excepto en la Argentina, Colombia, México y Panamá, donde corresponde al sector público no financiero, y en Bolivia (Estado Plurinacional de), el Brasil, Chile, Costa Rica y el Perú, donde corresponde al gobierno general. Los ingresos tributarios incluyen las contribuciones a la seguridad social. 
En los últimos años, en muchos países se aumentó la carga tributaria, producto de reformas que, entre otros objetivos, se orientaron a fortalecer la recaudación impositiva. Sin embargo, esa carga sigue siendo relativamente baja con respecto al nivel esperado en función del grado de desarrollo de cada país. En el gráfico III.17, se identifican tres grupos de países: un primer grupo cuya presión tributaria es más elevada que la que caracteriza a países que tienen un producto per cápita similar (destacan la Argentina, el Brasil y el Estado Plurinacional de Bolivia y, en menor medida, Nicaragua y el Uruguay); un segundo grupo cuya carga tributaria es semejante a la de otras economías que tienen un nivel de desarrollo similar (Costa Rica, Haití y Honduras), y un tercer grupo (11 países) que exhibe una presión impositiva inferior a la de otros países cuyo producto per cápita es similar.

Gráfico III.17

América Latina (19 paises): carga tributaria y PIB per cápita, alrededor de $2013^{\mathrm{a}}$

(En porcentajes del PIB y logaritmos)

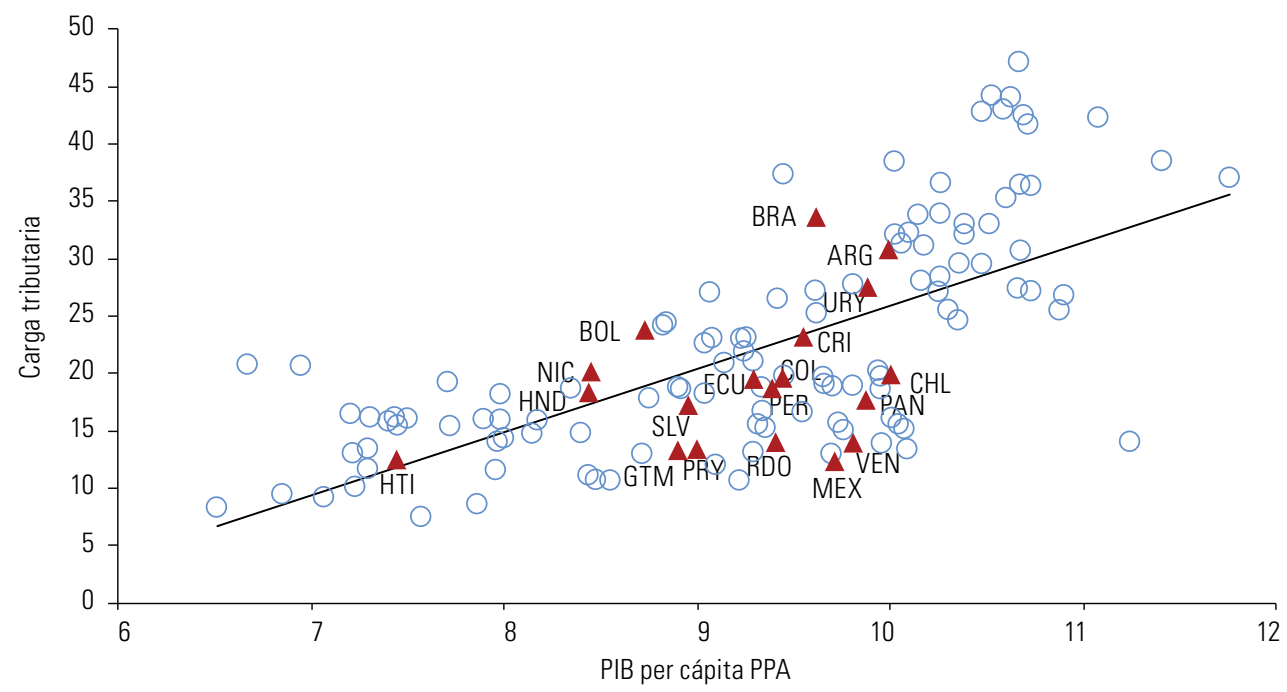

Fuente: Comisión Económica para América Latina y el Caribe (CEPAL), sobre la base de CEPALSTAT [base de datos en línea] http://estadisticas.cepal.org/cepalstat/ Portada.html; Organización de Cooperación y Desarrollo Económicos (OCDE), Base de datos OECDSTAT [en línea] http://stats.oecd.org/; Banco Mundial, World Development Indicators [base de datos en línea] http://databank.worldbank.org/data/reports.aspx?source=world-development-indicators.

Nota: Corresponde al último dato disponible en el período de 2011 a 2013. En el caso de los países de América Latina, la cobertura se refiere al gobierno central, excepto en el caso de la Argentina, Bolivia (Estado Plurinacional de), el Brasil, Chile, Colombia, Costa Rica y México, donde corresponde al gobierno general.

a En paridad del poder adquisitivo (PPA)

La carga tributaria promedio de la región es la mitad de la que se registra en el promedio de 15 países de la Comunidad Europea y se sitúa 13,5 puntos del PIB por debajo del promedio de los países de la OCDE (véase el gráfico III.18). Esta diferencia se debe en gran medida a las diferentes composiciones de los ingresos tributarios, en particular a la menor recaudación relativa por impuestos directos (progresivos) sobre la renta y la propiedad. Sobre todo, la diferencia es producto de la baja recaudación del impuesto a la renta personal en los países de la región, donde menos de un tercio de la recaudación corresponde a impuestos directos y el grueso de la carga recae en los impuestos sobre el consumo y otros impuestos indirectos, que tienen un fuerte sesgo regresivo. En el período de 2010 a 2015, en la región se recaudó, en promedio, el equivalente al 9,5\% del PIB en impuestos indirectos (en comparación con el 10,8\% en los países de la OCDE), en tanto que se obtuvo el equivalente al $6,0 \%$ del PIB de tributos directos (muy por debajo del $13,4 \%$ que se contabiliza en esos países).

La baja carga tributaria y el sesgo regresivo de su composición limitan la capacidad de la política fiscal para mejorar la distribución del ingreso en la región. En un estudio de 16 países se muestra que, antes de 
considerar los ingresos y los gastos públicos, el nivel de desigualdad promedio de los ingresos de mercado en los países de América Latina es levemente superior al valor promedio de la OCDE y que incluso hay países de la región que, desde este punto de vista, registran una menor desigualdad que las economías de ingresos altos. La diferencia entre unos países y otros se advierte luego de considerar los sistemas tributarios y el gasto social, que en la región tienen mucha menor eficacia que en los países desarrollados para mejorar la distribución del ingreso disponible. En Hanni, Martner y Podestá (2017, pág. 130), se estiman coeficientes de Gini antes y después de los impuestos directos y las transferencias en efectivo y en especie, y se concluye que la reducción de dicho coeficiente por efecto de la política fiscal en los países latinoamericanos (9 puntos porcentuales) es menor que en los países de la OCDE (23 puntos porcentuales) y en los de la Unión Europea (26 puntos porcentuales).

\section{Gráfico IIl.18}

América Latina (18 países), OCDE (34 países) y Unión Europea (15 países): composición de los ingresos tributarios, 1990-2015

(En porcentajes del PIB)

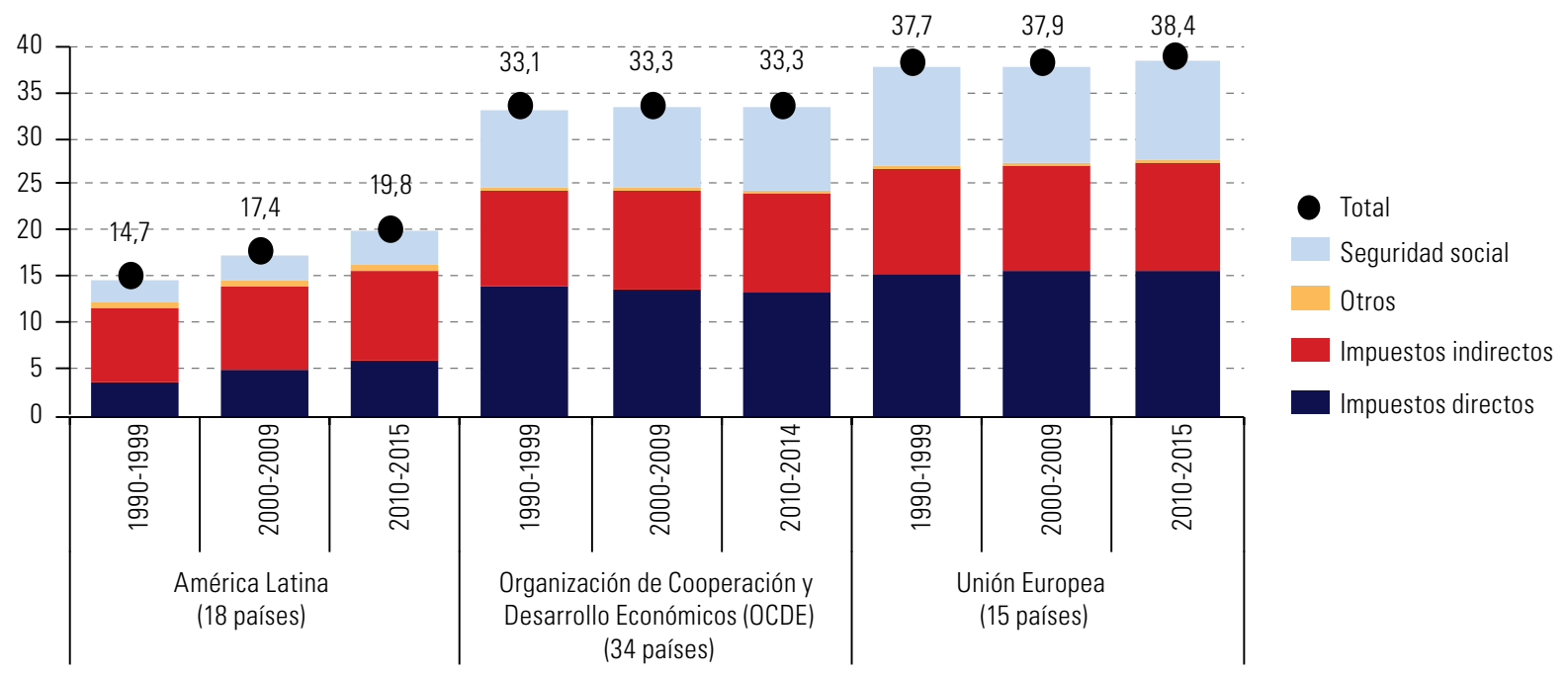

Fuente: Comisión Económica para América Latina y el Caribe (CEPAL), sobre la base de datos de la Organización de Cooperación y Desarrollo Económicos (OCDE). Nota: Las cifras correspondientes al promedio de los países miembros de la OCDE terminan en 2014.

\section{Débil poder redistributivo de la política fiscal}

La gran diferencia entre el poder redistributivo de la política fiscal de los países latinoamericanos y caribeños y el de las economías desarrolladas viene dada por las transferencias en efectivo y los impuestos directos, ya que la caída del coeficiente de Gini ocasionada por la distribución del gasto en educación y salud es similar en ambos grupos. En promedio, el coeficiente de Gini de la región cae apenas tres puntos porcentuales luego de la acción fiscal directa, mientras que la provisión pública de servicios de educación y salud lo reduce en seis puntos adicionales 22 . Por el contrario, en los países europeos y en otras economías de la OCDE, el efecto redistributivo conjunto de las transferencias monetarias y el impuesto sobre la renta personal es de 19 y 17 puntos porcentuales en promedio, respectivamente, mientras que la redistribución efectuada vía gasto público en especie se sitúa entre los seis y los siete puntos. En el gráfico III.19 se resalta que, en la región, la eficacia de los instrumentos de la política fiscal para reducir la desigualdad es muy heterogénea.

22 Este resultado, según el cual el gasto público social tiene un mayor efecto redistributivo que los impuestos directos en los países de América Latina y el Caribe, coincide con los de otros estudios que se llevaron a cabo tanto en América Latina como en países de la OCDE (Goñi, López y Servén, 2011; Lustig, Pessino y Scott, 2013; Joumard, Pisu y Bloch, 2012; Barreix, Bes y Roca, 2009). 


\section{Gráfico III.19}

América Latina y el Caribe (16 paises): reducción de la desigualdad medida según el coeficiente de Gini por instrumento de la política fiscal, alrededor de 2011

(En puntos porcentuales)

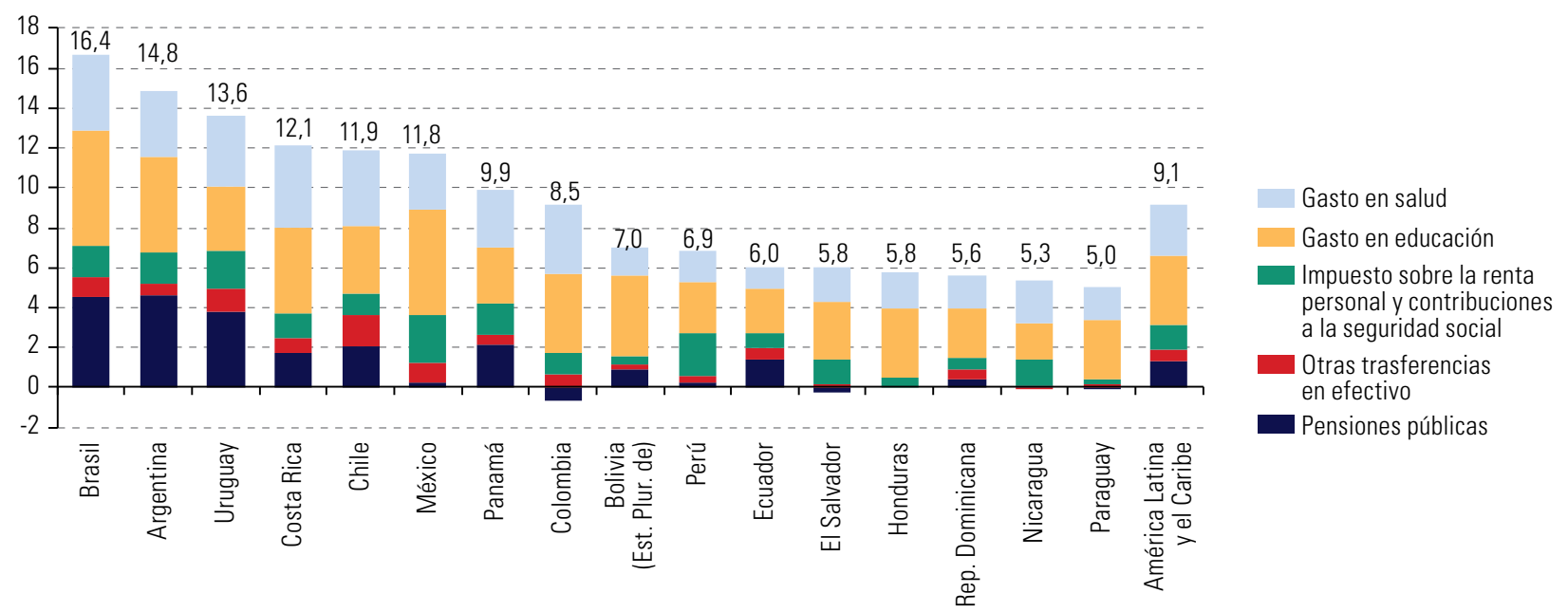

Fuente: M. Hanni, R. Martner y A. Podestá, "El impacto redistributivo de la acción fiscal en América Latina: los efectos de impuestos y transferencias públicas", Los efectos de la política fiscal sobre la redistribución en América Latina y la Unión Europea, Colección Estudios, № 8, Madrid, Programa EUROsociAL, 2014.

Nota: La información disponible en las encuestas de hogares no permite estimar el efecto redistributivo de las transferencias públicas monetarias en Honduras.

\section{a) Los impuestos directos sobre la renta}

La baja recaudación que se obtiene de los impuestos directos sobre la renta se explica en lo fundamental por la baja imposición a la renta de las personas físicas. En términos del PIB, la diferencia entre la tributación a la renta de las empresas no difiere demasiado entre los países de América Latina $(3,4 \%$ ) y los países desarrollados (2,9\% en la OCDE y 2,7\% en la Unión Europea). La carga de los impuestos sobre la renta de las familias, en cambio, es significativamente menor en América Latina (1,4\%) que en los países de la OCDE (8,4\%) o de la Unión Europea (10\%). Así, en el cuadro III.2 se observa que en los países de la región se recauda el equivalente al $4,7 \%$ del PIB por impuesto sobre la renta, y que las empresas aportan el $72 \%$ del total recaudado, mientras que las personas físicas contribuyen el $28 \%$ restante. En los países de la OCDE y la Unión Europea, estas proporciones están invertidas. El diferencial recaudatorio sobre la renta de las personas físicas es la brecha más importante en la comparación de las estructuras tributarias entre estos grupos de países.

\section{Cuadro III.2}

América Latina (18 paises): recaudación y participación relativa del impuesto a la renta de las empresas y de las personas físicas, alrededor de 2011

(En porcentajes del PIB y porcentajes)

\begin{tabular}{|c|c|c|c|c|c|}
\hline & & $\begin{array}{l}\text { Recaudació } \\
\text { rcentajes del }\end{array}$ & & $\begin{array}{r}\text { Participac } \\
\text { porce }\end{array}$ & $\begin{array}{l}\text { relativa } \\
\text { es) }\end{array}$ \\
\hline & Personas físicas & Empresas & Total & Personas físicas & Empresas \\
\hline Argentina & 1,7 & 3,7 & 5,3 & 31,1 & 68,9 \\
\hline Bolivia (Estado Plurinacional de) & 0,2 & 3,4 & 3,6 & 4,6 & 95,4 \\
\hline Brasil & 2,4 & 3,7 & 6,1 & 39,6 & 60,4 \\
\hline Chile & 1,4 & 6,3 & 7,7 & 18,6 & 81,4 \\
\hline Colombia & 0,2 & 4,6 & 4,8 & 4,4 & 95,6 \\
\hline Costa Rica & 1,3 & 2,7 & 4,0 & 32,9 & 67,1 \\
\hline Ecuador & 0,6 & 3,5 & 4,1 & 14,8 & 85,2 \\
\hline El Salvador & 2,2 & 2,4 & 4,5 & 48,1 & 51,9 \\
\hline Guatemala & 0,2 & 2,9 & 3,1 & 7,7 & 92,3 \\
\hline Honduras & 1,2 & 3,5 & 4,7 & 26,1 & 73,9 \\
\hline
\end{tabular}


Cuadro III.2 (conclusión)

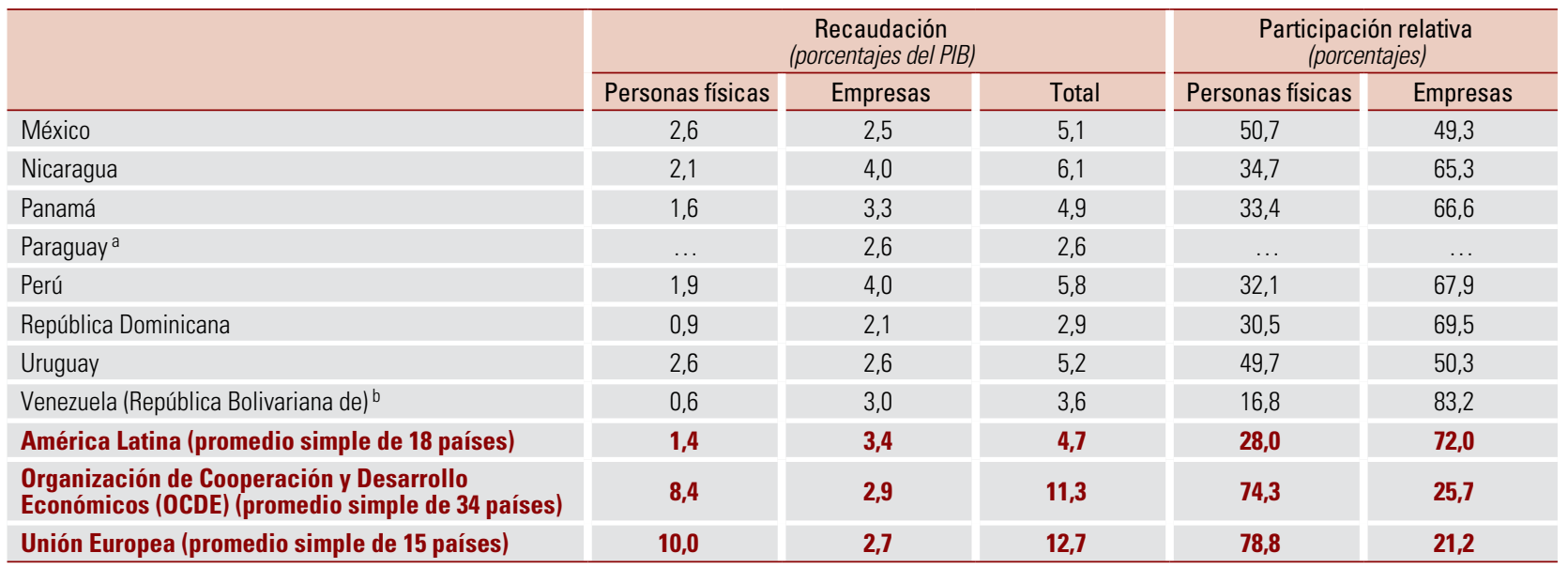

Fuente: Comisión Económica para América Latina y el Caribe (CEPAL), sobre la base de CEPALSTAT [base de datos en línea] http://estadisticas.cepal.org/cepalstat/ Portada.html; Banco Interamericano de Desarrollo (BID), Centro Interamericano de Administraciones Tributarias (CIAT) y Organización de Cooperación y Desarrollo Económicos (OCDE)

a En el Paraguay el impuesto a la renta de las personas físicas entró en vigencia el 1 de agosto de 2012.

b En la República Bolivariana de Venezuela la participación de las personas físicas y las empresas se ha estimado de acuerdo con su participación relativa en la información de presupuesto.

El escaso poder redistributivo del impuesto sobre la renta personal se debe esencialmente a la baja carga tributaria de los contribuyentes más ricos y constituye una de las manifestaciones más claras de la cultura del privilegio que se analiza en el capítulo VI.

\section{b) Los impuestos directos sobre la propiedad}

La reducida participación de los impuestos sobre el patrimonio constituye otra de las debilidades endémicas de los sistemas fiscales de la región, que erosiona sus bases imponibles y limita su capacidad redistributiva. Esta recaudación ha sido históricamente baja, al punto de estar casi ausente en los debates sobre herramientas fiscales disponibles para mejorar la distribución del ingreso. La tributación directa sobre la propiedad es una herramienta de gran potencial para gravar a las familias de los sectores más ricos. Este tipo de tributación abarca una amplia gama de instrumentos. Además de los impuestos sobre la propiedad o posesión de bienes inmuebles, en la región también se utilizan el impuesto a la transferencia de bienes inmuebles entre personas vivas (donaciones) y el impuesto a la propiedad de los vehículos automotores, al tiempo que algunos países tienen un impuesto sobre el patrimonio neto ${ }^{23}$. En 15 países de América Latina, la recaudación tributaria relacionada con los gravámenes al patrimonio en el período de 1990 a 2014 registra un valor promedio del $0,8 \%$ del PIB, que es casi la mitad del promedio de la OCDE en ese período (1,9\% del PIB).

\section{La evasión fiscal: una muestra de la cultura del privilegio}

La elevada evasión fiscal es otra causa de la relativa escasez de ingresos tributarios y es una fuente importante de desigualdad en la región. De acuerdo con la última información disponible, la tasa de evasión media del IVA se sitúa en el 27,8\%, con diferencias entre los países (CEPAL, 2016d). Por un lado, se encuentra el Uruguay, con la tasa de evasión más baja de la región; luego, hay un grupo de países que exhiben tasas cercanas o superiores al 20\%, pero inferiores al 30\% (varios de América del Sur y México), y, por último, hay otro grupo cuyos valores superan el 30\% (los de Centroamérica, el Ecuador y el Paraguay). Las estimaciones de la evasión al impuesto sobre la renta son mucho más elevadas: el promedio de la región alcanza casi el 50\% (47,5\%). En un extremo están Costa Rica, el Ecuador, Guatemala y la República Dominicana (con tasas cercanas al $65 \%$ ) y, en el otro, el Brasil, Chile y México, con valores significativamente menores (entre el $28 \%$ y el $31 \%$ ).

23 Un caso particular, poco comparable con el resto de los impuestos patrimoniales, remite a los impuestos que se aplican a los movimientos y las transacciones financieros y de capital, que fueron incorporados en un conjunto limitado de países durante la última década y mostraron un rendimiento recaudatorio aceptable (Gómez Sabaini y Morán, 2013). 


\section{Gráfico III.20}

América Latina (15 países): recaudación tributaria y evasión fiscal estimada, $2015^{a}$

(En porcentajes del PIB y millones de dólares)

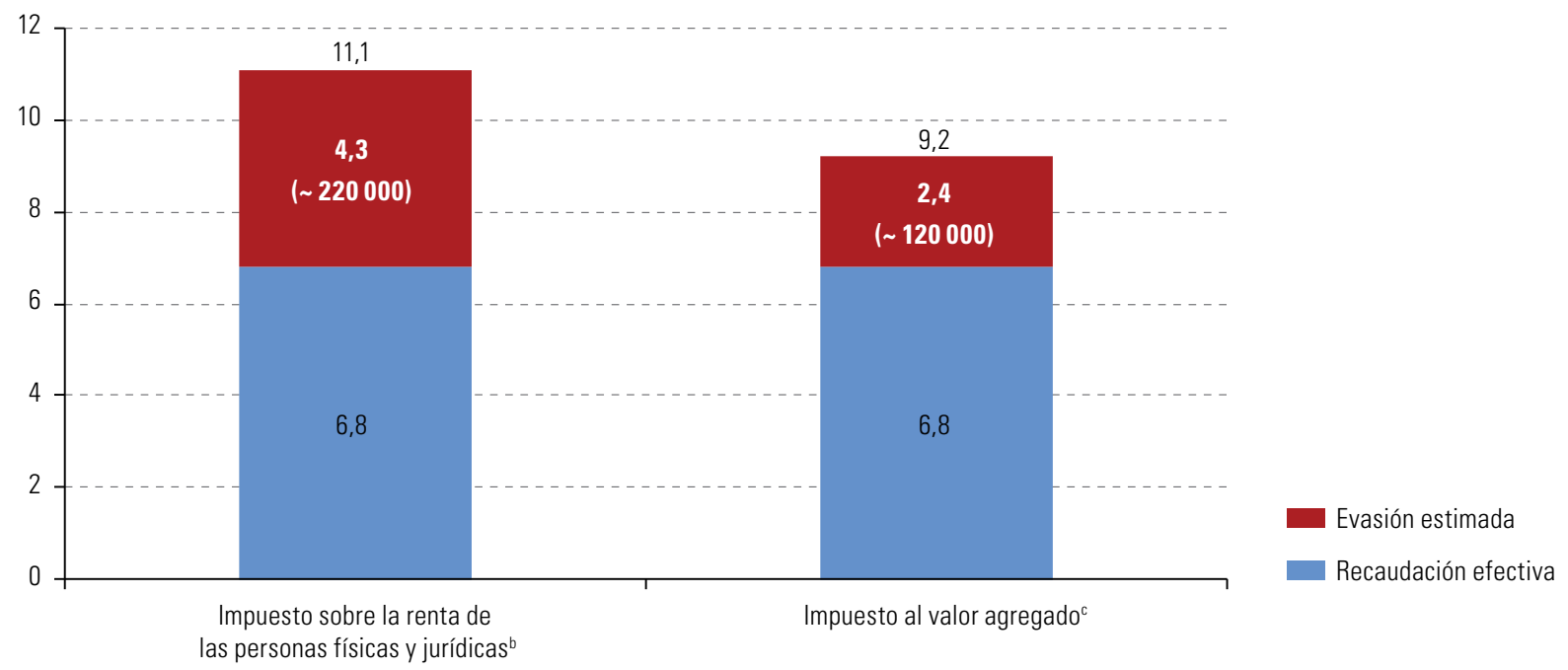

Fuente: Comisión Económica para América Latina y el Caribe (CEPAL).

a Se calculan la recaudación efectiva y la evasión estimada sobre la base de las cifras de la recaudación de ambos impuestos expresados en dólares; la suma de este valor se presenta como porcentaje del PIB de los países informados (promedio ponderado). Finalmente, se aplican los porcentajes al PIB de América Latina para estimar los valores regionales en dólares.

b Estimación sobre la base de datos procedentes de la Argentina, el Brasil, Chile, Colombia, Costa Rica, el Ecuador, El Salvador, Guatemala, México y el Perú.

c Estimación sobre la base de datos procedentes de la Argentina, Bolivia (Estado Plurinacional de), el Brasil, Chile, Colombia, Costa Rica, el Ecuador, El Salvador, Guatemala, México, Nicaragua, Panamá, el Perú, la República Dominicana y el Uruguay.

La CEPAL estima que el incumplimiento tributario asciende a un monto equivalente a 2,4 puntos porcentuales del PIB en el caso del IVA y 4,3 puntos porcentuales del PIB en el caso del impuesto sobre la renta (respecto de una recaudación efectiva de este impuesto equivalente a 68 puntos del PIB). Sumados, esos montos superan el porcentaje del PIB que los Gobiernos de América Latina destinan en promedio a inversión pública, que representó el 6,7\% del PIB en 2015 (CEPAL, 2017b), y equivalen, por ejemplo, a más de 13 veces la inversión pública en investigación y desarrollo de ese año.

En este marco, destaca la evasión de las empresas trasnacionales en sus operaciones internacionales -mediante arbitraje tributario a escala global- y de las personas con elevado patrimonio. UNCTAD (2015) estimó que las pérdidas globales en términos de ingresos tributarios no recaudados habrían alcanzado los 90.000 millones de dólares anuales en los países en desarrollo (200.000 millones a nivel mundial) durante el período 2009-2012. Asimismo, según la OCDE (2015), la pérdida recaudatoria provocada por los mecanismos de erosión de la base imponible y el traslado de beneficios (BEPS) se ubicaría entre los 100.000 y los 240.000 millones de dólares en 2014, y se estima que el impacto relativo es más grande en los países en desarrollo por su mayor dependencia fiscal respecto del impuesto sobre la renta de las sociedades.

La CEPAL ha estimado las salidas financieras ilícitas originadas en la manipulación de los precios de las exportaciones o las importaciones, así como los recursos que el fisco deja de recaudar debido a esta práctica (CEPAL, 2016d). Durante 2015, estas corrientes ilícitas habrían sumado más de 92.000 millones de dólares y representado cerca del 1,5\% del PIB regional (véase el gráfico III.21). El monto de los ingresos fiscales que se podrían percibir si estas actividades se controlaran y gravaran representaría el 0,5\% del PIB.

La erosión de la base tributaria adquiere rasgos específicos en los países en desarrollo, en particular en el caso de los sectores extractivos que tienen un peso importante en la economía; por ejemplo, en Hanni y Podestá (2016) se muestra que los flujos financieros ilícitos del sector minero en los países andinos son el resultado de problemas en la fiscalización de las exportaciones de esos productos. 


\section{Gráfico III.21}

América Latina y el Caribe: montos estimados de la manipulación de precios del comercio internacional de bienes, 2004-2015

(En millones de dólares)

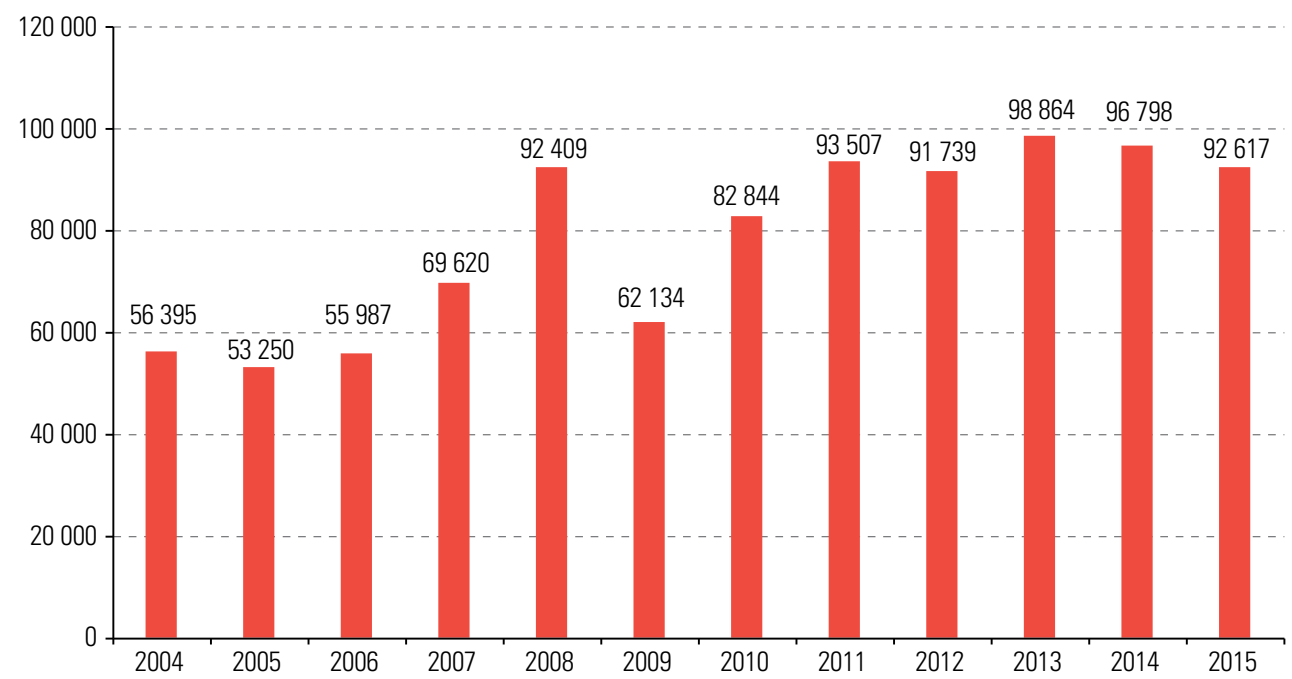

Fuente: Comisión Económica para América Latina y el Caribe (CEPAL).

Las prácticas de evasión y elusión no son un rasgo exclusivo de las empresas: también atañen a los particulares que tienen un patrimonio elevado. Se calcula que el $8 \%$ de la riqueza del mundo se encuentra en paraísos fiscales, lo que equivale a 7,6 billones de dólares (véase el cuadro III.3). Se estima que alrededor de 700.000 millones de dólares pertenecen a latinoamericanos, lo que representa el 22\% de la riqueza financiera de la región, y que la mayor parte de este monto (alrededor del $80 \%$ ) no ha sido declarada a las respectivas administraciones tributarias. Los resultados de programas recientes de regularización de activos no declarados son prueba del elevado grado de evasión de los sectores de altos ingresos ${ }^{24}$.

Cuadro III.3

Riqueza financiera nacional en paraísos fiscales, 2013

(En billones de dólares y porcentajes)

\begin{tabular}{|l|c|c}
\hline País o región & Riqueza financiera fuera del territorio & $\begin{array}{c}\text { Porcentaje respecto de la riqueza } \\
\text { financiera total del país o la región }\end{array}$ \\
\cline { 2 - 3 } Europa & 2,6 & 10 \\
\hline Estados Unidos & 1,2 & 4 \\
\hline Asia & 1,3 & 4 \\
\hline América Latina & 0,7 & 22 \\
\hline África & 0,5 & 30 \\
\hline Canadá & 0,3 & 9 \\
\hline Federación de Rusia & 0,2 & 52 \\
\hline Países del Golfo & 0,8 & 57 \\
\hline Mundial & 7,6 & 8 \\
\hline
\end{tabular}

Fuente: G. Zucman, The Hidden Wealth of Nations: The Scourge of Tax Havens, Chicago, University of Chicago Press, 2015.

24 En la Argentina, el Brasil y Chile, se regularizaron activos por montos equivalentes al 1,8\%, 0,8\% y 0,6\% del PIB, respectivamente. 
La predominancia de sistemas tributarios regresivos, con una elevada ponderación de los impuestos indirectos y menor recaudación relativa por impuestos directos sobre la renta y la propiedad, en particular sobre la renta personal, explican el reducido espacio fiscal con que cuenta la mayoría de los países de la región, así como el débil efecto redistributivo del accionar del Estado en general.

Una baja carga tributaria, con un claro sesgo regresivo, no solo tiene implicancias para las funciones redistributivas del Estado, sino que también limita el impacto de las políticas públicas. En la mayoría de los países de la región, el incremento de los ingresos fiscales a partir de 1990 permitió aumentar el gasto público en alrededor de 6 puntos porcentuales del PIB en promedio en los últimos 25 años. Ese incremento, sumado a la caída del pago de intereses de la deuda pública en los últimos años, elevó la disponibilidad de recursos públicos, lo que se tradujo en un aumento importante del gasto en educación y protección social e hizo posible un alza considerable del gasto de capital, que, partiendo de una base pequeña equivalente al 2,6\% del PIB en 1990 , alcanzó el 4,6\% en $2014^{25}$. Sin perjuicio de estos avances, el espacio fiscal para impulsar el cambio estructural progresivo sigue siendo limitado. De hecho, en un contexto de desaceleración, el gasto de capital se redujo en el período reciente y cayó 0,3 puntos porcentuales del PIB entre el período 2010-2014 y 2015-201626.

\section{Interacciones positivas o negativas entre distribución, crecimiento e inversión}

\section{El papel de las variables institucionales y estructurales}

La preocupación por el vínculo entre desigualdad y crecimiento es característica de los enfoques heterodoxos (la perspectiva ortodoxa suele plantear una relación positiva entre estas dos variables). En la corriente estructuralista, por ejemplo, aunque también en las tradiciones poskeynesiana y neokaleckiana, se suele analizar cómo los cambios en la distribución funcional del ingreso, al repercutir en la demanda agregada, afectan la trayectoria del producto y el empleo. Utilizando la terminología de Bhaduri y Marglin (1990), un régimen de crecimiento se encuentra liderado por los salarios (wage-led) si la mejora del salario real tiene un efecto expansivo sobre el consumo - y, a través del principio del acelerador, sobre la inversión-que compensa con creces el efecto contractivo que ejerce la caída de la tasa de ganancia sobre la inversión. En caso contrario, se estaría en presencia de un régimen de crecimiento liderado por los beneficios (profit-led).

No hay evidencia de la existencia generalizada de regímenes de crecimiento liderados por los beneficios, al menos cuando solo se considera la influencia de la distribución sobre los componentes internos de la demanda (Stockhammer, Onaran y Ederer, 2009; Onaran, Stockhammer y Grafl, 2011; Onaran y Galanis, 2012). En América Latina hay una menor cantidad de trabajos empíricos sobre el tema; el más comprehensivo es el de Alarco Tosoni (2016) que, en un estudio sobre 16 economías de la región, muestra que la mayoría de ellas tienen regímenes de crecimiento liderados por los salarios ${ }^{27}$.

En la práctica, la relación entre distribución y crecimiento depende de factores estructurales (productivos, geográficos) e institucionales (grado de apertura de la cuenta de capital, tipo de regulación del mercado laboral) que varían históricamente (Stockhammer, 2011). En las economías que desde el punto de vista comercial o financiero son más pequeñas y abiertas, es esperable que la relación entre el aumento de la igualdad y el crecimiento sea más débil que en las economías más grandes y cerradas, o incluso que sea negativa (cuando lideran los beneficios) (Blecker, 1989).

25 El mayor incremento en materia de gastos de capital se produjo en Panamá, el Ecuador y el Perú, y se destaca también el caso del Estado Plurinacional de Bolivia.

26 Más adelante se analizan la tendencia a la prociclicidad de la política fiscal, que se manifiesta, por ejemplo, en la retracción del gasto de capital, y su relación con el proceso de financierización que caracteriza a la región.

27 Según otros estudios, prevalecen los regímenes liderados por los beneficios, como en la Argentina y México (Onaran y Galanis, 2012) y en el Brasil (Araújo y Gala, 2012). Al igual que en el caso de los países desarrollados, las estimaciones realizadas en esos trabajos se basan en la dinámica de corto plazo. Los análisis en los que se incorpora un horizonte temporal más prolongado muestran que, por ejemplo, los regímenes de crecimiento de México (Caballero y López, 2012) y la Argentina, el Brasil, Chile y México (Reyes, 2018) son liderados por los salarios. 
Una forma de evaluar en qué medida las características estructurales inciden en la relación entre distribución y crecimiento es analizar cuánto se modifica el efecto positivo de la participación de la masa salarial sobre el consumo privado en distintas configuraciones institucionales, como el grado de financierización o apertura financiera de una economía o la complejidad de su sistema productivo. Una mayor financierización se asocia con ambientes de mayor volatilidad financiera, donde las decisiones de consumo y producción pueden estar condicionadas por una mayor incertidumbre y estar sujetas a una lógica de toma de decisiones cortoplacista. Una mayor complejidad productiva, en cambio, se vincula con la capacidad de la economía para trasladar el impulso derivado del incremento de la demanda efectiva hacia el conjunto de la economía mediante encadenamientos sectoriales, sin toparse de forma temprana con un problema de restricción de divisas.

La evidencia relativa a 25 países de la OCDE en el período de 1970 a 2015 indica que el efecto positivo de la participación de la masa salarial sobre el consumo privado se reduce cuanto mayor es el grado de apertura financiera y aumenta cuanto mayor es el grado de diversificación productiva de una economía (respecto a su propia historia) ${ }^{28}$. Este resultado sugiere que la relación entre distribución y crecimiento no es independiente de las características institucionales y estructurales de las economías.

La cuestión se torna más compleja cuando se consideran economías que, como las latinoamericanas y caribeñas, se encuentran sujetas al predominio de la balanza de pagos (Ocampo, 2011), es decir, cuya dinámica de corto plazo se encuentra más expuesta a los flujos internacionales de comercio y capital. En esas circunstancias, la reducción de los salarios, al incrementar el tipo de cambio real y la competitividad externa de la economía, podría inducir un aumento de las exportaciones (export-led) que compensara la caída del consumo interno (Blecker, 1989). Dinámicamente, un aumento de las exportaciones abriría el espacio necesario para la expansión de la demanda interna sin que de ello resulte un déficit insostenible en cuenta corriente, aunque el efecto del tipo de cambio real dependerá de las elasticidades precio de la demanda de exportaciones e importaciones ${ }^{29}$.

En los estudios sobre el vínculo entre la distribución y el crecimiento en las economías abiertas, se suele evaluar cuál es el efecto de los salarios que más pesa sobre la demanda privada. En estos análisis se parte del supuesto de que la mayor participación asalariada en el ingreso tiene un efecto positivo sobre el consumo (debido a que los asalariados tienen una mayor propensión a consumir que los perceptores de los ingresos derivados de la propiedad), pero un efecto negativo sobre la inversión (suponiendo que esta responde en mayor medida al margen de beneficios que al aumento de la demanda interna) y sobre las exportaciones netas (por su impacto en la competitividad externa). Un régimen de crecimiento se define como liderado por los salarios o, alternativamente, por las ganancias o las exportaciones, en función del efecto total que la participación de los salarios tiene sobre la demanda privada, y surge de la suma de los efectos individuales sobre cada componente (consumo, inversión y exportaciones).

Se hizo un análisis similar de la región en dos períodos (de 1950 a 1984 y de 1985 a 2014), con el objetivo de evaluar cómo cambian los efectos que la distribución funcional del ingreso tiene sobre el crecimiento según las instituciones económicas vigentes en cada momento ${ }^{30}$. El primer período se caracteriza por una mayor regulación de los flujos comerciales y financieros, así como por instituciones laborales más fuertes, reflejo de una participación más activa del Estado en la economía. Los resultados obtenidos muestran que el efecto total de la participación de la masa salarial sobre la demanda privada se redujo entre los períodos 1950-1984 y 1985-2014, lo que podría estar asociado a cambios institucionales ${ }^{31}$.

28 Se arriba a esta conclusión a partir de una estimación econométrica que se hizo sobre un panel de países de la OCDE acerca del efecto que los cambios en la masa salarial tienen sobre el consumo, mediado por variables que reflejan el grado de apertura financiera y el grado de diversificación productiva de cada economía. Los resultados muestran que el coeficiente correspondiente a la interacción entre la masa de salarios y el grado de apertura financiera es negativo, y el que corresponde a la interacción entre la masa de salarios y el grado de diversificación productiva es positivo.

29 En los estudios que apoyan el mantenimiento de un tipo de cambio real competitivo como ariete de la política industrial (Frenkel y Ros, 2006; Razmi, Rapetti y Skott, 2012; Bresser Pereira, 2012 y 2016; Ros, 2016), se supone que, en la práctica, prevalecen los regímenes liderados por los beneficios.

30 En relación con un conjunto de 16 países de América Latina, se estimó la elasticidad de los tres componentes de la demanda privada respecto de la participación de los salarios en el ingreso en los dos períodos mencionados. Luego, se obtuvo el efecto total sobre el producto, conforme a Alarco Tosoni (2016). Los resultados sugieren que el efecto positivo de los salarios sobre la demanda privada se redujo en el último período (de 1985 a 2014), fundamentalmente por el menor efecto positivo sobre el consumo

31 Alarco Tosoni (2017) realizó una estimación empírica relativa a los períodos 1950-1979 y 1980-2014, y encontró que la participación de los salarios en el ingreso tuvo un efecto positivo sobre el crecimiento en el primer período y uno negativo en el segundo. 
Los resultados sugieren que este cambio histórico se relaciona más con el debilitamiento del efecto positivo que el aumento salarial tiene sobre el consumo privado que con la agudización de sus efectos negativos sobre la inversión o las exportaciones. Estos resultados reflejan, por un lado, una baja sensibilidad del comercio exterior de las economías de la región a las variaciones de los precios relativos. Ello se explica porque el principal limitante de las exportaciones no es de carácter distributivo sino estructural y está vinculado con las grandes brechas de productividad que presenta gran parte de la producción transable de la región, salvo en algunos rubros específicos, como la producción de materias primas en América del Sur o algunas actividades manufactureras en Centroamérica y México ${ }^{32}$. La menor incidencia positiva de los salarios sobre el consumo privado, por otra parte, se encuentra en línea con lo observado en los países de la OCDE, donde se encontró una fuerte asociación entre la configuración institucional y el vínculo entre la distribución y el consumo. En contextos de mayor apertura comercial y financiera como el que rigió en el período 1985-2014, es esperable que el efecto de los salarios sobre el consumo privado sea menor, producto de la desindustrialización que tuvo lugar en varios países de la región en ese período y de la menor densidad de encadenamientos productivos resultante 33 .

Como se mencionó anteriormente, entre 2004 y 2014, el crecimiento económico de la región —cuyo ritmo ha sido decreciente en los últimos años - se produjo en el marco de un aumento de la participación asalariada en el ingreso. Esta dinámica, que reflejaría una relación positiva entre la distribución funcional del ingreso y el crecimiento (régimen liderado por los salarios), está más relacionada con un contexto exterior favorable - que permitió sortear la restricción de divisas- que con un cambio de régimen macroeconómico. En el gráfico III.22 se muestra este cambio de tendencia en la etapa más reciente. En él se ilustra la trayectoria de la participación asalariada en el PIB y el crecimiento económico promedio de América Latina, por períodos, entre 1950 y 2014. No obstante, cabe advertir que, aun luego de esta mejora ocurrida entre 2004 y 2014, la participación de los salarios en el ingreso se ubica en un nivel bajo tanto en términos históricos como en la comparación internacional. Esto es congruente con los resultados del análisis empírico, que arrojan una relación positiva más fuerte entre la participación asalariada en el ingreso y el crecimiento económico entre la década de 1950 y mediados de la década de 1980.

Gráfico III.22

América Latina y el Caribe: promedio de distribución y crecimiento por periodo, 1950-2014 (En porcentajes)

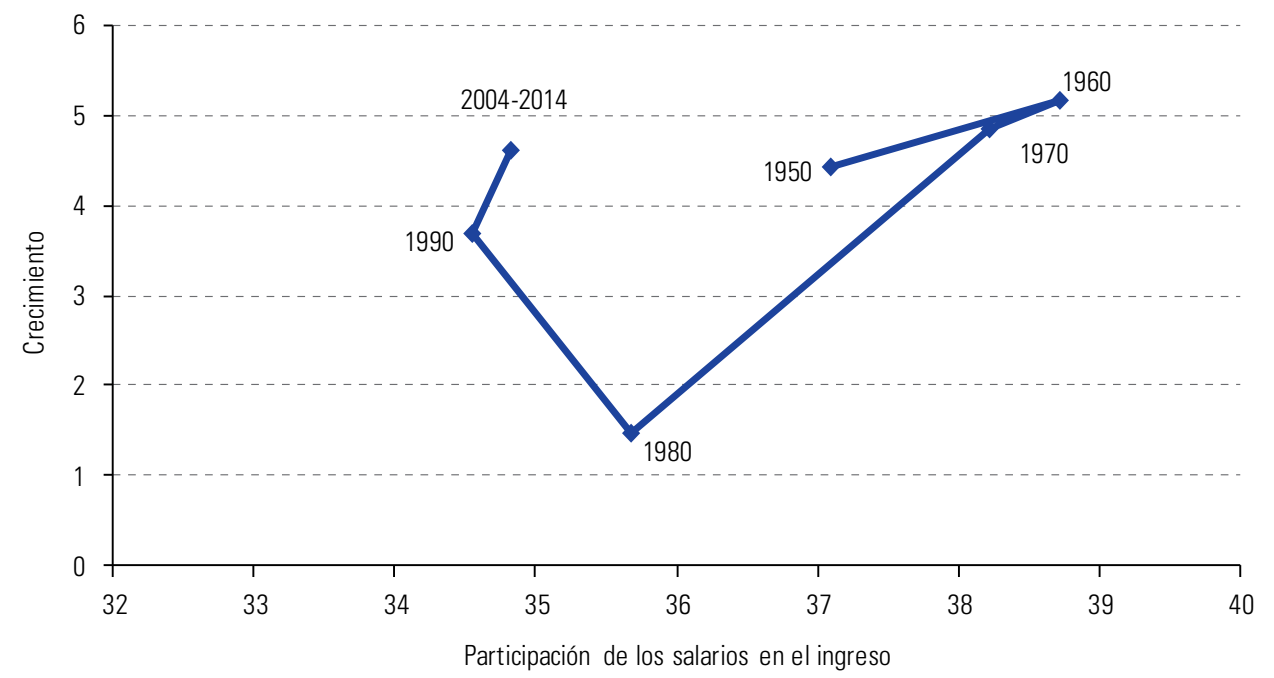

Fuente: Comisión Económica para América Latina y el Caribe (CEPAL), sobre la base de Banco Mundial y G. Alarco Tosoni, “Distribución factorial del ingreso y regímenes de crecimiento en América Latina, 1950-2012", Revista Internacional del Trabajo, vol. 135, № 1, Hoboken, Wiley, 2016.

Nota: La serie de la participación promedio de los salarios en el ingreso se suavizó con el filtro de Hodrick-Prescott.

32 En Bernat (2015) se puede hallar un ejercicio basado en el caso de América del Sur, en el que se hace un análisis empírico del efecto reducido que las devaluaciones cambiarias tienen en el desempeño exportador de los países en desarrollo.

33 Con respecto a la denominada desindustrialización temprana en América Latina, véanse Palma (2014) y Castillo y Martins (2016). 


\section{La relación virtuosa entre crecimiento e inversión}

Ya se hizo referencia al impacto negativo que la desaceleración de la inversión tuvo en el crecimiento de la región en el último quinquenio. En esta sección, se analiza cómo la disminución del crecimiento puede, a su vez, afectar negativamente la inversión. Como se aprecia en el cuadro III.4, existe una fuerte correlación entre los períodos de mayor tasa de inversión y los de elevado crecimiento.

\section{Cuadro III.4}

América Latina: tasa de variación anual de la inversión y del PIB, 1990-2015

(En porcentajes)

\begin{tabular}{|c|c|c|c|c|c|c|c|c|}
\hline \multirow{2}{*}{ Período } & \multicolumn{4}{|c|}{ América del Sur } & \multicolumn{4}{|c|}{ Centroamérica y México } \\
\hline & Total & Maquinaria & Construcción & PIB & Total & Maquinaria & Construcción & PIB \\
\hline $1990-2000$ & 5,2 & 6,5 & 3,9 & 3,2 & 9,5 & 11,9 & 7,2 & 3,5 \\
\hline 2001-2008 & 8,7 & 12,2 & 5,2 & 4,2 & 4,9 & 5,3 & 4,4 & 4,0 \\
\hline 2009 & $-8,3$ & $-16,5$ & $-0,1$ & $-0,4$ & $-13,7$ & $-19,3$ & $-8,2$ & $-0,7$ \\
\hline 2010 & 16,9 & 22,1 & 11,7 & 6,3 & 4,8 & 10,1 & $-0,6$ & 3,3 \\
\hline $2011-2015$ & 4,2 & 3,7 & 4,7 & 3,5 & 7,1 & 8,2 & 6,0 & 4,1 \\
\hline
\end{tabular}

Fuente: Comisión Económica para América Latina y el Caribe (CEPAL), sobre la base de datos del Fondo Monetario Internacional (FMI).

La evidencia muestra un elevado grado de asociación entre la tasa de variación de la formación bruta de capital fijo y el PIB. El promedio del coeficiente de correlación móvil (en una ventana de diez años) en el período 1980-2015 es estadísticamente significativo (0,87 en todo el período). Como se observa en el gráfico III.23, a partir de finales de la década de 1990, el grado de asociación entre ambas variables aumenta y pasa de un promedio de 0,74 entre 1990 y 2000, a 0,94 entre 2001 y 2010, y a 0,98 entre 2011 y 2015.

\section{Gráfico III.23}

América Latina: coeficiente de correlación móvil entre la tasa de variación de la formación bruta de capital fijo y del PIB, 1991-2016

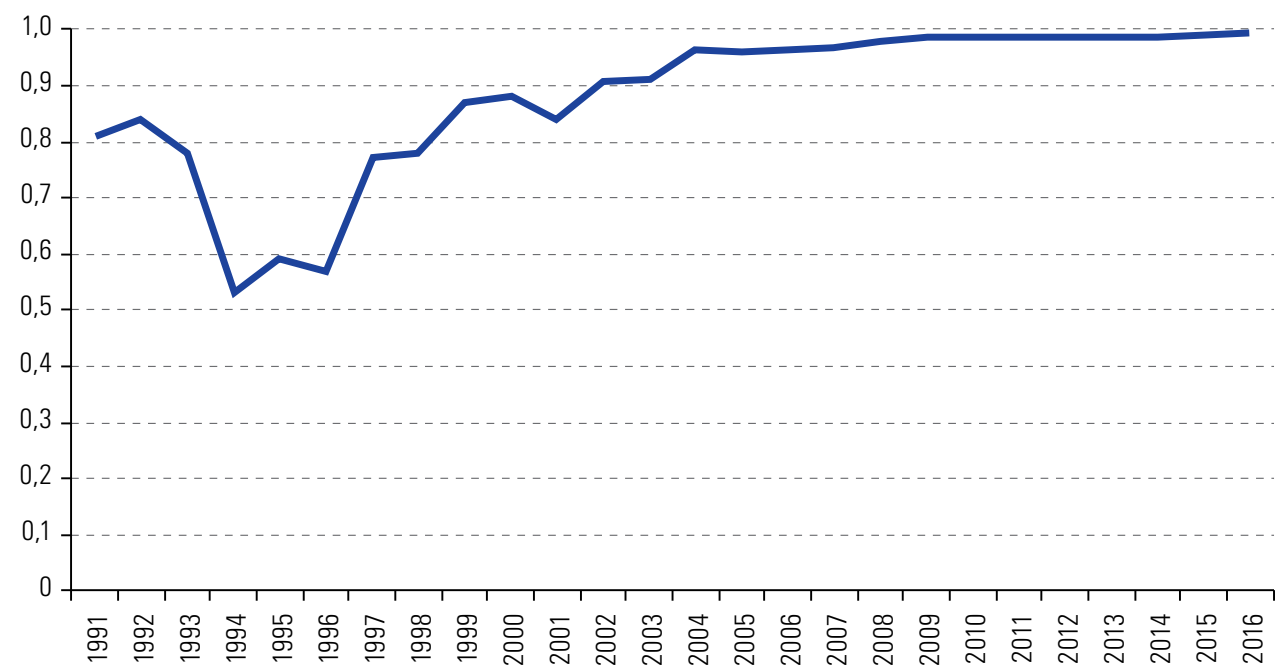

Fuente: Comisión Económica para América Latina y el Caribe (CEPAL), sobre la base de datos del Banco Mundial. 
Esta creciente asociación entre la tasa de crecimiento del PIB y la formación de capital refleja una relación de causalidad bidireccional entre estas dos variables. Por una parte, la inversión es uno de los componentes que dinamizan el crecimiento económico de corto plazo y amplían el crecimiento posible de largo plazo. Por otra, el crecimiento y las expectativas de mayor crecimiento son centrales para iniciar y sostener un proceso de inversión.

La relación bidireccional entre inversión y crecimiento surge del carácter dual de los efectos de la inversión. La inversión utiliza la capacidad productiva instalada no solo por el gasto directo sino también por el efecto que induce en los otros componentes de la demanda agregada. Un mayor efecto multiplicador del gasto de inversión genera una mayor demanda de insumos y productos terminados, que puede traducirse en una mayor utilización de la capacidad productiva. A la vez, el aumento de la inversión, en particular en maquinaria y equipos, expande la capacidad instalada y se transforma en una adición al acervo de capital.

El análisis empírico de la relación entre crecimiento e inversión refuerza las hipótesis de la bidireccionalidad. Para evaluar esa hipótesis se realizó un test de causalidad de Granger con información proporcionada por el Banco Mundial (que cuenta con datos sobre ambas variables, capital fijo y PIB, desde 1960 hasta 2016). Se observa que, cuanto más crece un país, mayor será su inversión en capital fijo en el siguiente período y, en algunos casos, en el subsiguiente. Por otra parte, cuando un país invierte más en capital fijo, el crecimiento aumenta. Los resultados indican que, en 12 de los 18 países de la muestra, hay una relación causal entre el crecimiento y la inversión. En Chile, el Estado Plurinacional de Bolivia, el Brasil, Colombia, el Perú, la República Bolivariana de Venezuela, Costa Rica y Panamá, la causalidad es bidireccional (no solo del crecimiento a la inversión sino también en el sentido contrario). En el Uruguay, Honduras, Nicaragua y la República Dominicana, la causalidad es unidireccional: solo el PIB tiene un impacto relevante sobre la inversión en capital fijo. Entre los países donde no se observa ningún sentido de causalidad entre el PIB y el capital fijo se encuentran la Argentina, México, el Paraguay, el Ecuador, Guatemala y el Salvador ${ }^{34}$.

Según el contexto institucional, así como las características del sistema productivo, la relación virtuosa entre distribución, crecimiento e inversión puede variar en intensidad. El hecho de que en las economías con un menor grado de apertura financiera se observe una fuerte relación positiva entre distribución y crecimiento no solo importa desde el punto de vista del diseño de las políticas públicas a nivel nacional, sino que también tiene implicancias para la agenda multilateral. Considerada como un todo, la economía mundial puede concebirse como una economía cerrada. Esto implica que un aumento de la participación de los salarios en el ingreso global debería generar el mismo efecto positivo sobre la demanda agregada y el crecimiento mundial que el aumento de la participación de los salarios en el ingreso nacional en el caso de una economía cerrada. La dificultad para alcanzar esta dinámica de manera conjunta y coordinada a escala internacional es lo que condujo a Raúl Prebisch a plantear la necesidad del principio de "reciprocidad" en la esfera global (Prebisch, 1959). En él se retoma la sugerencia de Keynes (1980) sobre la necesidad de instaurar mecanismos de cooperación multilateral que fuercen a los países superavitarios (acreedores) a afrontar, a través de la expansión del gasto, parte de la responsabilidad de ajustar los desbalances de pagos. De esa manera, se evita que toda la reversión de los desajustes externos recaiga sobre los países deficitarios (deudores).

La coevolución (a la baja) de la participación de la masa salarial en el ingreso y la inversión en los países desarrollados (véase el gráfico III.24) refleja las deficiencias del multilateralismo para resolver de manera colectiva el problema del estancamiento secular ${ }^{35}$. El sesgo recesivo planteado en el capítulo ll está vinculado de manera directa con esta dinámica, que emana de las economías centrales, involucra la desigualdad intensificada de la distribución del ingreso y condiciona profundamente las perspectivas de crecimiento global.

34 En esta inferencia se considera el $5 \%$ de error. Si se considerara el 10\%, el PIB tendría impacto sobre la inversión en capital fijo en los casos de México y el Ecuador.

35 Eggertsson, Mehrotra y Summers (2016) identifican el estancamiento secular con la coexistencia de tasas de interés bajas, tasas de inflación inferiores a las metas de las autoridades monetarias y un ritmo de crecimiento relativamente lento. 
Gráfico III.24

Países desarrollados seleccionados: participación de los salarios en el ingreso y tasa de inversión promedio, 1970-2010

(En porcentajes)

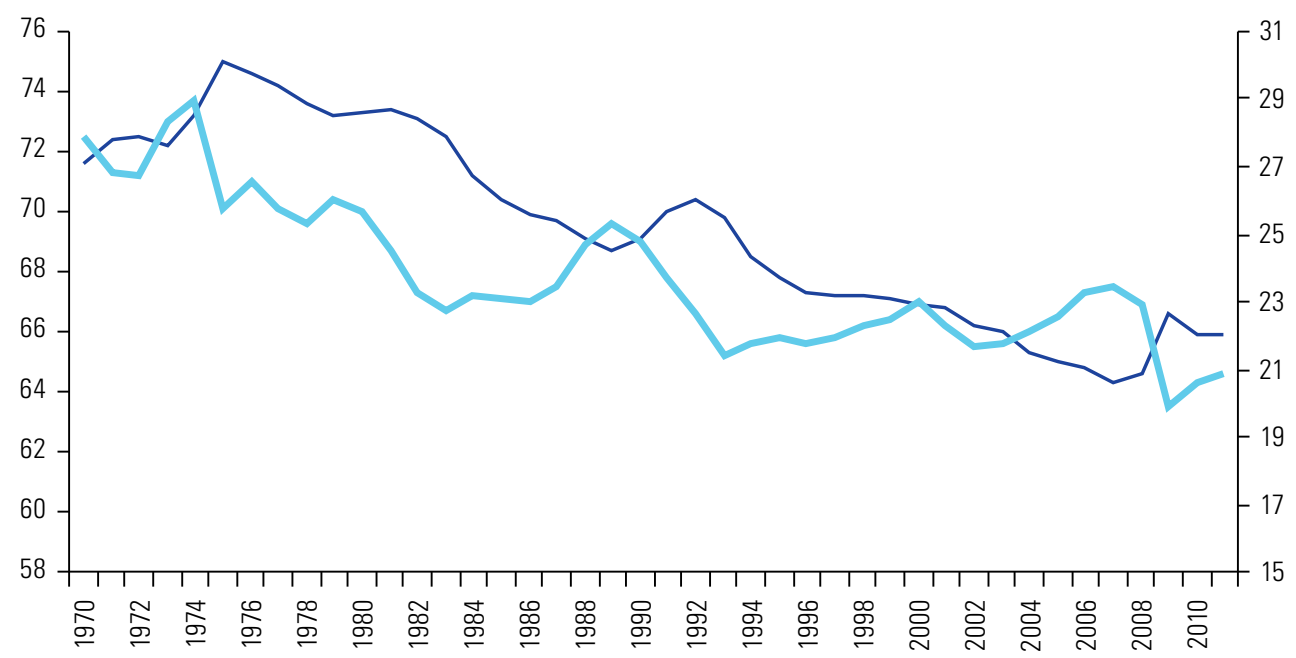

_ Inversión como porcentaje del PIB (eje derecho)

Participación de los salarios en el ingreso (eje izquierdo)

Fuente: Comisión Económica para América Latina y el Caribe (CEPAL), sobre la base de datos de la Organización de Cooperación y Desarrollo Económicos (OCDE) y el Banco Mundial.

a Alemania, Canadá, España, Estados Unidos, Francia, Italia, Japón y Reino Unido.

\section{E. La financierización aumenta la vulnerabilidad externa}

En un contexto de creciente globalización financiera, o financierización, el que los países de la región dependan más del crédito externo aumenta la exposición de estos a los ciclos de liquidez internacional. Existen distintas acepciones del término financierización, vinculadas con diferentes marcos analíticos. En términos generales, se lo asocia con la creciente importancia de los mercados financieros, las instituciones financieras y las élites financieras en el funcionamiento de las economías y sus instituciones de gobernanza, a nivel nacional e internacional (Epstein, 2006). Algunas de sus manifestaciones incluyen un sector financiero global cuyos montos de transacción superan con creces los de la economía real, que está liderado por instituciones financieras grandes y complejas caracterizadas por un elevado grado de interconectividad y concentración, y por una estructura de pasivos sesgada hacia el apalancamiento procíclico.

Partiendo de esta noción general, algunos autores se concentran en el aumento del peso que el sector financiero (que incluye el sector bancario, la industria de seguros y las actividades inmobiliarias) tiene en el producto, con el consecuente crecimiento de los resortes de poder de los actores financieros en ámbitos que trascienden las finanzas (Epstein y Montecino, 2015; Lapavitsas, 2014). Otros autores destacan el impacto del proceso de financierización en el sector no financiero, en particular en las empresas y los hogares. En las empresas, la financierización se manifiesta en una mayor orientación hacia las operaciones financieras, como las de crédito o las actividades de acarreo de divisas (carry trade) (cuya contracara, en ambos casos, sería la caída de las inversiones productivas) ${ }^{36}$. En los hogares, se vincula con un creciente endeudamiento de los trabajadores asalariados, que en un contexto de deterioro de sus ingresos reales tienden a complementar sus salarios con el crédito (Hein, 2012; Stockhammer, 2012). La financierización se asocia también con una lógica de la gobernanza corporativa caracterizada por la prevalencia de los intereses de los accionistas sobre

36 Véanse Orhangazi (2008), y De Souza y Epstein (2014). 
los de la gerencia (Froud y otros, 2006; Aglietta y Bretton, 2001; Epstein y Jorratt, 2016), que trae aparejado un acortamiento de los plazos requeridos para realizar los beneficios de una inversión (cortoplacismo) ${ }^{37}$.

En las economías en desarrollo, la tendencia a la financierización adopta formas asociadas a la posición subordinada de estas en la jerarquía monetaria global (Fischer, 2015; Kaltenbrunner y Painceira, 2016), que otorga un papel fundamental a la apertura de la cuenta financiera de la balanza de pagos. La financierización subordinada (Lapavitsas, 2014) o periférica (Becker y otros, 2010; Rodrigues, Santos y Teles, 2016) remite a las relaciones de dependencia que se ponen de manifiesto con mayor intensidad cuando el ciclo financiero global se constituye en el vector determinante de la dinámica en estas economías y da lugar a un régimen de acumulación dominado por las finanzas internacionales, pero con rasgos específicos. Estos atañen, en lo fundamental, a los efectos que produce la manera de operar del sistema financiero en la economía local y a los cambios que los movimientos de capitales transfronterizos inducen en el comportamiento de los actores (los bancos centrales, los bancos comerciales, las firmas y los hogares, e, incluso, el sistema político).

El concepto de financierización periférica es al capitalismo contemporáneo lo que la noción de capitalismo periférico de Prebisch (1981) era al capitalismo global de fines de la década de 1970. La financierización periférica refleja un conjunto de prácticas económicas caracterizadas por relaciones de subordinación con respecto al ciclo financiero global —y a los actores internos y externos que determinan su dinámica- que inducen cambios de comportamiento en los actores económicos y políticos locales que refuerzan el patrón de especialización existente y aumentan la vulnerabilidad externa. Estos rasgos fueron facilitados por la mayor liberalización de la cuenta financiera que caracterizó a los países de la región en comparación con otras regiones del planeta (CEPAL, 2012).

\section{Financierización periférica y endeudamiento}

En un contexto de financierización periférica, la apertura irrestricta de la cuenta financiera implica que las condiciones de liquidez internacionales (en buena medida derivadas de la política monetaria y la aversión al riesgo imperante en los países centrales) se transmitan prácticamente sin mediaciones hacia la periferia y se constituyan en un determinante fundamental de su dinámica económica de corto plazo ${ }^{38}$. Prebisch (1946) advirtió de forma temprana los riesgos de esta interdependencia cuando se refería a la subordinación de la dinámica económica latinoamericana al movimiento cíclico universal. Esa interdependencia se ha exacerbado en las últimas décadas como consecuencia de la mayor apertura financiera de la región. En momentos de auge, por ejemplo, para neutralizar los efectos negativos del ingreso masivo de capitales (como la apreciación cambiaria), los bancos centrales periféricos acumulan grandes reservas internacionales. Como contrapartida, suelen incurrir en operaciones financieras con los bancos locales que, debido a la alteración de la estructura temporal de sus activos, estimulan el otorgamiento de créditos de corto plazo (en general, para financiar el consumo de los hogares) en detrimento de los créditos de más largo plazo (Kaltenbrunner y Painceira, 2016).

El ingreso masivo de capitales desde el exterior configura un patrón de crecimiento que no necesariamente se traduce en un mayor potencial exportador. El sector privado no financiero, local e internacional, también suele aprovechar las condiciones de liquidez en los mercados globales para financiarse e invertir en activos locales, beneficiándose de los diferenciales en las tasas de retorno, otra vez sin una contrapartida en el plano productivo (Caballero, Panizza y Powell, 2015; Bruno y Shin, 2015; Serena y Moreno, 2016). Así, prevalecen los efectos distorsionadores y desestabilizadores propios de los flujos de capitales de corto plazo, que facilitan la formación de burbujas financieras y dan lugar a procesos de apreciación cambiaria que tienen efectos negativos en la producción (Rajan y Subramanian, 2011; Botta, Godin y Missaglia, 2015). Ha sido en reacción a este tipo de implicancias que algunos organismos internacionales, como el FMI, revisaron su postura en

37 En CEPAL (2010, cap. II) se puede hallar una discusión acerca de la relación entre el cortoplacismo y el deterioro de las inversiones de mayor potencial transformador en América Latina y el Caribe.

38 En estudios recientes se constata que la intensidad y la orientación de los flujos financieros internacionales se encuentra determinada, en mayor medida, por las condiciones globales de liquidez (factores de empuje o push factors) y, en menor medida, por la calidad de las instituciones 0 el buen comportamiento de las variables macroeconómicas fundamentales de cada país (factores de atracción o pull factors) (Aizenmann, Binici y Hutchinson, 2014; Eichengreen y Gupta, 2014; Cerutti, Claessens y Puy, 2015). Véase una revisión de la literatura en Koepke (2015). 
los últimos años para afirmar que la regulación de la cuenta de capital puede ser una herramienta de política necesaria y legítima (FMI, 2015) ${ }^{39}$.

Luego de la crisis de 2008 se produjo un gran crecimiento del mercado global de bonos. Las economías emergentes tuvieron una participación activa en este proceso en tanto su acervo total de emisiones internacionales aumentó de aproximadamente 500.000 millones de dólares en 2000 a aproximadamente 7 billones de dólares en 2016. Esto contrasta con el comportamiento de las economías desarrolladas, en la mayoría de las cuales se redujo el nivel de endeudamiento en el último período.

Un rasgo novedoso de este proceso de endeudamiento fue el papel que jugó el sector privado, cuya importancia relativa como emisor de valores internacionales frente al sector gubernamental aumentó en todas las regiones en desarrollo. Los países de la región no escaparon a los efectos de esta nueva fase del ciclo global de liquidez. La emisión de títulos de la deuda internacional, que se cifraba en 310.000 millones de dólares en el período 2000-2007, aumentó a 761.000 millones en 2017 (la Argentina, el Brasil, Chile, Colombia, México, el Perú y la República Bolivariana de Venezuela representan el 89\% de ese monto). Si bien el gobierno se mantiene como el emisor más importante de deuda internacional, su importancia relativa ha disminuido 40 .

El mayor endeudamiento del sector corporativo no financiero tiene tres consecuencias macroeconómicas para la región. En primer lugar, por encima de ciertos umbrales de deuda, los fondos obtenidos por las empresas no se destinan al financiamiento de inversiones productivas. En segundo lugar, se produce un cambio en la composición de la cuenta financiera de la balanza de pagos, en particular en relación con los flujos de portafolio. A partir de la crisis financiera global, los montos anuales acumulados de flujos asociados a la inversión en bonos, que son más sensibles a los cambios en el contexto externo, sobrepasan los vinculados con las operaciones de préstamo (véase el gráfico III.25).

\section{Gráfico III.25}

América Latina (paises seleccionados): flujos de deuda (bonos) y préstamos bancarios totales correspondientes al sector corporativo no financiero, 2001-2015

(En millones de dólares)

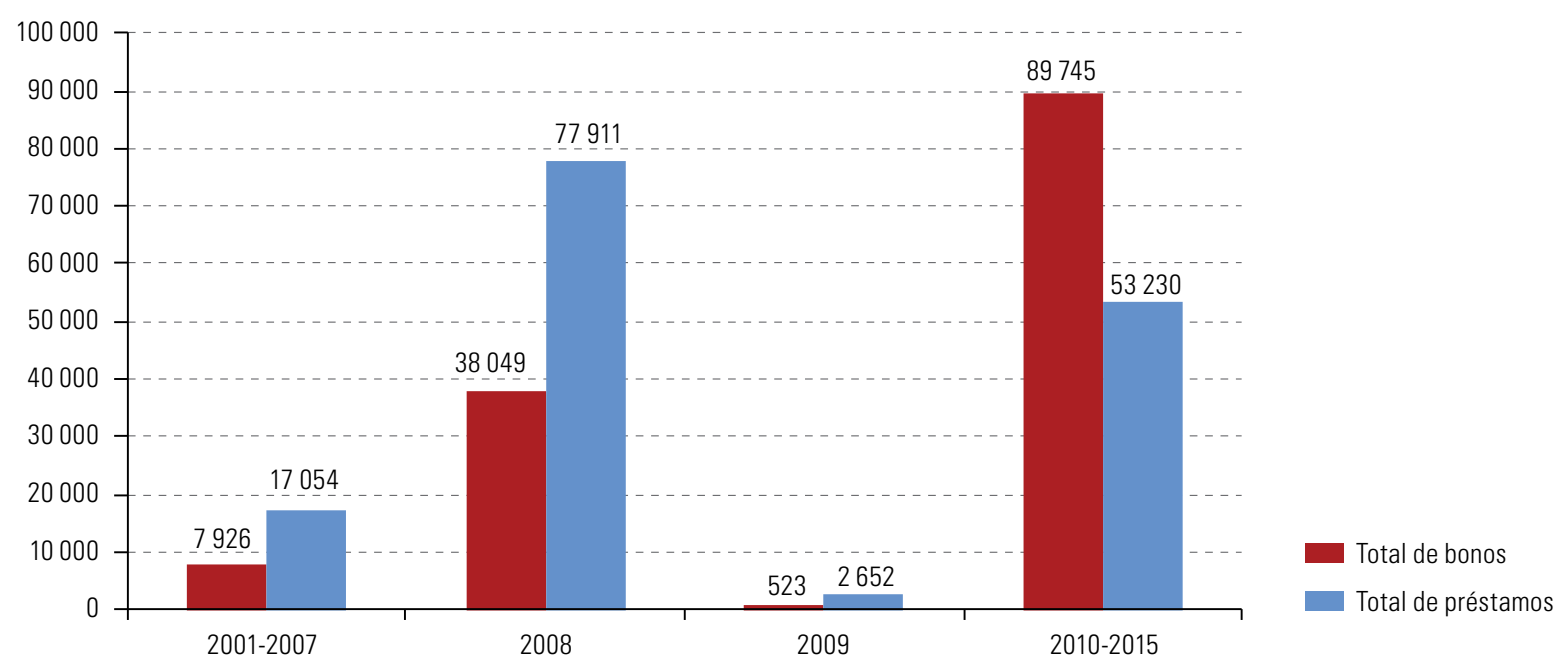

Fuente: Comisión Económica para América Latina y el Caribe (CEPAL), sobre la base de datos del Fondo Monetario Internacional (FMI).

a Argentina, Brasil, Colombia, Chile, México y Perú.

b Sobre la base de información trimestral.

Véase una revisión de la literatura reciente sobre este tema en Bastourre y Zeolla (2017).

40 En América del Sur y Centroamérica, entre el período 2000-2007 y el año 2017, la participación de la deuda pública como porcentaje del total disminuyó del 71,5\% al $44,7 \%$ y del $89,0 \%$ al $57,2 \%$, respectivamente. Mientras tanto, la participación de la deuda del sector corporativo no financiero en la deuda total aumentó del 2,0\% al 6,8\%, en Centroamérica, y del 12,2\% al 25,0\%, en América del Sur. 
Un tercer efecto es el aumento de la fragilidad financiera. Conforme a la metodología de Minsky, en la que se distingue entre estructuras de financiamiento cubiertas (hedged), especulativas y Ponzi, donde las dos últimas son las que implican una mayor fragilidad, la evidencia muestra un aumento de estas, sobre todo en el caso de las empresas más activas en la emisión del mercado de bonos internacional. Del total de empresas que emitieron deuda en los mercados internacionales de bonos, el porcentaje de las que se encontraban en una situación Ponzi aumentó del $13,2 \%$ al $21,1 \%$ entre 2009 y 2015 , y el de las que se hallaban en una situación especulativa, del 48,6\% al 57,1\% (véase el gráfico III.26).

\section{Gráfico III.26}

Proporción de empresas en situación Ponzi, especulativa o cubierta en los mercados internacionales de bonos, 2009-2015

(En porcentajes)

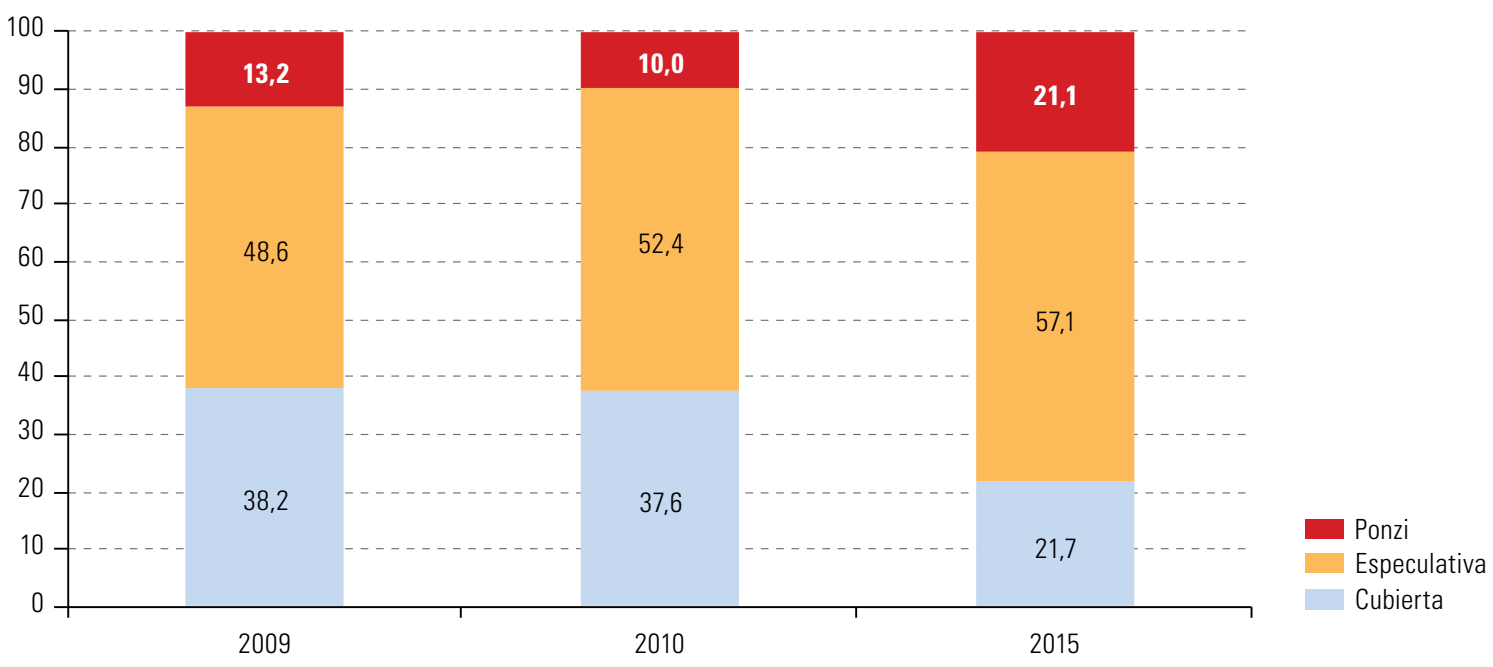

Fuente: Comisión Económica para América Latina y el Caribe (CEPAL), sobre la base de R. Mulligan "A sectoral analysis of the financial instability hypothesis", The Quarterly Review of Economics and Finance, vol. 53, № 4, Amsterdam, Elsevier, 2013; E. Torres Filho, N. Martins y C. Miaguti, "Minsky's financial fragility: an empirical analysis of electricity distribution companies in Brazil (2007-15)", Working Paper, No 896, Annandale-on-Hudson, Levy Economics Institute, 2017.

Otro aspecto que ha caracterizado el proceso de la financierización, sobre todo en los países desarrollados, se vincula con el endeudamiento de los hogares, que, en un contexto de estancamiento o deterioro del salario real, han pasado a financiar parte de su consumo (Boyer, 2000). Este fenómeno, que se caracteriza por una mayor independencia del consumo con respecto al ingreso, se estaría produciendo también en países de América Latina. El sistema financiero y la posibilidad de endeudamiento han dotado al consumo de la capacidad de constituirse en un componente parcialmente autónomo de la demanda y, en consecuencia, en un impulsor del crecimiento económico (CEPAL, 2017a, cap. III).

Este tipo de estrategia tiene una limitación importante que surge de la posibilidad de que el endeudamiento imponga una carga financiera desproporcionada en comparación con el ingreso, lo que puede generar situaciones insostenibles en el tiempo. En los casos del Brasil, Chile y Colombia, la evidencia muestra un aumento de la carga financiera en el período 2006-2016 y un claro aumento del crédito otorgado a los hogares como proporción del PIB en el período 2011-2016 (véase el gráfico III.27) ${ }^{41}$.

41 Entre 2006 y 2016, la carga financiera de los hogares aumentó del 17,4\% al 21,3\% en el Brasil y del 12,9\% al 15,4\% en Chile. En Colombia, aumentó del 21,2\% en 2010 al 22,0\% en 2014 y, en México, del 7,5\% en 2006 al 8,0\% en 2014. El incremento del crédito a los hogares como proporción del PIB fue más pronunciado entre 2011 y 2014: este indicador aumentó del 22,8\% al 23,4\% en el Brasil, del 33,3\% al 40,2\% en Chile, del 20,1\% al 25,2\% en Colombia y del 13,7\% al 15,5\% en México. 


\section{Gráfico III.27}

América Latina (países seleccionados): deuda de los hogares, 2011-2016

(En porcentajes del PIB)

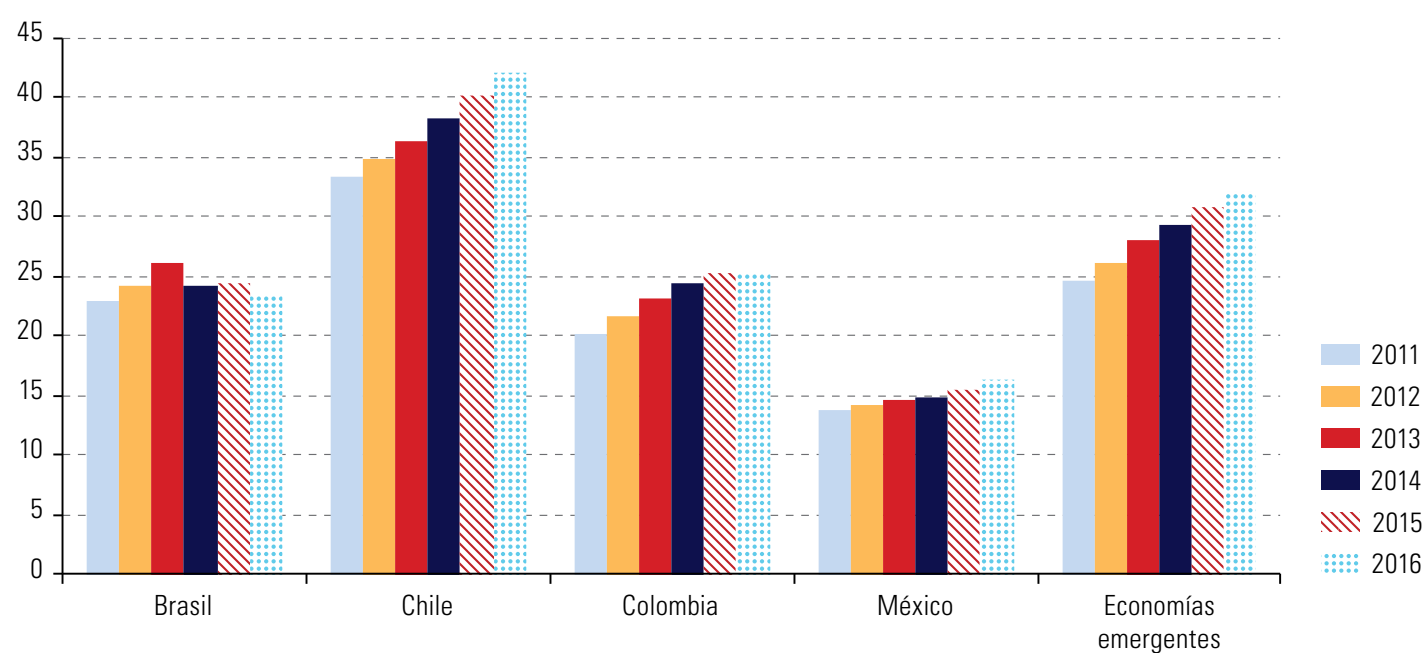

Fuente: Comisión Económica para América Latina y el Caribe (CEPAL), sobre la base de Banco de Pagos Internacionales (BPI), Base de datos Global Liquidity Indicators [en línea] http://www.bis.org/statistics/gli.htm.

\section{Mayor vulnerabilidad externa real y financiera}

Como resultado del endeudamiento externo, la vulnerabilidad externa de la región aumentó. En el gráfico III.28 se descompone la vulnerabilidad externa en sus determinantes reales y financieros ${ }^{42}$. En 21 de los 32 países de la muestra se registró un incremento en el nivel de vulnerabilidad externa real, sin observarse diferencias entre las subregiones. Por otra parte, en 27 de los 32 países se observa una mayor fragilidad financiera externa, aunque con disparidades importantes: los países del Caribe se encuentran en la mayoría de los casos en una situación mucho más vulnerable que los países de Centroamérica y América del Sur.

Las dimensiones real y financiera de la vulnerabilidad externa se retroalimentan, lo que acentúa la restricción externa al crecimiento. Esta retroalimentación puede analizarse extendiendo la ley de Thirlwall para incorporar otros componentes de la balanza de pagos, como los flujos por rentas y transferencias ${ }^{43}$. Una extensión de este tipo es particularmente necesaria en un contexto de creciente financierización, donde los flujos financieros tienden a ser cada vez más importantes en comparación con los flujos reales.

Las modificaciones de la condición de Thirlwall ${ }^{44}$ en lo que respecta a América del Sur muestran que, en general, incluir los flujos por rentas y transferencias hace que la tasa de crecimiento compatible con el equilibrio externo a largo plazo sea inferior a aquella en la que solo se tienen en cuenta los flujos de comercio (véase el gráfico III.29). En Centroamérica y México, en cambio, las trasferencias asociadas a las remesas pueden contrarrestar el déficit por rentas e incluso ampliar los límites al crecimiento compatible con el equilibrio externo. Aun así, la condición de deudores estructurales que caracteriza a todos los países de la región los

42 La vulnerabilidad real se calcula como el peso de las exportaciones primarias en los créditos de la cuenta corriente o el peso de las exportaciones de manufacturas, exportaciones de turismo e ingreso de remesas en los créditos de la cuenta corriente. En relación con cada país, se escoge el mayor de ambos cocientes, conforme a la metodología de Abeles y Valdecantos (2016). La vulnerabilidad externa financiera, por su parte, se calcula como los pasivos externos (incluido el acervo de inversión extranjera directa) menos las reservas internacionales, todo ello en relación con el PIB medido en paridad de poder adquisitivo.

43 Véase una extensión del análisis de la restricción externa a los problemas de financiamiento en Moreno-Brid (1998) y Barbosa-Filho (2001).

44 La condición ampliada Thirlwall se define como $y a^{*}=\frac{\phi_{1} \varepsilon . Z+\phi_{2} r+\phi_{3} t}{\pi}$, donde $\phi_{2}$ y $\phi_{3}$ son la relación de los flujos por rentas y transferencias, respectivamente, respecto a las importaciones, y $r$ y $t$ son la tasa de crecimiento de los flujos por rentas y transferencias, respectivamente. Se supone que el crecimiento mundial y el de los flujos por transferencias es del $2 \%$ y que el crecimiento de los flujos por rentas es del $5 \%$. 
deja en una posición de mayor vulnerabilidad frente a eventuales cambios en el ciclo financiero global, en especial en América del Sur y el Caribe.

Gráfico III.28

América Latina y el Caribe: vulnerabilidad externa real y financiera, 2005-2007 y 2014-2016

(En porcentajes)

\section{A. Vulnerabilidad real}

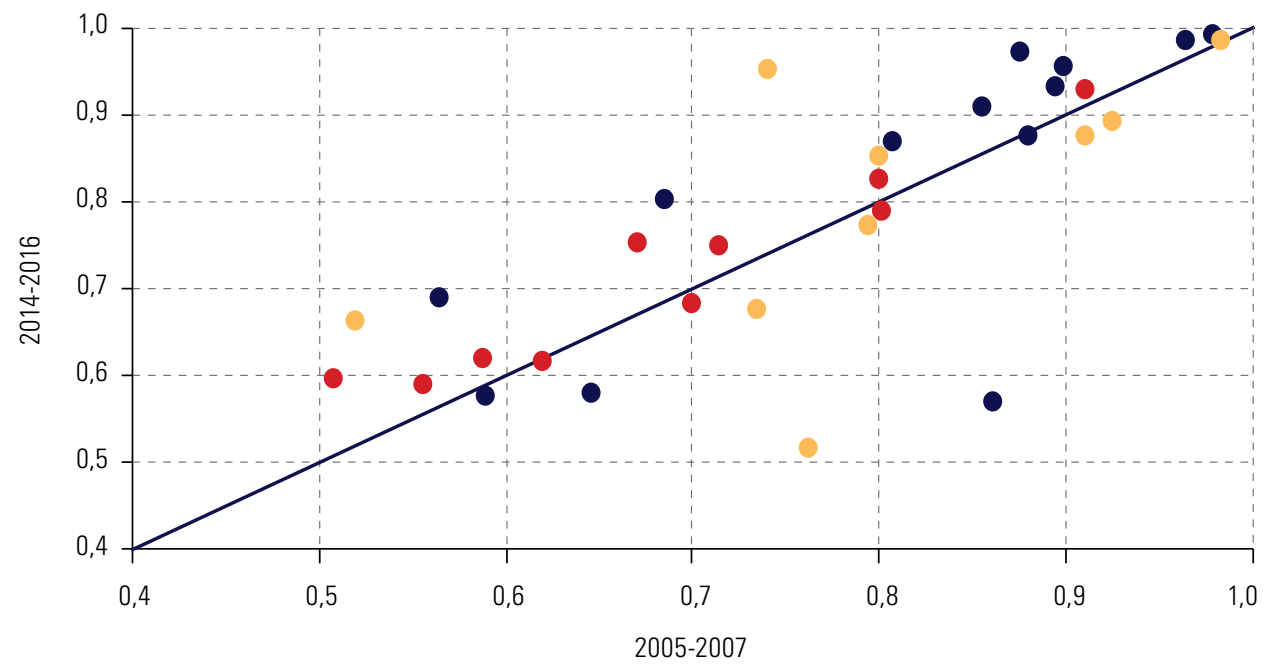

B. Vulnerabilidad financiera

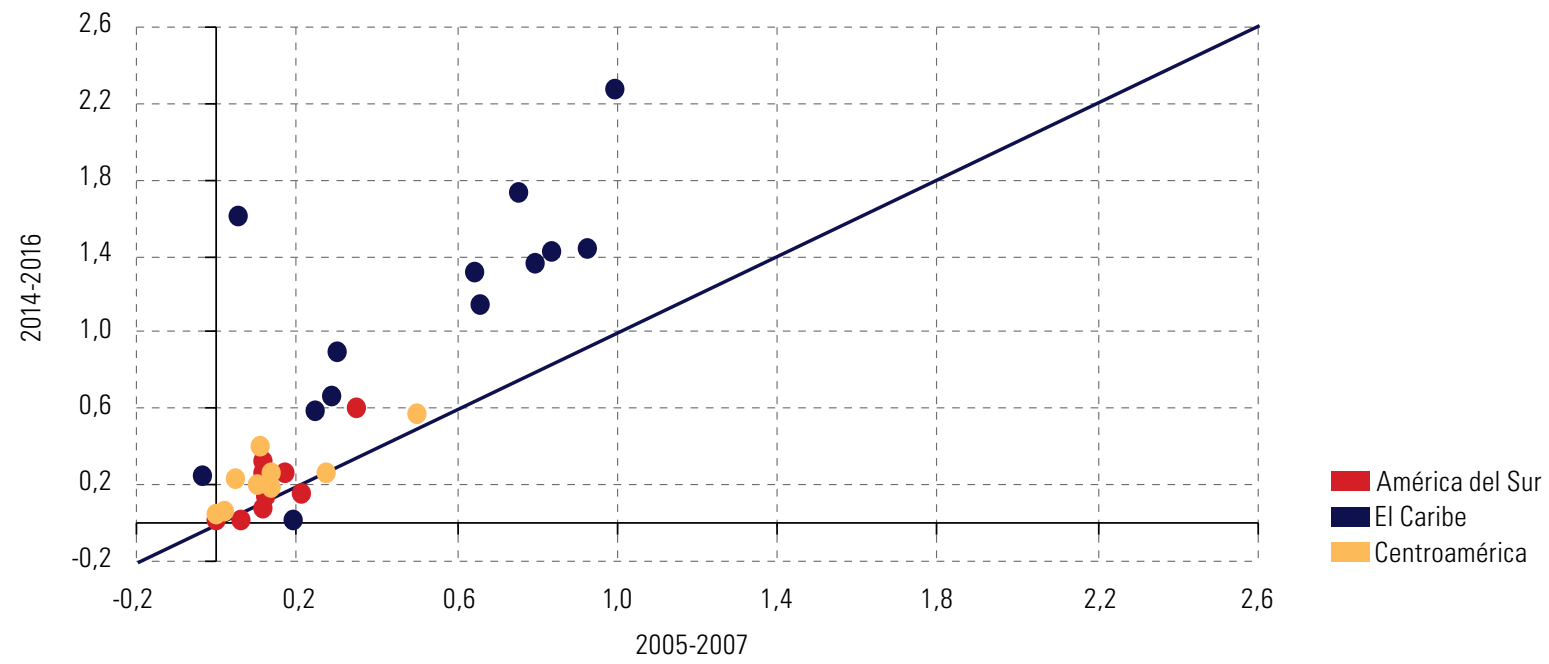

Fuente: Comisión Económica para América Latina y el Caribe (CEPAL), sobre la base de CEPALSTAT [base de datos en línea] http://estadisticas.cepal.org/cepalstat/ Portada.html; Conferencia de las Naciones Unidas sobre Comercio y Desarrollo (UNCTAD); Fondo Monetario Internacional (FMI), Base de datos International Financial Statistics (IFS) [en línea] http://data.imf.org/?sk=4C514D48-B6BA-49ED-8AB9-52B0C1A0179B; Base de datos World Economic Outlook (WE0) [en línea] http://www.imf.org/external/ns/cs.aspx?id=28. 


\section{Gráfico III.29}

América Latina (14 países): condiciones de crecimiento compatibles con el equilibrio externo para el periodo 2000-2016

(En porcentajes)

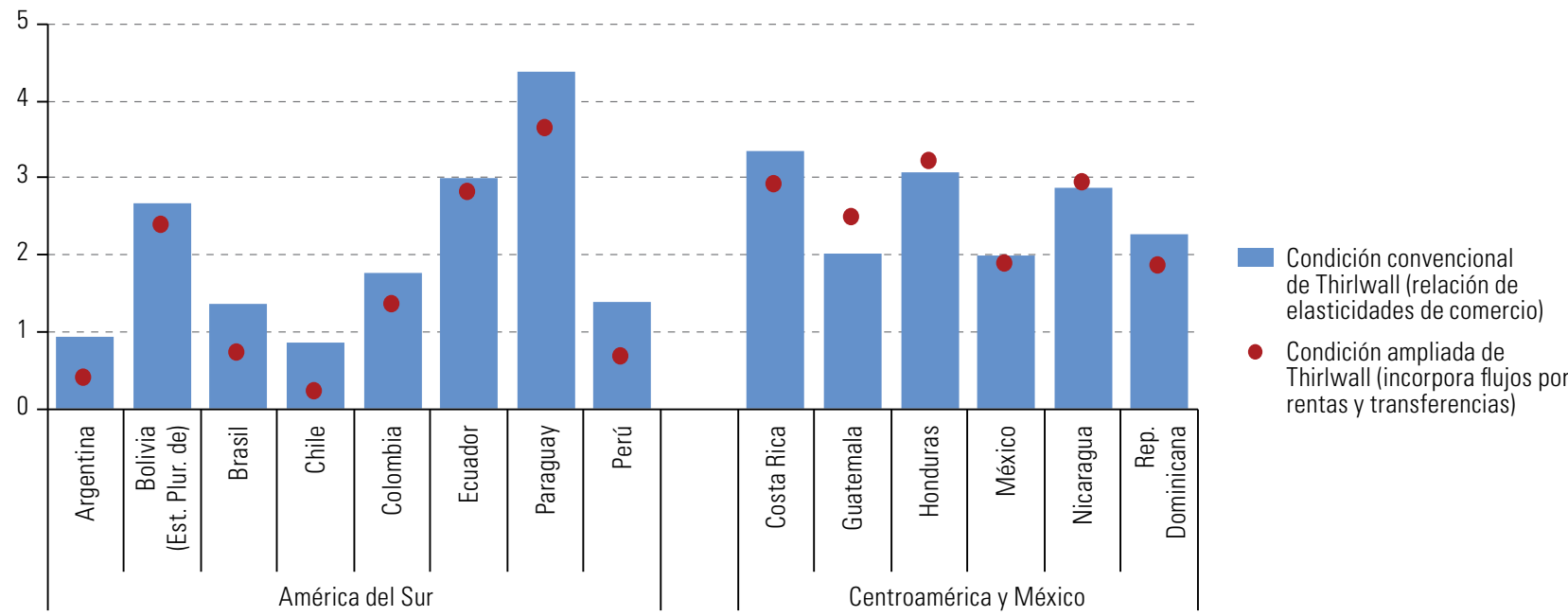

Fuente: Comisión Económica para América Latina y el Caribe (CEPAL), CEPALSTAT [base de datos en línea] http://estadisticas.cepal.org/cepalstat/Portada.html.

\section{Obstáculos para el crecimiento, la inversión y la diversificación productiva en el largo plazo}

Los efectos de la financierización no se limitan al impacto de corto plazo asociado a una mayor vulnerabilidad externa, sino que abarcan procesos que tienden a profundizar problemas estructurales que caracterizan a la región, como la desigualdad, la baja tasa de inversión y el reducido margen de maniobra macroeconómica.

La relación entre el avance de la financierización y el deterioro en la distribución del ingreso en los países desarrollados es uno de los hechos estilizados que se destacan en la literatura (véase el gráfico III.30). Se han identificado tres canales fundamentales mediante los cuales la financierización genera una mayor desigualdad: el cambio en la composición sectorial de la economía, el aumento de los salarios de los altos cargos gerenciales y los beneficios de los rentistas, y el debilitamiento de los sindicatos (Hein, 2012). La relación negativa entre financierización y distribución también parece verificarse en la región: en una muestra de 12 países, la participación asalariada en el ingreso cayó en siete casos entre la década de 1990 y el período 2006-201545.

El efecto negativo que la financierización genera tanto en la inversión productiva como en el gasto en investigación y desarrollo es otro de los hechos estilizados más sobresalientes de los países desarrollados en las últimas décadas (véase el gráfico III.31). Se han destacado diversos canales a través de los cuales el fenómeno afecta la tasa de inversión. Por un lado, los mayores niveles de inversión en activos financieros, que permiten obtener beneficios a más corto plazo, tienden a desplazar la inversión real, que suele tener un horizonte de realización mayor. Los recursos que se aplican al pago de una proporción prácticamente invariable de dividendos (derivado del predominio de los accionistas) también desplaza la inversión real, al reducir la disponibilidad de fondos internos para adquirir activos productivos. Desde una perspectiva dinámica, la aplicación de fondos al pago de intereses por servicios financieros también disminuye el capital disponible para la inversión (Orhangazi, 2008). Esta lógica parece afectar de manera particular el gasto en investigación y desarrollo, que constituye la base para lograr un aumento de la productividad que permita generar empleo y tasas de crecimiento sostenibles, pero que tiene un horizonte de realización cuyo plazo es mucho más largo.

45 Para llevar a cabo esta comparación, se tomaron los promedios correspondientes a los períodos 1990-1999 y 2006-2015. 


\section{Gráfico III.30}

América Latina y el Caribe: relación entre financierización y participación salarial en el ingreso, 1970-2014 (En porcentajes)

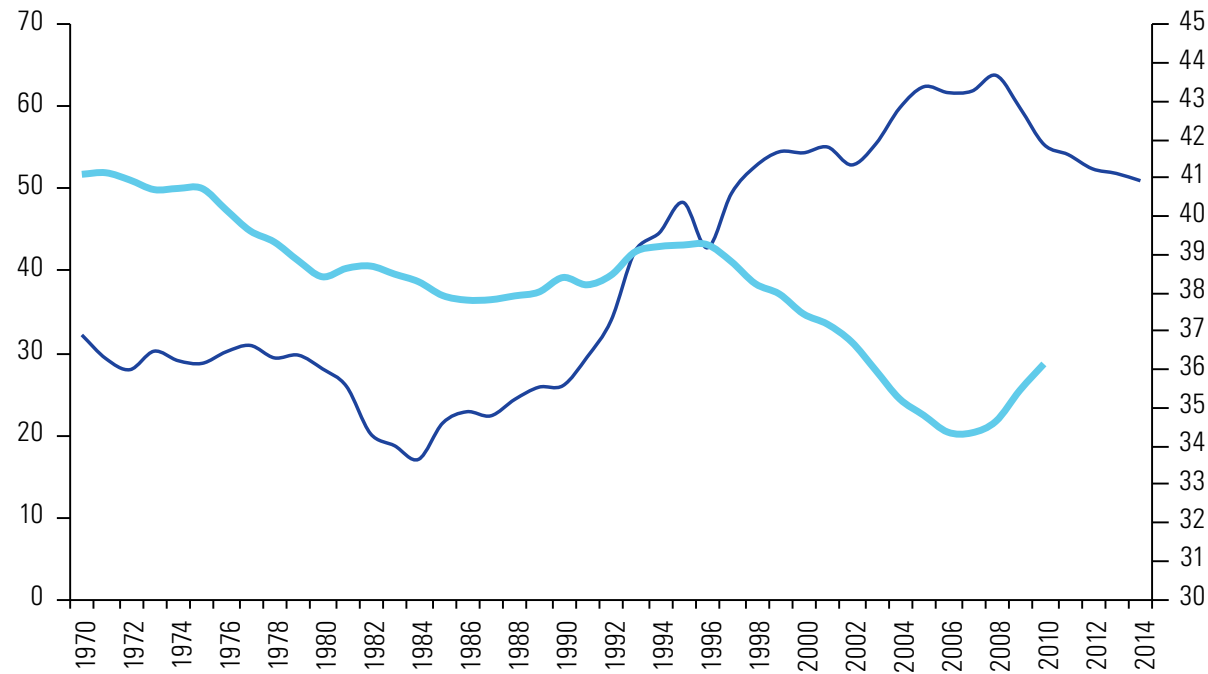

- Distribución funcional del ingreso (media móvil de 5 años, eje derecho)

— Índice de desregulación de la cuenta capital

Fuente: M. D. Chinn y H. Ito, "What matters for financial development? Capital controls, institutions, and interactions", Journal of Development Economics, vol. 81, № 1, Amsterdam, Elsevier, 2006; G. Alarco Tosoni, "Participación salarial y crecimiento económico en América Latina, 1950-2011", Revista CEPAL, № 113 (LC/G.2614-P), Santiago, Comisión Económica para América Latina y el Caribe (CEPAL), 2014.

\section{Gráfico III.31}

América Latina y el Caribe: relación entre financierización e inversión, 1970-2014

(En porcentajes del PIB y en número indice)

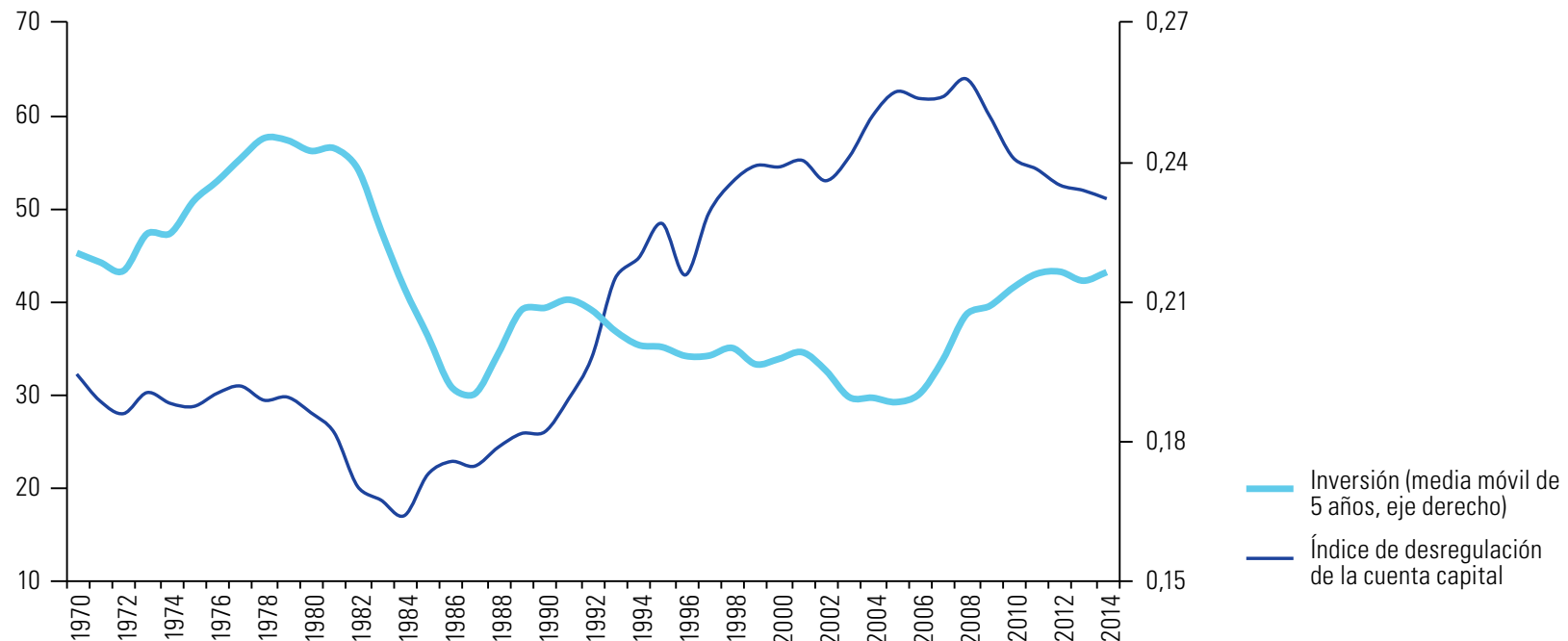

Fuente: M. D. Chinn y H. Ito, "What matters for financial development? Capital controls, institutions, and interactions", Journal of Development Economics, vol. 81, № 1, Amsterdam, Elsevier, 2006; Universidad de Groningen, Base de datos Penn World Table [en línea] https://www.rug.nl/ggdc/productivity/pwt/.

En el escenario de bajo crecimiento en el que se encuentra la región, la posibilidad de aplicar políticas macroeconómicas contracíclicas resulta esencial. Uno de los rasgos de la financierización (periférica) consiste en que la capacidad de los países en desarrollo para llevar adelante una política económica autónoma está muy limitada (Akyüz, 2007). Habida cuenta del predominio de las condiciones globales de liquidez (factores de empuje o push factors) sobre el desempeño macroeconómico de un país (factores de atracción o pull factors), los gobiernos se ven obligados a actuar de forma prudencial, procurando garantizar la estabilidad macrofinanciera de corto plazo, lo que frecuentemente introduce un sesgo procíclico a la política macroeconómica. 
Ese sesgo puede observarse en el gráfico III.32, que se construyó a partir de un panel de datos anuales que van de 2010 en adelante. Ante escenarios de escaso o nulo crecimiento, solo en la mitad de los casos los gobiernos instrumentaron políticas fiscales y monetarias expansivas; en la mayor parte de esos casos, ese impulso fue de baja intensidad ${ }^{46}$. Ello pone de manifiesto las limitaciones de las economías de la región para reaccionar de forma contracíclica o para hacerlo de manera decidida a fin de garantizar un ritmo de crecimiento más estable y elevado.

\section{Gráfico III.32}

América Latina y el Caribe (paises seleccionados): reacciones de política macroeconómica en situaciones de recesiones o desaceleraciones para el periodo $2010-2016^{a}$ (En porcentajes y diferencia anual de la tasa de interés)

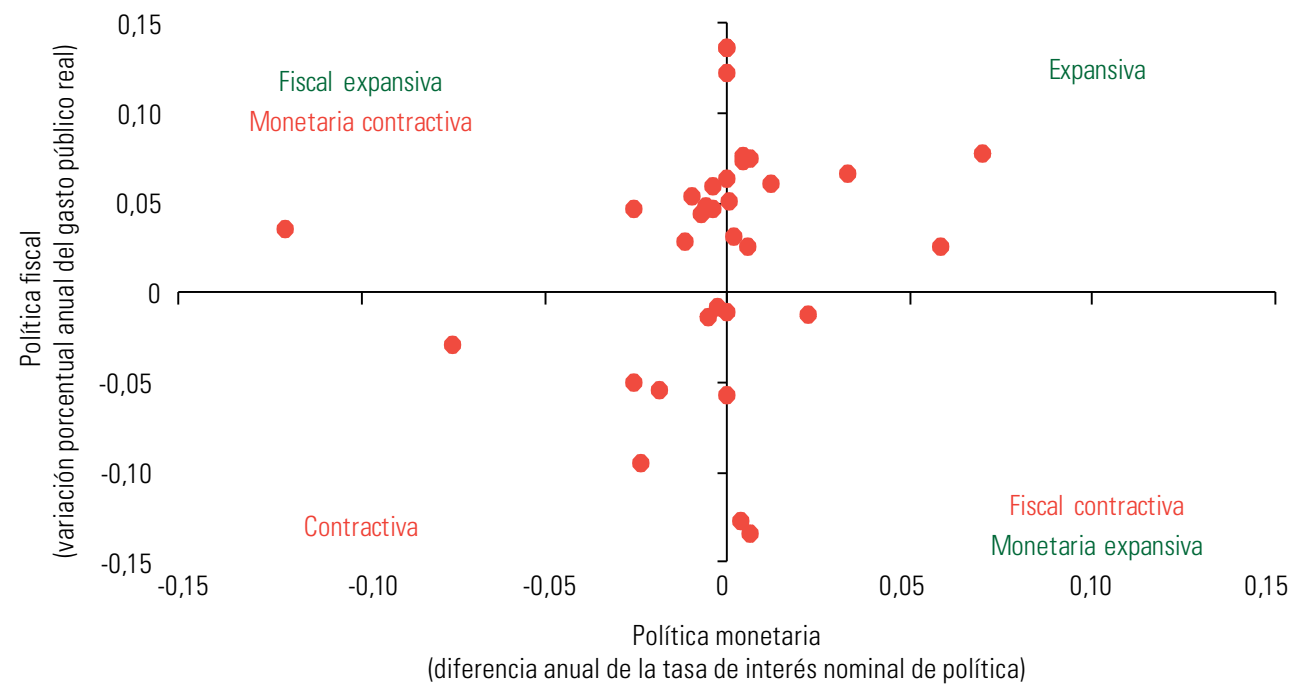

Fuente: Banco Interamericano de Desarrollo (BID) y Comisión Económica para América Latina y el Caribe (CEPAL), CEPALSTAT [base de datos en línea] http://estadisticas. cepal.org/cepalstat/Portada.html

a Argentina, Bahamas, Barbados, Belice, Brasil, Chile, Colombia, Costa Rica, El Salvador, Guatemala, Haití, Jamaica, México, Paraguay, Perú y República Dominicana.

La financierización es un fenómeno insoslayable para comprender el funcionamiento de la economía global. La constatación de un vínculo negativo entre la financierización, la vulnerabilidad externa y varios de los canales neurálgicos del cambio estructural progresivo pone bajo una nueva perspectiva la magnitud de los desafíos que enfrenta la región. La tendencia a la financierización en las últimas décadas, al acentuar la desigualdad, retardar la inversión y reducir el margen de maniobra contracíclico, contribuye a consolidar la dinámica de bajo crecimiento, así como el déficit de inversión resultante, en lugar de atraer capitales para estimular el desarrollo (como afirman los partidarios de las reformas de mercado). En consecuencia, en la agenda de cambio estructural progresivo, además de propender a una articulación más coherente entre las políticas industriales, sociales y ambientales (véase el capítulo VII), se deberá discutir, y eventualmente revisar, con el mismo énfasis, las medidas que en las últimas décadas facilitaron la creciente gravitación de las élites financieras en el funcionamiento de las economías de la región.

46 Los casos en que se registran reacciones contracíclicas tanto en la política fiscal como en la monetaria se concentran en las economías del Caribe. Salvo en algunas excepciones, como en Chile en 2014 y en México en 2013, en las economías de mayor porte de la región no se han observado reacciones contracíclicas de magnitud relevante en momentos de desaceleración o recesión. 


\section{Bibliografía}

Abeles, M., V. Amarante y D. Vega (2014), "Participación del ingreso laboral en el ingreso total en América Latina, 19902010", Revista CEPAL, № 114 (LC/G.2629-P), Santiago, Comisión Económica para América Latina y el Caribe (CEPAL), diciembre.

Abeles, M., A. Arakaki y S. Villafañe (2017), "Distribución funcional del ingreso en América Latina desde una perspectiva sectorial", serie Estudios y Perspectivas-Oficina de la CEPAL en Buenos Aires, No 53 (LC/TS.2017/39; LC/BUE/TS.2017/2), Santiago, Comisión Económica para América Latina y el Caribe (CEPAL), mayo.

Abeles, M. y S. Valdecantos (2016), "Vulnerabilidad externa en América Latina y el Caribe: un análisis estructural", serie Estudios y Perspectivas-Oficina de la CEPAL en Buenos Aires, № 49 (LC/L.4220; LC/BUE/L.228), Santiago, Comisión Económica para América Latina y el Caribe (CEPAL), agosto.

Aglietta, M. y R. Bretton (2001), "Financial systems, corporate control and capital accumulation," Economy and Society, vol. 30, No 4, Routledge, Taylor \& Francis.

Aguilar, P. (2011), "La feminización de la pobreza: conceptualizaciones actuales y potencialidades analíticas", Katálysis, vol. 14, № 1, Santa Catarina, Universidad Federal de Santa Catarina.

Aizenman, J., M. Binici y M. M. Hutchison (2014), "The transmission of Federal Reserve tapering news to emerging financial markets", NBER Working Paper, № 19980, Cambridge, Oficina Nacional de Investigaciones Económicas.

Akyüz, Y. (2014), "Internationalization of finance and changing vulnerabilities in emerging and developing economies", UNCTAD Discussion Paper, No 217, Ginebra, Conferencia de las Naciones Unidas sobre Comercio y Desarrollo (UNCTAD), noviembre.

(2007), "Global rules and markets: constraints over policy autonomy in developing countries", Discussion Paper, $N^{\circ}$ 2007/5, Ankara, Turkish Economic Association, julio.

Alarco Tosoni, G. (2017), "Ciclos distributivos y crecimiento económico en América Latina", Cuadernos de Economía, vol. 36, $N^{\circ} 72$, Bogotá, Universidad Nacional de Colombia.

(2016), "Distribución factorial del ingreso y regímenes de crecimiento en América Latina, 1950-2012", Revista Internacional del Trabajo, vol. 135, № 1, Hoboken, Wiley, marzo.

(2014), "Participación salarial y crecimiento económico en América Latina, 1950-2011", Revista CEPAL, No 113 (LC/ G.2614-P), Santiago, Comisión Económica para América Latina y el Caribe (CEPAL), agosto.

Amarante, V. y J. P. Jiménez (2015), "Desigualdad, concentración y rentas altas en América Latina," Desigualdad, concentración del ingreso y tributación sobre las altas rentas en América Latina, J. P. Jiménez (ed.), Libros de la CEPAL, № 134 (LC/G.2638-P), Santiago, Comisión Económica para América Latina y el Caribe (CEPAL), abril.

Amarante, V. y R. Arim (eds.) (2015), Desigualdad e informalidad: un análisis de cinco experiencias latinoamericanas, Libros de la CEPAL, № 133 (LC/G.2637-P), Santiago, Comisión Económica para América Latina y el Caribe (CEPAL), mayo.

Araújo, E., M. Bruno y D. Pimentel (2012), “Financialization against industrialization: a regulationnist approach of the Brazilian Paradox", Revue de la Régulation, № 11, Grenoble, Universidad Pierre Mendès France.

Araújo, E. y P. Gala (2012), "Regimes de crescimento econômico no Brasil: evidências empíricas e implicações de política", Estudos Avançados, vol. 26, № 75, São Paulo, Universidad de São Paulo, mayo-agosto.

Bairoch, P. y R. Kozul-Wright (1998), "Globalization myths: some historical reflections on integration, industrialization and growth in the world economy", Transnational Corporations and the Global Economy, R. Kozul-Wright y R. Rowthorn (eds.), Berlín, Springer.

Barbosa-Filho, N. (2001), "The balance of payments constraint: from balanced trade to sustainable debt", BNL Quarterly Review, № 219, Roma, Banca Nazionale del Lavoro, diciembre.

Barbosa-Filho, N. y L. Taylor (2006), "Distributive and demand cycles in the US economy: a structuralist Goodwin model", Metroeconomica, vol. 57, No3, Hoboken, Wiley.

Barreix, A., M. Bes y J. Roca (2009), Equidad fiscal en Centroamérica, Panamá y República Dominicana, Washington, D.C., Banco Interamericano de Desarrollo (BID)/Eurosocial.

Bastourre, D. y N. Zeolla (2017), "Regulación de la cuenta capital en un mundo financieramente complejo: evolución reciente y perspectivas en América Latina", serie Estudios y Perspectivas-Oficina de la CEPAL en Buenos Aires, № 52 (LC/L.4289), Santiago, Comisión Económica para América Latina y el Caribe (CEPAL), enero.

Beccaria, L. y otros (2013), "Urban poverty and labor market dynamics in five Latin American countries: 2003-2008", The Journal of Economic Inequality, vol. 11, № 4, Berlín, Springer, diciembre.

Becker, J. y otros (2010), "Peripheral financialization and vulnerability to crisis: a regulationist perspective," Competition \& Change, vol. 14, No 3-4, Thousand Oaks, SAGE Publications.

Bernat, G. (2015), "Tipo de cambio real y diversificación productiva en América del Sur", serie Estudios y PerspectivasOficina de la CEPAL en Buenos Aires, № 43 (LC/L.4031), Santiago, Comisión Económica para América Latina y el Caribe (CEPAL), junio. 
Bertranou, F. y R. Maurizio (2011), "The role of labour market and social protection in reducing inequality and eradicating poverty in Latin America", MPRA Paper, №39843, Munich, Universidad de Munich, agosto.

Bhaduri, A. y S. Marglin (1990), "Unemployment and the real wage: the economic basis for contesting political ideologies", Cambridge Journal of Economics, vol. 14, № 4, Oxford, Oxford University Press, diciembre.

Blecker, R. (2016), "Wage-led versus profit-led demand regimes: the long and the short of it", Review of Keynesian Economics, vol. 4, № 4, Cheltenham, Edward Elgar Publishing.

(1989), "International competition, income distribution and economic growth", Cambridge Journal of Economics, vol. 13, $N^{\circ}$ 3, Oxford, Oxford University Press, septiembre.

Bonizzi, B. (2013), "Financialization in developing and emerging countries: a survey", International Journal of Political Economy, vol. 42, № 4, Routledge, Taylor \& Francis.

Botta, A., A. Godin y M. Missaglia (2015), "Finance, foreign direct investment, and Dutch disease: the case of Colombia", Working Paper, $N^{\circ} 853$, Annandale-on-Hudson, Levy Economics Institute, noviembre.

Boyer, R. (2000), "Is a finance-led growth regime a viable alternative to Fordism? A preliminary analysis", Economy and Society, vol. 29, № 1, Abingdon, Routledge.

Breen, R. y C. García-Peñalosa (2005), "Income inequality and macroeconomic volatility: an empirical investigation", Review of Development Economics, vol. 9, № 3, Hoboken, Wiley, agosto.

Bresser Pereira, L. (2016), "Reflecting on new developmentalism and classical developmentalism", Review of Keynesian Economics, vol. 4, №3, Cheltenham, Edward Elgar Publishing.

(2012), "Summing up structuralist development macroeconomics and new developmentalism", Challenge, vol. 55, $N^{\circ} 5$, Routledge, Taylor \& Francis.

Bruno, V. y H. S. Shin (2015), "Global dollar credit and carry trades: a firm-level analysis", BIS Working Papers, N 510, Basilea, Banco de Pagos Internacionales (BPI), agosto.

Caballero, E. y J. López (2012), "Gasto público, impuesto sobre la renta e inversión privada en México", Investigación Económica, vol. 71, № 280, Ciudad de México, Universidad Nacional Autónoma de México (UNAM), abril-junio.

Caballero, J., U. Panizza y A. Powell (2015), "The second wave of global liquidity: why are firms acting like financial intermediaries?", Working Paper, NN HEIDWP21-2015, Ginebra, Graduate Institute of International and Development Studies, octubre.

Campos, R., E. Chávez y G. Esquivel (2014), "Los ingresos altos, la tributación óptima y la recaudación posible", documento preparado para el Premio Nacional de Finanzas Públicas, Ciudad de México, Centro de Estudios de las Finanzas Públicas (CEFP), agosto.

Castillo, M. y A. Martins (2016), "Premature deindustrialization in Latin America", serie Desarrollo Productivo, № 205 (LC/L.4183), Santiago, Comisión Económica para América Latina y el Caribe (CEPAL), junio.

CEPAL (Comisión Económica para América Latina y el Caribe) (2018), Balance Preliminar de las Economías de América Latina y el Caribe, 2017 (LC/PUB.2017/28-P), Santiago (2017a), Estudio Económico de América Latina y el Caribe, 2017 (LC/PUB.2017/17-P), Santiago, septiembre. (2017b), Panorama Fiscal de América Latina y el Caribe, 2017 (LC/PUB.2017/6-P), Santiago, marzo. (2016a), Autonomía de las mujeres e igualdad en la agenda de desarrollo sostenible (LC/G.2686/Rev.1), Santiago, diciembre.

(2016b), Panorama Social de América Latina, 2016 (LC/PUB.2017/12-P), Santiago, agosto.

(2016c), La matriz de la desigualdad social en América Latina (LC/G.2690.MDS.1/2), Santiago, octubre.

(2016d), Panorama Fiscal de América Latina y el Caribe, 2016 (LC/L.4140), Santiago, marzo.

(2016e), Ciencia, tecnología e innovación en la economía digital: la situación de América Latina y el Caribe (LC/ G.2685(CCITIC.2/3)), Santiago, septiembre.

(2016f), Horizontes 2030: la igualdad en el centro del desarrollo sostenible (LC/G.2660/ Rev.1), Santiago, julio.

(2012), Cambio estructural para la igualdad: una visión integrada del desarrollo (LC/G.2524(SES.34/3)), Santiago, julio.

(2010), La hora de la igualdad: brechas por cerrar, caminos por abrir (LC/G.2432(SES.33/3)), Santiago, mayo.

(2007), "Progreso técnico y cambio estructural en América Latina", Documentos de Proyectos (LCM.136), Santiago, octubre.

(2004), "Entender la pobreza desde la perspectiva de género," serie Mujer y Desarrollo, № 52 (LC/L.2063-P), Santiago, enero.

Cerutti, E., S. Claessens y D. Puy (2015), "Push factors and capital flows to emerging markets: why knowing your lender matters more than fundamentals", IMF Working Paper, NN 15-127, Washington, D.C., Fondo Monetario Internacional (FMI), junio.

Chinn, M. D., y H. Ito (2008), "A new measure of financial openness", Journal of Comparative Policy Analysis: Research and Practice, vol. 10, №3, Routledge, Taylor \& Francis, septiembre.

(2006), "What matters for financial development? Capital controls, institutions, and interactions", Journal of Development Economics, vol. 81, № 1, Amsterdam, Elsevier, octubre. 
Davis, L. (2013), “Financialization and the nonfinancial corporation: an investigation of firm-level investment behavior in the U.S., 1971-2011", Economics Department Working Paper series, № 2013-08, Amherst, Universidad de Massachusetts Amherst, agosto.

Demir, F. (2009), “Financial liberalization, private investment and portfolio choice: financialization of real sectors in emerging markets", Journal of Development Economics, vol. 88, № 2, Amsterdam, Elsevier, marzo.

De Souza, J. P. y G. Epstein (2014), "Sectoral net lending in six financial centers", PERI Working Paper series, N 346 , Amherst, Universidad de Massachusetts Amherst, marzo.

Dünhaupt, P. (2013), “The effect of financialization on labor's share of income", Working Paper, N 17/2013, Berlín, Berlin Institute for International Political Economy (IPE).

Eatwell, J. y L. Taylor (2001), Global Finance at Risk: The Case for International Regulation, Nueva York, The New Press.

Eggertsson, G., N. Mehrotra y L. Summers (2016), "Secular stagnation in the open economy", American Economic Review, vol. 106, №5, Pittsburgh, Asociación Estadounidense de Economía, mayo.

Eichengreen, B. (2001), "Capital account liberalization: what do cross-country studies tell us?", The World Bank Economic Review, vol. 15, N³, Washington, D.C., Banco Mundial, septiembre.

Eichengreen, B. y P. Gupta (2014), "Tapering talk: the impact of expectations of reduced federal reserve security purchases on emerging markets", Emerging Markets Review, vol. 25, Amsterdam, Elsevier, diciembre.

Epstein, G. (ed.) (2006), Financialization and the World Economy, Northampton, Edward Elgar.

Epstein, G. y J. A. Montecino (2015), "Banking from financial crisis to Dodd-Frank: five years on, how much has changed?", PERI Working Paper series, Amherst, Universidad de Massachusetts Amherst, julio.

Fairfield, T. y M. Jorratt (2016), "Top income shares, business profits, and effective tax rates in contemporary Chile", The Review of Income and Wealth, vol. 62, N S1, Hoboken, Wiley, agosto.

Feenstra, R., R. Inklaar y M. Timmer (2015), "The next generation of the Penn World Table", American Economic Review, vol. 105, N 10, Pittsburgh, Asociación Estadounidense de Economía [en línea] https://www.rug.nl/ggdc/docs/the_next_ generation_of_the_penn_world_table.pdf.

Fischer, A. (2015), "The end of peripheries? On the enduring relevance of structuralism for understanding contemporary global development", Development and Change, vol. 46, Hoboken, Wiley.

Fischer, S. (1998), "Capital account liberalization and the role of the IMF", Should the IMF pursue capital account convertibility?, S. Fischer y otros, Essays in International Finance, N²07, Princeton, Universidad de Princeton, mayo.

FMI (Fondo Monetario Internacional) (2015), “Managing capital outflows: further operational considerations”, IMF Policy Paper, Washington, D.C., diciembre.

Fraser, N. (2016), “Contradictions of capital and care", New Left Review, N 100, Londres, julio-agosto.

Frenkel, R. y J. Ros (2006), “Unemployment and the real exchange rate in Latin America”, World Development, vol. 34, $N^{\circ} 4$, Amsterdam, Elsevier, abril.

Froud, J. y otros (2006), Financialization and Strategy: Narrative and Numbers, Nueva York, Routledge.

Furceri, D. y P. Loungani (2015), "Capital account liberalization and inequality", IMF Working Paper, N 15/243, Washington, D.C., Fondo Monetario Internacional (FMI), noviembre.

Gómez Sabaini, J., J. Jiménez y D. Rossignolo (2012), “Imposición a la renta personal y equidad en América Latina: nuevos desafíos", serie Macroeconomía del Desarrollo, № 119 (LC/L.3477-P), Santiago, Comisión Económica para América Latina y el Caribe (CEPAL), julio.

Gómez Sabaini, J. y D. Morán (2013), "Política tributaria en América Latina: agenda para una segunda generación de reformas", serie Macroeconomía del Desarrollo, N 133 (LC/G.3632), Santiago, Comisión Económica para América Latina y el Caribe (CEPAL), junio.

Goñi, E., J. López y L. Servén (2011), "Fiscal redistribution and income inequality in Latin America", World Development, vol. 39, N 9, Amsterdam, Elsevier, septiembre.

Hall, R. (1988), "Intertemporal substitution in consumption", Journal of Political Economy, vol. 96, № 2, Chicago, University of Chicago Press, abril.

Hanni, M., R. Martner y A. Podestá (2017), "La incidencia distributiva de la fiscalidad en América Latina", Consensos y conflictos en la política tributaria de América Latina, J. Gómez Sabaini, J. Jiménez y R. Martner (eds.), Libros de la CEPAL, N 142 (LC/PUB.2017/5-P), Santiago, Comisión Económica para América Latina y el Caribe (CEPAL), marzo. (2014), "El impacto redistributivo de la acción fiscal en América Latina: los efectos de impuestos y transferencias públicas", Los efectos de la política fiscal sobre la redistribución en América Latina y la Unión Europea, Colección Estudios, N8, Madrid, Programa EUROsociAL, septiembre.

Hanni, M. y A. Podestá (2016), “Flujos financieros ilícitos en los países andinos: una mirada al sector minero", Documentos de Proyectos (LCM.724), Santiago, Comisión Económica para América Latina y el Caribe (CEPAL), diciembre.

Hansen, B. (1999), "Threshold effects in non-dynamic panels: estimation, testing and inference", Journal of Econometrics, vol. 93, N², Amsterdam, Elsevier, diciembre. 
Hein, E. (2015), "Finance-dominated capitalism and re-distribution of income: a Kaleckian perspective", Cambridge Journal of Economics, vol. 39, N 3, Oxford, Oxford University Press, mayo.

(2012), "Finance-dominated capitalism, re-distribution, household debt and financial fragility in a Kaleckian distribution and growth model", PSL Quarterly Review, vol. 65, №260, Roma.

Joumard, I., M. Pisu y D. Bloch (2012), "Less income inequality and more growth: are they compatible? Part 3. Income redistribution via taxes and transfers across OECD countries", OECD Economics Department Working Papers, № 926, París, Organización de Cooperación y Desarrollo Económicos (OCDE), enero.

Kaltenbrunner, A. y J. Painceira (2016), "International and domestic financialisation in middle income countries: the Brazilian experience", Working Paper series, № 146, Financialisation, Economy, Society and Sustainable Development (FESSUD).

Kapsos, S. (2005), "The employment intensity of growth: trends and macroeconomic determinants", Employment Strategy Paper, № 2005/12, Ginebra, Organización Internacional del Trabajo (OIT).

Keynes, J. (1980), "Activities 1940-1944. Shaping the post-war world: the clearing union", The Collected Writings of John Maynard Keynes, vol. 25, Londres, Macmillan.

Kiefer, D. y C. Rada (2015), "Profit maximising goes global: the race to the bottom", Cambridge Journal of Economics, vol. 39, N 5, Oxford, Oxford University Press, septiembre.

Koepke, R. (2015), "What drives capital flows to emerging markets? A survey of the empirical literature", MPRA Paper, $N^{\circ}$ 62770, Munich, Universidad de Munich, abril.

Kose, M., E. Prasad y M. Terrones (2008), "Does openness to international financial flows raise productivity growth?", NBER Working Paper, № 14558, Cambridge, Oficina Nacional de Investigaciones Económicas, diciembre.

Kose, M. y otros (2006), "Financial globalization: a reappraisal", NBER Working Paper, No 12484, Cambridge, Oficina Nacional de Investigaciones Económicas, agosto.

Lapavitsas, C. (2014), Profiting without producing: how finance exploits us all, Nueva York, Verso Books.

Lustig, N., C. Pessino y J. Scott (2013), "The impact of taxes and social spending on inequality and poverty in Argentina, Bolivia, Brazil, Mexico, Peru and Uruguay: an overview", CEQ Working Paper, № 13, Nueva Orleans, Universidad Tulane, abril.

Martínez, R. (2017), Institucionalidad social en América Latina y el Caribe, Libros de la CEPAL, № 146 (LC/PUB.2017/14-P), Santiago, Comisión Económica para América Latina y el Caribe (CEPAL), octubre.

McKinnon, R. (1973), Money and Capital in Economic Development, Washington, D.C., Brookings Institution Press.

Medeiros, M. y J. Costa (2008), "Is there a feminization of poverty in Latin America?", World Development, vol. 36, N 1, Amsterdam, Elsevier, enero.

Medeiros, C. y N. Trebat (2018), "Finance, trade, and income distribution in global value chains: implications for developing economies and Latin America," Estudios sobre financierización en América Latina, M. Abeles (ed.), Santiago, Comisión Económica para América Latina y el Caribe (CEPAL), en prensa.

Milberg, W. y D. Winkler (2013), Outsourcing Economics. Global Value Chains in Capitalist Development, Cambridge, Cambridge University Press.

Moreno-Brid, J. (1998), "On capital flows and the balance of payments constrained growth model," Journal of Post Keynesian Economics, vol. 21, № 2, Routledge, Taylor \& Francis.

Morgan, M. (2017), "Extreme and persistent inequality: new evidence for Brazil combining national accounts, surveys and fiscal data, 2001-2015", WID.world Working Paper, N²017/12, World Wealth and Income Database (WID.world).

Mulligan, R. (2013), "A sectoral analysis of the financial instability hypothesis", The Quarterly Review of Economics and Finance, vol. 53, № 4, Amsterdam, Elsevier, noviembre.

Ocampo, J. A. (2013), "Macroeconomía para el desarrollo: políticas anticíclicas y transformación productiva", Reflexiones sobre el desarrollo en América Latina y el Caribe: conferencias magistrales 2011-2012 (LC/G. 2563), Santiago, Comisión Económica para América Latina y el Caribe (CEPAL), enero.

(2011), “¿Cómo fue el desempeño de América Latina durante la crisis financiera global?", Ensayos Económicos, № 6162, Buenos Aires, Banco Central de la República Argentina, enero-junio.

OCDE (Organización de Cooperación y Desarrollo Económicos) (2015), Measuring and Monitoring BEPS. ACTION 11: 2015 Final Report, París.

Onaran, Ö. y G. Galanis (2012), "Is aggregate demand wage-led or profit-led? National and global effects", Conditions of Work and Employment series, No 40, Ginebra, Organización Internacional del Trabajo (OIT), octubre.

Onaran, Ö., E. Stockhammer y L. Grafl (2011), "Financialisation, income distribution and aggregate demand in the USA", Cambridge Journal of Economics, vol. 35, № 4, Oxford, Oxford University Press, julio.

Orhangazi, Ö. (2008), "Financialisation and capital accumulation in the non-financial corporate sector. A theoretical and empirical investigation on the US economy: 1973-2003", Cambridge Journal of Economics, vol. 32, № 6, Oxford, Oxford University Press, noviembre.

Palma, J. (2014), "De-industrialisation, 'premature' de-industrialisation and the Dutch-disease", Revista NECAT, vol. 3, N ${ }^{\circ}$, Santa Catarina, Universidad Federal de Santa Catarina, enero-junio. 
Pérez Caldentey, E., N. Favreau Negront y L. Mendez (2017), “Deuda del sector corporativo no financiero en América Latina y sus posibles implicaciones macroeconómicas", documento presentado en el taller ¿Cómo Dinamizar el Crecimiento Económico de América Latina y el Caribe?, Santiago, Comisión Económica para América Latina y el Caribe (CEPAL), 3 y 4 de octubre.

Prasad, E., R. Rajan y A. Subramanian (2007), "Foreign capital and economic growth", NBER Working Paper, N 13619, Cambridge, Oficina Nacional de Investigaciones Económicas, noviembre.

Prebisch, R. (1981), Capitalismo periférico: Crisis y transformación, Ciudad de México, Comisión Económica para América Latina y el Caribe (CEPAL)/Fondo de Cultura Económica.

(1959), El mercado común latinoamericano (E/CN.12/531), Santiago, Comisión Económica para América Latina y el Caribe (CEPAL), julio.

(1946), "Panorama general de los problemas de regulación monetaria y crediticia en el continente americano: América Latina", Memoria: Primera Reunión de Técnicos sobre Problemas de Banca Central del Continente Americano, Ciudad de México, Banco de México.

Rajan, R. y A. Subramanian (2011), "Aid, Dutch disease and manufacturing growth", Journal of Development Economics, vol. 94, No 1, Amsterdam, Elsevier, enero.

Razmi, A., M. Rapetti y P. Skott (2012), "The real exchange rate and economic development", Structural Change and Economic Dynamics, vol. 23, № 2, Amsterdam, Elsevier, junio.

Reyes, L. (2018), “ ¿Wage-led, profit-led o export-led? Un análisis empírico sobre los regímenes de crecimiento en América Latina", serie Estudios y Perspectivas-Oficina de la CEPAL en Buenos Aires, Santiago, Comisión Económica para América Latina y el Caribe (CEPAL), en prensa.

Rodrigues, J., A. Santos y N. Teles (2016), "Semi-peripheral financialisation: the case of Portugal," Review of International Political Economy, vol. 23, №3, Routledge, Taylor \& Francis.

Rodríguez Enríquez, C. (2012), “La cuestión del cuidado: ¿el eslabón perdido del análisis económico?", Revista CEPAL, N 106 (LC/G.2518-P), Santiago, Comisión Económica para América Latina y el Caribe (CEPAL), abril.

Rodrik, D. (1998), "Who needs capital-account convertibility?", Should the IMF Pursue Capital-Account Convertibility?, S. Fischer y otros, Essays in International Finance, N²07, Princeton, Universidad de Princeton, mayo.

Ros, J. (2016), "The real exchange rate, the real wage, and growth: a formal analysis of the 'development channel',' Macroeconomics and Development: Roberto Frenkel and the Economics of Latin America, M. Damil, M. Rapetti y G. Rozenwurcel (eds.), Nueva York, Columbia University Press.

Rossignolo, D., N. Oliva y N. Villacreses (2016), "Cálculo de la concentración de los altos ingresos sobre la base de los datos impositivos: un análisis para el Ecuador", serie Macroeconomía del Desarrollo, No 184 (LC/L.4278), Santiago, Comisión Económica para América Latina y el Caribe (CEPAL), diciembre.

Schumpeter, J. (1954), “The crisis of the tax state”, International Economic Papers, N 4, A. Peacock y otros (eds.), Londres, Macmillan.

Sepúlveda, C. y J. Martinez-Vazquez (2012), “Explaining property tax collections in developing countries: the case of Latin America", Decentralization and Reform in Latin America: Improving Intergovernmental Relations, G. Brosio y J. Jiménez (eds.), Chelthenham, Edward Elgar.

Serena, J. y R. Moreno (2016), “Domestic financial markets and offshore bond financing", BIS Quarterly Review, Basilea, Banco de Pagos Internacionales (BPI), septiembre.

Shaw, E. (1973), Financial Deepening in Economic Development, Nueva York, Oxford University Press.

Shin, H. Y. (2012), "Essays on the causes and consequences of the Asian financial crisis: financialization, stagnant corporate investment, and alternative measures of the Asian labor markets", tesis de doctorado en filosofía, Nueva York, New School University, febrero.

Steiner, A. y T. Saadma (2016), "Measuring de facto financial openness: a new index", Munich, Universidad de Munich [en línea] https://editorialexpress.com/cgi-bin/conference/download.cgi?db_name=EEAESEM2016\&paper_id=2412.

Stockhammer, E. (2012), "Financialization, income distribution and the crisis", Investigación Económica, vol. 71, № 279, Ciudad de México, Universidad Nacional Autónoma de México (UNAM), enero-marzo.

(2011), "Neoliberalism, income distribution and the causes of the crisis", The Financial Crisis: Origins and Implications, P. Arestis, R. Sobreira y J. L. Oreiro (eds.), Berlín, Springer.

(2009), "The finance-dominated accumulation regime, income distribution and the present crisis", Papeles de Europa, vol. 19, Madrid, Universidad Complutense de Madrid.

(2004), "Financialisation and the slowdown of accumulation", Cambridge Journal of Economics, vol. 28, N 5, Oxford, Oxford University Press, septiembre. Stockhammer, E., Ö. Onaran y S. Ederer (2009), “Functional income distribution and aggregate demand in the Euro area", Cambridge Journal of Economics, vol. 33, № 1, Oxford, Oxford University Press, enero. 
Summers, L. (2000), “International financial crises: causes, prevention, and cures", American Economic Review, vol. 90, $N^{\circ} 2$, Pittsburgh, Asociación Estadounidense de Economía, mayo.

Tan, J. (2014), “Running out of steam? Manufacturing in Malaysia," Cambridge Journal of Economics, vol. 38, N 1, Oxford, Oxford University Press, enero.

Thirlwall, A. (1979), "The balance of payments constraint as an explanation of the international growth rate differences", PSL Quarterly Review, vol. 32, No 128, Roma.

Tori, D. y Ö. Onaran (2015), "The effects of financialization on investment: evidence from firm-level data for the UK", Working Paper, No 1601, Leeds, Post Keynesian Economics Study Group (PKSG), enero.

Torres, E., N. Montani y C. Yukari (2017), “Minsky's financial fragility: an empirical analysis of electricity distribution companies in Brazil (2007-15)", Working Paper, № 896, Annandale-on-Hudson, Levy Economics Institute, septiembre.

UNCTAD (Conferencia de las Naciones Unidas sobre Comercio y Desarrollo) (2015), "An FDI-driven approach to measuring the scale and economic impact of BEPS", Working Paper, Ginebra, marzo.

Vázconez, A. (2012), "Mujeres, hombres, y las economías latinoamericanas: un análisis de dimensiones y políticas", La economía feminista desde América Latina: una hoja de ruta sobre los debates actuales en la región, V. Esquivel y otros (eds.), Santo Domingo, Entidad de las Naciones Unidas para la Igualdad de Género y el Empoderamiento de las Mujeres (ONU-Mujeres), junio.

Villatoro, P. y S. Cecchini (2018), “Discrepancias entre encuestas y registros: ¿cuál es el alcance de las transferencias no contributivas en América Latina?", serie Estudios Estadísticos, Santiago, Comisión Económica para América Latina y el Caribe (CEPAL), en prensa.

Weller, J. (2014), "Aspectos de la evolución reciente de los mercados laborales de América Latina y el Caribe", Revista CEPAL, N¹14 (LC/G.2629-P), Santiago, Comisión Económica para América Latina y el Caribe (CEPAL), diciembre.

Wichterich, C. (2012), "The other financial crisis: growth and crash of the microfinance sector in India", Development, vol. 55, $N^{\circ} 3$, Berlín, Springer, septiembre.

Zucman, G. (2015), The Hidden Wealth of Nations: The Scourge of Tax Havens, Chicago, University of Chicago Press. 


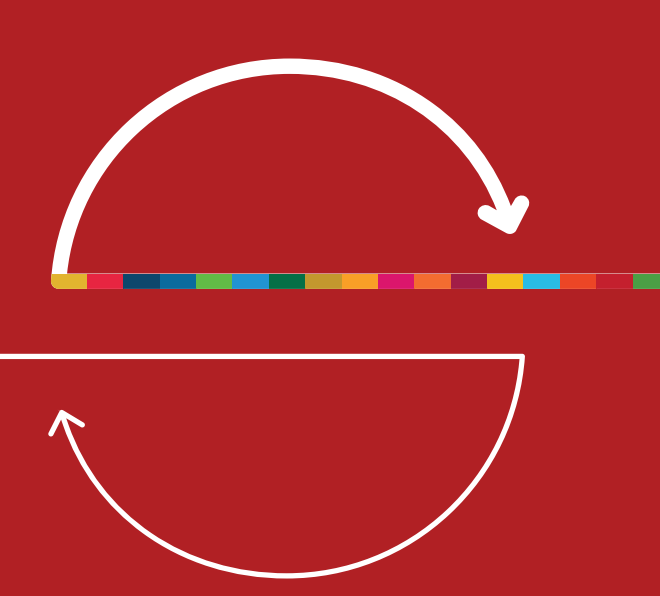

\section{CAPITULO} IV

\section{La desigualdad es ineficiente e insostenible}

Introducción

A. La desigualdad como obstáculo para el desarrollo

1. El costo de las brechas en la educación y la salud

2. La desigualdad de ingresos impide la movilidad intergeneracional

3. Un mercado laboral ineficiente: la persistente informalidad

4. Discriminación y oportunidades en el mercado laboral: la desigualdad de género

5. Efectos positivos de la protección social y el cuidado en el crecimiento y el empleo

B. Desafíos futuros: los cambios demográficos y la revolución tecnológica

1. Los efectos del envejecimiento, la participación laboral femenina y la educación

2. La disrupción tecnológica en el mercado de trabajo

Bibliografía 



\section{Introducción}

Uno de los principios rectores del pensamiento de la Comisión Económica para América Latina y el Caribe (CEPAL), que encontramos también en la Agenda 2030 para el Desarrollo Sostenible, es el posicionamiento de la igualdad como valor central del desarrollo. En los trabajos de la CEPAL se ha demostrado cómo la desigualdad "se extiende y refuerza en los ámbitos laboral y social y se entrelaza de diversas maneras con las desigualdades de género, las desigualdades étnicas y raciales, las desigualdades a lo largo del ciclo de vida y las desigualdades territoriales" (CEPAL, 2017a). En este capítulo, en lugar de abordarse los aspectos normativos presentados en documentos anteriores ${ }^{1}$, se analiza la desigualdad a través del examen de sus consecuencias y costos económicos y sociales. Desde una perspectiva estrictamente instrumental y centrada en lo económico, se analiza la siguiente pregunta: ¿cuáles son las razones para reducir la desigualdad?

La preocupación por la igualdad como una herramienta para promover el desarrollo no es nueva². La CEPAL ha insistido en la necesidad de un desarrollo que vincule el incremento de la igualdad con el de la productividad, las capacidades y la sostenibilidad del crecimiento, y ha defendido la tesis de la complementariedad de la igualdad social y la transformación de la estructura productiva. El desafío es identificar e implementar las sinergias entre ambas variables.

Los debates sobre distribución y crecimiento indican que la desigualdad, además de constituir una restricción para la reducción de la pobreza (véase el recuadro IV.1), implica pérdidas de productividad que generan costos significativos para las sociedades. En este capítulo se describen los vínculos entre los altos niveles de desigualdad en la región — cuya reducción se ha estancado en los últimos años-y los bajos niveles de productividad, tanto por la pérdida de capacidades (en educación o salud) como por la segmentación y la discriminación en el mercado de trabajo, que se retroalimentan con las desigualdades en el ámbito doméstico. Asimismo, se incorporan a la discusión dos elementos centrales para la evolución de la productividad de las economías de la región que supondrán grandes desafíos en un futuro cercano: el cambio demográfico y la revolución tecnológica.

\section{Recuadro IV.1}

La desigualdad del ingreso restringe la reducción de la pobreza

El crecimiento económico, entendido como el incremento del ingreso medio de los hogares, se vincula de manera aritmética con la pobreza y la desigualdad del ingreso (Bourguignon, 2003). La reducción de la pobreza monetaria en un país en un momento dado viene determinada en su totalidad por la tasa de crecimiento del ingreso medio de la población y los cambios en su distribución. Si no cambia la distribución, la reducción de la tasa de pobreza conlleva el crecimiento del ingreso medio. No obstante, podria suceder que un país incrementara su ingreso medio y también sus niveles de pobreza, si de manera simultánea aumentara la desigualdad. En los últimos 15 años se redujeron la pobreza y la desigualdad en la mayoría de los paises de América Latina, a la vez que se produjo un crecimiento del ingreso medio. El descenso de la desigualdad impulsó la disminución de la pobreza. Una manera de visualizar este resultado es calcular las tasas de pobreza que se registrarian en cada país si se hubiera producido el mismo crecimiento de la media del ingreso sin cambios en la distribución del ingreso, aplicando la metodología de Datt y Ravallion (1992).

En los paises donde la mejora distributiva no fue significativa, como México, los niveles de pobreza alcanzados en 2016 son relativamente similares a los que se habrian alcanzado sin cambios distributivos. En otros paises, como la Argentina, el Brasil, Chile o el Uruguay, donde la desigualdad del ingreso se redujo de manera considerable, los niveles de pobreza simulados son significativamente superiores a los que efectivamente se alcanzaron. El único pais en que la pobreza habria disminuido si no se hubiera producido un cambio distributivo es Costa Rica, donde la desigualdad de ingresos aumentó, lo que provocó un incremento de pobreza por este componente (véanse los gráficos). En resumen, mantener altos niveles de desigualdad implica resignarse a mayores tasas de pobreza.

Las principales tesis se desarrollan en documentos institucionales publicados a lo largo de casi una década. Véase CEPAL (2010, 2012, 2014, 2017a y 2017b). Véanse, por ejemplo, las reflexiones de Atkinson (2015) sobre Stiglitz (2012) o Pickett y Wilkinson (2009). 


\section{Recuadro IV.1 (conclusión)}

América Latina (17 paises): tasas de pobreza efectiva y tasa de pobreza simulada si no hubiera existido cambio distributivo, 2002-2016

(En porcentajes)

\section{A. Tasas de pobreza}

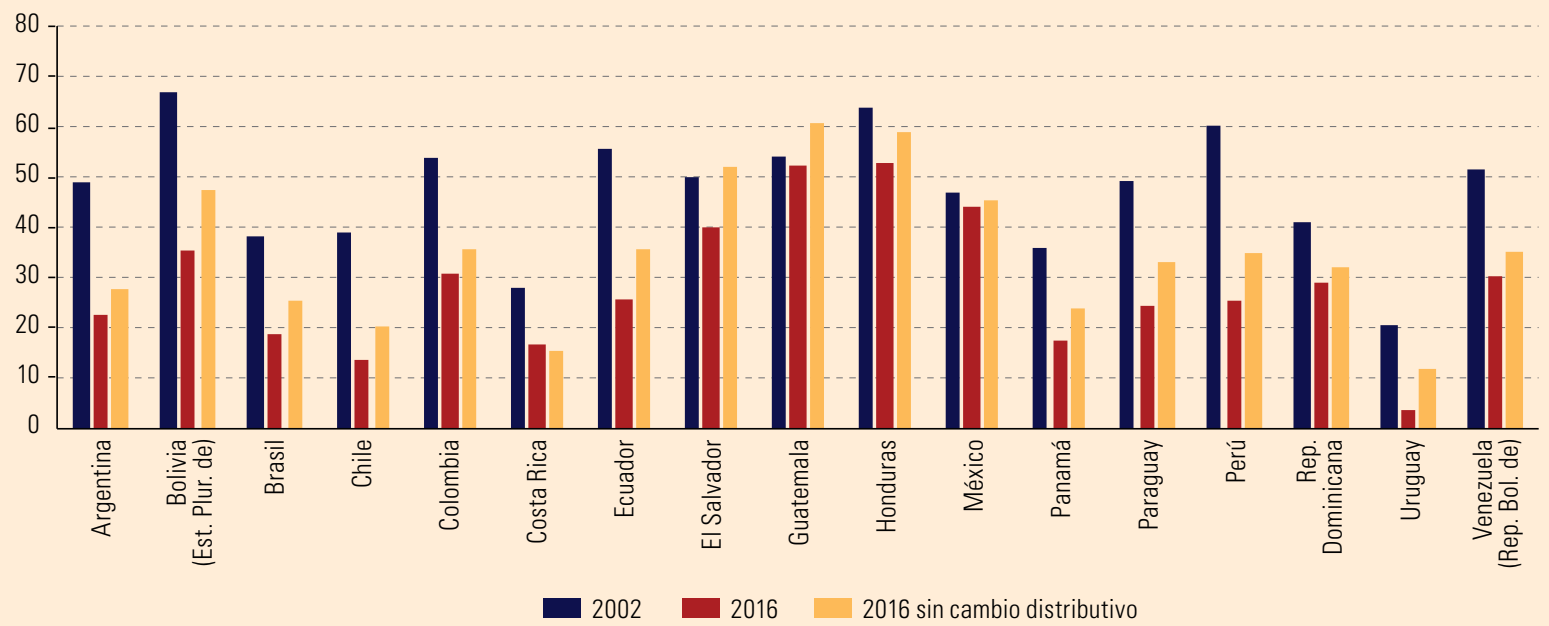

\section{B. Variación en las tasas de pobreza}

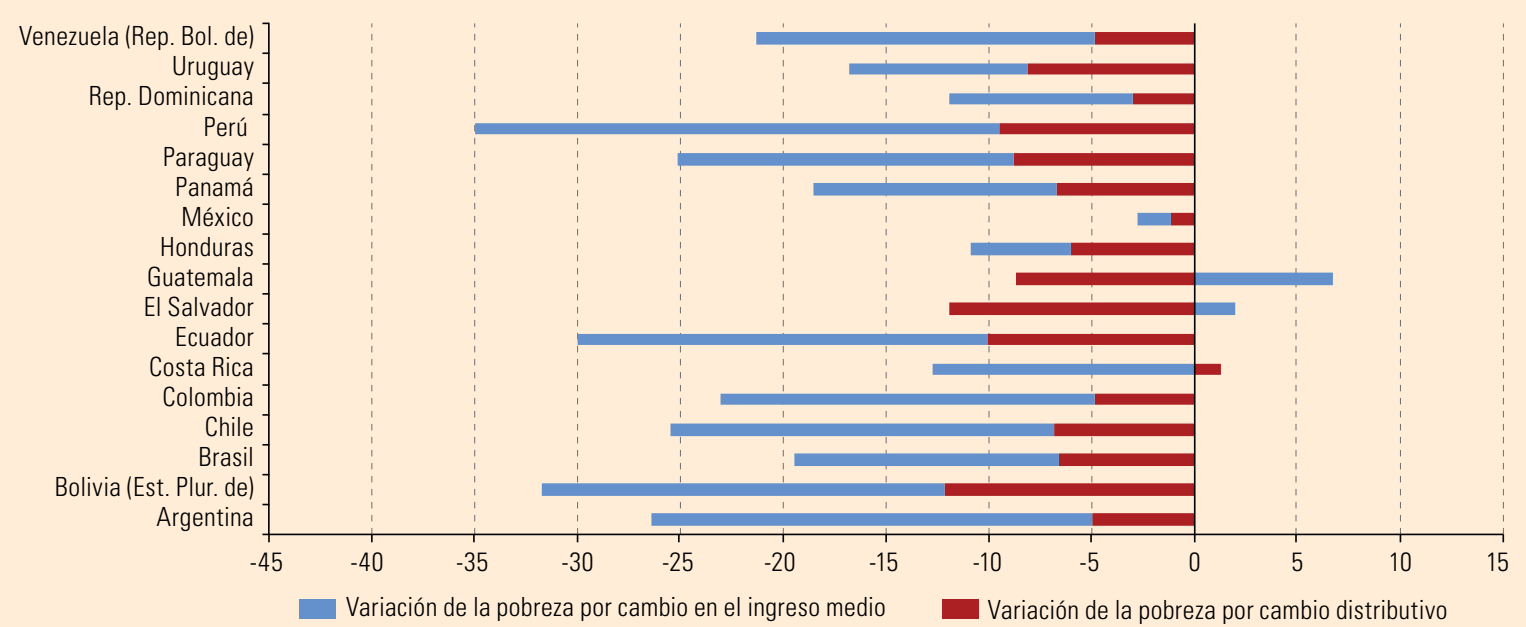

Fuente: Comisión Económica para América Latina y el Caribe (CEPAL), sobre la base de encuestas de hogares de los respectivos países.

Fuente: Comisión Económica para América Latina y el Caribe (CEPAL), sobre la base de F. Bourguignon, "The growth elasticity of poverty reduction: explaining heterogeneity across countries and time periods", Working Paper, № 28104, Washington, D.C., Banco Mundial, 2003; G. Datt y M. Ravallion, "Growth and redistribution components of changes in poverty measures: a decomposition with applications to Brazil and India in the 1980s", Journal of Development Economics, vol. 38, № 2, Amsterdam, Elsevier, 1992. 


\section{A. La desigualdad como obstáculo para el desarrollo}

El vínculo entre la igualdad y el crecimiento económico es uno de los más estudiados en la economía moderna. En el capítulo III se analizó este vínculo desde la perspectiva macroeconómica, poniendo de relieve la importancia de la inversión y el mercado de trabajo, entre otros factores. En el presente capítulo se complementa dicha perspectiva mediante el análisis de los vínculos entre crecimiento e igualdad a nivel sectorial y microeconómico, al tiempo que se discuten los potenciales efectos adversos de la desigualdad sobre el crecimiento ${ }^{3}$, aun cuando la evidencia empírica no sea concluyente, dado que los factores institucionales desempeñan un papel fundamental en este vínculo.

\section{El costo de las brechas en la educación y la salud}

Entre los canales que vinculan la desigualdad y el crecimiento, está especialmente extendida la idea de que altos niveles de desigualdad en el acceso a la educación constituyen una barrera a la difusión de capacidades ${ }^{4}$. Las tasas de retorno de los años de educación para la región muestran que los mayores saltos en términos de ingreso generado en el mercado laboral se dan, en primer lugar, al concluir la educación secundaria y, en mayor medida, al acceder a la educación terciaria y a la de posgrado. Además, los retornos de los años de educación para la población son heterogéneos, de acuerdo con algunos ejes de desigualdad social relevantes (véase el gráfico IV.1). A niveles educativos similares, las tasas de retorno -medidas como retribuciones en ingresos salariales-discriminan a las mujeres frente a los hombres, a los trabajadores informales frente a los formales, a los indígenas frente a los no indígenas y a los afrodescendientes frente a los no afrodescendientes. Las diferencias más notables en las tasas de retorno se encuentran al analizar la segmentación formal-informal de los mercados de trabajo, lo que remite a los problemas de heterogeneidad estructural de la región.

\section{Gráfico IV.1}

América Latina (17 paises): trayectorias salariales según años de estudio en asalariados de 20 años o más que trabajan 20 horas o más semanales, alrededor de $2015^{a}$

(Salarios con cero años de estudio de la categoria de comparación con menores ingresos=100)

\section{A. Trayectorias salariales de hombres y mujeres}

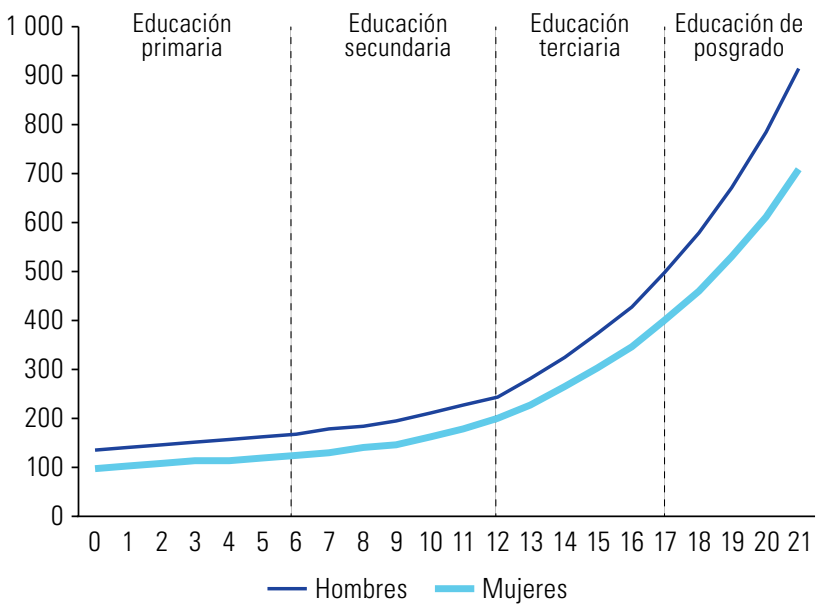

B. Trayectorias salariales en los sectores formal e informal ${ }^{b}$

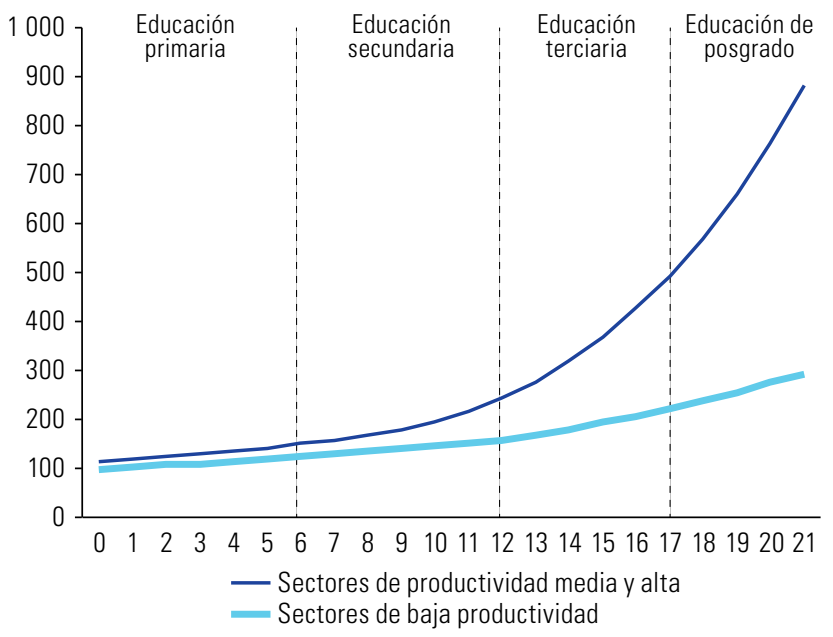

Véanse, entre otros, Rajan (2010), Stiglitz (2012) y Ostry, Berg y Tsangarides (2014).

Una formalización de esta idea puede encontrarse en Galor y Zeira (1993), que analizan los costos de la inversión en educación y las imperfecciones de los mercados financieros. 
Gráfico IV.1 (conclusión)

\section{Trayectorias salariales según origen étnicocd}

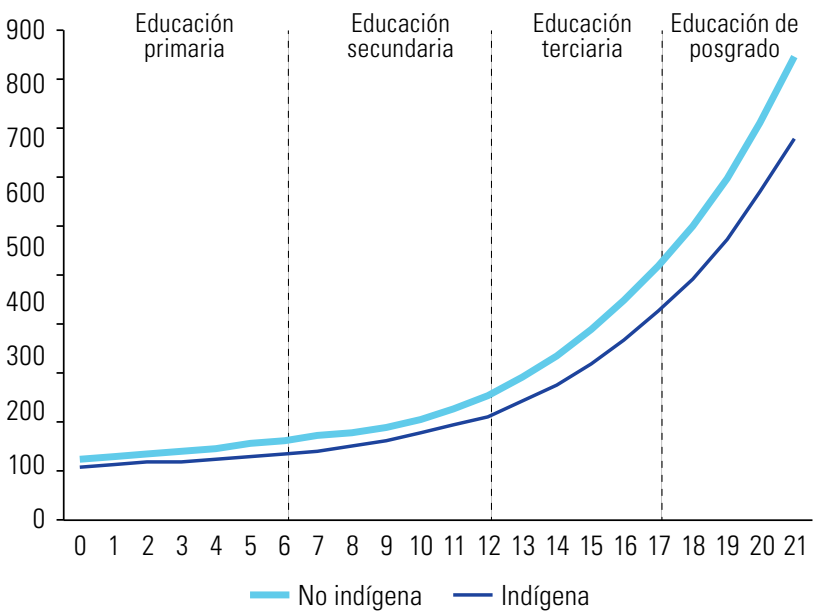

\section{Trayectorias salariales según origen racialef}

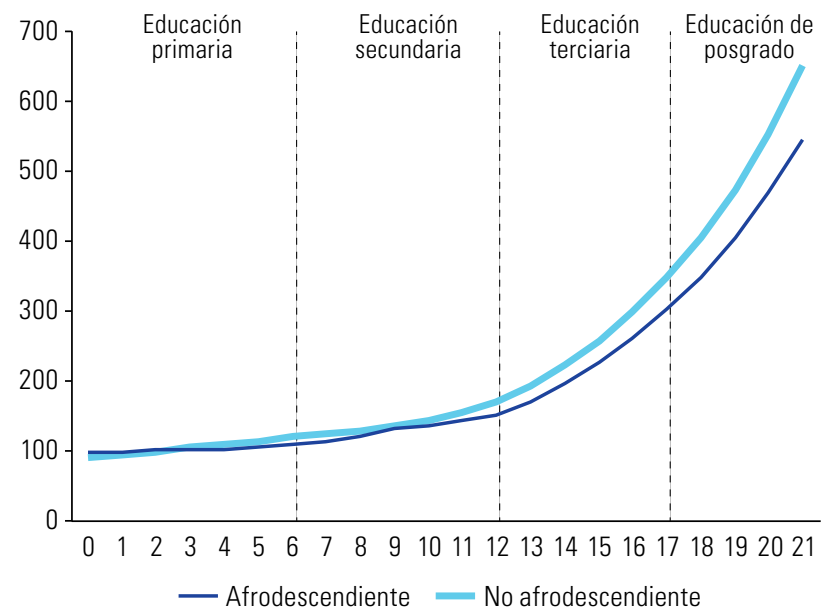

Fuente: Comisión Económica para América Latina y el Caribe (CEPAL), sobre la base de encuestas de hogares de los respectivos países.

Nota: Los países analizados son la Argentina, el Brasil, Bolivia (Estado Plurinacional de), Chile, Colombia, Costa Rica, el Ecuador, El Salvador, Guatemala, Honduras, México, Panamá, el Paraguay, el Perú, la República Dominicana, el Uruguay y Venezuela (República Bolivariana de).

a Promedio simple de las trayectorias de cada segmento del mercado de trabajo por país. La trayectoria dentro de cada segmento se calculó con un modelo separado.

b "Formal" se refiere a empleos de productividad media y alta e "informal" a empleos de baja productividad.

c Los análisis para esta categoría incluyen a ocho países de América Latina (Bolivia (Estado Plurinacional de), Brasil, Chile, Ecuador, Guatemala, México, Perú y Uruguay).

d La categoría "No indígena" no incluye a los afrodescendientes.

e Los análisis para esta categoría incluyen a cuatro países de América Latina (Bolivia (Estado Plurinacional de), Brasil, Ecuador y Uruguay).

f La categoría "No afrodescendiente" no incluye a los indígenas.

La falta de acceso a una educación de calidad puede conllevar la disminución de la capacidad de una persona para contribuir al proceso productivo de acuerdo con su potencial a lo largo de toda su vida. En América Latina, una proporción muy significativa de la población mayor de 18 años no alcanza todavía un nivel educativo equivalente al primer ciclo de secundaria completo, y a esto se suman notables diferencias entre el primer y el último quintil de ingresos (gráfico IV.2). Por otra parte, la situación de los distintos países es heterogénea. En un extremo, se encuentra Guatemala, donde solo el 50\% de la población mayor de 18 años alcanza un nivel educativo equivalente a la culminación del primer ciclo de secundaria. En el otro extremo se sitúa Chile, donde esta cifra supera el $80 \%$.

Diversos estudios han señalado la relevancia de la culminación de la enseñanza media para superar las situaciones de pobreza y acceder al empleo formal de calidad. La insuficiente acumulación educativa de la población activa es una restricción importante en términos de capacidades que tiene consecuencias sobre la productividad. Para realizar una aproximación a la pérdida de productividad de la economía es posible medir la relevancia de no haber completado el primer ciclo de la enseñanza media en términos de pérdida de ingresos de los hogares 5 .

En todos los países, el ingreso simulado que refleja la situación en la que todos los ocupados de entre 25 y 55 años han finalizado el primer ciclo de la enseñanza media es superior al que presentan actualmente los hogares (véase el gráfico IV.3). En los países donde las brechas son mayores (Guatemala y Honduras), la variación del ingreso de los hogares se ubica en torno al 25\%, mientras que en el otro extremo (Chile y Venezuela (República Bolivariana de)), la variación es inferior al $5 \%$.

5 La estimación consiste en calcular la diferencia entre el verdadero ingreso de los hogares y el que percibirían si los individuos que no alcanzaron este nivel educativo mínimo lo hubiesen alcanzado. En el caso de los individuos que alcanzaron ese mínimo, el ingreso no cambia. Para ello se utiliza una ecuación de Mincer en cada país, a fin de explicar el logaritmo del ingreso de los ocupados (excluyendo a los que se encuentran dentro del sistema educativo) de entre 25 y 55 años, en función de un conjunto de covariables. 


\section{Gráfico IV.2}

América Latina (17 países): conclusión del primer ciclo de educación secundaria, mayores de 18 años, según quintil de ingresos, alrededor de 2016

(En porcentajes)

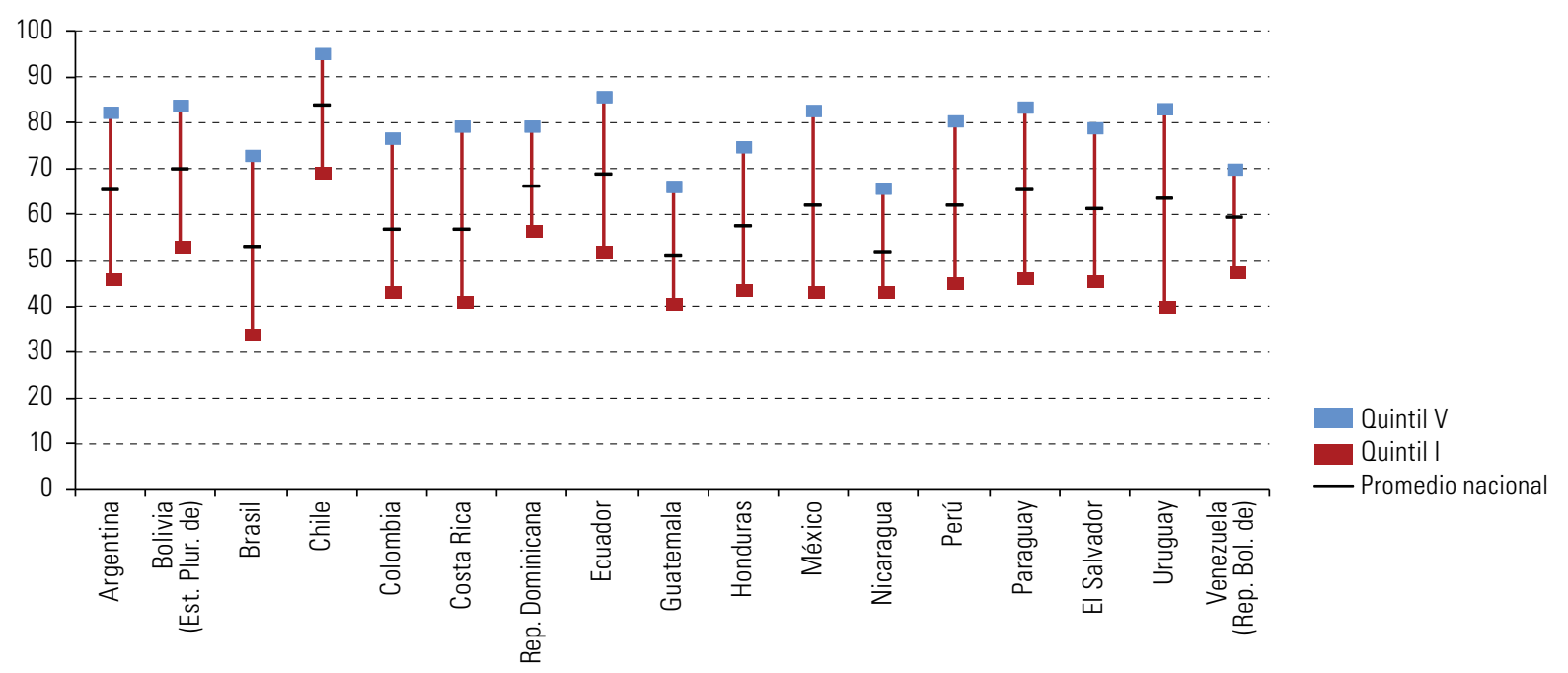

Fuente: Comisión Económica para América Latina y el Caribe (CEPAL), sobre la base de encuestas de hogares de los respectivos países.

\section{Gráfico IV.3}

América Latina (17 paises): incremento del ingreso de los hogares si la población hubiese completado el primer ciclo de la enseñanza media, alrededor de 2016

(En porcentajes)

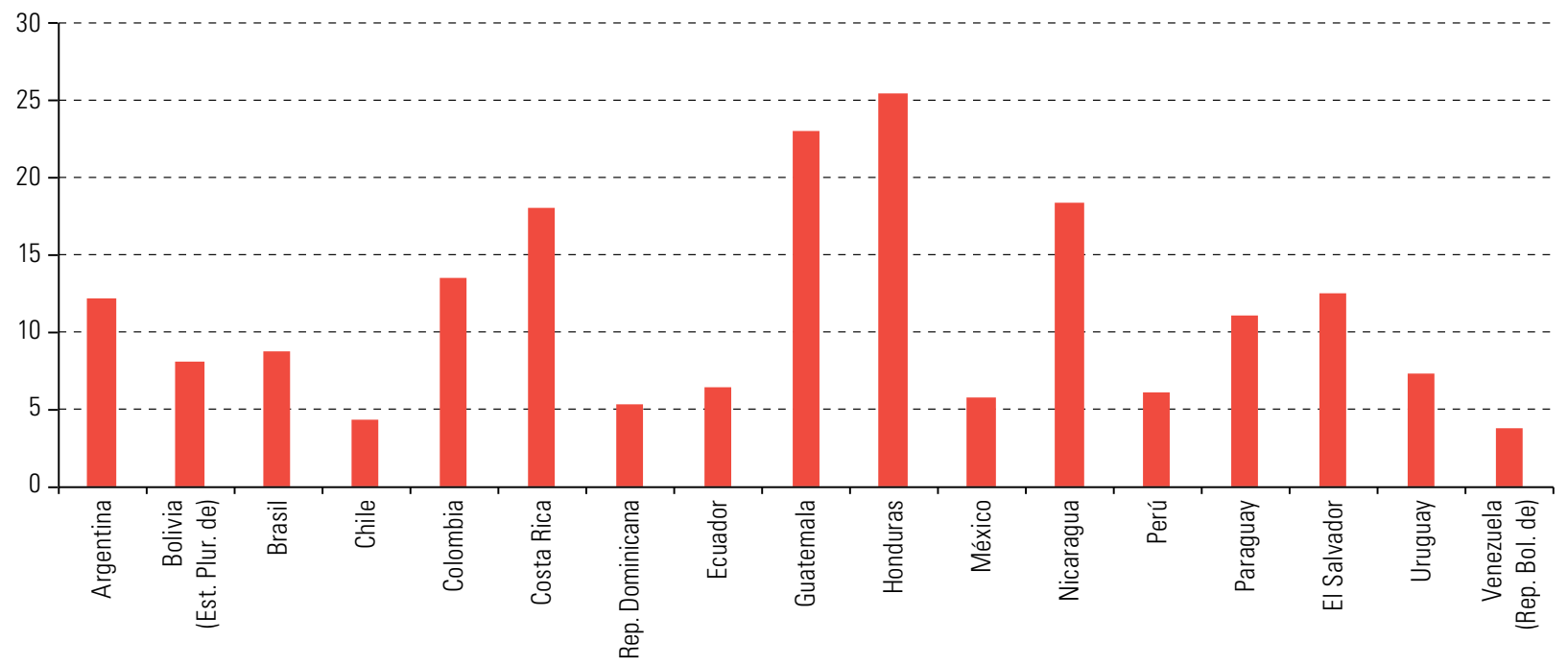

Fuente: Comisión Económica para América Latina y el Caribe (CEPAL), sobre la base de encuestas de hogares de los respectivos países.

Tanto en este ejercicio como en los que se presentan en las secciones siguientes, se supone que la mayor oferta de trabajadores se incorpora a los salarios vigentes. Se trata de una simplificación que no considera la capacidad del mercado laboral de absorber mano de obra de mayor calificación, ni los efectos de equilibrio general, ni los cambios tecnológicos en curso. En contextos económicos como los analizados en los capítulos II y III, este supuesto es improbable. El valor de los ejercicios presentados no radica en su poder predictivo, sino en su capacidad de ilustrar acerca de los costos de la desigualdad. 
Además de las pérdidas de productividad asociadas a no haber alcanzado determinados niveles educativos que pueden considerarse mínimos, subsisten importantes problemas relacionados con la calidad de la educación, aspecto fundamental para el desarrollo de capacidades. En el gráfico IV.4 se muestra que los países de América Latina que participaron en las pruebas del Programa para la Evaluación Internacional de Alumnos (PISA) de 2015 - a excepción de Chile- son los que, a nivel mundial, presentan el mayor porcentaje de estudiantes de 15 años que se encuentran por debajo del nivel mínimo de competencia esperado en matemáticas, lectura y ciencias. En efecto, un $62 \%$ de los estudiantes de la región que participaron en las pruebas no alcanza el nivel requerido en matemáticas, mientras que esta cifra asciende a un $45 \%$ en lectura y a un $50 \%$ en ciencias, lo que refleja las deficiencias en la calidad de la educación media en la región.

\section{Gráfico IV.4}

Niveles de desempeño de los estudiantes en las pruebas PISA por región y competencia

(matemáticas, lectura y ciencias), 2015

(En porcentajes)

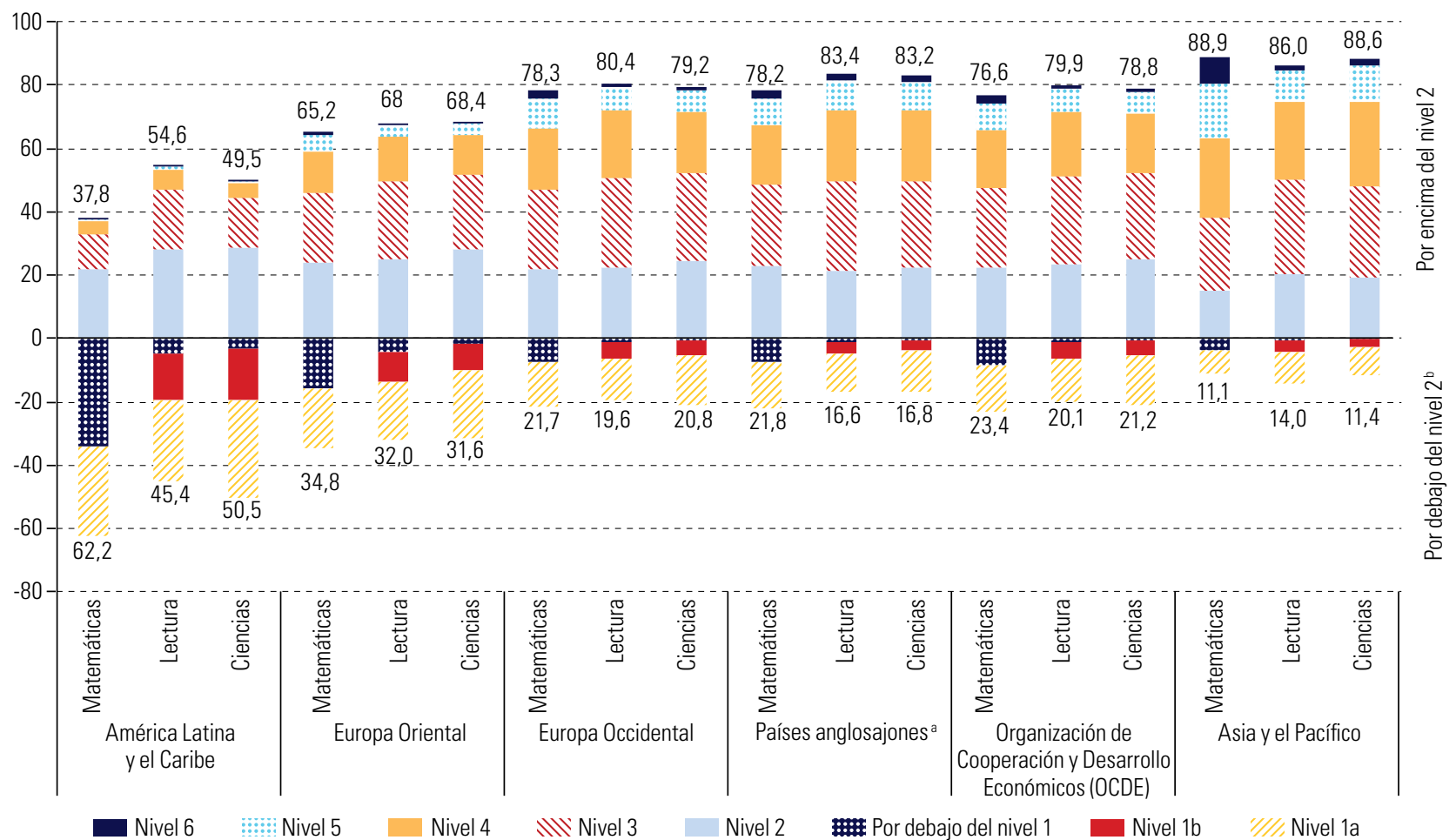

Fuente: Comisión Económica para América Latina y el Caribe (CEPAL), sobre la base de Organización de Cooperación y Desarrollo Económicos (OCDE), Programa para la Evaluación Internacional de Alumnos (PISA) 2015

a La categoría "Países anglosajones" incluye a Australia, el Canadá, los Estados Unidos, Nueva Zelandia y el Reino Unido.

${ }^{b}$ Los estudiantes que se sitúan en niveles inferiores a 2 (nivel 1a, nivel 1b y por debajo del nivel 1) no alcanzan el nivel básico de competencia esperado.

Otra dimensión clave para el logro de niveles de productividad más elevados es el ámbito de la salud, en el cual el cierre de brechas también puede constituir un aporte significativo. Las personas sanas y bien nutridas presentan mejores capacidades físicas y mentales para el trabajo, así como tasas más bajas de ausentismo. La salud también tiene un efecto indirecto sobre la productividad, al facilitar el desarrollo cognitivo, la capacidad de aprendizaje y el rendimiento escolar, así como la posibilidad de aprender y adquirir nuevas habilidades (Fogel, 2004). El gasto en salud es especialmente rentable cuando se dirige a la población de niños, niñas, adolescentes y jóvenes, ya que este tipo de intervenciones pueden prevenir problemas futuros de salud y favorecer el desarrollo cognitivo y de capacidades, lo 
que genera retornos económicos mediante el ahorro en costos de salud futuros y el aumento de la productividad (UNICEF, 2012) ${ }^{6}$.

Sin embargo, la relación entre salud e ingresos, tanto a nivel individual como de la sociedad, no presenta una causalidad unidireccional: gozar de buena salud puede ser tanto el resultado como la causa de percibir ingresos elevados ${ }^{7}$. En América Latina y el Caribe, se estima que el cambio anual en la esperanza de vida contribuyó al crecimiento del ingreso total en aproximadamente un 1,5\% anual de 1990 a 2000 y un 1,1\% anual de 2000 a 2011, en consonancia con las tendencias de desaceleración del aumento de la esperanza de vida observadas en los países de altos ingresos (véase el gráfico IV.5).

\section{Gráfico IV.5}

Contribución del cambio anual en la esperanza de vida al ingreso total por región, 1990-2000 y 2000-2011 (En porcentajes)

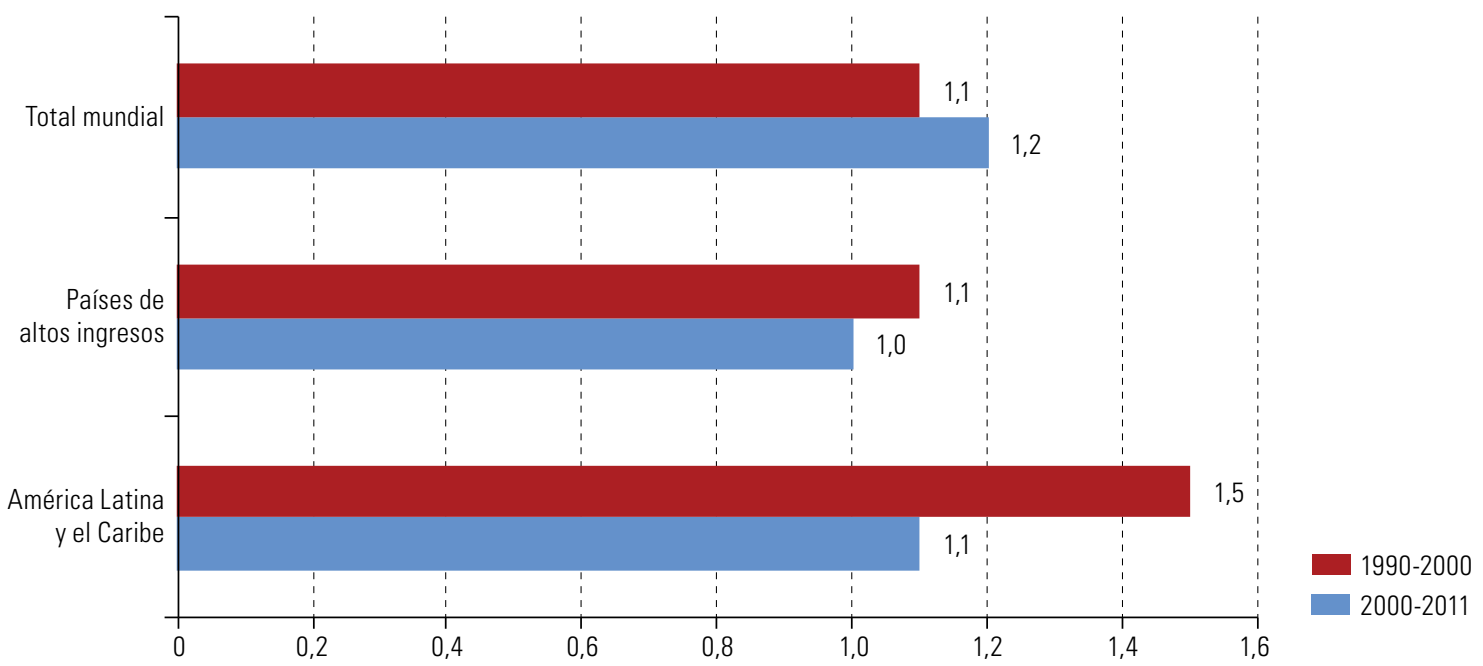

Fuente: Comisión Económica para América Latina y el Caribe (CEPAL), sobre la base de D. Jamison y otros, "Global health 2035: a world converging within a generation", The Lancet, vol. 382, № 9908, Amsterdam, Elsevier, 2013.

Nota: El ingreso total incluye el crecimiento del ingreso medido en las cuentas nacionales más el valor monetario de los años adicionales de vida ganados en ese período

La disminución de la maternidad adolescente también generaría efectos positivos en términos de productividad. A pesar de la drástica disminución de la fecundidad en América Latina y el Caribe a lo largo de las últimas décadas, esta sigue siendo elevada entre las adolescentes, particularmente entre aquellas provenientes de estratos económicos bajos, pertenecientes a pueblos indígenas y residentes en zonas rurales (CEPAL, 2017a). Se trata de una situación preocupante que se ha identificado como un factor clave de la transmisión intergeneracional de la pobreza debido a las marcadas consecuencias negativas de la maternidad durante la adolescencia, particularmente la adolescencia temprana (CEPAL, 2016b). Además de darse de manera desigual entre la población, la maternidad adolescente también perpetúa las desigualdades sociales, al afectar el nivel educativo alcanzado y las posibilidades presentes y futuras de las mujeres jóvenes para acceder al trabajo y a la protección social (CEPAL, 2016a). En promedio, las mujeres de 25 a 35 años de la región que fueron madres en la adolescencia estudiaron 3,2 años menos que las mujeres del mismo tramo etario que no fueron madres adolescentes (véase el gráfico IV.6).

6 Existen estudios en la región que avalan la relación costo-beneficio de las intervenciones para promover la salud infantil en áreas como la nutrición (Llanos y otros, 2007), el paludismo (Bleakley, 2010) y la vacunación contra neumococo y rotavirus (Constenla y otros, 2008; De Soárez y otros, 2008). La relación costo-beneficio en el caso de las intervenciones que buscan prevenir accidentes de tránsito en la población adolescente es de 5,6 (los beneficios quintuplican los costos) y en el de la vacunación contra el virus del papiloma humano (VPH) es de 17,0 (Sheehan y otros, 2017).

7 Aun así, diversos estudios intentan cuantificar los efectos de la salud sobre la productividad, el empleo y el crecimiento. Véanse, por ejemplo, 0MS (2011); Bloom, Canning y Sevilla (2004), y Alsan y otros (2008). 


\section{Gráfico IV.6}

América Latina (7 países): promedio de estudios de las mujeres de 25 a 35 años, según condición de madres adolescentes o no, 2008-2015

(En años)

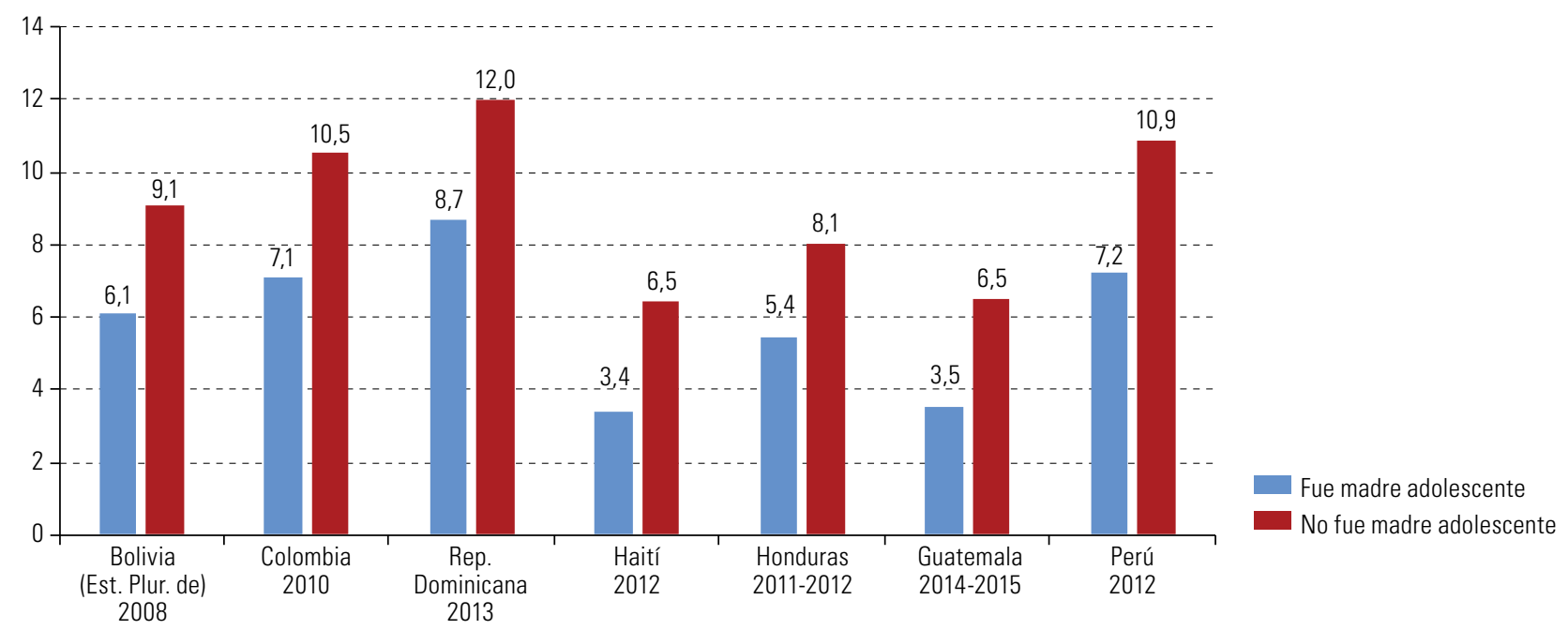

Fuente: Comisión Económica para América Latina y el Caribe (CEPAL), sobre la base de Encuestas de Demografía y Salud (DHS) de los países y años indicados.

Los efectos adversos de la maternidad precoz se extienden además a los niños nacidos de madres adolescentes, lo que genera también costos económicos futuros (CEPAL, 2016a).

Si se controla el factor del nivel educativo de la madre, los niños nacidos de mujeres que fueron madres en la adolescencia presentan una mayor prevalencia de desnutrición crónica, lo que genera costos relacionados con la productividad y los sistemas de salud (Fernández y otros, 2017). En este sentido, el gasto en salud durante la adolescencia tiene un efecto positivo triple, puesto que genera dividendos en esa etapa, en la adultez y en la siguiente generación.

\section{La desigualdad de ingresos impide la movilidad intergeneracional}

Existe una fuerte asociación entre mayor desigualdad de ingresos y menor movilidad entre generaciones (Corak, 2013). Esta asociación se evidencia en los países tanto desarrollados como en desarrollo. En América Latina y el Caribe (véanse el gráfico IV.7 y el recuadro IV.2), se observan algunas de las mayores correlaciones entre los ingresos de los padres y los de los hijos (medida por la elasticidad intergeneracional de ingresos) ${ }^{8}$. Los países no compensan los niveles más elevados de desigualdad con una mayor movilidad de ingresos; en los países donde las diferencias entre ricos y pobres son mayores, existe una probabilidad menor de pasar de pobre a rico. Si bien no es posible identificar causalidades, esta asociación positiva es relevante para comprender las implicancias dinámicas de los altos niveles de desigualdad regionales, como se señaló en el capítulo I.

8 La asociación empírica entre alta desigualdad y baja movilidad, conocida como la curva del Gran Gatsby, ha dado lugar a controversias entre los economistas. 


\section{Gráfico IV.7}

Movilidad intergeneracional y desigualdad de ingresos

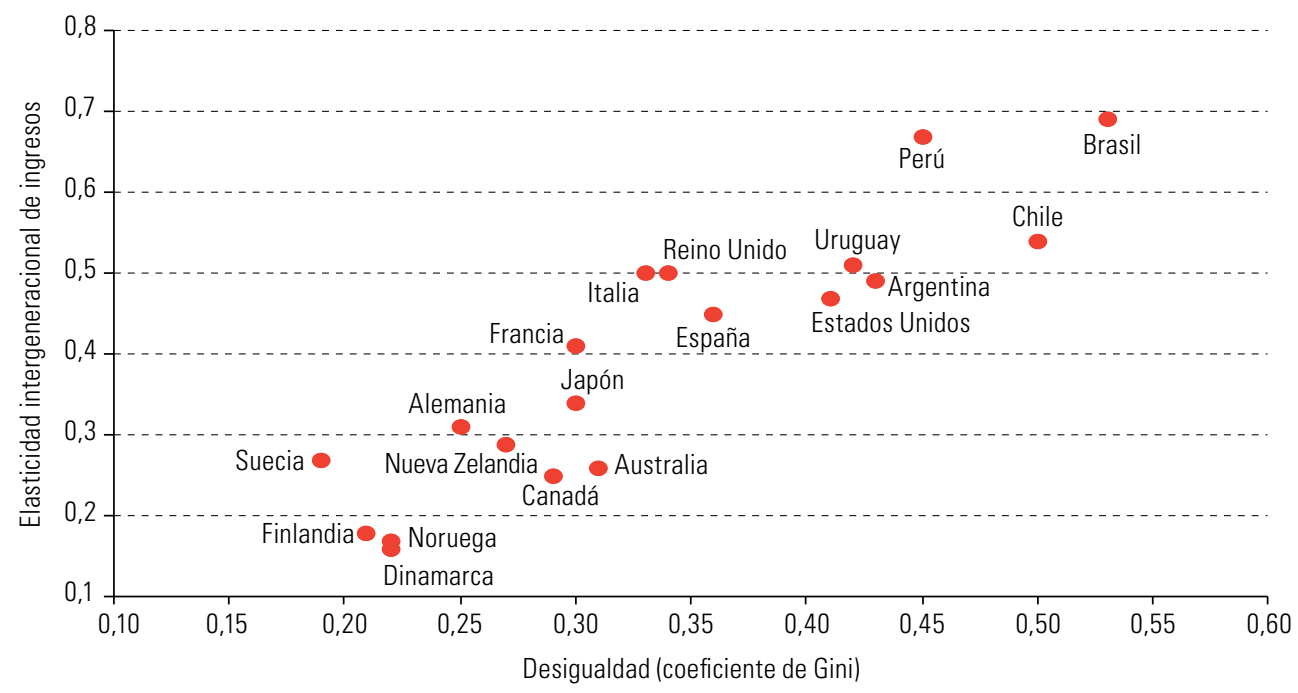

Fuente: F. Araya, "Una aproximación a la movilidad intergeneracional de los ingresos laborales en Uruguay", Tesis de maestría, Montevideo, Universidad de la República, 2017; M. Corak, "Income inequality, equality of opportunity, and intergenerational mobility", Journal of Economic Perspectives, vol. 27, № 3, Pittsburgh, Asociación Estadounidense de Economía, 2013; C. Dunn, "The intergenerational transmission of lifetime earnings: evidence from Brazil", The B.E. Journal of Economic Analysis \& Policy, vol. 7, № 2, Berlín, De Gruyter, 2007; N. Grawe, "Intergenerational mobility for whom? The experience of high- and low- earning sons in international perspective", Generational Income Mobility in North America and Europe, M. Corak (ed.), Cambridge, Cambridge University Press, 2004; J. Nuñez y L. Miranda, "Recent findings on intergenerational income and educational mobility in Chile", Documento de Trabajo, № 244, Santiago, Universidad de Chile, 2007; M. Jiménez y M. Jiménez, "La movilidad intergeneracional del ingreso: evidencia para Argentina", Documento de Trabajo, № 84, La Plata, Universidad Nacional de La Plata, 2009

\section{Recuadro IV.2}

La medición de la movilidad intergeneracional

Los estudios sobre movilidad intergeneracional de ingresos suelen analizar el vinculo entre el ingreso permanente de los padres y el de los hijos. Esto puede hacerse mediante el coeficiente de correlación entre las dos variables o a través de un coeficiente, que surge de estimar la regresión del nivel educativo de los hijos en función del nivel educativo de los padres, y que refleja la elasticidad intergeneracional del ingreso. Cuando el coeficiente se aproxima a uno, significa que un incremento de una cierta magnitud en el ingreso de los padres implicará un aumento prácticamente igual en el ingreso de los hijos; es decir, valores más altos de elasticidad intergeneracional del ingreso reflejan menor movilidad intergeneracional. La relación entre ambos indicadores es la siguiente: el coeficiente es igual al coeficiente de correlación entre la educación del padre y la del hijo, ponderado por la relación entre los desvios estándar de la educación de padres e hijos. Las divergencias entre ambos obedecen a cambios en la relación de desvios estándar (Daude y Robano, 2015).

Fuente: Comisión Económica para América Latina y el Caribe (CEPAL), sobre la base de C. Daude y V. Robano, "On intergenerational (im)mobility in Latin America", Latin American Economic Review, vol. 24, № 9, Berlín, Springer, 2015

Mediante la revisión de la información disponible sobre América Latina — que es escasa, debido a la ausencia de bases de datos adecuadas - es posible concluir que los niveles de movilidad intergeneracional son bajos en la región, incluso cuando se los compara con los de los Estados Unidos o el Reino Unido, países que destacan por su baja movilidad a nivel internacional (Azevedo y Bouillon, 2010). Otros trabajos (Hertz y otros, 2007; Torche, 2014; Daude y Robano, 2015) coinciden en resaltar los bajos niveles de movilidad intergeneracional, centrándose en la educación. En América Latina, la influencia del contexto familiar en los resultados educativos surge como característica distintiva. Torche (2014) advierte que los altos retornos de la educación en América Latina pueden transformarse en una trampa de meritocracia heredada, debido a las desigualdades de acceso y a las barreras para los individuos de hogares menos favorecidos en términos de cantidad y calidad de la educación. 
Daude y Robano (2015) evalúan los logros educativos de los hijos con respecto a los de los padres, comparando 18 países de la región sobre la base de información de la Corporación Latinobarómetro. Al comparar los resultados de sus estimaciones para América Latina con otras disponibles para el mundo, encuentran que el coeficiente de correlación entre el nivel educativo de los padres y el de los hijos es significativamente más alto en América Latina (véase el gráfico IV.8A). Además, las estimaciones para los distintos países de la región son marcadamente heterogéneas: mientras que en Costa Rica un incremento de 4 años en la educación de los padres supone 1,6 años más de educación para los hijos, en Guatemala la cifra se eleva a 3,4 años más (véase el gráfico IV.8B).

\section{Gráfico IV.8}

Movilidad intergeneracional educativa

A. Coeficiente de correlación entre la educación de los padres y la de los hijos por región, alrededor de 2008

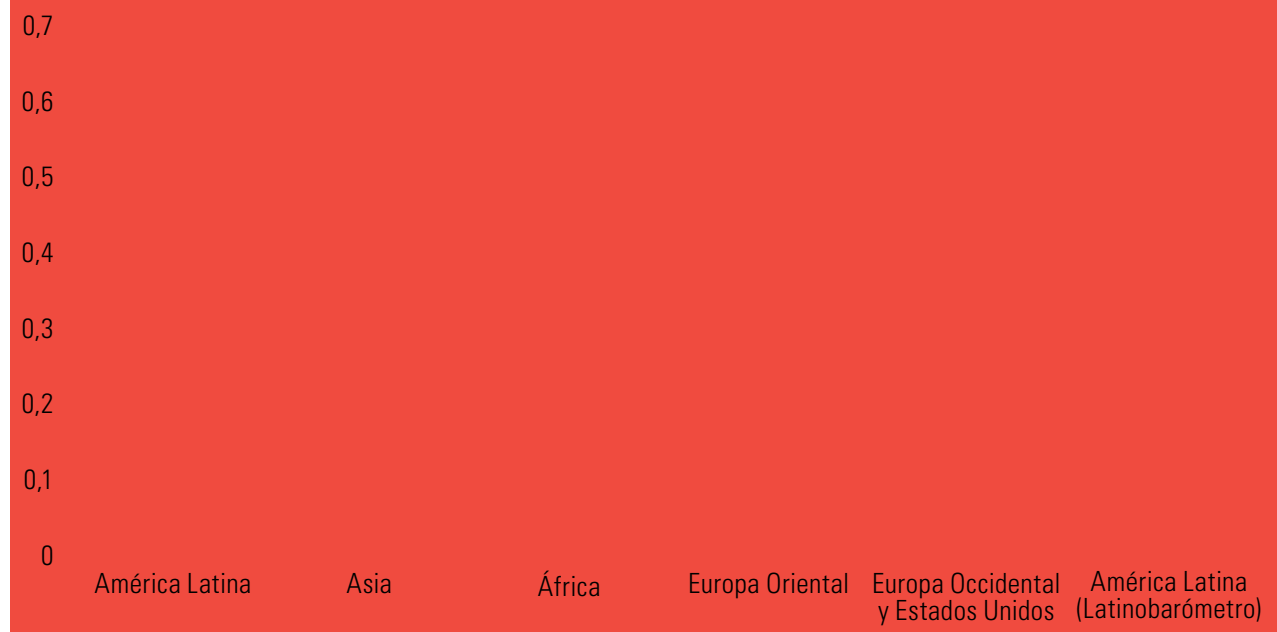

B. América Latina (18 países): coeficiente $\beta$ entre la educación de los padres y la de los hijos por país, alrededor de 2008

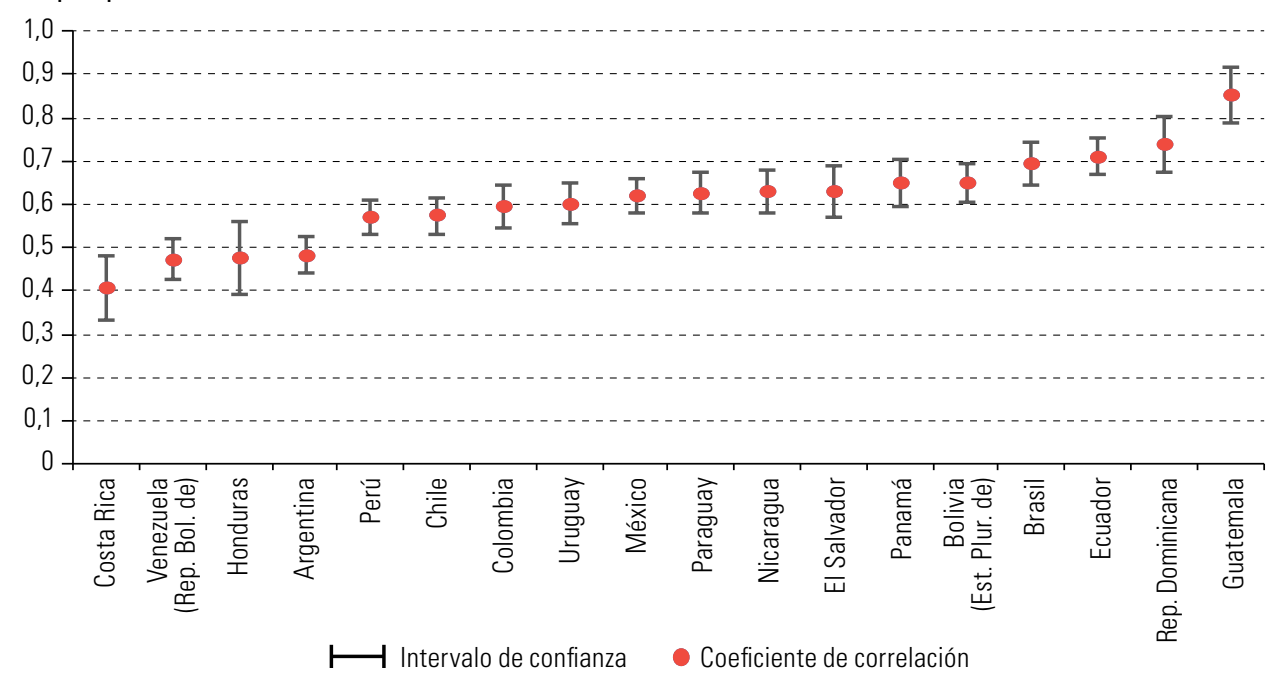

Fuente: Corporación Latinobarómetro; C. Daude y V. Robano, "On intergenerational (im)mobility in Latin America”, Latin American Economic Review, vol. 24, № 9, Berlín, Springer, 2015; T. Hertz y otros, "The inheritance of educational inequality: international comparisons and fifty-year trends", The B.E. Journal of Economic Analysis \& Policy, vol. 7, № 2, Berlín, De Gruyter, 2007. 
Otro estudio reciente también encuentra que la persistencia educacional es muy grande en la parte alta de la distribución (Neidhöfer, Serrano y Gasparini, 2017). Sin embargo, los autores añaden que la movilidad se ha incrementado en la parte baja de la distribución, debido a la expansión educativa que benefició a los niños de hogares más desaventajados ${ }^{9}$. En el gráfico IV.9 se muestra el porcentaje de hijos asociado con la clase educativa de los padres. La región presenta baja movilidad intergeneracional, dado que casi el $60 \%$ de los hijos con nivel educativo alto o bajo tuvieron padres con ese mismo nivel educativo. Solamente el $14 \%$ de los hijos de nivel educativo alto provienen de hogares con bajo nivel educativo.

Gráfico IV.9

América Latina (18 países): matriz de transicióna

(En porcentajes)

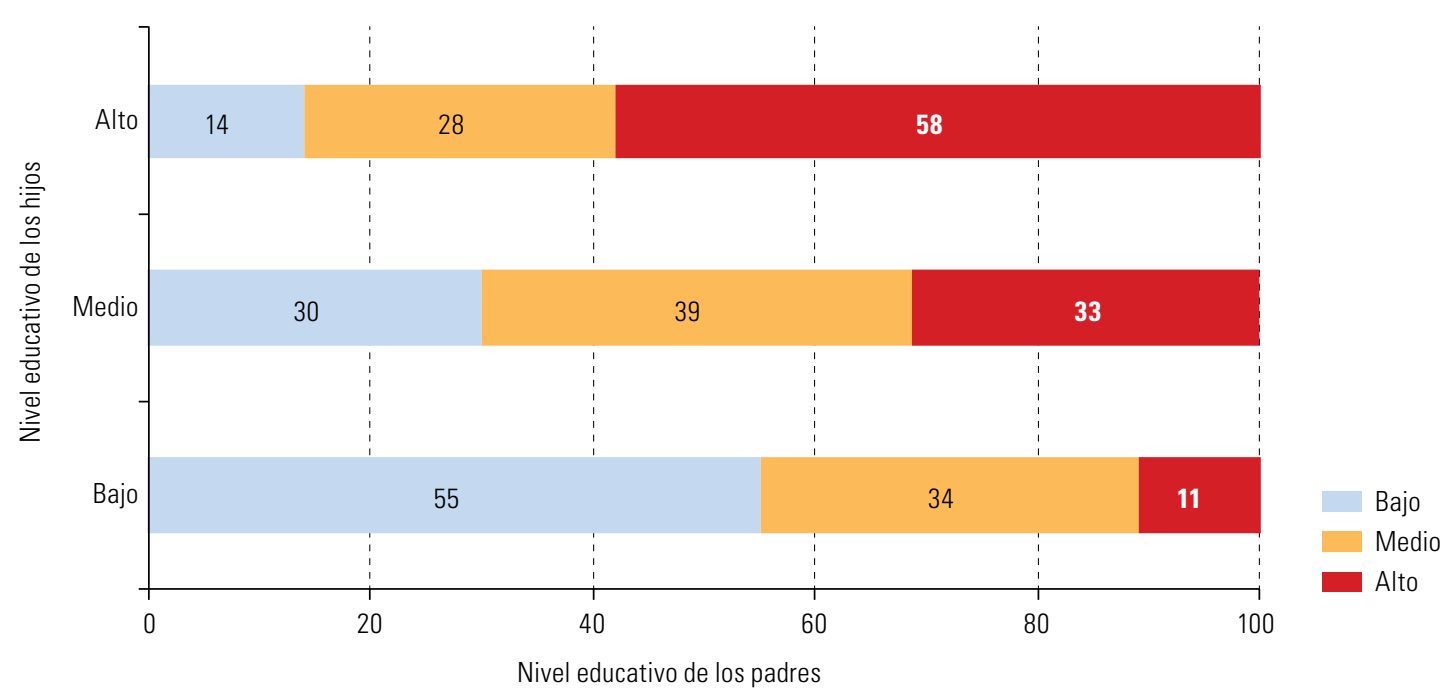

Fuente: G. Neidhöfer, J. Serrano y L. Gasparini, "Educational inequality and intergenerational mobility in Latin America: a new database", Documentos de Trabajo, № 215, La Plata, Universidad Nacional de La Plata, 2017 [en línea] http://www.cedlas.econo.unlp.edu.ar/wp/wp-content/uploads/doc_cedlas215.pdf.

a Datos de la Argentina, Bolivia (Estado Plurinacional de), el Brasil, Chile, Colombia, Costa Rica, el Ecuador, El Salvador, Guatemala, Honduras, México, Nicaragua, Panamá, el Paraguay, el Perú, la República Dominicana, el Uruguay y Venezuela (República Bolivariana de). Encuestas realizadas entre 1998 y 2015.

En síntesis, la distribución inicial de recursos determina las posibilidades de concreción de logros educativos, incluso cuando existe oferta de servicios públicos. Por lo tanto, las posibilidades de ser un trabajador calificado o no calificado - es decir, el potencial productivo de un individuo- están fuertemente correlacionadas con el origen de dicho individuo. Esto es un claro reflejo de la cultura del privilegio que ha dominado históricamente en nuestra región, donde se considera aceptable que la posición socioeconómica de los padres sea un factor determinante de las posibilidades de desarrollo de capacidades de las generaciones siguientes. Las posibilidades de movilidad intergeneracional son especialmente limitadas y esto debe llamar a reflexionar sobre las políticas públicas y el papel fundamental del universalismo sensible a las diferencias mediante la acción afirmativa que nivele oportunidades y el acceso a la educación y la capacitación. La ruptura del círculo vicioso entre alta desigualdad y baja movilidad hace necesario contar con políticas públicas desde las etapas más tempranas de la vida de los individuos.

\section{Un mercado laboral ineficiente: la persistente informalidad}

La mayor parte de las economías en desarrollo se caracterizan por la importancia de su sector informal (Schneider, 2012; Tornarolli y otros, 2014; La Porta y Shleifer, 2014) y por altos niveles de desigualdad de ingresos. Distintos estudios documentan la asociación positiva entre desigualdad de ingresos e informalidad

9 Adicionalmente, los autores encuentran que el crecimiento económico y el gasto público progresivo presentan una asociación positiva con la movilidad intergeneracional. 
en América Latina (Attanasio y Binelli, 2010; Binelli, 2016; Amarante, Arim y Yapor, 2016). Sin embargo, en términos teóricos, es difícil distinguir la causalidad de la relación y, por lo tanto, aquí no se argumenta que la desigualdad necesariamente provoca informalidad, sino que estos fenómenos suelen presentarse conjuntamente.

Pueden distinguirse argumentos acerca de dicha causalidad en ambos sentidos. Por ejemplo, en Chong y Gradstein (2007) se presenta un modelo en el que el incremento de la desigualdad de ingresos lleva al aumento de la informalidad, debido a que implica menos beneficios relativos de la formalidad para los individuos más pobres. También se ha argumentado que el aumento de la desigualdad de ingresos genera una mayor demanda de bienes informales, lo que fomenta el crecimiento del sector informal (Mishra y Ray, 2013). Otros autores han hecho hincapié en el impacto de la informalidad sobre la desigualdad, argumentando que el incremento de la informalidad conlleva una menor recaudación impositiva y afecta la capacidad redistributiva directa e indirecta del Estado, incidiendo en la distribución del ingreso (Loayza, 1997; Johnson, Kaufmann y Zoido, 1998; Schneider y Enste, 2000).

La aproximación empírica a la informalidad no es sencilla. Se pueden distinguir dos maneras de abordar esta cuestión: una de ellas conceptualiza la informalidad a través de la baja productividad, mientras que la otra se apoya en la falta de cumplimiento de la normativa legal para caracterizar e identificar al sector informal. En el primer caso, y en las aproximaciones basadas en el empleo, se suele definir al sector de baja productividad o informal a partir de la propuesta tradicional de la Organización Internacional del Trabajo (OIT), considerando trabajadores informales a los del servicio doméstico, los familiares no remunerados, los trabajadores privados en establecimientos con menos de cinco empleados y los trabajadores por cuenta propia con y sin local, excluyendo a administrativos, profesionales y técnicos ${ }^{10}$. En el segundo caso, para clasificar a un trabajador como formal o informal, se suele considerar si realiza aportes a la seguridad social o no. En el cuadro IV. 1 se muestra la superposición entre ambas aproximaciones en los países de la región: en promedio, el 83\% de los trabajadores que se clasifican como de baja productividad no realizan aportes a la seguridad social (con variaciones que van desde el $56 \%$ en el Uruguay hasta el $98 \%$ en Honduras y que tienen que ver con el tipo de inserción laboral y con la legislación vigente). Análogamente, el 89\% de los trabajadores que aportan a la seguridad social se clasifican como de productividad media y alta.

\section{Cuadro IV.1}

América Latina (9 paises): nivel de productividad y aportes a la seguridad social, alrededor de 2016 (En porcentajes)

\begin{tabular}{|l|c|c|}
\hline & $\begin{array}{c}\text { Trabajadores que no aportan a la seguridad social } \\
\text { entre los trabajadores de baja productividad }\end{array}$ & $\begin{array}{c}\text { Trabajadores de productividad media y alta entre } \\
\text { los trabajadores que aportan a la seguridad social }\end{array}$ \\
\cline { 2 - 3 } \cline { 1 - 3 } Argentina & 87,5 & 92,6 \\
\hline Brasil & 63,6 & 78,7 \\
\hline Chile & 67,7 & 87,3 \\
\hline Colombia & 89,7 & 84,0 \\
\hline Honduras & 98,0 & 93,9 \\
\hline México & 95,1 & 93,1 \\
\hline Perú & 99,0 & 97,4 \\
\hline Uruguay & 55,8 & 79,3 \\
\hline Venezuela (República Bolivariana de) & 93,8 & 93,1 \\
\hline Promedio & 83,4 & 88,8 \\
\hline
\end{tabular}

Fuente: Comisión Económica para América Latina y el Caribe (CEPAL), sobre la base de encuestas de hogares de los respectivos países.

Nota: Los datos corresponden a 2016 en el caso de la Argentina, Colombia, Honduras y el Perú; a 2015 en el del Brasil, Chile, el Uruguay y Venezuela (República Bolivariana de), y a 2014 en el de México.

10 Esta es la definición utilizada en la XV Conferencia Internacional de Estadísticos del Trabajo (CIET). Sin embargo, en la XVII CIET se distingue entre el sector informal y el empleo informal. Combinando ambas unidades, se considera informal todo empleo informal tanto en empresas del sector formal como en empresas del sector informal o en hogares. Esta definición incluye: i) trabajadores por cuenta propia en sus propias empresas del sector informal, ii) empleadores en sus propias empresas del sector informal, iii) trabajadores familiares auxiliares, iv) miembros de cooperativas de productores informales, v) empleados que tienen trabajos informales definidos según la relación de trabajo (que no está sujeta a la legislación laboral nacional, impuestos, protección social o prestaciones) y vi) trabajadores por cuenta propia que producen bienes exclusivamente para el propio uso final de su hogar. 
Por otro lado, si observamos los ingresos relativos de los trabajadores, el orden en términos de ingresos laborales mensuales y por hora es el siguiente: los trabajadores de baja productividad que no aportan son los de menores ingresos relativos, seguidos por los de alta productividad (categoría que en realidad engloba a los de productividad media y alta) que no aportan. En tercer lugar se encuentran los de baja productividad que aportan y, finalmente, los de alta productividad que aportan, que son quienes cuentan con los mayores ingresos relativos.

Esto se puede apreciar a través de los coeficientes de las variables binarias que distinguen a cada uno de estos grupos en ecuaciones salariales para los distintos países, omitiendo la categoría de los trabajadores de baja productividad que no aportan (cuadro IV.2). Cada uno de esos coeficientes se interpreta como el diferencial salarial en relación con la categoría omitida. A modo de ejemplo, en la Argentina, los trabajadores clasificados como de alta productividad que no aportan perciben una remuneración mensual un $10 \%$ superior a los de baja productividad que no aportan. A su vez, el diferencial de ingresos es de un 55\% para los trabajadores de baja productividad que aportan y de un $76 \%$ para los de alta productividad que aportan. Es decir que la condición de aportar o no aportar a la seguridad social es determinante en el ordenamiento de los trabajadores de acuerdo con sus ingresos. Aun cuando puede resultar simplista asociar la presencia de aportes a la seguridad social con la calidad del empleo, y sin desconocer sus limitaciones, los datos sugieren que se trata de una aproximación bastante precisa.

\section{Cuadro IV.2}

América Latina (9 paises): diferencial salarial en relación con los trabajadores de baja productividad que no aportan a la seguridad social, alrededor de 2016

(En porcentajes)

\begin{tabular}{|l|c|c|c|}
\hline & $\begin{array}{c}\text { Trabajadores de productividad } \\
\text { media y alta que no aportan }\end{array}$ & $\begin{array}{c}\text { Trabajadores de productividad } \\
\text { baja que aportan }\end{array}$ & $\begin{array}{c}\text { Trabajadores de productividad } \\
\text { media y alta que aportan }\end{array}$ \\
\cline { 2 - 4 } \cline { 3 - 4 } Argentina & 10,1 & 55,3 & 75,8 \\
\hline Brasil & 23,8 & 52,0 & 63,8 \\
\hline Chile & 33,1 & 44,0 & 65,4 \\
\hline Colombia & 41,9 & 69,4 & 92,1 \\
\hline Honduras & 64,7 & 97,1 & 111,3 \\
\hline México & 48,0 & 73,4 & 107,8 \\
\hline Perú & 36,0 & 79,4 & 82,2 \\
\hline Uruguay & 32,3 & 81,5 & 103,8 \\
\hline Venezuela (República Bolivariana de) & 5,4 & 7,2 & 12,5 \\
\hline Promedio & 32,8 & 62,1 & 79,4 \\
\hline
\end{tabular}

Fuente: Comisión Económica para América Latina y el Caribe (CEPAL), sobre la base de encuestas de hogares de los respectivos países.

Nota: Los datos corresponden a 2016 en el caso de la Argentina, Colombia, Honduras y el Perú; a 2015 en el del Brasil, Chile, el Uruguay y Venezuela (República Bolivariana de), y a 2014 en el de México.

La correlación positiva entre desigualdad de ingresos e informalidad (medida a través de la falta de aportes a la seguridad social) está presente en la región, tanto si se considera la información agregada, como si se analizan las trayectorias de los países. La fuerte penalización de ingresos laborales asociada a la condición de informalidad que se observa en el gráfico IV.10 puede interpretarse como una pérdida de ingresos o productividad en el presente. En este sentido, es posible estimar, sobre la base de la población asalariada, los costos asociados con la informalidad, entendidos como dicha pérdida de ingresos laborales y expresados como porcentaje del PIB (véase el gráfico IV.11) 11. En los 11 países analizados, los ingresos laborales se ubicarían entre 1 y 10 puntos porcentuales por encima de sus valores actuales si no existiera la informalidad laboral.

11 Los cálculos realizados no tienen en cuenta las dinámicas que podrían desarrollarse en caso de cerrarse las brechas de informalidad en el mercado laboral; más bien ofrecen una imagen estática de las posibles ganancias en masa salarial que se observarían si los asalariados informales percibieran ingresos similares a los de los asalariados formales. 


\section{Gráfico IV.10}

América Latina (16 países): desigualdad salarial (coeficiente de Gini) e informalidad, 1990-2014

A. Todos los países

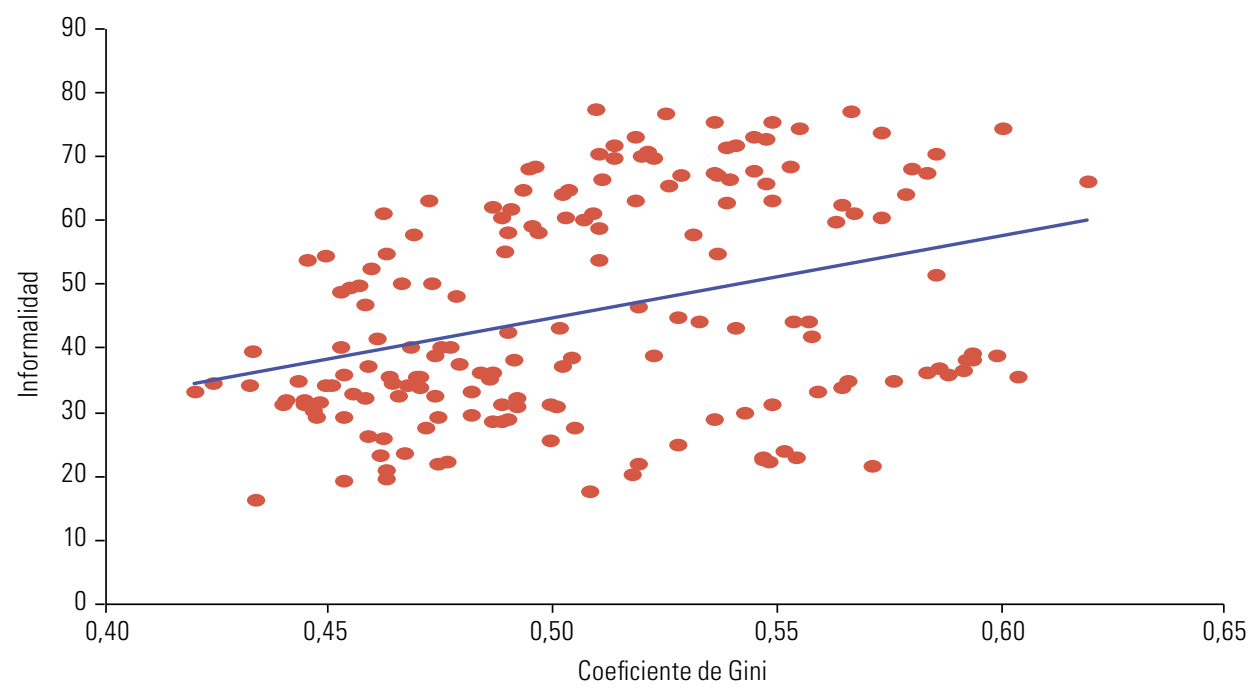

B. Por países

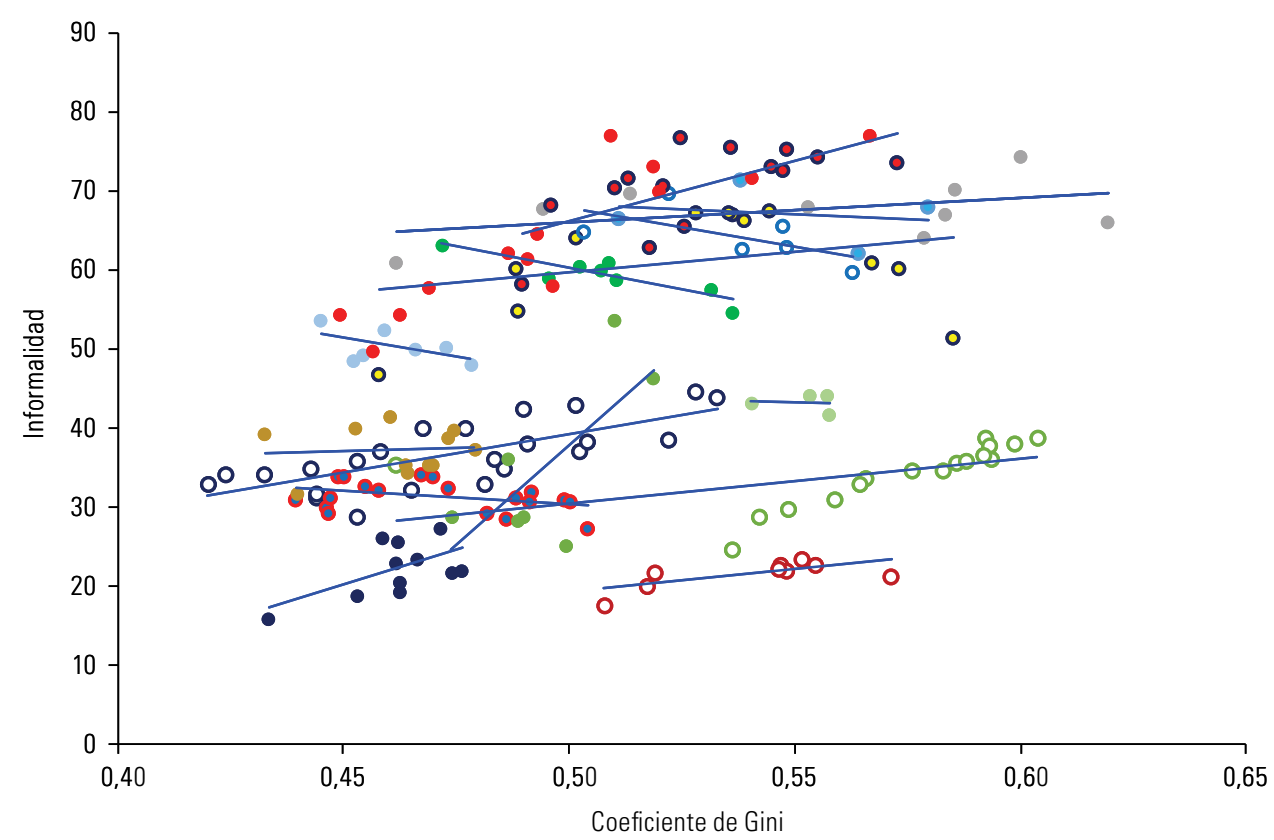

- Argentina

- Bolivia (Est. Plur. de)

- Brasil

- Chile

- Colombia

- Costa Rica

- Rep. Dominicana

- Ecuador

- El Salvador

- Guatemala

- México

- Nicaragua

- Paraguay

- Perú

- Uruguay

- Venezuela (Rep. Bol. de)

Fuente: Comisión Económica para América Latina y el Caribe (CEPAL), sobre la base de Universidad Nacional de la Plata/Banco Mundial, Base de Datos Socioeconómicos para América Latina y el Caribe (SEDLAC) [en línea] http://www.cedlas.econo.unlp.edu.ar/wp/estadisticas/sedlac/.

Nota: El concepto de informalidad se refiere a la falta de aportes a la seguridad social.

Por último, la informalidad genera costos relevantes en el mediano y largo plazo, en la medida en que implica que un alto porcentaje de los trabajadores no tendrá acceso a los beneficios jubilatorios contributivos al retirarse del mercado de trabajo. Para paliar esa ausencia de ingresos entre las personas mayores, los países deben realizar esfuerzos fiscales para expandir sus sistemas de protección social no contributiva, que surgen, en parte, como una alternativa frente a la falta de ahorro — solidario o individual - a lo largo de la vida laboral. Es un costo más provocado por los altos niveles de desigualdad e informalidad regionales, ya que, si no existiera esa informalidad, los recursos que deberían destinarse a las prestaciones no contributivas serían menores. La cobertura de las 
pensiones no contributivas varía considerablemente entre países, desde el $5 \%$ de la población de 60 años y más en El Salvador hasta la cobertura total de la población de 60 años y más en el Estado Plurinacional de Bolivia. Si bien el gasto aún representa un porcentaje relativamente bajo del PIB —el mayor peso corresponde al Estado Plurinacional de Bolivia, cuya pensión no contributiva, la Renta Dignidad, representa el 1,2\% del PIB-, el envejecimiento poblacional podría exigir mayores esfuerzos fiscales en el futuro (véase el gráfico IV.12).

\section{Gráfico IV.11}

América Latina (11 paises): pérdida salarial debida a la informalidad, alrededor de 2008 y 2016 (En porcentajes del PIB)

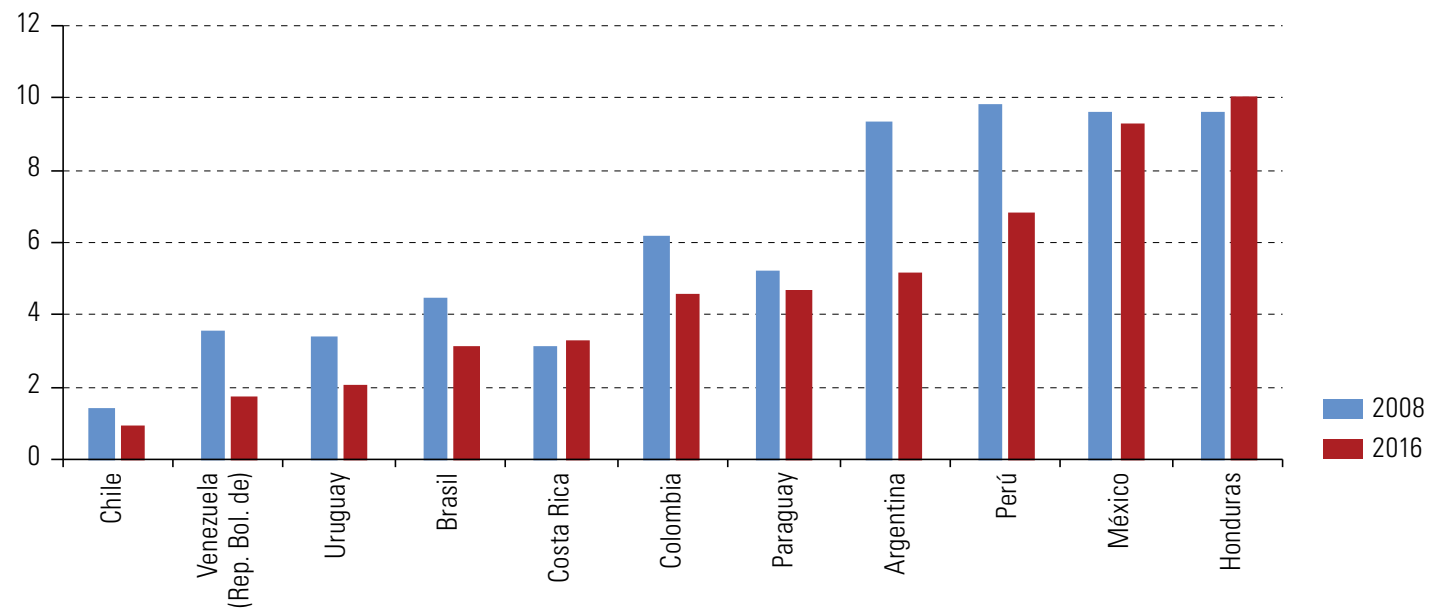

Fuente: Comisión Económica para América Latina y el Caribe (CEPAL), sobre la base de encuestas de hogares de los respectivos países.

Nota: Debido a la falta de datos actualizados, se utilizó la misma participación de la masa salarial (como porcentaje del PIB) para ambos años en el caso de la Argentina y el mismo registro de tasa de informalidad en el de la República Bolivariana de Venezuela. En el caso de Honduras se estimó la tasa de informalidad en función de los trabajadores que carecen de contrato laboral.

\section{Gráfico IV.12}

América Latina y el Caribe (15 países): cobertura y gasto de las pensiones no contributivas, 2015 (En porcentajes)

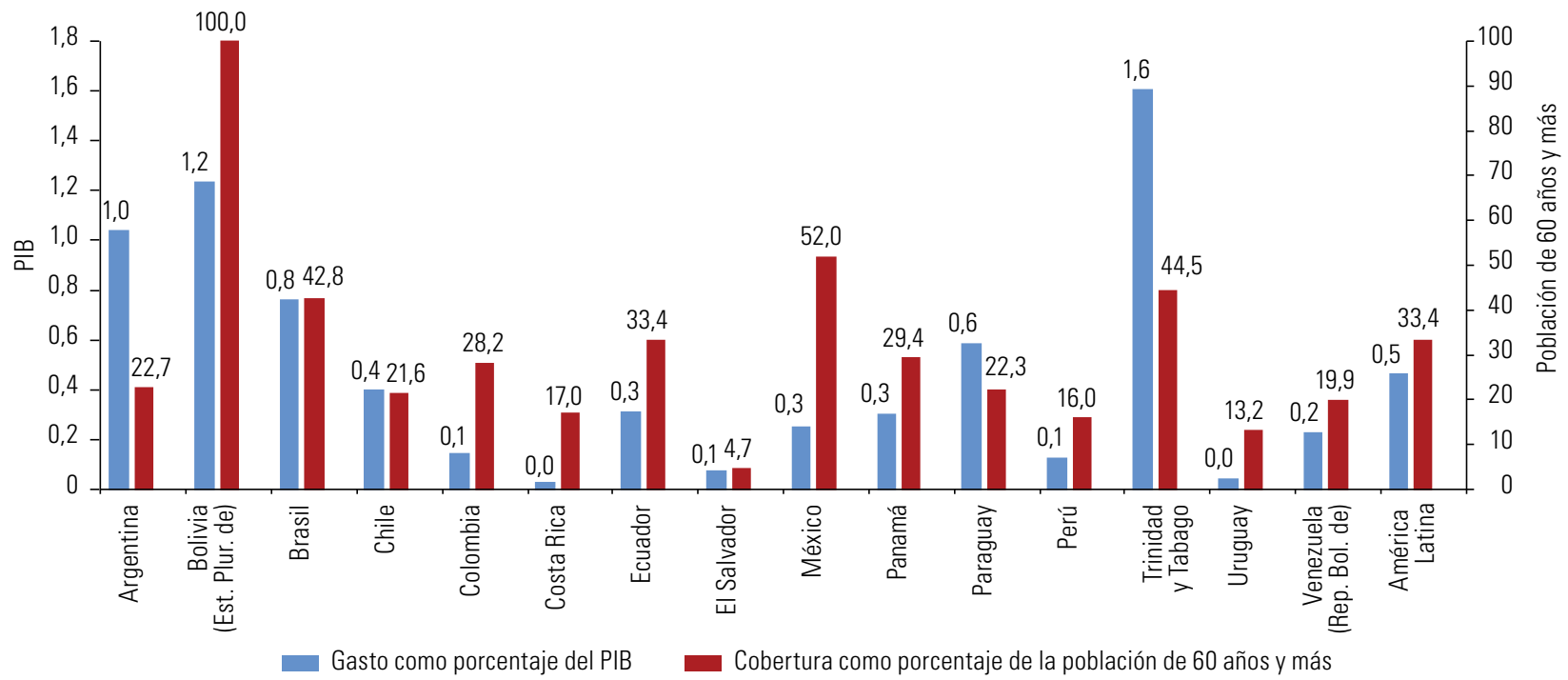

Fuente: Comisión Económica para América Latina y el Caribe (CEPAL), Base de datos de programas de protección social no contributiva en América Latina y el Caribe [en línea] http://dds.cepal.org/bpsnc/\#es.

Nota: Argentina: programa de pensiones no contributivas; Bolivia (Estado Plurinacional de): Renta Dignidad; Brasil: Beneficio de Prestación Continuada y Previdência Rural; Chile: Pensión Básica Solidaria; Colombia: Programa Colombia Mayor; Costa Rica: Régimen no Contributivo de Pensiones por Monto Básico; Ecuador: Pensión para Adultos Mayores del Bono de Desarrollo Humano; El Salvador: Nuestros Mayores Derechos; México: Programa de Pensión para Adultos Mayores y Pensión Alimentaria para Adultos Mayores de 68 años que Residen en la Ciudad de México; Panamá: 120 a los 65; Paraguay: Pensión Alimentaria para las Personas Adultas Mayores en Situación de Pobreza; Perú: Pensión 65; Trinidad y Tabago: Senior Citizens' Pension; Uruguay: pensiones no contributivas por vejez e invalidez; Venezuela (República Bolivariana de): Gran Misión en Amor Mayor. 


\section{Discriminación y oportunidades en el mercado laboral: la desigualdad de género}

El debate sobre la desigualdad suele centrarse en la dimensión vertical, es decir, en las diferencias entre ricos y pobres. Sin embargo, las desigualdades horizontales son también significativas, dado que reflejan la situación diferencial en función del sexo de las personas o la pertenencia a ciertos grupos de la población, como las poblaciones indígenas o afrodescendientes. Estas dos dimensiones de la desigualdad (vertical y horizontal) no están desconectadas, sino estrechamente relacionadas. Como plantea CEPAL (2017b), las diferencias de clase y las desigualdades de género, las étnicas y raciales, las relacionadas con las diferentes etapas del ciclo de vida y las territoriales son los ejes de la matriz de desigualdad social de América Latina. La existencia de estas desigualdades implica que el potencial de las personas no se desarrollará plenamente. Habrá un menor estímulo a la educación en el caso de las personas discriminadas (que no verán que esta se traduzca en mejores oportunidades laborales) y una pérdida de productividad y crecimiento en el conjunto de la sociedad.

Un ejercicio de estática comparativa desarrollado por CEPAL (2014) permite evaluar las ganancias que derivarían de eliminar las desigualdades de género en el mercado laboral. Con ese objetivo, se construyeron dos escenarios de cierre de las brechas de género presentes en dicho mercado: cierre de la brecha de participación y cierre de la brecha de ingresos salariales ${ }^{12}$. En primer lugar, se analizó qué sucedería si las mujeres en edades centrales (entre 14 y 65 años) presentaran tasas de actividad similares a las de los hombres, es decir, si se cerrara la brecha de participación entre hombres y mujeres. La segunda pregunta es qué sucedería si desaparecieran las desigualdades de ingresos entre hombres y mujeres. Se optó por eliminar las brechas de ingresos mensuales entre hombres y mujeres, lo que implica que no existiría diferencia en las horas trabajadas ${ }^{13}$. Por último, se analizó el cierre de ambas brechas de manera conjunta, considerando al mismo tiempo que se cierra la brecha de participación y que las mujeres que participan en el mercado laboral son remuneradas de igual forma que los hombres. Este es el escenario del que se esperan los mejores resultados, si se tiene en cuenta que los procesos más exitosos de inclusión de las mujeres en el mercado laboral, como el de los países nórdicos, se dan en el marco de un cierre progresivo y conjunto de ambas brechas.

En los tres escenarios se logran importantes incrementos en el ingreso de los hogares, con las consecuentes reducciones de pobreza y desigualdad. La magnitud de estos cambios dependerá del punto de partida de cada país y de dónde se ubican las mayores desigualdades de género en el mercado laboral. Si se cerrara la brecha de género en la tasa de actividad, se produciría un incremento del ingreso medio de los hogares que oscilaría entre el $3 \%$ y el $4 \%$ en la Argentina, el Brasil, Colombia, México y el Uruguay y alcanzaría niveles superiores al $10 \%$ en El Salvador, Honduras, Nicaragua y el Perú. Los países en que la tasa de actividad de las mujeres presenta una diferencia más marcada con respecto a la de los hombres son los que obtendrían mayores ganancias en términos del ingreso medio de los hogares si desaparecieran las brechas de participación (CEPAL, 2014b).

La eliminación de la brecha de ingresos entre hombres y mujeres genera incrementos inferiores a los observados en el escenario de participación, aunque positivos en la gran mayoría de los países. En Honduras la variación sería negativa, mientras que en México la variación sería nula y en la República Dominicana, de tan solo un $1 \%$. Esto se explica por el gran sesgo de selección que se observa en la ocupación de las mujeres en estos países, donde la participación más elevada corresponde a las mujeres de nivel educativo más elevado, que, por lo tanto, tienen mayores retornos esperados en el mercado laboral. Esto lleva a que se observen ingresos laborales promedio más altos entre las mujeres que entre los hombres y a que el cierre de la brecha provoque un descenso de los ingresos de las mujeres.

En todos los países, el cierre de ambas brechas de manera conjunta potencia los incrementos del ingreso promedio de los hogares obtenidos por separado (véase el gráfico IV.13). Esto se debe no solo a

12 En ambos ejercicios se controló por las características personales de mujeres y hombres que influyen en sus resultados en el mercado laboral; en especial, la edad y el nivel educativo.

13 Esto implica suponer que desaparecen los retornos diferentes al nivel educativo y a la experiencia que existen en el mercado y que favorecen a los hombres, y que hombres y mujeres reciben la misma remuneración en el mercado en función de su nivel educativo y edad. 
que se incorporarían al mercado laboral más mujeres, sino también a que estas mujeres, así como las que ya participan en el mercado, recibirían la misma remuneración que los hombres de iguales características. En este escenario, los ingresos de los hogares de América Latina serían considerablemente superiores, con incrementos que irían desde un 10\% en el Perú hasta más de un 30\% en Nicaragua.

\section{Gráfico IV.13}

América Latina (18 paises): cambios en el ingreso promedio de los hogares en tres escenarios de cierre de brechas de género (de participación, de ingresos y ambas), alrededor de 2012

(En porcentajes)

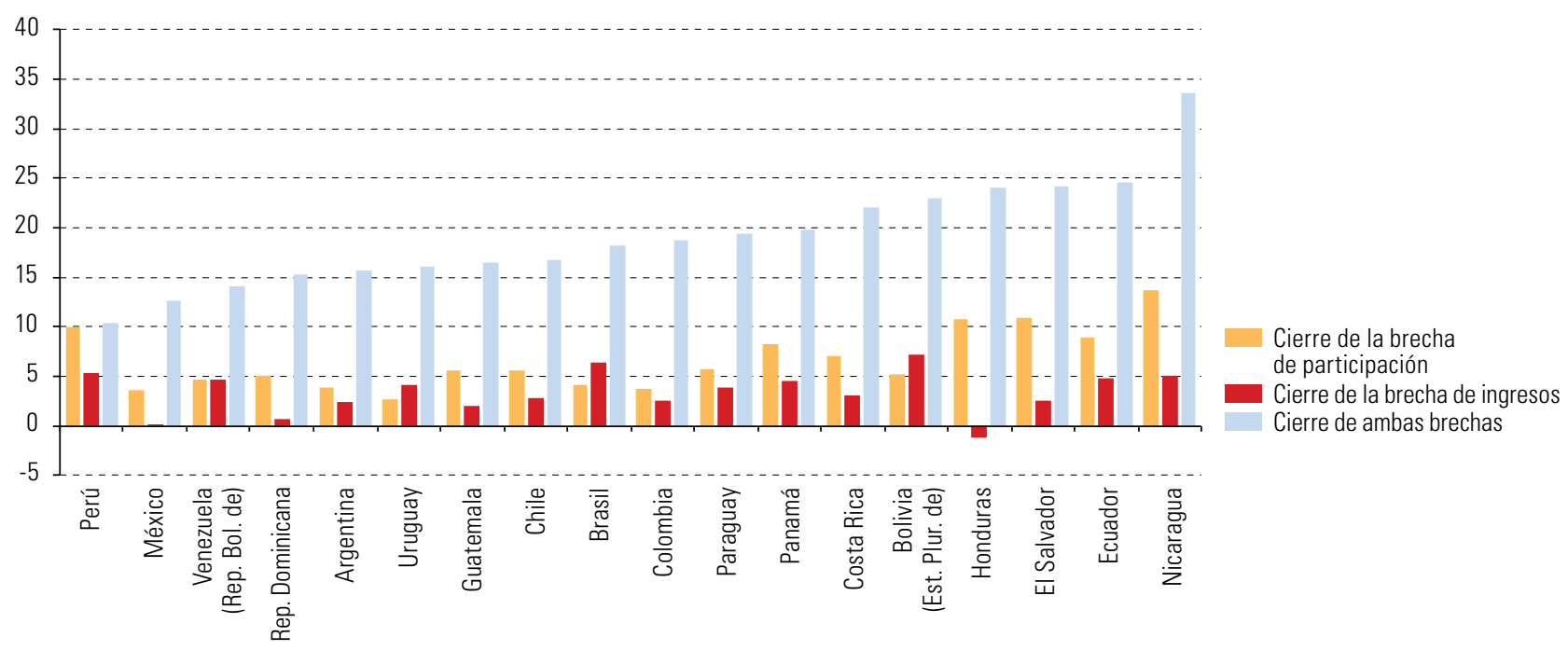

Fuente: Comisión Económica para América Latina y el Caribe (CEPAL), sobre la base de encuestas de hogares de los respectivos países.

Además de las consecuencias que produciría la incorporación de las mujeres al mercado de trabajo en términos del pleno ejercicio de su autonomía, la socialización más allá del hogar, la realización de capacidades y potencialidades y el acceso a la protección social contributiva, el ejercicio ilustra los efectos del incremento de los ingresos de los hogares, uno de los cuales sería la reducción de la pobreza. Por otra parte, las ganancias generadas por el aumento de la participación laboral femenina serían potencialmente superiores si las mujeres que se incorporaran al mercado de trabajo percibieran ingresos iguales a los de los hombres con el mismo nivel de calificación.

Se debe tener en cuenta que en este análisis no se consideran los efectos de equilibrio general, que podrían modificar los resultados de forma significativa. Por ejemplo, es esperable que los ingresos laborales de los hombres reaccionen al aumento de la oferta laboral dirigida a las mujeres. Asimismo, gran parte de las mujeres que no forman parte del mercado laboral realizan una proporción importante de las tareas no remuneradas que sostienen la reproducción de la fuerza de trabajo (cocinar, limpiar o cuidar de niños, personas mayores y enfermos, entre otras). Si las mujeres trabajaran en la misma medida que los hombres, no podrían realizar estas actividades de forma sostenible, por lo que estas tareas deberían redistribuirse entre los sexos y entre el Estado y las familias. En este sentido, las horas trabajadas de los hombres también reaccionarían ante un aumento de las horas trabajadas de las mujeres. A modo de ejemplo, en los países nórdicos, donde se han logrado los mayores avances en términos de igualdad de género en el mercado laboral, la tasa de actividad de los hombres es inferior a la observada en los países de América Latina (Amarante y Colacce, 2016). Esto muestra que la participación más equitativa de las mujeres y los hombres en el mercado laboral requiere ajustes simultáneos para ambos sexos.

Las desigualdades entre hombres y mujeres en relación con el tiempo dedicado al trabajo no remunerado están ampliamente documentadas en América Latina. En los últimos 25 años, la participación laboral femenina se incrementó significativamente: las tasas de actividad pasaron de un $41 \%$ en 1990 a alrededor de un 53\% en 2015. Sin embargo, esta participación continúa siendo sensiblemente inferior a la de los hombres y, entre las mujeres ocupadas, las horas de trabajo remuneradas son también menos que las de los hombres. Al mismo 
tiempo, los patrones de distribución del trabajo no remunerado en el interior de los hogares parecen ser más rígidos que los del trabajo remunerado. La consecuencia es que, en muchos países, la carga total de trabajo en los hogares es superior entre las mujeres que entre los hombres (CEPAL, 2017a).

Dada esta brecha, cabe preguntarse si las elecciones que realizan las parejas en el interior de los hogares en lo que respecta al reparto de la carga de trabajo remunerado y no remunerado son racionales desde el punto de vista económico. En otras palabras, si los mercados laborales presentan asimetrías de género que desincentivan la distribución equitativa del trabajo o si, por el contrario, son otros elementos asociados a las normas vigentes los que explican la persistencia de la división sexual del trabajo. Para abordar esta pregunta, se realiza un ejercicio de microsimulación sobre la base de encuestas de uso del tiempo en el cual se cierran, en primer lugar, las brechas entre hombres y mujeres ligadas a la división entre trabajo remunerado y no remunerado y, en segundo lugar, las brechas salariales. Posteriormente, se compara el ingreso laboral de los hogares en los distintos escenarios. La muestra seleccionada corresponde a hogares donde vive una pareja compuesta por un hombre y una mujer, al menos un integrante de la pareja está ocupado y ambos tienen entre 25 y 64 años $^{14}$.

Se parte de la situación real de los hogares, con la carga de trabajo remunerado y no remunerado que hombres y mujeres declaran en las encuestas, y se construyen dos escenarios. El primero consiste en suponer que la carga total de horas de trabajo remunerado y no remunerado del hogar se mantiene igual a la verdadera, pero las horas totales de trabajo remunerado y no remunerado del hogar se reparten de manera igualitaria entre los dos miembros de la pareja. Esto implica que, en promedio, los ingresos de los hogares se reducen en la parte que corresponde a la disminución de horas de trabajo remuneradas de los hombres y se incrementan en la parte que corresponde al aumento de horas remuneradas de las mujeres. El ingreso que percibirían las mujeres que se incorporan al mercado de trabajo sería igual al ingreso de mercado de las mujeres de la misma edad, región y nivel educativo, controlando por la presencia de hijos en el hogar. En el segundo escenario, se supone, además, que no existe brecha salarial entre hombres y mujeres, es decir, que las mujeres ganan lo mismo que los hombres de la misma edad y nivel educativo (controlando también por la presencia de hijos en el hogar).

En el gráfico IV.14 se muestra la distribución observada del trabajo remunerado y no remunerado promedio en la pareja. En los cinco países analizados, la distribución es similar: mientras que las mujeres realizan aproximadamente el $80 \%$ de las horas de trabajo no remunerado del hogar, los hombres realizan en torno al $70 \%$ de las horas de trabajo remunerado. En los ejercicios de simulación, ambos integrantes se dividen la carga de trabajo remunerado y no remunerado de manera equitativa (representada por la línea negra en el gráfico). En todos los países hay brechas de ingresos laborales entre hombres y mujeres, y estas brechas son significativamente menores cuando se consideran por hora que cuando se consideran en términos mensuales, debido a la diferencia de horas que dedican al trabajo remunerado los hombres y las mujeres.

Si las horas de trabajo remunerado y no remunerado se repartieran de manera equitativa entre hombres y mujeres, pero prevalecieran las desigualdades de ingresos laborales vigentes, el ingreso promedio de los hogares prácticamente no cambiaría, como se desprende de la comparación entre el escenario base y el escenario 1. Incluso se produciría una disminución relativamente significativa en el caso del Uruguay (gráfico IV.15). En este escenario, el reparto equitativo de las cargas de trabajo remunerado y no remunerado no cambiaría significativamente el ingreso de los hogares. En el escenario 2, donde además desaparecen las diferencias de ingresos laborales entre hombres y mujeres, sí se observa un alza importante en los ingresos promedio de los hogares.

En el escenario 1, aunque los ingresos de los hogares de al menos tres de los cinco países analizados no se verían mermados con una distribución equitativa del trabajo, en ellos se opta por una distribución desigual, probablemente a causa de las mayores dificultades de inserción laboral de las mujeres, así como de las normas prevalecientes, asociadas a un sistema de género hegemónico donde aún rige la visión tradicional sobre el rol femenino. En este caso, la discriminación de ingresos laborales y la segregación ocupacional podrían estar desempeñando un papel relevante a la hora de desincentivar la participación laboral femenina. Si la remuneración fuese la misma para ambos sexos (en función de las características de los individuos), los hogares podrían alcanzar un mayor nivel de bienestar económico del que poseen en la actualidad.

14 Sin desconocer la relevancia de otras conformaciones de hogar, el objetivo es restringir el análisis a un solo tipo de hogar. Los hogares escogidos representan el $21 \%$ del total en Chile, el $39 \%$ en México y el Uruguay, el $40 \%$ en Colombia y el $47 \%$ en el Perú. 


\section{Gráfico IV.14}

América Latina ( 5 países): distribución del trabajo remunerado y no remunerado en hogares donde vive una pareja, según sexo, 2007-2015

(En porcentajes)

\section{A. Trabajo remunerado}

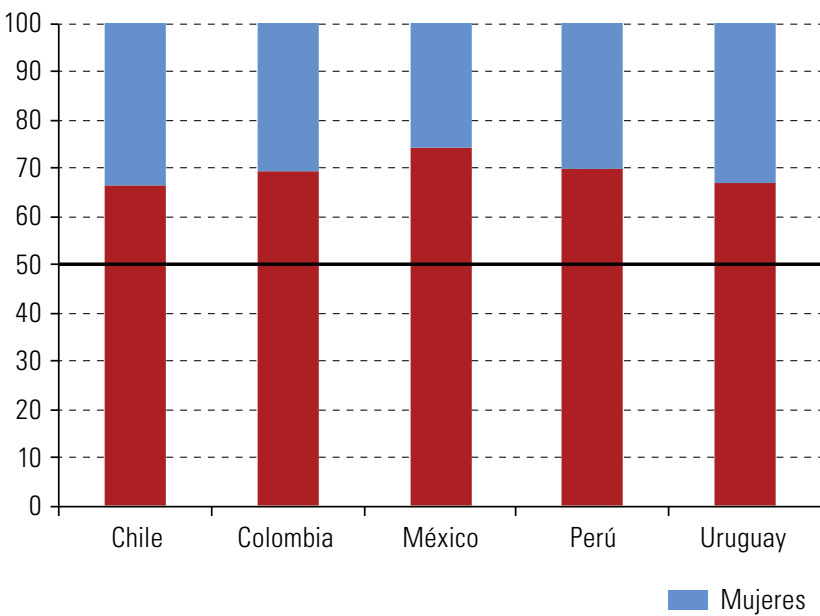

\section{B. Trabajo no remunerado}

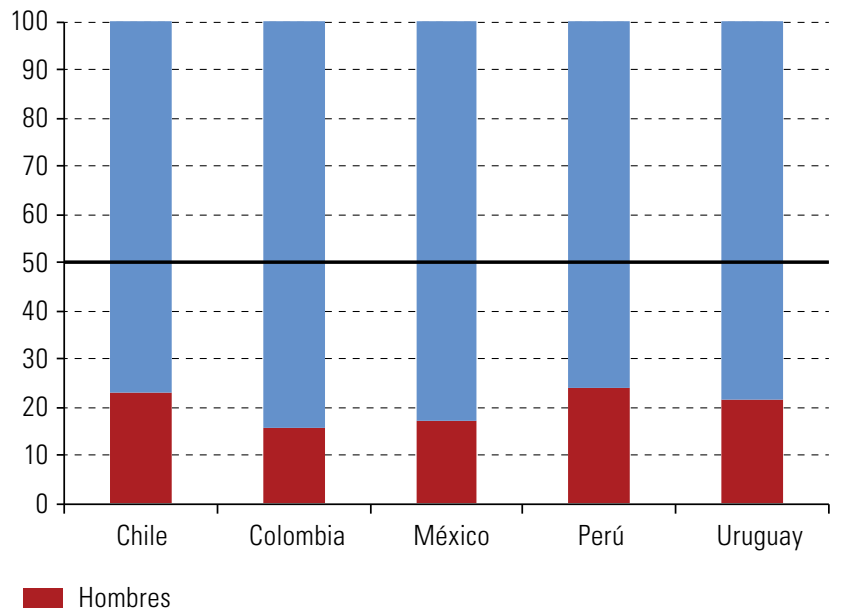

Fuente: Comisión Económica para América Latina y el Caribe (CEPAL), sobre la base de encuestas de uso del tiempo de los países seleccionados.

Nota: Los datos corresponden a 2015 en el caso de Chile, a 2010 en el de Colombia, el Perú y México y a 2007 en el del Uruguay.

\section{Gráfico IV.15}

América Latina (5 paises): ingreso de los hogares donde vive una pareja, escenarios 1 y 2 (Ingreso del hogar en escenario base=1)

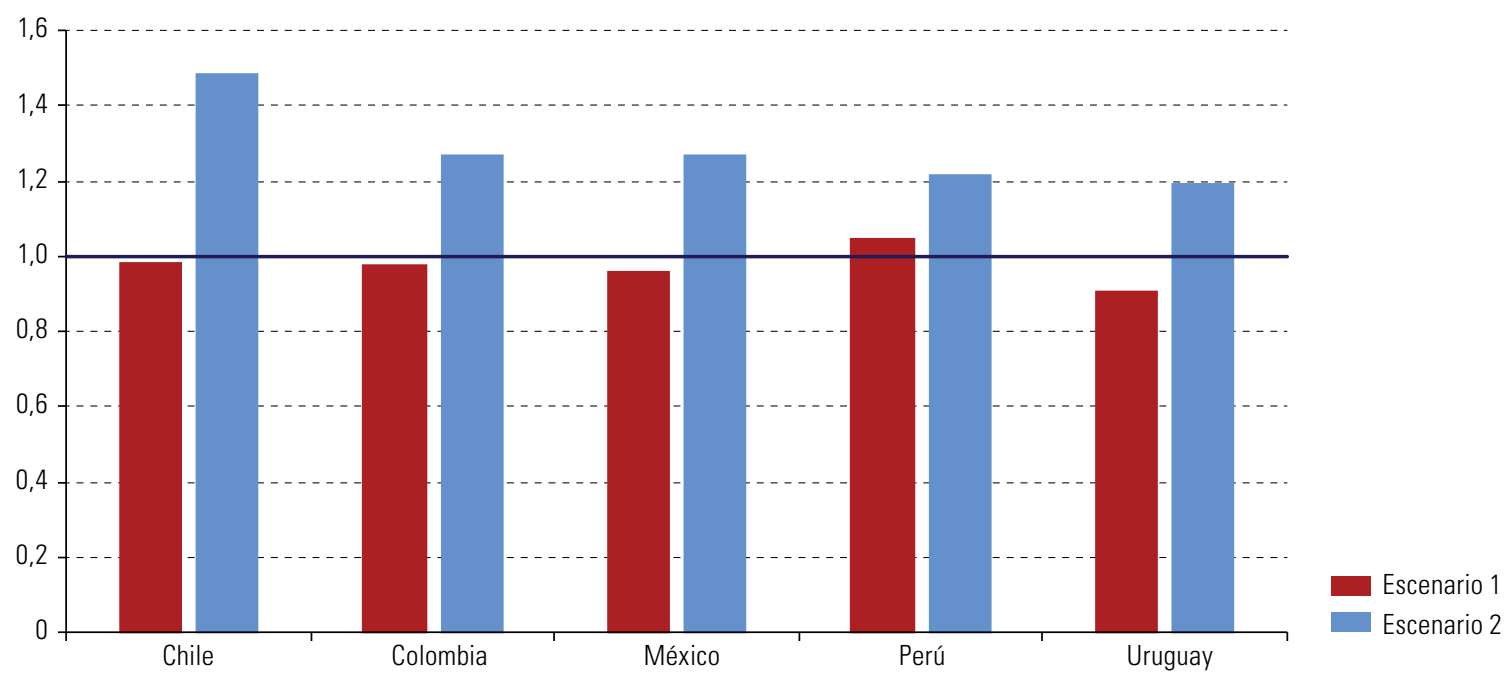

Fuente: Comisión Económica para América Latina y el Caribe (CEPAL), sobre la base de encuestas de uso del tiempo de los países seleccionados.

Nota: Los datos corresponden a 2015 en el caso de Chile, a 2010 en el de Colombia, el Perú y México y a 2007 en el del Uruguay.

El beneficio de una repartición más equitativa del trabajo no remunerado sería especialmente notable en los hogares de ingresos más bajos, donde la participación laboral femenina es menor. Sin embargo, las desigualdades de ingresos entre hombres y mujeres vigentes en los mercados laborales conspiran contra un reparto más equitativo de la carga de trabajo remunerado y no remunerado. Las políticas públicas, especialmente las referidas al mercado laboral y sus instituciones, deberían contribuir a generar las condiciones que incentiven un reparto más equitativo de dicha carga. 


\section{Efectos positivos de la protección social y el cuidado en el crecimiento y el empleo}

La protección social busca asegurar un nivel básico de ingresos, el acceso a los servicios —incluidos los de cuidado- y el desarrollo de las capacidades humanas y las oportunidades de trabajo decente a lo largo del ciclo de vida (Cecchini y Martínez, 2011). Contribuye a la realización de los derechos económicos, sociales y culturales, a la superación de la pobreza y a la reducción de la desigualdad, al tiempo que puede generar ganancias de productividad que impulsen el crecimiento (Arim, 2017; CEPAL, 2006).

La evidencia del impacto de las políticas de protección social proviene en gran medida del análisis de los programas de transferencias monetarias no contributivas para la superación de la pobreza. Esta evidencia permite adoptar una perspectiva diferente respecto de las políticas de protección social, que a menudo se consideran mecanismos de compensación potencialmente ineficientes que pueden generar dependencia de las políticas públicas, así como un problema para la sostenibilidad de las finanzas públicas.

La realidad muestra que esas transferencias han tenido efectos importantes en materia de matriculación, asistencia, progresión y retención escolar (CEPAL, 2014a) y han contribuido a mejorar el acceso a los servicios de salud, especialmente en relación con los controles preventivos y la cobertura de inmunización (Cecchini y Veras Soares, 2015). Sin embargo, las evaluaciones de impacto indican que los resultados en el aprendizaje, los resultados antropométricos y nutricionales y los efectos en el estado de salud son heterogéneos y dependen, en gran medida, de la cantidad y calidad de la oferta de servicios públicos universales (véase el recuadro IV.3).

Recuadro IV.3

Efectos de la protección social no contributiva en los indicadores finales de capacidades humanas

Existe vasta evidencia sobre los efectos positivos de los programas de transferencias condicionadas en la región. Báez y Camacho (2011) encuentran que los alumnos que participan en el programa Familias en Acción, de Colombia, tienen entre 4 y 8 puntos porcentuales más de probabilidades de terminar la secundaria que el grupo de control. García y otros (2012) señalan que la participación en dicho programa aumenta las puntuaciones en las pruebas estandarizadas de matemáticas en 1,07 desviaciones estándar. Barham, Macours y Maluccio (2013) y Barham y otros (2016) estiman los efectos de la Red de Protección Social de Nicaragua, diez años después de su inicio, en quienes participaron en el programa durante tres años, concentrándose principalmente en el logro educativo de los menores de edad que habian participado entre los 9 y los 12 años de edad. Sus resultados muestran una acumulación de 0,5 grados adicionales en la escuela y mejores resultados de aprendizaje. En México, el programa Prospera (antes denominado Oportunidades) ha contribuido a la reducción y casi desaparición de las brechas de género en la matriculación en estudios secundarios, sobre todo en zonas rurales (Parker, 2003), y ha incrementado la matricula y las tasas de promoción de los estudiantes indígenas (Escobar y González, 2002 y 2009). Por último, Rasella y otros (2013) indican que el programa Bolsa Família, en el Brasil, ha contribuido a disminuir un $17 \%$ la mortalidad de los niños menores de 5 años entre 2004 y 2009 , gracias a su efecto sobre las causas de muerte relacionadas con la pobreza, como la malnutrición y la disentería.

Fuente: Comisión Económica para América Latina y el Caribe (CEPAL), sobre la base de J. Baez y A. Camacho, "Assessing the long-term effects of conditional cash transfers on human capital: evidence from Colombia", IZA Discussion Paper, № 5751, Bonn, Institute for the Study of Labor (IZA), 2011; A. García y otros, "Impactos de largo plazo del programa Familias en Acción en municipios de menos de 100.000 habitantes en los aspectos claves del desarrollo del capital humano. Informe final", Bogotá, Unión Temporal Econometría/Departamento Nacional de Planeación (DNP), 2012 [en línea] https:// colaboracion.dnp.gov.co/CDT/Sinergia/Documentos/393_Impactos_de_Largo_Plazo_en_el_Programa_Familias_en_Accion_DOC.pdf; T. Barham, K. Macours y J. Maluccio, "More schooling and more learning? Effects of a three-year conditional cash transfer program in Nicaragua after 10 years", IDB Working Paper series, № 432, Washington, D.C., Banco Interamericano de Desarrollo (BID), 2013; T. Barham y otros, "Long-term impacts of conditional cash transfers in Latin America: review of the evidence", IDB Working Paper series, № 732, Washington, D.C., Banco Interamericano de Desarrollo (BID), 2016; S. Parker, "Evaluación del impacto de oportunidades sobre la inscripción escolar: primaria, secundaria y media superior", Documentos de Investigación, №6, Ciudad de México, Instituto Nacional de Salud Pública/Centro de Investigación y Docencia Económicas (CIDE), 2003; D. Rasella y otros, "Effect of a conditional cash transfer programme on childhood mortality: a nationwide analysis of Brazilian municipalities", The Lancet, vol. 382, № 9886, Amsterdam, Elsevier, 2013; A. Escobar y M. González, "Girls, mothers and poverty reduction in Mexico: evaluating Progresa-Oportunidades", The Gendered Impacts of Liberalization: Towards "Embedded Liberalism", S. Razavi (ed.) Nueva York, Routledge, 2009; "Documento final de diagnóstico cualitativo de hogares semiurbanos: localidades de 2500 a 50000 habitantes, 2001", Guadalajara, Centro de Investigaciones y Estudios Superiores en Antropología Social (CIESAS), 2002 [en línea] http://lanic.utexas.edu/project/etext/oportunidades/2002/escobar1.pdf. 
En relación con el empleo, los programas de transferencias monetarias para la superación de la pobreza no desincentivan la participación laboral a nivel de hogar y, de hecho, pueden fomentarla. Encontramos pruebas de ello tanto en ensayos controlados aleatorios en países de América Latina (Honduras, México y Nicaragua), Asia (Indonesia y Filipinas) y África (Marruecos) (Banerjee, Chassang y Snowberg, 2016) como en evaluaciones de impacto llevadas a cabo en América Latina (CEPAL, 2017a; CEPAL/OIT, 2014). En el caso del programa brasileño Bolsa Família, por ejemplo, la proporción de personas que buscan trabajo es significativamente mayor en los hogares usuarios del programa (De Oliveira y otros, 2007) y las tasas de participación laboral en los tres deciles inferiores de la distribución del ingreso son más elevadas entre los destinatarios del programa que entre los no destinatarios (Medeiros, Britto y Soares, 2008).

En Colombia, una evaluación de Familias en Acción muestra que este programa tiene un impacto positivo significativo sobre la tasa de ocupación en los hogares urbanos y redunda en una disminución de las tasas de inactividad y de desempleo de 3,2 puntos porcentuales y 0,7 puntos porcentuales, respectivamente. Además, genera un aumento del ingreso per cápita de los hogares de un $25 \%$ en promedio (Núñez, 2011). Los resultados relacionados con la inclusión laboral de las mujeres son mixtos (Holmes y otros, 2010). Los efectos diferenciados en hombres y mujeres se deben a razones que pueden actuar con diferente peso en cada caso, dependiendo de factores como el diseño de las condicionalidades, las características de los mercados de trabajo locales y la disponibilidad de servicios o prestaciones relacionadas con el cuidado. Una de ellas es el tiempo requerido para cumplir las condicionalidades de los programas y la carga de responsabilidad que ello representa, asignada primordialmente a las mujeres (CEPAL, 2014 y 2017b; Martínez y Voorend, 2008). Otra razón es que recibir regularmente la transferencia, aunque el monto sea pequeño, permite a las mujeres —insertas en el mercado de trabajo en peores condiciones que los hombres- no someterse a condiciones de trabajo demasiado desfavorables, como ingresos bajos, jornadas extensas, largos tiempos de desplazamiento entre la casa y el trabajo o la exposición a abusos (CEPAL, 2017a).

Los canales mediante los cuales la protección social puede afectar la productividad son diversos, están interconectados y se pueden dar a nivel micro —individual o de los hogares-, meso —comunidades y economías locales- y macro (Alderman y Yemtsov, 2012). Mediante la interacción de estos tres niveles $-\mathrm{y}$ la articulación con estrategias de desarrollo productivo y de promoción del trabajo decente, con enfoque de género y de promoción de la igualdad étnica y racial—, la protección social puede contribuir a crear un círculo virtuoso de generación de ingresos autónomos, con importantes efectos multiplicadores (CEPAL, 2017a; Hanlon, Barrientos y Hulme, 2010; Samson, 2009) ${ }^{15}$

A nivel individual, la protección social mejora los niveles de educación y salud, así como los indicadores de empleo y la capacidad de generar ingresos en las familias (Hanlon, Barrientos y Hulme, 2010; Samson, 2009). Las transferencias monetarias tienen también efectos multiplicadores sobre las economías locales, al aumentar el consumo y la demanda. Los participantes de los programas de protección social no contributiva gastan gran parte de las transferencias monetarias recibidas de los programas a nivel local, particularmente en alimentos (Cecchini, 2014; Ibarrarrán y otros, 2017), lo que genera externalidades positivas sobre los hogares no usuarios de los programas o los propietarios de negocios ${ }^{16}$. A nivel comunitario, el efecto multiplicador ocurre gracias a una mayor inversión pública en infraestructura.

Con respecto a las pensiones rurales en el Brasil, Schwarzer (2000) describe el efecto dinamizador del aumento del poder de compra de quienes reciben las transferencias monetarias en las economías de los municipios del estado de Paraná. El día de pago es cuando se "mueve la rueda de la economía" en las pequeñas localidades rurales y muchas empresas —entre las que se cuentan los bancos comerciales_ logran ganancias gracias a esas transferencias. Se han observado resultados similares en el caso de Bolsa Família: Luiz Pereira y otros (2008) encuentran que, en los cinco municipios de menor índice de desarrollo humano del

15 La magnitud del impacto de la protección social en el crecimiento económico se ve influida por el tamaño del gasto en protección social y su distribución. Aunque la protección social tenga efectos en la capacidad productiva a nivel individual o comunitario, es poco probable que su efecto directo sea significativo en el crecimiento agregado en países con bajos niveles de gasto social y gran desigualdad (Mathers y Slater, 2014).

16 Davis, Di Giuseppe y Zezza (2017), mediante modelos de equilibrio general basados en microdatos de encuestas de hogares, calculan los multiplicadores de las transferencias monetarias de siete programas en África Subsahariana y encuentran que todos generan efectos positivos en la economía local. Los multiplicadores de los ingresos reales oscilan entre 1,08 (Kenia) y 1,81 (Etiopía). 
Brasil en 2006, las transferencias monetarias del programa implican aumentos importantes en las ganancias de las tiendas que venden alimentos y que, si no existiera el programa, el comercio perdería un 40\% de sus ingresos. Asimismo, Landim (2009) muestra, para 5.500 municipios brasileños, que un incremento de un $10 \%$ anual per cápita de las transferencias del programa Bolsa Família aumenta el PIB municipal en un 0,6\%, debido en buena medida al aumento de la actividad comercial ${ }^{17}$.

A nivel agregado, el impacto de la protección social —contributiva y no contributiva— puede darse a raíz de las variaciones en la demanda agregada, los cambios en la participación laboral agregada y la activación de los mercados de capitales, por ejemplo, a través de los fondos de pensiones (Mathers y Slater, 2014; Alderman y Yemtsov, 2012), así como de la promoción de la cohesión social y la reducción de la violencia, acciones que contribuyen a crear un entorno más propicio para el crecimiento. Asimismo, la protección social puede actuar como un estabilizador económico durante las crisis, sosteniendo la demanda interna (Videt, 2014).

El efecto multiplicador de la protección social no actúa solamente a nivel local, sino también en el conjunto de la economía. En los Estados Unidos, en el marco del paquete de estímulo fiscal del gobierno de Barack Obama que se implementó para hacer frente a la crisis financiera de 2008, un incremento de un dólar en los cupones de alimentos tuvo un efecto multiplicador de 1,73 dólares del PIB, al tiempo que la extensión de los beneficios del seguro de desempleo generó un aumento de 1,63 dólares del PIB por cada dólar gastado (Zandi, 2009). A su vez, Chimerine, Black y Coffey (1999) estiman que el seguro de desempleo en los Estados Unidos desempeñó un papel anticíclico significativo en los cambios en el PIB real durante tres décadas, gracias a lo cual se conservaron en promedio 131.000 empleos anuales, y que cada dólar agregado a la economía por el seguro de desempleo incrementó el PIB en 2,15 dólares ${ }^{18}$. En el caso del Brasil, Mostafa, Monteiro y Ferreira (2010) y Côrtes, Monteiro y Guimarães (2013) estimaron los multiplicadores de corto plazo para transferencias monetarias gubernamentales. Sus resultados muestran que Bolsa Família tiene un efecto mayor que las demás prestaciones; por ejemplo, cada real invertido en el programa en 2009 agregó 1,78 reales al PIB del país ${ }^{19}$.

Otras políticas que buscan incrementar la igualdad y cuyos efectos pueden ser relevantes en relación con la productividad son las de cuidado infantil. Los sistemas de protección social en países desarrollados han hecho esfuerzos importantes para aumentar la extensión del cuidado infantil, basándose en distintos argumentos. Por un lado, la evidencia sobre los altos retornos de la educación inicial, en particular en el caso de los hogares que sufren mayores niveles de privación, es abundante y ha comenzado a ser utilizada como uno de los principales argumentos para la inversión en políticas públicas dirigidas a este grupo etario. Los trabajos más recientes sobre educación sostienen no solo que las habilidades adquiridas en las primeras etapas de la vida tienen rendimientos acumulativos sobre la adquisición de capacidades en las etapas siguientes, sino que, además, algunas habilidades son más difíciles de alcanzar después de cierta edad (Cunha y otros, 2006; Cunha y Heckman, 2010). Por otro lado, los servicios de cuidado infantil son un medio para estimular el mercado laboral y avanzar hacia la igualdad de género mediante el aumento de la tasa de participación laboral femenina.

En los países en desarrollo, las experiencias de políticas de esta índole, así como el análisis de sus efectos, son más recientes ${ }^{20}$. En relación con los efectos en el desarrollo infantil, los datos se concentran en los programas de cuidado o desarrollo infantil focalizados en los niños más vulnerables, y los resultados son, por lo general, positivos. Probablemente esto se debe a las alternativas que tendrían esos niños si no asistieran a un centro de cuidados, es decir, lo que harían si no dispusieran de estos servicios. Los efectos dependen de la calidad de los servicios y del cuidado y la estimulación que recibirían en sus casas. En el caso de los niños

17 Adicionalmente, se observa que el dinero invertido en el programa regresa a las arcas públicas municipales. Así, un aumento del 10\% de la población destinataria incrementa en promedio la recaudación de impuestos municipal en un 1,05\%, mientras que un aumento del 10\% en el valor de las transferencias incrementa la recaudación en un $1,36 \%$.

18 El seguro de desempleo cubrió en promedio a 5 millones de personas en el momento más crítico de las recesiones, atenuando la pérdida de PIB real en aproximadamente un 15\% trimestral durante las cinco recesiones que se presentaron entre 1969 y principios de la década de 1990.

19 Las otras prestaciones analizadas son el Beneficio de Prestación Continua (BPC), el seguro de desempleo, el abono salarial, el Régimen General de Previsión Social, el Régimen Propio de Previsión Social y el Fondo de Garantía del Tiempo de Servicio (FGTS).

20 El principal problema de las evaluaciones es la identificación del efecto causal de las políticas, ya que las familias que optan por la utilización de los servicios de cuidado tienen, por lo general, particularidades que pueden repercutir en la participación laboral de las mujeres y en el desarrollo de los niños, aun si no asistieran a estos servicios. La revisión se centra en los estudios que toman en cuenta esta endogeneidad, concentrándose en evaluaciones de impacto (ex post) de los programas de cuidado infantil. 
que provienen de contextos más desfavorecidos y cuyos cuidadores (madres, padres o abuelos, entre otros) tienen bajos niveles educativos, incluso los servicios de baja calidad pueden tener consecuencias positivas en su desarrollo cognitivo y no cognitivo (Cascio y Whitmore, 2013).

La situación de los servicios universales de cuidado infantil es ambigua. En la revisión bibliográfica que presenta Cascio (2015), se encuentran efectos positivos en los resultados cognitivos y no cognitivos. Asimismo, los servicios de alta calidad pueden aumentar la asistencia de los adultos a centros educativos y su empleabilidad. En casi todos los estudios, los resultados son mejores para los niños que provienen de hogares más vulnerables, aunque los resultados positivos disminuyen o desaparecen a medida que crecen. En los casos en que la calidad es baja, los efectos de las políticas de cuidado pueden incluso ser negativos.

En América Latina, los investigadores documentan efectos positivos en el desarrollo de los niños, aun cuando la calidad de los servicios difiere sustancialmente entre los países y territorios de esta región ${ }^{21}$. En el Ecuador y en uno de los estudios disponibles sobre Chile, se concluye que los servicios de cuidado de baja calidad producen efectos negativos. En general, dichos efectos dependen de la edad (son mayores en el caso de los niños de más edad), la vulnerabilidad de los hogares y la duración de la exposición al programa (una exposición más prolongada potencia los efectos). En los estudios en que se evalúan los efectos (en la Argentina, Colombia y el Uruguay), años después de la asistencia del niño al servicio de cuidado, se comprueba que estos son persistentes. Respecto a la participación laboral de las mujeres, Del Boca (2015) se centra en estudios realizados en Europa y los Estados Unidos y encuentra que los efectos dependen del punto de partida de cada país en relación con esa variable. En países donde la participación era relativamente baja, los programas de cuidado infantil producen por lo general efectos positivos. Si la participación era alta, los programas no logran mejoras en la oferta laboral dirigida a las mujeres y generan básicamente un efecto de desplazamiento entre los cuidados informales y los formales. En general, los efectos difieren entre grupos y benefician más a las mujeres con menor nivel educativo.

En América Latina, los estudios que analizan los efectos de los servicios de cuidado infantil en la participación laboral de las madres muestran la importancia de contar con programas cuya extensión horaria cubra la jornada laboral, así como el efecto significativo del número de hijos y de sus edades, incluidos los que no se ven directamente afectados por la política evaluada ${ }^{22}$. En Chile, donde los servicios de cuidado a menores de 6 años son de horario parcial y, por lo tanto, no permiten combinar la vida laboral de las madres con el trabajo remunerado a tiempo completo, no se producen efectos sobre su participación laboral. Sin embargo, cuando se analizan los programas de extensión del horario escolar, sí se encuentran efectos positivos y significativos.

En la Argentina, el efecto en la participación laboral de las mujeres se observa exclusivamente en los casos en que el hijo que accede al servicio de preescolar es el menor, mientras que en el Uruguay se encuentra un efecto positivo de las escuelas de tiempo completo sobre la participación laboral de las madres que no conviven con niños menores de 6 años. Los resultados de los estudios realizados en Río de Janeiro, Colombia, el Ecuador y México, que se refieren a programas más focalizados en situaciones de vulnerabilidad, son siempre positivos y los efectos son mayores para las madres que no trabajaban antes de que sus hijos accedieran al programa.

21 Los estudios de programas focalizados a los que se hace referencia son Behrman, Cheng y Todd (2004) sobre el Estado Plurinacional de Bolivia, Attanasio, Meghir y Vera-Hernández (2007) y Bernal y otros (2009) sobre Colombia, Rosero y Oosterbeek (2011) sobre el Ecuador, Ángeles y otros (2011) sobre México y Urzúa y Veramendi (2011) y Noboa-Hidalgo y Urzúa (2012) sobre Chile. Cuatro estudios analizan programas universales: Berlinski, Galiani y Gertler (2009) en la Argentina y Berlinski, Galiani y Manacorda (2008), Borraz y Cid (2013) y Mullin y Vairo (2015) en el Uruguay.

22 Se hace referencia a los estudios de Berlinski y Galiani (2007) y Berlinski, Galiani y McEwan (2011) sobre la Argentina, Nollenberger y Perazzo (2016) y Vairo (2014) sobre el Uruguay, Barros y otros (2011) sobre Río de Janeiro, Attanasio, Meghir y Vera-Hernández (2007) sobre Colombia, Rosero y Oosterbeek (2011) sobre el Ecuador y Ángeles y otros (2011) sobre México. Destaca el elevado número de estudios sobre Chile: Encina y Martínez (2009), Medrano (2009), Aguirre (2011), Bentancor (2013), Manley y Vázquez (2013), Contreras, Sepúlveda y Cabrera (2010) y Martínez y Perticará (2017). 


\section{B. Desafíos futuros: los cambios demográficos y la revolución tecnológica}

La estructura productiva, la distribución del ingreso, las relaciones de género y étnico-raciales, el territorio y el medioambiente son eslabones críticos para el logro de los Objetivos de la Agenda 2030, pues tejen vínculos que aumentan las brechas. Reconocer sus interacciones es imprescindible para superar esas brechas y cumplir el mandato de que nadie se quede atrás. El análisis desarrollado en las secciones anteriores de este capítulo alerta sobre los fuertes efectos de la desigualdad en la productividad y los desafíos que enfrentan los países de la región. Ahora es necesario proyectar estos desafíos hacia el futuro.

Dos elementos deben incorporarse al análisis, debido a la relevancia de su probable impacto en la productividad. Por un lado, las transformaciones demográficas que los países de la región atraviesan a diferentes ritmos tendrán implicancias muy diversas en términos de su productividad. Por otro lado, la dinámica del cambio tecnológico genera inquietudes en relación con sus posibles efectos sobre el mercado de trabajo. El logro de niveles de productividad más elevados mediante el uso de tecnologías avanzadas puede implicar disrupciones significativas en el corto plazo, al volver obsoletas las habilidades de algunos trabajadores y desplazarlos potencialmente del mercado laboral. En ambos procesos, no hay destinos inexorables, sino el imperativo de anticiparse mediante el diálogo social y las respuestas de política pública adecuadas a cada país.

\section{Los efectos del envejecimiento, la participación laboral femenina y la educación}

La transición demográfica implica el progresivo envejecimiento de la población —es decir, la disminución del número de niños y el aumento del de personas mayores-y, en general, una tendencia a la estabilización de la estructura poblacional. Este proceso es el resultado de la disminución de las tasas de fecundidad y de mortalidad, reflejo del desarrollo. Sin embargo, en la región, el avance de este proceso es dispar. En muchos países, el período en el que se registra el porcentaje más elevado de población en edad de trabajar y con capacidad de ahorrar, conocido como bono demográfico, durará aún varios años. En otros, su final se encuentra más cercano. En ambos casos, es pertinente analizar los desafíos que se presentarán para sostener el crecimiento.

Para ello, se elaboraron tres escenarios que reflejan qué sucedería con la mano de obra y la productividad de los países en 2050: i) si solamente se produjeran cambios demográficos, pero se mantuvieran constantes los niveles de actividad por tramo de edad y sexo actuales de cada país; ii) si, además de los cambios demográficos, se incrementara la tasa de actividad femenina y se alcanzaran las tasas de los países que tienen mejores desempeños en la actualidad, y iii) si se produjera un aumento del nivel educativo de la población ${ }^{23}$. Estos escenarios no son proyecciones de lo que sucederá con los niveles de actividad y la productividad de los países de la región, sino que se elaboran para motivar el análisis de las trayectorias posibles ${ }^{24}$. Aunque los flujos migratorios pueden alterar la oferta de trabajo y su productividad, no se consideran en este ejercicio debido a la complejidad de su modelización ${ }^{25}$.

En el gráfico IV.16 se presentan los resultados para cinco países —cada uno de ellos representativo de un grupo de países con características similares— de la evolución de la tasa de actividad, que refleja la oferta

23 El detalle de la construcción de estos escenarios se puede consultar en Colacce y Manzi (2017). Las proyecciones de base de los escenarios i y ii difieren de las del escenario iii, dado que en este último se toman en cuenta los efectos de la educación y su evolución en los niveles de fecundidad y mortalidad. Para el escenario iii, se toma en cuenta la propuesta de Lutz, Butz y Samir (2014).

24 La elaboración de proyecciones de la población económicamente activa (PEA) y, por ende, de la tasa de actividad ha sido abordada, entre otros, por CEPAL (2017b). En este trabajo se encuentra que el efecto puramente demográfico llevaría a un aumento de la PEA de 203 millones de personas entre 1980 y 2050 . Por otro lado, el efecto participación, obtenido de mantener las estructuras de edad de 1980 pero permitiendo la variación de la participación, sería un aumento de la PEA de 185 millones de personas en el mismo período.

25 La modelización de la migración es muy difícil, debido a la imprevisibilidad de la combinación de las condiciones que operan como causas endógenas en los países de origen y las condiciones en los países de destino. En los dos conjuntos de proyecciones de población utilizados se supone que los flujos de migración se mantienen constantes hasta 2050 
laboral $^{26}$. Hay importantes diferencias entre los países y entre los escenarios para cada país, en lo referido tanto a los niveles como a la evolución. En el escenario demográfico, la tasa de actividad disminuye en tres de los cinco grupos de países. Esto implica que, en la mayoría de los países de la región, la evolución esperada de la composición por edad y sexo de la población presionaría a la baja la tasa de actividad, dado que crecería el peso de las personas mayores, que participan menos del mercado laboral. De hecho, cuando se observa esta tasa en las edades centrales (entre 20 y 59 años), las caídas son mucho más moderadas, lo que indica que el descenso observado se explica por el aumento del peso de los tramos de edad más avanzada.

\section{Gráfico IV.16}

América Latina (5 paises): evolución de la tasa de actividad por países y escenarios, 2015-2050 (En porcentajes)

\section{A. Cambio demográfico}

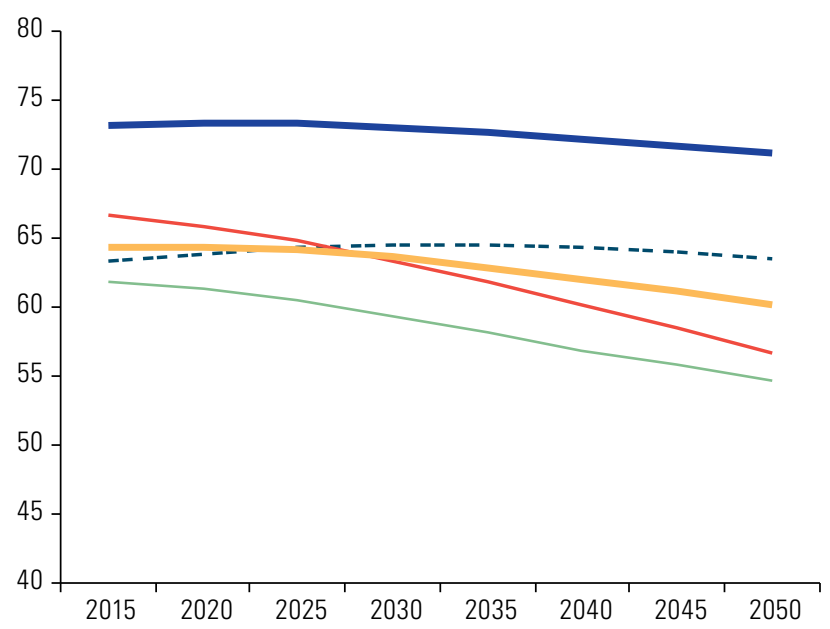

\section{Aumento del nivel educativo}

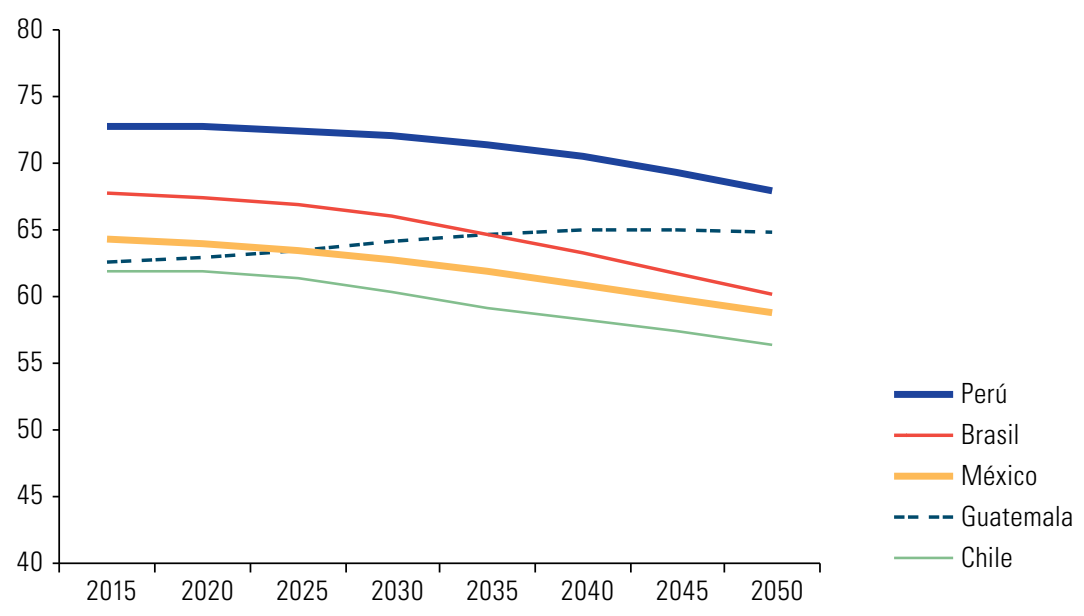

\section{B. Aumento de la tasa de actividad femenina}

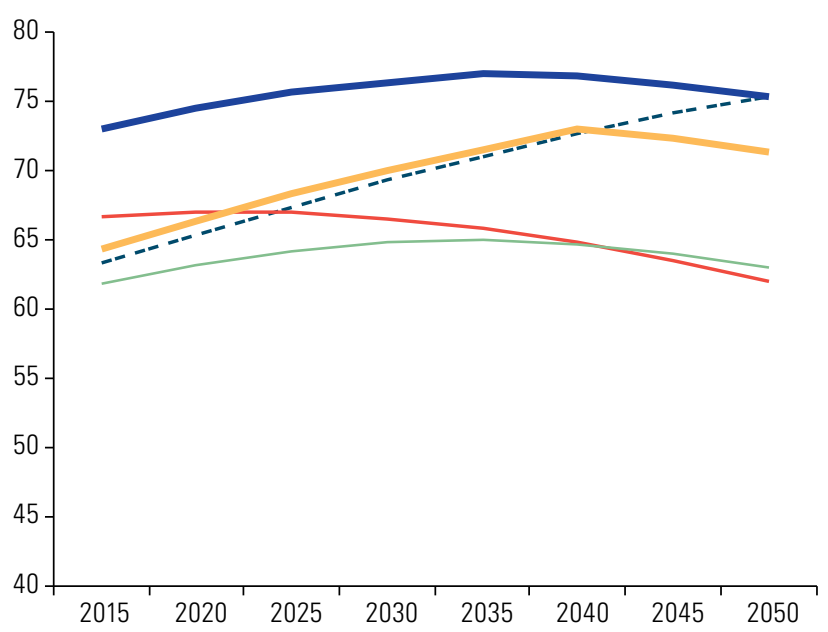

Fuente: Comisión Económica para América Latina y el Caribe (CEPAL), sobre la base de Naciones Unidas, "World Population Prospects: The 2017 Revision", 2017 [en línea] https://esa.un.org/unpd/wpp/; y Wittgenstein Centre for Demography and Global Human Capital, "Wittgenstein Centre Data Explorer" [en línea] http://www.wittgensteincentre.org/dataexplorer.

26 Los grupos, construidos sobre la base de la técnica estadística de clústers, son: i) Argentina, Chile, Costa Rica y República Dominicana; ii) Ecuador, Panamá, Venezuela (República Bolivariana de), El Salvador y México; iii) Brasil y Uruguay; iv) Guatemala, Honduras y Nicaragua, y v) Bolivia (Estado Plurinacional de), Colombia, Paraguay y Perú. En Colacce y Manzi (2017) se detalla la metodología de construcción de los grupos. En los casos en que se encuentran diferencias importantes entre el país seleccionado como representante del clúster y alguno de los países que lo componen, se señala en una nota al pie. 
Los efectos son más acusados en los países en los que la transición demográfica está más avanzada, representados por los resultados del Brasil y Chile, que registrarían tasas de actividad significativamente menores en el horizonte temporal analizado. En el otro extremo, los países representados por Guatemala (Guatemala, Honduras y Nicaragua) y el Perú (Bolivia (Estado Plurinacional de), Paraguay y Perú), no enfrentan riesgos de disminución de la población activa por factores demográficos, dado que su transición demográfica aún se encuentra en etapas incipientes ${ }^{27}$.

Frente a la presión ejercida por la estructura de edad y sexo de la población, los otros dos escenarios consideran factores exógenos a la demografía que pueden influir directamente en los niveles de actividad de la población y explican gran parte de la evolución pasada de la tasa de actividad: la incorporación masiva de las mujeres y el aumento del nivel educativo ${ }^{28}$.

Cuando se supone que las tasas de actividad femenina se incrementan, se logran mejoras en la evolución de la tasa de actividad global en todos los países. En México y en Guatemala, se alcanzarían niveles de actividad superiores a los observados, lo que se explica por el bajo nivel de actividad de las mujeres de estos países y su estructura de población menos envejecida. En Chile y el Perú, la incorporación masiva de las mujeres al mercado laboral mitigaría los efectos negativos de la evolución demográfica ${ }^{29}$. Incluso se lograría un crecimiento de la tasa de actividad en el mediano plazo, que después se vería compensado por el peso de los factores demográficos. Por el contrario, en el Brasil (y el Uruguay), el incremento de la participación laboral de las mujeres no sería suficiente para mantener los niveles actuales, y se produciría un descenso cercano al $5 \%$ de la tasa de actividad total.

Finalmente, en el escenario de aumento del nivel educativo, la tendencia de los resultados es similar a la observada en el escenario demográfico, con variaciones relativamente menores. Los supuestos subyacentes en este escenario producen dos efectos. En primer lugar, el aumento del nivel educativo presionaría al alza la tasa de actividad, dado que las personas más educadas presentan una participación más elevada, tanto por edad como por sexo. En segundo lugar, el aumento de la tasa de educación tiene efectos sobre la fecundidad y la mortalidad y potencia los efectos del cambio demográfico, lo que presiona a la baja la tasa de actividad.

Dado que las modificaciones en la composición de los trabajadores en términos de sexo, edad y nivel educativo repercuten en el aporte que pueden realizar a la producción, es relevante considerar los cambios de productividad implícitos en cada uno de los escenarios. Se utiliza como variable sustitutiva de la productividad el ingreso laboral de cada grupo (por edad, sexo y nivel educativo, según corresponda) y se asume que las relaciones entre los grupos no se modificarán con el tiempo. La evolución de la productividad por habitante se puede explicar a partir de tres componentes: i) la cantidad de trabajadores (a mayor cantidad de trabajadores, mayor productividad por habitante); ii) cuánto aporta cada trabajador, lo que puede resumirse en la productividad por trabajador, y iii) la evolución del número de habitantes del país (véase el gráfico IV.17).

En el escenario puramente demográfico, las diferencias observadas en la trayectoria de la productividad se explican por la etapa de la transición demográfica en que se encuentran los países. Mientras que los países en etapas tempranas de la transición (Guatemala, México y Perú) lograrían incrementos significativos de productividad agregada en el período de 35 años considerado ${ }^{30}$, los países en que la transición está más avanzada (Brasil y Chile) presentarían reducciones de la productividad, aunque poco significativas (inferiores al $5 \%)$. El principal canal mediante el que se procesan estos cambios es la variación en la cantidad de personas en edad de trabajar: en el primer grupo aumenta el peso relativo de estas edades y en el segundo grupo sucede lo contrario. Por otro lado, en todos los países aumenta el peso de los trabajadores de los tramos de edad más productivos (entre los 30 y los 50 años), lo que presiona al alza la productividad. De todos modos, más allá de los avances, los niveles de productividad en los tres países del primer grupo continuarían bajos.

27 Aun en estos casos se mantienen importantes diferencias en la tasa de actividad global en la región, de casi diez puntos porcentuales entre los países con la tasa más alta (Perú) y la más baja (Chile).

28 En este trabajo no se contempla una tercera tendencia: el aumento de la edad de jubilación de la población. Parte de este comportamiento podría estar incorporado en el aumento del nivel educativo, dado que la tasa de actividad entre las personas mayores de 60 años se eleva al incrementarse el nivel educativo.

29 El comportamiento de Bolivia (Estado Plurinacional de), la República Dominicana y el Paraguay es diferente al del país representativo de sus grupos respectivos. Estos países se comportan de forma similar a México y Guatemala, debido al aumento de su tasa de actividad, que continúa creciendo hasta 2050.

30 Dos países del clúster representado por Chile (Argentina y República Dominicana) presentan también aumentos significativos de productividad, mientras que en el Uruguay esta registra un leve incremento (2\%) y en Colombia no se modifica. 


\section{Gráfico IV.17}

Evolución de la tasa de productividad por habitante, por países y escenarios, 2015-2050

(En dólares en paridad del poder adquisitivo (PPA))

\section{A. Cambio demográfico}

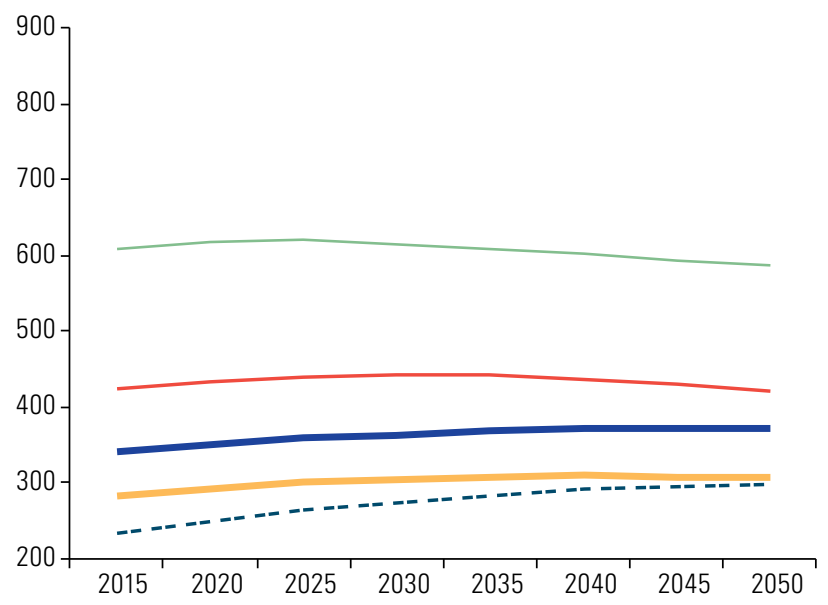

\section{Aumento del nivel educativo}

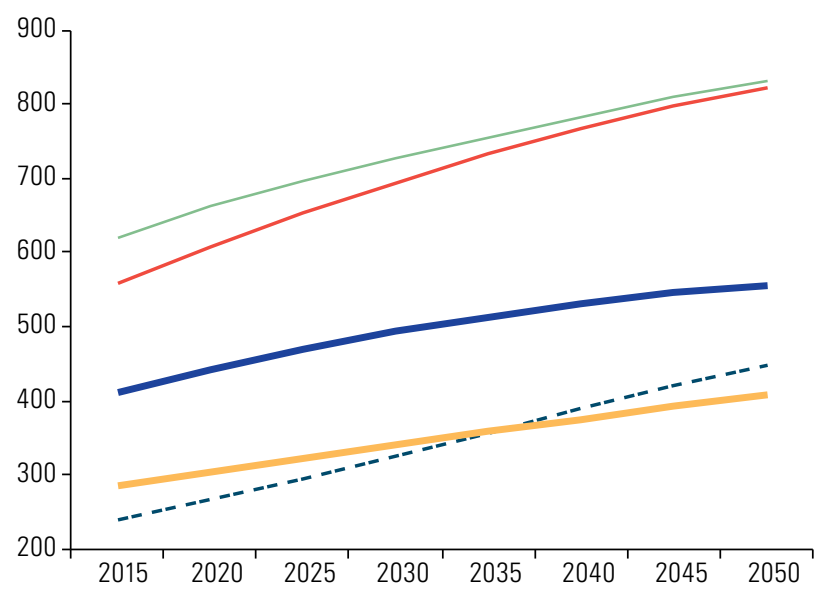

\section{B. Aumento de la tasa de actividad femenina}

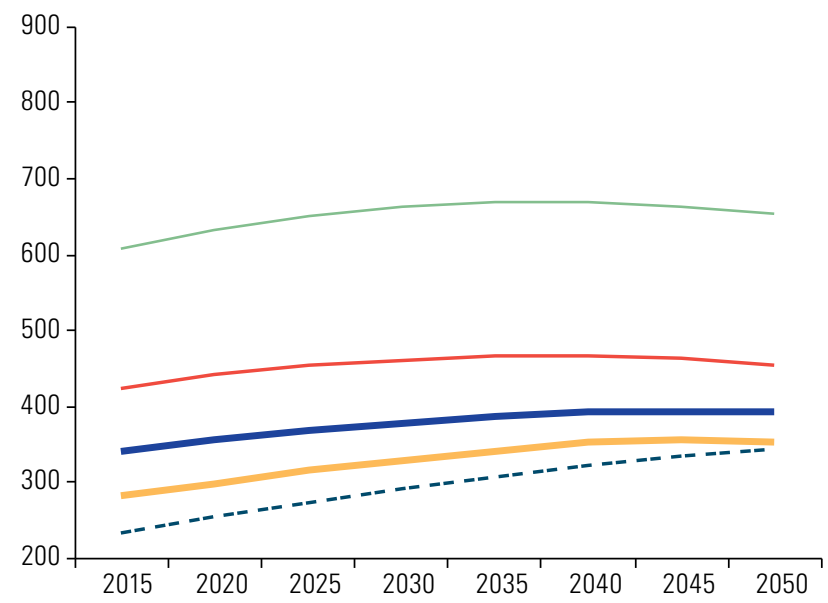

Fuente: Comisión Económica para América Latina y el Caribe (CEPAL), sobre la base de Naciones Unidas, "World Population Prospects: The 2017 Revision", 2017 [en línea] https://esa.un.org/unpd/wpp/; y Wittgenstein Centre for Demography and Global Human Capital, "Wittgenstein Centre Data Explorer" [en línea] http:// www.wittgensteincentre.org/dataexplorer.

Cuando se incorporan las mujeres al mercado laboral, hay una mejora de productividad en todos los países. Esto se debe a que se incrementa la cantidad de personas en el mercado laboral, lo que aumenta el producto total de forma significativa. Sin embargo, en Colacce y Manzi (2017) se muestra que el resultado de la productividad por trabajador presentaría una evolución más limitada que en el caso de la productividad por habitante. El motivo es que en la simulación se supone que la incorporación de las mujeres al mercado laboral no alteraría las brechas de género en los ingresos laborales que se observan en la actualidad, brechas que en este ejercicio se asimilan a diferencias de productividad. Esto implica que las nuevas trabajadoras que se incorporarían al mercado laboral tendrían niveles de productividad inferiores al promedio, presionando a la baja la productividad por trabajador.

El ejercicio también demuestra que el único camino para revertir la caída de la productividad agregada en el caso de los países más avanzados en la transición demográfica es el incremento del nivel educativo, ya que la productividad más elevada asociada a la educación compensaría el descenso en la cantidad de trabajadores generado por el cambio demográfico. 
Estos resultados indican que los países de la región se enfrentan a tensiones diferentes en relación con su evolución demográfica y los efectos sobre la productividad. En algunos países (Brasil, Chile, Colombia, Costa Rica y Uruguay), solo mediante cambios de mucha relevancia en la incorporación de las mujeres al mercado de trabajo y, especialmente, en el nivel educativo se lograrían incrementos relevantes de la productividad. En la mayoría de los países de la región (Bolivia (Estado Plurinacional de), Ecuador, El Salvador, Guatemala, Honduras, México, Nicaragua, Paraguay, Perú, República Dominicana y Venezuela (República Bolivariana de)), el factor demográfico todavía juega a favor y existe espacio para explotar el bono demográfico. En ellos, el problema son los bajos niveles de productividad. Dos países (Argentina y Panamá) se ubican en una situación intermedia, con aumentos muy bajos de productividad en el escenario demográfico (un 5\% y un 3\%, respectivamente). En todos los casos, es necesario generar condiciones institucionales y políticas orientadas a aumentar la productividad mediante la incorporación de nuevos trabajadores o el incremento de su nivel educativo. Solo así se asegurarían las condiciones para el crecimiento sostenido una vez alcanzada la etapa del envejecimiento.

\section{La disrupción tecnológica en el mercado de trabajo}

Las plataformas digitales globales analizadas en el capítulo II han introducido modelos de negocios de alta rentabilidad y productividad laboral. Los diferentes tipos de plataformas presentan distintos patrones de demanda de trabajo, pero en general requieren menos empleos para realizar un volumen dado de negocios ${ }^{31}$. También cambia el tipo de empleos requeridos: en algunos casos, la demanda se concentra en personal altamente calificado; en otros, en servicios de terceros ligados a la plataforma con condiciones laborales de menor calidad.

La revolución digital se concreta en innovaciones disruptivas que dan lugar a nuevos modelos de producción y consumo que pueden englobarse en los tres siguientes: la economía de costo marginal cero, Internet industrial y la economía bajo demanda. Cada uno de ellos tiene no solo implicancias en términos de productividad, patrones de producción y modelos de organización y negocios, sino también efectos significativos en la cantidad y la calidad de empleo (véase el diagrama IV.1). Para 2020 se calcula que, en promedio, más de un tercio de las habilidades básicas requeridas en la mayoría de las ocupaciones serán habilidades que en la actualidad no se consideran cruciales para el trabajo y no se generan en los sistemas educativos (CEPAL, 2016c).

La acelerada disminución del costo de los robots y su mayor funcionalidad acelera su adopción en distintos sectores industriales y en diversos países, independientemente del costo de la mano de obra local ${ }^{32}$. El avance tecnológico permite producir robots de tamaño manejable y fácilmente incorporables a la estructura productiva, desde robots industriales hasta robots de manejo de inventarios, así como capaces de prestar servicios en centros de llamadas (call centers). Esto, junto con la caída de su costo, acelerará la incorporación de los robots a los procesos productivos. En 2015, el costo de un robot soldador era de 8 dólares por hora, el equivalente al costo de la mano de obra para la misma labor en el Brasil. Se estima que en 2018 esta equivalencia se dará también en el sector manufacturero de México (véase el gráfico IV.18).

31 En 1990, los tres principales fabricantes de automóviles de Detroit tenían ingresos nominales de 250.000 millones de dólares, una capitalización de mercado de 36.000 millones de dólares y 1,2 millones de empleados. En 2014, las tres mayores empresas de Silicon Valley obtuvieron ingresos de 247.000 millones de dólares y una capitalización de mercado de más de un billón de dólares, con solo 137.000 empleados (The Economist, 2016).

32 En 2015, las ventas de robots alcanzaron las 253.748 unidades, impulsadas principalmente por la demanda de las industrias electrónica, metalúrgica y química, en tanto que la industria automotriz concentró cerca del $40 \%$ del total. A la mayor demanda de robots industriales le sigue la de robots de servicios, lo que implica un giro importante, dados sus efectos en el mercado de trabajo. En el mismo año se vendieron 41.060 robots de servicios profesionales, el $46 \%$ de los cuales se instalaron en sistemas logísticos, el 27\% en servicios de defensa, el 16\% en los sectores de agricultura y ganadería y el 3\% en el área médica (Federación Internacional de Robótica, 2016a, 2016b y 2016c). 
Diagrama IV.1

La disrupción tecnológica y el nuevo contexto laboral

\section{Economía de costo marginal cero}

- Nuevos modelos de producción y distribución de bienes y servicios digitales

- Costo marginal muy bajo de distribución y duplicación

- Producción por empresas y por consumidores

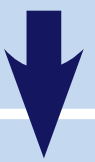

- Recalificación profesional y mejora de capacidades en los ámbitos de desarrollo de software y análisis de datos

\section{Menos puestos}

\section{Internet industrial}

- Nuevos modelos industriales y procesos de producción que utilizan:

Máquinas y sensores conectados a través de Internet

Robots y aprendizaje automático (machine learning)

Sistemas ciberfísicos

- Capacidades cognitivas complejas, resolución de problemas y análisis de datos, habilidades sociales, pensamiento crítico y aprendizaje activo

\section{Menos puestos} y nuevas capacidades
Economía bajo demanda

- Modelos de negocios con empleos temporales y en los que las organizaciones pactan contratos de corto plazo con trabjadores independientes

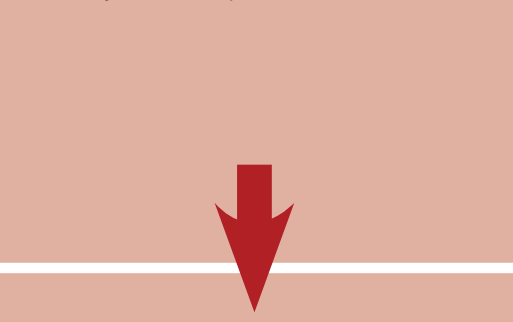

- Capacidades digitales básicas

\section{Empleos de menor calidad}

Fuente: Comisión Económica para América Latina y el Caribe (CEPAL).

\section{Gráfico IV.18}

Brasil y México: evolución del costo medio de un robot soldador y de la mano de obra manufacturera, 2015-2032 (En dólares por hora)

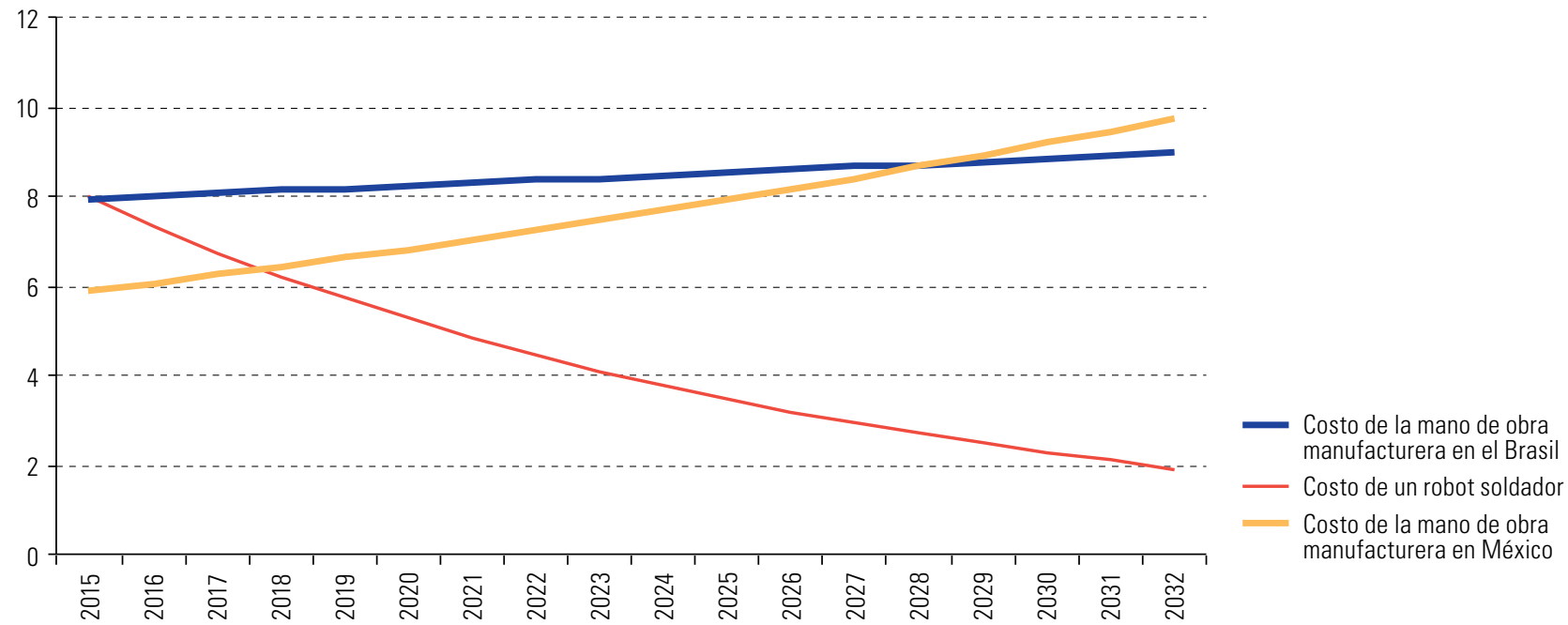

Fuente: Comisión Económica para América Latina y el Caribe (CEPAL).

El efecto de las nuevas tecnologías en el mercado de trabajo, en términos de desplazamiento de trabajadores, dependerá de la estructura de ocupaciones imperante, que varía entre países (véase el recuadro IV.4). Dependerá también de los costos de introducción de nuevas tecnologías -entre los que se incluyen los costos de adquisición, ajuste, instalación, capacitación, mantenimiento y actualización-y de los requisitos del entorno en cuanto a infraestructura, que podría hacer que pasar de una sustitución tecnológicamente posible a una sustitución económicamente viable resultara más complejo en los países de América Latina y el Caribe que en los países desarrollados (Weller, 2017). 


\section{Recuadro IV.4}

Cambio tecnológico y mercado de trabajo en el Uruguay y la Argentina

En el estudio de Apella y Zunino (2017) sobre la Argentina y el Uruguay se analiza el posible impacto del cambio tecnológico en la demanda de trabajo y se alerta sobre el significativo incremento de la probabilidad de que se genere desempleo tecnológico, fenómeno asociado a la menor demanda de trabajadores intensivos en tareas manuales rutinarias. Adicionalmente, se podria producir un incremento de la brecha de ingresos laborales entre los trabajadores de ocupaciones intensivas en tareas cognitivas no rutinarias y los trabajadores ocupados en tareas manuales ${ }^{a}$. De esta manera, el proceso de cambio tecnológico podría generar una reducción de la demanda de empleo de ingresos medios (en general, asociado con tareas rutinarias manuales) y aumentar la polarización del mercado de trabajo entre dos tipos de empleo: i) actividades de menor remuneración asociadas con el desarrollo de tareas manuales no rutinarias y ii) actividades con ingresos laborales más elevados relacionadas con tareas cognitivas no rutinarias (véase el siguiente gráfico).

Argentina y Uruguay: probabilidad de desocupación según tipo de tarea, 2015

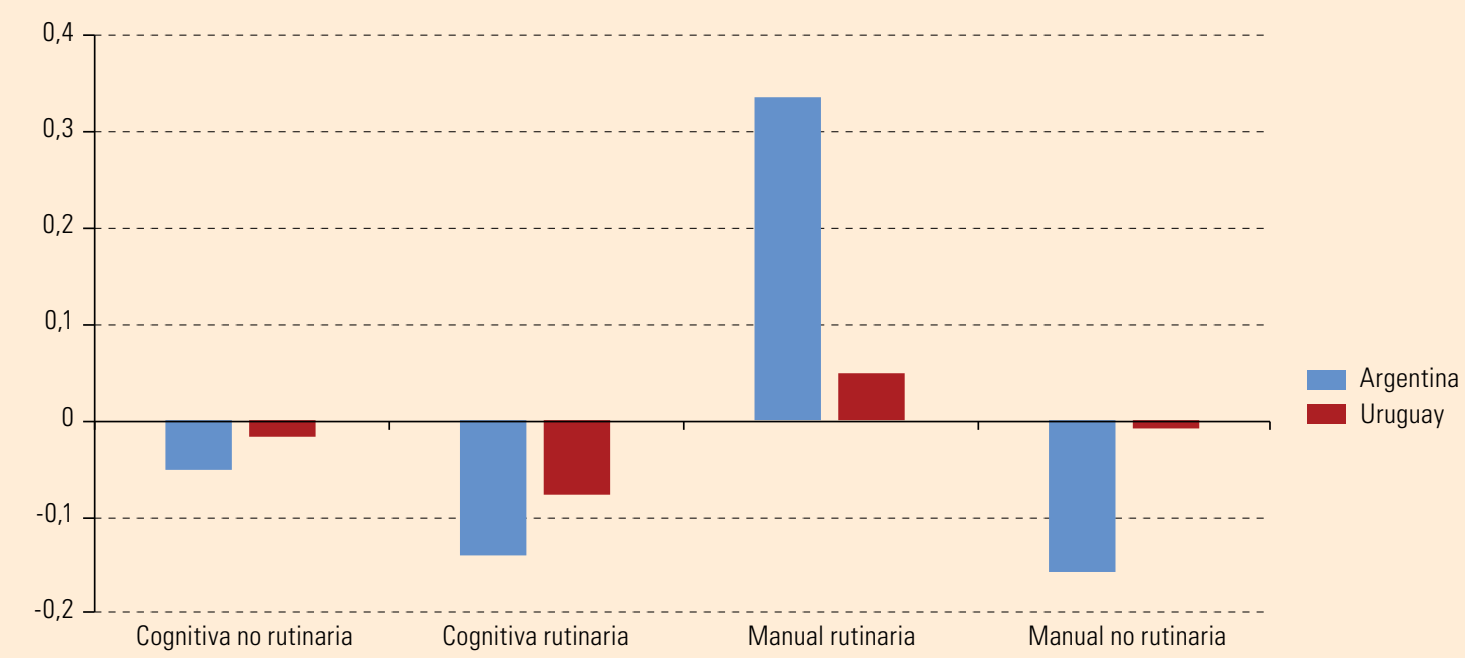

Fuente: Comisión Económica para América Latina y el Caribe (CEPAL), sobre la base de I. Apella y G. Zunino, "Cambio tecnológico y el mercado de trabajo en Argentina y Uruguay: un análisis desde el enfoque de tareas", serie de Informes Técnicos del Banco Mundial en Argentina, Paraguay y Uruguay, № 11 , Montevideo, Banco Mundial, 2017.

Nota: El coeficiente de las tareas manuales no rutinarias no es estadísticamente significativo para el Uruguay. El resto de los coeficientes son significativos al $1 \%$.

a Los autores utilizan un modelo probit para estimar la probabilidad de estar desocupado en función de la intensidad tecnológica asociada a la tarea que realiza el individuo, y variables de control como edad, años de estudio y una variable binaria que indica el sexo.

Las nuevas actividades productivas crearán nuevos empleos calificados y necesitarán de nuevas capacidades. Sin embargo, es posible que la nueva demanda de trabajo no sea suficiente para compensar la pérdida de puestos resultante de la automatización de los procesos productivos y de gestión que afectará principalmente a las tareas más rutinarias (Foro Económico Mundial, 2015) ${ }^{33}$. El mayor desafío de la nueva revolución no se deriva únicamente del incremento de la automatización de ese tipo de tareas, sino también del avance de las capacidades cognitivas de los robots y las máquinas derivado del desarrollo de las tecnologías de inteligencia artificial. Esto hace prever un impacto significativo en el mercado laboral. En MGI (2017a y 2017b), se estima

33 En los países más desarrollados, las actuales tendencias llevarían a una pérdida neta de más 5,1 millones de puestos laborales en el período 2015-2020, con una pérdida total de 7,1 millones de puestos — dos tercios de los cuales se concentran en actividades administrativas y de oficina- y la generación de 2 millones de empleos en otros grupos de puestos. Los sectores en los que el empleo crecería —operaciones financieras y de ventas, gestión, informática y matemáticascrearían una cantidad de puestos de trabajo menor que la que se perdería en las áreas afectadas negativamente por el cambio tecnológico — tareas de oficina y administrativas, manufactura y construcción-. Estos resultados serían particularmente negativos en el caso de las capas medias de la población y las mujeres, debido a su elevada participación en tareas administrativas (CEPAL, 2016c). 
que, si bien menos del $5 \%$ de los trabajos serían susceptibles de ser totalmente automatizados, el $60 \%$ de las ocupaciones tendrían al menos un 30\% de actividades automatizables mediante la adaptación de las tecnologías actuales. Si bien estos resultados son importantes, la extrema diversidad de la evaluación de los efectos de la automatización en el empleo, que se muestra en el cuadro IV.3, obliga a ser cautelosos al realizar apreciaciones cuantitativas sobre esos efectos en el corto plazo.

\section{Cuadro IV.3}

Efectos previstos de la automatización en el empleo

- Frey y Osborne (2017)

El 47\% de las ocupaciones en los Estados Unidos tienen un riesgo alto de automatización

- Citigroup (2016)

El 57\% de los empleos en los países de la Organización de Cooperación y Desarrollo Económicos (OCDE) son susceptibles de ser automatizados

\section{- Arntz, Gregory y Zierahn (2016)}

Solo el 9\% de los empleos de 21 países de la OCDE son automatizables

\section{- Foro Económico Mundial (2016)}

Se perderían 5,1 millones de empleos en 15 grandes economías entre 2015 y 2020, como resultado de una pérdida bruta de 7,1 millones

de empleos y una creación bruta de 2 millones de empleos

\section{- MGI (2017a y 2017b)}

El $60 \%$ de las ocupaciones cuentan con al menos un 30\% de actividades laborales automatizables

Fuente: McKinsey Global Institute (MGI), A Future That Works: Automation, Employment, and Productivity, San Francisco, 2017; "Where will Latin America's growth come from?", Discussion Paper, San Francisco, 2017; C. Frey y M. Osborne, "The future of employment: how susceptible are jobs to computerization?", Technological Forecasting and Social Change, vol. 114, Amsterdam, Elsevier, 2017; Citigroup, Technology at Work v2.0: The Future Is Not What It Used to Be, Oxford, 2016; M. Arntz, T. Gregory y U. Zierahn, "The risk of automation for jobs in OECD countries: a comparative analysis", OECD Social, Employment and Migration Working Paper, № 189, París, Organización de Cooperación y Desarrollo Económicos (OCDE), 2016; Foro Económico Mundial, The Future of Jobs: Employment, Skills and Workforce Strategy for the Fourth Industrial Revolution, Ginebra, 2016.

Siguiendo el enfoque de las actividades que componen cada ocupación, Cadena y otros (2017) y MGI (2017b) estiman que, en siete países latinoamericanos, la mitad del tiempo de trabajo sería potencialmente automatizable, lo que tendría un efecto equivalente a la pérdida de 76,4 millones de empleos de tiempo completo (full-time equivalent workers), con salarios del orden de 970.000 millones de dólares. Por su parte, Weller (2017) evalúa que la pérdida sería del orden de los 8 millones de puestos de trabajo, al tiempo que en OCDE/CEPAL/CAF (2016), sobre la base de datos del Foro Económico Mundial y la OIT, se estima una pérdida neta de 3,4 millones de puestos de trabajo hacia 2030 (entre el $1 \%$ y el $2 \%$ del empleo de América Latina), que se concentraría en la industria manufacturera, las funciones administrativas y de apoyo y la construcción. Pese a estas grandes diferencias, las estimaciones coinciden en que los efectos de las nuevas tecnologías serán importantes. Por otra parte, existe el riesgo de que los trabajadores con menor calificación sean los más perjudicados, así como de que se produzca un deterioro de la calidad del empleo debido a la precarización del empleo más calificado.

La pérdida de puestos de trabajo debida a las nuevas tecnologías es solo una parte de la historia. La experiencia de revoluciones tecnológicas anteriores apunta a que la creación de empleo en el largo plazo supera ampliamente la pérdida de puestos. Dos dinámicas explican este resultado. Por un lado, la incorporación de las nuevas tecnologías aumenta la productividad, reduce el costo de los bienes y, además de aumentar el bienestar de los consumidores, libera ingresos para la demanda de otros bienes. Por otro lado, la creación de productos innovadores genera nuevas demandas, como sugería Veblen (1914), al afirmar que "la invención es la madre de la necesidad". Por ello, pese a que el efecto neto sobre el empleo en el corto plazo pueda ser negativo, es posible obtener resultados positivos en el largo plazo en la medida en que la incorporación de las nuevas tecnologías se combine con políticas orientadas a la promoción del empleo de calidad ${ }^{34}$.

La robótica lleva a situaciones en las que el costo de la mano de obra deja de ser un factor determinante de la localización de las plantas de producción. Así, está dando lugar a la relocalización de las plantas productivas

34 Aunque la acción política y la resistencia de los actores perjudicados podrían enlentecer la transición a nivel microeconómico en el corto plazo, las experiencias ludistas de negociación colectiva por disturbio (collective bargaining by riot) no fueron capaces de impedir el triunfo del capitalismo industrial (Hobsbawm, 1952). 
en las ubicaciones más avanzadas en materia tecnológica, tendencia contrapuesta a la experimentada en la fase previa de la globalización. En definitiva, el impacto de los nuevos modelos de negocios en la economía y la sociedad desafía las actuales estructuras productivas, mercados, normas y regulaciones, lo que exigirá revisar los mecanismos de gobernanza. Este desafío es especialmente importante para una región como América Latina y el Caribe, que deberá hacer frente a fuertes presiones para reducir los costos laborales en la medida en que las nuevas tecnologías aumenten su difusión en el sector productivo e incrementen la debilidad de actores colectivos como los sindicatos. En una región con tan alta informalidad como América Latina y el Caribe, este problema reviste particular gravedad.

Otro tema que ha atraído la preocupación de los encargados de adoptar decisiones y de la sociedad en general es el de los efectos de la digitalización en la distribución del ingreso y la riqueza derivados de la escala y la intensidad de capital de las plataformas globales. El rápido progreso tecnológico y la integración económica global han sido los mayores determinantes de la prosperidad mundial, al tiempo que han impulsado cambios permanentes en la economía y han afectado profundamente su estructura. El cambio tecnológico y el desarrollo de las cadenas globales de valor fueron los dos factores que más influyeron en la caída de la participación de la fuerza laboral en el ingreso nacional.

En los países desarrollados, la participación del trabajo en el ingreso nacional ha mostrado una tendencia decreciente desde la década de los ochenta. Alcanzó su mínimo durante la crisis financiera y posteriormente no se recuperó. La mitad de esa disminución puede atribuirse a los efectos del cambio tecnológico. El progreso de las tecnologías digitales y la automatización de las actividades rutinarias incidieron en las proporciones de capital y trabajo empleadas en los procesos productivos y en su contribución al ingreso nacional. Por otro lado, la creciente integración mundial mediante cadenas globales de valor tuvo un impacto más reducido —aproximadamente un $50 \%$ menor que el del cambio tecnológico-y afectó sobre todo a los trabajadores menos calificados.

En las economías emergentes, la integración y el progreso técnico han contribuido a sostener la productividad y el crecimiento. Al mismo tiempo, han desempeñado un papel importante en la disminución de la participación de la fuerza laboral en el ingreso nacional. En dichas economías, la integración mundial fue responsable de la mayor parte del cambio en la participación laboral, mientras que la tecnología tuvo un papel secundario, debido a la menor proporción de empleos automatizables y el menor grado de sofisticación tecnológica del proceso productivo. La tecnología absorbió funciones rutinarias realizadas por trabajadores de mediana calificación, y este efecto se vio reforzado por la integración en el mercado mundial y el acceso a mano de obra más barata.

El estudio del impacto de las nuevas tecnologías y los nuevos procesos de organización de la producción en el mundo del trabajo no es nuevo. Desde fines de la década de 1980, la crisis del fordismo y la irrupción de las tecnologías microelectrónicas dieron lugar a análisis que consideraban inevitable la disminución o la desaparición progresiva del empleo formal, protegido y regulado, así como el debilitamiento de la acción sindical (Abramo, 2015). Sin embargo, la evolución del mercado de trabajo en América Latina a partir del comienzo del siglo XXI indica que los efectos de esas tendencias no eran inevitables y que dependían, en gran medida, de las estrategias de desarrollo de los países.

El impacto de los cambios dependerá de las dinámicas macroeconómicas y las formas de organización del trabajo, así como de factores políticos e institucionales, entre los que se incluyen la acción del Estado y de las instituciones públicas, la regulación laboral, la organización sindical y la capacidad de crear espacios de negociación colectiva y diálogo social (CEPAL, 2017a). Las profundas transformaciones del mundo del empleo requerirán una nueva institucionalidad laboral y nuevos mecanismos de redistribución del poder que compensen la pérdida o el debilitamiento de la capacidad de negociación del mundo sindical que podría acarrear la automatización, así como la relocalización de la producción. Desde esta perspectiva, es clave la capacidad con que las instituciones y políticas públicas respondan y se anticipen a los cambios. Por un lado, es necesario cambiar la estructura productiva e incentivar la reasignación de los trabajadores de baja y media calificación hacia tareas no automatizables. Los sistemas de formación y capacitación tienen un papel central en esta labor, ya que deben preparar a las nuevas generaciones y recalificar a las presentes para tareas con un alto contenido no rutinario. Por otro lado, los sistemas de protección social deben adecuarse para enfrentar estos desafíos, avanzando en el diseño y la implementación de alternativas adecuadas y factibles. 


\section{Bibliografía}

Abramo, L. (2015), Uma década de promoção do trabalho decente no Brasil: uma estratégia de ação baseada no diálogo social, Ginebra, Organización Internacional del Trabajo (OIT), diciembre.

Acemoglu, D. y D. Autor (2011), "Skills, tasks and technologies: Implications for employment and earnings", Handbook of Labor Economics, vol. 4, D. Card y O. Ashenfelter (eds.), Berlín, Elsevier.

Aguirre, R. (2011), "El reparto del cuidado en América Latina", El trabajo del cuidado en América Latina y España, Documento de Trabajo, № 54, M. Á. Durán (coord.), Madrid, Fundación Carolina.

Alderman, H. y R. Yemtsov (2012), "Productive role of safety nets: background paper for the World Bank 2012-2022 Social Protection and Labor Strategy", Discussion Paper, No 1203, Washington, D.C., Banco Mundial, marzo.

Alsan, M. y otros (2008), "The consequences of population health for economic performance" Health, Economic Development and Household Poverty: From Understanding to Action, S. Bennett, L. Gilson y A. Mills (eds.), Abingdon, Routledge.

Amarante, V. y M. Colacce (2016), "Mercado laboral y productividad", Cambio demográfico y desafíos económicos y sociales en el Uruguay del siglo XXI (LC/L.4121), R. Rofman, V. Amarante e I. Apella (eds.), Santiago, Comisión Económica para América Latina y el Caribe (CEPAL)/Banco Mundial, marzo.

Amarante, V., R. Arim y M. Yapor (2016), "Decomposing inequality changes in Uruguay: the role of formalization in the labor market", IZA Journal of Labor \& Development, vol. 5, № 1, Berlín, Springer, diciembre.

Ángeles, G. y otros (2011), “Evaluación de impacto del programa Estancias Infantiles para apoyar a madres trabajadoras: informe final de la evaluación de impacto," Cuernavaca, Instituto Nacional de Salud Pública, julio [en línea] http://www. normateca.sedesol.gob.mx/work/models/SEDESOL/EvaluacionProgramasSociales/Evaluacion_Impacto/EI_PEI_2011/ Inf_Final_PEl.pdf.

Apella, I. y G. Zunino (2017), "Cambio tecnológico y el mercado de trabajo en Argentina y Uruguay: un análisis desde el enfoque de tareas", serie de Informes Técnicos del Banco Mundial en Argentina, Paraguay y Uruguay, № 11, Montevideo, Banco Mundial, mayo.

Araya, F. (2017), “Una aproximación a la movilidad intergeneracional de los ingresos laborales en Uruguay,"Tesis de maestría, Montevideo, Universidad de la República, agosto.

Arim, R. (2017), "Cambio estructural y distribución del ingreso: disyuntivas para la coyuntura. Borrador", documento preparado para la Segunda Reunión de la Conferencia Regional sobre Desarrollo Social de América Latina y el Caribe y el Noveno Foro Ministerial para el Desarrollo de América Latina y el Caribe, Montevideo, Comisión Económica para América Latina y el Caribe (CEPAL), 25 a 27 de octubre.

Arntz, M., T. Gregory y U. Zierahn (2017), "Revisiting the risk of automation", Economics Letters, vol. 159, Amsterdam, Elsevier, octubre.

(2016), "The risk of automation for jobs in OECD countries: a comparative analysis", OECD Social, Employment and Migration Working Papers, № 189, París, Organización de Cooperación y Desarrollo Económicos (OCDE), mayo.

Atkinson, A. (2015), Inequality: What Can Be Done?, Cambridge, Harvard University Press, mayo.

Attanasio, O. y C. Binelli (2010), "Mexico in the 1990s: the main cross-sectional facts", Review of Economic Dynamics, vol. 13, $N^{\circ} 1$, Amsterdam, Elsevier, enero.

Attanasio, O., C. Meghir y M. Vera-Hernández (2007), "Investigating different benefits of workfare programs", Londres, University College London/Instituto de Estudios Fiscales [en línea] https://pdfs.semanticscholar.org/2290/1a929d234 c3b4f493813d85afb9386a30b5f.pdf.

Autor, D. (2015), "Why are there still so many jobs? the history and future of workplace automation", Journal of Economic Perspectives, vol. 29, № 3, Pittsburgh, Asociación Estadounidense de Economía.

Azevedo, V. y C. Bouillon (2010), "Intergenerational social mobility in Latin America: a review of existing evidence", Revista de Análisis Económico, vol. 25, №2, Santiago, Universidad Alberto Hurtado.

Baez, J. y A. Camacho (2011), "Assessing the long-term effects of conditional cash transfers on human capital: evidence from Colombia," IZA Discussion Paper, № 5751, Bonn, Institute for the Study of Labor (IZA), mayo.

Banco Mundial (2016), "Informe sobre el Desarrollo Mundial 2016. Dividendos digitales: panorama general", World Development Report, № 102724, Washington, D.C., enero.

Banerjee, A., S. Chassang y E. Snowberg (2016), "Decision theoretic approaches to experiment design and external validity", NBER Working Paper, № 22167, Cambridge, Oficina Nacional de Investigaciones Económicas (NBER), abril.

Barham, T., K. Macours y J. Maluccio (2013), "More schooling and more learning? Effects of a three-year conditional cash transfer program in Nicaragua after 10 years", IDB Working Paper series, № 432, Washington, D.C., Banco Interamericano de Desarrollo (BID), julio.

Barham, T. y otros (2016), "Long-term impacts of conditional cash transfers in Latin America: review of the evidence", IDB Working Paper series, No 732, Washington, D.C., Banco Interamericano de Desarrollo (BID), octubre. 
Barros, R. y otros (2011), "Uma avaliação do impacto da qualidade da creche no desenvolvimento infantil", Pesquisa e Planejamento Econômico, vol. 41, № 2, Brasilia, Instituto de Investigación Económica Aplicada (IPEA), agosto.

Behrman, J., Y. Cheng y P. Todd (2004), "Evaluating preschool programs when length of exposure to the program varies: a nonparametric approach", The Review of Economics and Statistics, vol. 86, № 1, Cambridge, The MIT Press, febrero.

Berlinski, S. y S. Galiani (2007), "The effect of a large expansion of pre-primary school facilities on preschool attendance and maternal employment", Labour Economics, vol. 14, № 3, Amsterdam, Elsevier.

Berlinski, S., S. Galiani y P. Gertler (2009), "The effect of pre-primary education on primary school performance", Journal of Public Economics, vol. 93, № 1-2, Amsterdam, Elsevier, febrero.

Berlinski, S., S. Galiani y M. Manacorda (2008), "Giving children a better start: preschool attendance and school-age profiles", Journal of Public Economics, vol. 92, No 5-6, Amsterdam, Elsevier.

Berlinski, S., S. Galiani y P. McEwan (2011), "Preschool and maternal labor market outcomes: evidence from a regression discontinuity design", Economic Development and Cultural Change, vol. 59, № 2, Chicago, University of Chicago Press.

Bernal, R. y otros (2009), "Evaluación de impacto del Programa Hogares Comunitarios de Bienestar del ICBF", serie Documentos CEDE, № 16, Bogotá, Universidad de los Andes, julio.

Bentancor, A. (2013), "Desigualdades territoriales en los mercados laborales en Chile," Documento de Trabajo, № 6, Santiago, Centro Latinoamericano para el Desarrollo Rural (RIMISP), junio.

Binelli, C. (2016), "Wage inequality and informality: evidence from Mexico", IZA Journal of Labor \& Development, vol. 5, $N^{\circ} 1$, Berlín, Springer, diciembre.

Bleakley, H. (2010), "Malaria eradication in the Americas: a retrospective analysis of childhood exposure", American Economic Journal: Applied Economics, vol. 2, №2, Pittsburgh, Asociación Estadounidense de Economía, abril.

Bloom, D., D. Canning y J. Sevilla (2004), "The effect of health on economic growth: a production function approach", World Development, vol. 32, No 1, Amsterdam, Elsevier, enero.

Borraz, F. y A. Cid (2013), "Preschool attendance and school-age profiles: a revision," Children and Youth Services Review, vol. 35, № 5, Amsterdam, Elsevier, mayo.

Bourguignon, F. (2003), "The growth elasticity of poverty reduction: explaining heterogeneity across countries and time periods", Working Paper, № 28104, Washington, D.C., Banco Mundial.

Cadena, A. y otros (2017), "El salto de productividad", Robotlución: el futuro del trabajo en la integración 4.0 de América Latina, Revista Integración y Comercio, vol. 21, № 42, Washington, D.C., Banco Interamericano de Desarrollo (BID), agosto.

Cascio, E. (2015), "The promises and pitfalls of universal early education", IZA World of Labor 2015, № 116, Bonn, Instituto para el Estudio del Trabajo (IZA), enero.

Cascio, E. y D. Whitmore (2013), "The impacts of expanding access to high-quality preschool education", NBER Working Paper, № 19735, Cambridge, Oficina Nacional de Investigaciones Económicas (NBER), diciembre.

Cecchini, S. (2014), "Transferencias monetarias y empleo: ¿círculo vicioso o virtuoso?", Madrid, Programa EUROsociAL, 18 de noviembre [en línea] http://reciprocamente.eurosocial-ii.eu/transferencias-monetarias-y-empleo-circulo-viciosoo-virtuoso-de-simone-cecchini-cepal/.

Cecchini, S. y R. Martínez (2011), Protección social inclusiva en América Latina: una mirada integral, un enfoque de derechos, Libros de la CEPAL, № 111 (LC/G.2488-P), Santiago, Comisión Económica para América Latina y el Caribe (CEPAL), marzo.

Cecchini, S. y F. Veras Soares (2015), "Conditional cash transfers and health in Latin America," The Lancet, vol. 385, № 9975, Amsterdam, Elsevier, abril.

CEPAL (Comisión Económica para América Latina y el Caribe) (2017a), Brechas, ejes y desafíos en el vínculo entre lo social y lo productivo (LC/CDS.2/3), Santiago.

(2017b), Observatorio Demográfico, 2016. Proyecciones de Población (LC/PUB.2017/3-P), Santiago, marzo.

(2016a), La matriz de la desigualdad social en América Latina (LC/G.2690(MDS.1/2)), Santiago.

(2016b), Desarrollo social inclusivo: una nueva generación de políticas para superar la pobreza y reducir la desigualdad en América Latina y el Caribe (LC/L.4056/Rev.1), Santiago, enero.

(2016c), Panorama de la Inserción Internacional de América Latina y el Caribe, 2016 (LC/G.2697-P), Santiago.

(2014a), Pactos para la igualdad: hacia un futuro sostenible (LC/G.2586(SES.35/3)), Santiago, abril.

(2014b), Panorama Social de América Latina, 2014 (LC/G.2635-P), Santiago.

(2012), Cambio estructural para la igualdad: una visión integrada del desarrollo (LC/G.2524(SES.34/3)), Santiago, julio. (2010), La hora de la igualdad: brechas por cerrar, caminos por abrir (LC/G.2432(SES.33/3)), Santiago, mayo.

(2006), La protección social de cara al futuro: acceso, financiamiento y solidaridad (LC/G.2294(SES.31/3)), Santiago, febrero.

CEPAL/OIT (Comisión Económica para América Latina y el Caribe/Organización Internacional del Trabajo) (2014), "Los programas de transferencias condicionadas y el mercado laboral", Coyuntura Laboral en América Latina y el Caribe, № 10 (LC/L.3815), Santiago, mayo. 
Chimerine, L., T. Black y L. Coffey (1999), “Unemployment insurance as an automatic stabilizer: evidence of effectiveness over three decades", Unemployment Insurance Occasional Paper, N 99-8, Washington D.C., Departamento del Trabajo de los Estados Unidos, julio.

Chong, A. y M. Gradstein (2007), "Inequality and informality”, Journal of Public Economics, vol. 91, No 1-2, Amsterdam, Elsevier, febrero.

Colacce, M. y P. Manzi (2017), “El cuidado de la población uruguaya y la creación del Sistema Nacional Integrado de Cuidados: una mirada de largo plazo", serie Estudios y Perspectivas-Oficina de la CEPAL en Montevideo, N 27 (LC/TS.2017/43; LC/MVD/TS.2017/2), Santiago, Comisión Económica para América Latina y el Caribe (CEPAL), agosto.

Constenla D. y otros (2008), "Cost-effectiveness of pneumococcal conjugate vaccination in Latin America and the Caribbean: a regional analysis", Revista Panamericana de Salud Pública, vol. 24, N 5, Washington, D.C., Organización Mundial de la Salud (OMS), noviembre.

Contreras, D., P. Sepúlveda y S. Cabrera (2010), “The effects of lengthening the school day on female labor supply: evidence from a quasi-experiment in Chile", serie Documentos de Trabajo, N³23, Santiago, Universidad de Chile, julio.

Corak, M. (2013), "Income inequality, equality of opportunity, and intergenerational mobility", Journal of Economic Perspectives, vol. 27, №3, Pittsburgh, Asociación Estadounidense de Economía.

Côrtes, M., F. Monteiro y P. Guimarães (2013), “Efeitos macroeconômicos do Programa Bolsa Família: uma análise comparativa das transferências sociais", Programa Bolsa Família: Uma Década de Inclusão e Cidadania, T. Campello y M. Côrtes (coords.), Brasilia, Instituto de Investigación Económica Aplicada (IPEA).

Cunha, F. y J. Heckman (2010), "Investing in our young people", NBER Working Paper, N 16201, Cambridge, Oficina Nacional de Investigaciones Económicas (NBER), julio.

Cunha, F. y otros (2006), "Interpreting the evidence on life cycle skill formation", Handbook of the Economics of Education, E. Hanushek y F. Welch (eds.), Amsterdam, Elsevier.

Datt, G. y M. Ravallion (1992), "Growth and redistribution components of changes in poverty measures: a decomposition with applications to Brazil and India in the 1980s", Journal of Development Economics, vol. 38, N², Amsterdam, Elsevier, abril.

Daude, C. y V. Robano (2015), “On intergenerational (im)mobility in Latin America”, Latin American Economic Review, vol. 24, No 9, Berlín, Springer, diciembre.

Davis, B., S. Di Giuseppe y A. Zezza (2017), “Are African households (not) leaving agriculture? Patterns of households' income sources in rural Sub-Saharan Africa", Food Policy, vol. 67, Amsterdam, Elsevier, febrero.

De Oliveira, A. y otros (2007), "Primeiros resultados da análise da linha de base da pesquisa de avaliação de impacto do Programa Bolsa Familia", Avaliação de Políticas e Programas do MDS: Resultados, vol. 2, J. Vaitsman y R. Paes-Sousa (orgs.), Belo Horizonte, Universidad Federal de Minas Gerais.

De Soárez, P. y otros (2008), "Cost-effectiveness analysis of routine rotavirus vaccination in Brazil", Revista Panamericana de Salud Pública, vol. 23, N 4, Washington, D.C., Organización Mundial de la Salud (OMS), abril.

Del Boca, D. (2015), "Child care arrangements and labor supply", IDB Working Paper series, N 569, Washington, D.C., Banco Interamericano de Desarrollo (BID), febrero.

Dunn, C. (2007), "The intergenerational transmission of lifetime earnings: evidence from Brazil", The B.E. Journal of Economic Analysis \& Policy, vol. 7, N², Berlín, De Gruyter.

Encina, J. y C. Martínez (2009), “Efecto de una mayor cobertura de salas cuna en la participación laboral femenina: evidencia de Chile", serie Documentos de Trabajo, N³03, Santiago, Universidad de Chile, noviembre.

Escobar, A. y M. González (2009), "Girls, mothers and poverty reduction in Mexico: evaluating Progresa-Oportunidades", The Gendered Impacts of Liberalization: Towards "Embedded Liberalism", S. Razavi (ed.) Nueva York, Routledge. (2002), "Documento final de diagnóstico cualitativo de hogares semiurbanos: localidades de 2500 a 50000 habitantes, 2001", Guadalajara, Centro de Investigaciones y Estudios Superiores en Antropología Social (CIESAS), agosto [en línea] http://lanic.utexas.edu/project/etext/oportunidades/2002/escobar1.pdf.

Federación Internacional de Robótica (2016a), World Robotics Report 2016, Frankfurt am Main. (2016b), World Robotics 2016: Industrial Robots, Frankfurt am Main. (2016c), World Robotics 2016: Service Robots, Frankfurt am Main.

Fernández, A. y otros (2017), “Impacto social y económico de la malnutrición: modelo de análisis y estudio piloto en Chile, el Ecuador y México", Documentos de Proyectos (LC/TS.2017/32), Santiago, Comisión Económica para América Latina y el Caribe (CEPAL), abril.

Fogel, R. (2004), "Health, nutrition and economic growth", Economic Development and Cultural Change, vol. 52, No 3, Chicago, University of Chicago Press, abril.

Foro Económico Mundial (2015), “Bridging the skills and innovation gap to boost productivity in Latin America. The competitiveness lab: a World Economic Forum initiative", Insight Report, Ginebra, enero. 
Frey, C. y M. Osborne (2017), "The future of employment: how susceptible are jobs to computerization?", Technological Forecasting and Social Change, vol. 114, Amsterdam, Elsevier, enero.

Galor, O. y J. Zeira (1993), "Income distribution and macroeconomics", The Review of Economic Studies, vol. 60, № 1, Oxford, Oxford University Press, enero.

García, A. y otros (2012), "Impactos de largo plazo del programa Familias en Acción en municipios de menos de 100.000 habitantes en los aspectos claves del desarrollo del capital humano. Informe final", Bogotá, Unión Temporal Econometría/Departamento Nacional de Planeación (DNP), mayo [en línea] https://colaboracion.dnp.gov.co/CDT/Sinergia/ Documentos/393_Impactos_de_Largo_Plazo_en_el_Programa_Familias_en_Accion_DOC.pdf.

Grawe, N. (2004), "Intergenerational mobility for whom? The experience of high- and low- earning sons in international perspective", Generational Income Mobility in North America and Europe, M. Corak (ed.), Cambridge, Cambridge University Press.

Hanlon, J., A. Barrientos y D. Hulme (2010), "Pro-poor growth: turning a \$1 grant into $\$ 2$ income", Just Give Money to the Poor: The Development Revolution from the Global South, Londres, Kumarian Press.

Havnes, T. y M. Mogstad (2009), "No child left behind: universal child care and children's long-run outcomes", IZA Discussion Paper, № 4561, Bonn, Institute for the Study of Labor (IZA), noviembre.

Hertz, T. y otros (2007), "The inheritance of educational inequality: international comparisons and fifty-year trends", The B.E. Journal of Economic Analysis \& Policy, vol. 7, № 2, Berlín, De Gruyter.

Hobsbawm, E. (1952), "The machine breakers", Past \& Present, vol. 1, № 1, Oxford, Oxford University Press, febrero.

Holmes, R. y otros (2010), "Cash transfers and gendered risks and vulnerabilities: lessons from Latin America", ODI Background Note, Londres, Overseas Development Institute (ODI), octubre.

Ibarrarán, P. y otros (eds.) (2017), Así funcionan las transferencias condicionadas: buenas prácticas a 20 años de implementación, Washington, D.C., Banco Interamericano de Desarrollo (BID).

Jamison, D. y otros (2013), "Global health 2035: a world converging within a generation", The Lancet, vol. 382, № 9908, Amsterdam, Elsevier, diciembre.

Jiménez, M. y M. Jiménez (2009), "La movilidad intergeneracional del ingreso: evidencia para Argentina", Documento de Trabajo, No 84, La Plata, Universidad Nacional de La Plata, marzo.

Johnson, S., D. Kaufmann y P. Zoido (1998), "Regulatory discretion and unofficial economy", American Economic Review, vol. 88, No 2, Berlín, Springer, mayo.

Kuznets, S. (1955), "Economic growth and income inequality", The American Economic Review, vol. 45, № 1, Pittsburgh, Asociación Estadounidense de Economía, marzo.

Landim, P. (2009), “Relatório final: os efeitos do Programa Bolsa Família sobre a economia dos municípios brasileiros", São Paulo, Insper, agosto [en línea] http://www.ipcig.org/publication/mds/33P.pdf.

La Porta, R. y A. Shleifer (2014), "Informality and development", Journal of Economic Perspectives, vol. 28, № 3, Pittsburgh, Asociación Estadounidense de Economía.

Llanos, A. y otros (2007), "Cost-effectiveness of a folic acid fortification program in Chile", Health Policy, vol. 83, № 2-3, Amsterdam, Elsevier, marzo.

Loayza, N. (1997), "The economics of the informal sector: a simple model and some empirical evidence from Latin America", Policy Research Working Paper, No 1727, Washington, D.C., Banco Mundial, febrero.

Luiz Pereira, L. y otros (2008), "Efeitos do Programa Bolsa Família nas condições de vida de beneficiários em municípios de muito baixo IDH", Brasilia, Centro Internacional de Políticas para el Crecimiento Inclusivo (CIP-CI) [en línea] http:// www.ipcig.org/publication/mds/33M.pdf.

Lutz, W., W. Butz y K. Samir (eds.) (2014), World Population and Human Capital in the Twenty-First Century, Londres, Oxford University Press, octubre.

Manley, J. y F. Vásquez (2013), "Childcare availability and female labor force participation: an empirical examination of the Chile Crece Contigo program", Working Paper series, № 2013-03, Towson, Universidad de Towson, diciembre.

Mathers, N. y R. Slater (2014), "Social protection and growth: research synthesis", Canberra, Overseas Development Institute (ODI) [en línea] http://www.social-protection.org/gimi/gess/RessourcePDF.action?ressource.ressourceld=54036.

Martínez, C. y M. Perticará (2017), "Childcare effects on maternal employment: evidence from Chile," Journal of Development Economics, vol. 126, Amsterdam, Elsevier, mayo.

Martínez, J. y K. Voorend (2008), "Transferencias condicionadas e igualdad de género: ¿blancos, negros o grises?", Revista de Ciencias Sociales (Cr), vol. 4, № 122, San José, Universidad de Costa Rica.

MGI (McKinsey Global Institute) (2017a), A Future That Works: Automation, Employment, and Productivity, San Francisco, enero. (2017b), "Where will Latin America's growth come from?", Discussion Paper, San Francisco, abril.

Medeiros, M., T. Britto y F. Soares (2008), "Targeted cash transfer programmes in Brazil: BPC and the Bolsa Familia, Working Paper, № 46, Brasilia, Programa de las Naciones Unidas para el Desarrollo (PNUD). 
Medrano, P. (2009), "Public day care and female labor force participation: evidence from Chile", serie Documentos de Trabajo, №306, Santiago, Universidad de Chile, diciembre.

Mincer, J. (1958), "Investment in human capital and personal income distribution", Journal of Political Economy, vol. 66, $N^{\circ} 4$, Chicago, University of Chicago Press, agosto.

Mishra, A. y R. Ray (2013), "Informality, corruption and inequality", Bath Economics Working Paper, № 13/10, Bath, Universidad de Bath.

Mostafa, J., F. Monteiro y P. Ferreira (2010), "Efeitos econômicos do gasto social no Brasil", Perspectivas da Política Social no Brasil, vol. 8, J. Castro y otros (orgs.), Brasilia, Instituto de Investigación Económica Aplicada (IPEA).

Mullin, G. y M. Vairo (2015), "El impacto de la expansión de la educación preescolar en Uruguay: un análisis en base al enfoque de igualdad de oportunidades", serie Documentos de Investigación Estudiantil, Nº1/2015, Montevideo, Universidad de la República, marzo.

Neidhöfer, G., J. Serrano y L. Gasparini (2017), “Educational inequality and intergenerational mobility in Latin America: a new database", Documentos de Trabajo, № 215, La Plata, Universidad Nacional de La Plata, agosto [en línea] http:// www.cedlas.econo.unlp.edu.ar/wp/wp-content/uploads/doc_cedlas215.pdf.

Noboa-Hidalgo, G. y S. Urzúa (2012), "The effects of participation in public child care centers: evidence from Chile”, Journal of Human Capital, vol. 6, No 1, Chicago, University of Chicago Press.

Nollenberger, N. e I. Perazzo (2016), "Efectos de la provisión universal de educación preescolar sobre la asistencia y la participación laboral femenina: evidencia para el caso uruguayo", serie Documentos de Trabajo, № 04/2016, Montevideo, Universidad de la República, agosto.

Núñez, J. (coord.) (2011), "Evaluación del programa Familias en Acción en grandes centros urbanos: informe final", Bogotá, Centro Nacional de Consultoría, diciembre [en línea] https://issuu.com/carlosgutierrez30/docs/evaluaci_n_ del_programa_familias_e.

Nuñez, J. y L. Miranda (2007), "Recent findings on intergenerational income and educational mobility in Chile," Documento de Trabajo, № 244, Santiago, Universidad de Chile, junio.

OCDE/CEPAL/CAF (Organización de Cooperación y Desarrollo Económicos/Comisión Económica para América Latina y el Caribe/Banco de Desarrollo de América Latina) (2016), Perspectivas Económicas de América Latina 2017: Juventud, Competencias y Emprendimiento (LC/G.2689), París, octubre.

OMS (Organización Mundial de la Salud) (2011), Scaling Up Action Against Noncommunicable Diseases: How Much Will it Cost?, Ginebra.

Ostry, J., A. Berg y C. Tsangarides (2014), "Redistribution, inequality, and growth", IMF Staff Discussion Note, NN SDN/14/02, Washington, D.C., Fondo Monetario Internacional (FMI), febrero.

Parker, S. (2003), "Evaluación del impacto de oportunidades sobre la inscripción escolar: primaria, secundaria y media superior", Documentos de Investigación, № 6, Ciudad de México, Instituto Nacional de Salud Pública/Centro de Investigación y Docencia Económicas (CIDE), marzo.

Pickett, K. y R. Wilkinson (2009), The Spirit Level: Why More Equal Societies Almost Always Do Better, Londres, Allen Lane. Rajan, R. (2010), Fault Lines: How Hidden Fractures Still Threaten the World Economy, Princeton, Princeton University Press.

Rasella, D. y otros (2013), "Effect of a conditional cash transfer programme on childhood mortality: a nationwide analysis of Brazilian municipalities", The Lancet, vol. 382, № 9886, Amsterdam, Elsevier, julio.

Rosero, J. y H. Oosterbeek (2011), "Trade-offs between different early childhood interventions: evidence from Ecuador", Tinbergen Institute Discussion Paper, № 102/3, Amsterdam, Tinbergen Institute.

Samson, M. (2009), "Social cash transfers and employment: a note on empirical linkages in developing countries", Promoting Pro-Poor Growth: Employment, París, Organización de Cooperación y Desarrollo Económicos (OCDE).

Schneider, F. (2012), "The shadow economy and work in the shadow: what do we (not) know?", IZA Discussion Paper, $N^{\circ} 6423$, Bonn, Institute for the Study of Labor (IZA), marzo.

Schneider, F. y D. Enste (2000), "Shadow economies: size, causes, and consequences", Journal of Economic Literature, vol. 38, No 1, Pittsburgh, Asociación Estadounidense de Economía, marzo.

Schwarzer, H. (2000), "Impactos socioeconômicos do sistema de aposentadorias rurais no Brasil: evidências empíricas de um estudo de caso no estado do Pará", Texto para Discussão, № 729, Río de Janeiro, Instituto de Investigación Económica Aplicada (IPEA), junio.

Sheehan, P. y otros (2017), "Building the foundations for sustainable development: a case for global investment in the capabilities of adolescents", The Lancet, vol. 390, № 10104, Amsterdam, Elsevier, octubre.

Stiglitz, J. (2012), The Price of Inequality: How Today's Divided Society Endangers Our Future, Nueva York, W.W. Norton.

The Economist (2016), "The superstar company. A giant problem. The rise of the corporate colossus threatens both competition and the legitimacy of business", Londres, 17 de septiembre.

Torche, F. (2014), "Movilidad intergeneracional y desigualdad: el caso latinoamericano", Annual Review of Sociology, vol. 40, Palo Alto, Annual Reviews, julio. 
Capitulo IV

Comisión Económica para América Latina y el Caribe (CEPAL)

Tornarolli, L. y otros (2014), “Exploring trends in labor informality in Latin America, 1990-2010", Documento de Trabajo, $N^{\circ} 159$, La Plata, Universidad Nacional de La Plata, mayo.

UNICEF (Fondo de las Naciones Unidas para la Infancia) (2012), A brief review of the social and economic returns to investing in children [en línea] https://www.unicef.org/socialpolicy/files/Investing_in_Children_19June2012_e-version_FINAL.pdf. Urzúa, S. y G. Veramendi (2011), "The impact of out-of-home childcare centers on early childhood development", IDB Working Paper series, N²40, Washington, D.C., Banco Interamericano de Desarrollo (BID), junio.

Vairo, M. (2014), “Efectos de la extensión de la jornada escolar sobre la participación laboral femenina: evidencia del programa de Escuelas de Tiempo Completo", documento presentado en las Jornadas Académicas de la Facultad de Ciencias Económicas y de Administración, Montevideo, Universidad de la República, 7 a 9 de octubre.

Van Lancker, W. y J. Ghysels (2011), "Who reaps the benefits? The social distribution of public childcare in Sweden and Flanders", Working Paper, № 11/06, Antwerp, Universidad de Antwerp, abril.

Veblen, T. (1914), The Instinct of Workmanship and the State of the Industrial Arts, Nueva York, Macmillan.

Videt, B. (2014), "Social protection for inclusive growth. How welfare schemes might contribute to economic growth", The Broker, Amsterdam, Foundation for International Development Publications (IDP), 16 de enero [en línea] http://www. thebrokeronline.eu/Articles/Social-protection-for-inclusive-growth.

Weller, J. (2017), "Las transformaciones tecnológicas y su impacto en los mercados laborales", serie Macroeconomía del Desarrollo, № 190 (LC/TS.2017/76), Santiago, Comisión Económica para América Latina y el Caribe (CEPAL), septiembre. Zandi, M. (2009), "The economic impact of the American recovery and Reinvestment act", Moody's Investors Service, enero [en línea] http://williambessette.com/Economic_Stimulus_House_Plan_012109.pdf.

158 

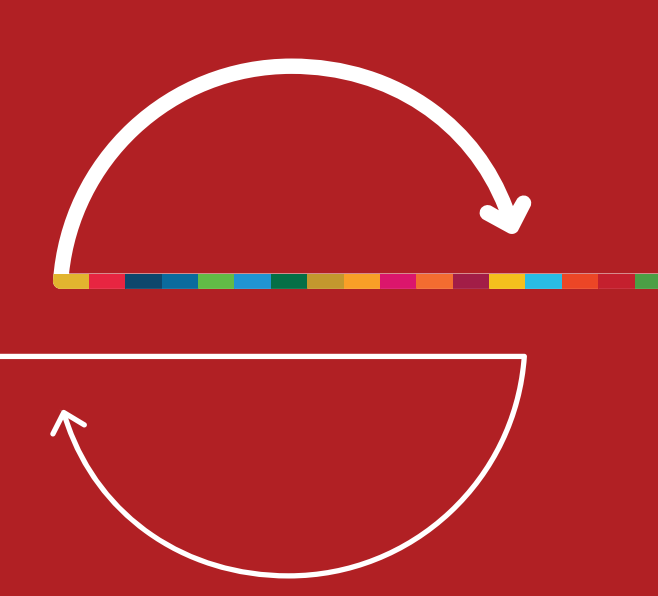

\section{CAPITULO}

V

\section{Desigualdades que segregan} y deterioran: territorio

\section{y medio ambiente}

\section{Introducción}

A. El territorio como expresión de los desequilibrios del modelo económico

1. El espacio de la desigualdad

2. La infraestructura refuerza la inercia del modelo

3. La nueva ruralidad

B. Las ciudades: centros dinámicos que reproducen la segmentación

1. Antiguos y nuevos rezagos

2. La segregación niega el derecho a la ciudad

3. La movilidad urbana como expresión de la desigualdad

C. El estilo de desarrollo erosiona sus bases ambientales

1. La degradación del territorio destruye ecosistemas y suelos

2. El cambio climático: contaminación global e impactos localizados

3. La urgencia de aumentar la tasa de descarbonización

D. Fuentes de energía renovables: un nuevo horizonte de inversiones

1. La necesidad de una nueva matriz energética

2. La presencia del carbono en la matriz eléctrica disminuye lentamente

3. Complementariedad e integración entre las energías renovables

E. Las bases de una estructura de baja eficiencia productiva y energética

Bibliografía 



\section{Introducción}

En los capítulos anteriores, se analizaron diversas dimensiones de la desigualdad, así como las consecuencias negativas que esta conlleva en términos de productividad, al limitar el desarrollo de capacidades y las oportunidades para ponerlas en práctica. Este capítulo aborda otras dimensiones que se relacionan estrechamente con las ya estudiadas. Una de ellas es su expresión territorial, ya que la pobreza o los bajos niveles de desarrollo se concentran en ciertas áreas y no en otras. Las ciudades son parte de esta dinámica territorial que tiende a concentrar el desarrollo en algunos espacios y a generar polarizaciones, tanto en las propias ciudades como en su relación con el mundo rural. Otras desigualdades se relacionan con el deterioro ambiental: son los sectores de menores recursos los que sufren en mayor medida las consecuencias negativas de la contaminación en zonas urbanas, y los campesinos pobres los que deben trabajar en los ecosistemas rurales más degradados. Por otra parte, la infraestructura existente y los patrones de inversión en dicha infraestructura consolidan y reproducen las desigualdades territoriales y ambientales.

Estas nuevas expresiones de la desigualdad se refieren, entonces, al territorio, las ciudades, la infraestructura y el medio ambiente. El desarrollo territorial desigual, las brechas de infraestructura y el deterioro selectivo del medio ambiente son dimensiones de la desigualdad interconectadas. Por ello, su análisis en conjunto permite identificar los límites del modelo actual y discutir las bases de un nuevo modelo coherente con la Agenda 2030 para el Desarrollo Sostenible. El nuevo modelo se apoya en el reconocimiento de la función del medio ambiente y los recursos naturales como "base de la sustentación material, ecosistémica, ambiental y energética de los procesos económicos" (Sunkel, 1996). Este análisis se contextualiza en un escenario donde el cambio climático es una restricción adicional que limita el margen de acción de las políticas y, al mismo tiempo, abre horizontes de inversión en torno a la innovación y el cambio estructural.

Cada una de esas dimensiones (territorio, ciudades, medio ambiente e infraestructura) interactúa con las otras y puede generar disyuntivas (trade-offs) —cuando, por ejemplo, una obra de infraestructura tiene un impacto negativo en el medio ambiente- o sinergias — cuando, por ejemplo, una infraestructura resiliente disminuye las desigualdades territoriales-. Una de las variables clave que definen las interacciones entre estas cuatro dimensiones es la intensidad y dirección del progreso técnico. Para alcanzar el desarrollo sostenible es necesario reducir la brecha tecnológica y orientar la innovación y el cambio estructural hacia un aumento de la eficiencia energética y un cambio de la matriz energética que reduzca las emisiones de dióxido de carbono $\left(\mathrm{CO}_{2}\right)$ por unidad de energía consumida. Un esfuerzo en esta dirección es esencial para salir de una situación de escasa inversión, bajo crecimiento, poco aumento de la productividad y estancamiento de la eficiencia energética en la región, y hacer compatible la aceleración del crecimiento con la creación de empleo y el objetivo de disminuir su impacto ambiental. En este capítulo, se hace hincapié en las interdependencias entre esas cuatro dimensiones y su interacción con la desigualdad y el progreso técnico como elementos clave para avanzar hacia la propuesta de un nuevo modelo de desarrollo basado en un gran impulso ambiental.

\section{A. El territorio como expresión de los desequilibrios del modelo económico}

\section{El espacio de la desigualdad}

El núcleo de la moderna teoría de la economía regional es un modelo centro-periferia cuyas variables principales (retornos crecientes, patrones de especialización y derrames tecnológicos localizados) son las que la Comisión Económica para América Latina y el Caribe (CEPAL) y los pioneros de la teoría del desarrollo destacaron en su momento ${ }^{1}$. Indivisibilidades, complementariedades y economías externas dan lugar a una fuerte inercia de las trayectorias tecnológicas y productivas (path dependency) difícil de revertir sin políticas de diversificación (Arthur, 1994).

El modelo centro-periferia es el núcleo de la teoría de la economía regional (véase Brakman, Garretsen y Marrewijk, 2011, cap. 3). Sobre este modelo en la tradición cepalina, véanse Prebisch (1976, 1981), De Mattos (1988), Rodríguez (1980, 2006), Cimoli, Porcile y S. Rovira (2010), Bárcena y Prado (2016) e Infante (2016). 
Esa dinámica genera marcadas disparidades espaciales entre los países y dentro de ellos (CEPAL, 2016a, 2015b). La elevada concentración de la producción en un pequeño grupo de sectores y grandes empresas modernas — la heterogeneidad estructural- se expresa en el territorio de los países de la región a través de una concentración de la población y la producción más aguda que en las economías desarrolladas, y que genera desigualdades en las condiciones de vida (Cuervo 2004; CEPAL, 2015c). En algunos países, los niveles de concentración son extraordinariamente altos. Un ejemplo es Panamá, donde, en la provincia del mismo nombre, sede de la capital, se concentran el $71 \%$ del PIB y el $51 \%$ de la población, a pesar de que esta provincia representa solo el $16 \%$ de la superficie del país. En otros países, los niveles de concentración son menores debido a la existencia de más de un centro urbano importante, como en el Ecuador y el Estado Plurinacional de Bolivia, pero, aun así, son elevados en comparación con el resto del mundo. Como se verá más adelante, la tendencia a la concentración va acompañada de una gran expansión de las principales áreas metropolitanas.

Las disparidades espaciales en la producción se asocian a diferencias de productividad: la productividad media en las áreas metropolitanas centrales es sistemáticamente superior a la del resto de los territorios, aunque existe una gran heterogeneidad en la región ${ }^{2}$. Las diferencias de productividad e ingresos reflejan no solo los retornos crecientes, sino también la cercanía al poder político, la transferencia de riqueza desde los territorios que generan productos básicos hacia esas áreas y su mayor dotación de infraestructura. Son el resultado de los patrones de producción y de las decisiones políticas sobre la asignación de la inversión pública y la dotación de infraestructura; es decir, de las reglas del juego no incluyentes y la cultura del privilegio que han predominado en la historia económica de la región (véase el capítulo VI).

Las disparidades regionales se manifiestan en la dispersión de la productividad media entre territorios, medida por la desviación estándar del logaritmo del PIB per cápita entre las regiones. En primer lugar, se constata que la dispersión en la región es mayor que en los dos países desarrollados incluidos en el gráfico V.1. Aunque la dispersión se mantuvo elevada entre 1995 y 2015, experimentó un leve descenso o convergencia entre 2000 y 2010-2011. Posteriormente se detuvo e incluso llegó a aumentar. Esto podría asociarse al auge de los productos básicos — producidos generalmente en territorios o regiones menos desarrollados_, que indujo un crecimiento superior a la media nacional en varios de ellos. En segundo lugar, las políticas sociales y económicas implementadas en algunos países que buscaban favorecer a las regiones más pobres, como el nordeste del Brasil, impulsaron la producción de bienes y servicios para el consumo local.

\section{Gráfico V.1}

Grado de dispersión del ingreso (evolución de las disparidades subnacionales del PIB por habitante), 1995-2015 (Desviación estándar de logaritmos del PIB per cápita)

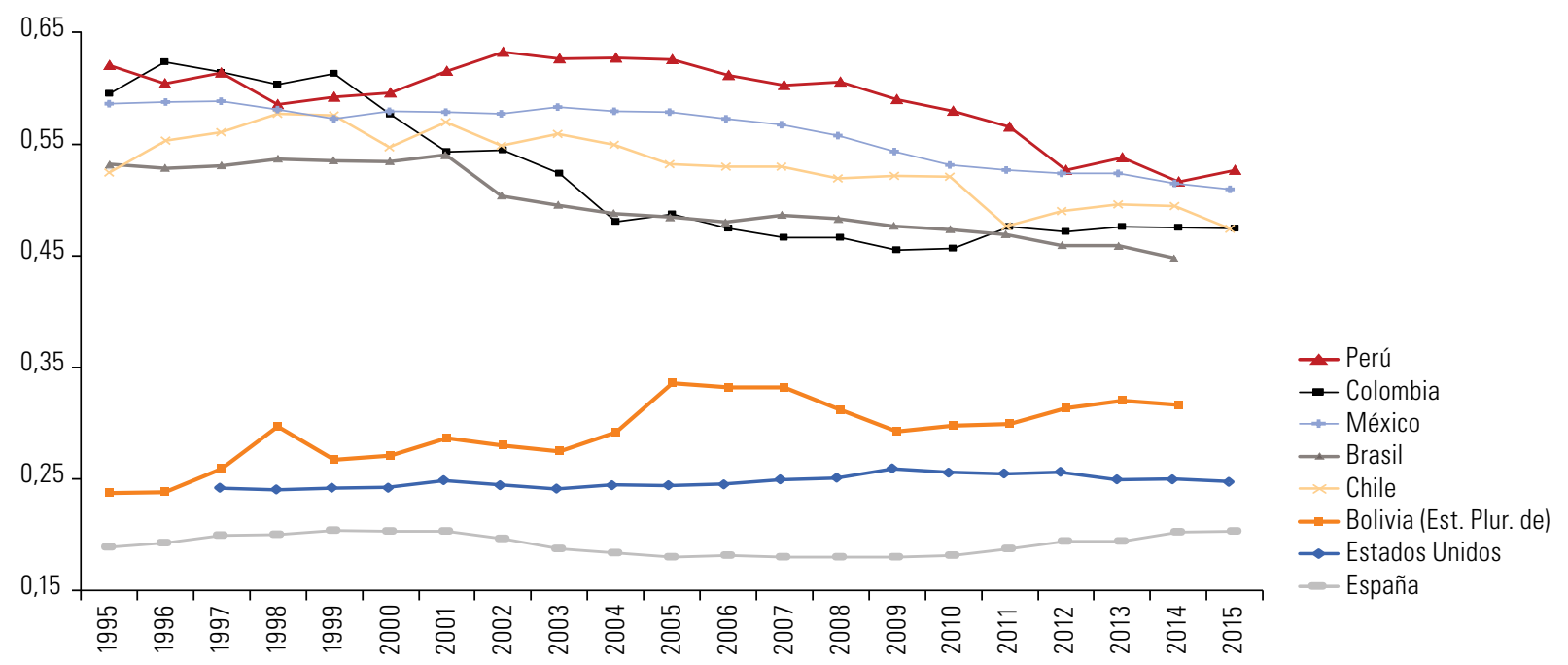

Fuente: Comisión Económica para América Latina y el Caribe (CEPAL), sobre la base de estadísticas oficiales de las cuentas nacionales de los países.

2 Algunos países, como el Brasil, Panamá y el Perú, muestran diferencias especialmente grandes, mientras que otros, como la Argentina y Chile, presentan una mayor integración territorial. 
El índice de desarrollo regional latinoamericano (IDR) de 2015, elaborado por la CEPAL, ofrece una perspectiva más amplia de las desigualdades territoriales. A diferencia de los análisis tradicionales de disparidades territoriales que toman como patrón de referencia los promedios de cada país, el IDR compara el nivel de desarrollo relativo de 175 entidades territoriales de 8 países latinoamericanos con los promedios de la región (véase el mapa V.1) ${ }^{3}$. Este enfoque incorpora dimensiones adicionales al PIB por habitante, como la salud, la educación y el acceso a los servicios de vivienda. EI IDR de 2015 permite identificar las macrorregiones con mayores rezagos relativos en materia de desarrollo económico-social, entre las que se encuentran el nordeste del Brasil, el suroeste de México y las zonas andinas y amazónicas de Bolivia (Estado Plurinacional de), Colombia, el Ecuador y el Perú. Por el contrario, los territorios con los mejores resultados son normalmente las capitales o las áreas metropolitanas más grandes.

\section{Mapa V.1}

América Latina (8 países): indice de desarrollo regional (IDR) 2015
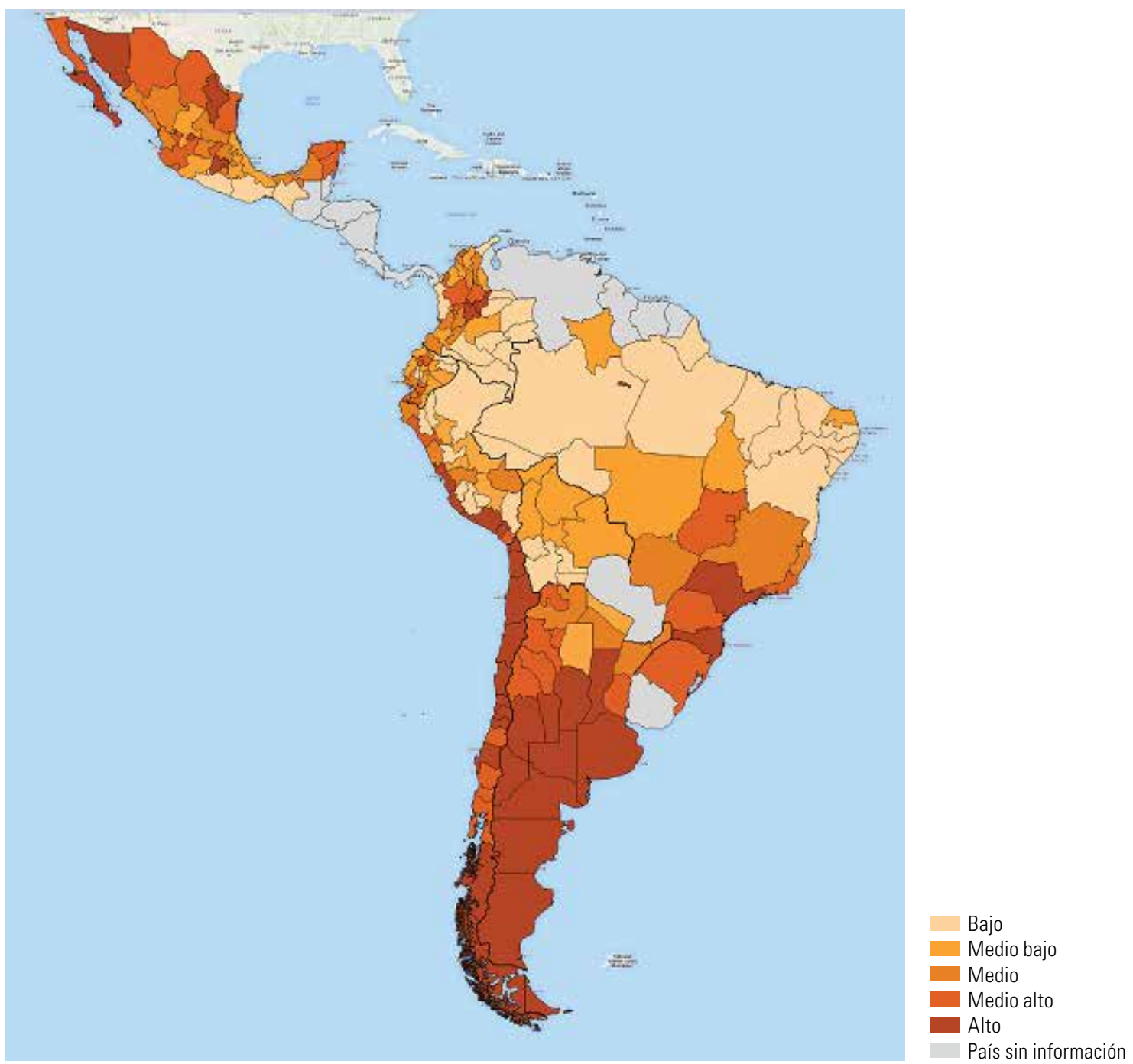

Fuente: Comisión Económica para América Latina y el Caribe (CEPAL), Panorama del Desarrollo Territorial en América Latina y el Caribe, 2015(LC/W.671), Santiago, 2015. a Los países analizados son la Argentina, Bolivia (Estado Plurinacional de), el Brasil, Chile, Colombia, el Ecuador, México y el Perú.

Nota: Los límites y los nombres que figuran en este mapa no implican su apoyo o aceptación oficial por las Naciones Unidas.

3 El IDR es un índice compuesto elaborado sobre la base de 10 variables (porcentaje de población rural, tasa de ocupación, PIB per cápita sin minería extractiva, tasa de analfabetismo, población con educación superior, tasa de mortalidad infantil, esperanza de vida, tasa de homicidios, vivienda sin agua interior, hogares/vivienda con computador), para 8 países y 175 entidades territoriales del primer nivel de las divisiones político-administrativas (región, estado, provincia y departamento), tomando como año de referencia 2015, o en torno a 2015. Las variables son normalizadas para generar un puntaje en función del cual se agrupan por quintiles de grados de desarrollo denominados alto, medio alto, medio, medio bajo y bajo. En el interior de las 175 entidades también existe una fuerte heterogeneidad. Véase una descripción de la metodología en CEPAL (2017b, anexo 1). 
Si se dividen las regiones en cinco estratos de desarrollo en función de este indicador, se observa que en los territorios con niveles medio bajo y bajo del IDR residen más de 87 millones de personas, cerca del $18 \%$ de la población total de los países analizados, mientras que su participación en el PIB alcanza solo el 9\%. En el estrato alto, la población suma 158 millones de personas, que representan el $32 \%$ del total de los ocho países y generan el $47 \%$ de su PIB. Las diferencias entre los estratos son también muy marcadas en los indicadores sociales de esperanza de vida, mortalidad infantil, analfabetismo y acceso al agua potable (véase el gráfico V.2). Por ejemplo, la mortalidad infantil se duplica en los territorios que tienen un IDR bajo en comparación con los que tienen un IDR elevado.

\section{Gráfico V.2}

América Latina (8 paises): indicadores seleccionados del IDR 2015, según estratos de desarrolloa (Promedios simples)

\section{A. Esperanza de vida (en años)}

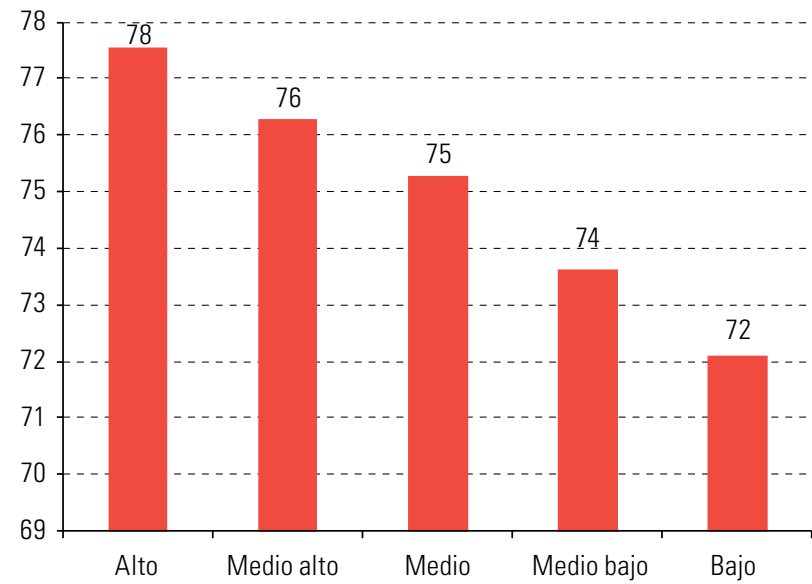

C. Tasa de analfabetismo (en porcentajes)

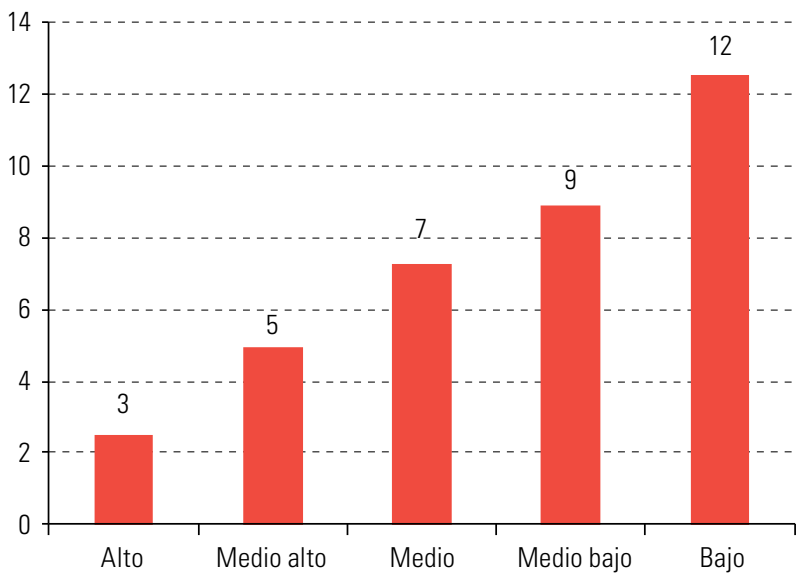

B. Mortalidad infantil (por cada 1.000 nacidos vivos)

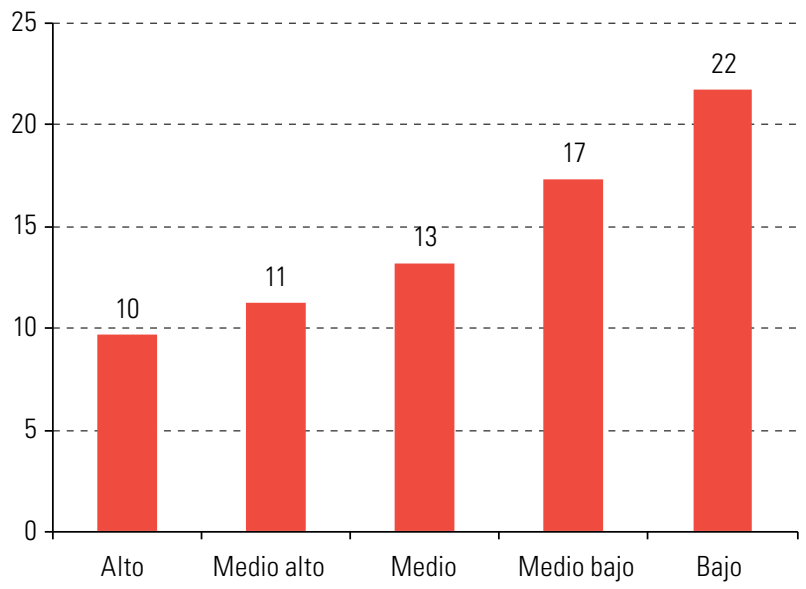

D. Viviendas sin agua interior (en porcentajes)

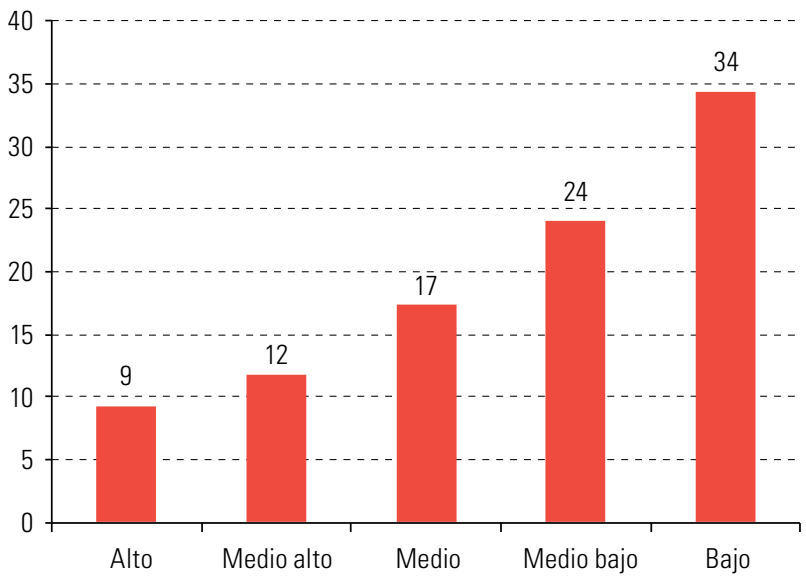

Fuente: Comisión Económica para América Latina y el Caribe (CEPAL), Panorama del Desarrollo Territorial en América Latina y el Caribe, 2015(LC/W.671), Santiago, 2015. a Los países analizados son la Argentina, Bolivia (Estado Plurinacional de), el Brasil, Chile, Colombia, el Ecuador, México y el Perú.

Este patrón concentrado en lo territorial se apoya en una infraestructura en parte heredada y se reproduce en las tendencias recientes de la inversión en dicha infraestructura. 


\section{La infraestructura refuerza la inercia del modelo}

\section{a) Un modelo basado en los recursos naturales}

En sus orígenes, el desarrollo de la infraestructura en la región estuvo asociado al modelo primario exportador y orientado a hacer llegar los recursos naturales a los puertos sin que se avanzara significativamente en las conexiones internas o hacia otros países de la región. La importancia de los recursos naturales como base de la inserción internacional de la región sigue siendo muy elevada, lo que conlleva un cierto grado de vulnerabilidad externa. Los problemas asociados a la dependencia de estos recursos como fuente principal de competitividad de la región han sido un tema tradicional entre los analistas del desarrollo, al que se suma la urgencia del desafío de la sostenibilidad. En efecto, la región tiene una riqueza de recursos naturales renovables y no renovables que ha sido explotada sin criterios de sostenibilidad social, ambiental y económica ${ }^{4}$. En materia energética, cuenta con un gran potencial en el ámbito de las fuentes renovables (como la hidráulica, la solar o la eólica), que presentan, además, una notable complementariedad geográfica y estacional. Sin embargo, la región depende principalmente de los hidrocarburos: tres cuartas partes de la oferta energética provienen de esta fuente, un tema sobre el que se volverá más adelante.

Otro aspecto que debe considerarse es que los países de la región cuentan con una extraordinaria biodiversidad. Presentan una gran variedad de climas y tipos de ecosistemas, y una enorme diversidad de flora, más de la mitad de la cual es única. Son centros de origen y diversidad de un gran número de especies vegetales y animales. Muchos de ellos, como el Brasil, Colombia, el Ecuador, México, el Perú y Venezuela (República Bolivariana de), son megadiversos por su gran riqueza de especies; en especial de aves, mariposas, reptiles y plantas con flores. A esta riqueza se suman los activos biológicos y ecológicos de sus áreas rurales, que contienen cuatro de los ocho centros de origen de plantas cultivadas, según Vavilov ${ }^{5}$. Contar con diversidad de recursos genéticos es vital para adaptarse a las nuevas condiciones generadas por el cambio climático, como el estrés por sequía, los cambios de temperatura y su variación extrema, las enfermedades y plagas y el aumento de la salinidad. La biodiversidad es un pilar en la construcción de una bioeconomía diversificada. Muchos daños ambientales constituyen pérdidas irreparables del patrimonio natural que limitan las opciones de desarrollo de las futuras generaciones.

En este contexto, la región exporta sus recursos naturales sin internalizar en sus precios los costos ambientales de su explotación, al tiempo que paga caro las rentas tecnológicas incorporadas en los bienes importados. Este comercio desigual desplaza los costos ambientales de los países centrales a los países periféricos (Martínez Alier y Roca, 2013). En el gráfico V.3 se muestra que América del Sur es exportadora neta de materiales — principalmente biomasa, minerales y combustibles fósiles-y que el saldo negativo de su balanza comercial física (entrada de materiales por importación menos salida de materiales por exportación) ha aumentado en el nuevo milenio. No se han aprovechado las externalidades tecnológicas y productivas que podrían surgir de la explotación de los recursos naturales, lo que ha dado lugar a la concentración de sus beneficios en pocas áreas y un tejido productivo poco diversificado (García Alonso, 2017).

4 América Latina y el Caribe posee el 33\% del agua (CEPAL, 2014), el 15\% de la superficie agrícola (FAOSTAT, 2017b) y una amplia proporción de las reservas probadas de minerales metálicos del mundo. En el caso del litio, de acuerdo con USGS (2017), la Argentina, el Brasil y Chile poseen el 68\% del total de las reservas probadas mundiales. Adicionalmente, la Argentina, Bolivia (Estado Plurinacional de) y Chile cuentan con el 19,3\%, el 24,2\% y el 21,9\%, respectivamente, de las reservas potenciales de este metal a nivel mundial (Perrotti y Coviello, 2015). Con respecto al cobre, Chile, México y el Perú concentran el $47 \%$ de las reservas probadas mundiales. Según USGS (2014), se han identificado reservas potenciales de este metal de aproximadamente 2.100 millones de toneladas, de las cuales el 21,4\% podrían estar ubicadas en América del Sur y el 2\% en Centroamérica y el Caribe. En el caso de la bauxita, según el USGS (2017), América del Sur y el Caribe podrían contar con el $21 \%$ de las reservas potenciales mundiales.

5 En la década de 1920, el geneticista Nikolai Vavilov estudió el origen y la distribución de las principales especies de plantas cultivadas en el mundo y estableció ocho centros de origen. Por su parte, el Centro Mundial de los Vegetales (World Vegetable Center) ha identificado más de 130 genes asociados a la respuesta a la sequía de parientes silvestres del tomate y ha introducido a las líneas comerciales genes de los tomates de los desiertos chilenos (CONABI0, s/f). http://www. biodiversidad.gob.mx/genes/centrosOrigen/centrosPlantas1a.html. "Centros de plantas cultivadas". 


\section{Gráfico V.3}

América del Sur (9 paises): exportaciones, importaciones y balanza comercial física, 2002-2016

(En millones de toneladas)

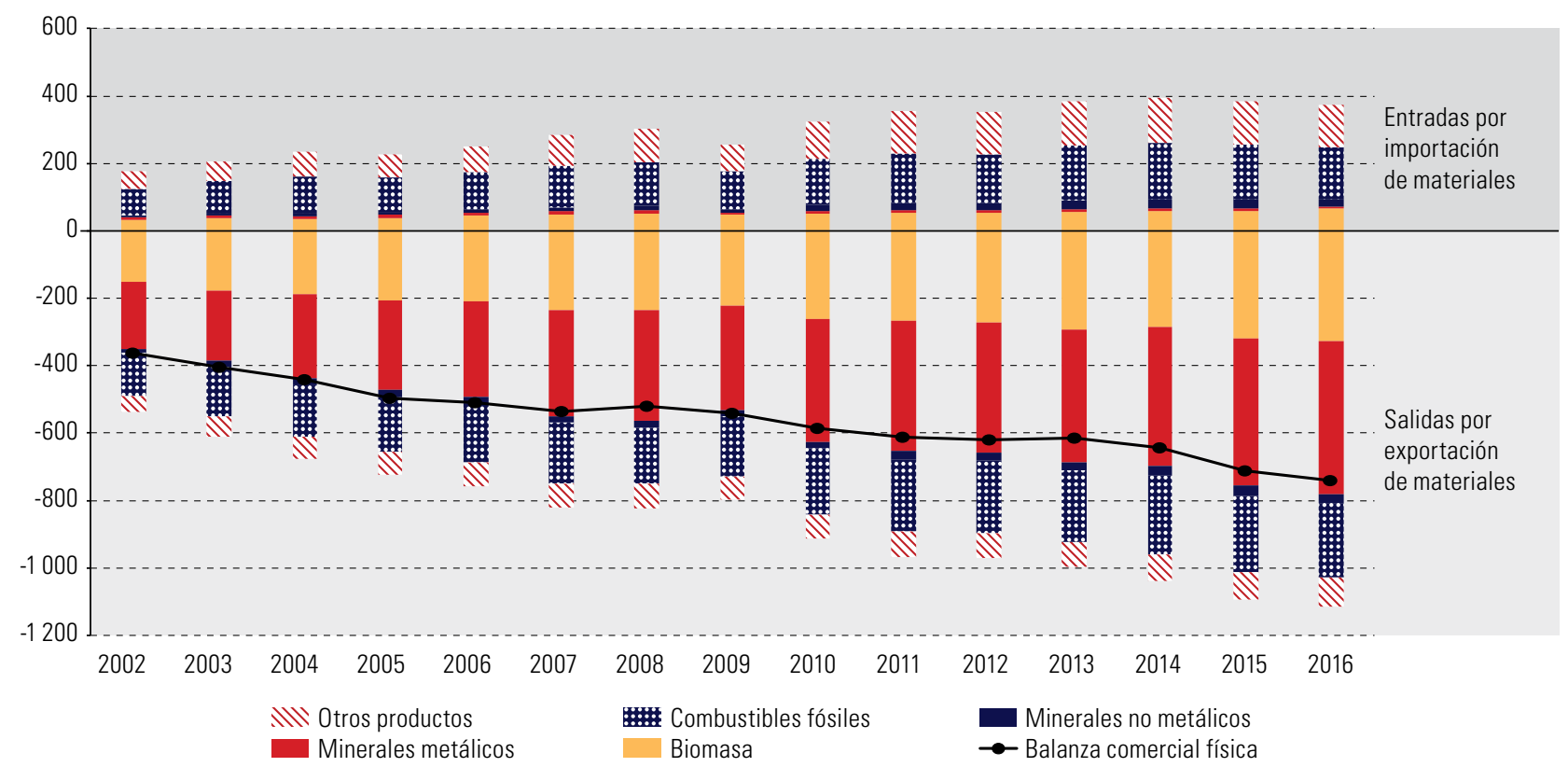

Fuente: Comisión Económica para América Latina y el Caribe (CEPAL), sobre la base de información de la Base de Datos Estadísticos de las Naciones Unidas sobre el Comercio de Productos Básicos (COMTRADE).

a Los países analizados son la Argentina, Bolivia (Estado Plurinacional de), el Brasil, Chile, Colombia, el Ecuador, el Perú, el Paraguay y el Uruguay.

En muchos casos, la expansión del modelo extractivo se ha traducido en conflictos sociales y ambientales vinculados al desarrollo de ese tipo de actividades y a nuevos proyectos de infraestructura. Los conflictos tienen sus raíces en factores estructurales, entre los que se encuentran los altos niveles de pobreza, la desigualdad, la ausencia del Estado en vastos territorios, la histórica discriminación de los pueblos indígenas y otros grupos sociales, la falta de provisión de servicios básicos y la resistencia del statu quo (Ramos, Muñoz y Pérez, 2017).

\section{b) Un desarrollo de la infraestructura insuficiente e ineficiente}

La infraestructura de la región mantiene, en general, su marca de origen como modelo de enclave (Muñoz y Pérez, 2017), ya que nació para llevar la producción minera y agrícola a los puertos para su exportación. El mapa V.2 muestra cómo los nodos de infraestructura están articulados con la explotación y exportación de los recursos naturales extractivos. Con el tiempo, la malla de transporte se ha actualizado en términos de capacidad y calidad, pero la conectividad de los territorios en cada país o a través de la región sigue siendo insuficiente.

Buena parte de los asentamientos y las actividades productivas de la región está asociada a la actividad económica próxima a las costas y a los recursos naturales, principalmente en América del Sur. Las posibilidades de interconexión entre modos de transporte siguen siendo precarias o adolecen de complicaciones técnicas. En algunos casos, esto ocurre porque la malla fue diseñada para no permitir la interconexión regional por razones de seguridad nacional, concentración económica o influencia política. Como resultado, los altos costos logísticos frenan la integración y los encadenamientos productivos. 


\section{Mapa V.2}

América Latina y el Caribe: recursos naturales extractivos e infraestructura de transporte, 2017

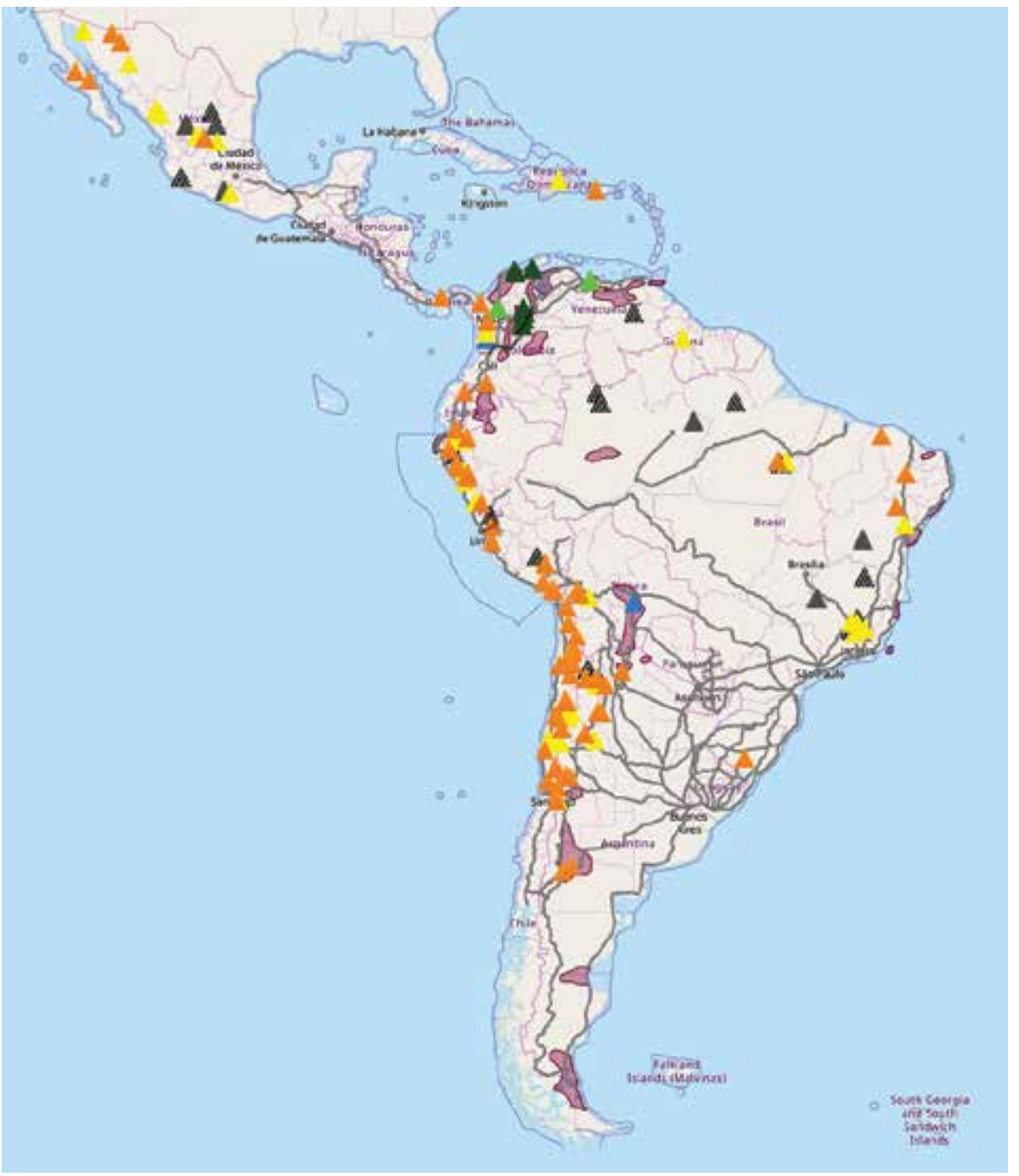

Fuente: Comisión Económica para América Latina y el Caribe (CEPAL), sobre la base de información de la Base de Datos Estadísticos de las Naciones Unidas sobre el Comercio de Productos Básicos (COMTRADE).

Nota: Los límites y los nombres que figuran en este mapa no implican su apoyo o aceptación oficial por las Naciones Unidas.

Las conexiones internas y entre países de la región no solo están fragmentadas, sino que son ineficientes en términos económicos y ambientales. El principal modo de transporte del comercio intrarregional en América del Sur es el marítimo, que representa un $63 \%$ del volumen total y un $46,3 \%$ del valor total según datos de 2013; el resto es dominado por el transporte por carretera, que representa un 30,4\% del volumen y un $39,5 \%$ del valor. En lo referente al transporte en el interior de los países, un $86 \%$ del volumen total de las operaciones se realiza por carretera. Los datos a nivel nacional sugieren el mismo patrón en el transporte interno de carga, es decir, la predominancia del transporte por carretera, incluso en los países que disponen de redes ferroviarias o fluviales, como la Argentina, el Brasil, Colombia o México (véanse los gráficos V.4 y V.5). 


\section{Gráfico V.4}

América del Sur: distribución modal del comercio intrarregional, 2013

(En porcentajes del volumen y valor)

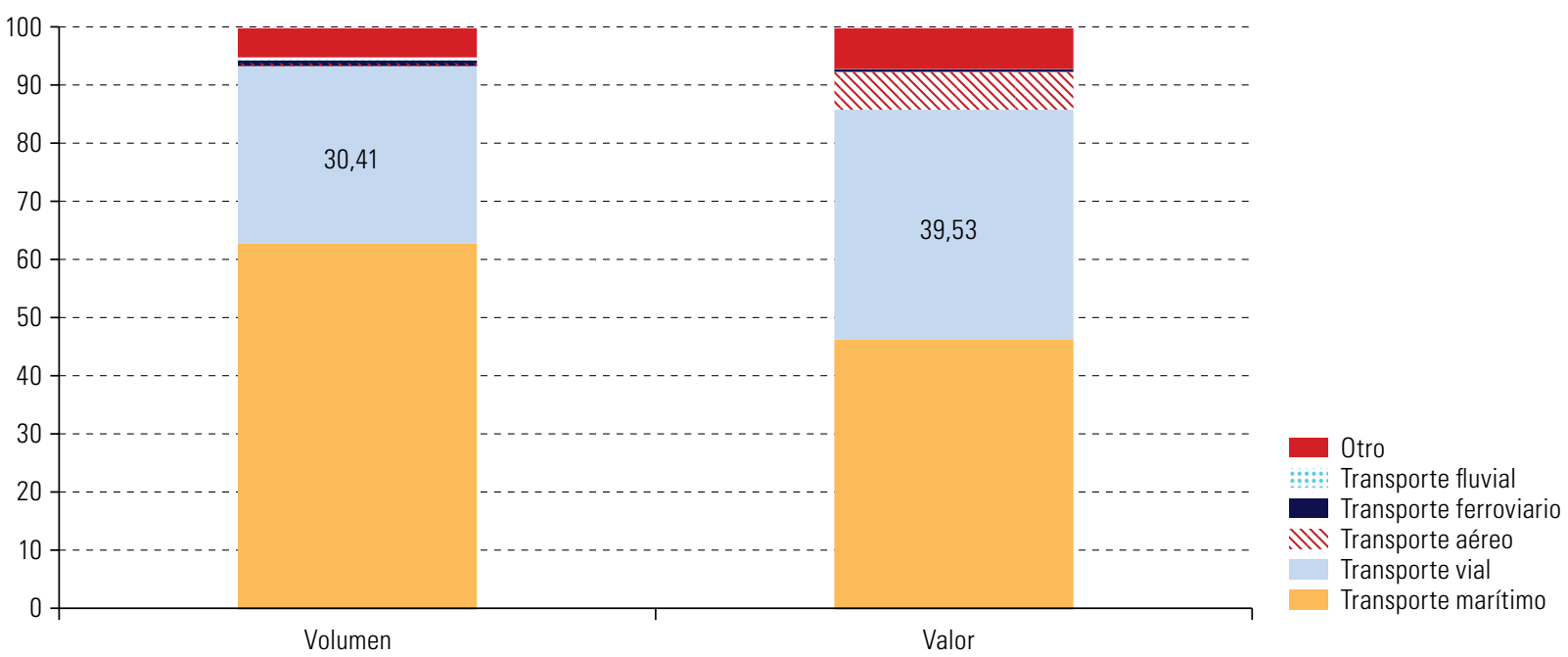

Fuente: Comisión Económica para América Latina y el Caribe (CEPAL), Base de datos de transporte internacional (BTI).

\section{Gráfico V.5}

América Latina (4 paises): reparto modal interno, 2013

(En porcentajes de toneladas transportadas por kilómetro)

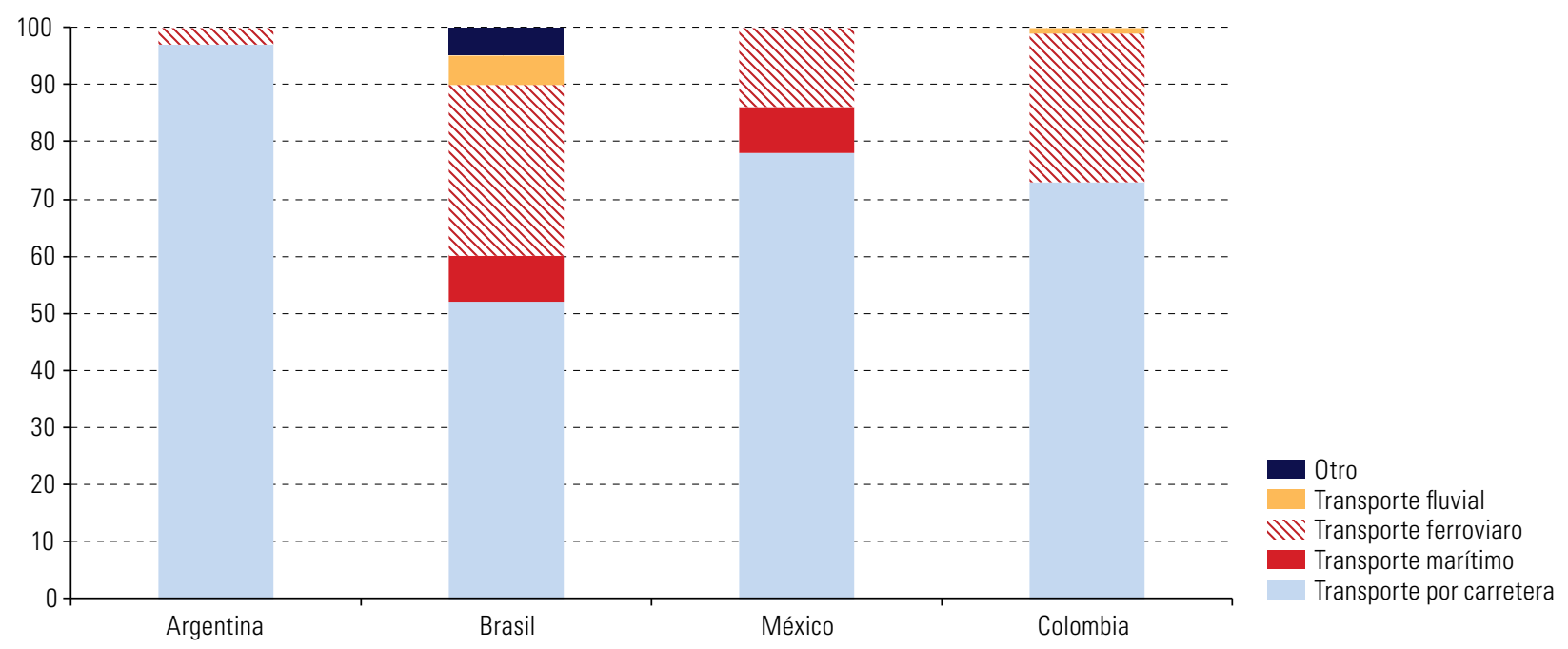

Fuente: Comisión Económica para América Latina y el Caribe (CEPAL), sobre la base de las estadísticas nacionales, 2013.

Nota: La información referente a Colombia se mide en toneladas. 
El reparto modal implica grandes pérdidas de eficiencia energética y un gran consumo de energía no renovable con elevadas emisiones de carbono. Por el contrario, se subutilizan las ventajas regionales en términos de capacidad, complementariedad y uso de energía de los modos de transporte fluvial y ferroviario ${ }^{6}$.

Ese espacio para la política de inversión pública no se ha aprovechado adecuadamente. La insuficiente conectividad terrestre, la desigualdad en el acceso a los servicios básicos y avanzados de infraestructura y los patrones de insostenibilidad ambiental revelan las limitaciones del enfoque tradicional de políticas de inversión pública en la región. Un problema fundamental es la insuficiencia de los recursos: el nivel más elevado de inversión en infraestructura se observó en los años ochenta, con un promedio del 3,6\% del PIB y un máximo del 4,1\% del PIB en 1987 (véase el gráfico V.6).

\section{Gráfico V.6}

América Latina (6 paises): inversión en infraestructura por sector (público y privado), 1980-2015 (En porcentajes del PIB)

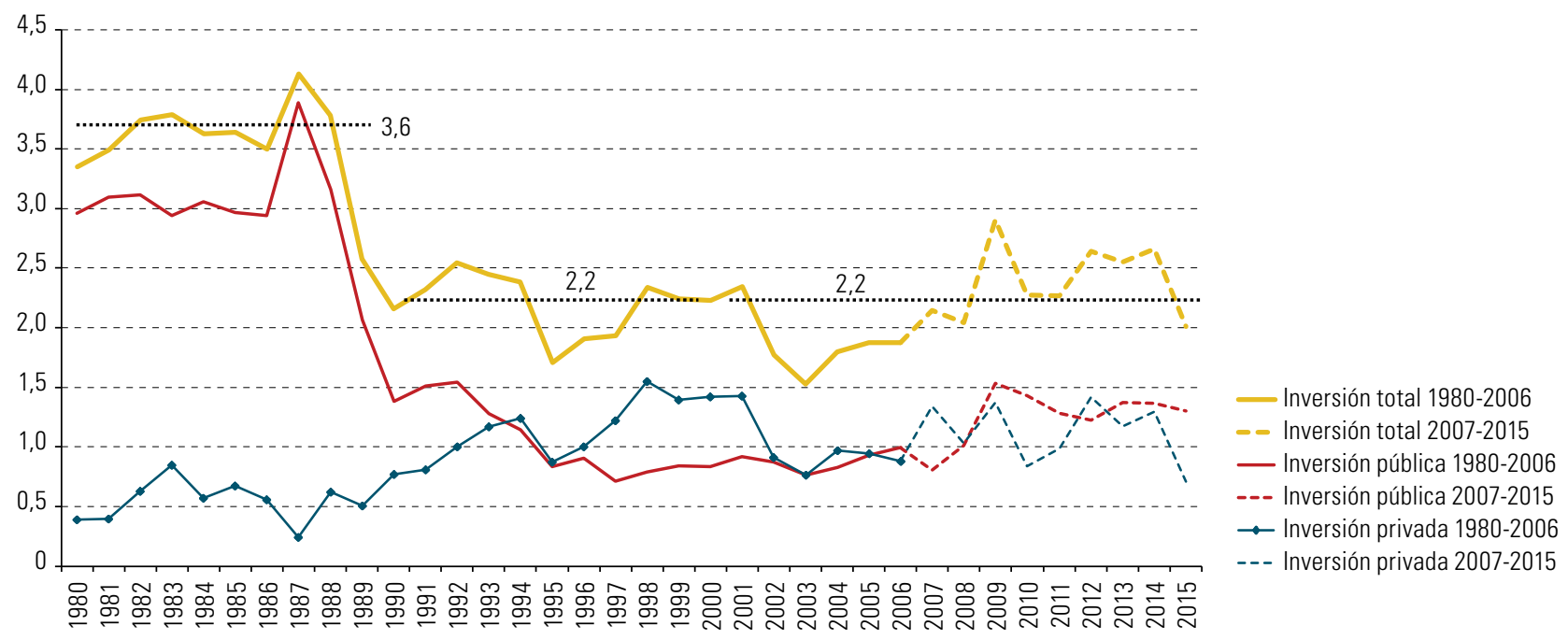

Fuente: Comisión Económica para América Latina y el Caribe (CEPAL), sobre la base de C. Calderón y L. Servén, "Infrastructure in Latin America”, World Bank Policy Research Working Paper, № 5317, Washington, D.C., Banco Mundial, 2010 para el período de 1980 a 2006 y Datos de Inversión en Infraestructura Económica (INFRALATAM) [en línea] http://infralatam.info/ para el período de 2007 a 2013.

Nota: Se analizan los sectores de transporte, energía, telecomunicaciones, agua y saneamiento. En el sector del transporte se incluyen solamente carreteras y ferrocarriles, excepto en el caso de las inversiones públicas de la Argentina, que comprenden el total de transporte. En el sector de la energía se incluye solo la electricidad.

a Los países incluidos son la Argentina, el Brasil, Chile, Colombia, México y el Perú. En 2015 no se incluye a Chile.

La falta de datos armonizados dificulta la comparación entre regiones del mundo, pero las estimaciones para el transporte evidencian la posición débil de América Latina y el Caribe en lo referido al monto de la inversión en infraestructura y a su calidad respecto de otros países o regiones. La relación entre el componente de infraestructura del Índice de Desempeño Logístico y la inversión en infraestructura per cápita muestra un rezago entre 2008 y 2015. Si bien la región invierte un porcentaje del PIB similar, o incluso superior, al de otras regiones, tiene una inversión per cápita menor incluso que la de China, donde, entre 2007 y 2016, no solo se expandió la infraestructura, sino que esta expansión fue acompañada de un aumento de calidad (véase el gráfico V.7).

6 Las 30.000 toneladas métricas que transportan 1.000 camiones se podrían transportar en una barcaza o en 24 trenes. Con la misma cantidad de diésel (1 t) que utiliza un camión con carga de una tonelada para recorrer 241 km, una barcaza puede recorrer más de cuatro veces dicha distancia (991km) y el tren, más de tres veces (769 km) (Comisión Permanente de Transporte de la Cuenca del Plata, 2015). 


\section{Gráfico V.7}

Inversión per cápita en infraestructura de transporte: carreteras y ferrocarriles, 2008-2015 (Inversión per cápita en dólares (eje izquierdo) y componente de la calidad de infraestructura en el indice de desempeño logístico (eje derecho))

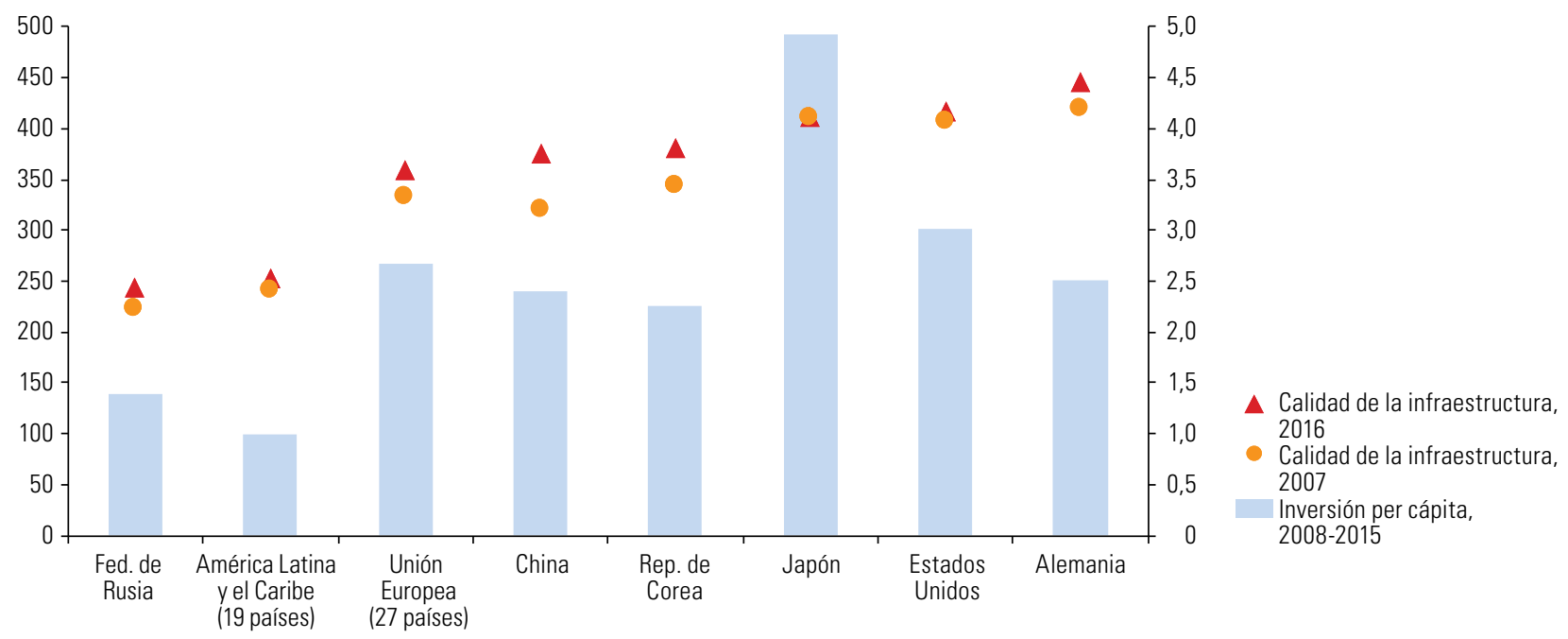

Fuente: Comisión Económica para América Latina y el Caribe (CEPAL), sobre la base de Datos de Inversión en Infraestructura Económica (INFRALATAM) [en línea] http://infralatam.info/; Organización de Cooperación y Desarrollo Económicos (OCDE) y Banco Mundial.

En América Latina, la infraestructura vial recibe más del 70\% de la inversión en el sector del transporte, lo que deja pocos recursos a los modos fluvial y ferroviario, que son más eficientes desde el punto de vista ambiental (véase el gráfico V.8).

\section{Gráfico V.8}

América Latina: inversión en infraestructura por modo de transporte, 2008-2015

(En porcentajes del PIB)

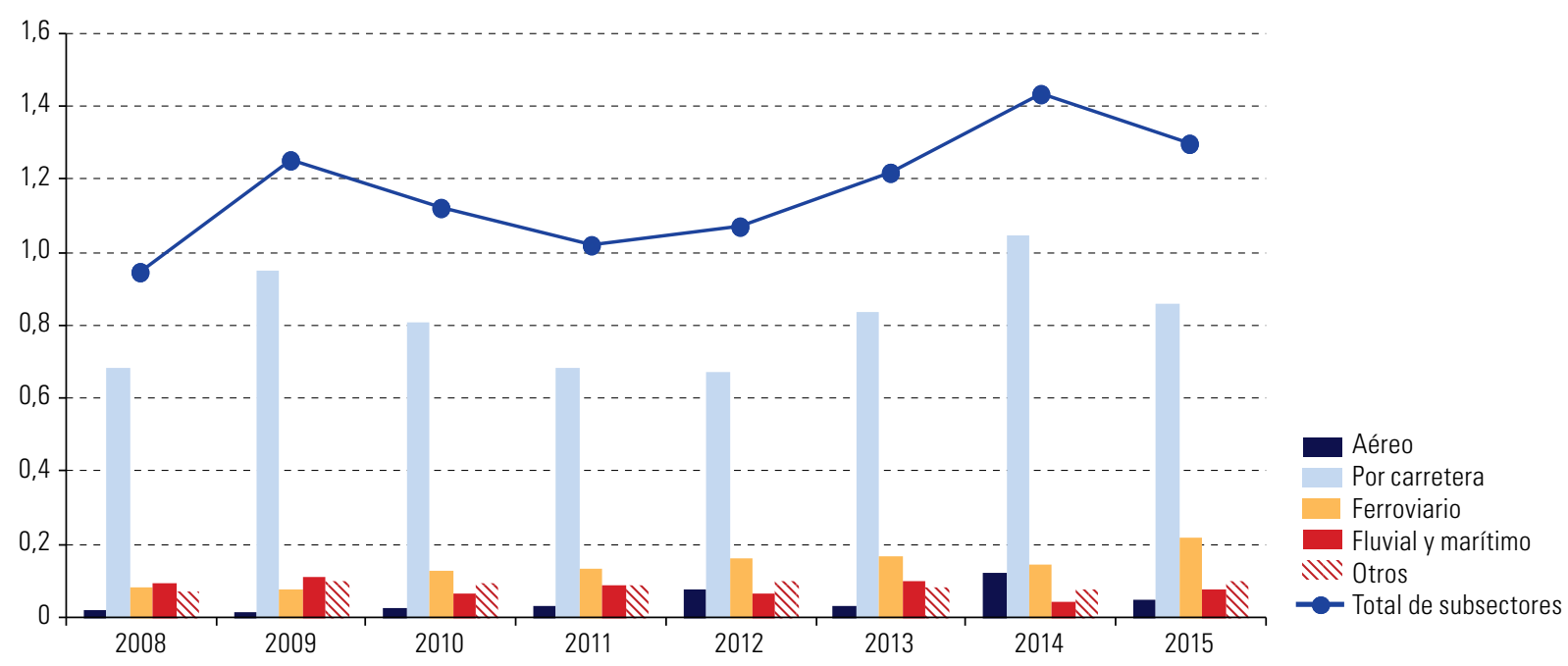

Fuente: Comisión Económica para América Latina y el Caribe (CEPAL), sobre la base de Datos de Inversión en Infraestructura Económica (INFRALATAM) [en línea] http://infralatam.info/.

La inversión en infraestructura vial se ha financiado principalmente con recursos públicos y ha contado con inversión privada mediante modelos de asociación público-privada. Las vías terrestres tienen un peso sustancial en la inversión en infraestructura, a diferencia de lo que se observa en países donde el Estado promueve un mayor equilibrio entre los distintos modos de transporte, sobre todo por medio de la inversión en ferrocarriles (véase el gráfico V.9). 


\section{Gráfico V.9}

Inversión en infraestructura por modo de transporte, 2008-2015

(En porcentajes de participación de cada subsector)

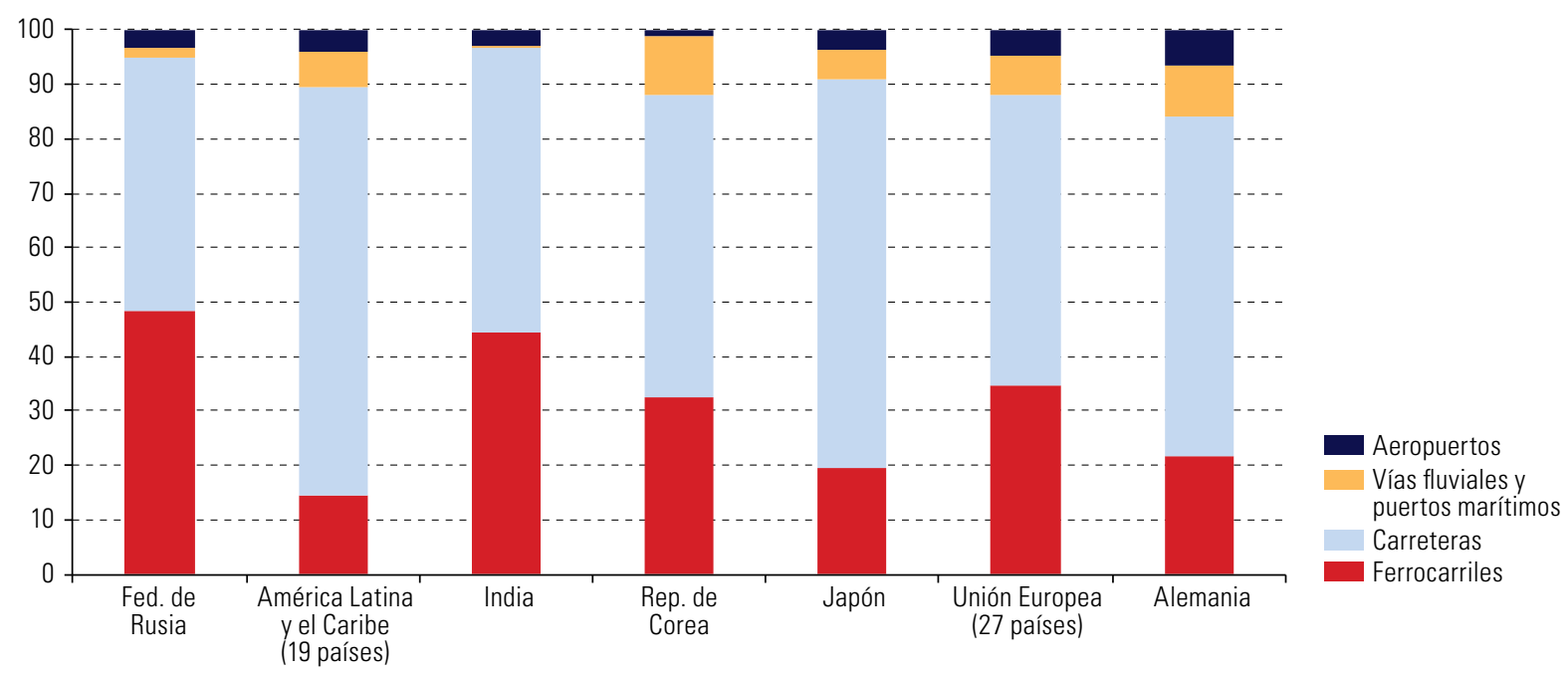

Fuente: Comisión Económica para América Latina y el Caribe (CEPAL), sobre la base de datos de la Organización de Cooperación y Desarrollo Económicos (OCDE) y del Banco Mundial.

Según el Sistema de Información de Proyectos del Consejo Suramericano de Infraestructura y Planeamiento (COSIPLAN), los planes de inversión para la próxima década tienden a mantener el sesgo a favor del modo vial y a reproducir la geografía de la infraestructura económica orientada principalmente a la exportación de productos básicos. Los nuevos proyectos se orientan a la ampliación de capacidad y el mejoramiento de la calidad de las obras, pero no incrementan la conectividad de la red.

En suma, el nivel y la composición de la inversión en infraestructura no corresponden a las necesidades del siglo XXI y refuerzan patrones que conllevan problemas de sostenibilidad social, ambiental y económica. Una mayor integración territorial (entre los países de la región y en su interior) que abra nuevas oportunidades de comercio, la inversión en nuevas modalidades de transporte más eficientes en relación con el uso de la energía y el cierre de brechas en la infraestructura digital son pasos necesarios para que la infraestructura deje de ser un factor de inercia y reproducción de desigualdades y se transforme en un instrumento de creación de nuevas trayectorias productivas.

\section{La nueva ruralidad}

El mundo rural, concepto más amplio que el de zonas rurales y definido como un complejo territorial en interacción con el mundo urbano y los distintos gradientes que existen entre lo urbano y lo rural, ha experimentado grandes transformaciones en las últimas décadas. En la región, la nueva ruralidad no se comprende todavía en toda su complejidad económica, social, ambiental y cultural, y no hay plena conciencia acerca de sus potencialidades para la construcción de un estilo de desarrollo compatible con la Agenda 2030 para el Desarrollo Sostenible.

Frecuentemente, se concibe la relación entre lo rural y lo urbano como una contraposición y no como una interacción con posibilidades de complementación. Se reduce la dimensión rural a la producción agropecuaria, se asume que la tendencia natural de la ruralidad es hacia la extinción y que su destino ineludible es la migración de la población rural hacia ciudades del país o fuera de este, y no se valora el nuevo papel de los territorios rurales en la lucha contra el cambio climático. Las estadísticas subestiman la importancia del mundo rural y pueden llegar a sobreestimar el grado de urbanización real de la región. Un análisis desagregado revela que muchas de las poblaciones que oficialmente se consideran urbanas en realidad gravitan en torno a dinámicas rurales. 
El mundo rural y sus territorios conforman un tejido productivo de gran diversidad donde se combinan producciones agrícolas, ganaderas, silvícolas y forestales, más o menos innovadoras y cada vez más integradas a cadenas de valor, en las que la producción de bienes se combina con la prestación de servicios ambientales. Asimismo, existen diversas formas de ocupación y empleo: la autoocupación, el trabajo asalariado, la residencia rural con trabajo urbano o la residencia urbana con trabajo rural y la migración temporal y circular. En este entramado, coexisten la producción agropecuaria tradicional con las pequeñas industrias rurales; el campesinado de pequeña escala con complejos agroindustriales e incluso con grandes empresas manufactureras; pequeñas obras de infraestructura con megaproyectos de desarrollo o productores que dependen esencialmente de la tierra con productores que dependen de los recursos lacustres y las costas marinas. Esto demuestra que, frente a la imagen de lo rural como lo estático, en realidad existe un mundo rural en constante movimiento e interacción.

La distancia entre el mundo rural y el urbano ha disminuido. En la mayoría de los países de la región, las inversiones en infraestructura carretera redujeron la distancia y el tiempo de traslado entre los territorios rurales, las cabeceras urbanas y las grandes ciudades. La introducción y generalización del uso de las tecnologías digitales disminuyó la distancia entre el mundo rural y el urbano en lo referente al acceso a la información, aunque las brechas de conectividad son todavía importantes. Sin embargo, esta disminución de distancias no fue acompañada de una reducción proporcional de las brechas territoriales y de bienestar. En el mundo rural, la incidencia de la pobreza es más alta, como también lo es su severidad e intensidad. Allí se encuentran, asimismo, los mayores rezagos en educación, salud, nutrición, seguridad y protección social, acceso al agua potable y a los servicios públicos, calidad de la vivienda y esperanza de vida. Parte de las desigualdades territoriales discutidas antes son una expresión de las desigualdades que existen entre el mundo rural y el urbano. Para poder hacerles frente es necesario entender las especificidades del mundo rural.

Aunado a lo anterior se encuentra el hecho de que en el mundo rural se han producido transformaciones socioculturales de largo recorrido. Entre ellas, destacan la creciente importancia y los nuevos roles de las mujeres, los jóvenes, los pueblos indígenas y las poblaciones afrodescendientes. Aunque persisten brechas importantes, las mujeres rurales han podido alcanzar mayores niveles educativos y una participación más activa en los procesos productivos, incluido el acceso a la propiedad o el usufructo de la tierra. Además, hay una juventud rural más educada, con nuevas expectativas y aspiraciones, que frecuentemente no encuentra oportunidades y proyectos de vida acordes con sus nuevas condiciones y circunstancias. Construir una ruralidad atractiva para los jóvenes es un desafío considerable en la formulación de políticas públicas. Recuperar el atractivo del ámbito rural y conseguir una nueva ruralidad incluyente e igualadora es fundamental para que los territorios rurales se beneficien de la posibilidad de contar con jóvenes cada vez más educados y con mayor capacidad de innovación.

En países con poblaciones indígenas significativas, como Bolivia (Estado Plurinacional de), el Ecuador, Guatemala o México, la participación relativa de los indígenas en las poblaciones rurales es cada vez mayor. Por lo tanto, la agenda rural está cada vez más atravesada por la agenda indígena, que incluye una visión integral de ese mundo, como territorio y hábitat, y no solo como espacio y recurso productivo. Por otra parte, es necesario visibilizar y formular políticas públicas para las poblaciones afrodescendientes rurales, que son significativas en diversos países y constituyen uno de los grupos sociales más invisibilizados.

La construcción de una nueva ruralidad incluyente y sostenible implica un proceso de recuperación del atractivo del mundo rural y pasa por dos procesos complementarios, articulados e interdependientes. Por un lado, una estrategia para cerrar las brechas sociales entre el mundo rural y el urbano con políticas destinadas a disminuir desigualdades, entre las que pueden mencionarse la mejora de la calidad de los bienes y servicios públicos y una nueva generación de políticas de protección y seguridad social que rebasen los límites de las transferencias monetarias condicionadas. Por otro lado, se requiere una estrategia de cambio estructural progresivo que agregue valor a la producción rural y eleve la calidad de la ocupación. 


\section{B. Las ciudades: centros dinámicos que reproducen la segmentación}

El aumento de la productividad y la concentración de las actividades dinámicas en el territorio se dan en el espacio urbano. La dinámica centro-periferia se refleja, en muchos casos, en una dinámica asimétrica campo-ciudad. Se refleja también en los problemas de concentración de la pobreza en ciertas áreas urbanas y en la ausencia, en muchas partes de la ciudad, de los bienes públicos que el Estado debería proveer. Los niveles de urbanización de la región están entre los más elevados del mundo —alrededor del 80\%, según ONU-Hábitat (2016) — aunque existe una alta heterogeneidad entre países y con respecto al tamaño poblacional de los asentamientos clasificados como ciudades ${ }^{7}$. La urbanización continúa aumentando, aunque con menor rapidez que en décadas pasadas (véase el gráfico V.10). Si bien la concentración urbana se consolidó en el siglo $X X$, sus raíces son muy anteriores, y en algunos casos llegan a la época precolombina, en función de los patrones de dominación política.

\section{Gráfico V.10}

Tendencias de la urbanización en el mundo: población urbana como porcentaje de la población total, 1950-2050

(En porcentajes)

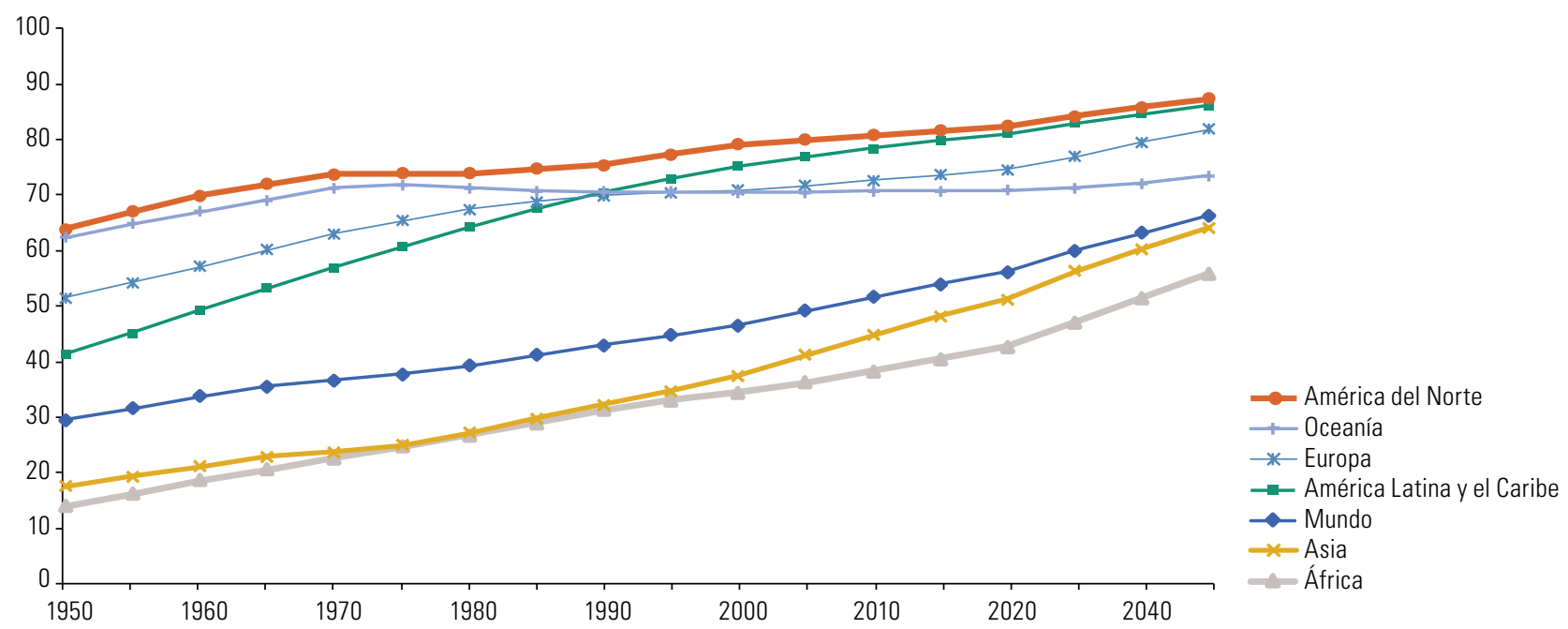

Fuente: Naciones Unidas, World Urbanization Prospects: The 2014 Revision (ST/ESA/SER.A/366), Nueva York, 2015.

La región tiene cuatro megaciudades que, junto con sus zonas metropolitanas, cuentan con más de 10 millones de habitantes: dos de ellas (São Paulo y Ciudad de México) se encontraban entre las 10 mayores del mundo en 2015 y otras dos (Río de Janeiro y Buenos Aires) se ubicaban entre las 20 mayores ${ }^{8}$. El peso relativo de las ciudades con más de 1 millón de habitantes aumentó de un 13\% en 1950 a un 36,3\% en 2010 (véase el gráfico V.11); en ese universo, el estrato más dinámico fue el de las ciudades de 1 a 5 millones de habitantes, que aumentaron de un $16 \%$ en 1975 a un 24,8\% en 2015, mientras que el estrato de más de 10 millones de habitantes, que se incrementó notablemente hasta 1995, disminuyó levemente a partir de entonces.

7 Por ejemplo, el Instituto Nacional de Estadística y Geografía de México (INEGI) considera los asentamientos con al menos 2.500 personas como áreas urbanas, y el Instituto Geográfico Nacional de Argentina (IGN) considera como tales los asentamientos con al menos 2.000 personas.

8 Bogotá y Lima podrían alcanzar ese tamaño en los próximos años. 


\section{Gráfico V.11}

Peso relativo de las ciudades de más de 1 millón de habitantes en la población urbana de América Latina y el Caribe, 1975-2015

(En porcentajes)

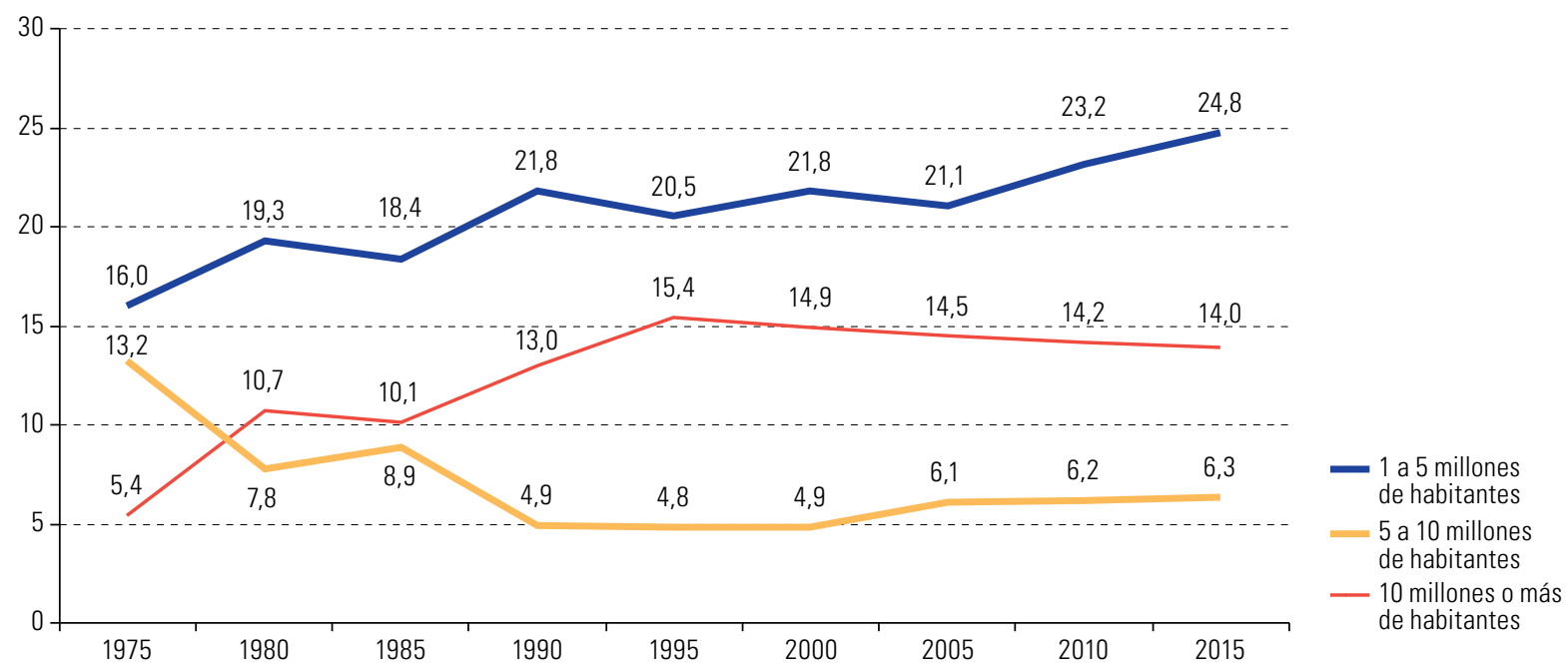

Fuente: Comisión Económica para América Latina y el Caribe (CEPAL), sobre la base de datos de la División de Población de las Naciones Unidas.

En la región, la urbanización ha venido acompañada por la persistencia de grandes brechas socioeconómicas en los ingresos y otras dimensiones de la desigualdad: la elevada segregación residencial; la inseguridad, que afecta especialmente a los más pobres; la desigualdad en la movilidad urbana, las posibilidades de acceso a espacios públicos y las áreas verdes, y las diversas consecuencias de la contaminación ambiental. La desigualdad de ingresos afecta de manera aguda a las ciudades: el peso del quintil más rico de la población en los ingresos totales oscila entre el $40 \%$ en Montevideo, La Paz (Estado Plurinacional de Bolivia) y Caracas y cifras cercanas al $60 \%$ en Santiago, Brasilia y Santo Domingo. Esta desigualdad es un reflejo más de la persistencia y las nuevas normas de la cultura del privilegio.

Por su parte, la desigualdad en la distribución del ingreso, medida por el coeficiente de Gini, presenta comportamientos diferentes según el país. Mientras que en 11 de los 18 países considerados en el gráfico V.12, la desigualdad en las ciudades capitales fue inferior a la observada a nivel nacional, en los otros 7 se dio el fenómeno inverso. La tendencia a la reducción de la desigualdad que se dio en la región en la década de 2000 se manifestó también en las ciudades capitales. En 10 de ellas, el coeficiente disminuyó a un ritmo mayor que el $1 \%$ anual, y en 5 de ellas, la caída fue superior al 2\% anual (La Paz, Managua, Lima, Buenos Aires y Panamá), como se muestra en Jordán, Riffo y Prado (2017).

Si bien las ciudades latinoamericanas más grandes son centros dinámicos en sus países, presentan un rezago considerable en comparación con sus pares de otras partes del mundo y exhiben niveles de productividad media muy inferiores a los de las ciudades del mundo desarrollado. La productividad media por ocupado en las áreas o regiones metropolitanas de Ciudad de México, Buenos Aires, Santiago o São Paulo oscila entre los 30.000 y los 40.000 dólares anuales, mientras que en Oslo, San Francisco (Estados Unidos), París o Washington D.C., supera los 160.000 dólares anuales (véase el gráfico V.13). Esta brecha se explica, además de por los respectivos grados de desarrollo, por los patrones de especialización productiva, las políticas y patrones de ocupación del suelo y la ineficiencia en el sistema de transporte urbano, factores que se discuten más adelante. Esta es otra expresión de la brecha tecnológica y de productividad que separa a la región de la frontera internacional. 


\section{Gráfico V.12}

América Latina y el Caribe (18 países): coeficiente de Gini por área geográfica, 2013

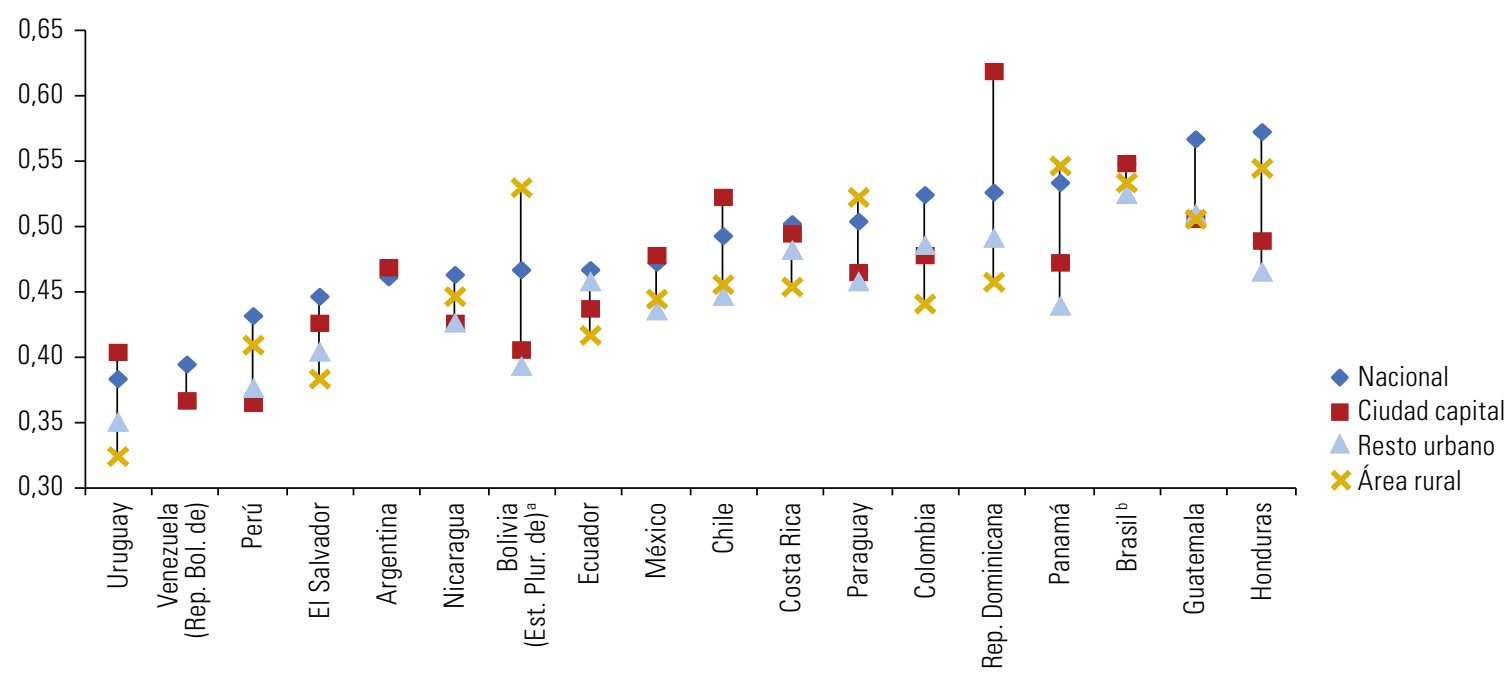

Fuente: R. Jordán, L. Riffo y A. Prado (coords.), “Desarrollo sostenible, urbanización y desigualdad en América Latina y el Caribe: dinámicas y desafíos para el cambio estructural", Documentos de Proyectos (LC/PUB.2017/19), Santiago, Comisión Económica para América Latina y el Caribe (CEPAL), 2017.

a El dato relativo a la ciudad capital corresponde a La Paz.

${ }^{b}$ El dato relativo a la ciudad capital corresponde a Brasilia, São Paulo y Río de Janeiro.

\section{Gráfico V.13}

Productividad laboral media de ciudades seleccionadas, 2010

(En miles de dólares)

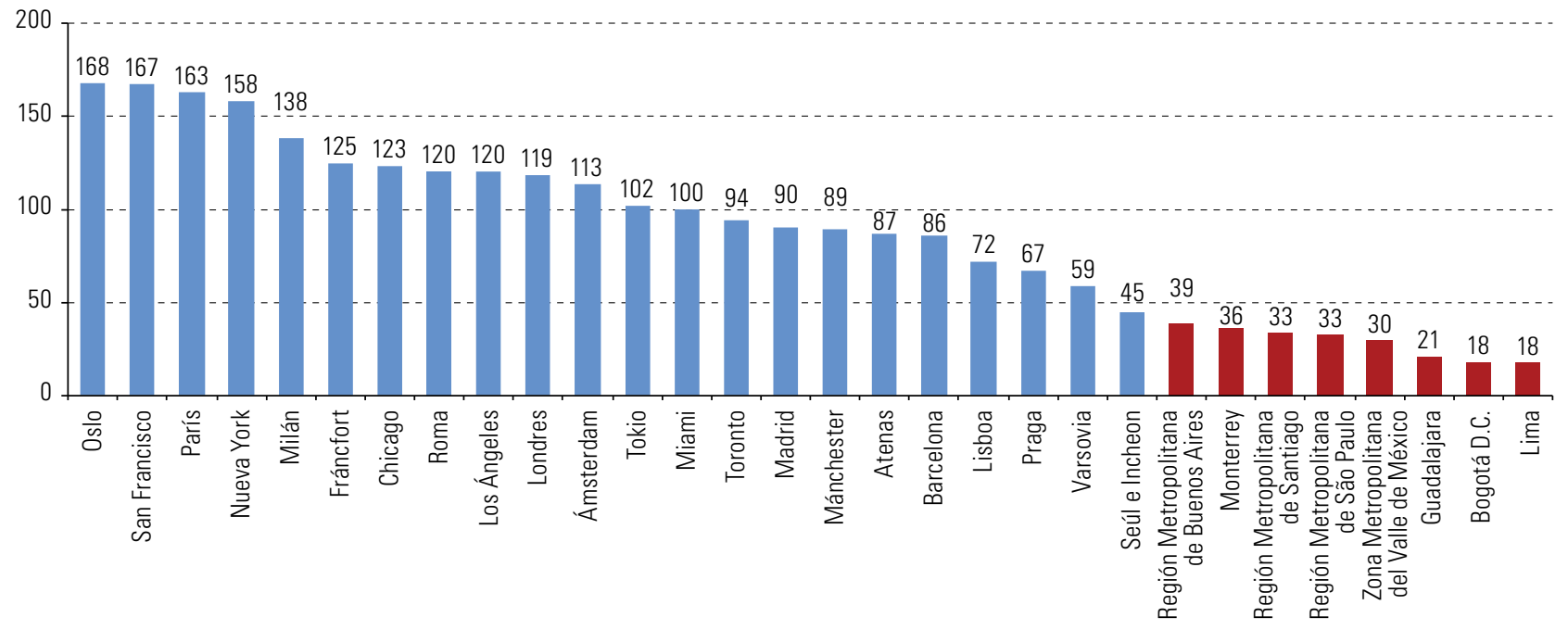

Fuente: Comisión Económica para América Latina y el Caribe (CEPAL), sobre la base de estadísticas oficiales de los países y Organización de Cooperación y Desarrollo Económicos (OCDE), OECD.Stat.

\section{Antiguos y nuevos rezagos}

Las deficiencias de infraestructura urbana no se registran solamente en la conectividad terrestre. Persisten brechas internas de acceso a infraestructura básica de agua potable y saneamiento, que se amplifican al comparar las zonas rurales y urbanas. No menos importante, debido a su impacto sobre la productividad, es el rezago en algunos componentes de la infraestructura digital, clave para la competitividad en el contexto de la revolución tecnológica en curso. 


\section{a) Brechas en los servicios básicos}

La cobertura de saneamiento es más amplia en los hogares del quintil de ingresos más altos que en el de ingresos más bajos y la brecha es mucho mayor en las áreas rurales que en las ciudades. Las brechas de acceso a la energía eléctrica difieren considerablemente entre países y presentan valores muy altos en El Salvador y Guatemala (véanse los gráficos V.14 y V.15).

\section{Gráfico V.14}

América Latina y el Caribe (17 países): diferencias en la cobertura de saneamiento entre los hogares urbanos del quintil de mayores ingresos y del quintil de menores ingresos

(En puntos porcentuales)

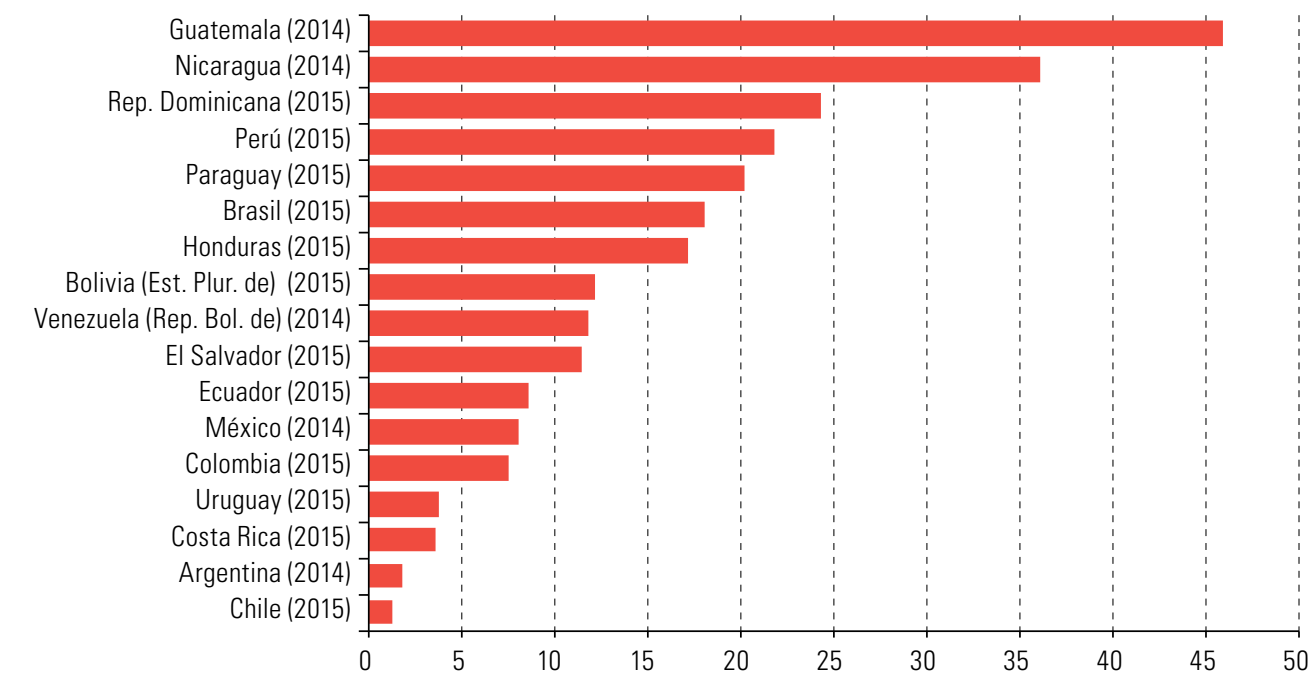

Fuente: Comisión Económica para América Latina y el Caribe (CEPAL), sobre la base del Banco de Datos de Encuestas de Hogares (BADEHOG).

\section{Gráfico V.15}

América Latina y el Caribe (15 paises): acceso a la energía eléctrica en los hogares urbanos del quintil de mayores ingresos y del quintil de menores ingresos

(En porcentajes)

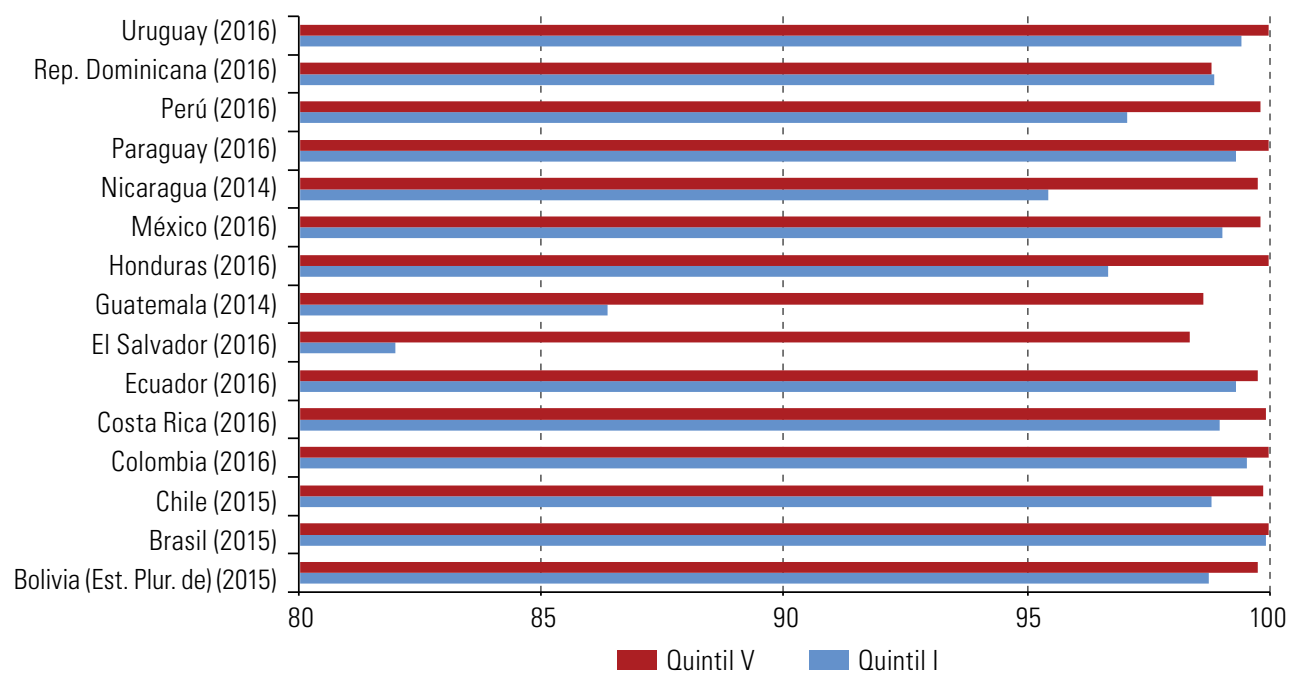

Fuente: Comisión Económica para América Latina y el Caribe (CEPAL), sobre la base del Banco de Datos de Encuestas de Hogares (BADEHOG). 
Estas brechas son también de tipo cualitativo. En algunos hogares de ingresos más reducidos, el acceso al agua y el saneamiento se da mediante soluciones tecnológicas que no aseguran una calidad comparable a la de los hogares de mayores ingresos (por ejemplo, pileta o fuente pública a cierta distancia de la casa, pozo o carro repartidor en comparación con la red de agua potable con conexión domiciliaria; o bien, letrina o fosa séptica en lugar de la red de alcantarillado con conexión domiciliaria). Además, ese acceso, en el caso del agua, es muchas veces intermitente y vulnerable a interrupciones ocasionadas por sequías u otras razones.

\section{b) Insuficiencia de la infraestructura digital}

También en los servicios más avanzados, como el acceso a las tecnologías digitales, existen brechas importantes según el nivel de ingresos (véase el gráfico V.16). Pese a haber aumentado el acceso a Internet en prácticamente todos los quintiles en los últimos años, la diferencia entre el número de hogares con acceso a esta tecnología en el quintil de mayores ingresos y el de menores ingresos (quintil V/ quintil I) continúa siendo notable: casi 4 veces más en Chile y Costa Rica; entre 8 y 9 en el Uruguay, el Ecuador y Brasil; 21 en el Estado Plurinacional de Bolivia, y 45 en el Perú. Esto dificulta el acceso en línea a los servicios de salud, educación y gobierno, y también afecta negativamente al comercio electrónico entre los países de América Latina, que podría convertirse en una herramienta de integración regional, particularmente en materia de bienes y servicios digitales. Todos estos servicios y aplicaciones necesitan una infraestructura de calidad y masificar el acceso a ella.

\section{Gráfico V.16}

América Latina (9 paises): hogares con acceso a Internet por quintil de ingresos, alrededor de 2011 y 2015 (En porcentajes)

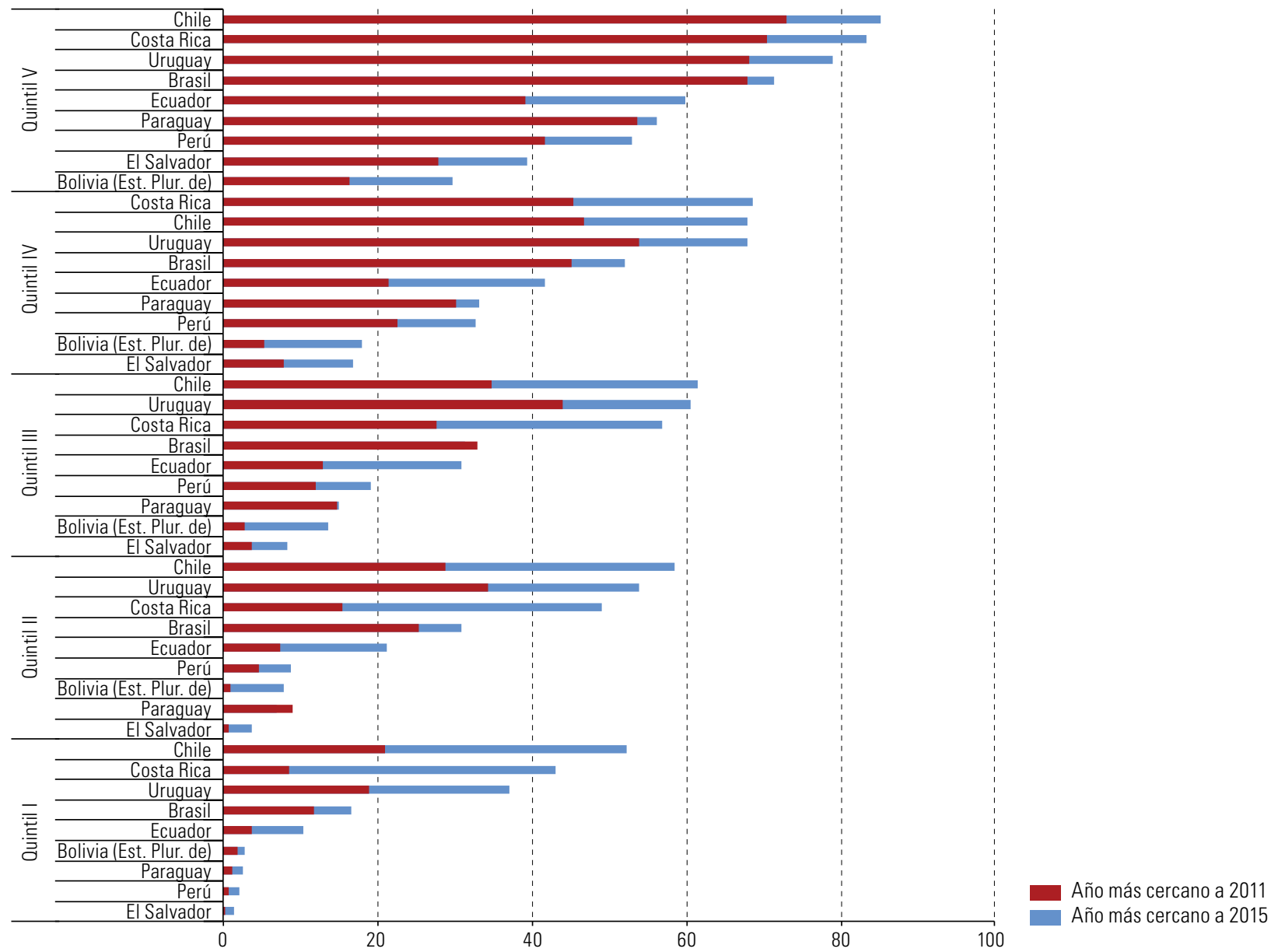

Fuente: Comisión Económica para América Latina y el Caribe (CEPAL), Observatorio Regional de Banda Ancha (ORBA), sobre la base de las encuestas de hogares.

Nota: La metodología de cálculo del ingreso per cápita de los hogares sufrió modificaciones entre los períodos considerados. Los tipos de conexión a Internet que se incluyen en los diferentes países son los siguientes: en el Paraguay, Internet por cable o wifi e Internet por módem USB; en el Ecuador, acceso telefónico, línea dedicada, cable módem y banda ancha móvil; en el Uruguay, banda ancha fija, banda ancha móvil y línea dedicada; en Chile, banda ancha fija y banda ancha móvil contratada y prepago, además de teléfono móvil u otro dispositivo móvil. En Costa Rica, en la encuesta se consulta a nivel de vivienda, que puede incluir más de un hogar. 
En el primer trimestre de 2017, la cobertura de las redes 3G era superior al $90 \%$ en una muestra de 18 países de la región, mientras que la cobertura de las redes $4 \mathrm{G}$ era de cerca del $70 \%$. Sin embargo, aún persiste una amplia brecha relacionada con la demanda (cobertura menos demanda efectiva del servicio), ya que el promedio de suscriptores era de solo un 53\% de la población cubierta.

La calidad de las conexiones de banda ancha depende de su velocidad, que determina a qué servicios y aplicaciones es posible acceder ${ }^{9}$. En la región hay diferencias notables entre países, por ejemplo Chile y Uruguay cuentan con velocidades casi seis veces superiores a la del Paraguay, que es el más rezagado (véase el gráfico V.17). Incluso los países más avanzados de la región solo cuentan con velocidades cercanas a la mitad del promedio de los países de la Organización de Cooperación y Desarrollo Económicos (OCDE). Esto indica que las brechas de infraestructura analizadas previamente también están presentes en la infraestructura destinada a responder a la revolución tecnológica.

\section{Gráfico V.17}

América Latina (12 países): velocidades de conexión a Internet, cuarto trimestre de 2016 (En megabits por segundo (Mb/s))

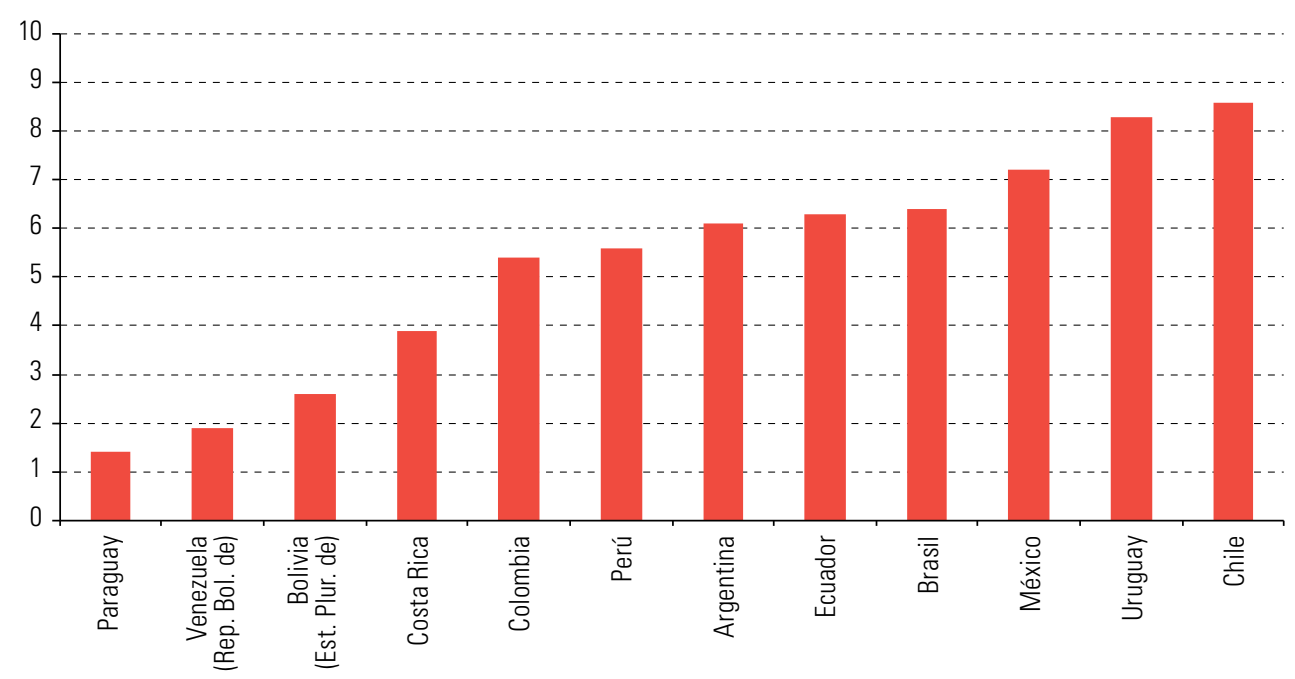

Fuente: Comisión Económica para América Latina y el Caribe (CEPAL), Observatorio Regional de Banda Ancha (ORBA), sobre la base de Akamai Technologies, Akamai's State of the Internet. 012016 Report, vol. 9, № 1, Cambridge, junio, 2016.

\section{La segregación niega el derecho a la ciudad}

\section{a) Segregación residencial}

Entre 2000 y 2015 se produjo un proceso de rápida urbanización de la región, durante el cual aumentó el consumo de suelo por habitante y, con ello, la ineficiencia en el uso del ambiente y del espacio. La expansión de la mancha urbana aumenta, además, los costos de las redes de agua, electricidad, transporte, comunicación y carreteras. A medida que las ciudades amplían su cobertura espacial y se reduce la densidad de la población (véase el gráfico V.18), se incrementa el costo social por habitante (CEPAL, 2017a) y la apropiación de valor por parte de la actividad inmobiliaria. La ineficiencia y la desigualdad, una vez más, van de la mano, ya que la expansión de la mancha urbana se asocia a segregaciones urbanas derivadas del autoaislamiento de los sectores más ricos o la expulsión de los más pobres hacia ciertas áreas periféricas (CEPAL, 2014b).

Aunque también se registran migraciones intraurbanas o intrametropolitanas de grupos de ingresos medios y altos hacia algunas áreas de la periferia urbana, no se produce una reducción sistemática de la segregación residencial ni interacción social entre los grupos socioeconómicos residentes en las periferias (CEPAL, 2014b). Más aún, la fuga de los estratos medios y altos hacia el uso de servicios privados y la privatización

9 Para medir de manera más precisa la calidad, este parámetro se combina con otros, como el tiempo de latencia y la tasa de variabilidad de la latencia (jitter). 
de los espacios públicos (un ejemplo de esta tendencia es la proliferación de condominios y barrios cerrados) refuerzan el patrón de ciudades segregadas y fragmentadas (Caldeira, 2000) e impiden el encuentro social.

\section{Gráfico V.18}

América Latina: densidad urbana en ciudades seleccionadas, 1990-2014

(En personas por hectárea)

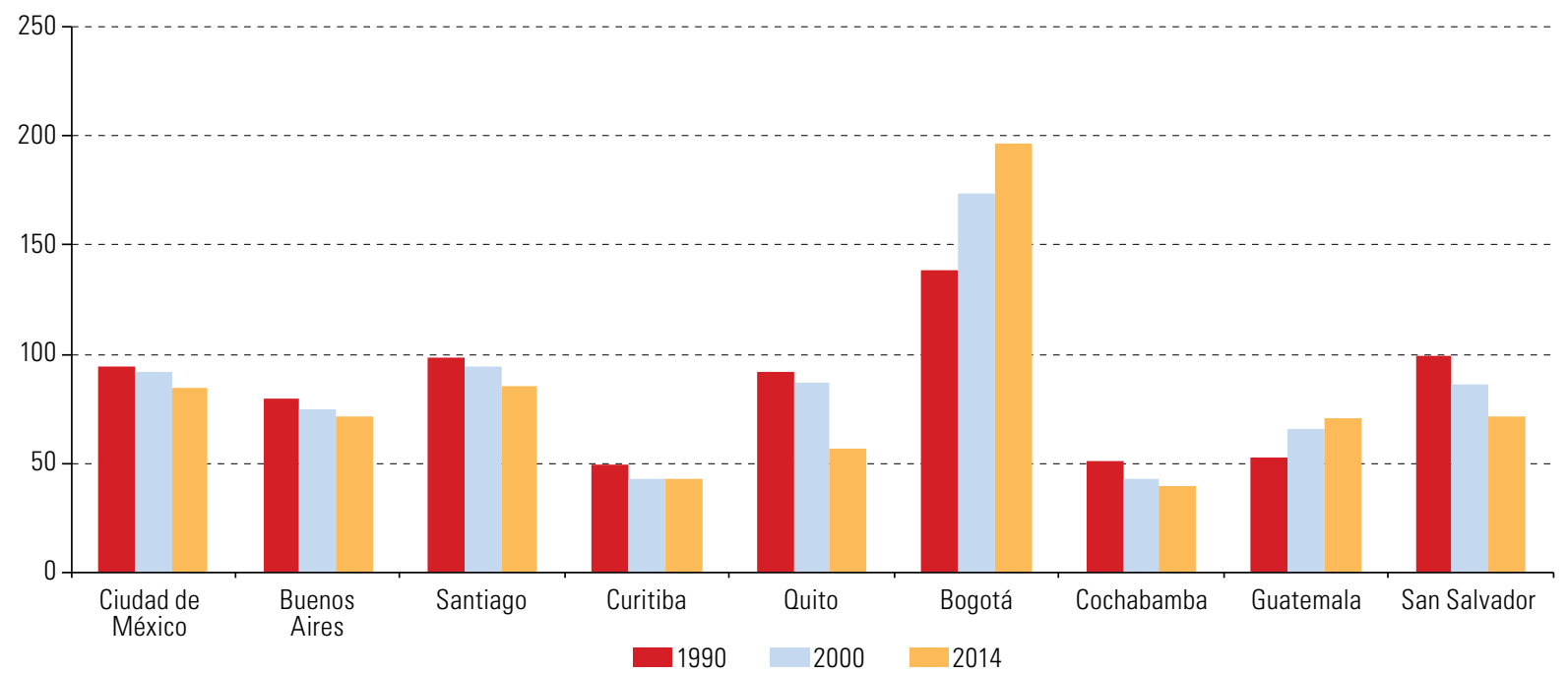

Fuente: Comisión Económica para América Latina y el Caribe (CEPAL), sobre la base de S. Angel y otros, Atlas of Urban Expansion, Cambridge, Massachusetts, Lincoln Institute of Land Policy, junio de 2012.

Nota: Los datos para 2014 corresponden al año más cercano disponible.

Otro factor que aumenta la desigualdad en las ciudades son las brechas de acceso a viviendas de calidad y al suelo urbano. Muchos países han implementado programas de subsidio a la demanda para reducir el déficit cuantitativo de vivienda, que, efectivamente, han reducido ese déficit, pero también han tenido efectos negativos en materia de expansión periférica y segregación socioeconómica residencial. El abandono de la vivienda es un síntoma claro de la ineficiencia de formular por separado la política de vivienda y la política urbana. Por ejemplo, en 2010, había 5 millones de viviendas abandonadas en México, cifra que correspondía al $14 \%$ del parque habitacional del país. Entre las causas de abandono figuraban la migración internacional, la inseguridad y el desempleo locales, pero también los efectos de las políticas públicas de vivienda subsidiada, dado que el $80 \%$ de los créditos hipotecarios públicos concedidos entre 2006 y 2010 se otorgaron en los municipios con mayor nivel de vivienda deshabitada (Sánchez y Salazar, 2011, págs. 66-72). Entre las causas de abandono de la vivienda, un 38\% de los encuestados destaca la falta de servicios y un $31 \%$, la distancia al trabajo o el centro de estudio (ONU-Hábitat, 2011, pág.51) ${ }^{10}$.

Asimismo, una gestión del suelo urbano poco eficiente y una inversión en servicios de agua y saneamiento insuficiente contribuyen a la persistencia de tugurios de elevado costo para sus habitantes, quienes frecuentemente deben afrontar mayores riesgos por la exposición a enfermedades contagiosas o transmisibles y a los desastres naturales, que aumentan debido al cambio climático ${ }^{11}$. Por otra parte, los costos para la política pública son elevados, pues regularizar la informalidad urbana es caro. En la región, el porcentaje de personas que viven en tugurios se redujo del 34\% al $21 \%$ entre 1990 y 2014 (véase el gráfico V.19). Si se consideran los valores absolutos, aunque 2 millones de personas dejaron los tugurios, más de 100 millones viven aún en este tipo de asentamiento.

10 En el Brasil, Chile y la República Bolivariana de Venezuela también se registran porcentajes importantes de viviendas deshabitadas: un 9,02\%, un 9,6\% y un 7,7\% de las unidades habitacionales totales, respectivamente (López Moreno, 2014).

11 El término "tugurio" hace referencia a un fenómeno conocido en diversos países como "villas miseria", "pueblos jóvenes", "campamentos", "cantegriles" o "favelas", entre otros. 


\section{Gráfico V.19}

América Latina y el Caribe: población urbana que vive en tugurios, 1990-2014

(En millones y porcentajes)

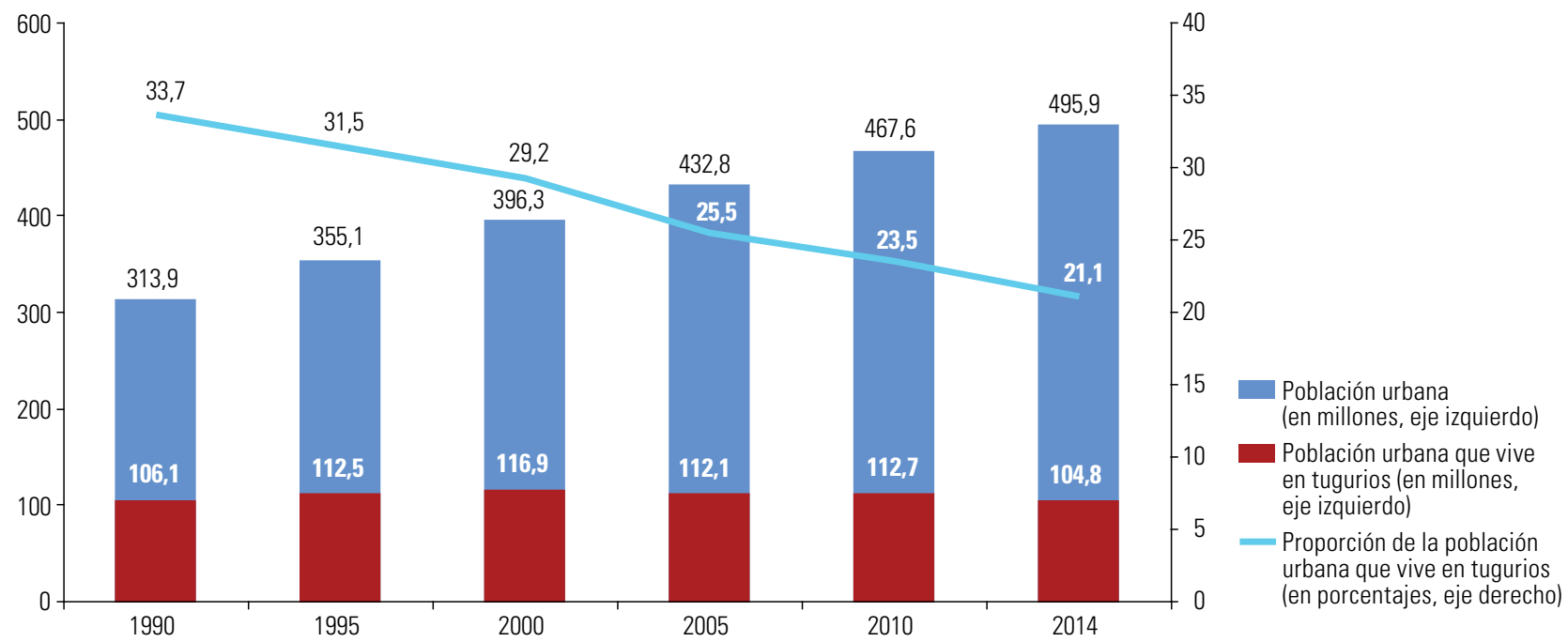

Fuente: Programa de las Naciones Unidas para los Asentamientos Humanos (ONU-Hábitat), "Global Urban Indicators Database", Nairobi [base de datos en línea] https://unhabitat.org/books/global-urban-indicators-database/.

\section{b) Derecho a la ciudad}

Como resultado del carácter desigual y excluyente de las ciudades, se ha comenzado a reivindicar con fuerza el derecho a la ciudad, en gran parte gracias al impulso de movimientos sociales, tanto en los países de la región como en el escenario internacional. Ejemplo de ello es la negociación de la Nueva Agenda Urbana, aprobada en la Conferencia de las Naciones Unidas sobre la Vivienda y el Desarrollo Urbano Sostenible (Hábitat III), celebrada en 2016.

El derecho a la ciudad es un derecho colectivo que se fundamenta en el control democrático sobre el proceso de desarrollo urbano, es decir, es un derecho más amplio que la libertad individual de acceder a bienes y servicios urbanos (Lefebvre, 1968; Harvey, 2008)12. Además de insistir en el carácter público de la ciudad, el derecho a la ciudad ofrece un marco para abordar problemas específicos y graves en la región: el acceso desigual al suelo urbano, a vivienda adecuada y a servicios y equipamientos de calidad, cuya carencia, además de efectos sociales, produce impactos ambientales negativos.

El derecho a la ciudad se manifiesta en las políticas a través de dos dimensiones. En primer lugar, la participación ciudadana en la gestión urbana —el "derecho a participar"-, que incluye experiencias innovadoras, como los presupuestos participativos que han surgido en la región. En segundo lugar, la promoción de ciudades inclusivas mediante normativas urbanas —el "derecho a habitar"—-(Fernandes, 2007). Con respecto a la segunda dimensión, varios países de la región (de forma más avanzada, el Brasil, Colombia y el Ecuador) cuentan con una legislación urbana que permite la aplicación de instrumentos de gestión del suelo y planificación urbana, a fin de ofrecer vivienda social bien ubicada, inversión en infraestructura con

12 El sistema de las Naciones Unidas no cuenta con una definición oficial del derecho a la ciudad. Como resultado de la falta de consenso sobre su definición y aceptación entre los Estados Miembros, en la Nueva Agenda Urbana se hace referencia a este concepto como "ciudades para todos." En la resolución A/ HRC/35/L.30/Rev.1 del Consejo de Derechos Humanos, aprobada en junio de 2017, se definen las "ciudades para todos" rescatando conceptos que aparecen también en la legislación urbana de varios países y ciudades de la región, como la función social de la ciudad. De esta manera, la resolución reafirma "el ideal de ciudades para todos — refiriéndose al uso y el disfrute de las ciudades y los asentamientos humanos en pie de igualdad, con el objetivo de alentar la integración y velar por que todos los habitantes, de generaciones actuales y futuras, sin discriminación de ningún tipo, puedan construir ciudades y asentamientos humanos justos, seguros, saludables, accesibles, asequibles, resilientes y sostenibles, y habitar en ellos, a fin de promover la prosperidad y la calidad de vida para todos-. ideal que propugna ciudades y asentamientos humanos que, entre otras cosas, cumplan su función social". 
objetivos de inclusión social y urbanización de asentamientos informales. Asimismo, en algunas ciudades, como São Paulo, el reconocimiento legal de la función social de la propiedad urbana ha permitido desarrollar mecanismos de financiamiento con base en la plusvalía del suelo urbano y en instrumentos basados en la concesión de derechos de construcción, que se han constituido en una fuente importante de financiamiento para la infraestructura urbana ${ }^{13}$. Además de las legislaciones nacionales, existen normas a nivel de ciudades que incorporan el concepto de derecho a la ciudad. Un caso destacado es el de la Constitución Política de la Ciudad de México de 201714; dentro del amplio espectro de derechos que en ella se garantizan, se subraya el derecho a la ciudad ${ }^{15}$.

A pesar de estos avances, los marcos normativos y las políticas en varios países y ciudades de la región, la experiencia de las últimas décadas demuestra que la aplicación de los instrumentos y las políticas de inclusión urbana, si se comparan tanto las distintas ciudades como las sucesivas administraciones políticas de una misma ciudad, han carecido de uniformidad y coherencia.

\section{La movilidad urbana como expresión de la desigualdad}

\section{a) Los patrones de movilidad urbana}

La situación de la movilidad urbana es otra muestra de desigualdad, ineficiencia productiva y energética y deterioro ambiental. Aunque el $60 \%$ de la población de las áreas metropolitanas de la región se traslada a pie, en bicicleta o en medios de transporte públicos, las sociedades gastan tres veces más en vehículos privados que en sistemas de transporte colectivo ${ }^{16}$. El automóvil ocupa 30 veces más espacio por persona movilizada que un autobús y 5 veces más que una bicicleta (CEPAL, 2017a). Al mismo tiempo, la duración de un recorrido en autobús es entre un $50 \%$ y un $220 \%$ mayor que la de un viaje en automóvil, como resultado de la segregación espacial y de sistemas públicos de movilidad que favorecen a los sectores de ingresos más altos (CAF, 2016a).

Existen diferencias de género en el reparto modal de la movilidad urbana: el transporte público y los desplazamientos a pie tienen un peso relativo mayor en los viajes de las mujeres que en los de los hombres. En los viajes de los hombres, la movilidad en automóvil o motocicleta tiene una participación mayor que en los de las mujeres (Jaimurzina, Muñoz y Pérez-Salas). Favorecer el transporte privado motorizado, además de tener un impacto ambiental negativo, prioriza los patrones de movilidad de los hombres. Mejorar la calidad del transporte público a través de, entre otras cosas, la disminución de la duración de los trayectos, promovería la igualdad de género en las ciudades.

Hay un amplio espacio para aumentar la participación de modos más limpios de transporte público. Según el Observatorio de Movilidad Urbana ${ }^{17}$ del Banco de Desarrollo de América Latina (CAF) (2015), el 56,4\% de los viajes diarios se realiza en transporte colectivo, y de estos, los metros y trenes eléctricos cubren aproximadamente el 16\%. En las 29 ciudades incluidas en el Observatorio, Vasconcellos y Mendonça (2016)

13 Como ocurre también con la concesión onerosa de certificados de potencial adicional de construcción (CEPAC) aplicados en São Paulo.

14 Su inspiración principal fue la Carta de la Ciudad de México por el Derecho a la Ciudad. La Constitución hace referencia a la garantía del derecho a la ciudad y a sus objetivos en las secciones dedicadas a la planeación del desarrollo (artículo 15) y la regulación del suelo (artículo 16.c), integrándolo en los procesos que rigen de forma más directa el carácter del desarrollo urbano.

15 El artículo 12 afirma lo siguiente: 1) La Ciudad de México garantiza el derecho a la ciudad que consiste en el uso y el usufructo pleno y equitativo de la ciudad, fundado en principios de justicia social, democracia, participación, igualdad, sustentabilidad, de respeto a la diversidad cultural, a la naturaleza y al medio ambiente. 2) El derecho a la ciudad es un derecho colectivo que garantiza el ejercicio pleno de los derechos humanos, la función social de la ciudad, su gestión democrática y asegura la justicia territorial, la inclusión social y la distribución equitativa de bienes públicos con la participación de la ciudadanía.

16 Según CAF (2009), “las sociedades han invertido sumas muy elevadas para construir vías y sistemas, y para adquirir vehículos de transporte. [...] las inversiones más grandes se efectúan en vehículos privados (63\%) y en vías urbanas (17\%). Las inversiones en sistemas de transporte colectivo (rieles y vehículos colectivos) corresponden a $20 \%$ del total"

17 El Observatorio de Movilidad Urbana, que informa sobre 29 ciudades, se inició en 2009 con datos de 15 áreas metropolitanas de 9 países de la región: Belo Horizonte (Brasil), Bogotá, Buenos Aires, Caracas, Ciudad de México, Curitiba (Brasil), Guadalajara (México), León (Nicaragua), Lima, Montevideo, Porto Alegre (Brasil), Río de Janeiro (Brasil), San José, Santiago y São Paulo (Brasil). En 2016 se agregaron otras 14 ciudades: Barranquilla (Colombia), Brasilia, Cali (Colombia), Florianópolis (Brasil), Manaos (Brasil), Medellín (Colombia), Montería (Colombia), Panamá, Pereira (Colombia), Quito, Recife (Brasil), Rosario (Argentina), Salvador de Bahía (Brasil) y Santa Cruz de la Sierra (Bolivia (Estado Plurinacional de)). Por otra parte, los datos de Montevideo se sustituyeron por los de su área metropolitana. 
indican que el $49 \%$ de los espacios destinados al transporte colectivo son utilizados por los autobuses, el 7,5\% por los metros y el 4,6\% por los trenes urbanos. Así, con el 12,1\% del espacio, el transporte limpio (el metro y el tren) moviliza al $16 \%$ de los pasajeros del sistema público. Dado que las líneas de metro y los trenes son una solución probada para la movilidad sostenible, constituyen importantes oportunidades de inversión para responder con inclusión social y eficiencia económica y ambiental a la demanda de movilidad de las ciudades y así mejorar su competitividad y dinamismo.

Para hacer frente a la congestión y la contaminación en el ámbito urbano, recientemente se han puesto en marcha algunas iniciativas importantes en la región. A inicios del siglo XXI, se introdujeron los sistemas con autobuses en carriles confinados. Estas experiencias fueron exitosas, pero han decaído debido a la saturación de los servicios y a que no se han podido superar las deficiencias en materia de cobertura y calidad. Por otra parte, se han instalados teleféricos como forma de transporte en ciudades como Medellín (Colombia), La Paz (Estado Plurinacional de Bolivia) y Ecatepec (México) y se ha expandido el uso de las bicicletas y la infraestructura correspondiente (en Bogotá, Ciudad de México, Buenos Aires y Santiago, entre otras). Pese a estos avances, las crecientes tasas de motorización hacen prever un incremento de las presiones sobre el espacio público y de las externalidades negativas (véase el gráfico V.20). En la región, el aumento de la motorización muestra una tendencia semejante a la de los Estados Unidos, donde la tasa se acerca al 80\%, o a la de Noruega, con una tasa cercana al $60 \%$.

\section{Gráfico V.20}

América Latina (13 paises): tasa de motorización, PIB per cápita y comparación con las tendencias de los Estados Unidos y Noruega, 2005-2015

(Tasa cada 1.000 habitantes y dólares en paridad del poder adquisitivo a precios constantes de 2011)

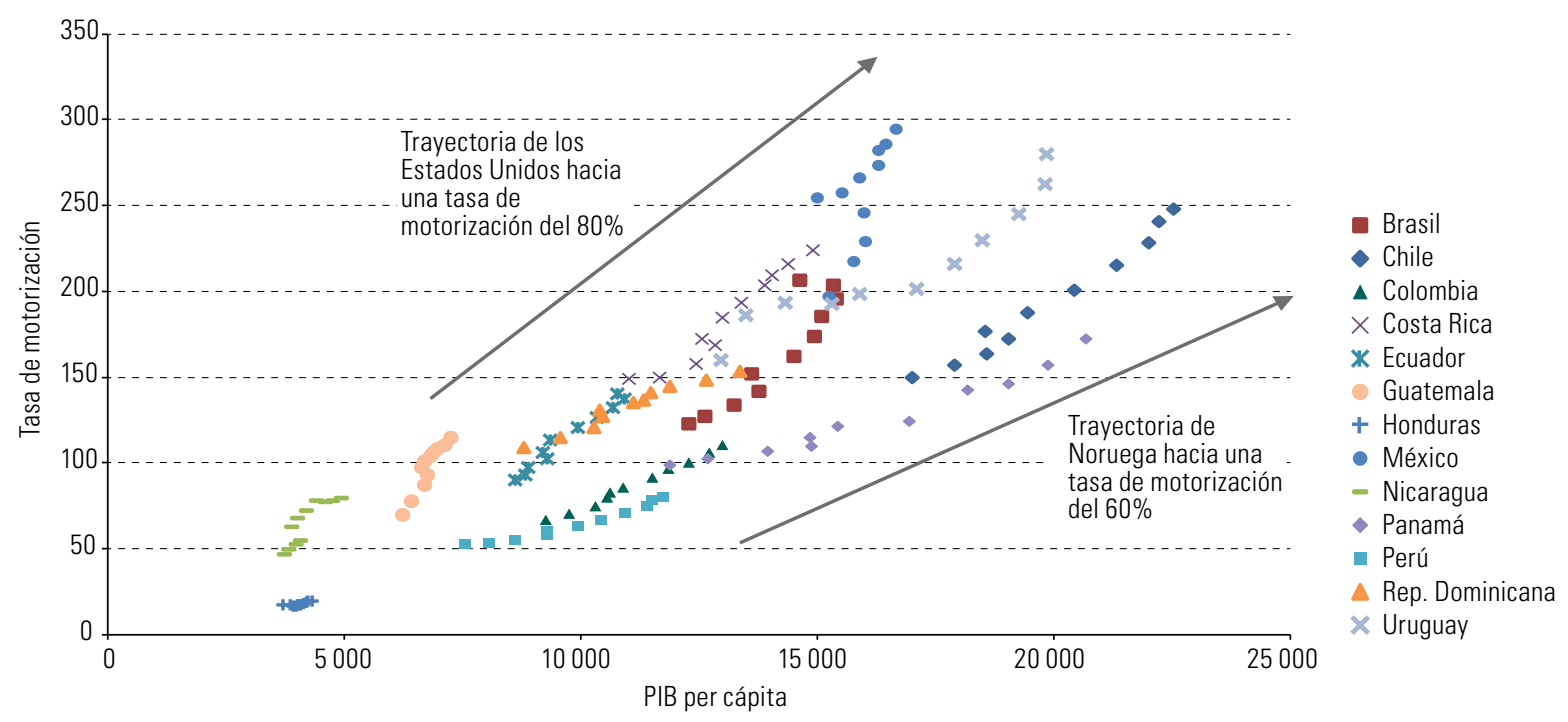

Fuente: Comisión Económica para América Latina y el Caribe (CEPAL), sobre la base de información de Organización Internacional de Constructores de Automóviles (OICA) y Banco Mundial, World Development Indicators.

La segregación espacial, la congestión y el rezago en la implementación de sistemas públicos adecuados aumentan los tiempos de viaje e impulsan la fuga de usuarios de estos servicios (véase el gráfico V.21) ${ }^{18}$. Esa fuga tiene determinantes similares a la que se da desde los servicios públicos hacia los servicios privados en materia de educación, salud, seguridad e incluso agua potable.

18 La participación del transporte público en el total del transporte ha descendido en una muestra de ciudades latinoamericanas que incluye a Montevideo, Quito, Santiago y São Paulo (Brasil) (CAF, 2016a). 


\section{Gráfico V.21}

América Latina (12 áreas metropolitanas): tiempo de viaje en automóviles privados y autobús, 2014

(En minutos por viaje)

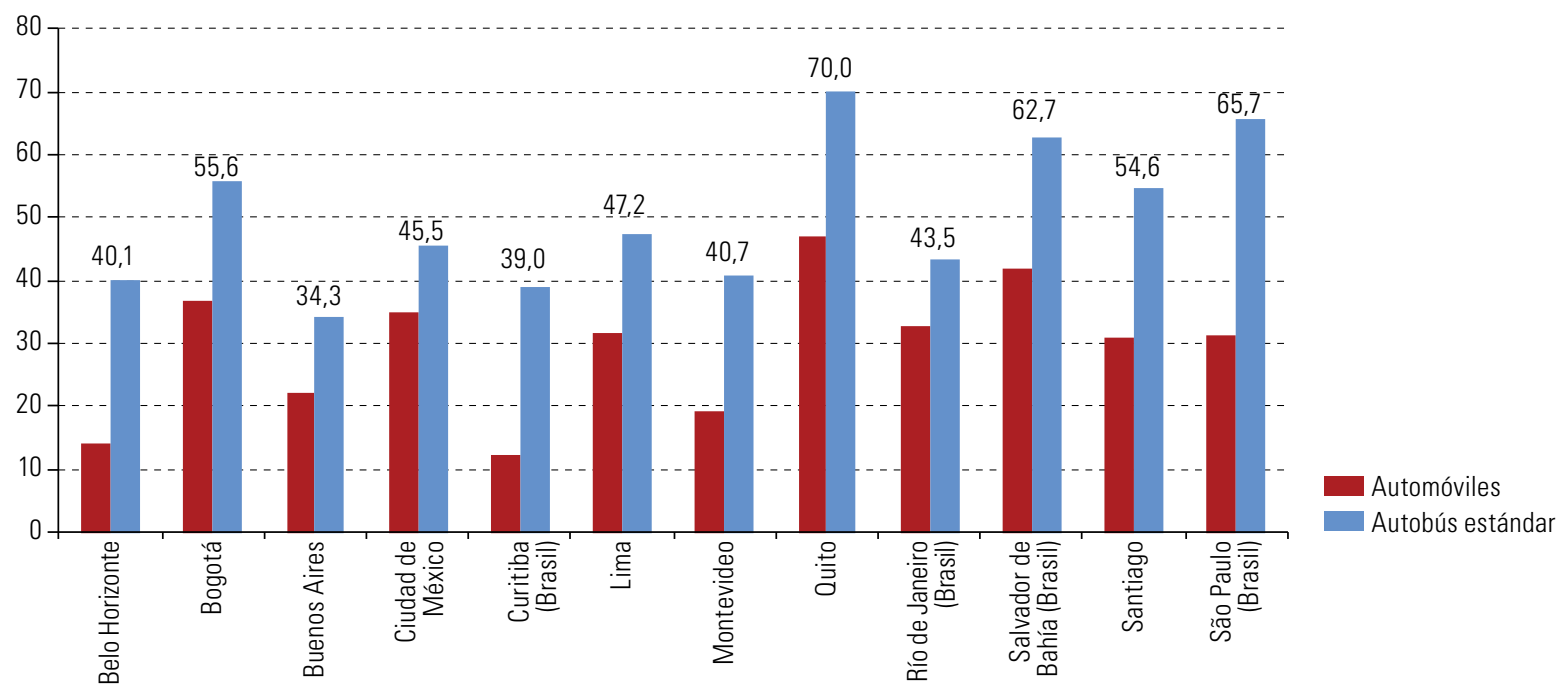

Fuente: Banco de Desarrollo de América Latina (CAF), “Observatorio de Movilidad Urbana", 2016 [en línea] https://www.caf.com/es/temas/o/observatorio-de-movilidad-urbana/.

\section{b) El impacto ambiental del modelo de movilidad}

Más allá de los costos en términos de tiempo de desplazamiento, la ineficiencia de las modalidades dominantes de trasporte urbano en la región tiene efectos en el patrón de consumo de energía y, por consiguiente, en la contaminación urbana y la salud de las personas. En efecto, un automóvil individual emite 2,5 veces más $\mathrm{CO}_{2}$ por pasajero que un viaje equivalente en autobús y 5 veces más que un viaje en metro (CEPAL, 2017a).

En 2014, el uso de vehículos motorizados individuales (automóviles y motocicletas) en 29 grandes ciudades de la región consumía el $66 \%$ de la energía utilizada en el sector del transporte, mientras que los autobuses consumían el $30 \%$ y los vehículos sobre rieles, el $4 \%$. Aproximadamente un $94 \%$ del transporte utiliza como fuente de energía los derivados del petróleo (Enerdata, 2015), lo que frena la descarbonización de la matriz energética. Aunque algunos países como Chile, Costa Rica, el Ecuador y el Uruguay han realizado avances en la descarbonización de su producción eléctrica, todavía no se han registrado efectos importantes en el sector del transporte ${ }^{19}$.

El transporte privado no solo es ineficiente en términos de energía, sino también de contaminación. En el cuadro V.1 se muestra que el transporte individual es el principal responsable de la emisión de contaminantes, con la excepción de los óxidos de nitrógeno $\left(\mathrm{NO}_{x}\right)$. En su conjunto, el transporte urbano es una importante fuente de emisiones de gases de efecto invernadero en la región, que genera el 38\% de las emisiones de $\mathrm{CO}_{2}$ por la quema de combustibles fósiles, en comparación con el $21 \%$ de la producción de electricidad y el $17 \%$ de la industria (ONU-Habitat, 2012). Mientras que, a nivel mundial, el transporte produce el $25 \%$ de las partículas finas en suspensión (PM2,5) en las ciudades (Karaguliana y otros, 2015), esta cifra aumenta al 34\% en el Brasil y al 30\% en el resto de la región. En el caso de las partículas suspendidas de hasta 10 micrones (PM10), el transporte emite el 38\% de ellas. En términos relativos, el transporte urbano en la región es más contaminante que el promedio mundial.

19 La electrificación del transporte permitiría reducir el contenido de carbono de la matriz energética, pero no se reducirían significativamente las emisiones de partículas gruesas (MP10), salvo el carbón negro de la combustión, pues provienen también del desgaste del material rodante. 


\section{Cuadro V.1}

América Latina y el Caribe: emisión de contaminantes por modo de transporte (En porcentajes del total por contaminante)

\begin{tabular}{|c|c|c|c|c|c|}
\hline Vehículo & $\begin{array}{l}\text { Monóxido de carbono } \\
\text { (CO) }\end{array}$ & Hidrocarburos $(\mathrm{HC})$ & $\begin{array}{c}\text { Óxidos de } \\
\text { nitrógeno }\left(\mathrm{NO}_{\mathrm{x}}\right)\end{array}$ & $\begin{array}{c}\text { Material particulado } \\
\text { de hasta } \\
10 \text { micrones (MP10) }\end{array}$ & $\begin{array}{c}\text { Dióxido de } \\
\text { carbono }\left(\mathrm{CO}_{2}\right)\end{array}$ \\
\hline Individual & 74,2 & 69,5 & 23,6 & 82,3 & 74,6 \\
\hline Colectivo & 25,8 & 30,5 & 76,4 & 17,7 & 25,4 \\
\hline
\end{tabular}

Fuente: Banco de Desarrollo de América Latina (CAF), 2014.

En 2014, en casi todas las ciudades incluidas en el gráfico V.22, la concentración de material particulado de tamaño inferior a 2,5 micrones (MP2,5) — que pueden pasar a la corriente sanguínea-e inferior a 10 micrones (MP10) sobrepasaba los límites recomendados y la norma establecida por la Organización Mundial de Salud (OMS) (OMS, 2016), y superaba las concentraciones registradas en algunas capitales de países desarrollados como París, Berlín o Madrid.

\section{Gráfico V.22}

Ciudades seleccionadas: concentración de MP10 y MP2,5 en 2014

$\left(\right.$ En $\left.\mu g / m^{3}\right)$

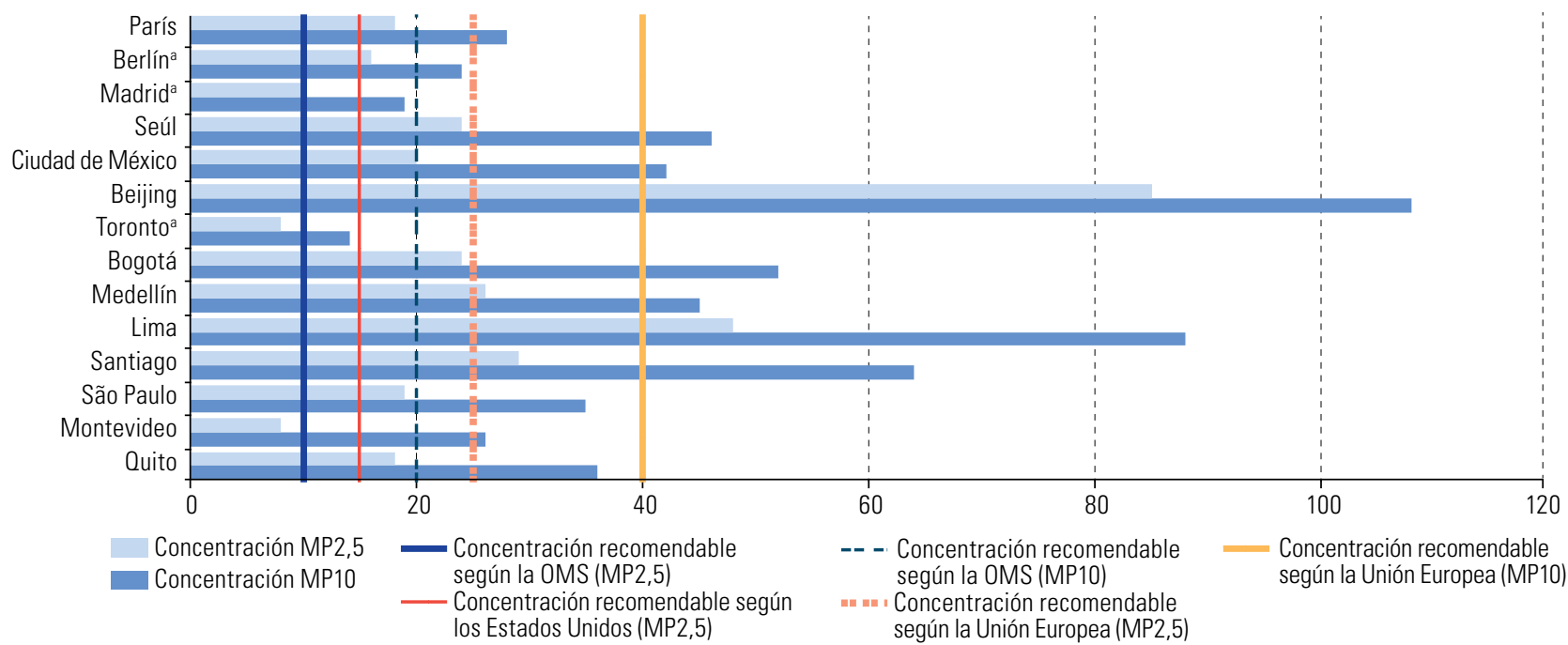

Fuente: Comisión Económica para América Latina y el Caribe (CEPAL), sobre la base de Organización Mundial de la Salud (OMS), "Global Urban Ambient Air Pollution Database" 2016 [base de datos en línea] http://www.who.int/phe/health_topics/outdoorair/databases/cities/en/.

a Concentración media anual en 2013.

Las emisiones afectan la salud pública y tienen consecuencias económicas y sociales. Al mismo tiempo, son la expresión de la desigualdad, en la medida en que los sectores sociales que menos emisiones generan son los que más sufren sus consecuencias. En CEPAL (2017a), se estima que en la región anualmente se pierde el equivalente a alrededor de 560.000 años de vida por razones derivadas de problemas ambientales.

En suma, si bien se han registrado mejoras, los costos de la contaminación, de la energía y el tiempo utilizados para el transporte, de los servicios que se expanden junto con la mancha urbana, además de los asociados a los rezagos en el tratamiento de residuos, vinculan la desigualdad, las pérdidas de productividad y la insostenibilidad ambiental. El sistema de transporte es parte de un círculo vicioso de desigualdad, asignación irracional de recursos, deterioro ambiental y empeoramiento de la calidad de vida. Es, por lo tanto, otra cara de la ineficiencia de la desigualdad. Por ello, debe convertirse en una de las preocupaciones fundamentales de las políticas públicas, en particular de las orientadas a la descarbonización y la reducción de la desigualdad urbana. 


\section{El estilo de desarrollo erosiona sus bases ambientales}

La problemática ambiental se entrecruza con las del territorio, la infraestructura y las ciudades. De ahí la propuesta de la CEPAL de tomar un "gran impulso ambiental" como eje estratégico de la política industrial y tecnológica, ya que esto permite atacar diversos problemas de manera articulada, explorando las complementariedades entre las políticas. La idea es superar una configuración no deseable de baja competitividad, rezago tecnológico y elevada ineficiencia ambiental y avanzar en dirección de un modelo compatible con la Agenda 2030 y los Objetivos de Desarrollo Sostenible.

\section{La degradación del territorio destruye ecosistemas y suelos}

Los cambios en los ecosistemas repercuten en los regímenes de sustento económico y a menudo tienen consecuencias negativas: se pasa de tierras productivas a tierras degradadas y desertificadas en diferentes grados; de una oferta abundante de agua a sequías, escasez y déficits hídricos; de un clima equilibrado a extremos climáticos con efectos catastróficos; de ecosistemas saludables a entornos contaminados y empobrecidos solo para proporcionar servicios ambientales; de un océano productivo a la acidificación de sus aguas y pérdida de productividad de su biomasa. En otras palabras, aumenta la vulnerabilidad y la desarticulación económica. En una región que depende de su patrimonio natural, la capacidad para desarrollar procesos productivos sostenibles que generen empleos e ingresos está relacionada con la capacidad del ambiente para proporcionar agua, suelos fértiles, un clima equilibrado y otros servicios ambientales.

El cambio de uso del suelo es fuente del $49 \%$ de las emisiones de gases de efecto invernadero en la región (CEPAL, 2015a), donde, desde 1990, se ha perdido el 9,4\% de la superficie de los bosques (PNUMA, 2016). En América del Sur, donde se sitúan importantes ecosistemas como la Amazonia, la cobertura forestal pasó del 52,2\% en 1990 al 47,7\% en 2015 (CEPAL, 2016e). La pérdida de hectáreas boscosas es producto de la expansión de las áreas agropecuarias, por lo que si se utilizaran procesos más eficientes y sostenibles en esas actividades se podría aumentar la producción sin reducir la cobertura forestal. Sin embargo, la mayor parte de los países aún no ha adoptado este tipo de procesos a gran escala. La pérdida de bosques también tiene consecuencias para las áreas urbanas, pues altera el equilibrio hídrico: al perderse en gran medida el efecto de la evapotranspiración, se producen sequías prolongadas.

La importancia de la actividad agropecuaria en la balanza comercial de los países, especialmente en el Cono Sur, es un determinante clave en la reducción de los bosques. La participación de la región en las exportaciones agropecuarias mundiales aumentó de un $10 \%$ en 2000 a un 13\% en 2015. En América del Sur se originó, en promedio, el 80\% del valor de las exportaciones agropecuarias regionales; en México, el 11\%; en Centroamérica, el 7\%, y en el Caribe, solo el 1\%. El Brasil pasó de ser el undécimo exportador agropecuario mundial en 2000 a ser el quinto en 2015, con una participación del 5\%, y el mayor exportador agropecuario mundial en términos netos, seguido por la Argentina (2\%) y México (1,7\%) (CEPAL, 2017c).

Existe el riesgo de que el potencial agroexportador de la región se siga expandiendo a expensas de la desforestación (véase el gráfico V.23). De hecho, se proyecta que entre 2016 y 2025 América Latina sea la región del mundo donde más aumente la superficie de cultivos agroexportables (24\%). Esta expansión está asociada a los cultivos de soja (un 29\% del total), principalmente en el Brasil y la Argentina (OCDE/FAO, 2016).

La desertificación es otra consecuencia de la actividad agropecuaria insostenible (véase el gráfico V.24). La desertificación de tierras agrícolas erosiona las bases de la economía; es una pérdida de recursos productivos que merma la producción y genera pobreza. En el gráfico V.24 se muestran los altos niveles de desertificación de algunos países expresados en porcentajes del territorio. El Programa de las Naciones Unidas para el Desarrollo (PNUD) (2015) calcula que en la región hay aproximadamente un 60\% de tierras áridas; además, más de 300 millones de hectáreas son tierras agrícolas desertificadas, que equivalen a aproximadamente el $20 \%$ del territorio aprovechable. El Fondo Internacional de Desarrollo Agrícola (FIDA) estima que en 2050 el $50 \%$ de las tierras productivas estarán desertificadas (FIDA, 2010). La degradación de los suelos se expresa también en su menor fertilidad y en la pérdida de carbono orgánico. 


\section{Gráfico V.23}

América Latina y el Caribe: pérdida de superficie forestal y expansión del área agropecuaria, 1990-2014

(En millones de hectáreas)

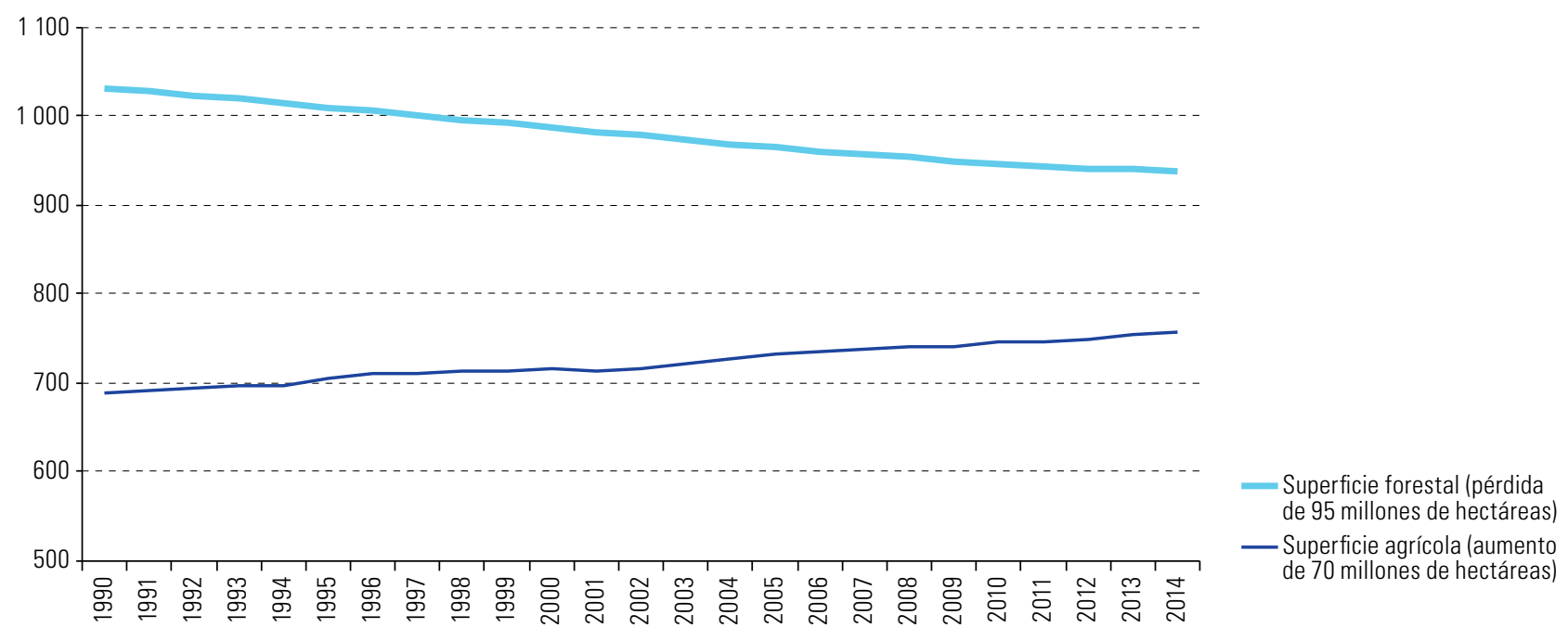

Fuente: Organización de las Naciones Unidas para la Alimentación y la Agricultura (FAO), Base de Datos Estadísticos Sustantivos de la Organización (FAOSTAT) [en línea] http://www.fao.org/faostat/es/\#home.

\section{Gráfico V.24}

América Latina y el Caribe (11 países): territorios desertificados o en proceso de desertificación ${ }^{a}$

(En porcentajes del territorio)

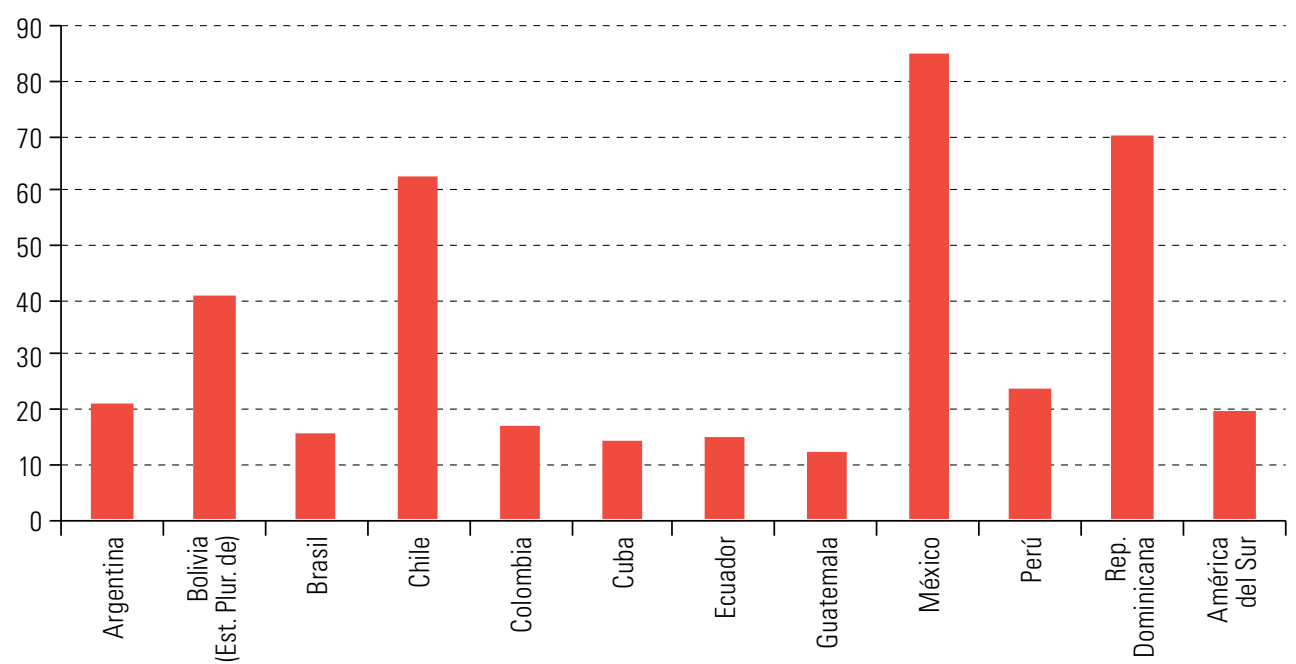

Fuente: Comisión Económica para América Latina y el Caribe (CEPAL), sobre la base de Unión Europea/Organización de las Naciones Unidas para la Alimentación y Agricultura (FA0), Atlas de suelos de América Latina y el Caribe, Luxemburgo, 2014, y Convención de las Naciones Unidas de Lucha Contra la Desertificación (UNCCD), Country Profiles: Latin America and the Caribbean Region, Bonn, 2015, y datos de la UNCCD sobre el quinto proceso de presentación de informes y examen de la Convención de las Naciones Unidas de Lucha contra la Desertificación.

a Último año con información disponible: Argentina, 2011; Brasil, 2004; Colombia, 2010; Cuba, 2006; Ecuador, 2005; Guatemala, 2014; República Dominicana, 2010; Bolivia (Estado Plurinacional de), México y Perú, 2012.

De forma paralela a la degradación del suelo, se detecta un gran aumento del uso de fertilizantes para compensar la pérdida de recursos naturales — lo que no siempre se logra-. Al mismo tiempo, se utilizan con mayor intensidad los pesticidas, como fungicidas, herbicidas e insecticidas, que representan una amenaza para la salud de las personas y para el medio ambiente y los servicios que ofrece. Esas tendencias son captadas 
al analizar la dinámica de la productividad de la tierra: el informe Perspectiva Global de la Tierra (UNCCD, 2017) muestra indicios de un descenso de la productividad del suelo en aproximadamente el $20 \%$ de la superficie terrestre mundial con vegetación. Las regiones más afectadas son América del Sur y África, con un 27\% y un $22 \%$, respectivamente.

La degradación de bosques, suelos y agua es parte de un círculo vicioso que lleva a pérdidas de empleo e ingresos y a un aumento de la pobreza y desigualdad a mediano y largo plazo, pese a que pueda significar mayores ingresos para algunos sectores a corto plazo. Los costos ambientales del desarrollo no son una preocupación nueva para la comunidad internacional, pero solo se han comenzado a adoptar medidas globales para reducirlos en años recientes. Esos costos representan ineficiencias de un sistema que es desigual desde un punto de vista intertemporal (las generaciones futuras tendrán que convivir con ecosistemas con menos capacidad de sostener el crecimiento que los que tuvieron a su disposición las generaciones pasadas) y de cada generación (los pobres cargan con los mayores costos de la degradación ambiental). La implementación de la Agenda 2030 para el Desarrollo Sostenible se relaciona estrechamente con el patrón de inversión y, por ende, con la trayectoria de uso de la energía y los recursos naturales. Dicha implementación lleva a invertir en sectores productivos que utilicen métodos de producción limpia para desacoplar el crecimiento económico de la extracción material y del consumo energético, temas que se abordan a continuación.

\section{El cambio climático: contaminación global e impactos localizados}

Los efectos de los eventos climáticos extremos, que han aumentado por el cambio climático, se sienten cada vez con más fuerza en la región. Se han incrementado tanto su frecuencia como el costo económico de la consiguiente destrucción (véase el gráfico V.25). Esto ocurre por la combinación de una mayor exposición a esos eventos y la degradación de los ecosistemas que ayudan a mitigarlos y facilitan la adaptación. Además, el cambio climático conlleva una doble inequidad: los grupos de mayores ingresos son los principales emisores de gases de efecto invernadero — son los mayores consumidores de combustibles fósiles-, pero los más pobres son los más vulnerables a sus efectos, dada su menor capacidad de adaptación.

\section{Gráfico V.25}

América Latina y el Caribe: costo de los eventos meteorológicos extremos, 1961-2015

(En miles de millones de dólares corrientes)

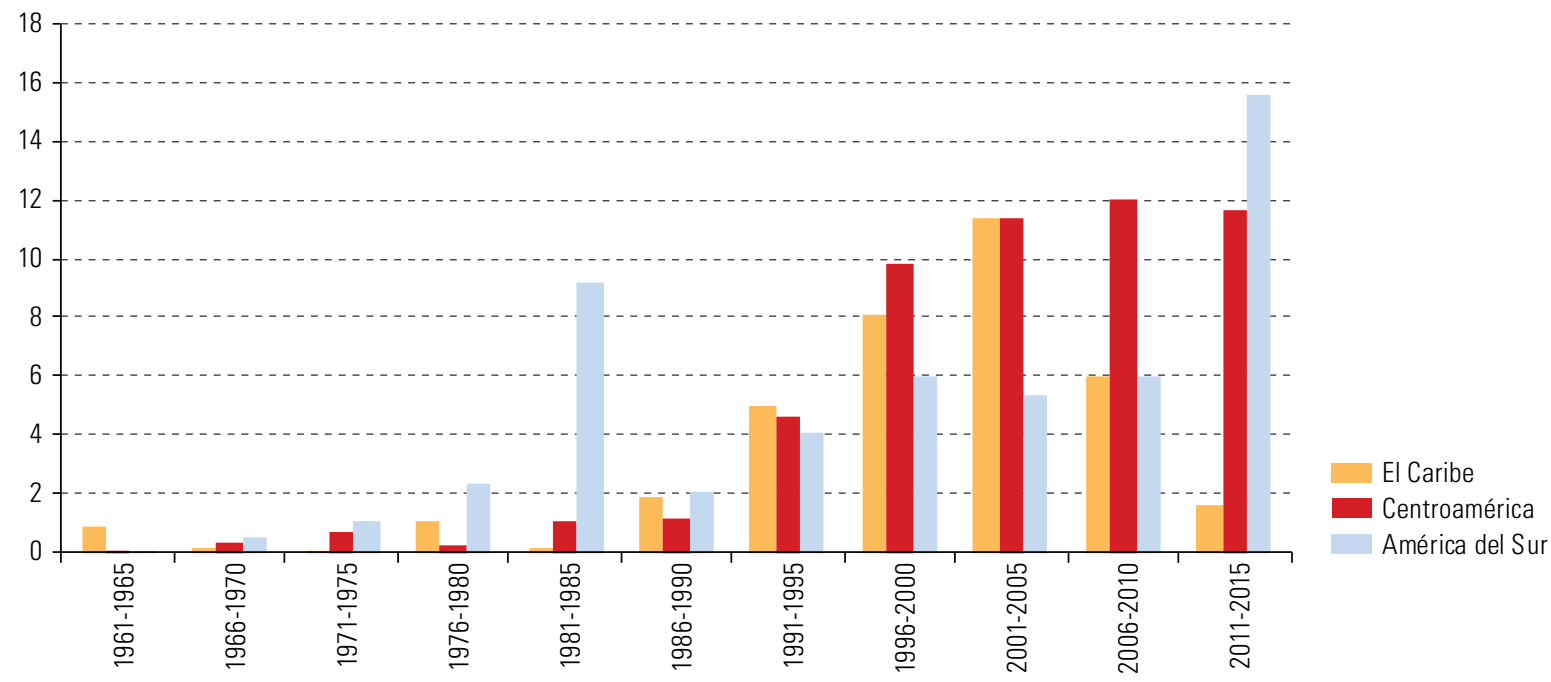

Fuente: Comisión Económica para América Latina y el Caribe (CEPAL), sobre la Base de Datos Internacional sobre Desastres (EM-DAT), 2016 [en línea] http://www.emdat.be/. 
Las estimaciones de los costos económicos que causaría un aumento de $2,5^{\circ} \mathrm{C}$ de la temperatura del planeta (lo que ocurriría con alta probabilidad alrededor de 2050) oscilan entre un 1,5\% y un $5 \%$ del PIB actual de la región, como se muestra en el gráfico V.26 (CEPAL, 2015a) ${ }^{20}$.

\section{Gráfico V.26}

América Latina y el Caribe: impacto económico de un aumento de $2,5^{\circ} \mathrm{C}$ de la temperatura del planeta según diferentes estimaciones, segunda mitad del siglo XXI

(En porcentajes del PIB regional)

Banco Interamericano de Desarrollo (BID)/CEPAL/ World Wide Fund for Nature (WWF) (2013)

Modelo AD-WITCH (Bosetti y otros, 2009)

Modelo ICES (Bosello y otros, 2009)

Mendelsohn y otros (2000)

Nordhaus y Boyer (2000)

Pierce y otros (1996)

Tol (Frankhauser y Tol, 1996)

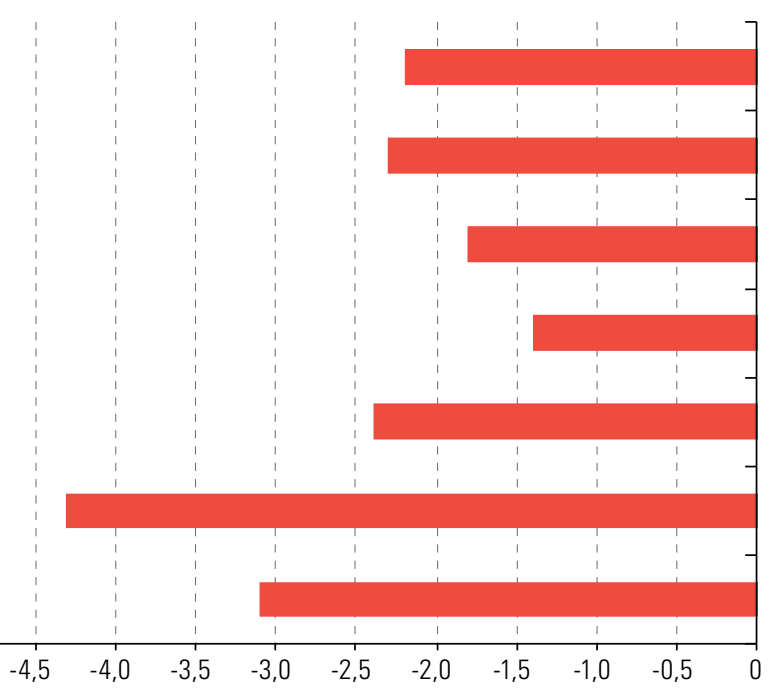

Fuente: Comisión Económica para América Latina y el Caribe (CEPAL), La economía del cambio climático en América Latina y el Caribe: paradojas y desafíos del desarrollo sostenible (LC/G.2624), Santiago, 2015, y F. Bosello y otros, "Market- and policy-driven adaptation", Smart Solutions to Climate Change: Comparing Costs and Benefits, Cambridge, Cambridge University Press, 2010.

El impacto del cambio climático es heterogéneo entre los países y en su interior, así como entre las distintas actividades económicas. Debido a la sensibilidad de la agricultura y la ganadería a las condiciones climáticas, es muy probable que el sector agropecuario sea el más afectado en términos de ingresos netos y productividad (Mendelsohn y Dinar, 2009), lo que resulta preocupante para los países de la región en los que ese sector tiene una importancia estratégica (CEPAL, 2017d).

Las zonas costeras son vulnerables al aumento del nivel del mar y los efectos conjuntos de las inundaciones, la erosión de las playas y la destrucción de las infraestructuras costera y portuaria, con sus correspondientes impactos económicos, sociales y ambientales (CEPAL, 2017a, 2014a). Para la adaptación de dichas infraestructuras es necesario considerar esa vulnerabilidad en las evaluaciones de impacto ambiental, preferentemente en un marco regional, para evitar una competencia regulatoria negativa (race to the bottom).

América Latina y el Caribe cuenta con una alta disponibilidad media de recursos hídricos, distribuida de manera heterogénea entre países (CEPAL, 2014c; Magrin y otros, 2007). El cambio climático, al modificar los patrones de precipitación, la humedad del suelo y la escorrentía y acelerar el derretimiento de los glaciares, afectará la disponibilidad de agua para el consumo humano y las actividades económicas, como la agricultura y la industria. En algunas zonas, el cambio hidrológico afectará la producción hidroeléctrica21. Por lo tanto, es necesario evaluar las prácticas actuales de manejo del agua para reducir el desequilibrio entre la oferta y la demanda y disminuir la vulnerabilidad futura, así como llevar a cabo reformas normativas y jurídicas que faciliten la gestión eficiente y eficaz de los recursos hídricos (Magrin y otros, 2014; Magrin, 2015).

En América Latina y el Caribe el cambio climático también tendrá un efecto negativo en la distribución e incidencia de enfermedades transmisibles como la malaria, el dengue y el cólera (Magrin y otros, 2007). Por otra parte, el aumento de la temperatura en localidades contaminadas desencadenará retroalimentaciones

20 Si bien estas estimaciones son inciertas y conservadoras, se limitan a ciertos sectores y regiones y tienen limitaciones metodológicas, son útiles para la política pública.

21 Por ejemplo, en Colombia se verían alteradas la disponibilidad de agua y la generación de energía hidroeléctrica, y en el Perú el retroceso de los glaciares podría afectar la disponibilidad de agua para los centros de población y el sector eléctrico, lo que entrañaría un costo adicional anual estimado de entre 212 millones y 1.500 millones de dólares para la generación de energía (CEPAL, 2014c). 
químicas y emisiones locales que incrementarán las concentraciones máximas de ozono y de partículas finas en suspensión (PM2,5) (IPCC, 2013) en ciudades que ya presentan una contaminación atmosférica elevada, en muchos casos por encima de los niveles máximos recomendados en términos de salud (CEPAL, 2014c). Todo ello constituirá una carga económica adicional para los sistemas de salud de los países de la región.

Los desastres naturales son otra fuente significativa de costos para la región. Entre 1970 y 2017, estos alcanzaron los 258.000 millones de dólares: el 42\% de esta suma en Centroamérica y México, el 39\% en América del Sur y el 19\% en el Caribe (CEPAL, 2017d). Además de las pérdidas económicas que implican los desastres naturales, sus consecuencias pueden aumentar la pobreza y acentuar la desigualdad, haciendo retroceder el desarrollo de un país o de un territorio.

Los impactos del cambio climático no se limitan a ciertos sectores o actividades económicas, pues tienen canales de transmisión al resto de la sociedad mediante alteraciones de la producción y las finanzas públicas. El descenso de la actividad económica disminuye los ingresos tributarios derivados de la agricultura, el turismo o el sector portuario, entre otros. Por otra parte, los impactos del cambio climático demandan mayores gastos e inversión pública para atender las consecuencias de eventos extremos como inundaciones, sequías y huracanes, así como para implementar medidas de adaptación a las nuevas condiciones climáticas y reducir la vulnerabilidad de la población.

Los costos de adaptación de la región se estiman en aproximadamente un 0,4\% de su PIB actual (véase el gráfico V.27), aunque esas estimaciones contienen un alto nivel de incertidumbre y muy probablemente tenderán a aumentar22 (Banco Mundial, 2010b; Vergara y otros, 2013). Desde el punto de vista económico tiene sentido invertir en adaptación, ya que su costo es casi diez veces menor que el de la inacción. Por otro lado, la inversión en adaptación tiene efectos dinamizadores en la economía, sobre todo si impulsa el cambio técnico y la diversificación productiva.

\section{Gráfico V.27}

América Latina y el Caribe: costo estimado anual de la adaptación al cambio climático, por sectores a 2050 (En porcentajes del PIB regional)

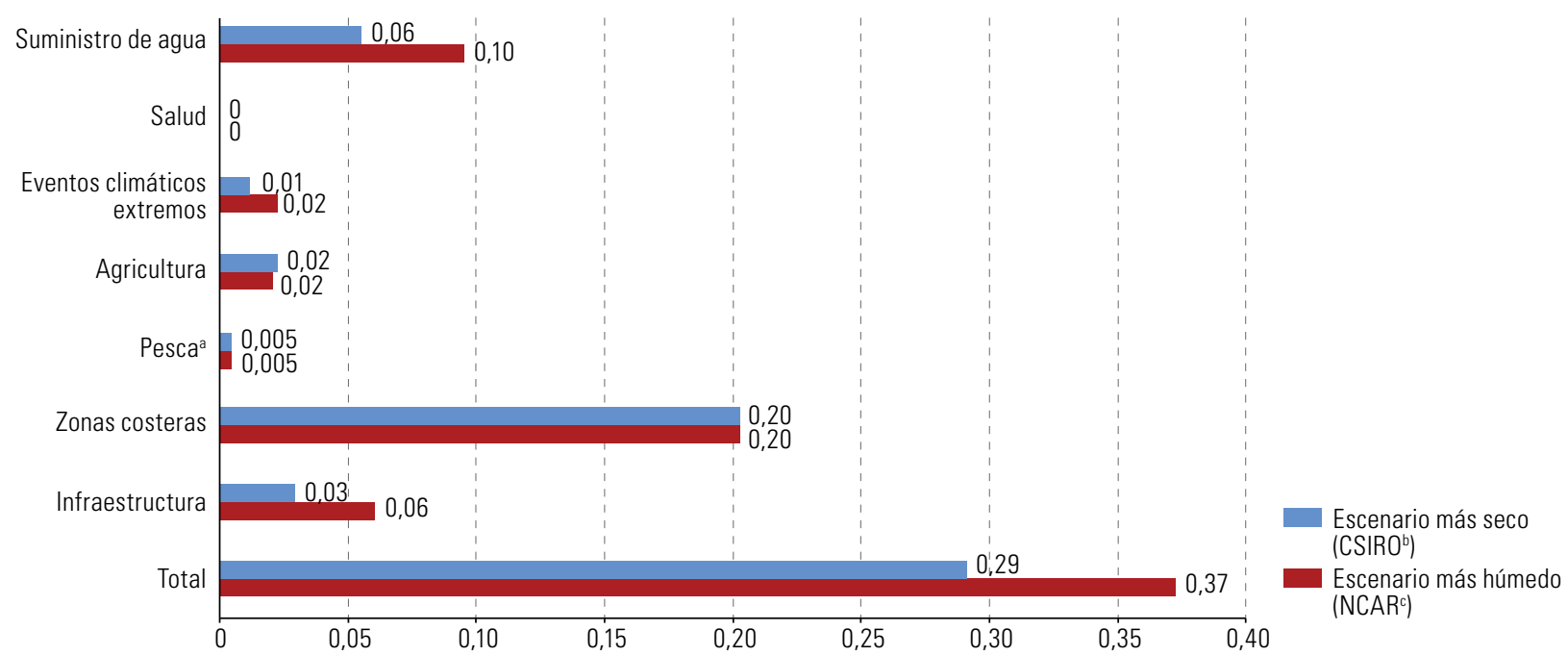

Fuente: Comisión Económica para América Latina y el Caribe (CEPAL), La economía del cambio climático en América Latina y el Caribe: paradojas y desafíos del desarrollo sostenible (LC/G.2624), Santiago, 2015, y Banco Mundial, The Cost to Developing Countries of Adapting to Climate Change: New Methods and Estimates, Washington, D.C., 2010.

a Sector pesquero: rango medio (de 0,18 a 0,36 y de 0,18 a 0,35 para los modelos NCAR y CSIRO, respectivamente).

b Organización de Investigaciones Científicas e Industriales del Commonwealth.

c Centro Nacional de Investigaciones Atmosféricas de los Estados Unidos.

22 El Banco Mundial (2010a) estima que los costos de adaptación en relación con la agricultura, los recursos hídricos, la infraestructura, las zonas costeras, la salud, los eventos climáticos extremos y la pesca serán inferiores al 0,3\% del PIB de la región, es decir, oscilarán entre los 16.800 y los 21.500 millones de dólares al año hasta 2050 (2010a). Según Agrawala y otros (2010), los costos de adaptación en relación con la irrigación, la infraestructura hídrica, la protección costera, los sistemas de alerta temprana, la inversión en asentamientos resistentes al clima, la refrigeración, el tratamiento de enfermedades, y la investigación y el desarrollo para la adaptación estarán cerca del 0,24\% del PIB regional. Dado que la adaptación requiere inversiones públicas y privadas que pueden dinamizar la actividad económica, este cálculo de costos es bruto y no considera los efectos multiplicadores de esas inversiones. 
La realidad de los países caribeños es especialmente ilustrativa de la tensión entre la contaminación global y sus muy diferentes efectos en distintos países. Entre 1990 y 2017 se registraron en el Caribe 345 desastres vinculados al clima, 12 por año. Este tipo de evento daña de manera considerable la infraestructura económica de los pequeños Estados insulares en desarrollo, mengua sus logros sociales y profundiza las desigualdades. El impacto anual de estos desastres en su acervo de capital sería, en términos relativos, muy superior al que se daría en Europa o Asia Central: equivale al 20\% de su gasto social anual (UNISDR, 2015). Esto lleva a un desvío importante de la cartera de inversiones y de los recursos presupuestarios, que deben ser reorientados para reconstruir estas economías y reducir el impacto en la población afectada. Eso sucedió, por ejemplo, en el caso de los desastres originados por la temporada de huracanes de 2017, cuyos impactos en algunos de los Estados insulares superaron el $50 \%$ del PIB.

Su naturaleza de pequeños Estados insulares — que les impide aprovechar economías de escala— y los reiterados esfuerzos de reconstrucción los han llevado a crónicos déficits gemelos (fiscal y de cuenta corriente) y, en consecuencia, a grandes niveles de endeudamiento. En 2016, la deuda pública de los gobiernos centrales del Caribe variaba entre el $50 \%$ y el $125 \%$ del PIB (en el caso de Jamaica). Debido a sus elevadas deudas, estos países deben tomar créditos con una mayor prima de riesgo y enfrentan una mayor inestabilidad cambiaria y una gran fragilidad financiera, que los obliga a aplicar políticas restrictivas y reducir la inversión pública. En promedio, el pago de intereses de la deuda pública absorbe en el Caribe alrededor del $15 \%$ de las recaudaciones tributarias. En Jamaica y Barbados, 1 de cada 3 dólares recaudados por impuestos se destina al pago de intereses. El servicio total de la deuda, incluida su amortización, conlleva en promedio erogaciones del 30\% de los ingresos del gobierno central (esta cifra alcanza el $84 \%$ en Jamaica y el $47 \%$ en Antigua y Barbuda). Paradójicamente, cinco países del Caribe están clasificados como países de ingreso alto (Antigua y Barbuda, Bahamas, Barbados, Saint Kitts y Nevis y Trinidad y Tabago), por lo que no pueden optar a créditos concesionales. Los ocho países restantes (Belice, Granada, Guyana, Jamaica, San Vicente y las Granadinas, Santa Lucía y Suriname) se clasifican como de renta media-alta. Esta situación debilita aún más su situación financiera.

El desarrollo sostenible es particularmente difícil en condiciones de grave riesgo de desastres. Por ello, urge aumentar la resiliencia de las estructuras económicas en el Caribe e implementar estrategias de adaptación al cambio climático. La CEPAL ha propuesto una estrategia de alivio de la deuda para la subregión y la creación de un fondo caribeño de resiliencia. Esta iniciativa está dirigida a los países caribeños que tengan un bajo crecimiento a pesar de haber llevado a cabo reformas para mejorar su desempeño económico, que tengan una deuda insostenible a pesar de haber tomado medidas de consolidación fiscal, que tengan un servicio de deuda que haya reducido su espacio fiscal y la inversión en infraestructura y que demuestren tener considerables dificultades para lograr los Objetivos de Desarrollo Sostenible (incluida la adaptación al cambio climático) debido a problemas fiscales.

La reducción de la deuda funciona de la siguiente manera: para los países con una elevada deuda oficial, consistiría en usar fondos climáticos, como el Fondo Verde para el Clima, para saldar las deudas multilaterales y bilaterales con una tasa de descuento. En el caso de deuda elevada con acreedores privados, se negociarían planes de recompra. El fondo caribeño de resiliencia tiene tres componentes:

i) En el caso de desastres naturales: fondos para la recuperación de la actividad económica y la reconstrucción de infraestructura con elementos de reducción del riesgo de desastres. Son recursos complementarios a iniciativas como el Fondo de seguro contra riesgos de catástrofe para el Caribe (CCRIF).

ii) En el caso de choques externos: financiamiento frente a estos choques para los países caribeños de renta alta que no tengan acceso a financiamiento concesional.

iii) Cambio climático: recursos para proyectos de infraestructura, en particular medidas de mitigación y adaptación al cambio climático. 
En resumen, el estilo de desarrollo predominante genera ineficiencias y pérdidas de productividad en los más diversos ámbitos. Sobre la base del modelo de vínculos económicos globales de la Organización Internacional del Trabajo (OIT), se ha estimado que, si la situación no cambia, los niveles mundiales de productividad laboral serán un 2,4\% menores a los actuales en 2030 y habrán caído un 7,2\% en 2050 (OIT, 2012). Estas estimaciones coinciden con las de diversos estudios de evaluación de los daños económicos producidos por la degradación del medio ambiente y la pérdida de los servicios de los ecosistemas básicos. Si no se ponen en práctica políticas de mitigación del cambio climático, habrá una pérdida del 14\% del consumo global per cápita de aquí a 2050 (Stern, 2006; OCDE, 2012). Estos efectos podrían profundizar la desigualdad, porque afectan especialmente a grupos que tienen poca capacidad para protegerse o exigir políticas de prevención o reparación.

\section{La urgencia de aumentar la tasa de descarbonización}

\section{a) La huella material y la huella de carbono}

La extracción total de recursos naturales -el volumen extraído del ambiente natural, excepto el de aire y agua (IRP/PNUMA, 2016) — produce una huella material que, si se compara con el PIB, es un indicador de la intensidad de uso de esos recursos. Entre 1970 y 2010 creció la extracción total en la región y la intensidad del uso de los recursos no se desacopló del crecimiento económico (PNUMA, s/f; Banco Mundial, 2015). Un perfil exportador de alto impacto material implica una elevada ineficiencia económica y ambiental (PNUMA, 2011), cuya superación pasa por incorporar tecnologías que permitan sostener empleos e ingresos sin destruir el capital natural.

En el mismo sentido, las emisiones del sector de la energía aumentaron de 2,2 toneladas per cápita a aproximadamente 3 toneladas per cápita en la región entre 1990 y 2014 (véase el gráfico V.28), un nivel superior al que se esperaba alcanzar en 2050. Entre 2006 y 2011, las emisiones energéticas totales se incrementaron un 14,2\% (Banco Mundial, 2015). Por el lado positivo, se redujeron las emisiones por cambios en el uso del suelo.

\section{Gráfico V.28}

América Latina y el Caribe: emisiones per cápita de $\mathrm{CO}_{2}$ equivalente, 1990-2014

(En toneladas)

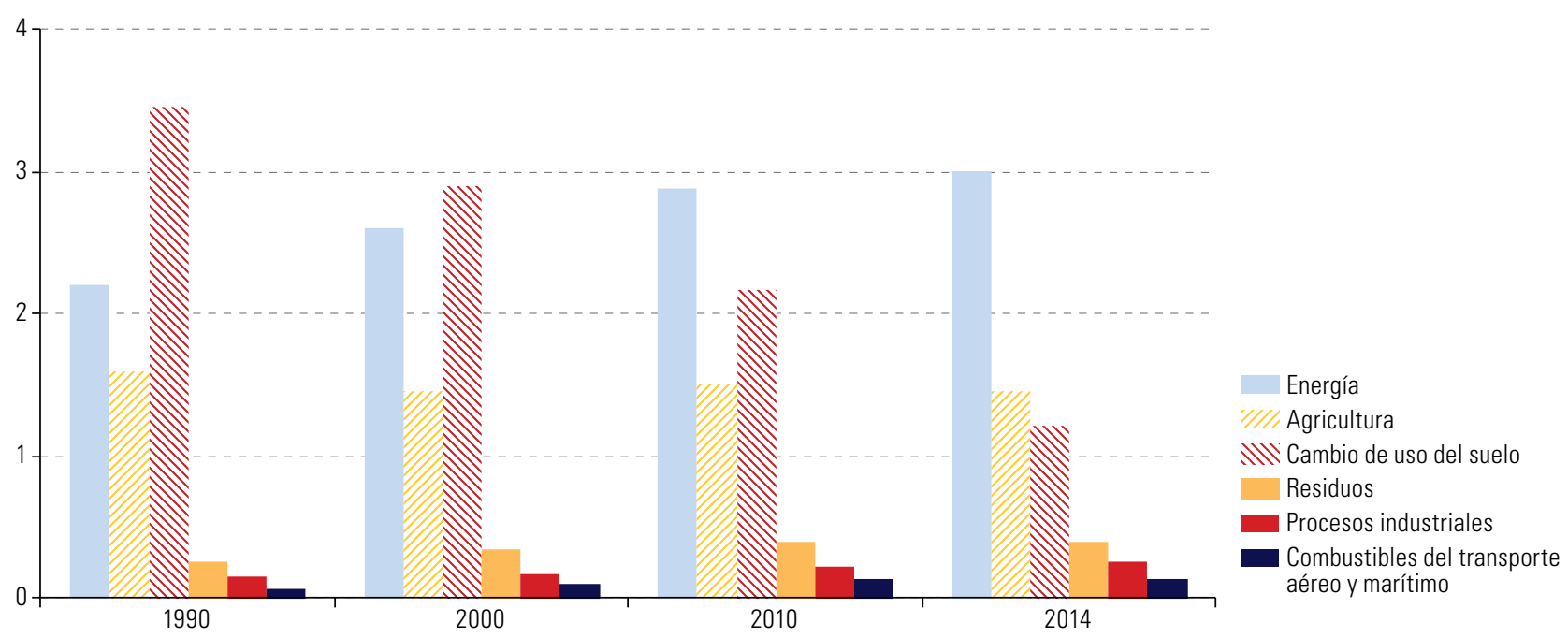

Fuente: Comisión Económica para América Latina y el Caribe (CEPAL), sobre la base de World Resources Institute, “CAIT Climate Data Explorer” [en línea] http://cait.wri.org. 


\section{b) Trayectoria de la intensidad energética y carbónica de la economía}

En las publicaciones sobre la materia, se ha sugerido que la degradación del medio ambiente —medida por las emisiones de $\mathrm{CO}_{2} \mathrm{u}$ otros contaminantes - se comporta de acuerdo con la curva ambiental de Kuznets (una $U$ invertida): cuando los niveles de ingreso per cápita son bajos la degradación es reducida, aumenta a medida que se elevan dichos niveles de ingreso y disminuye tras alcanzar un cierto nivel crítico. La curva ambiental de Kuznets se explicaría por la acción de dos fuerzas: el cambio estructural, asociado al tránsito desde una economía agraria (poco contaminante) a una economía industrial (más contaminante) y de esta a una economía basada en servicios (menos contaminante), y el cambio tecnológico, en especial el cambio de la matriz energética, en respuesta a una mayor demanda de tecnologías limpias por parte de los consumidores, cuya valoración del medio ambiente aumenta una vez que alcanzan niveles elevados de ingreso.

En algunas economías europeas y norteamericanas se ha producido una caída importante de la relación entre las emisiones de $\mathrm{CO}_{2}$ y el ingreso per cápita, como lo prevé la curva ambiental de Kuznets (véase el gráfico V.29), y en las economías asiáticas esta relación ha aumentado a medida que estos países se industrializaban. Sin embargo, economías como las de África Subsahariana, el Oriente Medio o África Septentrional no han seguido el mismo patrón. En América Latina y el Caribe, esa relación ha permanecido constante. El hecho de que la hipótesis de la curva ambiental de Kuznets no siempre se confirme indica que la relación entre contaminación e ingreso per cápita es menos directa de lo que se había asumido inicialmente. Esto se debe a que las dos fuerzas determinantes de la curva (el cambio estructural y el cambio técnico) dependen de políticas e instituciones cuya operación puede provocar la detención prematura del avance hacia la etapa menos contaminante.

\section{Gráfico V.29}

Evolución de la relación entre el PIB per cápita y la intensidad carbónica de la economía, 1971-2014

(En kilogramos de $\mathrm{CO}_{2}$ por cada dólar del PIB y dólares constantes de 2010)

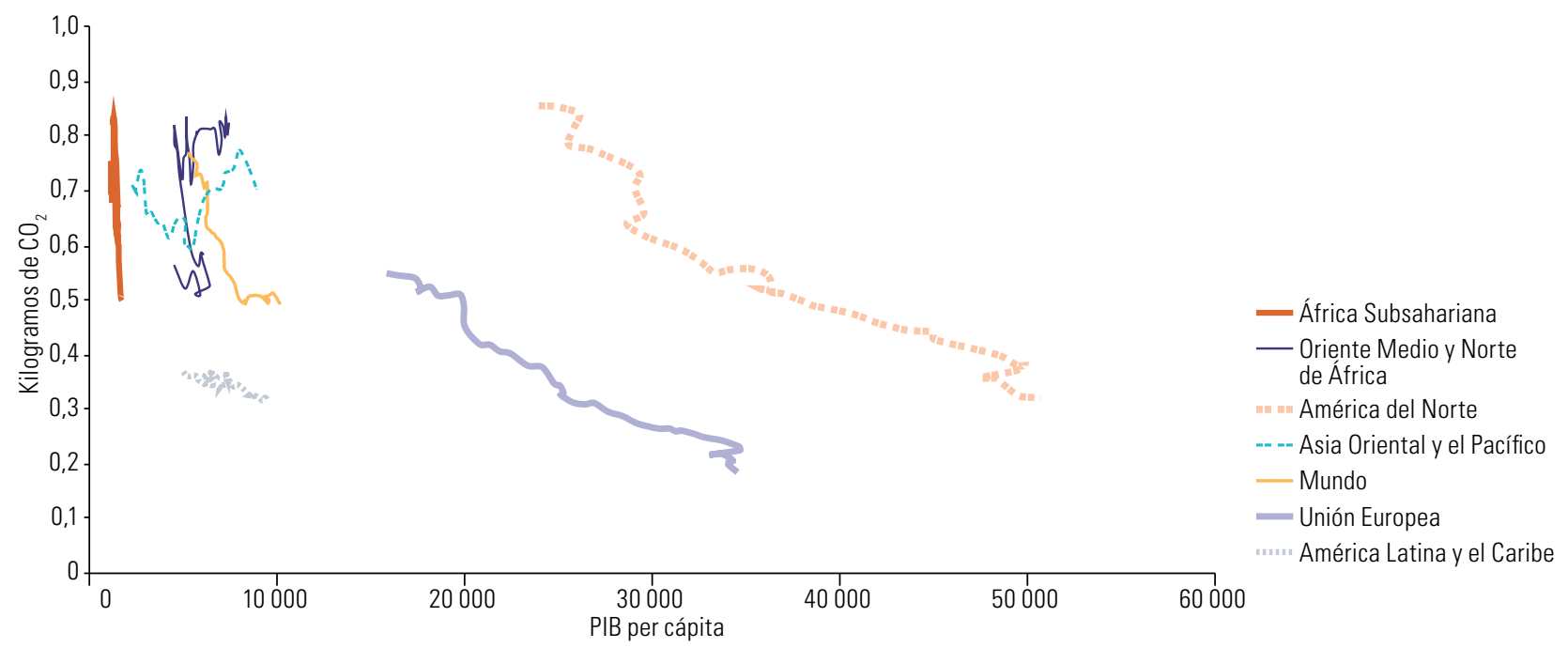

Fuente: Comisión Económica para América Latina y el Caribe (CEPAL), sobre la base de Banco Mundial, "World Development Indicators", 2017 [en línea] http://data. worldbank.org/data-catalog/world-development-indicators.

La reducción de las emisiones requiere una transformación tecnológica de gran alcance que aún no se ha logrado en la región. Por un lado, deben disminuir las emisiones contaminantes por unidad de energía consumida; por otro, debe reducirse el consumo de energía por unidad de ingreso per cápita. En el gráfico V.30, en el que se muestra la energía consumida por unidad de ingreso, se observa que los avances en este campo 
han sido insuficientes. Los niveles actuales de emisiones y eficiencia energética están estancados muy lejos de los niveles deseables para el desarrollo sostenible y de los alcanzados en otras partes del mundo. De continuar esta tendencia, se incumplirían las metas climáticas del Acuerdo de París y los Objetivos de Desarrollo Sostenible. Se trata de una trayectoria insostenible a mediano y largo plazo.

\section{Gráfico V.30}

Evolución de la relación entre el PIB per cápita y la intensidad energética de la economía, 1971-2014

(En kilogramos de petróleo equivalente por cada 1.000 dólares del PIB y dólares constantes de 2010)

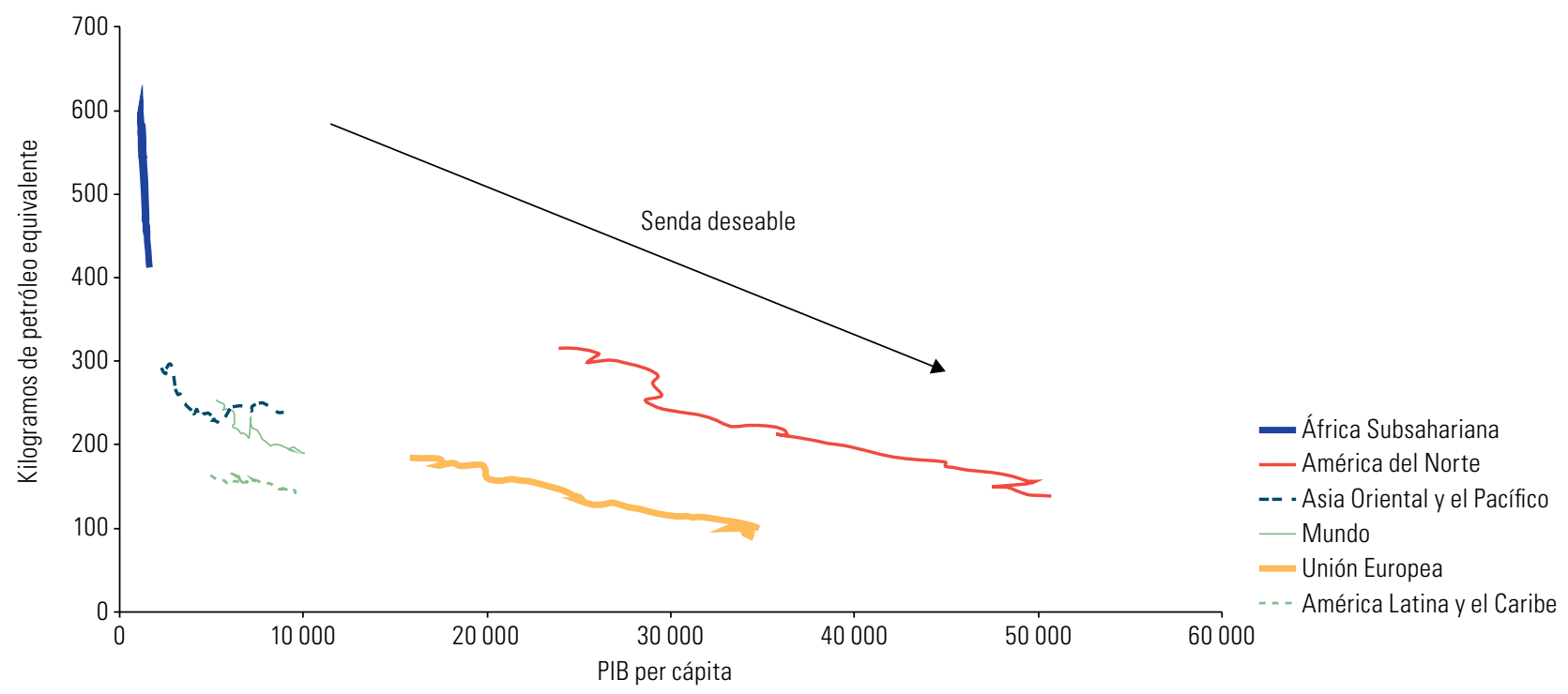

Fuente: Banco Mundial, “World Development Indicators", 2017 [en línea] http://data.worldbank.org/data-catalog/world-development-indicators.

En 1971, la región mostraba una intensidad energética relativamente baja en comparación con el resto del mundo. Esta intensidad no ha experimentado grandes cambios, lo que puede estar asociado a un efecto cerrojo (lock-in) en la estructura económica; hasta ahora, no existe un desacople significativo entre el crecimiento económico y sus requerimientos energéticos. Esto contrasta con el esfuerzo de la Unión Europea, que ha disminuido su intensidad energética por debajo de la de América Latina y el Caribe, e incluso de la de los Estados Unidos y el Canadá, lo que pone de relieve la importancia de las políticas orientadas al uso eficiente de la energía y a la diversificación de la oferta energética.

La baja eficiencia ambiental puede limitar la tasa de crecimiento compatible con el mantenimiento de las tasas de empleo, en la medida en que no se desacoplen las emisiones y el crecimiento del PIB (véase el recuadro V.1). De la misma forma, en ciudades muy desiguales en las que haya áreas sin bienes públicos — transporte, educación, seguridad ciudadana, un medio ambiente no contaminado — la productividad se reducirá a causa del tiempo de transporte, la mala salud y la pérdida de vidas humanas, así como un acceso insuficiente a la educación. Finalmente, la desigualdad afecta a la hora de decidir sobre las modalidades de infraestructura en que invertir, lo que repercute en la eficiencia energética y productiva. 


\section{Recuadro V.1}

El umbral mínimo necesario de crecimiento y las emisiones de gases de efecto invernadero

Mantener un ritmo de crecimiento compatible con la necesaria generación de empleo requiere politicas energéticas que permitan desacoplar el crecimiento económico de la producción de emisiones de gases de efecto invernadero (GEI), de forma acorde con las metas climáticas. En la región, el crecimiento necesario para absorber el aumento de la población, o umbral mínimo necesario en la generación de empleos, se encuentra en alrededor del 2,2\% (capítulo III), mientras que la tasa de crecimiento promedio del PIB se sitúa en alrededor del 3,2\% desde 2000.

Los escenarios de emisiones de GEl para 2030 permiten estimar, sobre la base de estas dos tasas de crecimiento, los esfuerzos necesarios para alcanzar una meta de mitigacióna . El escenario "constante" considera que todo sigue igual hasta 2030: el mismo crecimiento del PIB y la misma tasa de descarbonización de la economía desde 2000 hasta la fechab. En el escenario "alternativo I", la economía crece a la tasa del umbral mínimo necesario (2,2\%), y la tasa de descarbonización es la misma que la del escenario constante. El escenario "alternativo II" toma la tasa de crecimiento del umbral mínimo y la tasa de descarbonización de la economía necesaria para cumplir la meta de reducción de emisiones. El escenario "alternativo III" se basa en la tasa de crecimiento histórica del PIB, y la tasa de descarbonización se ajusta para lograr en 2030 la meta de mitigación regional del 30\% con respecto al escenario constante en que todo seguiría igual.

Estimaciones de crecimiento anual del PIB y descarbonización, 2030

\begin{tabular}{lccc|cc}
\hline Escenario & Constante & Alternativo I & Alternativo II & Alternativo III \\
\cline { 5 - 6 } \cline { 4 - 5 } Crecimiento del PIB & 3,2 & 2,2 & 2,2 & 3,2 \\
\hline Tasa de descarbonización & $-1,1$ & $-1,1$ & $-2,1$ & $-3,1$ \\
\hline
\end{tabular}

Fuente: L. Galindo y otros, "Cambio climático, consumo, gasolinas, empleo y pobreza: Ios números de una ecuación no sostenible en América Latina", 2018 , inédito.

Estimación de las emisiones de gases de efecto invernadero, 2030

(En gigatoneladas de $\mathrm{CO}_{2}$ equivalente)

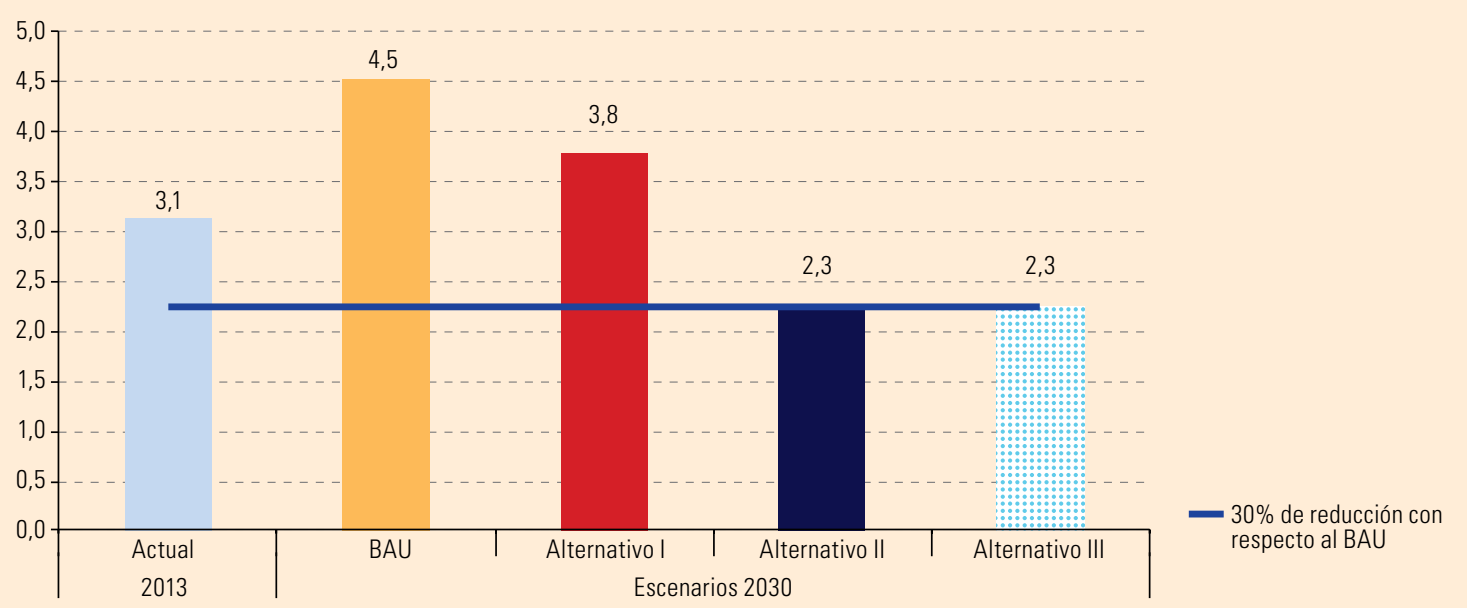

Fuente: L. Galindo y otros, “Cambio climático, consumo, gasolinas, empleo y pobreza: los números de una ecuación no sostenible en América Latina”, 2018, inédito.

En este ejercicio la meta es de 2,3 gigatoneladas (Gt) de $\mathrm{CO}_{2}$ equivalente. Las emisiones regionales serán superiores a la meta en 2030 a menos que se duplique la tasa de descarbonización en un escenario de bajo crecimiento (alternativa II) o que se triplique en un escenario de crecimiento como el experimentado desde 2000 hasta la fecha (alternativa III) mediante la mejora de la eficiencia energética, la reducción del uso de fertilizantes químicos y una matriz energética con menor uso de combustibles fósiles.

Fuente: L. Galindo y otros, "Cambio climático, consumo, gasolinas, empleo y pobreza: Ios números de una ecuación no sostenible en América Latina", 2018 , inédito. ${ }^{a}$ En este ejercicio no se consideran las emisiones por cambio de uso de suelo y silvicultura; se asume que las emisiones de este sector se reducen a cero.

b Esta es la tasa de desacople del crecimiento económico respecto al crecimiento de las emisiones; un signo negativo implica desacople, mientras que uno positivo implica que la relación se hace más estrecha. 


\section{Fuentes de energía renovables: un nuevo horizonte de inversiones}

En la región, la generación de emisiones de $\mathrm{CO}_{2}$ depende de la participación de los combustibles fósiles en la matriz energética: $74 \%$ en total, $44 \%$ en la generación eléctrica y más del $90 \%$ en el transporte. Para descarbonizar la economía es necesario producir electricidad a partir de fuentes renovables, así como transitar hacia una movilidad eléctrica que no haga uso de los combustibles fósiles. El reto es compatibilizar el crecimiento económico con cambios en el patrón de producción y consumo de energía y así desacoplar el aumento de las emisiones del crecimiento del PIB. Esto se puede logar aumentando la participación de las fuentes de energía renovables en ámbitos como el transporte y mejorando la eficiencia de la estructura productiva y de la operación de las ciudades.

\section{La necesidad de una nueva matriz energética}

Las energías renovables son fundamentales y deben desempeñar un papel central en el cambio de la matriz energética. Sin embargo, en los últimos dos decenios su oferta en la región ha disminuido en términos relativos, con la excepción de Centroamérica (véase el recuadro V.2).

Recuadro V.2

La transición energética de Centroamérica

Para reducir su vulnerabilidad frente a los choques petroleros, los paises centroamericanos iniciaron un ciclo de expansión de las energias renovables a partir de los primeros años del presente siglo. Para ello implementaron leyes de promoción de las energias renovables (que incluian beneficios fiscales como la exoneración de los aranceles de importación para los bienes de capital y la exoneración del impuesto sobre la renta en los primeros años de operación del proyecto) y licitaciones por tecnologia que facilitaron el desarrollo de las energias renovables convencionales y no convencionales (solar y eólica). A nivel subregional, en 2007 se aprobó la Estrategia Energética Sustentable Centroamérica 2020, que incorpora una visión común de desarrollo e integración energética y metas para reducir la dependencia de los hidrocarburos, aumentar la participación de las fuentes renovables, reducir la emisión de gases de efecto invernadero, aumentar la cobertura de energía eléctrica e incrementar la eficiencia energética. A finales de 2014 se concluyó el Sistema de Interconexión Eléctrica de los Paises de América Central (SIEPAC), una inversión multinacional de alrededor de 500 millones de dólares que incluye una infraestructura de transporte eléctrico de $1.800 \mathrm{~km}$ de longitud: se extiende desde Guatemala hasta Panamá y enlaza las seis zonas metropolitanas de esos paises.

Como resultado de esas acciones, ha aumentado sostenidamente la participación de las energías renovables en el total, que en 2016 alcanzaba ya el 67\% de la producción de electricidad. Destaca el crecimiento exponencial de las energias solar y eólica, con una capacidad instalada de 1.620 megavatios (MW) y una producción de energia de 4.500 gigavatios hora (GWh) ese año (el $9 \%$ de la producción total). En Costa Rica se lograron en 2016 más de 300 dias continuos con producción totalmente renovable, por lo que estas fuentes representaron más del 98\% de su producción eléctrica (véanse los gráficos 1 y 2).

Las siguientes cifras muestran la relevancia de cada tipo de tecnologia renovable en la producción de electricidad en 2016: la energia geotérmica representó más del 26\% en El Salvador; en Nicaragua, el 17\% fue producido a partir de fuentes eólicas; los ingenios azucareros aportaron el 16\% en Guatemala, y en Honduras el 10\% fue producido con fuentes solares. Las operaciones del SIEPAC permitieron aumentar el comercio internacional de electricidad. En 2016, el volumen de transacciones internacionales (importaciones más exportaciones) alcanzó un récord cercano a los 4,6 teravatios hora (TWh); el 9\% de la energía eléctrica producida fue destinada al mercado regional.

Todos los paises han tomado medidas para impulsar la eficiencia energética, y en tres de ellos (Costa Rica, Panamá y Nicaragua) se han aprobado leyes especificas sobre este tema. Además, se han apoyado cambios en los patrones de consumo de energía y la diversificación de sus fuentes a partir de la apertura de las redes de transmisión y distribución a las energias renovables de pequeña escala (generación distribuida), asi como el uso de automóviles eléctricos y de biocombustibles. 


\section{Recuadro V.2 (conclusión)}

\section{Gráfico 1}

Centroamérica: composición de la generación de energía, 2016

(En porcentajes)

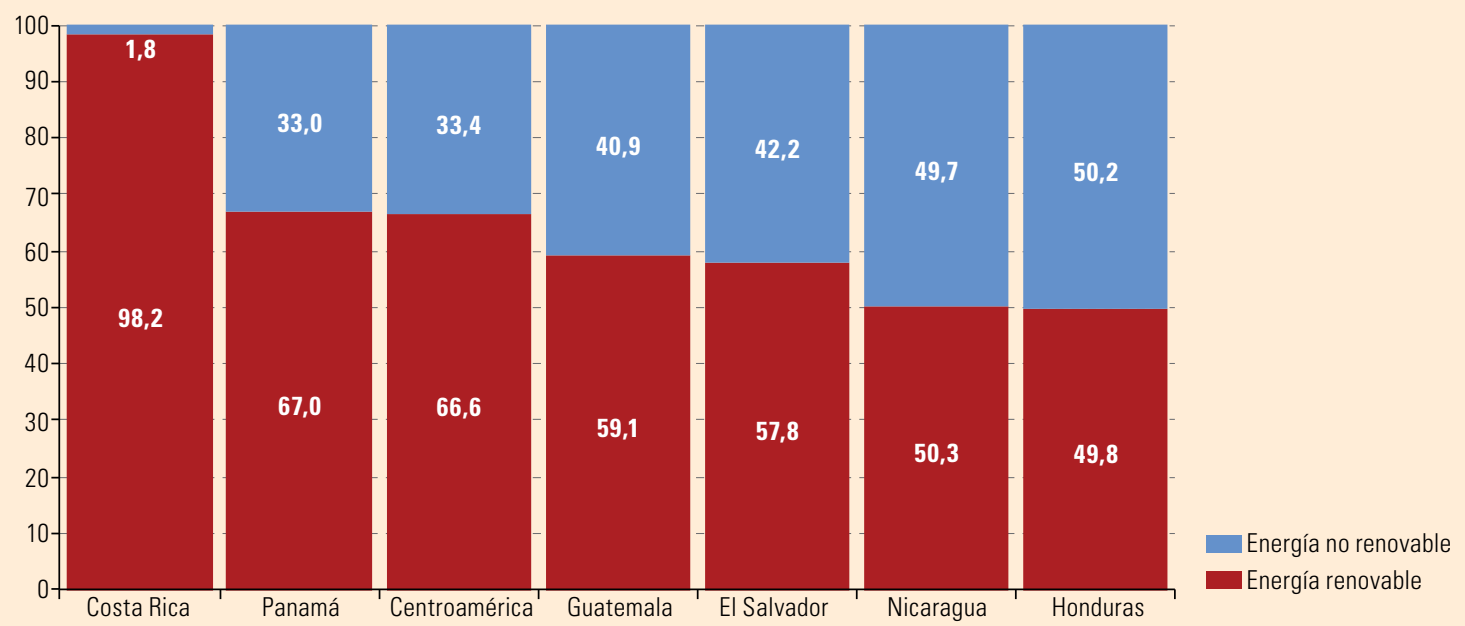

Fuente: Comisión Económica para América Latina y el Caribe (CEPAL), sobre la base de cifras oficiales.

\section{Gráfico 2}

Centroamérica: generación eléctrica a partir de las energias solar y eólica, 1995-2016 (En GWh)

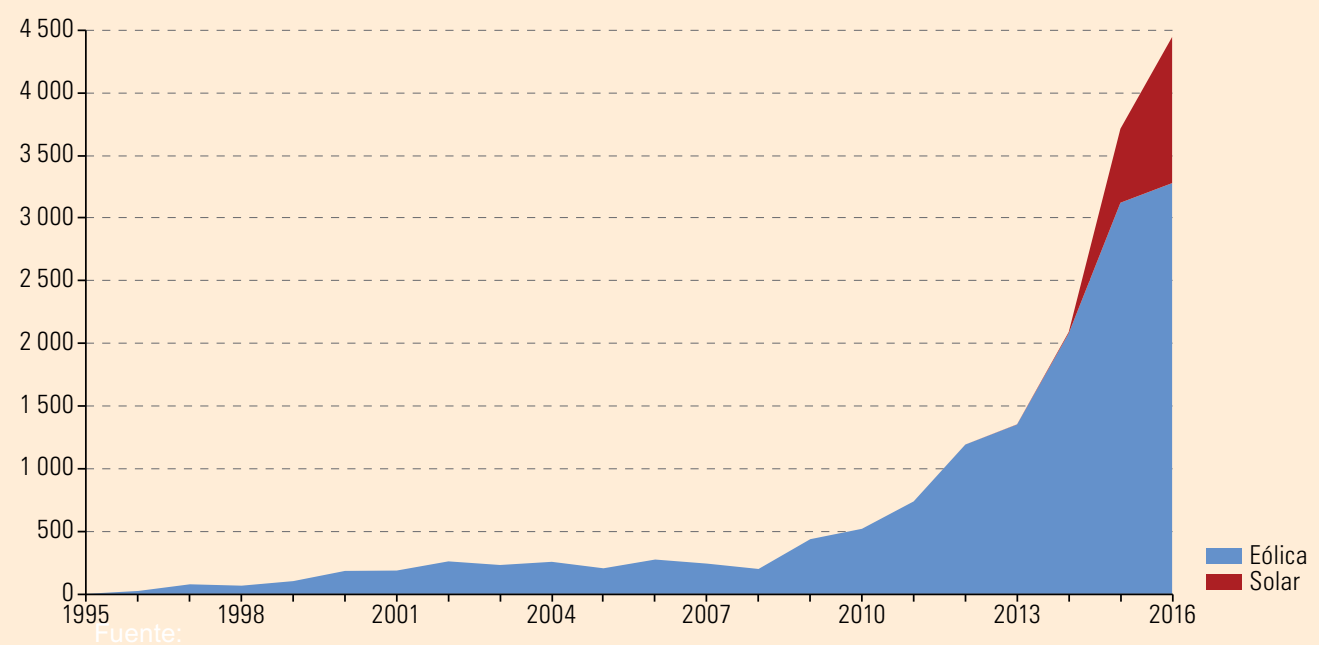

Fuente: Comisión Económica para América Latina y el Caribe (CEPAL), sobre la base de cifras oficiales.

Fuente: Comisión Económica para América Latina y el Caribe (CEPAL), sobre la base de M. Rojas Navarrete, Estadísticas del subsector eléctrico de los países del Sistema de la Integración Centroamericana (SICA), 2016 (LC/MEX/TS.2017/35), Ciudad de México, Comisión Económica para América Latina y el Caribe (CEPAL), sede subregional de la CEPAL en México, 2017. 
La oferta total de energía todavía depende en un $74 \%$ de los hidrocarburos, a pesar del enorme potencial de las fuentes renovables y su complementariedad geográfica y estacional. En términos absolutos, la generación de energía renovable creció de 77 millones de toneladas equivalentes de petróleo (MTEP) en 1971 a 209 millones en 2013, pero su participación en el total de energía primaria disminuyó de un $31 \%$ a aproximadamente un 24\% (BID, 2016a; OLADE, 2016), al contrario de lo que sería necesario para reducir su huella ambiental. Entre 1990 y 2015, la proporción renovable de la matriz energética disminuyó de un 28,9\% a un $24,9 \%$, como se observa en el gráfico V.31.

\section{Gráfico V.31}

América Latina y el Caribe: proporción renovable de la oferta energética total, 1990-2015

(En porcentajes)

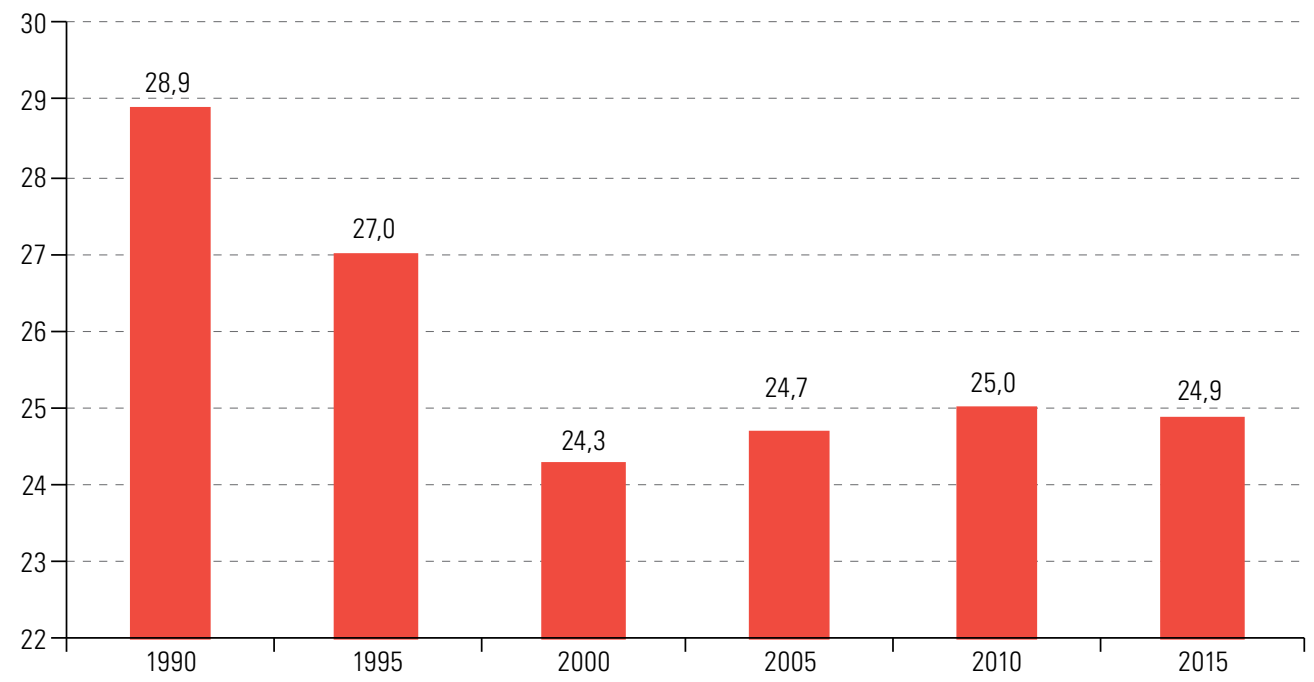

Fuente: Comisión Económica para América Latina y el Caribe (CEPAL), sobre la base de Bases de Datos y Publicaciones Estadísticas (CEPALSTAT) y Sistema de Información Económica Energética de la Organización Latinoamericana de Energía SIEE) [en línea] http://estadisticas.cepal.org/cepalstat/Portada.html; http:// www.olade.org/producto/sie-regional-2/modulo-siee/.

Nota: Incluye la oferta de las siguientes fuentes energéticas: geotermia, hidroenergía, leña cuyo uso es considerado sostenible, productos de caña y otras fuentes renovables (como las energías solar y eólica).

El desafío es de gran magnitud, ya que en la región más de 26 millones de personas (4\% de la población) aún carecen de acceso a la electricidad. Además, al menos 87 millones de personas (un 15\%) todavía emplean biomasa no sostenible - - leña y carbón vegetal- con fines de calefacción. El uso constante de esta biomasa está fuertemente asociado a menores niveles de ingresos y tiene consecuencias negativas sobre la salud, sobre todo debido a la contaminación intradomiciliaria, que afecta en mayor medida a mujeres y niños (BID, 2016a). Las emisiones de la quema de combustibles fósiles y de la producción de cemento aumentaron de 2,2 toneladas a aproximadamente 3 toneladas per cápita entre 1990 y 2015, por encima del nivel esperado para 2050. Entre 2006 y 2011 las emisiones totales se incrementaron un 14,2\% (Banco Mundial, 2015), en contraste con las metas de desarrollo y climáticas, que requieren, en primer lugar, estabilizar las emisiones y después reducirlas.

El limitado avance de las energías renovables implica la pérdida de oportunidades en la generación de ingresos y puestos de trabajo ${ }^{23}$. La energía fotovoltaica, por ejemplo, crea el doble de empleos por GWh que la generación de electricidad mediante carbón mineral o gas natural: la estimación más conservadora es de

23 Según la Agencia Internacional de Energías Renovables (IRENA) (2016b), la duplicación de la oferta de energías renovables en la matriz de México y el Brasil de aquí a 2030 aumentaría su PIB más de un 1\%. En 2015, más de dos millones de personas trabajaban en el sector de las energías renovables en la región; en el Brasil, la energía eólica generaba 41.000 empleos, lo que corresponde al 64\% de los empleos en energía eólica de la región. Solo en 2016 esta energía generó más de 30.000 empleos (ABEEÓLICA, 2017b). Las proyecciones de NRDC/ACERA (2013) sugieren que si se supliera el 20\% de la electricidad de Chile con energía proveniente de fuentes renovables se podría generar un aumento del 0,6\% del PIB y 7.800 empleos. PwC (2015) estima que el desarrollo de 21 GW de energía proveniente de fuentes renovables en México en 2029 podría generar un efecto acumulativo en el PIB de 27.000 millones de dólares (2\% del PIB de 2013) y crear 134.000 empleos. Todas las fuentes de energía renovables combinadas podrían generar 182.000 empleos en México en 2029 (PwC, 2015). El Brasil ya tiene aproximadamente 1 millón de empleados en el sector de los biocombustibles líquidos (etanol) (IRENA, 2016a). 
0,4 empleos por GWh, mientras que la mejor estimación para los combustibles fósiles es de 0,2 empleos por GWh (UKERC, 2014). Según datos de la Agencia Internacional de Energías Renovables (IRENA, 2016b), el 46\% del suministro total de energía primaria de la región proviene del petróleo; dado que esa variable representa solo el $31 \%$ del total en el resto del mundo, hay espacio para cambiar la matriz hacia las energías provenientes de fuentes renovables y aprovechar sus oportunidades para la expansión del ingreso y del empleo. La misma fuente contabiliza más de 8,1 millones de empleos en el sector de las energías renovables en el mundo. Según la OIT (2016a), en el Brasil, 2,9 millones de personas están contratadas en sectores con bajas emisiones de carbono, lo que equivale a un 6,6\% del mercado de empleo formal. En México existen 1,8 millones de empleos directos relacionados con las bajas emisiones, lo que representaba un 4,4\% de la población ocupada en 2011 (OIT, 2013)24. En 2013 había en el Uruguay 44.108 empleos verdes, que representaban el 2,72\% de la mano de obra ocupada (OIT, 2016b).

\section{La presencia del carbono en la matriz eléctrica disminuye lentamente}

En la Agenda 2030 para el Desarrollo Sostenible y el Acuerdo de París se requiere un porcentaje creciente de fuentes renovables en la matriz energética. De acuerdo con IRENA (2016d), la inversión anual mundial en generación de energías renovables aumentó de 50.000 millones de dólares en 2004 a 360.000 millones de dólares en 2015, y un $85 \%$ de esas inversiones se realizaron en países del Grupo de los 20 (G20). En la proyección de inversiones para 2020 (IRENA, 2015), la participación de la región es de alrededor del 6\% (21.000 millones de dólares). La baja participación de las energías renovables en la región muestra que existe aún amplio espacio para desarrollar el cambio estructural necesario.

En la matriz eléctrica de América del Sur, por ejemplo, se anticipa un incremento de las inversiones en energías renovables no convencionales, principalmente la eólica y la solar (CAF, 2016b), cuya participación en el total de inversiones aumentaría del 5,3\% en 2016 a más del 37\% en 2030 (véase el gráfico V.32). Ese aumento apenas permitiría llegar hasta una potencia instalada (la capacidad de energía que puede generar y proveer una central eléctrica en condiciones ideales) equivalente a cerca del 7,6\% de la matriz eléctrica en 2030 en comparación con el actual 3,9\%. La generación efectiva (el rendimiento real con que operan las plantas generadoras), llegaría en 2030 al 5,3\% de la matriz eléctrica del 2,9\% que se registraba en 2015 (véase el gráfico V.33).

\section{Gráfico V.32}

América del Sur: distribución de las inversiones en la matriz eléctrica según las fuentes de generación, 2016 y 2030 (En porcentajes)

\section{A. Distribución de las inversiones en proceso en 2016}

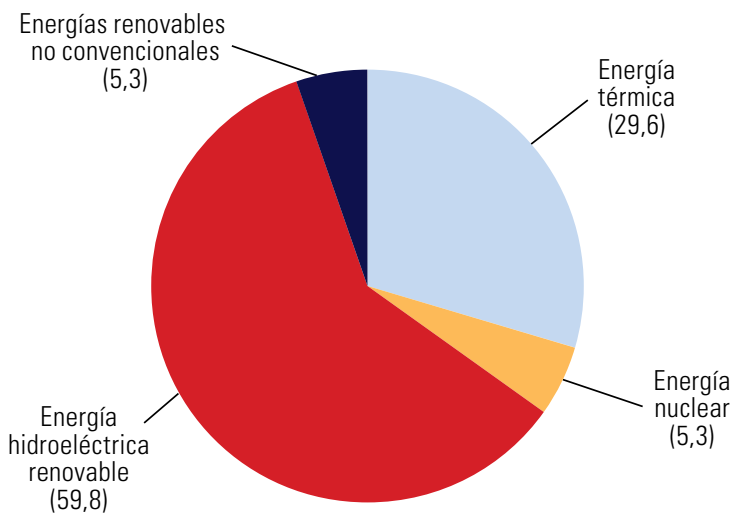

B. Distribución de las inversiones anticipada para 2030

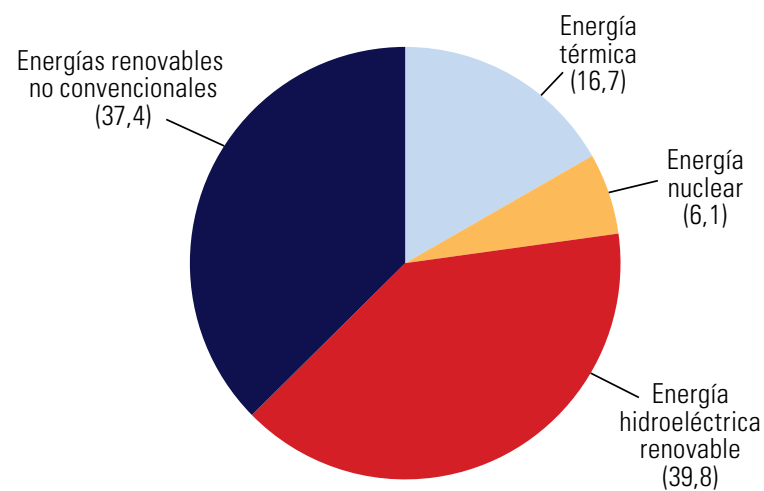

Fuente: Comisión Económica para América Latina y el Caribe (CEPAL), sobre la base de Banco de Desarrollo de América Latina (CAF), “Proyectos Estratégicos para Seguridad Energética Regional (PRESER)", Caracas, 2016.

24 Los sectores con mayor porcentaje de empleos verdes en ese país son: el reciclaje de residuos (12\%), la construcción sostenible (11\%), la energía eléctrica renovable (9\%), el aprovechamiento forestal y la reforestación (8\%), la industria limpia $(7 \%)$ y la agricultura orgánica (6\%). 


\section{Gráfico V.33}

América del Sur: potencia instalada y generación efectiva de las energías renovables no convencionales como parte de la matriz eléctrica, 2015 y 2030

(En porcentajes)

\section{A. Potencia instalada, 2015}

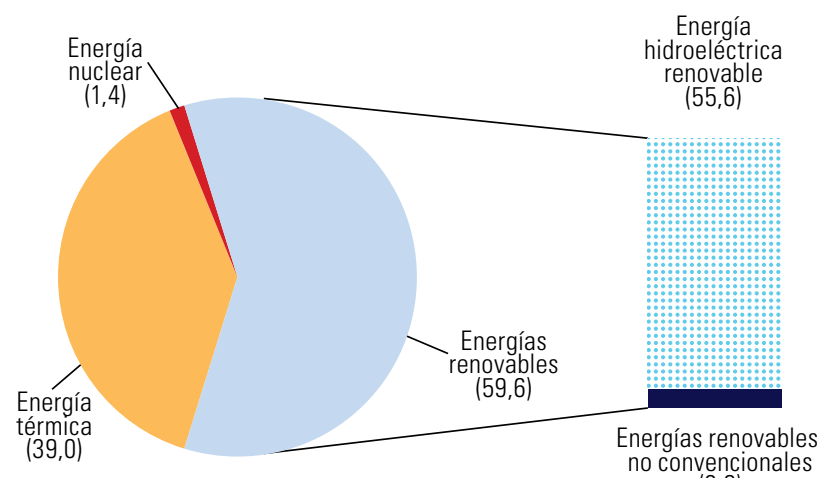

$(3,9)$

\section{B. Potencia instalada, 2030}

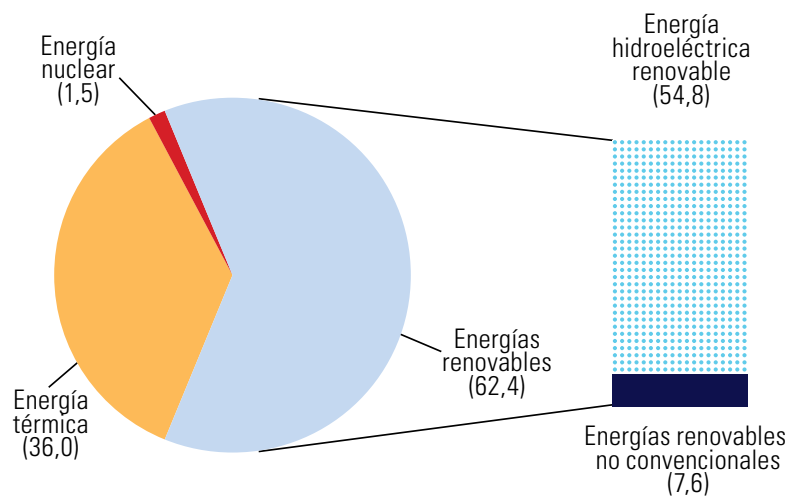

D. Generación efectiva, 2030

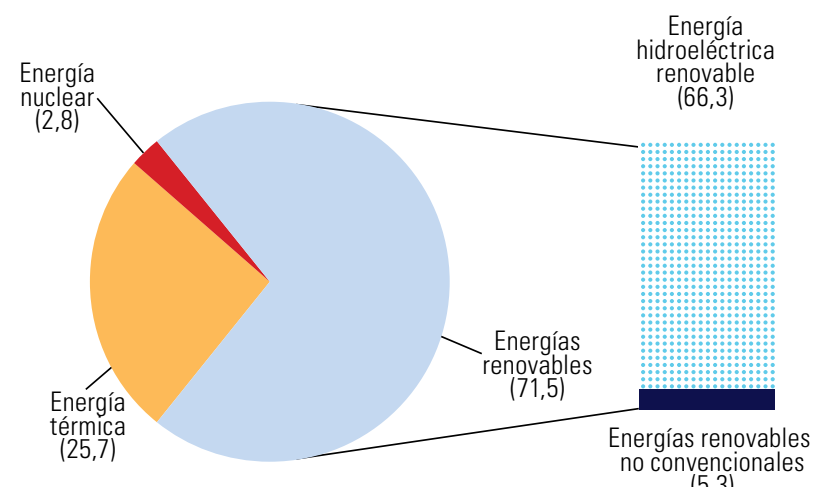

$(5,3)$

Fuente: Comisión Económica para América Latina y el Caribe (CEPAL), sobre la base de Banco de Desarrollo de América Latina (CAF) "Proyectos Estratégicos para Seguridad Energética Regional (PRESER)", Caracas, 2016b.

Los patrones de inversión actuales y proyectados son insuficientes para producir un cambio profundo en la estructura energética de la región. De hecho, entre 2014 y 2016 se produjo un considerable y preocupante descenso de las inversiones en energías renovables (véase el gráfico V.34).

Los factores que explican la escasa penetración de las energías renovables en la región son la falta de compromisos formales de reducción de gases con efecto invernadero por parte de los países, la ralentización de la economía mundial, la significativa volatilidad del precio del petróleo y la inercia de las políticas regulatoria y fiscal.

Para avanzar en estos campos son necesarias políticas orientadas a promover nuevos proyectos de eficiencia energética, como sistemas para almacenar los grandes volúmenes de energía producidos de manera intermitente por las fuentes renovables, aprovechando los abundantes recursos naturales de la región (agua y litio) y generando encadenamientos productivos ligados a su producción y aplicaciones tecnológicas. La situación actual es incongruente con el enorme potencial de energía renovable eólica y solar que existe en la mayoría de los países. El margen para aumentar la penetración de estas fuentes es enorme. 


\section{Gráfico V.34}

América Latina y Caribe: inversiones en energías renovables, 2004-2016

(En miles de millones de dólares)

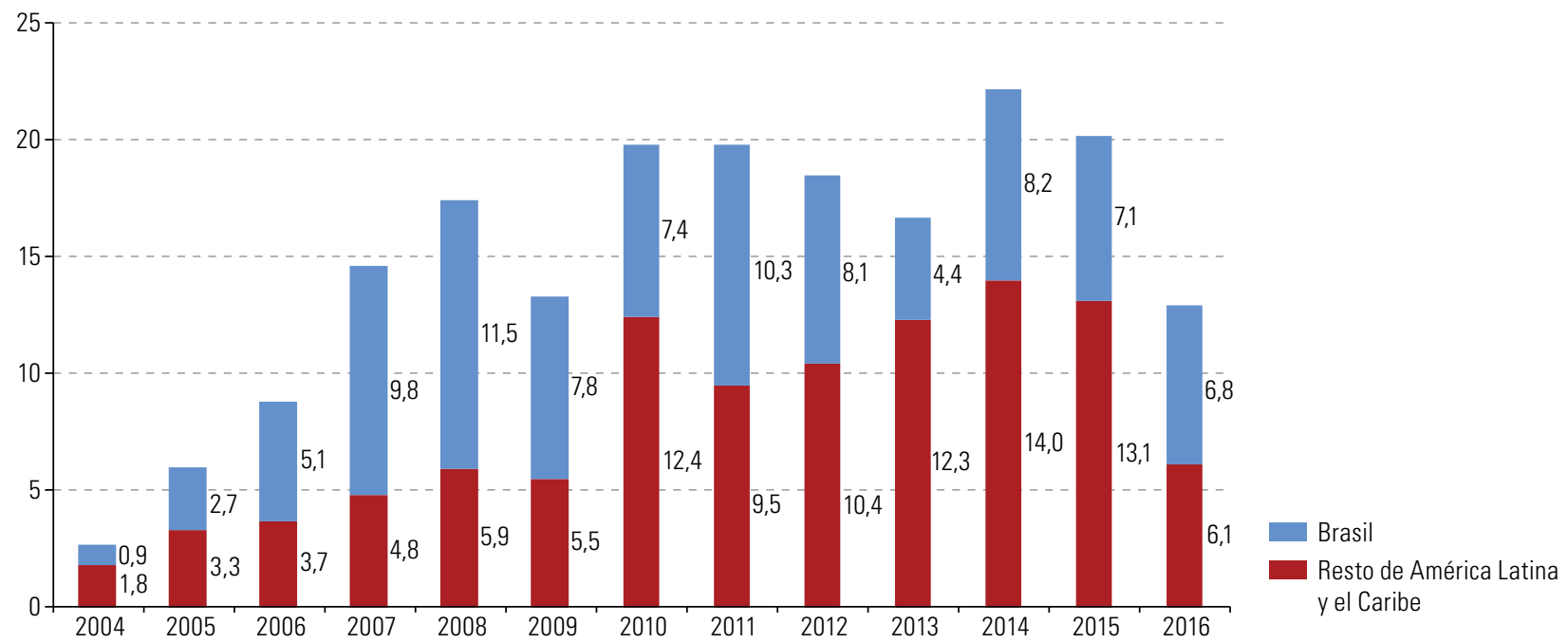

Fuente: Agencia Internacional de Energías Renovables (IRENA), "Featured Dashboard" [en línea] http://resourceirena.irena.org/gateway/dashboard/?topic=6\&subTopic=11, 2017.

\section{Complementariedad e integración entre las energías renovables}

La generación hidroeléctrica es vulnerable a los fenómenos climáticos como El Niño, La Niña o la desecación. Dada la creciente oposición a la construcción de embalses, fuente de importantes conflictos socioambientales, al igual que la minería, es necesario que los procesos de licenciamiento sean más transparentes y participativos. En cambio, los proyectos que aprovechan energías renovables como la eólica y la solar son más pequeños ${ }^{25}$, están geográficamente dispersos, tienen menos implicaciones ambientales y, por tanto, enfrentan menores barreras en cuanto a los permisos ambientales. Además, su período de construcción (18 a 24 meses) es menor que los 5 a 7 años que se necesitan en promedio para completar un proyecto hidroeléctrico, y son soluciones atractivas para llevar la electricidad a comunidades aisladas.

Los abundantes recursos energéticos renovables de la región (agua, viento y sol) pueden ser complementarios geográfica y estacionalmente (véanse los mapas V.3 y V.4). Por ejemplo, el caudal del río San Francisco, principal fuente de producción hidroeléctrica del nordeste del Brasil, se reduce durante el verano, estación en la que aumenta la velocidad del viento ${ }^{26}$. En este sentido, la complementación entre los países y dentro de estos podría conducir a procesos técnicos y políticos virtuosos para la integración energética regional. Este cambio de paradigma es una oportunidad para que los reguladores anticipen las innovaciones del sistema eléctrico.

25 Si se comparan con proyectos hidroeléctricos grandes como Belo Monte (11.233 MW) en el Brasil o Ituango (2.400 MW) en Colombia, o con proyectos potenciales como HidroAysén en Chile (2.000 MW).

26 Según Vergara y otros (2013), el Banco Mundial analizó esta complementariedad en Colombia y encontró que la energía eólica está disponible durante los períodos de sequía, cuando su contribución al sistema es más necesaria y cuando la demanda alcanza su punto máximo. 
Mapa V.3

América Latina y el Caribe: potencial eólico, 2005

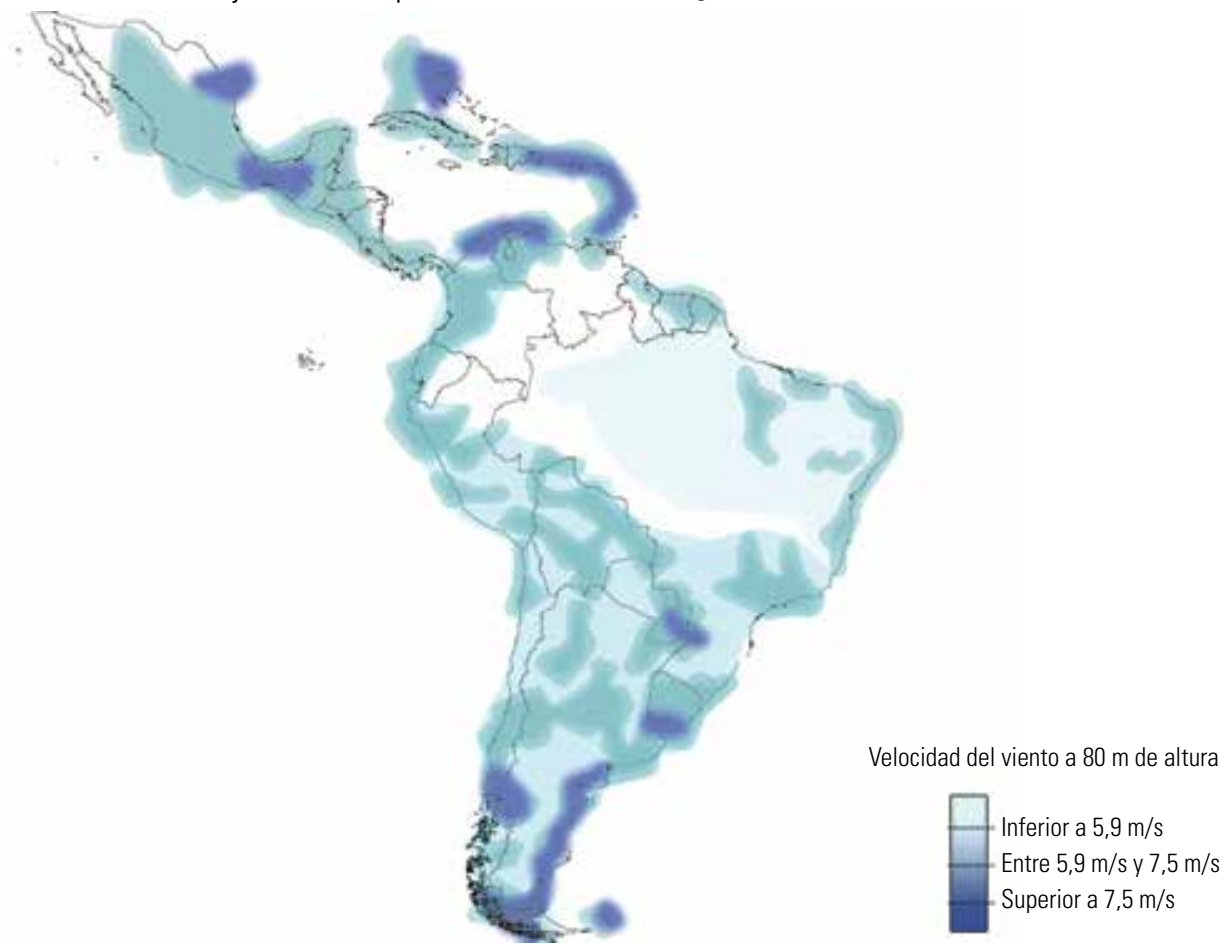

Fuente: Comisión Económica para América Latina y el Caribe (CEPAL), sobre la base de Journal of Geophysical Research: Biogeosciences, vol. 110, 2005 y SolarGis [base de datos en línea] https://solargis.com/.

Nota: Los límites y los nombres que figuran en este mapa no implican su apoyo o aceptación oficial por las Naciones Unidas.

Mapa V.4

América Latina y el Caribe: potencial solar, 2009-2013

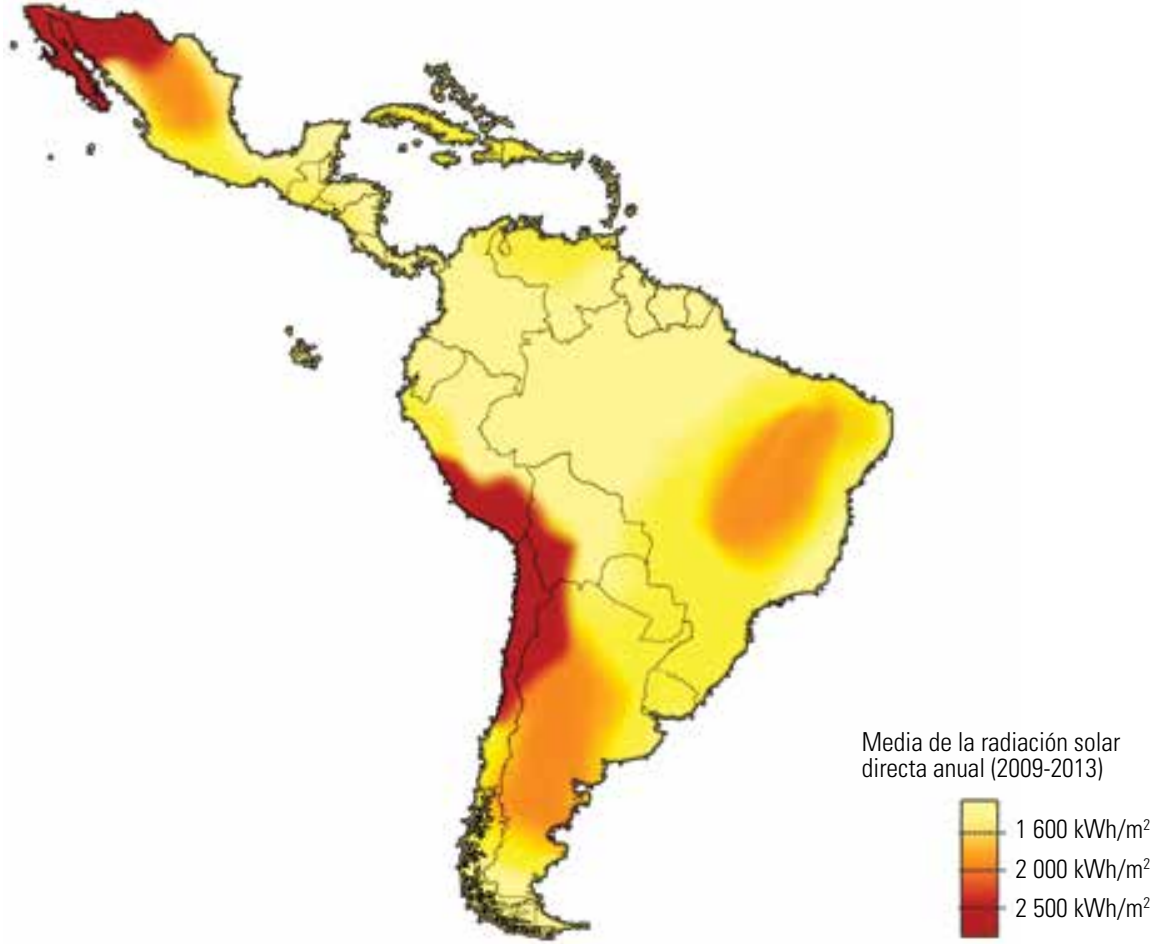

Fuente: Comisión Económica para América Latina y el Caribe (CEPAL), sobre la base de Journal of Geophysical Research: Biogeosciences, vol. 110, 2005 y SolarGis [base de datos en línea] https://solargis.com/.

Nota: Los límites y los nombres que figuran en este mapa no implican su apoyo o aceptación oficial por las Naciones Unidas. 
Tras casi un decenio de ausencia, la complementación energética ha vuelto a la mesa de discusión, especialmente en América del Sur, debido a la volatilidad del precio del petróleo; el descubrimiento de grandes yacimientos de gas de esquisto (particularmente en la Argentina, el Brasil, Colombia y México); el incremento de la oferta de energías renovables (principalmente eólica y solar) en la Argentina, el Brasil, Chile, México y el Uruguay, al igual que en Centroamérica; la expectativa de crecimiento de la demanda energética; los obstáculos a la aprobación de proyectos hidroeléctricos grandes y medianos, y el rol de la eficiencia energética a la hora de combatir el cambio climático. El Acuerdo de París hace hincapié en el papel de esas energías en el cumplimiento de las contribuciones determinadas a nivel nacional de cara a la descarbonización de las economías. La Agenda 2030, en sus Objetivos de Desarrollo Sostenible relacionados con la energía (ODS 7) y el cambio climático (ODS 13), contiene ambiciosas metas en materia de energías renovables, eficiencia energética, acceso a fuentes de energías modernas y cooperación internacional sectorial. La energía, como recurso estratégico y con connotación geopolítica, puede ser una fuerza importante en favor de la integración regional.

\section{E. Las bases de una estructura de baja eficiencia productiva y energética}

En los capítulos anteriores se analizó el impacto de la desigualdad en la productividad y la construcción de capacidades de las economías latinoamericanas. En este capítulo se trataron sus efectos en el territorio, la infraestructura, las ciudades y el medio ambiente. En estos cuatro niveles se reproduce un patrón en que la elevada concentración de ingresos y capacidades lleva a una escasa difusión de tecnología y a costos elevados en términos de horas de trabajo, salud de las personas, consumo de energía y destrucción de los recursos naturales.

De continuar el actual estilo de desarrollo, una aceleración del crecimiento mundial implicaría sobrepasar los límites ambientales del planeta. Las externalidades negativas asociadas a ese estilo deterioran el bienestar de las generaciones presentes, sobre todo de los más pobres, y desafían la igualdad intergeneracional, ya que los intereses de las próximas generaciones en preservar el ambiente no están representados en las políticas públicas. Por ello, la Agenda 2030 para el Desarrollo Sostenible va más allá de la simple integración de políticas sociales, económicas y ambientales, y debe interpretarse como un nuevo estilo de desarrollo y crecimiento con los consiguientes nuevos patrones de producción y consumo.

En la región se ha creado una situación de desigualdad y baja eficiencia productiva y ambiental, cuyas características se resumen en el diagrama V. ${ }^{27}$. Entre los bloques del diagrama existen múltiples interconexiones, de las que se muestran las dos más importantes. La primera tiene como centro la desigualdad: una estructura productiva poco diversificada, con fuerte dependencia de los recursos naturales y muy vulnerable a los choques externos refuerza la desigualdad al crear insuficientes empleos de calidad, a lo que se añade la desigualdad educativa y de oportunidades que reduce las capacidades y la innovación.

La revolución tecnológica tiene también un papel central, pero sus efectos van en una sola dirección, ya que es fundamentalmente exógena a las economías de la región. Esta revolución tendrá un fuerte impacto en los patrones de especialización y en las posibilidades de transitar por una senda baja en carbono, por lo que es necesario que los países de la región internalicen capacidades para difundir el progreso técnico, innovar y reducir la brecha con el mundo desarrollado y así romper el cerrojo tecnológico, productivo y ambiental.

En ese marco, las cuatro dimensiones estudiadas en este capítulo componen una estructura de baja eficiencia energética y productiva. Si bien la desigualdad y la dinámica tecnológica influyen en gran medida en la inercia del modelo, son también reflejo de una configuración política que hace difícil cambiar su trayectoria. En el siguiente capítulo se trata dicha configuración y la forma en que se expresa en los planos institucional y cultural. Un ejemplo de esta expresión es el comportamiento de los patrones de inversión pública y privada en infraestructura que refuerzan las distorsiones históricas. La inversión en energía y transporte en las grandes ciudades y los territorios más desarrollados mantiene las desigualdades y refuerza el modelo de insuficiente conexión entre los países, así como entre las regiones periféricas y las más avanzadas de cada país. Este patrón es incompatible con el desarrollo sostenible; es causa y resultado de la persistencia de la desigualdad.

27 El contenido de cada cuadro del diagrama se discute en profundidad en los respectivos capítulos. 


\section{Diagrama V.1}

América Latina y el Caribe: focos de reproducción del efecto cerrojo (lock-in) de un equilibrio de bajo dinamismo

\author{
Estructura productiva \\ Rezago tecnológico, poco peso de actividades \\ con alto componente de investigación y desarrollo. \\ Exportación de recursos naturales y manufacturas \\ con poco valor agregado. \\ Vulnerabilidad externa e inestabilidad \\ del crecimiento. \\ Poca intensidad y duración \\ del auge del ciclo.
}

\section{Eficiencia productiva}

Bajo nivel y lento crecimiento de la productividad. Brechas de acceso y bloqueo de trayectorias de aprendizaje.

Límites a la inversión y a los retornos crecientes entre inversión, crecimiento y productividad (al estilo Kaldor-Schumpeter).

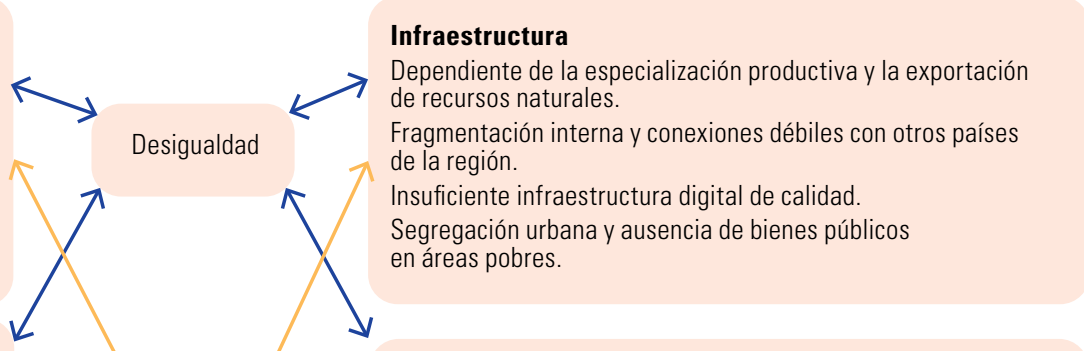

\section{Eficiencia ambiental}

Destrucción y pérdida de productividad del capital natural. Matriz energética basada en combustibles fósiles. Concentración en los modos de transporte más contaminantes y costosos.

Pérdida de tiempo de trabajo y de bienestar en las grandes ciudades.

Costos nacionales y regionales del cambio climático global.

Mal manejo de residuos.

Fuente: Comisión Económica para América Latina y el Caribe (CEPAL).

\section{Bibliografía}

ABEEólica (Asociación Brasileña de Energía Eólica) (2017a), “Dados mensais. Fevereiro de 2017", São Paulo.

(2017b), "Brasil sobe no ranking mundial de capacidade instalada de energia eólica" [en línea] http://www.abeeolica. org.br/noticias/brasil-sobe-no-ranking-mundial-de-capacidade-instalada-de-energia-eolica/.

Agrawala, S. y otros (2010), "Plan or react?: analysis of adaptation costs and benefits using integrated assessment models", OECD Environment Working Papers, vol. 23, № 23.

AIE (Agencia Internacional de la Energía) (2016), Key World Energy Statistics, París.

Angel, S. y otros (2012), Atlas of Urban Expansion, Cambridge, Massachusetts, Lincoln Institute of Land Policy, junio.

ANTP (Asociación Nacional de Transportes Públicos) 2015), "Sistema de Mobilidade Urbana. Relatório 2014", São Paulo [en línea] http://www.antp.org.br/sistema-de-informacoes-da-mobilidade/apresentacao.html.

Aprosoja Brasil (2016), "Produtividade da soja é a mesma há 15 anos" [en línea] http://www.projetosojabrasil.com.br/ produtividade-da-soja-e-a-mesma-ha-15-anos/.

Arthur, B. (1994), Increasing Returns and Path-Dependency in Economics, Ann Arbor, Michigan University Press.

Banco Mundial (2017), "World Development Indicators" [en línea] http://data.worldbank.org/data-catalog/world-developmentindicators.

(2015), "World Bank Open Data" [base de datos en línea] http://data.worldbank.

(2010a), Natural Hazards, UnNatural Disasters: The Economics of Effective Prevention, Washington, D.C.

(2010b), "The cost to developing countries of adapting to climate change. New methods and estimates", Working Paper, N ${ }^{\circ} 55726$, Washington, D.C.

Banco Mundial y otros (2016), "Notas de discusión de políticas: integración regional en el contexto de la desaceleración económica", Documento presentado en la Octava Reunión de Ministros de Hacienda de América y el Caribe, Washington, D.C., 5 de octubre.

Bárcena, A. y A. Prado (2016), El imperativo de la igualdad: por un desarrollo sostenible en América Latina y el Caribe, Buenos Aires, Comisión Económica para América Latina y el Caribe (CEPAL)/Siglo XXI.

BCC Research (2015), Global Markets for Environmental Remediation Technologies.

Berger, R. (2014), Informe sobre el mercado de las tecnologías ambientales a nivel mundial [en línea] http://www. forumambiental.org/pdf/Greentech2014.pdf.

BID (Banco Interamericano de Desarrollo) (2016a), “¿Luces encendidas? Necesidades de energía para América Latina y el Caribe al 2040", Monografía del BID, № 378, Washington, D.C. [en línea] https://publications.iadb.org/ handle/11319/7361 ? locale-attribute=es\&. 
(2016b), “Carreteras y capital natural: gestión de las dependencias y de los efectos sobre los servicios ecosistémicos para inversiones sostenibles en infraestructura vial," Monografía del BID, N 476, Washington, D.C.

Biggs, R., M. Schlüter y M. Schoon (2015), Principles for Building Resilience: Sustaining Ecosystem Services in SocialEcological Systems, Cambridge, Cambridge University Press.

BNDES (Banco Nacional para el Desarrollo Económico y Social del Brasil) (2016), "O desenrolar da energia eólica no Brasil", Río de Janeiro [en línea] http://www.bndes.gov.br/wps/portal/site/home/conhecimento/noticias/noticia/energia-eolica-brasil. (2015), "Fundo Clima - energias renováveis", Río de Janeiro [en línea] https://www.bndes.gov.br/wps/portal/site/home/ financiamento/produto/fundo-clima-energias-renovaveis.

Brakman, S. H. Garretsen y C. van Marrewijk (2011), The New Introduction to Geographical Economics, Cambridge University Press.

Brasil (2017), "Percentual obrigatório de biodiesel no óleo diesel passa para 8\%", Brasília [en línea] http://www.brasil.gov. br/economia-e-emprego/2017/03/percentual-obrigatorio-de-biodiesel-no-oleo-diesel-passa-para-8.

CAF (Banco de Desarrollo de América Latina) (2016a), "Observatorio de Movilidad Urbana” [en línea] http://www.caf.com/ es/temas/o/observatorio-de-movilidad-urbana/bases-de-datos.

(2016b), "Proyectos Estratégicos para Seguridad Energética Regional (PRESER)," Caracas.

(2009), Observatorio de Movilidad Urbana para América Latina: información para mejores políticas y mejores ciudades, Río de Janeiro.

Caldeira, T. (2000), Cidade de muros: crime segregação e cidadania em São Paulo, São Paulo, Editora de Universidade de São Paulo.

Calderón, C. y L. Servén (2010), “Infrastructure in Latin America”, World Bank Policy Research Working Paper, N 5317 , Washington, D.C., Banco Mundial.

Cámara de Comercio de Bogotá (2016), “Taller sobre Cosméticos e ingredientes naturales: mercado, tendencias y pasos para ser una empresa de biocomercio ético" [en línea] https://www.ccb.org.co/Clusters/Cluster-de-Cosmeticos/ Noticias/2016/Octubre/Pasos-para-ser-una-empresa-de-biocomercio-etico.

CMNUCC (Convención Marco de las Naciones Unidas sobre el Cambio Climático) (2015), Adoption of the Paris Agreement (FCCC/CP/2015/L.9/Rev.1), París, diciembre [en línea] https://unfccc.int/resource/docs/2015/cop21/eng/l09r01.pdf. (2007), Vulnerability and adaptation to climate change in small island developing States [en línea] http://unfccc.int/ files/adaptation/adverse_effects_and_response_measures_art_48/application/pdf/200702_sids_adaptation_bg.pdf.

CEPAL (Comisión Económica para América Latina y el Caribe) (2017a), "Panorama multidimensional del desarrollo urbano en América Latina y el Caribe", Documentos de Proyectos (LC/TS.2017/67), Santiago.

(2017b), "Panorama del desarrollo territorial de América Latina y el Caribe", Documentos de Proyectos (LCM.671). Santiago.

(2017c), Perspectivas del Comercio Internacional de América Latina y el Caribe (LC/PUB.2017/22-P), Santiago.

(2017d), La economía del cambio climático en América Latina y el Caribe: una visión gráfica (LC/TS.2017/84/Rev.1), Santiago, diciembre.

(2016a), Horizontes 2030: la igualdad en el centro del desarrollo sostenible, (LC/G.2660/Rev.1), Santiago.

(2016b), Agenda 2030 y los Objetivos de Desarrollo Sostenible: una oportunidad para América Latina y el Caribe (LC/G.2681/Rev.2), Santiago, abril.

(2016c), Anuario Estadístico de América Latina y el Caribe 2016 (LC/PUB.2017/2-P), Santiago.

(2016d), "Territorio e igualdad. Planificación del desarrollo con perspectiva de género", Manuales de la CEPAL, N 4 (LC/L.4237), Santiago, octubre.

(2016e), CEPALSTAT [base de datos en línea] http://estadisticas.CEPAL.org/CEPALstat/web_CEPALstat/Portada. asp?idioma $=\mathrm{i}$.

(2015a), La economía del cambio climático en América Latina y el Caribe: paradojas y desafíos del desarrollo sostenible (LC/G.2624) Santiago, febrero.

(2015b), Anuario Estadístico de América Latina y el Caribe, 2015 (LC/G.2656-P), Santiago.

(2015c), Panorama Social de América Latina, 2015 (LC/G.2691-P), Santiago, octubre.

(2014a), Pactos para la igualdad: hacia un futuro sostenible (LC/G.2586 (SES.35/3)), Santiago.

(2014b), Panorama Social de América Latina, 2014 (LC/G.2635-P), Santiago.

(2014c), La economía del cambio climático en América Latina y el Caribe: paradojas y desafíos. Síntesis 2014 (LC/L.3895), Santiago, diciembre.

(2012), Cambio estructural para la igualdad: una visión integrada del desarrollo (LC/G.2524(SES.34/3)), Santiago, julio. (2010), La hora de la igualdad: brechas por cerrar caminos por abrir (LC/G.2432(SES.33/3)), Santiago. 
CEPAL/FAO/IICA (Comisión Económica para América Latina y el Caribe/Organización de las Naciones Unidas para la Alimentación y la Agricultura/Instituto Interamericano de Cooperación para la Agricultura) (2017), "La bioeconomía: oportunidades y desafíos para el desarrollo rural, agrícola y agroindustrial en América Latina y el Caribe", Boletín CEPALFAO-I/CA [en línea] http://repositorio.cepal.org/bitstream/handle/11362/42724/1/S1701068_es.pdf.

CETESB (Compañía de Tecnología de Saneamiento Ambiental) (2014), Plano de Controle de Poluição Veicular 2014-2016, São Paulo.

Cimoli, M., G. Porcile y S. Rovira (2010), "Structural change and the BOP-constraint: why did Latin America fail to converge?", Cambridge Journal of Economics, vol. 34, N 2.

Comisión Europea (2016), Trends in Global CO2 Emissions: 2016 Report [en línea] http://edgar.jrc.ec.europa.eu/news_docs/ jrc-2016-trends-in-global-co2-emissions-2016-report-103425.pdf.

(2015), World Atlas of Desertification (WAD) [en línea] http://wad.jrc.ec.europa.eu/.

(2014), Construir una infraestructura verde para Europa [en línea] http://ec.europa.eu/environment/nature/ecosystems/ docs/GI-Brochure-210x210-ES-web.pdf.

(2012), Innovating for Sustainable Growth: a Bioeconomy for Europe, Directorate-General for Research and Innovation.

Comisión Permanente de Transporte de la Cuenca del Plata (2015), “Hidrovía Paraná Paraguay: camino clave para el desarrollo de la región" [en línea] http://www.agroindustria.gob.ar/sitio/areas/ss_mercados_agropecuarios/jornadas_ congresos/_archivos/000101_2017/000100_Infraestructura\%20y\%20Log\%C3\%ADstica/000104_Hidrov\%C3\%ADa\%20 Paran\%C3\%A1\%20Paraguay.pdf.

CONABIO (Comisión Nacional para el Conocimiento y Uso de la Biodiversidad de México) (s/f), "Centros de plantas cultivadas" [en línea] http://www.biodiversidad.gob.mx/genes/centrosOrigen/centrosPlantas1a.html.

Crutzen, P. J. (2002), "Geology of mankind: the Anthropocene", Nature, vol. 415, № 23.

Cuervo, L. M. (2004), "Desarrollo económico y primacía urbana en América Latina: una visión histórica comparativa", El rostro urbano de América Latina, A. Ribeiro (ed), Buenos Aires Consejo Latinoamericano de Ciencias Sociales (CLACSO).

De Mattos, C. (1988), "Los procesos de concentración territorial del capital en la formación de los sistemas nacionales latinoamericanos. Versión preliminar," Santiago, Instituto Latinoamericano y del Caribe de Planificación Económica y Social (ILPES) [en línea] http://repositorio.cepal.org/bitstream/handle/11362/33304/S8800602_es.pdf.

EIA (Administración de Información Energética) (2017), Levelized Cost and Levelized Avoided Cost of New Generation Resources in the Annual Energy Outlook 2017 [en línea] https://www.eia.gov/outlooks/aeo/pdf/electricity_generation.pdf.

EIU/BID (Economist Intelligence Unit/Banco Interamericano de Desarrollo) (2017), Avances y desafíos para el reciclaje inclusivo: evaluación de 12 ciudades de América Latina y el Caribe, Nueva York.

El Diario (2015), "El tren de alta velocidad Río-Sao Paulo dejó de ser una prioridad para Brasil," junio [en línea] http://www. eldiario.es/economia/velocidad-Rio-Sao-Paulo-prioridad-Brasil_0_396861565.html.

ELD Initiative (2015), The Value of Land: Prosperous Lands and Positive Rewards through Sustainable Land Management, Bonn.

Eletrobras (2016), Relatório Anual 2016 [en línea] http://eletrobras.com/pt/SobreaEletrobras/Relatorio_Anual_Sustentabilidade/2016/ Relatorio-Anual-Eletrobras-2016.pdf.

EMBRAPA (Empresa Brasileña de Investigación Agropecuaria) (2017), “Soja em números (safra 2016/2017)," Londrina [en línea] https://www.embrapa.br/web/portal/soja/cultivos/soja1/dados-economicos.

EM-DAT (The International Disaster Database) (2016) [en línea] http://www.emdat.be/.

Enerdata (2015), Research on Energy Efficiency, CO2 Emissions, Energy Consumption, Forecast.

EPE (Empresa de Pesquisa Energética) (2016), Energia termelétrica: gás natural, biomassa, carvão, nuclear, M. T. Tolmasquim (coord), Rio de Janeiro.

FAO (Organización de las Naciones Unidas para la Alimentación y la Agricultura) (2017a), "Alimentación y agricultura sostenibles" [en línea] www.fao.org/sustainability/es.

(2017b), base de datos FAOSTAT [en línea] www.faostat.fao.org.

(2015), Global Forest Resources Assessment 2015: Desk reference [en línea] http://www.fao. org/3/a-i4808e.pdf.

Fernandes, E. (2007), "Constructing the 'Right to the City' in Brazil," Social \& Legal Studies, vol. 16, № 2.

Ferrario, F. y otros (2014), "The effectiveness of coral reefs for coastal hazard risk reduction and adaptation", Nature Communications, vol. 5, №3794.

FIDA (Fondo Internacional de Desarrollo Agrícola) (2010), "Desertification", Roma.

FMI (Fondo Monetario Internacional) (2015), "From ambition to execution: policies in support of sustainable development goals", IMF Staff Discussion Note, NN IMF/15/18.

Folk, C., C. R. Carpenter y B. H. Walker (2010), "Resilience thinking: integrating resilience, adaptability and transformability", Ecology and Society, vol. 15, № 20.

Freeman, C. (2008), Systems of Innovation: Selected Essays in Evolutionary Economics, Cheltenham, Elgar. 
García Alonso, L. (2017), "Aspectos metodológicos en el vínculo entre recursos naturales y logística regional", Documento de Proyecto (LC/TS.2017/21), Santiago, Comisión Económica para América Latina y el Caribe (CEPAL).

Golden, J. S. y otros (2015), An Economic Impact Analysis of the U.S. Biobased Products Industry: A Report to the Congress of the United States of America, Duke Center for Sustainability \& Commerce/Supply Chain Resource Cooperative, North Carolina State University.

Green, J. y S. Sánchez (2012), Air Quality in Latin America: An Overview, Washington, D.C., Clean Air Institute [en línea] http://www.cleanairinstitute.org/ calidaddelaireamericalatina/cai-report-english.pdf.

Harris, J. M. (2013), “Keynesianismo verde: más allá de los modelos de crecimiento estándar", Documento de Trabajo, No 13-02, Medford, Global Development and Environment Institute, Tufts University.

(2008), "Ecological macroeconomics: consumption, investment, and climate change", Working Paper, Nº8-02, Medford, Global Development and Environment Institute, Tufts University.

Harvey, D. (2008), "The right to the city", New Left Review, vol. 53, septiembre-octubre.

Henry, G., E. Trigo y E. Hodson de Jaramillo (2014), “Bioeconomía en América Latina diferentes vías, resultados preliminares y buenas prácticas", Hacia una Bioeconomía en América Latina y el Caribe en asociación con Europa, E. Hodson de Jaramillo (ed.), Bogotá, Editorial Pontificia Universidad Javeriana.

Herren, H. y otros (2011), Green Jobs for a Revitalized Food and Agriculture Sector, Roma, Organización de las Naciones Unidas para la Alimentación y la Agricultura (FAO).

Heusser, N. (2017), “La deuda de Chile con los trenes", Diario La Hora, enero [en línea] http://www.lahora.cl/2017/01/ladeuda-chile-los-trenes/.

Holanda, A. (2004), "Biodiesel e inclusão social. Ariosto Holanda", Série Cadernos de Altos Estudos, N 1, Brasília, Câmara dos Deputados.

Holling, C. S. (2001), "Understanding the complexity of economic, ecological and social systems", Ecosystems, vol. 4.

Hoornweg, D. y P. Bhada-Tata (2012), "What a waste: a global review of solid waste management", Urban Development Series Knowledge Papers, N 15, Washington, D.C, Banco Mundial, marzo.

Hunter D. y V. Heywood (eds.) (2011), Parientes silvestres de los cultivos: manual para la conservación in situ, Roma, Bioversity International.

Infante, R. (comp.) (2016), “Desarrollo inclusivo en América Latina: textos seleccionados 2009-2016", Páginas Selectas de la CEPAL (LC/M.35), Santiago, Comisión Económica para América Latina y el Caribe (CEPAL).

IPCC (Grupo Intergubernamental de Expertos sobre el Cambio Climático) (2013), Cambio Climático 2013: bases físicas. Contribución del Grupo de Trabajo I al Quinto Informe de Evaluación del Grupo Intergubernamental de Expertos sobre el Cambio Climático. Resumen para responsables de políticas, Cambridge/ Nueva York, Cambridge University Press [en línea] https://www.ipcc.ch/pdf/assessment-report/ar5/wg1/WG1AR5_SPM_brochure_es.pdf.

IRENA (Agencia Internacional de Energías Renovables) (2017a), Rethinking Energy 2017, Abu Dhabi.

(2017b), Renewable Energy Auctions: Analysing 2016, Abu Dhabi. (2016a), Renewable Energy and Jobs: Annual Review 2016, Abu Dhabi. (2016b), Renewable Energy Market Analysis: Latin America, Abu Dhabi. (2016c), Renewable Energy Benefits: Measuring the Economics, Abu Dhabi [en línea] www.irena.org/DocumentDownloads/.../IRENA_Measuring-the-Economics_2016.pd.

(2016d), G20 Toolkit for Renewable Energy Deployment: Country options for sustainable growth based on Remap, Abu Dhabi. (2015), Rethinking Energy: Renewable Energy and Climate Change, Abu Dhabi.

IRP/PNUMA (Panel Internacional de Recursos/Programa de las Naciones Unidas para el Medio Ambiente) (2016), Global Material Flows and Resource Productivity: Assessment Report for the UNEP International Resource Panel, París.

ITD-UPM/BID (Centro de Innovación en Tecnología para el Desarrollo Humano/Banco Interamericano de Desarrollo) (2014), Gestión integral de los residuos sólidos: el modelo de ciudad saludable en Perú, Madrid [en línea] http://nube.cesvima. upm.es/public.php?service=files\&t=3b7beace51654ea674024eb7697d6aee\&download.

Jaimurzina, A., C. Muñoz y G. Pérez-Salas (2017), “Género y transporte: experiencias y visiones de política pública en América Latina", serie Recursos Naturales e Infraestructura, № 184 (LC/TS.2017/125), Santiago, Comisión Económica para América Latina y el Caribe (CEPAL).

Jaimurzina, A., G. Pérez-Salas y R. Sánchez (2015), “Políticas de logística y movilidad para el desarrollo sostenible y la integración regional", serie Recursos Naturales e Infraestructura, № 174 (LC/L. 4107), Santiago, Comisión Económica para América Latina y el Caribe (CEPAL).

Jordán, R., L. Riffo y A. Prado (coords.) (2017), “Desarrollo sostenible, urbanización y desigualdad en América Latina y el Caribe: dinámicas y desafíos para el cambio estructural", Documentos de Proyectos (LC/PUB.2017/19), Santiago, Comisión Económica para América Latina y el Caribe (CEPAL). 
Karaguliana, F. y otros (2015), “Contributions to cities' ambient particulate matter (PM): A systematic review of local source contributions at global level", Atmospheric Environment, vol. 120, Elsevier, noviembre.

La Nación (2017), "Alstom busca su revancha en la Argentina", abril [en línea] http://www.lanacion.com.ar/2009736-alstombusca-su-revancha-en-la-argentina.

(2012), “Brasil planea tener un tren de alta velocidad en 2018", agosto [en línea] http://www.lanacion.com.ar/1502161brasil-planea-tener-un-tren-de-alta-velocidad-en-2018.

La República (2012), “Primer tren de alta velocidad de América Latina operará en Brasil en el 2018”, agosto [en línea] http:// larepublica.pe/tecnologia/654843-primer-tren-de-alta-velocidad-de-america-latina-operara-en-brasil-en-el-2018.

Lefebvre, H. (1968), Le droit à la ville, París, Anthropos.

López Moreno, E. (2014), "Ghost cities and empty houses: wasted prosperity", American International Journal of Social Science, vol. 3, N², marzo.

Magrin, G. (2015), “Adaptación al cambio climático en América Latina y el Caribe”, Documentos de Proyectos, Nº 692 (LCM.692), Santiago, diciembre.

Magrin, G. y otros (2014), “Chapter 27. Central and South America," Climate Change 2014: Impacts, Adaptation, and Vulnerability. Part B: Regional Aspects. Contribution of Working Group II to the Fifth Assessment Report of the Intergovernmental Panel on Climate Change, V. R. Barros y otros (eds.), Cambridge, Cambridge University Press.

(2007), "Latin America", Climate Change 2007: Impacts, Adaptation and Vulnerability. Working Group I/ Contribution to the Fourth Assessment Report of the Intergovernmental Panel on Climate Change, M. L. Parry y otros (eds.), Grupo Intergubernamental de Expertos sobre el Cambio Climático, Cambridge, Cambridge University Press.

Markets and Markets (2017), “Market reports" [en línea] http://www.marketsandmarkets.com/food-and-beverages-marketresearch-6.html.

(2016), Biostimulants Market by Active Ingredient (Humic Substances, Seaweed, Microbials, Trace Minerals, Vitamins \& Amino Acids), Crop Type (Row Crops, Fruits \& Vegetables, Turf \& Ornamentals), Formulation, Application Method, and Region - Global Forecast to 2022 [en línea] http://www.marketsandmarkets.com/Market-Reports/biostimulantmarket-1081.html.

Martínez-Alier, J. y J. Roca (2013), Economía ecológica y política ambiental, Ciudad de México, Fondo de Cultura Económica.

Mazzucato, M. (2013), “Finance, innovation and growth: creative destruction vs. destructive creation", Industrial and Corporate Change, vol. 22, $\mathrm{N}^{\circ} 4$, agosto.

Mazzucato, M. y C. Pérez (2014), "Innovation as growth policy: the challenge for Europe", SPRU Working Paper Series, N SWPS 2014-13, julio.

Mecanismo Mundial de la UNCCD (Convención de las Naciones Unidas de Lucha contra la Desertificación en los Países Afectados por Sequía Grave o Desertificación, en particular África) (2015), El fondo de neutralidad en la degradación de la tierra: un proyecto de fondo de inversión innovador, París, diciembre.

Mendelsohn, R. y A. Dinar (2009), Climate change and agriculture: an economic analysis of global impacts, adaptation and distributional effects, Edward Elgar, octubre.

Mendoza, M.A. (2014), "Panorama preliminar de los subsidios y los impuestos a las gasolinas y diésel en los países de América Latina", Documentos de Proyectos (LCM.641), Santiago, Comisión Económica para América Latina y el Caribe/ Agencia Alemana de Cooperación Internacional (CEPAL/GIZ).

Metro de Bogotá (2017), "Resultados de la estructuración primera línea del metro de Bogotá," noviembre [en línea] http://www.metrodebogota.gov.co/sites/default/files/Reuni\%C3\%B3n\%20de\%20Cierre\%20Estructuraci\%C3\%B3n\%20 Tecnica\%20-\%20Ciudadan\%C3\%ADa\%20Nov. \%2014\%20a\%2016\%202017\%20PDF.pdf.

Ministerio del Medio Ambiente del Brasil (2017), "PROCONVE: Programa de Controle de Poluição do Ar por Veículos Automotores" [en línea] http://www.mma.gov.br/estruturas/163/_arquivos/proconve_163.pdf.

Ministerio del Medio Ambiente del Perú (2016), “El Modelo de Negocio de Biocomercio: innovación para el desarrollo sostenible", documento presentado en el taller Identificación de Barreras al Comercio de Productos Peruanos de Biocomercio y otros Derivados de la Biodiversidad, Lima, Conferencia de las Naciones Unidas sobre Comercio y Desarrollo (UNCTAD), agosto [en línea] http://unctad.org/meetings/en/Presentation/ditc-ted-16082016-peru-Sesion2-MINAM.pdf.

Muñoz, C. y G. Pérez (2017), “Reflexiones sobre el rol de la logística en la explotación sostenible de los recursos naturales en América Latina y el Caribe", Boletín FAL, N³57, Santiago, Comisión Económica para América Latina y el Caribe (CEPAL), mayo.

Naciones Unidas (2015a), Transforming Our World: the 2030 Agenda for Sustainable Development (A/RES/70/1), octubre. (2015b), "Informe de síntesis sobre el efecto agregado de las contribuciones previstas determinadas a nivel nacional" (FCCC/CP/2015/7) [en línea] http://unfccc.int/resource/docs/2015/cop21/spa/07s.pdf.

NRDC/ACERA (Natural Resources Defense Council/Asociación Chilena de Energías Renovables) (2013), “Beneficios económicos de energías renovables no convencionales en Chile", septiembre. 
Observatório ABC (Agricultura de Baixo Carbono) (2017), Agricultura de baixa emissão de carbono: Observatório ABC avaliação do uso estratégico das áreas prioritárias do Programa $A B C$, São Paulo, Fundación Getúlio Vargas, abril. (2015), Invertendo o sinal de carbono da agropecuária brasileira: Uma estimativa do potencial de mitigação de tecnologías do Plano ABC de 2012 a 2023, São Paulo, Fundación Getúlio Vargas, julio.

OCDE (Organización de Cooperación y Desarrollo Económicos) (2012), Perspectivas ambientales de la OCDE hacia 2050, París, OECD Publishing, marzo.

OCDE/FAO (Organización de Cooperación y Desarrollo Económicos/Organización de las Naciones Unidas para la Alimentación y la Agricultura) (2016), Perspectivas agrícolas 2016-2025, París, OECD Publishing.

OIT (Organización Internacional del Trabajo) (2016a), Empleos verdes: informe de avance 2014-2015, Turín.

(2016b), Empleos verdes para un desarrollo sostenible: el caso uruguayo, Montevideo, junio.

(2013), Evaluación del potencial de empleos verdes en México, Ginebra, septiembre [en línea] http://www.ilo.org/ wcmsp5/groups/public/--ed_emp/--emp_ent/documents/project/wcms_250699.pdf.

(2012), Hacia el desarrollo sostenible: oportunidades de trabajo decente e inclusión social en una economía verde, Ginebra.

OMS (Organización Mundial de la Salud) (2016), "Global Urban Ambient Air Pollution Database" [base de datos en línea] http://www.who.int/phe/health_topics/outdoorair/databases/cities/en/.

ONU-Hábitat (Programa de las Naciones Unidas para los Asentamientos Humanos) (s/f), "Global Urban Indicators Database", Nairobi [base de datos en línea] https://unhabitat.org/books/global-urban-indicators-database/. (2016), Urbanization and Development: Emerging Futures. World Cities Report 2016, Nairobi.

(2012), Estado de las ciudades de América Latina y el Caribe 2012, Nairobi.

(2011), Estado de las Ciudades de México 2010/2011, Ciudad de México.

(2010), Solid Waste Management in the World's Cities: Water and Sanitation in the World's Cities 2010, Londres [en línea] http://mirror.unhabitat.org/pmss/listltemDetails.aspx?publicationID=2918.

OPS/AIDIS/BID (Organización Panamericana de la Salud/Asociación Interamericana de Ingeniería Sanitaria/Banco Interamericano de Desarrollo) (2010), Informe de la evaluación regional del manejo de residuos sólidos urbanos en América Latina y el Caribe 2010 [en línea] http://idbdocs.iadb.org/wsdocs/getdocument.aspx?docnum=36466973.

Otero, A. (2011), "Análisis de generación complementaria entre energía hidráulica y eólica. Caso: generación ISAGENProyectos eólicos en la Guajira Colombiana", tesis para optar al grado de magister, Medellín, Universidad Nacional de Colombia.

Perotti, R. y M. Coviello (2015), "Governance of strategic minerals in Latin America: the case of lithium", Documentos de proyectos (LCM.669), Santiago, Comisión Económica para América Latina y el Caribe (CEPAL), septiembre.

PNUD (Programa de las Naciones Unidas para el Desarrollo) (2015), Chile: instrumentos y estrategias para combatir la desertificación, Santiago, diciembre.

PNUMA (Programa de las Naciones Unidas para el Medio Ambiente) (s/f), "Environment Live Database" [base de datos en línea] uneplive.unep.org.

(2017), The Emissions Gap Report 2017, Nairobi.

(2016), GEO-6: Regional Assessment for Latin America and the Caribbean, Nairobi.

(2011), Decoupling Natural Resource Use and Environmental Impacts from Economic Growth, Nairobi.

PNUMA/Frankfurt School of Finance and Management (2016), Global Trends in Renewable Energy Investment 2016 [en línea] http://fs-unep-centre.org/sites/default/files/publications/globaltrendsinrenewableenergyinvestment2016lowres_0.pdf.

Porcile, G. (2016) "Tecnología, medio ambiente y desarrollo: una nueva mirada al gran impulso ambiental", Santiago, Comisión Económica para América Latina y el Caribe (CEPAL), inédito.

(2011), "La teoría estructuralista del desarrollo", El desarrollo inclusivo en América Latina y el Caribe: ensayos sobre políticas de convergencia productiva para la igualdad, Libros de la CEPAL, № 112 (LC/G.2500-P), Santiago, Comisión Económica para América Latina y el Caribe (CEPAL), septiembre.

Porcile, G. y S. Rovira (2016), “¿Hacia un nuevo estilo de desarrollo? La Agenda 2030 y el big push ambiental”, Puentes, vol. 17, № 5, Ginebra, Centro Internacional de Comercio y el Desarrollo Sostenible (ICSTD).

Poschen, P. (2015), "Do we have to choose between creating jobs and protecting the climate?", Organización Internacional del Trabajo (OIT), junio, [en línea] http://www.ilo.org/global/about-the-ilo/newsroom/news/WCMS_373207/lang--en/ index.htm.

Prebisch, R. (1981), Capitalismo periférico: crisis y transformación, Ciudad de México, Fondo de Cultura Económica.

(1980), "Biosfera y desarrollo", Revista de la CEPAL, № 12 (E/CEPAL/G.1130), Santiago, Comisión Económica para América Latina y el Caribe (CEPAL), diciembre.

(1976), "Crítica al capitalismo periférico", Revista de la CEPAL, № 1, Santiago, Comisión Económica para América Latina y el Caribe (CEPAL).

PwC (PricewaterhouseCoopers) (2015), "Estudio sobre las inversiones necesarias para que México cumpla con sus metas de energías limpias," octubre [en línea] https://www.pwc.com/mx/es/industrias/energia/archivo/20151018-gp-cespedes.pdf. 
QYResearch (2018), Global Biological Organic Fertilizer Market Professional Survey Report 2017, enero.

Ramos, S., E. Muñoz y G. Pérez (2017), “La gobernanza de los recursos naturales y los conflictos en las industrias extractivas: el caso de Colombia", serie Recursos Naturales e Infraestructura, № 181 (LC/TS.2017/71), Santiago, Comisión Económica para América Latina y el Caribe (CEPAL), septiembre.

REN21 (Red de Políticas de Energía Renovable para el siglo XXI) (2016), Renewables 2016 Global Status Report, París.

Robertson, J. (2010), Building a Green Economy, Citizens Climate Lobby, septiembre [en línea] https://citizensclimatelobby. org/files/building-a-green-economy.pdf.

Rodríguez, A., A. Mondaini y M. Hitschfeld (2017), "Bioeconomía en América Latina y el Caribe, contexto global, regional y perspectivas", serie Desarrollo Productivo, N² 215 (LC/TS.2017/96), Santiago, Comisión Económica para América Latina y el Caribe (CEPAL), noviembre.

Rodríguez, O. (2006), El estructuralismo latinoamericano, Ciudad de México, Siglo XXI.

(1980), La teoría del subdesarrollo de la CEPAL, Ciudad de México, Siglo XXI.

Rosenstein-Rodan, P. (1961), "Notes on the Theory of the 'Big Push'," Economic Development for Latin America, Palgrave MacMillan, Londres.

Samaniego, J. y H. Schneider (2017), "Financiamiento para el cambio climático en América Latina y el Caribe en 2015", Documentos de Proyectos (LC/TS.2017/9), Santiago, Comisión Económica para América Latina y el Caribe (CEPAL), febrero.

Sánchez, L. y C. Salazar (2011), "Lo que dicen las viviendas deshabitadas sobre el censo de población 2010", Coyuntura Demográfica, № 1.

Secretaría de Comunicaciones y Transportes de México (2017a), "Tren suburbano del valle de México", Secretaría de Comunicaciones y Transportes, noviembre [en línea] http://www.sct.gob.mx/transporte-y-medicina-preventiva/transporteferroviario-y-multimodal/tren-suburbano/.

(2017b), "Tren eléctrico de Guadalajara", Secretaría de Comunicaciones y Transportes, noviembre [en línea] http:// www.sct.gob.mx/transporte-y-medicina-preventiva/transporte-ferroviario-y-multimodal/tren-electrico-de-guadalajara/.

Sharrock, S., S. Oldfield y O. Wilson (2014), "Plant conservation report 2014: A review of progress in implementation of the Global Strategy for Plant Conservation 2011-2020", CBD Technical Series, № 81, Montreal, Secretaría del Convenio sobre Diversidad Biológica (SCDB).

Steffen, W. y otros (2015), "Planetary boundaries: guiding human development on a changing planet", Science, vol. 347, $N^{\circ} 6223$, febrero.

Stern, N. (2006), The Economics of Climate Change, Nueva York, Cambridge University Press.

Sunkel, O. (comp.) (1996), Sustentabilidad ambiental del crecimiento económico chileno, Santiago, Programa de Desarrollo Sustentable, Centro de Análisis de Políticas Públicas, Universidad de Chile.

(1970), "Desarrollo, subdesarrollo, dependencia, marginación y desigualdades espaciales: hacia un enfoque totalizante", Revista EURE, vol. 1, № 1, Santiago, Pontificia Universidad Católica de Chile (PUC).

Technavio (2016), “Global Cosmeceuticals Market 2017-2021", noviembre.

Transparency Market Research (2015), "Organic Personal Care Products Market - Global Industry Analysis, Size, Share, Growth, Trends and Forecast 2014 - 2020", marzo.

Trigo, E. y otros (2015), "La bioeconomía argentina: alcances, situación actual y oportunidades, para el desarrollo sustentable", Buenos Aires, Bolsa de Cereales de Buenos Aires [en línea] http://www.bolsadecereales.com/ver-bioeconomia-580. (2014), "Hacia un desarrollo de la bioeconomía en América Latina y el Caribe", Hacia una Bioeconomía en América Latina y el Caribe en asociación con Europa, Bogotá, Pontificia Universidad Javeriana, noviembre.

UITP (Unión Internacional de Transporte Público) (2016), Metro América Latina: perspectivas y tendencias, São Paulo, octubre [en línea] http://www.latinamerica.uitp.org/sites/default/files/Relat\%C3\%B3rio\%20Metr\%C3\%B4s_UITP\%20 Am\%C3\%A9rica\%20Latina_ESP.pdf.

UKERC (UK Energy Research Centre) (2014), Low Carbon Jobs: The Evidence for Net Job Creation from Policy Support for Energy Efficiency and Renewable Energy, Londres, noviembre.

UNASUR/CEPAL (Unión de Naciones Suramericanas/Comisión Económica para América Latina y el Caribe) (2016), Panorama Social y Económico Suramericano, 2016 (LC/L.4274), Santiago, diciembre.

UNCCD (Convención de las Naciones Unidas de Lucha contra la Desertificación en los Países Afectados por Sequía Grave o Desertificación, en Particular en África) (2017), Perspectiva Global de la Tierra, Bonn.

(2015), Country Profiles: Latin America and the Caribbean Region, Bonn.

UN COMTRADE (Base de Datos Estadísticos de las Naciones Unidas sobre el Comercio de Productos Básicos) (2017) [base de datos] https://comtrade.un.org/data/.

UNCTAD (Conferencia de las Naciones Unidas sobre Comercio y Desarrollo) (2012), Trade and Biodiversity: The Biograde Experiences in Latin America, Ginebra.

Unión Europea/FAO (Organización de las Naciones Unidas para la Alimentación y la Agricultura) (2014), Atlas de Suelos de América Latina y el Caribe, Luxemburgo. 
UNISDR (Oficina de las Naciones Unidas para la Reducción del Riesgo de Desastres) (2016), The Sustainable Development Goals Report 2016, Nueva York.

_ (2015), Global Assessment Report on Disaster Risk Reduction. Making Development Sustainable: The Future of Disaster Risk Management, Ginebra.

_(2013), Annual Report 2013, Ginebra.

(2011), Annual Report 2011, Ginebra.

Universidad de Nueva York/Instituto Lincoln de Políticas de Suelo/ONU-Hábitat (2016), "Atlas of Urban Expansion" [base de datos en línea] http://www.atlasofurbanexpansion.org/.

USGS (Servicio Geológico de los Estados Unidos) (2017), "Mineral Commodity Summaries 2017" [en línea] https://minerals. usgs.gov/minerals/pubs/mcs/2017/mcs2017.pdf.

(2014), Global Mineral Resource Assessment: Estimate of Undiscovered Copper Resources of the World, 2013, enero.

Vanguardia (2017), “Cancelación del tren rápido México-Querétaro podría costarle a México ¡600 mdd!", noviembre [en línea] https://www.vanguardia.com.mx/articulo/cancelacion-del-tren-rapido-mexico-queretaro-china-podria-costarlemexico-600-mdd-a-a.

Vasconcellos, E., y A. Mendonça (2016), Observatorio de Movilidad Urbana: Informe 2015-2016 (resumen ejecutivo), Caracas, Banco de Desarrollo de América Latina (CAF).

Vergara, W. y otros (2013), The Climate and Development Challenge for Latin America and the Caribbean: Options for Climate-Resilient, Low-carbon Development, Washington D.C., Banco Interamericano de Desarrollo (BID), abril.

Weston, D. (2013), "State of the planet, Kyoto and technical fixes", The Political Economy of Global Warming: The Terminal Crisis, Londres, Routledge. 

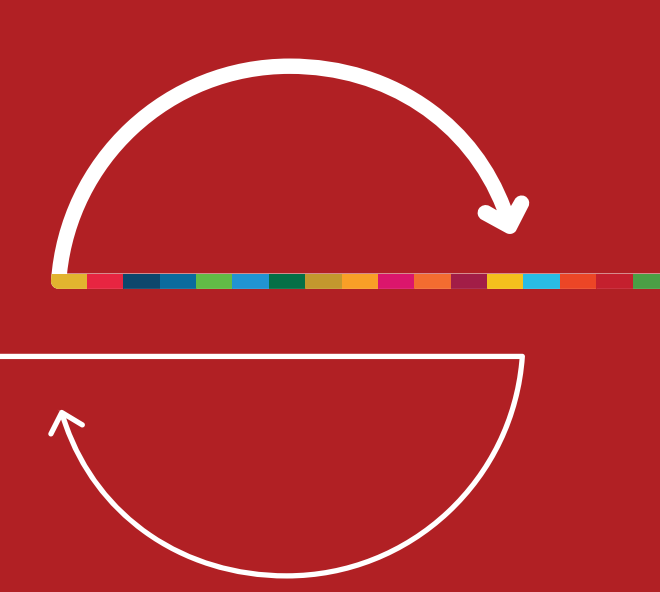

\section{CAPITULO}

VI

\section{La economía política de la desigualdad y la cultura del privilegio}

A. Instituciones igualitarias e instituciones excluyentes

B. La economía política del desarrollo

1. Las raíces de la heterogeneidad estructural

2. Los costos de la liberalización financiera

3. Cambio estructural y diversificación productiva

C. Desigualdad y fragmentación en las relaciones sociales

1. Una región sin guerras, pero marcada por la violencia

2. Insuficiente respaldo a la democracia

D. Cultura del privilegio, rentismo y desigualdad

1. Los campos de la cultura del privilegio

2. Fortalecer la cultura de la igualdad erosiona la cultura del privilegio

Bibliografia 



\section{A. Instituciones igualitarias e instituciones excluyentes}

El papel de las instituciones — las reglas del juego y normas formales e informales de comportamiento que delimitan y estructuran la interacción entre actores- en el proceso de desarrollo es un tema de creciente importancia, pues el ambiente institucional en que los agentes deciden altera sustancialmente las trayectorias de crecimiento y distribución de la economía. Desde la perspectiva de este documento, los interrogantes fundamentales son los siguientes: qué reglas del juego son las más propicias para promover un desarrollo sostenible y cómo se logra que estas surjan y perduren en el tiempo.

Las instituciones no son exógenas al sistema económico. Interactúan con estructuras que definen quiénes son los actores relevantes, su poder económico y sus espacios de cooperación y conflicto, al tiempo que están enraizadas en la historia. Los poderes económicos y políticos se refuerzan mutuamente y pueden conducir a sociedades segregadas, en que una parte importante de la población pierde, en la práctica, el acceso a las capacidades y oportunidades de las que disfruta la élite.

Es posible ser más específico con relación a las formas que adopta la interacción entre el poder político, el poder económico y las instituciones, e identificar dos casos polares. El primero son las instituciones excluyentes, que, mediante mecanismos de segregación, impiden a la mayor parte de la población el acceso a las capacidades y oportunidades asociadas al desarrollo sostenible. Estas instituciones surgen y se fortalecen cuando los poderes políticos y económicos están fuertemente concentrados en un pequeño grupo, lo que se expresa en altos niveles de desigualdad de riqueza e ingresos y en sistemas políticos autoritarios o con limitada participación efectiva de los grupos menos favorecidos. En estas economías se producen pocos bienes públicos y tanto el número como la cobertura de las organizaciones sociales y políticas son reducidos.

Por el contrario, son instituciones igualitarias aquellas que promueven el desarrollo de las capacidades del conjunto de la población, amplían oportunidades e impiden cualquier índole de segregación o discriminación. A la igualdad económica se suma la igualdad política, reflejada en un sistema democrático que garantiza el pleno ejercicio de los derechos civiles a todos los ciudadanos. La igualdad de acceso y oportunidades supone la eliminación no solo de las formas explícitas o implícitas de discriminación, como la discriminación por religión, sexo, etnia o casta, sino también de las que se derivan de asimetrías en el poder económico de los actores. Las instituciones igualitarias surgen y se fortalecen en economías menos desiguales y sistemas políticos democráticos.

La interacción entre las variables económicas y las instituciones no es un tema nuevo ${ }^{1}$. La contraposición entre instituciones igualitarias y excluyentes tiene muchos puntos en común con la que existe entre instituciones inclusivas e instituciones extractivas, sugerida por Acemoglu y Robinson (2006), y la del "estado natural" o de acceso limitado frente al "orden de libre acceso", de North, Wallis y Weingast (2009). De igual manera, las asimetrías de poder (externas e internas), su impacto sobre las reglas de funcionamiento de la economía y las restricciones que imponen a las estrategias de los actores son una parte central de la reflexión estructuralista. El método histórico-estructural destaca que los caminos del desarrollo están condicionados por las configuraciones de poder que emergieron del pasado colonial y las luchas entre clases dominantes y subordinadas en la vida independiente de las naciones latinoamericanas y caribeñas (Sunkel y Paz, 1970; Cardoso y Faletto, 1977)². Ese pasado dejó un legado de marcada desigualdad, derivada de la concentración de la tierra y el uso extendido de diversas modalidades de trabajo forzado. Si bien existe una gran heterogeneidad en la trayectoria que siguieron los países de la región en el siglo XX, los problemas de concentración del poder persistieron, como atestiguan la larga lista de regímenes autoritarios y la inestabilidad de la democracia (O'Donnell, Schmitter y Whitehead, 1991).

El reconocimiento de que las instituciones son una dimensión central del sistema económico es el núcleo analítico del viejo institucionalismo (Veblen) y ha sido analizado por los historiadores económicos que compararon las trayectorias de desarrollo de distintos países (Moore, 1966) y, en particular, de las llamadas economías de asentamiento reciente (Álvarez y Bértola, 2007). También ha sido un tema recurrente en la tradición de la Comisión Económica para América Latina y el Caribe (CEPAL).

La importancia de la historia a la hora de abrir o cerrar caminos al desarrollo, destacada en el análisis histórico-estructural, representa lo que posteriormente se llamaría "dependencia de la trayectoria" (path dependency) (Arthur, 1994; Palley, 2017). 
Las instituciones igualitarias son relevantes no solo en relación con los temas clásicos de inclusión política y económica, sino también con las tres dimensiones del desarrollo sostenible: i) la social, en términos de igualdad multidimensional; ii) la de aprendizaje o convergencia con el mundo desarrollado, en términos de ingreso y capacidades tecnológicas, y iii) la ambiental, es decir, que el proceso de convergencia sea compatible con la preservación de los recursos naturales y el medio ambiente para las futuras generaciones (CEPAL, 2016).

La desigualdad en América Latina y el Caribe ha generado y reproduce instituciones excluyentes que limitan el espacio de las políticas de cambio estructural que están en el núcleo del desarrollo sostenible. Al mismo tiempo, generan sociedades fragmentadas y culturas del privilegio hostiles al aprendizaje, la innovación y la productividad ${ }^{3}$.

\section{B. La economía política del desarrollo}

\section{Las raíces de la heterogeneidad estructural}

América Latina y el Caribe nació a la vida independiente con patrones muy concentrados de distribución de los activos y el ingreso. Si bien es improbable que esas condiciones iniciales expliquen por sí solas la situación de la región en el siglo XXI, hay factores relacionados con la desigualdad y la especialización internacional que cruzan su historia y ayudan a caracterizar las barreras que impiden la transformación de las estructuras económicas.

La crisis de 1930 marcó una profunda ruptura con el patrón de crecimiento seguido durante la primera globalización, cuando la región se insertaba (con notorias diferencias entre un país y otro) en la división internacional del trabajo clásica (materias primas en la periferia, manufacturas en el centro), correspondiente a la hegemonía inglesa (CEPAL, 2002). La crisis, el colapso del patrón oro y la caída del comercio mundial se tradujeron en grandes cambios políticos y económicos, con el ascenso de nuevos actores, el debilitamiento de las oligarquías tradicionales y el avance de la industrialización amparada en la protección (tarifaria y no tarifaria) y los tipos de cambio múltiples. En general, surgieron patrones de industrialización sustitutiva en respuesta al cierre de los mercados tradicionales de exportación y, posteriormente, durante la Segunda Guerra Mundial, al hecho de que la producción industrial de los países centrales era absorbida por el esfuerzo bélico. Estos patrones se mantuvieron y reforzaron durante el período de escasez de dólares (dollar shortage) hasta fines de los años cincuenta, cuando los países europeos recuperaron la convertibilidad de sus monedas.

Durante el auge de la sustitución de importaciones entre 1955 y 1980 (o de la industrialización liderada por el Estado, en la definición de Bértola y Ocampo, 2012), hubo procesos significativos de aprendizaje, sobre todo en la Argentina, el Brasil y México. Estos se expresaron en el aumento del peso de las exportaciones industriales en el total de las exportaciones y, en algunos casos, en exportaciones de tecnología llave en mano. El Brasil y México llegaron a ser considerados parte del grupo de las economías de reciente industrialización junto con los tigres asiáticos. Las capacidades generadas en esos años contribuyeron a la conformación de enclaves de excelencia que aún sobreviven o fueron la base de la reconversión de algunas industrias en la década de 1990. Este fue un período de grandes avances y transformaciones sociales y económicas, que Hirschman (1986) llamó les trente glorieuses de América Latina.

Mientras tanto, las crisis recurrentes del sector externo, la dependencia de las exportaciones de recursos naturales y bienes de menor intensidad tecnológica, y la persistencia de la desigualdad indicaban que la política industrial no había creado las condiciones necesarias para la convergencia internacional. La brecha tecnológica no se cerró de manera de permitir que la industria compitiera sobre la base de sus capacidades. A un patrón rentista basado en los recursos naturales le sucedió un patrón con un peso creciente de las cuasirrentas

Las instituciones excluyentes no son incompatibles con tasas de crecimiento elevadas durante ciertos períodos. No obstante, en la medida en que se extiende el período de análisis, surge con más claridad una relación negativa entre ambas variables. El efecto negativo de las instituciones excluyentes se vuelve más evidente cuando el objeto de estudio es más amplio que el crecimiento económico e incluye también la distribución del ingreso y el cuidado del medio ambiente. Sobre la relación entre instituciones y desigualdad, véase Chong y Gradstein (2007). 
del privilegio asociadas a lo que Fajnzylber (1983) Ilamó "proteccionismo frívolo" (sobre el que advirtiera tempranamente Prebisch, 1963). La redistribución de rentas — que debería haber sido un instrumento flexible que se desplazaba en el tiempo hacia nuevos sectores - se volvió parte de un equilibrio político desafiado constantemente por la restricción externa. Ese equilibrio era inestable, como reflejan los ciclos de freno y arranque (stop and go) del patrón de crecimiento y la creciente conflictividad social y política.

Fajnzylber (1983) destacó la importancia de contar con un núcleo endógeno de actores con intereses articulados en torno al cambio técnico y la reducción de brechas para el éxito de las políticas de cambio estructural. En los países más dinámicos del este de Asia, ese núcleo estaba conformado por una red de encargados de formular políticas y ejecutivos de empresas públicas y privadas, cuyos intereses y poder se expandían con la transformación de la economía y la creciente competitividad de sus empresas en los mercados internacionales. Mientras que en la República de Corea las grandes empresas nacionales fueron un actor clave, la experiencia de la provincia china de Taiwán dejó más espacio a la actuación de las empresas medianas. En China, el núcleo endógeno adoptó la forma de la asociación entre empresas extranjeras (limitadas a algunos sectores) y empresas nacionales públicas y privadas.

En estos casos, la transferencia de tecnología para construir capacidades propias y reducir brechas fue un objetivo preponderante de las políticas. El Estado mantenía con el sector empresarial un vínculo que Evans y Heller (2015) Ilamaron "autonomía enraizada" (embedded autonomy): al tiempo que el flujo de información y el monitoreo entre los sectores público y privado era intenso, había una distancia que impedía que los encargados de formular políticas fueran cooptados o capturados por el sector privado. Esto permitió a los primeros distribuir rentas de tal forma que los sectores favorecidos cambiaban a medida que la estructura productiva se complejizaba y se alcanzaban las metas de productividad y exportación. Algunos actores se erguían sobre sus propias fuerzas, y los que no lo lograban eran efectivamente penalizados. El énfasis exportador del patrón de crecimiento fue clave para tener un punto de referencia claro en cuanto a las metas a alcanzar y su vínculo con el aprendizaje (Amsden, 1989; Wade, 1992; Poo, 2014).

En el plano internacional, las industrializaciones del este de Asia contaron con el apoyo de los Estados Unidos (que era uno de los principales mercados de exportación y fuente de tecnología), en función de la importancia de esa región en la geopolítica de la Guerra Fría. En el caso de la República de Corea, los Estados Unidos promovieron una reforma agraria en la temprana posguerra, con importantes implicaciones en términos de la economía política del desarrollo (Kim, 2016), una estrategia casi diametralmente opuesta a la que adoptaron en el caso latinoamericano.

El crecimiento en América Latina y el Caribe se dio a la manera de las burbujas identificadas por Nochteff, en lugar de mediante la reducción de brechas. Los cambios en el tiempo obedecieron a cambios en el tipo de cuasirrentas no tecnológicas predominante y en el poder relativo de los actores, sin que las cuasirrentas tecnológicas se volvieran el motor schumpeteriano de la expansión económica. En ese contexto, la heterogeneidad y fractura entre los agentes fue una constante 4 . La importancia de estas fracturas se ve en la dinámica de las alianzas que se crean y deshacen, tanto en la fase de la industrialización sustitutiva como después de las reformas promercado de finales de los años ochenta y principios de los años noventa. Su impacto sobre el sistema político y la cultura se discute más adelante.

Durante la industrialización sustitutiva, el sistema implícito de transferencia de rentas a la industria fue la combinación de inflación y sobrevaluación de la moneda. No obstante, esta política generaba sus propios anticuerpos. En lo político, la inflación erosionaba el apoyo de los trabajadores a la industria y la sobrevaluación acentuaba la oposición de los exportadores, que se hacía más intensa cuando los términos de intercambio se volvían menos favorables o la demanda externa se tornaba menos dinámica. Por otra parte, los desequilibrios en la balanza de pagos reforzaban periódicamente el poder de los sectores exportadores tradicionales, en

Según Doner y Schneider (2016), el principal obstáculo político para la construcción de instituciones es la fragmentación de grupos sociales, en especial las empresas y los trabajadores, y la consiguiente ausencia de fuertes coaliciones comprometidas con la productividad y la diversificación. Las trayectorias de crecimiento hacia un nivel de ingresos medianos fracturaron los grupos — sobre todo las empresas y los trabajadores— que constituyen las posibles bases sociales de una política de desarrollo. En términos más estrictos, las grandes empresas se dividen en empresas nacionales y extranjeras, los trabajadores se dividen en los sectores formal e informal, y las sociedades en general están fragmentadas por una gran desigualdad. Estas divisiones fracturan los intereses y dificultan el logro de coaliciones. 
la medida en que se imponía la necesidad de promover sus exportaciones para evitar o mitigar una crisis cambiaria. Se creaban alianzas cambiantes entre trabajadores industriales, sectores medios, productores industriales para el mercado interno y productores primarios para el mercado internacional ${ }^{5}$. En lo económico, los industriales establecidos veían con sospecha el avance de nuevas industrias en encadenamientos hacia atrás, ya que eso les obligaba a pagar más caro por sus insumos, lo que reducía la protección efectiva de la cual gozaban. Las crisis externas hacían inevitable la desvalorización del tipo de cambio y contraían la demanda interna sin estimular la demanda externa en la misma medida debido a la baja elasticidad-precio de las exportaciones. Estos fueron límites políticos y económicos de primera importancia para el avance de la industrialización (Hirschmann, 1968).

La adopción de las políticas del consenso de Washington (liberalización comercial y financiera, privatización y desregulación) desde mediados de los años ochenta generó expectativas de una nueva era de expansión para la región (Stalling y Peres, 2000). Estas políticas se racionalizaban en términos de reducir las oportunidades de captación de rentas de los sectores protegidos (disminuir las rentas del privilegio). La idea era que bastaría desmontar las distorsiones de las políticas intervencionistas del pasado para relanzar el crecimiento. Como en el caso de la liberalización financiera de los años setenta, esa expectativa no se confirmó. La liberalización comercial no generó aprendizaje donde no existían los agentes capaces de aprender, los procesos productivos en los que se aprende o las instituciones que los apoyan. La desregulación y las privatizaciones dieron lugar a transferencias masivas de rentas a los actores posicionados en lugares privilegiados, sin que, en la mayoría de los casos, esto se tradujera en aumentos de la inversión o la productividad. Las reformas promercado y el consenso de Washington fueron procesos con muy poca correspondencia con la impersonalidad del orden de acceso abierto al que se refieren North, Wallis y Weingast (2009).

Más aún, aumentó la fractura o heterogeneidad entre los actores. En el plano microeconómico, se incrementó la importación de insumos intermedios y se redujo el grado de integración de muchas cadenas productivas, con un aumento de la eficiencia de las empresas líderes a costa de la desaparición de pequeñas y medianas empresas (pymes). En el plano macroeconómico, la liberalización de la cuenta de capital abrió un nuevo ciclo de apreciación del tipo de cambio que, en países como la Argentina, el Brasil y el Uruguay, culminó con crisis externas muy fuertes (sobre todo en la Argentina y el Uruguay) a finales de los años noventa y comienzos de la década de 2000. Esto generó un notable aumento del desempleo y la informalidad, y, con ello, de la desigualdad.

Por último, aunque no por eso menos importante, las economías de la región han mostrado grados elevados de informalidad del empleo y (con algunas excepciones) bajos niveles de sindicalización, lo que tiene un peso significativo en la configuración del cuadro de fragmentación de intereses. El impacto se da en varios niveles. Primero, la informalidad implica que ni los trabajadores ni los empresarios ven su relación como un vínculo estable y de largo plazo, lo que reduce el interés de los primeros en los resultados de la empresa y de los segundos en capacitarlos (en la medida en que un trabajador más capacitado puede migrar a una empresa competidora). Segundo, la ausencia de formas de representación y negociación institucionalizadas hace más difícil al arbitraje de los conflictos y la definición de metas distributivas y de productividad. El cambio técnico se percibe como un sendero hacia el desempleo y no hacia la capacitación del trabajador y el aumento del salario real. Tercero, el hecho de que una parte importante de los trabajadores se encuentre sin mecanismos de defensa aumenta la inestabilidad del sistema político y abre espacios a políticas insostenibles porque potencia al máximo la puja redistributiva, alimentando procesos inflacionarios y la sobrevalorización de la moneda nacional.

En este contexto, se configura un estilo de desarrollo de capitalismo jerárquico (Doner y Schneider, 2016). Muchas de las empresas clave en la economía son subsidiarias de transnacionales y, por lo tanto, están sujetas a la planificación y el control de sus casas matrices; muchas de las principales empresas nacionales aún son de propiedad familiar, y las relaciones entre capital y trabajo no disponen de los espacios de negociación que

Véase un análisis de estas alianzas y su inestabilidad en O’Donnell (1978). 
se observan en los capitalismos corporativos del norte de Europa ${ }^{6}$. Las sociedades altamente jerárquicas y fragmentadas hacen más difíciles los acuerdos políticos para la implementación eficaz de las políticas de cambio estructural.

\section{Los costos de la liberalización financiera}

La segunda mitad de la década de 1970 agregó un nuevo factor a la inestabilidad del crecimiento de la región. La emergencia de un mercado financiero internacional fuera de las regulaciones nacionales (el mercado de eurodólares) y los enormes excedentes reciclados por los grandes exportadores de petróleo después del primer choque de precios en 1974 (los petrodólares) capturaron la dinámica del sector externo. A partir de entonces, los actores ligados al sector financiero asumieron un papel de creciente importancia. Los ciclos económicos pasaron a ser comandados principalmente por los ciclos de liquidez de los mercados financieros internacionales, más que por los ciclos del comercio internacional. La liberalización de la cuenta de capital (en un primer momento en los países del Cono Sur, a mediados de los años setenta, y posteriormente en el conjunto de los países de la región en la década de 1990) acentuó el predomino de la balanza de pagos en el desempeño macroeconómico de la región (Ocampo, 2013).

La primera gran manifestación de este tipo de rentismo y sus consecuencias negativas para la productividad y el crecimiento ocurrió con la crisis de la deuda de principios de los años ochenta, que puso fin a la fase de la industrialización previa. Su intensidad, sin embargo, no fue consecuencia de las políticas de industrialización sustitutiva. La crisis golpeó con la misma intensidad a países que habían mantenido esta estrategia (como el Brasil y México) y a los que habían liberalizado el comercio y abierto la cuenta de capital en los años setenta (como la Argentina, Chile y el Uruguay). El punto en común fue la combinación de la abundancia de capital externo, la disposición de los países a recurrir a ese capital para sostener el crecimiento en condiciones de poca competitividad externa (con el consiguiente aumento de la deuda externa) y el gran incremento de las tasas de interés internacionales a partir de 1979. Contrariamente, los países asiáticos exitosos, pese a haber sido golpeados por la crisis internacional, la superaron con rapidez porque habían mantenido cerrada la cuenta de capital e implementado políticas industriales selectivas de diversificación exportadora que absorbieron mejor el choque externo.

Los factores de economía política internacional —la desigualdad de poder entre los actores - fueron determinantes de la intensidad de la crisis y su costo para la región. Los países debieron negociar individualmente con un cártel de bancos acreedores que tenía el pleno apoyo de las grandes instituciones financieras internacionales. El resultado de esta desigual negociación fue una gigantesca transferencia de rentas hacia los bancos extranjeros, con consecuencias muy negativas en los niveles de inversión y crecimiento, lo que dio inicio a lo que se llamó la "década perdida". Al rentismo interno se sumó un cambio en las condiciones de funcionamiento de la economía internacional en que las cuasirrentas de oligopolio del sector financiero internacional se multiplicaron con rapidez (por ejemplo, en los Estados Unidos, los beneficios reales del sector financiero aumentaron un 800\% entre 1980 y 2005, mientras que su participación en el PIB casi se duplicó entre 1988 y 2007) (Acemoglu y Robinson, 2013, pág. 182).

Así, en lugar de la captación, por parte de las economías de la región, de una fracción de las cuasirrentas tecnológicas creadas por las empresas innovadoras en la economía mundial (a partir de la reducción de la brecha tecnológica), se dio una captación masiva de cuasirrentas del privilegio por parte de los acreedores de los países centrales, en función de su capacidad de resolver con mucho mayor facilidad sus problemas de acción colectiva, con la ayuda de las instituciones financieras internacionales (en particular, el Fondo Monetario Internacional (FMI) y el Banco Mundial). La crisis de la deuda también redefinió la economía política interna. La capacidad del Estado de formular e implementar políticas se debilitó marcadamente por tres razones. En

\footnotetext{
Este argumento converge con un punto que Medina Echavarría retoma en sus estudios sobre la sociología del desarrollo en la región: la persistencia de formas de organización tradicional de la sociedad que resisten las reglas de la racionalidad weberiana en el Estado y las empresas. "La estructura tradicional ha sido relativamente permeable y (...) esa porosidad (le) ha permitido absorber los elementos de modernidad que necesita sin quebrar por eso su estructura misma" (Medina, citado por Rodríguez, 2007, pág. 173).
} 
primer lugar, por la restricción fiscal. Como la deuda externa privada fue asumida por los Estados nacionales, la crisis se convirtió en una crisis fiscal, disminuyendo la capacidad de implementar políticas que dependieran mucho de inversiones o subsidios públicos. En segundo término, los Estados debieron negociar de manera recurrente las condiciones del pago de la deuda. La condicionalidad de los préstamos implicaba aceptar una estrategia de crecimiento hostil a las políticas industriales. Por último, los países concentraron sus esfuerzos en el pago de la deuda y en contener la dinámica inflacionaria, que en algunos casos relevantes alcanzó niveles de hiperinflación. Los fenómenos inflacionarios asociados a la transferencia de recursos al exterior y la crisis fiscal aumentaron los niveles de pobreza e indigencia. No había, en tales circunstancias, tiempo ni recursos para pensar a largo plazo.

La liberalización financiera ensayada temprano —en los años setenta— en el Cono Sur supuestamente permitiría que los actores económicos accedieran más fácilmente al crédito, eliminando el rentismo asociado al acceso privilegiado al financiamiento en un contexto de represión financiera. Lo que ocurrió en realidad fue una acentuación de las prácticas rentistas, con un papel nuevo y más dinámico de los actores del sector financiero, basado en su capacidad de arbitraje de las diferencias de tasas de interés internas y externas, las burbujas crediticias en el mercado inmobiliario y el riesgo moral proveniente de la seguridad del rescate ante la crisis (Palma, 2012). Esta transferencia regresiva de ingresos (en cada país y entre economías deudoras y acreedoras) no estuvo asociada al aumento de la productividad, sino a su colapso. La liberalización financiera no significó un aumento de las tasas de inversión, sino una caída drástica bajo el impacto de la crisis de la deuda. La apertura de la cuenta de capital que se procesa a partir de los años noventa coincide con tasas muy bajas de formación de capital físico (en realidad, ni siquiera superiores, en promedio, a las de la década perdida). Solo se recupera la inversión con la bonanza de las materias primas después de 2004, y aun así llega a niveles inferiores a los de la década de 1970.

La liberalización de la cuenta de capital es un factor determinante de la economía política de la región y de los límites a la autonomía de la política económica. Por una parte, porque refuerza la ventaja de mantener recursos en activos financieros más líquidos y de corto plazo frente a activos físicos específicos que son la materialización del cambio estructural y resultan más vulnerables a los efectos del ciclo. Los activos financieros tienen mayor facilidad para evitar la tributación y más capacidad de respuesta ante las oportunidades de arbitraje, mientras que el resultado de la inversión en activos físicos (como construir una fábrica o comprar una máquina) está atado a lo que ocurra en el mercado del bien final. La respuesta racional del capital productivo es mantener cierta parte de su cartera de inversiones en activos financieros, ampliando la brecha entre los intereses de las grandes empresas, que pueden diversificarse de esta manera, y los capitalistas de menor porte y el mundo del trabajo.

Por otra parte, la apertura de la cuenta de capital actúa como una espada de Damocles sobre la política económica, al dar poder de veto a los agentes con más liquidez, en la medida en que la salida de capitales se intensifica si la política adopta una dirección que ellos perciben como menos confiable. Este poder de veto es significativo porque puede manifestarse en un plazo breve, de semanas o días, mientras que los inversores en activos físicos, y en especial los trabajadores, no cuentan con mecanismos equivalentes de defensa. Finalmente, la deuda pública en manos de los actores financieros no solo es una fuente importante de cuasirrentas de oligopolio, sino que también refuerza la eficacia de su poder de veto sobre las políticas monetaria y fiscal. Los encargados de la deuda pública se ven obligados a monitorear permanentemente la reacción de esos agentes (que se expresa en su demanda de títulos públicos) ante cualquier medida de política económica.

La historia económica de la República de Corea deja algunas enseñanzas respecto del papel de la apertura de la cuenta de capital. Ese país solo la liberalizó (de forma gradual) en los años noventa, cuando ya tenía una economía diversificada y competitiva. China mantuvo hasta 2010 un tipo de cambio depreciado como un instrumento complementario a una política industrial mediante la cual accedía a nuevos mercados y sectores. Estas economías han sido clasificadas como "basadas en la cuenta corriente" en el manejo del tipo de cambio y la política monetaria, mientras que las economías latinoamericanas serían dominadas por la cuenta de capital (Dooley, Folkerts-Landau y Garber, 2003; Frieden, 2015). En la región, la restricción externa frena la expansión de la economía antes de alcanzar el pleno empleo, a no ser en breves períodos, barrera que se agudiza con la tendencia a la apreciación del tipo de cambio, como se analizó en el capítulo III. 
Una pregunta que se presenta naturalmente es por qué la apreciación periódica del tipo de cambio real, con sus consecuencias de inestabilidad y crisis, ha sido tan persistente. Hay razones de economía política que explican este fenómeno. La apreciación es una gran fuente de rentas para los inversores que ingresan en períodos en que el tipo de cambio se valoriza y las tasas de interés en las economías periféricas son más altas que en los países centrales, y que salen masivamente cuando los riesgos de desvalorización aumentan, agudizando la intensidad de la crisis externa y tornándola una profecía autocumplida. Las burbujas que se generan en distintos mercados, sobre todo el inmobiliario, refuerzan el alza y acentúan la caída, proceso en el que se dan grandes transferencias de rentas que debilitan la inversión, el crecimiento y el aumento de la productividad?.

\section{Cambio estructural y diversificación productiva}

Las políticas afectadas por la economía política de la desigualdad son muy diversas. En esta sección interesa destacar las que tienen que ver con la diversificación de la estructura productiva. En términos amplios, estas se denominan políticas industrial y tecnológica, y abarcan lo que en otros contextos se ha llamado políticas de desarrollo productivo, políticas sectoriales y políticas relativas al sistema nacional de innovación. El foco en estas políticas se explica porque son imprescindibles para lograr un cambio en el patrón de producción y consumo en la región, como el requerido por el desarrollo sostenible y el gran impulso ambiental ${ }^{8}$.

La Comisión Económica para América Latina y el Caribe (CEPAL) sostiene que, en un mundo en que los patrones predominantes de producción y consumo se han vuelto insostenibles, la región debe adoptar un estilo de desarrollo basado en un gran impulso ambiental. Transformar estos patrones $-\mathrm{y}$, por consiguiente, la matriz energética, la base tecnológica, la articulación entre los distintos sectores y su peso relativo en la economía- requiere un salto cualitativo en las políticas industrial y tecnológica. Este salto es especialmente difícil de lograr en un mundo en que la revolución tecnológica redefine sistemáticamente la dirección e intensidad del progreso técnico, y, con ellas, los parámetros a partir de los cuales los agentes toman decisiones.

La experiencia internacional ofrece algunas enseñanzas importantes sobre el papel de las políticas de cambio estructural, que se resumen a continuación.

- Todos los países han usado y usan algún tipo de política sectorial, y esto es válido tanto para países en desarrollo como desarrollados (Stiglitz, 2014; Cimoli y Dosi, 2017). Los motivos son los más variados, como los relacionados con la carrera armamentista y espacial, la seguridad alimentaria, la prevención o mitigación de los efectos del cambio climático, y las demandas de los sistemas de salud, o los vinculados a objetivos económicos más tradicionales, como reducir el desempleo, diversificar la matriz productiva y aumentar en ella el peso de los sectores de alta tecnología.

- Existe una gran similitud entre los instrumentos de política de cambio estructural adoptados por los casos exitosos de convergencia internacional en la posguerra (la República de Corea, la provincia china de Taiwán y, más recientemente, China) y los adoptados por los casos (mucho más numerosos) de divergencia y fracaso de dicha política ${ }^{9}$. Más que en una diferencia de formulación e instrumentos, la clave del éxito o fracaso de la política de cambio estructural reposa en la fase de implementación.

- La principal diferencia que surge al comparar los casos exitosos y no exitosos es la capacidad de la política de definir y monitorear metas de desempeño, penalizando de manera efectiva las estrategias basadas exclusivamente en proteger cuasirrentas derivadas de los recursos naturales, la mano de obra barata o los privilegios políticos, y estimulando la generación de cuasirrentas derivadas del aprendizaje

\footnotetext{
Aldair Turner (2016) considera que la expansión exponencial del sistema financiero desde fines de los años ochenta es una gran externalidad negativa que compromete el funcionamiento del conjunto del sistema económico. Cecchetti y Kharroubi (2012) destacan un punto similar y encuentran una relación negativa (a partir de cierto punto crítico) entre el crecimiento del sector financiero, el crecimiento económico y el aumento de la productividad. La evidencia es clara: el crecimiento más rápido del sector financiero es malo para el crecimiento real agregado. Una interpretación de esto es que los auges financieros son inherentemente malos para el crecimiento tendencial.

8 Este concepto, introducido en CEPAL (2016), se discute en el capítulo VII.

9 En este contexto, la definición de éxito o fracaso solo atañe a la reducción de la brecha tecnológica, ya que ninguno de los ejemplos mencionados satisface plenamente la definición de desarrollo sostenible.
} 
y la innovación. Esta capacidad se relaciona con la construcción de coaliciones que sustenten política y socialmente las políticas industrial y tecnológica.

- La capacidad de los agentes y de las instituciones de aprender, evolucionar y ajustarse es primordial para que la política industrial cumpla sus objetivos. En un mundo incierto, en que los choques en los mercados financieros y en la tecnología son tan imprevisibles como de largo alcance, la capacidad de adaptarse tiene un papel incluso más importante que en condiciones de estabilidad global. Cuando existe esa capacidad, los aparentes fracasos en algunos sectores se transforman posteriormente en condiciones que permiten avanzar. Cuando dicha capacidad está ausente, los fracasos son sumamente costosos, lo que refuerza las barreras al desarrollo.

Las coaliciones en torno a una política se forman para crear o defender rentas o cuasirrentas de distinto tipo ${ }^{10}$. Algunas están asociadas a la innovación (cuasirrentas tecnológicas), otras al acceso a mano de obra barata (cuasirrentas lewisianas) o a recursos naturales abundantes (cuasirrentas ricardianas), y otras se crean mediante barreras a la entrada de nuevos competidores, basadas en economías de escala o barreras políticas (cuasirrentas del privilegio). El papel de la política industrial es administrar este proceso de creación y destrucción de rentas de manera de privilegiar a los innovadores y las cuasirrentas que provienen del conocimiento ${ }^{11}$.

Más específicamente, la política industrial y tecnológica debe transferir parte de las cuasirrentas derivadas de posiciones de privilegio, bajos salarios o recursos naturales para fortalecer a los actores que crean cuasirrentas a partir del aprendizaje y la innovación. Más aún, las cuasirrentas que crean estos últimos en muchos casos provienen de reducir o diluir las que obtienen las empresas en la frontera tecnológica en los países avanzados. La redistribución y creación de cuasirrentas tecnológicas a nivel interno guarda entonces correspondencia con la redistribución de cuasirrentas a nivel internacional (a favor del país periférico) cuando existe un proceso de cierre de la brecha tecnológica entre el centro y la periferia.

El problema político que encierra una estrategia de convergencia tecnológica de este tipo es sumamente difícil de resolver. Los sectores que obtienen cuasirrentas elevadas derivadas de los recursos naturales o del trabajo barato en general son muy poderosos en los países periféricos y pueden bloquear la política industrial. A su vez, los que reciben protección y subsidios (otorgados en función de una expectativa de aprendizaje y de aumentos de la productividad en el tiempo) podrían apoderarse de cuasirrentas del privilegio si no hay un monitoreo y un castigo efectivo ante la ausencia de inversión en aprendizaje tecnológico.

Las coaliciones políticas predominantes en una economía rezagada tecnológicamente tenderán a bloquear el esfuerzo de diversificación productiva o a convertir la política industrial en una nueva variedad de las cuasirrentas del privilegio. La razón es que la política industrial tiene costos para estos actores (financiar los bienes públicos necesarios para insertarse en la revolución tecnológica o pagar precios más altos por algunos bienes intermedios o de capital durante la transición), mientras que los beneficios son inciertos y pueden favorecer a actores muy distintos a los empresarios tradicionales (por ejemplo, nuevos empresarios con el capital humano y la disposición para asumir los riesgos de ingresar en sectores de más alta intensidad tecnológica). El incentivo para proteger y reproducir las cuasirrentas existentes aumenta con la brecha tecnológica respecto del mundo desarrollado, ya que esta refleja el grado de dificultad que enfrentan los actores empresariales en economías periféricas para competir mediante la innovación con los actores de las economías centrales ${ }^{12}$.

10 Las cuasirrentas son los pagos a un factor de producción por encima de su costo de oportunidad. Estos pagos pueden derivar de una rigidez temporal de un factor de producción o de posiciones de oligopolio, monopolio o poder político en las organizaciones. Las cuasirrentas se distinguen de las rentas porque estas se asocian a la oferta fija de un factor de producción (generalmente la tierra), mientras que las cuasirrentas son temporarias. Por ejemplo, el monopolio concedido por una patente puede expirar después de un cierto tiempo o nuevos productos y procesos pueden reducir la posición ventajosa inicial del innovador, aun en presencia de una patente. De la misma manera, la oferta del factor fijo por excelencia — la tierra— puede aumentar a medida que el progreso técnico vuelve productivas tierras que antes no lo eran. Las rentas de privilegio comprometen el dinamismo del sistema económico y no guardan relación con la contribución de los distintos actores a la productividad (Stiglitz, 2013, cap. 2).

11 Este punto lo resume Nochteff (1996, pág. 115): "En resumen, lo que se postula es que la economía está en proceso de desarrollo solo si las cuasirrentas tecnológicas predominan sobre los demás tipos de cuasirrentas. En caso contrario, los períodos de expansión son considerados "burbujas" con respecto al desarrollo apoyado en la innovación".

12 Kahn y Blackenburg (2009, pág. 11) sugieren que el éxito o fracaso de las políticas industriales se explica, precisamente, por la mayor o menor compatibilidad entre las coaliciones políticas y el manejo de rentas a favor del aprendizaje y la innovación. El principal argumento es que el manejo de rentas para la adquisición de tecnología no solo se ve limitado por las capacidades del Estado, sino también, y a menudo principalmente, por limitaciones políticas que impiden la puesta en marcha de estrategias específicas para el manejo de rentas. El éxito o el fracaso de las estrategias de manejo de rentas para la industrialización está, en gran medida, determinado por la compatibilidad de las estrategias tecnológicas e institucionales para el desarrollo tardío con limitaciones políticas que surgen de constelaciones de poder internas de la sociedad, así como de influencias transnacionales (externas). 
El manejo de las rentas debe verse desde una perspectiva dinámica. No todas las rentas del privilegio, los recursos naturales o la mano de obra barata son enemigos de la innovación. La clave es en qué medida estos tipos de cuasirrentas se usan para generar (o se transforman en) cuasirrentas de innovación. Un sector beneficiado por la política industrial (ya sea vertical u horizontal), que logra competir inicialmente con base en el apoyo que le proporciona esa política, combinará durante un cierto tiempo las cuasirrentas del privilegio con las que provienen del aprendizaje. Un sector intensivo en recursos naturales que usa la ventaja proporcionada por esos recursos para agregar conocimiento a la producción combinará las cuasirrentas ricardianas con las schumpeterianas, y una economía que inicialmente compite con base en tipos de cambio real muy altos y costo salarial muy bajo combinará rentas lewisianas y del privilegio con las schumpeterianas. Lo que importa en un proceso de desarrollo es que el peso de las cuasirrentas de la innovación aumente en el tiempo y que las transferencias de cuasirrentas entre sectores se realicen con ese objetivo.

El pleno acceso del mundo del trabajo a la salud y a la educación es una condición necesaria para que una política de desarrollo sostenible sea eficaz debido a las externalidades positivas que produce. Los efectos redistributivos de esas políticas deben darse no solo entre sectores económicos, sino también entre el capital y el trabajo, como parte de la creación de bienes públicos en un mundo basado en la competencia en capacidades.

Una economía muy dependiente de los recursos naturales o de la mano de obra barata genera una dinámica política que tiende a frenar la diversificación. Los actores con mayor poder económico ven como una amenaza la redistribución de rentas, ya sea hacia los sectores de menores ingresos o a favor de otros sectores productivos que compiten mediante la innovación. Estos actores no necesitan (sino de manera muy limitada) trabajadores con elevado capital humano; tienen más incentivos para invertir en actividades no productivas (como represión o corrupción), tienen menos incentivos para moverse hacia actividades donde la competencia en innovación es más intensa (especialmente cuando la brecha tecnológica es alta) y también tienen menos incentivos para invertir en bienes públicos (tenderán a producir los bienes de forma privada o como bienes de club, restringidos a un grupo pequeño de agentes).

En resumen, la política industrial y tecnológica para el desarrollo sostenible —en la dirección de un cambio estructural progresivo que incluya las dimensiones de absorción del progreso técnico, empleo de calidad y cuidado ambiental - será exitosa si las empresas favorecidas por las políticas crean cuasirrentas basadas en el conocimiento y si, pasado cierto tiempo, esas empresas dejan de ser favorecidas para que se apoye a sectores más dinámicos en el plano de la tecnología y de la demanda efectiva, configurando un proceso ascendente en las capacidades y presencia en los mercados mundiales.

\section{Desigualdad y fragmentación en las relaciones sociales}

La desigualdad no solo tiene consecuencias económicas, sino también políticas, sociales y culturales. Tiende a reproducir sociedades fragmentadas, con baja interacción social, limitada confianza recíproca, débil sentido de pertenencia, acotada percepción de proyectos comunes y poca propensión a la colaboración y a la valoración y defensa de los bienes públicos. Esto se manifiesta en diversos ámbitos de las relaciones sociales. En esta sección se analizan dos de ellos — la violencia y el respaldo a la democracia—, que se eligieron porque reflejan el poder de disgregación de las instituciones excluyentes en las sociedades de la región.

\section{Una región sin guerras, pero marcada por la violencia}

América Latina y el Caribe no es solo la región más desigual del mundo, sino también la más violenta —medida por la tasa de homicidios por cada 100.000 habitantes - si se excluyen áreas en guerra o conflictos armados. Aunque es una región de paz, en la que no existen enfrentamientos bélicos entre países y donde los conflictos armados internos han ido finalizando mediante negociaciones políticas, los homicidios dolosos alcanzan números mayores a los que corresponderían a su grado de desarrollo económico, político y social.

En 2015, la tasa mundial de homicidios fue de 8,3 por cada 100.000 habitantes, número que refleja una pequeña disminución respecto de 2010 (véase el gráfico VI.1). En ese contexto, todas las subregiones de 
América Latina y el Caribe sufrieron un aumento de la tasa de homicidios, aunque con gran heterogeneidad. En Centroamérica y México se dio la peor situación y la tasa quintuplicó la media global, al tiempo que los países del Caribe alcanzaron tasas de 25 por cada 100.000 habitantes, lo que significa que ocupan el tercer lugar entre las regiones que viven las peores situaciones en el mundo. El promedio de América del Sur es resultado de dos situaciones diferentes: mientras que la Argentina, Chile y el Uruguay mostraban tasas menores a la media global, en el Brasil, Colombia y Venezuela (República Bolivariana de) dicha media se multiplicaba por entre tres y siete. En términos dinámicos, sin embargo, el peor deterioro relativo se dio en el Cono Sur, donde la tasa aumentó más del $60 \%$.

\section{Gráfico Vl.1}

Tasa de homicidios en el mundo por cada 100.000 habitantes, por regiones y subregiones, 2010 y 2015

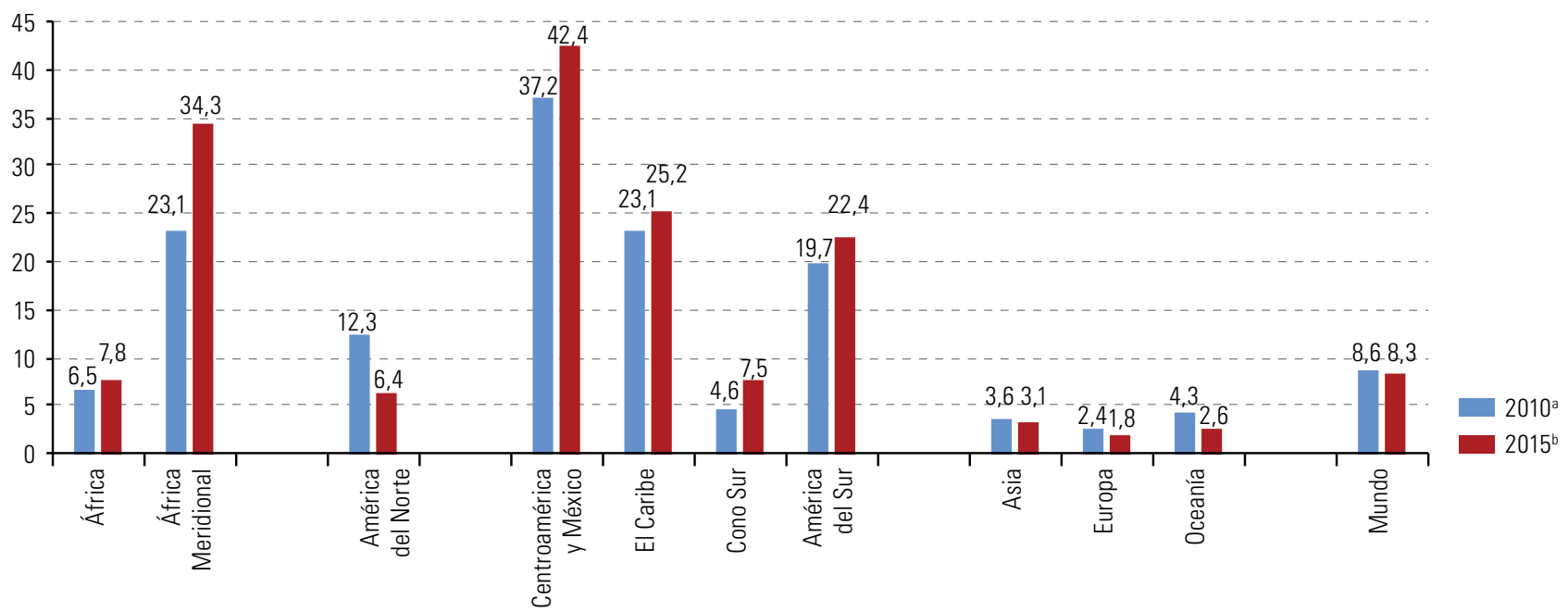

Fuente: Comisión Económica para América Latina y el Caribe (CEPAL), sobre la base de Oficina de las Naciones Unidas contra la Droga y el Delito (UNODC), Statistics [en línea] https://www.unodc.org/unodc/en/data-and-analysis/statistics.html, 2017.

a Para 2010, el promedio simple por subregiones incluye: África (47 países), África Meridional (5 países), América del Norte (4 países), Centroamérica y México (8 países), el Caribe (16 países), Cono Sur (3 países: Argentina, Chile y Uruguay), América del Sur (9 países), Asia (49 países), Europa (42 países), Oceanía (11 países), Mundo (110 países).

b Para 2015, el promedio simple por subregiones incluye: África (31 países), África Meridional (1 país), América del Norte (4 países), Centroamérica y México (5 países), el Caribe (4 países), Cono Sur (3 países: Argentina, Chile y Uruguay), América del Sur (7 países), Asia (22 países), Europa (33 países), Oceanía (3 países), Mundo (110 países).

La violencia y los altos niveles de homicidio no son fenómenos nuevos en el continente americano, en general, y en América Latina y el Caribe, en particular. Los elevados registros existen por lo menos desde la década de 1950 y disminuyeron a finales del siglo XX. Sin embargo, en las dos décadas del presente siglo la mejora se detuvo y se registró un marcado deterioro, en particular en México, el triángulo norte de Centroamérica y algunos países del Caribe.

Para el conjunto de la región, el origen de la violencia estaría cambiando de motivos políticos a causas vinculadas a la delincuencia común y al crimen organizado. En este contexto, ha ganado visibilidad y repudio el feminicidio en tanto expresión extrema de la desigualdad de las relaciones de género y el camino que aún queda por recorrer para garantizar a las mujeres el derecho a una vida libre de violencia. Su intensidad, sobre todo en el triángulo norte de Centroamérica y en la República Dominicana, es un indicador de la persistencia y gravedad de la violencia de género.

La relación entre desigualdad y violencia es compleja: la correlación positiva entre ambas en el mediano y largo plazo no explica su variación en el corto plazo. Tiende a confirmarse, mientras tanto, una correlación significativa entre la desigualdad y diferentes formas de muerte violenta, como el homicidio intencional en los países de menor desarrollo y el suicidio en los más desarrollados (Wilkinson y Pickett, 2009). 
En el gráfico VI.2, que vincula el coeficiente de Gini con la tasa de homicidios en 18 países de la región, se muestra que muy pocos países se encuentran por debajo de la media de tasas de homicidio a escala global. Hay excepciones, como Chile, donde conviven una alta desigualdad con bajas tasas de homicidio, y situaciones contrarias, como las de El Salvador o Venezuela (República Bolivariana de), que dan cuenta de tasas de homicidios muy altas y niveles de desigualdad relativamente bajos. El Brasil y México, por su parte, parecen ajustarse mejor al patrón que asocia una elevada desigualdad con un alto nivel de violencia.

\section{Gráfico Vl.2}

América Latina (18 paises): tasa de homicidios por cada 100.000 habitantes e índice de Gini (valores entre 0 y 1 ), 2014

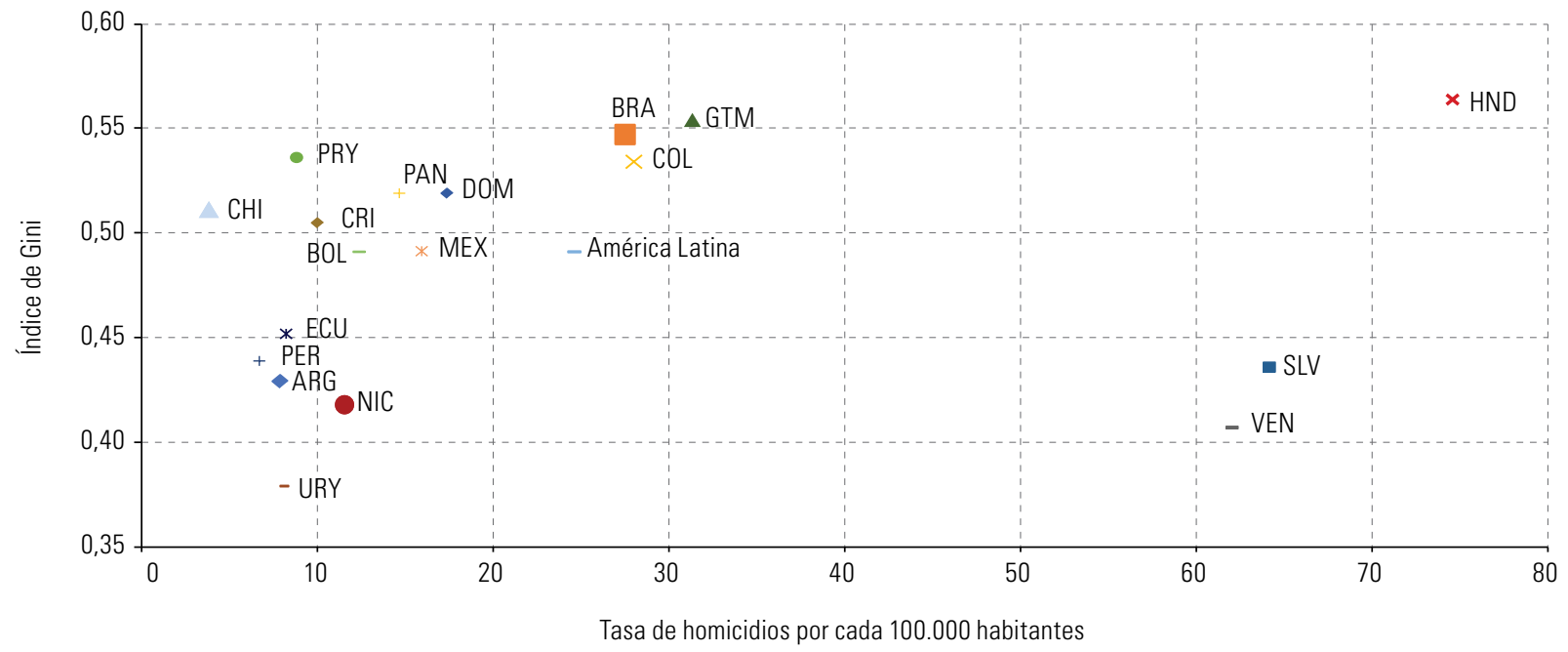

Fuente: Comisión Económica para América Latina y el Caribe (CEPAL), sobre la base de Oficina de las Naciones Unidas contra la Droga y el Delito (UNODC), Statistics [en línea] https://www.unodc.org/unodc/en/data-and-analysis/statistics.html, 2017; Base de datos CEPALSTAT [en línea] http://estadisticas.cepal.org/ cepalstat/WEB_CEPALSTAT/estadisticasIndicadores.asp?idioma=e y Banco Mundial, Índice de Gini [en línea] https://datos.bancomundial.org/indicador/ SI.POV.GINI?locations=AR-BR-GT-NI-UY, 2017

a El índice de Gini corresponde al último año disponible (2014). En los casos de la Argentina y Nicaragua, el dato es del Banco Mundial. Para las tasas de homicidios se dispone de datos hasta 2015. Sin embargo, para comparar con el último dato disponible del índice de Gini se recuperaron las cifras de 2014, excepto en Bolivia (Estado Plurinacional de) y Nicaragua (2012). De acuerdo con la Clasificación Internacional de Delitos con Fines Estadísticos, los homicidios intencionales incluyen: asesinato, matanza de honor, asalto grave que conduce a la muerte, muerte como resultado de actividades terroristas, asesinatos relacionados con la dote, feminicidio, infanticidio, homicidio voluntario, ejecuciones extrajudiciales, homicidios causados por el uso excesivo de la fuerza por agentes de la ley/funcionarios estatales. Los homicidios intencionales excluyen: muerte por intervenciones legales, homicidio justificable en legítima defensa, tentativa de homicidio intencional, homicidio sin el elemento de intención (homicidio no intencional); homicidio no negligente (no culposo) o involuntario, suicidio asistido o incitación al suicidio, feticidio ilegal eutanasia, muerte por conflicto armado.

En los estudios sobre violencia se distingue entre tasa efectiva y percepción subjetiva, esto es, entre el número de delitos cometidos y la percepción de inseguridad en la ciudadanía. Conforme a datos de Latinobarómetro para 2016, un 43\% de las personas en la región consideraba que podría ser víctima de un delito todo el tiempo o casi todo el tiempo, frente a solo un $13 \%$ que se consideraba completamente segura (véase el cuadro VI.1). Esta alta percepción de inseguridad, que llega a casi el $87 \%$ si se agregan las personas que se consideran posibles víctimas algunas veces u ocasionalmente, tiene implicaciones en la subjetividad social, la modificación de hábitos de conducta, la utilización de los espacios públicos, el aumento de los gastos en seguridad para el Estado, las empresas y las familias, la profundización de la segmentación territorial, la aceptación de medidas que restringen libertades, la indiferencia frente a los abusos en las políticas de seguridad e incluso el desprestigio del discurso sustentado en los derechos humanos.

Importantes recursos públicos que podrían destinarse al financiamiento de la inversión, las políticas de ciencia y tecnología o la protección social se canalizan hacia los rubros de seguridad. En un contexto de creciente inquietud por la inseguridad, esos gastos son inelásticos a la baja y con tendencia al alza, en la medida en que reducirlos implicaría un costo político elevado. Las políticas de ajuste fiscal rara vez tocan los rubros de seguridad; más bien, tienden a reducir la inversión pública e incluso la protección social. Así, entre 2000 y 2015, la región aumentó el gasto en defensa, seguridad y orden público del 1,7\% al 2,6\% del PIB (CEPAL, 2017). 


\section{Cuadro Vl.1}

América Latina (18 países): frecuencia con que las personas piensan que pueden llegar a ser víctimas de un delito ${ }^{a}$

(En porcentajes)

\begin{tabular}{|c|c|c|c|c|c|c|c|}
\hline Frecuencia & 2007 & 2009 & 2010 & 2011 & 2013 & 2015 & 2016 \\
\hline Todo o casi todo el tiempo & 38 & 31 & 33 & 39 & 44 & 41 & 43 \\
\hline Algunas veces & 35 & 39 & 35 & 37 & 28 & 28 & 29 \\
\hline Ocasionalmente & 18 & 21 & 21 & 16 & 16 & 17 & 14 \\
\hline Nunca & 8 & 9 & 10 & 7 & 12 & 13 & 13 \\
\hline
\end{tabular}

Fuente: Comisión Económica para América Latina y el Caribe (CEPAL), sobre la base de Latinobarómetro 2017 [en línea] http://www.latinobarometro.org/latOnline.jsp.

a La información corresponde a: Argentina, Bolivia (Estado Plurinacional de), Brasil, Chile, Colombia, Costa Rica, Ecuador, El Salvador, Guatemala, Honduras, México, Nicaragua, Panamá, Paraguay, Perú, República Dominicana, Uruguay y Venezuela (República Bolivariana de). Sin información para 2008.

El aumento de los gastos en seguridad se relaciona con lo que los estudiosos del derecho denominan "demagogia penal", que propugna castigos más severos, la disminución de los beneficios penitenciarios, la rebaja de la edad penal y la reinstalación de la pena de muerte, y que justifica, en casos extremos, las ejecuciones extrajudiciales. Esto se ajusta a la evolución del indicador de percepción de la seguridad. En 2015, en 18 países de la región, un 63\% de las personas consideraba que vivir en su país se había vuelto más inseguro, al tiempo que solo el 9\% pensaba lo contrario (véase el gráfico VI.3).

\section{Gráfico Vl.3}

América Latina (18 paises): percepción de la seguridad en el pais, 2007-2015

(En porcentajes)

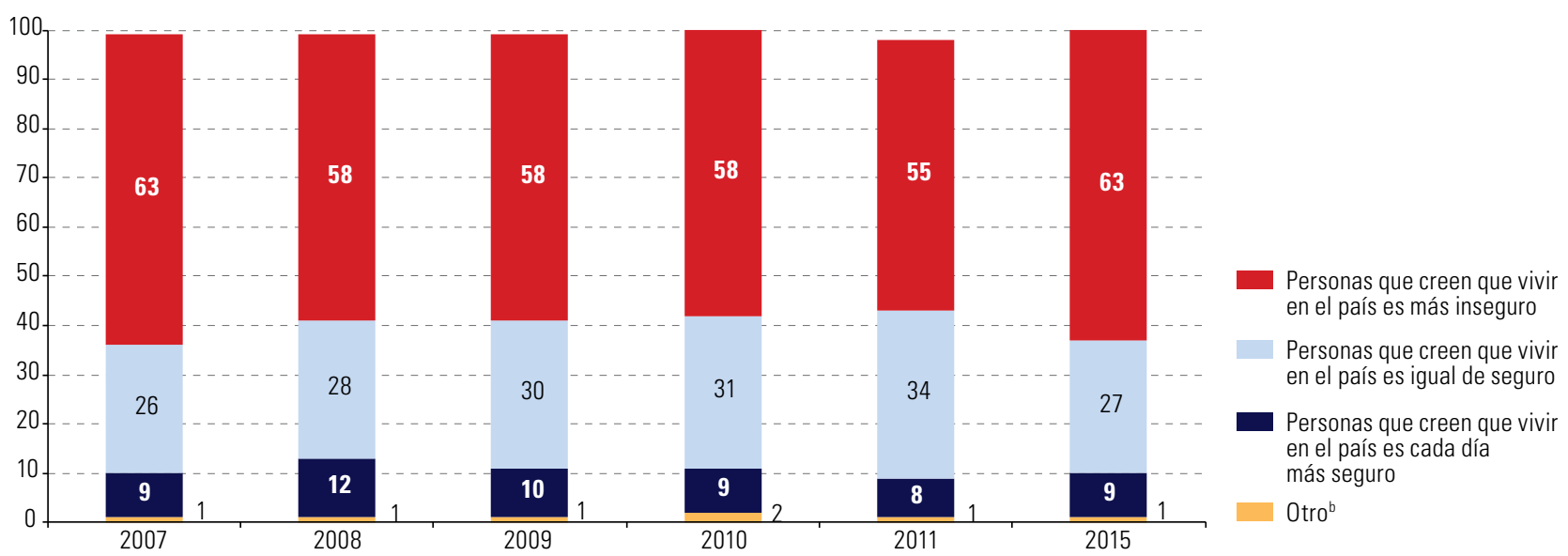

Fuente: Comisión Económica para América Latina y el Caribe (CEPAL), sobre la base de Latinobarómetro 2017 [en línea] http://www.latinobarometro.org/latOnline.jsp. Nota: La suma de los porcentajes puede no coincidir con el $100 \%$ debido al redondeo de las cifras.

a La información corresponde a: Argentina, Bolivia (Estado Plurinacional de), Brasil, Chile, Colombia, Costa Rica, Ecuador, El Salvador, Guatemala, Honduras, México, Nicaragua, Panamá, Paraguay, Perú, República Dominicana, Uruguay y Venezuela (República Bolivariana de).

b La categoría Otro incluye los porcentajes de las personas que no contestaron o no sabían al momento de realizar la encuesta.

\section{Insuficiente respaldo a la democracia}

Uno de los avances más importantes de la región es haber terminado con los regímenes y dictaduras militares frecuentes en el siglo pasado, que perpetraron graves violaciones a los derechos humanos. Hoy se realizan elecciones con regularidad y se ha consolidado la democracia política, aunque en un cuadro de gran heterogeneidad. Estos logros no están libres de riesgos y retrocesos. El respeto formal a la legalidad puede convivir con el debilitamiento de la democracia como orden político de plena vigencia de derechos y separación efectiva de poderes. 
A pesar de sus limitaciones, el retorno a la democracia y su normalización ha sido un proceso civilizatorio de enorme importancia. Sin embargo, no ha ido acompañado de una expansión equivalente de la plena igualdad de derechos económicos y sociales. El efecto redistributivo de los regímenes democráticos ha sido limitado. Aún hay brechas en el goce de los derechos políticos, económicos y sociales, y no ha sido suficientemente cerrada la brecha entre ciudadanía política y ciudadanía social. No deja de ser una importante señal de alerta que, entre 1995 y 2016, el porcentaje de la población que considera que la democracia es preferible a cualquier otra forma de gobierno no supera el $60 \%$. Además, un $20 \%$ considera que en algunas circunstancias es preferible un gobierno autoritario y un $20 \%$ es indiferente si se le da a elegir entre un régimen democrático y uno autoritario (véase el gráfico VI.4).

\section{Gráfico VI.4}

América Latina: apoyo a la democracia, 1995-2016a

(En porcentajes)

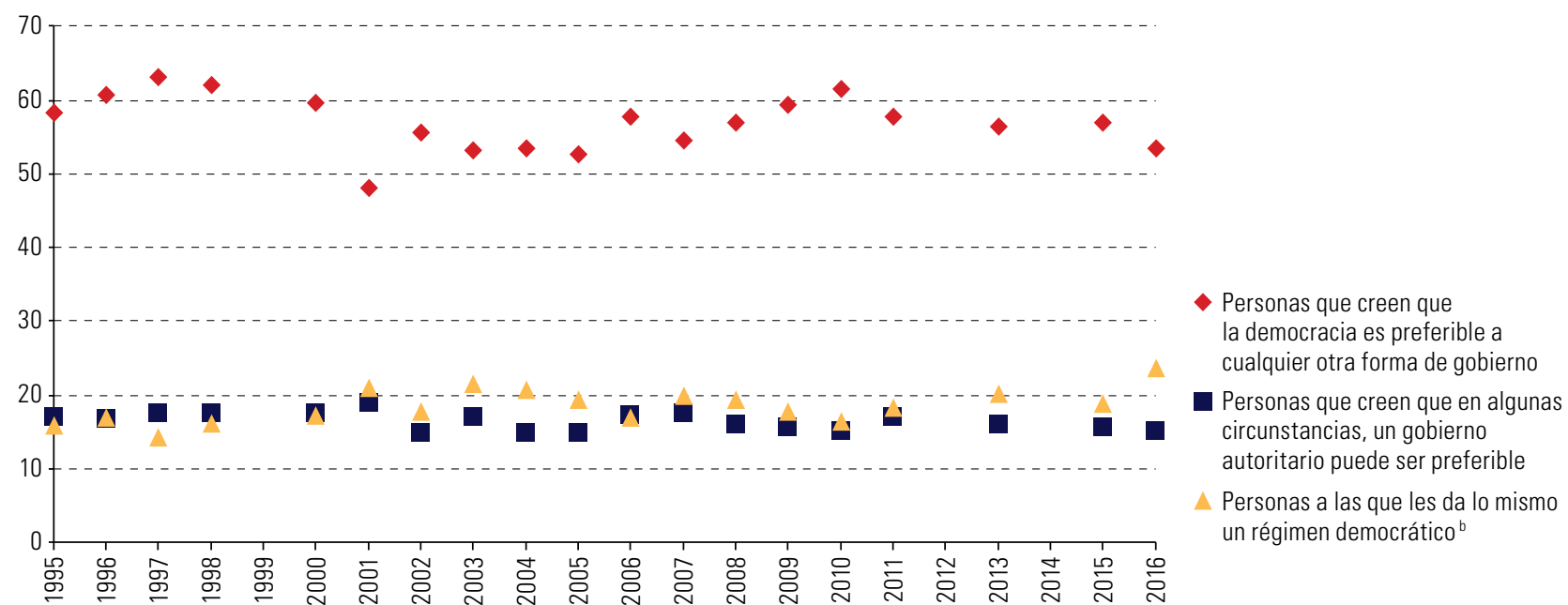

Fuente: Comisión Económica para América Latina y el Caribe (CEPAL), sobre la base de Latinobarómetro 2017 [en línea] http://www.latinobarometro.org/latOnline.jsp. a No se dispone de información para 1999, 2012 y 2014. En 1995 la información corresponde a ocho países (Argentina, Brasil, Chile, México, Paraguay, Perú, Uruguay y Venezuela (República Bolivariana de)). En el período 1996-1998 corresponde a 17 países (Argentina, Bolivia (Estado Plurinacional de), Brasil, Chile, Colombia, Costa Rica, Ecuador, El Salvador, Guatemala, Honduras, México, Nicaragua, Panamá, Paraguay, Perú, Uruguay y Venezuela (República Bolivariana de)). En el período 20002002 corresponde a 17 países (Argentina, Bolivia (Estado Plurinacional de), Brasil, Chile, Colombia, Costa Rica, Ecuador, El Salvador, Guatemala, Honduras, México, Nicaragua, Panamá, Paraguay, Perú, Uruguay y Venezuela (República Bolivariana de)). En 2003 corresponde a 16 países (Argentina, Bolivia (Estado Plurinacional de), Brasil, Chile, Colombia, Costa Rica, Ecuador, El Salvador, Guatemala, Honduras, México, Panamá, Paraguay, Perú, Uruguay y Venezuela (República Bolivariana de)). En el período 2004-2011 corresponde a 18 países (Argentina, Bolivia (Estado Plurinacional de), Brasil, Chile, Colombia, Costa Rica, Ecuador, El Salvador, Guatemala, Honduras, México, Nicaragua, Panamá, Paraguay, Perú, República Dominicana, Uruguay y Venezuela (República Bolivariana de)). En 2013,2015 y 2016 corresponde a 18 países (Argentina, Bolivia (Estado Plurinacional de), Brasil, Chile, Colombia, Costa Rica, Ecuador, El Salvador, Guatemala, Honduras, México, Nicaragua, Panamá, Paraguay, Perú, República Dominicana, Uruguay y Venezuela (República Bolivariana de)).

${ }^{\mathrm{b}}$ No se incluye el porcentaje de personas que no sabe o no responde a la pregunta.

Lo expuesto muestra que grandes segmentos de la población están insatisfechos con los resultados de una democracia poco efectiva a la hora de reducir las desigualdades, deficiente en el desempeño de los órganos del Estado, poco confiable en materia de probidad de servidores públicos y con alto riesgo de captura de las instituciones públicas por parte de los grupos de poder e interés. El insuficiente respaldo a la democracia como régimen y bien público no puede atribuirse mecánicamente a la persistencia de las desigualdades en la región, ya que también hay factores políticos, sociales y culturales en juego. No obstante, puede conjeturarse que la profundidad de las desigualdades, su persistencia y su resiliencia frente a políticas orientadas a reducirla juegan un papel en la indiferencia, el desapego y la limitada vida cívica y política en la región.

Otra señal de alerta es la disminución de la percepción ciudadana del nivel de desarrollo de la democracia. A pesar de que la valoración de los regímenes de la región como totalmente democráticos subió del $6 \%$ al $11 \%$ entre 1997 y 2016 , también aumentó del $5 \%$ al $11 \%$ el porcentaje de personas que los consideraron no democráticos (véase el gráfico VI.5). 


\section{Gráfico VI.5}

América Latina: percepción ciudadana del nivel de desarrollo de la democracia, 1997 y $2016^{a}$

(En porcentajes)

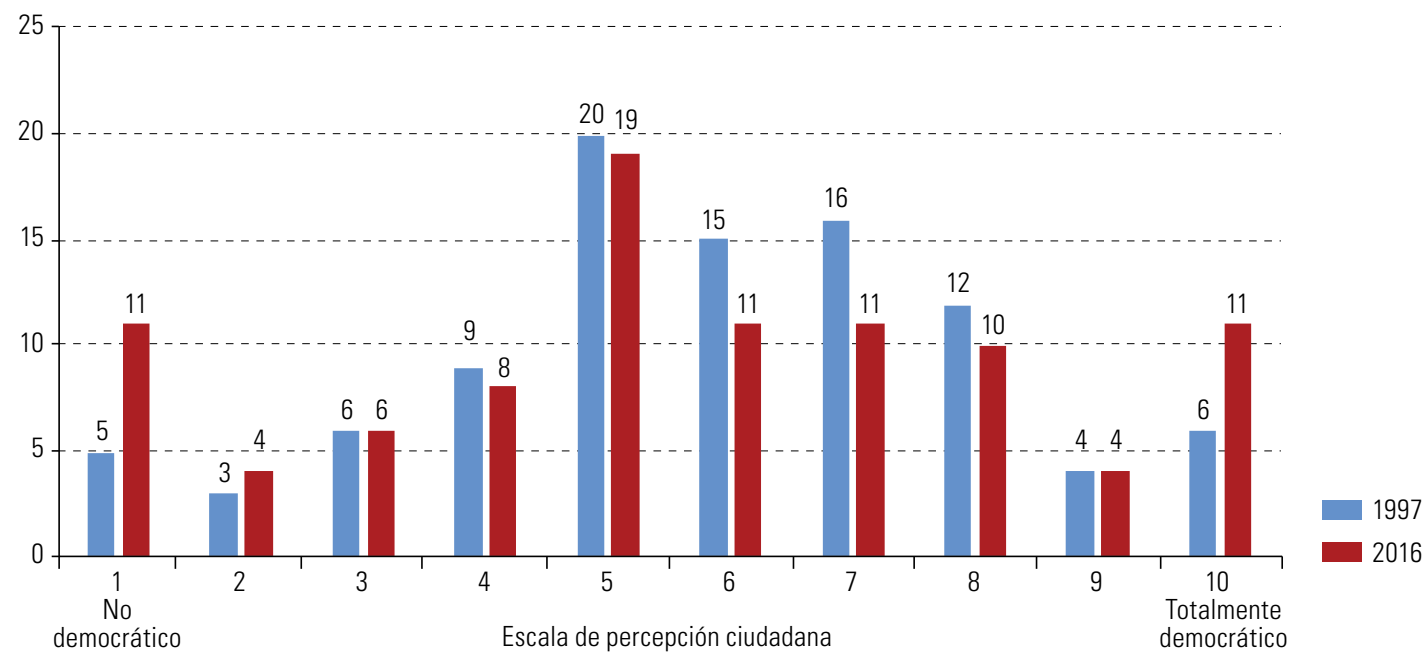

Fuente: Comisión Económica para América Latina y el Caribe (CEPAL), sobre la base de Latinobarómetro 2017 [en línea] http://www.latinobarometro.org/latOnline.jsp.

La desigualdad y las privaciones asociadas a la pobreza tienen implicaciones en la participación de los sectores con menores ingresos y mayores carencias en los asuntos públicos. En los países en donde el voto no es obligatorio, la tasa de participación electoral de esos sectores es menor -en algunos casos notablemente menor- que la de los sectores de ingresos medios y altos, lo que debilita su capacidad de incidencia en los asuntos públicos. Además, es frecuente que entre los más pobres operen redes de clientela y mecanismos ilegítimos de inducción del voto. Se reproduce así una democracia insuficiente en calidad y capacidad redistributiva, que se alimenta de una ciudadanía con márgenes limitados de autonomía y capacidad efectiva de incidencia en las decisiones públicas.

\section{Cultura del privilegio, rentismo y desigualdad}

Pensar los desafíos del desarrollo desde la economía política pone de relieve la importancia de los actores, sus intereses y su poder para incidir en la política y en las políticas, así como de las instituciones que orientan sus comportamientos. Y nada está más enraizado en las instituciones y los actores que la cultura entendida como visión de mundo, valores y normas que orientan proyectos y acciones, y formas de relacionarse con la naturaleza y con los demás. Se habla, por ejemplo, de cultura política, de cultura cívica, de cultura ambiental e incluso de cultura productiva para enfatizar dimensiones del desarrollo que no son tanto objeto de política, sino rasgos que, al formar parte de un patrimonio intangible de la sociedad, pueden favorecer o trabar la profundización de la democracia, la transformación de la estructura productiva, la sostenibilidad en relación con recursos estratégicos y calidad de vida, o la solidaridad colectiva. Así como el ambiente institucional en que los agentes interactúan y deciden es clave para las trayectorias de crecimiento y distribución de sus frutos, también es clave la cultura como sustrato en que se asientan las instituciones o como conjunto de valores desde los cuales se debaten y formulan decisiones estratégicas.

Aunque la cultura no determina de manera absoluta los estilos de desarrollo, la sostenibilidad del crecimiento y la distribución de sus frutos, sí los condiciona en una u otra dirección. Por ello, importa considerar la dimensión cultural del desarrollo, a sabiendas de que los cambios culturales tienden a darse en ciclos más largos de tiempo que los cambios tecnológicos o los cambios en políticas. De manera inversa, la cultura también puede moldearse y transformarse desde la difusión del cambio técnico y desde la política y las políticas. 
Existe una dialéctica entre cultura e instituciones que puede surtir efectos virtuosos o viciosos en la dinámica del desarrollo. Una cultura proclive a la innovación, el cuidado ambiental y la igualdad de derechos, por ejemplo, tenderá a plasmarse en instituciones que promuevan un desarrollo sostenible con la igualdad como valor fundamental. En esta dialéctica, la economía política es un eslabón clave, puesto que pone en relación valores y prácticas colectivas internalizadas con los esfuerzos de gestión y planificación para orientar el desarrollo en una dirección específica. La política y las políticas pueden reproducir y consolidar relaciones sedimentadas entre cultura e instituciones (o entre valores, organizaciones y prácticas establecidas) o, por el contrario, apuntar a modificar estas relaciones.

La relación entre cultura e instituciones es de determinación recíproca, y las instituciones, en la medida en que incluyen normas, disposiciones y comportamientos, se cimentan en la cultura, o sea, en visiones de mundo y de sociedad. Hay, a la inversa, transformaciones político-institucionales que repercuten en la cultura del desarrollo, vale decir, los valores que más profunda y capilarmente afectan el modo en que la sociedad se entiende para producir, distribuir capacidades y oportunidades, y velar por la sostenibilidad de cara a las futuras generaciones.

América Latina y el Caribe vive hoy una inflexión crucial en las tensiones entre dos matrices opuestas de la cultura del desarrollo: i) la cultura del privilegio, que ha predominado históricamente, y ii) la cultura de la igualdad, que emerge en el horizonte de la igualdad de derechos, como valor fundamental de las democracias del siglo XXI, a la luz de crecientes demandas ciudadanas en el ámbito social y del reconocimiento recíproco.

La cultura del privilegio es un sistema de valores que ordena prácticas establecidas, en el que se considera aceptable que un grupo de la población, caracterizado jerárquicamente por su adscripción étnica o racial o de género, por su posición socioeconómica, por su pertenencia a élites políticas o culturales, por su estatus de clase o por su filiación sanguínea o de herencia, tenga ventajas sobre el resto de la sociedad. Estas ventajas se dan con referencia a las condiciones para el desarrollo de capacidades y la formación de capital cultural; el uso de redes de relaciones para obtener contratos y hacer negocios, y acceder a mejores puestos de trabajo y a mayores remuneraciones y facilidades de financiamiento; el poder en instancias de deliberación o decisión; la voz en los circuitos comunicacionales donde se imponen ideas, ideologías y agendas políticas; el acceso a recursos públicos para beneficio privado; la impunidad o facilidades especiales frente a la justicia ante hechos relacionados con delitos económicos, daños a terceros, formas ilícitas de poder sobre otros y discriminación; y la capacidad de presión, negociación, manipulación y veto frente a políticas y estamentos del gobierno o del Estado.

Como se señaló en el capítulo I, la cultura del privilegio denota la naturalización del privilegio en la sociedad, o al menos en el imaginario colectivo de algunos grupos sociales. Esto implica, por una parte, que quienes detentan privilegios lo asumen como dado y deseable. La cultura del privilegio supone, pues, la normalización de una asimetría en los derechos y deberes de ciudadanía que consagra y reproduce un orden desigual en términos de titularidad efectiva de derechos, participación en la deliberación política, distribución de capacidades y beneficios del progreso económico y social.

Esta cultura del privilegio en la región tiene una raigambre histórica que se remonta a los patrones de colonización, caracterizados por la apropiación de recursos naturales por parte de élites políticas y económicas, la explotación forzada de fuerza de trabajo, la privación de plena ciudadanía para gran parte de la sociedad y la concentración del poder sobre bases adscriptivas y estamentales.

La cultura del privilegio también se manifiesta en el racismo y la deshumanización que fundamentó la trata transatlántica de africanos y la práctica de la esclavitud, que, en algunos países, sobrevivió como forma de subyugación y explotación económica hasta fines del siglo XIX. El legado de la esclavitud, las relaciones sociales producidas por su práctica y las múltiples discriminaciones que persisten hasta hoy tienen un impacto crucial en las desigualdades étnico-raciales en la región. En 2013, los países miembros de la Comunidad del Caribe (CARICOM) formaron una Comisión de Reparaciones de la Comunidad del Caribe para establecer un caso ético y legal para el pago de reparaciones por parte de los gobiernos de los antiguos poderes coloniales a las naciones de la CARICOM en razón de los crímenes del genocidio contra los pueblos originarios, la trata transatlántica de esclavos y el sistema racista de la esclavitud. El Plan de Diez Puntos de la CARICOM para 
la Justicia Reparatoria, además de destacar aspectos de identidad histórica y cultural, vincula el legado del sistema de esclavitud con los problemas contemporáneos del desarrollo subregional, como las carencias en materia de salud pública, educación y transferencia de tecnologías, resaltando su profundo y persistente impacto histórico.

Esa cultura, surgida durante el régimen colonial, pasó por distintas fases en las repúblicas del siglo XIX y en las primeras etapas de modernización en el siglo XX, perpetuando y recreando un patrón de asimetrías sociales en virtud del cual una parte de la población (las élites en que se concentró el poder político y económico) mantuvo privilegios en la apropiación de rentas derivadas sobre todo del acceso a los recursos naturales y al financiamiento público, en patrones de consumo que imitaban los de sus pares en el mundo industrializado, en relaciones estrechas con mercados externos, en concentración de poder político (o, en su defecto, fáctico) y en participación en redes que facilitan la preservación de situaciones de privilegio en múltiples ámbitos (laboral, de justicia, de financiamiento, de influencia, de comunicación, de acceso a mercados, de concesiones y exenciones).

Esta cultura del privilegio fue impugnada por los grandes movimientos sociales, las revoluciones populares y los liderazgos de matriz nacional-popular, y también fue cuestionada por la fuerte valorización de la democracia política desde fines del siglo XX y el ascenso de las demandas y los derechos sociales en la primera década del siglo XXI. En la escena democrática han irrumpido actores que han ampliado la contestación de privilegios en la relación capital-trabajo, y la relación entre clases sociales, hacia otras formas en que los privilegios se ejercen en relaciones de género, sexo, condición étnico-racial y territorio.

No obstante, la cultura del privilegio sigue siendo reproducida y expresada por sectores de la sociedad que movilizan sus redes y recursos para preservar asimetrías de base, marcadas por la cuna, el patrimonio, el capital cultural y la dotación de activos. Como las instituciones productivas y de política económica, esta cultura también está enraizada en las estructuras económicas en que se define el protagonismo de los actores y el poder que detentan.

La relación entre cultura del privilegio y heterogeneidad estructural en América Latina y el Caribe es bidireccional. Las brechas en productividad, la articulación asimétrica con mercados internacionales, la apropiación concentrada de la riqueza en la explotación de recursos naturales y la baja disposición a implementar reformas estructurales se enmarcan en una herencia cultural signada por relaciones de privilegio. Hay imbricación entre una estructura productiva que opera como fábrica de la desigualdad y una cultura del privilegio enraizada en una historia de asimetrías en los recursos productivos, el desarrollo de capacidades y los espacios de influencia.

Existe, además, una fuerte relación entre cultura del privilegio y rentismo. El uso de condiciones de privilegio para capitalizar la explotación de recursos naturales con escaso valor agregado, aprovechar el bajo costo de la fuerza de trabajo para mantener bajos costos de producción y competir sin grandes esfuerzos en innovación, utilizar la financierización para apropiarse de rentas especulativas o perpetuar una fiscalidad débil y el uso de recursos públicos para beneficio privado se nutren de una matriz común. El privilegio se expresa aquí como acceso privativo a estas fuentes de renta. Se repite, bajo distintas formas, la apropiación selectiva y concentrada de oportunidades de riqueza con bajos niveles de inversión e innovación, y altos niveles de desigualdad.

La cultura del privilegio tiene una estrecha relación con estructuras de concentración de recursos e instituciones de concentración de poder. Cuanto más fuerte es la cultura del privilegio, más tiende a darse una relación disfuncional entre instituciones y estructuras, vale decir, menos innovación hay en ambos lados porque el sistema de privilegios permea estructuras e instituciones, porque los poderes fácticos tienen una capacidad de veto sobre el cambio institucional que la voluntad política no logra torcer o porque en una cultura del privilegio hay recompensas mutuas entre élites políticas y económicas que desmovilizan. En la cultura del privilegio también importan las instituciones cuando operan al servicio de los grupos que detentan privilegios, en campos tan diversos como la justicia penal y financiera, las regulaciones tributarias y el control impositivo, el régimen de propiedad de la tierra, el control de poblaciones en riesgo o de poblaciones consideradas un riesgo para terceros, y las regulaciones en el trato entre géneros, pueblos indígenas o grupos étnicos. 
Pero no todo es fatalidad. Desde la política y las políticas, las instituciones también pueden generar transformaciones. En relación con la estructura, las instituciones pueden reforzar la heterogeneidad estructural como fábrica de la desigualdad o bien revertir dicha heterogeneidad mediante políticas industriales, fiscales, sociales y del mercado de trabajo. Las reformas institucionales se forjan para transformar las estructuras desde la acción y regulación públicas. Otras instituciones se vuelven necesarias, por ejemplo, para avanzar hacia una sociedad del conocimiento, responder a demandas de mayor bienestar y oportunidades, y cambiar la forma de producción para mejorar la inserción en la economía internacional.

El impulso desde la creación o el cambio de instituciones puede, por otra parte, tensionar estructuras consideradas anacrónicas, injustas y disfuncionales al desarrollo. Este cambio institucional responde tanto a demandas sociales de igualdad y mayor acceso a los frutos del progreso, como a la emergencia de tecnocracias públicas con nuevas visiones sobre cómo orientar la economía y los patrones productivos. No es claro ni está garantizado que estos cambios socaven la cultura del privilegio, pero sí son una condición necesaria. La dialéctica entre cambio institucional y cambio estructural es positiva, siempre que se oriente hacia mayores derechos adquiridos, menores brechas sociales, mayor control y sanción sobre prácticas abusivas, mejor distribución de capacidades en los términos que demanda la sociedad del conocimiento, mayores espacios de cooperación de los actores laborales y productivos, y un compromiso más claro entre la iniciativa privada y el apoyo público. Todos estos elementos fortalecen una cultura de derechos ciudadanos y, por lo mismo, socavan la cultura del privilegio.

En síntesis, desde la perspectiva de la economía política, la cultura del privilegio se expresa en instituciones y prácticas entronizadas en sectores en los que esos privilegios se ejercen en sentido contrario a la orientación del desarrollo planteada en este documento: la conservación de grandes desigualdades sociales y la resistencia a reformas de sesgo redistributivo, una cultura productiva con fuerte componente rentista y escaso impulso a la innovación, y un modelo de desarrollo en el que la dimensión de sostenibilidad, sobre todo ambiental, tiene débil presencia. Esta cultura del privilegio coincide con instituciones excluyentes, es decir, instituciones que movilizan mecanismos de segregación, discriminan el acceso de diferentes grupos de población a capacidades y oportunidades, y reproducen altos niveles de desigualdad y concentración de riqueza. De manera inversa, las instituciones igualitarias, al difundir capacidades y oportunidades, y sancionar todo tipo de discriminación y segregación, erosionan la cultura del privilegio y permiten ir construyendo una cultura ciudadana centrada en la igualdad de derechos. Lo que en un momento puede darse como si fuera natural -los privilegios de unos en detrimento de otros-, en otro momento puede impugnarse desde las demandas sociales y desde políticas en favor de la igualdad y las dinámicas comunicacionales que movilizan.

\section{Los campos de la cultura del privilegio}

La igualdad de derechos tiene un largo camino por recorrer. La cultura del privilegio implica la negación del vínculo social de reciprocidad. A la inversa, la ausencia de este vínculo es lo que alimenta la cultura del privilegio, que se funda en una relación asimétrica en distintos aspectos: posibilidad de actuar, poder, retribuciones, reconocimientos, accesos, vínculos. A continuación, se identifican algunos de los campos en que se ejerce esta cultura.

La segregación territorial refuerza la pertenencia en función del ingreso, el capital cultural y las redes de relaciones. Las grandes ciudades trazan verdaderos mapas de la cultura del privilegio en que se combina lo estético, lo cultural y lo social. El lugar define la trayectoria tanto física como biográfica. En las grandes metrópolis latinoamericanas hay zonas urbanas donde los bolsones de pobreza y marginalidad operan como profecías autocumplidas de fracaso escolar, precariedad laboral y maternidad precoz. El lugar marca una línea divisoria entre afortunados y condenados, que no es definitiva ni debe verse con el sesgo de la fatalidad, pero que implica probabilidades muy diferentes en los guiones de vida.

Esto se extiende a países enteros: en el Brasil o el Perú, por ejemplo, nacer en los municipios, estados o departamentos más pobres o de mayor dispersión poblacional implica tener una esperanza de vida más corta que la que se tiene al nacer en las grandes ciudades o en zonas más ricas. La localización geográfica 
como fuente de privilegios se multiplica estableciendo diferencias en las ciudades y entre zonas geográficas. En contrapartida, el barrio o la comuna pobre se estigmatiza, lo que traba la inclusión.

La segmentación en la educación hace de esta un espacio de diferenciación para la preservación de privilegios. Los colegios de élite de alto costo, cuyas barreras de entrada se asocian a redes de relaciones, pertenencia a grupos específicos y capital cultural de origen, reproducen estas diferencias entre generaciones. La vida en la escuela fecunda, a su vez, redes de relaciones para la generación siguiente. El efecto de pares con mayor capital cultural y el apoyo familiar para el desarrollo de capacidades producen un efecto de blindaje, una homogeneidad positiva que marca una diferencia y un privilegio respecto de quienes no acceden a esas escuelas.

La atención sanitaria es otro campo de la cultura del privilegio. El contraste en el trato entre la atención pública y la privada exacerba la percepción del privilegio. Quienes se atienden en el sistema público se sienten discriminados por tener que soportar largas esperas para recibir atención, por los meses de demora para acceder a consultas por patologías cuya atención oportuna significa una diferencia en el bienestar y la calidad de vida, por el trato que reciben del personal profesional, paraprofesional y administrativo en los centros de atención y por las condiciones inhóspitas que enfrentan cuando deben internarse o aguardar en salas de espera atiborradas. El derecho a la salud se vive como jerarquía de ciudadanos de primera y segunda categoría.

El acceso desigual a la justicia se da según el nivel socioeconómico, la localización geográfica e incluso la condición étnico-racial y el género. La cultura del privilegio se fortalece cada vez que el dinero o los contactos marcan la diferencia entre ser o no ser sancionado por un delito. También hay privilegios en que la diferencia está marcada por prejuicios y discriminaciones que sedimentan sesgos en la justicia respecto de las mujeres, los indígenas, los jóvenes de sectores urbanos populares, las personas lesbianas, gais, bisexuales, transgénero e intersexuales (LGBTI) y los afrodescendientes.

Un extremo dramático se da en el sistema penal. Las cárceles latinoamericanas están hacinadas, fuera de control y sobrepasadas por la violencia, y parte de la población carcelaria está a la espera de la resolución de sus causas, muchas veces con prisión preventiva y procesos que no avanzan. El contraste entre esta falla en la protección judicial, en un extremo, y la semiinmunidad de cuello blanco, en el otro, refuerza la cultura del privilegio.

Las redes de influencia son decisivas en materias tan diversas como el acceso a los empleos públicos de alta remuneración y a los directorios de empresas, la adjudicación de licitaciones de obras y servicios privatizados, la obtención de fondos públicos de inversión o subsidio, el acceso fácil al financiamiento, las asimetrías de información para inversiones de rápida capitalización, la agilización de trámites, la obtención de favores públicos y la reducción de tiempos de espera en servicios públicos. La persistencia de redes de influencia como mecanismo incluyente-excluyente en múltiples accesos refuerza la cultura del privilegio porque ratifica un régimen de diferencias en logros basado solamente en sistemas de pertenencia. Así como existe discriminación de género, con privilegios para los hombres cuando, ante un mismo nivel educacional o igual capacidad para un puesto, la retribución en ingresos es menor para las mujeres, del mismo modo, ante similares logros educativos, la probabilidad de acceder a un puesto de trabajo de mayor calificación o mejor remunerado es más alta cuando se tienen redes de influencia definidas por origen de clase o estatus.

El poder de veto que ostenta el mundo empresarial y financiero frente a poderes representativos no es nuevo: es un poder fáctico. Sus prácticas incluyen decisiones privadas y discrecionales que pueden debilitar una agenda pública e incluso poner en jaque un gobierno. La idea de que el veto es posible mediante el juego de poderes fácticos forma parte de una cultura del privilegio. El fortalecimiento de la institucionalidad democrática permite mitigar estas prácticas, pero no las suprime. Reaparecen cuando se las creía obsoletas o cuando los actores que las ejercen consideran que pueden generar, ante políticas que consideran adversas, situaciones de caos financiero, escasez de oferta, desprestigio de líderes políticos en los medios de comunicación, fuga de capitales o contracción de la inversión. 


\section{Fortalecer la cultura de la igualdad erosiona la cultura del privilegio}

El refuerzo mutuo de la cultura e institucionalidad democráticas lleva a un cuestionamiento cada vez más frontal de la cultura y el ejercicio del privilegio. La cultura democrática debe confrontar la cultura del privilegio y lo hace en los aspectos que se detallan a continuación.

En primer lugar, en la defensa de grupos o sectores de la población discriminados, negados o excluidos de los beneficios del progreso y de reciprocidad en el trato. Las demandas de movimientos de mujeres, indígenas y afrodescendientes, junto con otras en campos como la orientación sexual y la identidad de género, la identidad generacional o la diversidad cultural en general, interpelan día a día a la sociedad y confrontan las formas seculares de discriminación y de ejercicio de privilegios por género, sexo, condición étnico-racial y generación. El derecho a la diferencia va de la mano, o se complementa, con la igualdad de derechos.

En segundo término, la cultura democrática, cuando se refuerza y activa con la institucionalidad democrática, se traduce en menor tolerancia al ejercicio de privilegios y mayor empoderamiento para impugnarlos. Cuando esa cultura y esa institucionalidad se encuentran, funciona el efecto demostración: siempre que un privilegio no solo es impugnado, sino que queda reconocido como éticamente inadmisible, procesado en una instancia jurídica o sancionado políticamente, tiene un efecto simultáneo en una práctica puntual y en la cultura en que se asienta. Denunciar, interrumpir y sancionar un privilegio es interpelarlo como cultura.

En tercer lugar, la primera década del siglo XXI registra en los regímenes democráticos de la región un amplio abanico de reformas constitucionales, sociales, fiscales y judiciales surgidas al calor de mayores demandas de bienestar, igualdad efectiva de derechos, presencia del Estado y no discriminación. Estas reformas tienen una eficacia política y práctica, y un valor comunicacional. Los temas son muy diversos: pensiones universales, exigibilidad jurídica de prestaciones sociales, asambleas constituyentes de amplia participación, incorporación de las demandas históricas y del reconocimiento de los pueblos, leyes y procedimientos para sancionar la corrupción, reformas tributarias para gravar ganancias y rentas, sistemas de cuidado infantil y de protección social. Hay un camino de ida y vuelta entre una mayor conciencia sobre la igualdad de derechos y las reformas en el campo de la política y la justicia que movilizan a la sociedad con instrumentos para protegerse de riesgos y abusos. La eliminación del carácter mercantil de las prestaciones sociales en algunos países de la región es una poderosa señal en pro de una cultura de la igualdad de derechos. Esto marca una inflexión respecto de las décadas precedentes de sesgo privatista en lo social o con pocos logros en esa área, y va de la mano de un cambio en la cultura ciudadana que afirma la dignidad y la asocia a derechos efectivos y no solo nominales.

Como anverso y reverso de la moneda, una fiscalidad progresiva y una política social expansiva concurren para institucionalizar la sanción a la cultura del privilegio. Si las reformas en favor de un mayor bienestar social, sobre todo asociado a la dignidad ciudadana, erosionan la cultura del privilegio, desandar estas reformas genera un escepticismo que infunde nuevos bríos a la cultura del privilegio. De allí que también sea decisivo cuidar las conquistas y evitar que el peso de nuevas restricciones en el entorno internacional o los cambios de gobiernos nacionales reviertan el avance. Esto dificultaría la emergencia de nuevos patrones de producción y consumo basados en el esfuerzo, la cooperación y el aprendizaje tecnológico. El gran impulso ambiental es también una transformación cultural. La cultura del privilegio es incompatible con la cultura del esfuerzo y la cooperación. 


\section{Bibliografía}

Acemoglu, D. y J. A. Robinson (2013), "Economics versus politics: pitfalls of policy advice," Journal of Economic Perspectives, vol. $27, N^{\circ} 2$.

(2006), Economic Origins of Dictatorship and Democracy, Cambridge, Cambridge University Press.

Acemoglu, D., S. Johnson y J. A. Robinson (2004), "Institutions as the fundamental cause of long-run growth", NBER Working Paper, No 10481.

Álvarez, J. y L. Bértola (2007), "So similar, so different: New Zealand and Uruguay in the world economy", Settler Economies in World History, C. Lloyd, J. Meltzer y P. Sutch (eds.), Brill, Leiden.

Amsden, A. (1989), Asia's Next Giant: South Korea and Late Industrialization, Nueva York, Oxford University Press.

Arthur, B. (1994), Increasing Returns and Path-Dependency in Economics, Ann Arbor, Michigan University Press.

Banco Mundial (2017), Datos de libre acceso del Banco Mundial [en línea] https://datos.bancomundial.org.

Bértola, L. y J.A. Ocampo (2012), The Economic Development of Latin America Since Independence, Oxford University Press.

Bowles, S. (2012), The New Economics of Inequality and Redistribution, Cambridge University Press.

(1998), "Endogenous preferences: The cultural consequences of markets and other economic institutions", Journal of Economic Literature, vol. 36, № 1, marzo.

Cardoso, F.H. y E. Faletto (1977), Dependencia y desarrollo en América Latina, Buenos Aires, Siglo XXI.

Cecchetti, S. y E. Kharroubi (2012), "Reassessing the impact of finance on growth", BIS Working Papers, № 381, julio.

Chong, A. y M. Gradstein (2007), "Inequality and institutions", The Review of Economics and Statistics, agosto, vol. 89, № 3.

Cimoli, M. y G. Dosi (2017) "Industrial policy in learning economies", Efficiency, Finance and Varieties of Industrial Policy,

A. Norman y J. Stiglitz (eds.), Nueva York, Columbia Univeristy Press.

CEPAL (Comisión Económica para América Latina y el Caribe) (2017), base de datos CEPALSTAT [en línea] http://interwp. cepal.org/sisgen/Consultalntegrada. asp?ldAplicacion=38\&idTema=882\&idlndicador=3126\&idioma=e.

(2016), Horizontes 2030: la igualdad en el centro del desarrollo sostenible (LC/G.2660/ Rev.1), Santiago.

(2015), La nueva revolución digital: de la Internet del consumo a la Internet de la producción (LC/L.4029 (CMSI.5/4)), Santiago.

(2010), La hora de la igualdad: brechas por cerrar caminos por abrir (LC/G.2432(SES.33/3)), Santiago.

(2002), Globalización y desarrollo (LC/G.2157 (SES.29/3)), Santiago.

Cohen, M., N. Lupu y E. Zechmeister (2017), The Political Culture of Democracy in the Americas, 2016/17: A Comparative Study of Democracy and Governance, Agencia de los Estados Unidos para el Desarrollo Internacional (USAID)/LAPOP Barómetro de las Américas.

Corporación Latinobarómetro (2017), "Banco de Datos" [en línea] http://www.latinobarometro.org/latContents.jsp.

Doner, R. y B. Ross Schneider (2016), "The middle-income trap: more politics than economics", World Politics, vol. 68, № 4.

Dooley, M.P., D. Folkerts-Landau y P. Garber (2003), "An essay on the revived Bretton Woods System", NBER Working Paper, No 9971, septiembre.

Fajnzylber, F. (1983), La industrialización trunca de América Latina, Ciudad de México, Nueva Imagen.

Evans, P. y P. Heller (2015), "Human development, State transformation and the politics of the developmental State", The Oxford Handbook of Transformations of the State, S. Leibfried y otros (eds.), Oxford, Oxford University Press.

Frieden, J.A. (2015), Currency Politics: the Political Economy of Exchange Rate Policy, Princeton University Press.

Hirschman, A.O. (1986), "The political economy of Latin American development: seven exercises in retrospection, Working Paper, № 88, Kellogg Institute, diciembre.

(1968), "The political economy of import-substituting industrialization in Latin America", Quaterly Journal of Economics, vol. LXXXII, No 1, febrero.

Jaitman, L. (2017), Los costos del crimen y la violencia. Nueva evidencia y hallazgos en América Latina y el Caribe, Washington D.C., Banco Interamericano de Desarrollo (BID).

Kahn, M. y S. Blankenburg (2009), "The political economy of industrial policy in Asia and Latin America", The Political Economy of Capabilities Accumulation: the Past and Future of Policies for Industrial Development, M. Cimoli, G. Dosi y J. E. Stiglitz (eds.), Oxford University Press.

Kim, I. (2016), "Land Reform in South Korea under the U.S. military occupation, 1945-1948", Journal of Cold War Studies, vol. 18, No2.

Lo Vuolo, R. y L. Goldberg (2006), Falsas promesas. Sistemas de previsión social y régimen de acumulación, Buenos Aires, Miño y Dávila.

Moore, B (1966), The Social Origins of Dictatorship and Democracy: Lord and Peasant in the Making of the Modern World, Boston, Beacon Press. 
Moretti, E. (2004), "Human capital externalities in cities", Handbook of Regional and Urban Economics, J. V. Henderson y J. F. Thisse (eds.), 1, vol. 4, Elsevier.

Naciones Unidas (2015), "Statistical Annex", The World's Women 2015: Trends and Statistics [en línea] https://unstats. un.org/unsd/gender/worldswomen.html.

Nochteff, H. (1996), "La experiencia argentina: ¿desarrollo o sucesión de burbujas?", Revista de la CEPAL, № 59 (LC/G.1931-P), Santiago, Comisión Económica para América Latina y el Caribe (CEPAL), agosto.

North, D.C., J.J. Wallis y B.R. Weingast (2009), Violence and Social Orders: A Conceptual Framework for Interpreting Recorded Human History, Nueva York, Cambridge University Press.

Ocampo, J.A. (2013), "Balance of payments dominance: its implications for macroeconomic policy", Working Paper, $N^{\circ} 268$, Initiative for Policy Dialogue (IPD), octubre.

O'Donnell, G. (1978), "State and alliances in Argentina, 1956-1976", Journal of Development Studies, vol. 15, № 1.

O'Donnell, G., P. Schmitter y L. Withehead (eds.) (1991), Transitions from Authoritarian Rule: Comparative Perspectives, The Johns Hopkins University Press.

Palley, T. (2017), "A theory of economic policy lock-in and lock-out via hysteresis: rethinking economists' approach to economic policy", Economics, vol. 11, № 2017-18..

Palma, J.G. (2012), "How the full opening of the capital account to highly liquid financial markets led Latin America to two and a half cycles of 'mania, panic and crash'", Cambridge Working Papers in Economics, No 1201, enero.

Prebisch, R. (1963), Hacia una dinámica del desarrollo latinoamericano, Ciudad de México, Fondo de Cultura Económica.

Poo, D. (2014), "China's development trajectory: A strategic opening for industrial policy in the South", Discussion Paper, $N^{\circ} 218$, Conferencia de las Naciones Unidas sobre Comercio y Desarrollo (UNCTAD), diciembre.

Rodríguez, O. (2007), El estructuralismo latinoamericano, Ciudad de México, Comisión Económica para América Latina y el Caribe (CEPAL)/Siglo XXI.

Stalling, B. y W. Peres (2000), Growth, Employment and Equity: The Impact of Economic Reforms in Latin America and the Caribbean, Washington, D.C., Brookings Institution Press.

Stiglitz, J. (2014), "Leaders and followers: perspectives on the Nordic Model and the economics of innovation", NBER Working Paper, № 20493, septiembre.

(2013), The Price of Inequality: How Today's Divided Society Endangers Our Future, Nueva York, Norton.

Sunkel, O. y P. Paz (1970), El subdesarrollo latinoamericano y la teoría del desarrollo, Ciudad de México, Siglo XXI.

Turner, A. (2016), Between Debt and the Devil: Money, Credit and Fixing Global Finance, Princeton University Press.

Wade, R. (1992), "East Asia's economic success: conflicting perspectives, partial insights, shaky evidence", World Politics, vol. 44, N² 2, enero.

Wilkinson, R. y K. Pickett (2009), The Spirit Level. Why More Equal Societies Almost Always Do Better, Bloomsbury Press. 


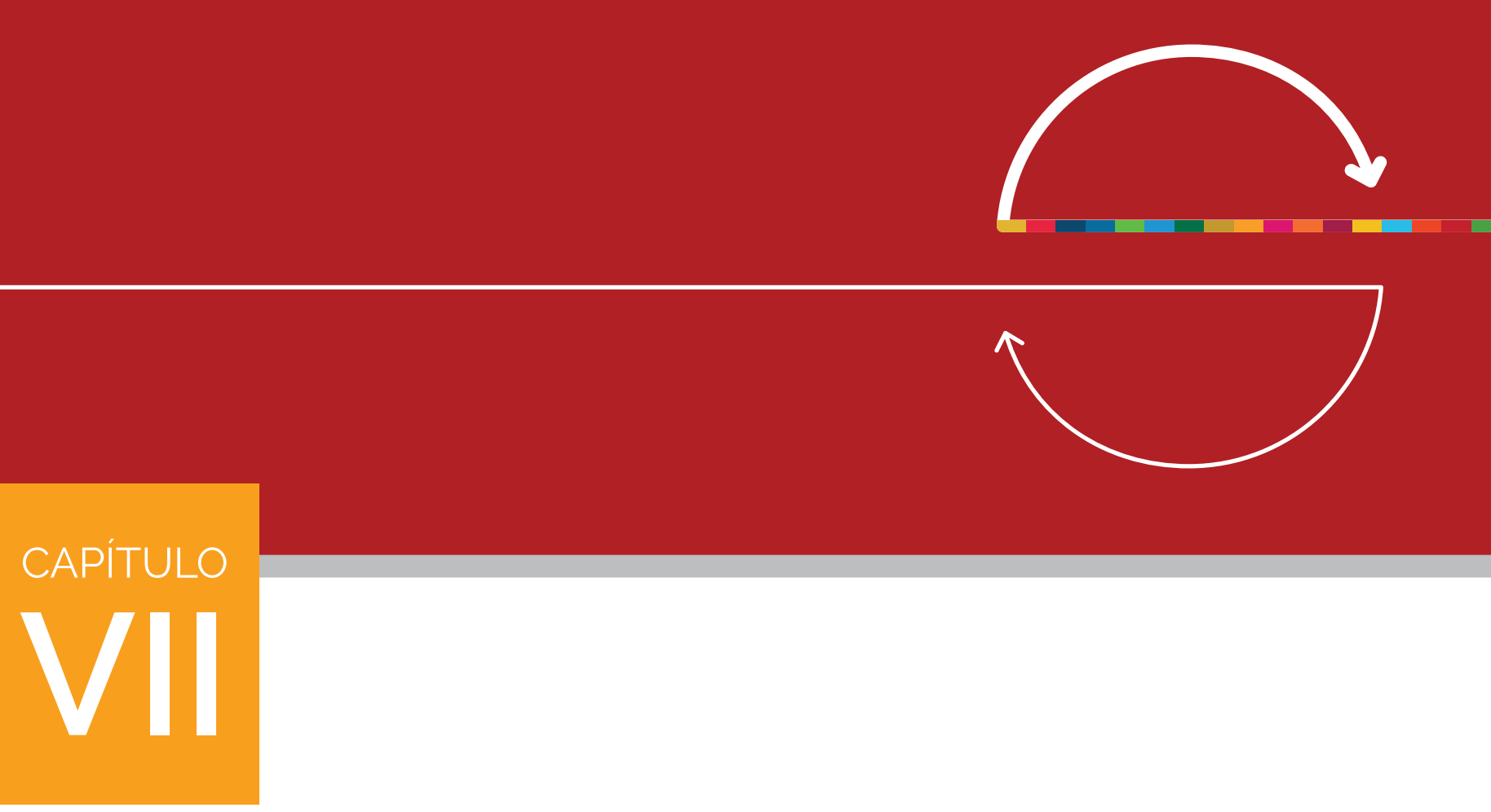

\section{Orientaciones estratégicas}

Introducción

A. Macroeconomía para el desarrollo

1. De la estabilidad monetaria a la estabilidad financiera

2. Fiscalidad para el crecimiento y la igualdad

B. Estado de bienestar: ejercicio de los derechos y aumento de la productividad

1. La protección del gasto público social mediante una tributación progresiva

2. Readecuación de la educación al nuevo contexto tecnológico

3. Fortalecimiento de los sistemas de protección social y cuidado

4. El ingreso básico: ¿una opción?

C. Tres ejes de la descarbonización: digitalización, ciudades sostenibles y energías renovables

1. Un gran impulso ambiental para el cambio estructural progresivo

2. Políticas industriales y tecnológicas para la digitalización de la producción

3. Ciudades sostenibles como motores del desarrollo

4. El sector energético como motor del cambio

D. La transparencia y la confianza en las instituciones facilitan la implementación de políticas para promover el gran impulso ambiental

E. A modo de cierre

Bibliografía 



\section{Introducción}

La desigualdad es ineficiente. La cultura del privilegio y el actual estilo de desarrollo generan brechas que aumentan, en lugar de reducir, las diferencias entre los centros y las periferias, a la vez que generan un grado insostenible de polarización de los ingresos. La incertidumbre macroeconómica, la irrupción geopolítica de China, la revolución tecnológica y la agudización de la crisis ambiental son factores adicionales que incrementan la complejidad del escenario internacional. Para responder a estos cambios se requieren decisiones estratégicas cooperativas a nivel global, regional y nacional, bajo un enfoque multilateral y con la participación de todos los actores involucrados. En este marco, la Comisión Económica para América Latina y el Caribe (CEPAL) reafirma su tesis de que los países de la región deben poner en marcha un nuevo paradigma de desarrollo basado en un gran impulso ambiental.

La revolución tecnológica y la crisis ambiental reducen el horizonte temporal de intervención. La actual generación es la primera que no puede negar la magnitud de estos cambios y posiblemente la última que puede sentar las bases y poner en marcha un nuevo régimen económico, social y político que compatibilice un crecimiento económico más igualitario con el cuidado del medio ambiente. Frente a ello, la Agenda 2030 para el Desarrollo Sostenible incluye tres ejes de acción clave para el nuevo modelo: una macroeconomía para el desarrollo, un estado de bienestar basado en derechos y aumentos de la productividad y la descarbonización de la economía y la sociedad.

La Agenda 2030 y los Objetivos de Desarrollo Sostenible (ODS) son una respuesta de la comunidad internacional a las tensiones acumuladas en la globalización. La creciente desigualdad en muchos países, la persistencia de los desequilibrios financieros globales, el impacto de las migraciones internacionales y el cambio climático no pueden ser enfrentados solamente con políticas nacionales. Por su propia naturaleza, requieren un contexto de cooperación internacional que apoye esas políticas y haga frente a los efectos que alcanzan de manera transversal a todos los países. Una crisis financiera en un país genera externalidades negativas que rápidamente se propagan al resto del mundo; aunque las emisiones de $\mathrm{CO}_{2}$ son generadas por todo el planeta, se sienten con mayor intensidad en algunas regiones, y la pobreza y la inestabilidad de una economía genera corrientes migratorias súbitas y de grandes proporciones que pueden tener efectos negativos en otras economías. Todos estos son problemas cuya solución no se define en un país; la cooperación internacional es un instrumento irreemplazable para avanzar hacia una economía internacional más estable y sostenible.

En el documento presentado por la CEPAL en la Primera Reunión del Foro de los Países de América Latina y el Caribe sobre el Desarrollo Sostenible, celebrada en Ciudad de México en 2017 (CEPAL, 2017a), se discuten varias formas de cooperación internacional como complemento necesario a las políticas nacionales a favor de la Agenda 2030 y los ODS. La aplicación de políticas fiscales expansivas (junto con inversiones destinadas a promover senderos de desarrollo bajos en carbono) en los países que presenten un superávit en el comercio internacional ayudaría a equilibrar este comercio sin graves secuelas para el empleo y el crecimiento de los países deficitarios, y al mismo tiempo incrementaría el crecimiento global y la sostenibilidad. La cooperación multilateral permitiría restaurar la capacidad de los Gobiernos de actuar en forma coordinada para estabilizar las finanzas globales y controlar sus efectos sobre las economías nacionales, lo que evitaría burbujas especulativas y la agudización del ciclo económico, con sus graves consecuencias para el empleo. Asimismo, la aprobación de acuerdos internacionales en torno a los derechos laborales y el estado de bienestar permitiría reducir los riesgos de una competencia predatoria en que el salario fuera la principal variable de ajuste para elevar las exportaciones y atraer el capital extranjero. Las estrategias basadas en la reducción salarial representan el predominio de una competitividad espuria por encima de enfoques orientados a reducir las brechas y la erosión de la base tributaria sobre la que se construyen los bienes públicos indispensables para el funcionamiento de la democracia. Un sistema multilateral abierto al comercio en el que se redujeran las asimetrías productivas y tecnológicas favorecería la creación de empleo en los países menos desarrollados y disminuiría las tensiones políticas asociadas a la migración. Solo creando empleos y oportunidades en los países en desarrollo podrá reducirse la migración hacia el mundo desarrollado, hoy desbordada por las desigualdades de ingreso y riqueza y el rápido aumento de la población en muchos de los países en desarrollo.

Ante este contexto, se presentan en el presente capítulo orientaciones estratégicas para el diseño de políticas de desarrollo sostenible en distintos ámbitos en América Latina y el Caribe. En lo que se refiere a 
la macroeconomía, se reafirma la necesidad de una política orientada al desarrollo que, además de controlar la inflación, refuerce los instrumentos contracíclicos y vincule los objetivos de crecimiento económico y estabilidad financiera con otros igualmente importantes, como la transformación productiva y la mejora de la distribución del ingreso (CEPAL, 2010). En cuanto a las políticas sociales, el enfoque de derechos y la búsqueda de la igualdad sustantiva se sitúan como ejes de los nuevos regímenes de bienestar, para conformar un estilo de desarrollo que coloque la igualdad y la sostenibilidad en el centro, alcanzar los Objetivos de Desarrollo Sostenible y aprovechar las sinergias entre igualdad y crecimiento. En materia ambiental, la atención se centra en tres pilares de la descarbonización: la digitalización de la sociedad y la producción, en particular de las microempresas y pequeñas y medianas empresas (MIPYMES), debido a su peso en la generación de empleos y salarios; el desarrollo de ciudades sostenibles, y el impulso de las energías renovables.

Implementar esas líneas estratégicas y avanzar en el cumplimiento de la Agenda 2030 implica trabajar con un enfoque en el que la jerarquización de objetivos, la periodización de acciones, la movilización de recursos y la implementación coordinada de los instrumentos de política estén en el centro de los procesos decisorios a nivel global, regional y nacional.

\section{A. Macroeconomía para el desarrollo}

La estabilidad macroeconómica es necesaria para un crecimiento sostenible e inclusivo. La crisis mundial de 2008 resaltó la fuerte vinculación entre los ciclos externos, la dinámica económica de los países de la región y su margen de maniobra en materia de política macroeconómica. Aunque, en promedio, las tasas de crecimiento mundial actuales son menores a las registradas durante "la gran moderación" (que se extendió desde la segunda mitad de la década de 1980 hasta 2007), la economía internacional muestra signos de recuperación y se espera una leve mejora en los términos de intercambio; esto favorecerá el desempeño de los países de América del Sur, productores de recursos naturales. Por otro lado, un crecimiento más dinámico en los Estados Unidos tendría efectos positivos en Centroamérica y México y el Caribe, aunque estos podrían verse impedidos por decisiones políticas. Las tasas de interés internacionales se sitúan en un nivel históricamente bajo, que se mantendría pese a la reversión de las políticas de expansión cuantitativa por parte de la Reserva Federal de los Estados Unidos ${ }^{1}$.

Este contexto abre una oportunidad para que los países de la región adopten una postura más proactiva y orienten sus políticas a promover un cambio estructural progresivo. Esta respuesta es aún más urgente dadas las incertidumbres que plantea la recuperación de la economía mundial. Por ello, en esta sección se presenta un marco para el análisis crítico del enfoque macroeconómico dominante y diseñar una política macroeconómica para un crecimiento más igualitario e inclusivo. La CEPAL propone una política macroeconómica para el desarrollo que combine políticas anticíclicas con una estrategia de diversificación productiva, y resalta la necesidad de diseñar políticas fiscales que sustenten la generación de bienes y servicios públicos y promuevan la creación de un estado de bienestar.

\section{De la estabilidad monetaria a la estabilidad financiera}

Como se señala a lo largo del documento, es necesario incrementar el ritmo de crecimiento para retomar el dinamismo de la inversión y mejorar el mercado de trabajo, además de diversificar la economía para que la región aproveche todo el potencial de la demanda externa.

La existencia de diferenciales de tasas de interés positivos con el resto del mundo amplía el espacio para mantener bajas las tasas de interés nominales y reales, como ya han hecho varios de los países de la región, sin poner en riesgo la estabilidad de precios. Dado que, además, la región registró tasas de crecimiento históricamente bajas entre 2012 y 2017 y, en la mayoría de los países, la inflación está por debajo de los umbrales de tolerancia, es posible compatibilizar la preocupación por la estabilidad nominal con la preocupación por el crecimiento, el cambio estructural y la igualdad.

Desde hace un decenio y medio, las tasas de interés reales externas muestran una tendencia a la baja (Summers, 2016). 
Uno de los principales desafíos es fortalecer la capacidad de traspaso de las políticas monetarias más flexibles desde los bancos centrales al resto del sistema financiero y, a través de este canal, a la economía real. Las autoridades monetarias de las economías desarrolladas enfrentan restricciones para alcanzar ese objetivo, pero en los países de la región el mecanismo de transmisión es incluso más limitado por la excesiva exposición de los sistemas locales a los ciclos de liquidez internacional, producto de la ausencia o debilidad de las políticas macroprudenciales, en un contexto de apertura de la cuenta de capital.

El mantenimiento de una estructura interna de tasas de interés nivelada con las tasas de interés externas brinda la holgura de liquidez necesaria para promover el cambio estructural progresivo, y evita las operaciones de arbitraje y acarreo (carry-trade) que han proliferado en algunos países de la región y que agudizan la financierización, obstaculizando la inversión (véase el capítulo III y Shin, 2016). Los países de la región deben transitar de una política monetaria dedicada al control de la tasa de inflación como objetivo primordial hacia un enfoque más amplio e integral que, al mismo tiempo que promueve la estabilidad financiera, sea compatible con un mayor ritmo de crecimiento. Esto implica flexibilizar el manejo de la liquidez según lo requieran las circunstancias y contar con una regulación financiera más activa que ajuste de manera dinámica los parámetros regulatorios para mantener un nivel deseado de fortaleza en el sistema financiero, con el fin de minimizar el riesgo sistémico ${ }^{2}$. De lograrse estos objetivos, la tasa de interés y la oferta monetaria tendrían un menor peso en el manejo de la demanda agregada.

El conjunto de estos instrumentos, es decir, la política macroprudencial, busca limitar la acumulación de estructuras financieras frágiles, incluida la prevención de las burbujas de activos y crédito. Los riesgos sistémicos no solo se vinculan con la dinámica de activos y pasivos financieros. En la actualidad, podrían estar agudizándose burbujas climáticas; es decir, riesgos ambientales de alcance sistémico que no se reflejan en el valor de los activos y que el sistema financiero no tiene en cuenta adecuadamente. En este sentido, la internalización del riesgo climático debería expresarse en tasas de interés y primas que distingan entre las inversiones altas en carbono (más riesgosas) y las bajas en carbono (con menores riesgos). En las decisiones de inversión, la preferencia por inversiones bajas en carbono debería expresarse en las tasas de descuento.

La historia de la región muestra que la dinámica del crecimiento de corto y largo plazo se relaciona no solo con el comportamiento de variables reales como la productividad y la inversión, sino también con la estabilidad crediticia y financiera. Además, el sector financiero tiende a ampliar las fluctuaciones de la demanda agregada y la actividad real.

Como se argumenta en el capítulo III, en un contexto de creciente endeudamiento del sector privado, velar por la estabilidad financiera es un requisito para garantizar un crecimiento sostenido de largo plazo. Por un lado, el aumento del endeudamiento de los hogares en varios países de la región plantea la posibilidad de que una situación de endeudamiento imponga una carga financiera desproporcionada en comparación con el ingreso, lo que puede generar situaciones insostenibles en el tiempo. Esto tendría consecuencias negativas para la igualdad, ya que los hogares de menores ingresos son los que soportan las mayores cargas financieras, sufren las peores condiciones de acceso a préstamos y enfrentan la mayor vulnerabilidad ante cambios de las condiciones crediticias. Por el otro, en el sector empresarial no financiero, un mayor endeudamiento podría llevar a ajustes de los niveles de producción e inversión; esto tendría efectos macroeconómicos negativos si se trata de un grupo de empresas importantes en la producción y la inversión, dado que puede perjudicar el crecimiento de largo plazo, la generación de empleo y la distribución del ingreso.

Mantener la estabilidad financiera requiere, como condición sine qua non, proteger las economías de los vaivenes del ciclo financiero internacional. Las economías con mayor profundización financiera y liquidez en los mercados son las que más capital atraen y las más expuestas a los cambios abruptos de los mercados financieros (Eichengreen y Gupta, 2015). Esto lleva a reconocer las limitaciones y la vulnerabilidad asociadas a la apertura financiera (véase el capítulo III y Marcus, 2016). Incluso cuando el ciclo financiero internacional no es impulsado por inversiones de corto plazo o asociado a reversiones súbitas de flujos financieros, los vaivenes en los mercados de crédito internacionales pueden crear distorsiones financieras y reales importantes. En el mundo

El riesgo sistémico es el riesgo de una interrupción de los servicios financieros causada por un trastorno total o parcial del sistema financiero, que puede tener importantes repercusiones negativas sobre la economía real. 
en desarrollo, esta dinámica se hizo evidente en el impacto que las políticas monetarias no convencionales (flexibilización cuantitativa) tuvieron en la volatilidad cambiaria y los precios de las materias primas.

Por esta razón, organismos internacionales como el Fondo Monetario Internacional (FMI) se han sumado a la recomendación histórica de la CEPAL de administrar los flujos de capital transfronterizos como una forma de mantener la estabilidad y una precondición para la puesta en práctica de políticas contracíclicas. En un contexto global financierizado, la posibilidad de generar nuevos instrumentos para manejar la demanda agregada está supeditada en gran medida a la regulación de los flujos internacionales de capital.

Los tipos de cambio nominales tienen comportamientos volátiles que se acentúan en contextos institucionales de libre movilidad de los flujos internacionales de capital: se comportan como un activo financiero más al responder a los retornos esperados en los mercados a futuro, que presentan fuertes componentes especulativos. En ese contexto es crucial administrar la cotización cambiaria, lo que supone un desafío cada vez más significativo. La dinámica típicamente procíclica de los flujos financieros internacionales suele influir en esas cotizaciones, induciendo fuertes revaluaciones (o devaluaciones) en los auges (o las crisis) que desequilibran la cuenta corriente. La administración de los flujos transfronterizos de capital daría a las autoridades monetarias un mayor margen de acción que el que tienen actualmente para adoptar regímenes de flotación administrada y alinear la política cambiaria con los requerimientos de la economía real.

\section{Fiscalidad para el crecimiento y la igualdad}

Para desarrollar políticas fiscales que apoyen el cambio estructural progresivo y la igualdad es esencial contar con un marco de estabilidad financiera y mayor previsibilidad. Esas políticas deben desempeñar un papel más activo para que la región pueda seguir una senda de crecimiento alto, sostenible e inclusivo. El contexto actual de lento crecimiento exige políticas que no solo suavicen las fluctuaciones cíclicas, sino que también corrijan los rasgos del ciclo que perjudican el crecimiento y la estructura productiva. El logro de estos objetivos pasa por una movilización considerable de recursos internos, lo que requerirá endurecer la lucha contra el incumplimiento tributario.

La política fiscal es importante porque es un instrumento clave para manejar la demanda agregada. En particular, es fundamental blindar la inversión pública frente a los altibajos de la actividad económica y evitar que, con un criterio de corto plazo, se utilice como variable de ajuste en las fases descendentes del ciclo. La propensión al comportamiento procíclico, frecuente en los países de la región, disminuye la capacidad para emprender proyectos de inversión y prolonga la intensidad y la duración de la desaceleración, lo que dificulta el restablecimiento de los equilibrios macroeconómicos. Esta propuesta implica que los criterios de consolidación fiscal no deben ni pueden responder solo a umbrales nominales, que además son de difícil verificación empírica ${ }^{3}$.

La influencia del Estado en el proceso de acumulación de capital físico va más allá de su intervención directa. En este sentido, la CEPAL impulsa la instauración de marcos fiscales inclusivos que promuevan la inversión. Entre otras cosas, esos marcos deben favorecer inversiones que faciliten la integración territorial, mediante la coordinación de iniciativas para habilitar actividades localizadas y superar las trampas de pobreza. A menudo, desde la óptica del Estado se privilegian grandes proyectos de infraestructura, en lugar de coordinar inversiones inclusivas en áreas como la urbanización, la construcción o renovación de viviendas, el agua potable y el tratamiento de residuos o el desarrollo de comunas rurales.

Como se sugirió en el capítulo $\mathrm{V}$, las inversiones territoriales integradas son fundamentales para apoyar acciones mancomunadas en áreas geográficas determinadas. Si bien estas iniciativas localizadas representan

Aunque existe consenso acerca del hecho de que la acumulación ininterrumpida de deuda pública conlleva efectos negativos para el crecimiento económico, no hay acuerdo sobre el umbral de deuda por encima del cual se compromete el crecimiento. En tal sentido, más que poner el foco en el nivel de la deuda (que correspondería a un enfoque estático, no apropiado en un contexto de crecimiento económico), es importante considerar la trayectoria de la deuda pública. De hecho, esa trayectoria puede ser tan importante como el nivel de deuda, o incluso más, para las perspectivas de crecimiento futuro. Los países con niveles de deuda elevados en proceso de disminución tienden a crecer tan rápidamente como los países con niveles de deuda más bajos. 
montos menores que los grandes proyectos nacionales, son importantes para alcanzar objetivos de desarrollo y pueden tener un efecto significativo en el crecimiento de largo plazo. Asimismo, fomentan la inclusión de la población rural, que sigue siendo muy significativa en muchos países.

Los planes de inversión gestionados desde la esfera pública podrán revertir la caída de las tasas de inversión, asegurar ganancias de productividad de largo plazo y competitividad en áreas estratégicas para el cambio estructural y reducir las brechas de infraestructura. Esos planes pueden conjugar emprendimientos que interactúen mutuamente, movilicen financiamiento público y privado, fomenten el crecimiento y el empleo con una perspectiva estratégica y territorial, y promuevan energías limpias y renovables.

La política fiscal contribuye a la creación de una sociedad más inclusiva mediante la provisión de bienes y servicios públicos que aumentan el bienestar material y la igualdad de derechos. El gasto público en educación y en salud tiene una incidencia favorable en la distribución del ingreso, lo que se observa en la reducción del coeficiente de Gini, pero los resultados en la región no han sido satisfactorios si se los compara con los de otras regiones. Son necesarios mayores esfuerzos para aumentar y mejorar la provisión de bienes y servicios públicos de calidad. Por otra parte, la eficiencia y eficacia del gasto público siguen siendo muy heterogéneas en la región: en muchos países se podrían lograr los mismos resultados con menos recursos. Sin desconocer los problemas de la calidad del gasto, en la mayoría de los países de la región la insuficiencia del gasto es la principal limitación o restricción para proveer bienes públicos. En realidad, el problema es doble: se gasta poco y, al mismo tiempo, en muchos casos se gasta mal.

El cumplimiento de los objetivos de la política fiscal dependerá de la medida en que se movilicen suficientes recursos internos. Esa movilización no es solo un medio para financiar el desarrollo sostenible; es un componente endógeno del mismo proceso de desarrollo. La recaudación de recursos, especialmente desde el ámbito público, no es neutra en términos de impacto en la sociedad o en la evolución de la economía. En ese sentido, el desarrollo de la región se ve obstaculizado por una estructura tributaria sesgada hacia los impuestos indirectos regresivos, con niveles elevados de evasión fiscal y una alta dependencia de los ingresos derivados de la explotación de recursos naturales no renovables.

Hacer frente a estos desafíos, especialmente en un contexto de bajo crecimiento, exige políticas innovadoras y nuevos pactos fiscales. Numerosos países de la región han aprobado reformas tributarias en los últimos años, y muchas de ellas incluyen acciones para aumentar la equidad y la progresividad. Al mismo tiempo, se están adoptando medidas para enfrentar la evasión y elusión fiscales y mejorar la administración de los sistemas impositivos. Estas iniciativas se han visto respaldadas por el aumento de la cooperación regional e internacional en asuntos fiscales y financieros.

Como se señala en CEPAL (2016a), "en una agenda de cambio estructural progresivo, la política fiscal debe ser entendida en términos dinámicos y en conexión con las restantes áreas del sistema económico". Esto implica, por un lado, articular esta política con las otras políticas económicas, sobre todo la industrial y la tecnológica. No solo es importante el carácter contracíclico de la política fiscal, sino también en qué sectores se focaliza; en este sentido, existe un amplio margen para la selectividad estratégica. Por otro lado, la política fiscal debe articularse con la política ambiental para cambiar los incentivos de rentabilidad entre sectores (aumentar la rentabilidad relativa de los sectores más intensivos en conocimiento y menos contaminantes), internalizar las externalidades negativas y reducir la tasa de agotamiento de los recursos no renovables. Un primer paso en esta dirección sería disminuir paulatinamente los subsidios al consumo de combustibles fósiles e implementar impuestos ambientales. Como se subraya más adelante, el financiamiento blando — subsidiado con recursos fiscales - para el desarrollo de actividades vinculadas a la provisión de energía a partir de fuentes renovables es otro paso en esa dirección (CEPAL, 2016a). A esto se refiere la CEPAL cuando, al promover el gran impulso ambiental, aboga por un keynesianismo ambiental: se trata de propiciar estímulos fiscales que sostengan el nivel de actividad y propendan a una transformación de la estructura productiva.

La implementación de una estrategia como la del gran impulso ambiental necesita de una coalición social y política alineada con sus principales objetivos, es decir, un gran impulso político. El diseño institucional y las prioridades que definen la implementación de la política macroeconómica no son ajenos a esta problemática. En ese sentido, aumentar el margen de maniobra macroeconómica exigiría rediscutir las medidas y el contexto 
normativo que facilitaron la financierización, responsable de haber exacerbado los vaivenes del ciclo financiero internacional y el efecto de los choques de la balanza de pagos en la dinámica macroeconómica. Para alcanzar una nueva institucionalidad financiera son necesarias acciones globales y regionales sustentadas en coaliciones sociales y políticas que las impulsen y sostengan en el tiempo.

\section{B. Estado de bienestar: ejercicio de los derechos y aumento de la productividad}

Las transformaciones por las que pasa la economía mundial tienen fuertes repercusiones sobre los regímenes de bienestar. Estos enfrentan riesgos de precarización y desprotección asociados a las nuevas formas de trabajo y a los efectos de tendencias demográficas como el envejecimiento y la intensificación de las migraciones. En la región estas tendencias se presentan en una coyuntura caracterizada por un crecimiento económico débil, especialmente en los países de América del Sur.

En este contexto, el debate sobre la cuestión social es insoslayable. Pese a que persisten enfoques que ponen el acento en la necesidad de un Estado mínimo, el principio de subsidiariedad, la preeminencia del mercado y el impulso de políticas sociales en clave residual, cada vez es más evidente que por esa ruta no se cierran las brechas de la desigualdad ni se abate la pobreza de manera sostenida, y que es necesario pensar en una nueva institucionalidad social que enfrente los problemas del actual estilo de desarrollo y los desafíos que emanan de los cambios globales analizados en el capítulo II.

En los enfoques más ortodoxos, las políticas sociales son concebidas como mecanismos compensatorios. Sin embargo, en los últimos años han quedado cada vez más patentes los efectos beneficiosos a largo plazo de las políticas igualadoras; la mirada sobre el papel de estas políticas y sus efectos ha cambiado. Se ha reconsiderado la sinergia entre igualdad y crecimiento, en la medida en que muchas políticas sociales, por su impacto en las capacidades humanas, contribuyen al incremento de la productividad de los individuos, por lo que constituyen un estímulo al crecimiento económico.

La igualdad de derechos sigue siendo más una aspiración que una realidad. No solo hay brechas dentro de los servicios provistos por el sector privado, los provistos por el sector público y entre ellos, sino también una marcada desigualdad entre quienes acceden a los servicios y transferencias de tipo contributivo y los que acceden a los servicios y las transferencias no contributivas. Estas diferencias se agudizan según el sexo, la edad, la pertenencia étnica y racial, el territorio de residencia o la situación de discapacidad de las personas. Por lo tanto, para avanzar hacia un estilo de desarrollo que coloque la igualdad y la sostenibilidad en el centro y alcanzar los Objetivos de la Agenda 2030, es necesario hacer del enfoque de derechos y la búsqueda de la igualdad sustantiva los ejes estructurantes de los nuevos regímenes de bienestar.

\section{La protección del gasto público social mediante una tributación progresiva}

Si bien el objetivo principal de las políticas sociales es asegurar el cumplimiento de los derechos económicos, sociales y culturales de la población, el gasto público social es también una inversión en las capacidades humanas a lo largo del ciclo de vida, y un componente clave del gran impulso ambiental. Al lograr mejores niveles de educación, salud, protección y cuidado en la población (mediante una sólida institucionalidad y una gestión efectiva), se estimula la innovación, el crecimiento y el desarrollo sostenible 4 .

En términos de eficiencia económica, las políticas sociales orientadas a la primera infancia y a la infancia —etapas críticas del ciclo de vida, en las que se sientan las bases para el desarrollo de las personas - tienen efectos mucho más marcados en la formación de capacidades que iniciativas similares llevadas a cabo en edades subsiguientes (Heckman, 2013). Aunque sus frutos no sean evidentes a corto plazo, estas inversiones son un fundamento imprescindible del cambio estructural necesario para avanzar en la senda del desarrollo sostenible, así como para aprovechar el bono demográfico (Rofman, Amarante y Apella, 2016). 
Se requiere una nueva articulación entre la estructura productiva y el régimen de bienestar que refleje que lo social no se juega solo en lo social ni lo económico se juega solo en lo económico: estas dimensiones son interdependientes. Las políticas de desarrollo social inclusivo, que brindan servicios y prestaciones sociales de calidad y sensibles a las diferencias, aumentan la productividad de los trabajadores, permiten un mayor cuidado del medio ambiente y refuerzan la resiliencia ante los desastres asociados a fenómenos naturales (CEPAL, 2017b).

La experiencia de los países nórdicos ilustra cómo las políticas redistributivas y el incremento de la tasa de crecimiento pueden ir de la mano. Dinamarca, Finlandia, Islandia, Noruega y Suecia presentan elevados niveles de igualdad y comparten características en cuanto a su nivel de desarrollo del estado de bienestar y su organización del mercado laboral. En el modelo nórdico, eficiencia e igualdad se refuerzan mutuamente. Aun cuando las instituciones y políticas surgieron para facilitar soluciones a problemas sociales y laborales, están alineadas con la asignación eficiente de recursos y el crecimiento económico (Vartiainen, 2014; Dølvik y otros, 2015). La determinación de los salarios por medio de mecanismos institucionales no regidos exclusivamente por el mercado, una de sus principales innovaciones, se traduce en una mayor productividad media y una menor distancia entre las empresas más y menos productivas (Moene y Wallerstein, 2006) ${ }^{5}$.

En los años ochenta e inicios de los años noventa se produjo una retracción del estado de bienestar en América Latina y el Caribe. En el último decenio y medio, esta se ha revertido parcialmente mediante un aumento del gasto público social que ha permitido avances en la cobertura y los servicios educativos y de la salud, así como incrementos en la cobertura de los sistemas de pensiones y de las transferencias monetarias para familias con hijos y para adultos mayores (véase el gráfico VII.1). Se implementaron también nuevas regulaciones y normas relativas al mercado laboral, además de políticas activas de empleo (Filgueira, 2015; CEPAL, 2017c).

\section{Gráfico VIl.1}

América Latina (19 paisesa): gasto social del sector público, por funciones ${ }^{b}, 2000-2015$ (En porcentajes del PIB)

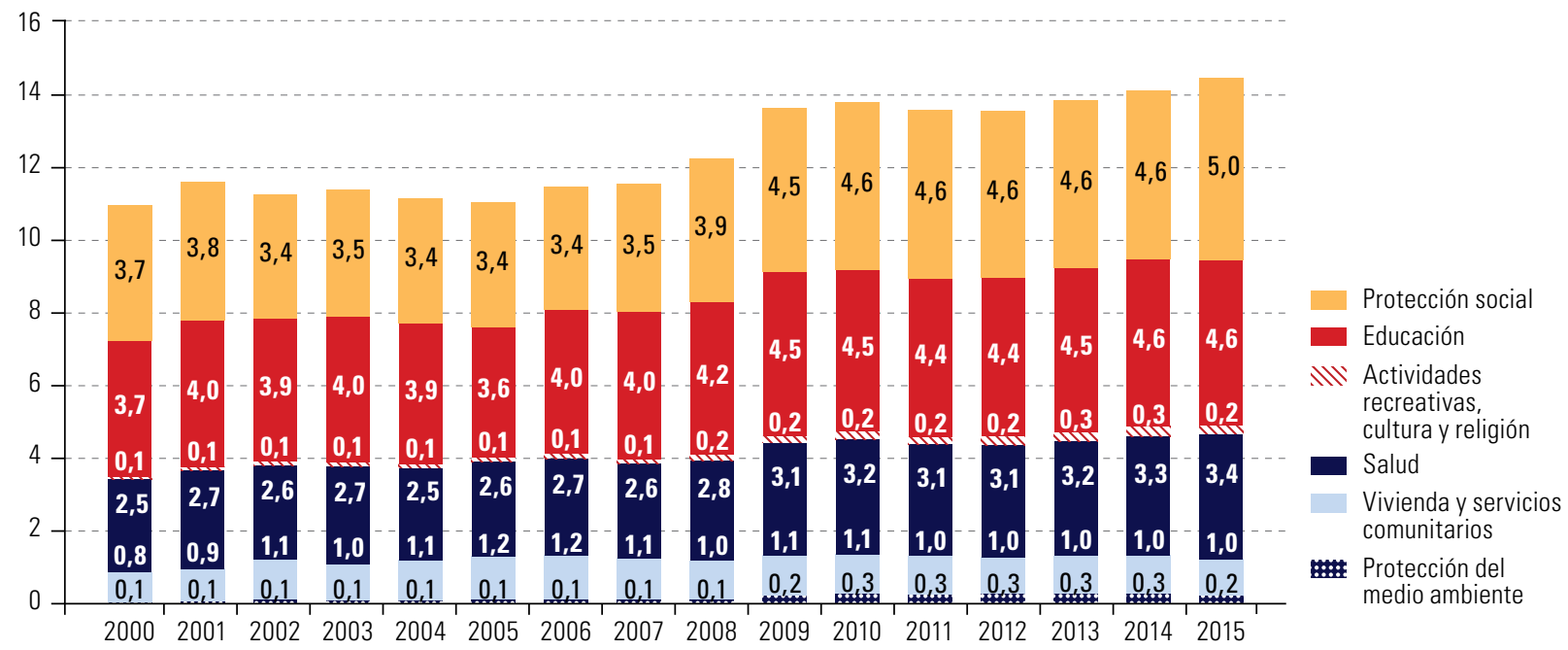

Fuente: Comisión Económica para América Latina y el Caribe (CEPAL), Panorama Social de América Latina, 2016 (LC/PUB.2017/12-P), Santiago, 2017.

a Promedio simple de 19 países: Argentina, Bolivia (Estado Plurinacional de), Brasil, Colombia, Costa Rica, Ecuador, El Salvador, México y Perú, donde existe una cobertura mayor que la del gobierno central, y Chile, Guatemala, Haití, Honduras, Nicaragua, Panamá, Paraguay, República Dominicana, Uruguay y Venezuela (República Bolivariana de), donde existe una cobertura de gobierno central. En el caso de Bolivia (Estado Plurinacional de) y Panamá se cuenta con información hasta 2014 y en el caso de Venezuela (República Bolivariana de), hasta 2009.

b Esta clasificación proporciona información sobre el conjunto de las funciones del Gobierno y no coincide necesariamente con la información generada a través de cuentas satélite de funciones específicas.

Moene y Wallerstein (2006) destacan el modelo de negociación de Rehn-Meidner en Suecia, que iguala los salarios de trabajadores comparables entre diferentes empresas. 
El crecimiento del gasto público social en la región —sustentado por mayores ingresos tributarios-se ajusta a la trayectoria de los países de la Organización de Cooperación y Desarrollo Económicos (OCDE) (véase el gráfico VII.2). No obstante, la región aún se encuentra lejos de los países desarrollados en términos de niveles de gasto y tributación, así como de impacto redistributivo (CEPAL, 2017a). Para corregir esta situación es preciso reformar los sistemas tributarios para hacerlos más progresivos, enfrentar la evasión fiscal, limitar los incentivos tributarios que erosionan las bases impositivas y mejorar la efectividad del gasto social (CEPAL, 2017b). Para ello, se han de alcanzar pactos en pro de la igualdad que den una orientación estratégica al desarrollo y socaven la cultura y las prácticas marcadas por los privilegios. Los pactos para la igualdad, la sostenibilidad y el cambio estructural —como el pacto fiscal, el pacto social y el pacto laboral (CEPAL, 2014) — son las bases sociales y políticas necesarias para avanzar en materia de políticas públicas que reduzcan brechas y hagan frente a la cultura del privilegio.

\section{Gráfico VII.2}

América Latina y paises de la Organización de Cooperación y Desarrollo Económicos (OCDE): gasto público social, carga tributaria y PIB per cápitaa ${ }^{1}$ 1990-2015

(En porcentajes del PIB y dólares de 2010 en paridad del poder adquisitivo)

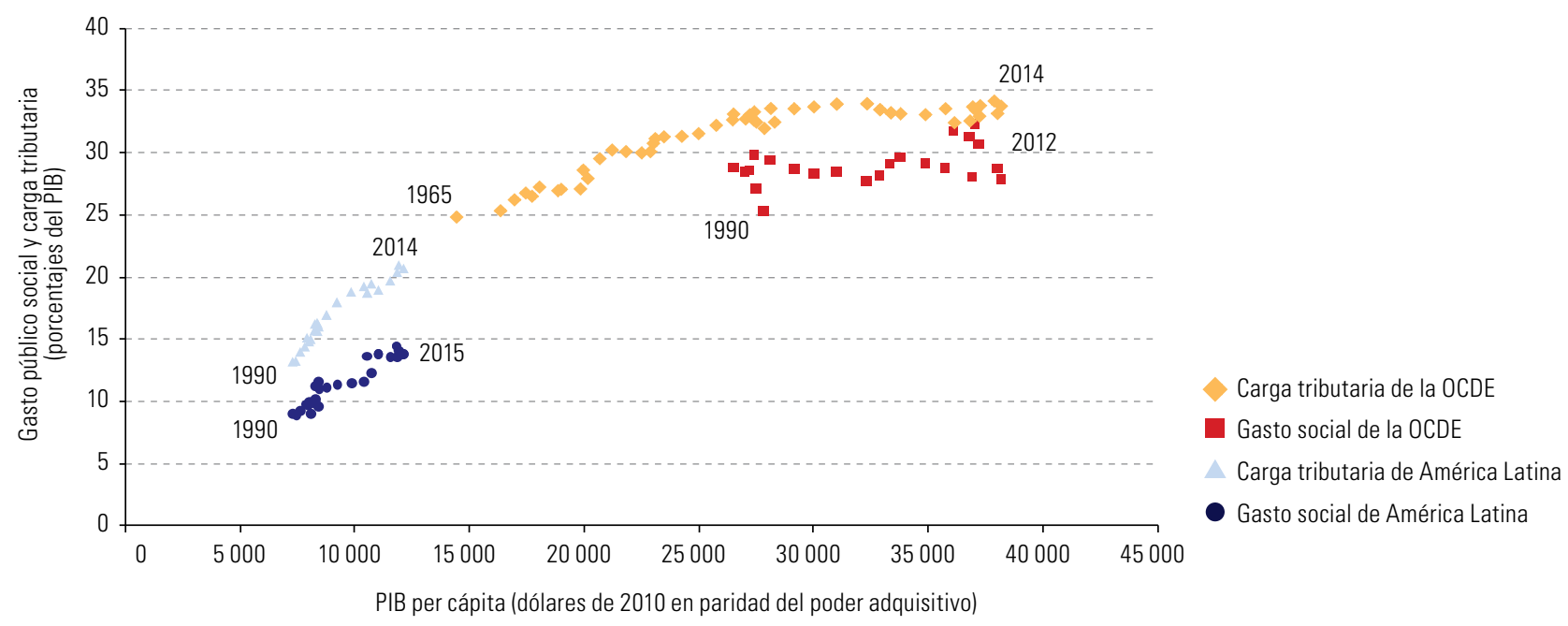

Fuente: Comisión Económica para América Latina y el Caribe (CEPAL), Panorama Social de América Latina, 2016 (LC/PUB.2017/12-P), Santiago, 2017

a Tanto en las series de América Latina como de la OCDE se consideran sociales las siguientes funciones: i) protección del medio ambiente, ii) vivienda y servicios comunitarios, iii) salud, iv) actividades recreativas, cultura y religión, v) educación y vi) protección social.

\section{Readecuación de la educación al nuevo contexto tecnológico}

La educación es una condición para la plena participación en la vida económica, política y social. En todo el mundo, una de las principales políticas para responder a los potenciales efectos negativos de la automatización en el empleo es invertir en educación; se considera a la innovación como un eje de las estrategias de enseñanza y generación de capacidades que permitirá a los niños interactuar en la sociedad del futuro (OCDE, 2016). Los rápidos cambios tecnológicos y la automatización en los sistemas de producción conllevan desafíos no solo para los sistemas escolares, sino también para los sistemas de educación superior y de formación continua de capacidades. Ante la rapidez del cambio técnico, es necesario generar las nuevas habilidades que se requerirán en el mercado del trabajo.

De acuerdo con Mercadante (2017), a fin de impartir una educación de calidad y pertinente se ha de brindar una formación sólida en lenguaje, matemáticas y tecnologías digitales, así como habilitar a los estudiantes en capacidades amplias; es necesario promover capacidades más generales que permitan a las personas 
plantear, analizar y resolver problemas cada vez más complejos y adaptarse a los procesos de aprendizaje y reconversión a lo largo de la vida. En particular, la capacidad de "aprender a aprender" y de "aprender a desaprender" (Morin, 1992) permite renovarse y adaptarse a los nuevos requerimientos de un mundo que vive un cambio tecnológico acelerado. Asimismo, hay que avanzar hacia un concepto de educación que reconozca la importancia de la igualdad y de los derechos e incorpore la diversidad étnica y sociocultural a los requisitos de formación ciudadana más generales (CEPAL, 2017b).

En particular, es importante priorizar: i) la formación regular en ciencias, tecnología, ingeniería y matemáticas (disciplinas CTIM) en el sistema escolar; ii) el desarrollo de habilidades sociales y conductuales, así como las capacidades de liderazgo y gestión, pues las capacidades con menor posibilidad de ser automatizadas son la percepción, la manipulación de problemas complejos, la inteligencia creativa y la inteligencia social; iii) el desarrollo del pensamiento crítico, la resolución de problemas y la creatividad, para lo que se requieren capacidades como curiosidad, imaginación y capacidad crítica; iv) las habilidades para operar en un mundo digitalizado ${ }^{6}$; v) el aumento de las horas de formación y experiencia en empresas y lugares de trabajo, y vi) capacidades para el aprendizaje activo a lo largo de la vida.

Asimismo, es necesario superar la segmentación de los sistemas educativos, que separan de manera temprana las trayectorias de estudios técnicos de las de formación general o académica, y que refuerzan la formación de las mujeres en áreas de ocupación feminizadas y de menores ingresos. Ello permitiría avanzar hacia modelos integrados que promuevan la igualdad de género. Es necesario un cambio de lógica en el currículo, la infraestructura, la formación docente y el ámbito cultural para superar prejuicios sobre las especialidades y los roles considerados femeninos, así como sobre la educación técnico-profesional, que suele ser terminal y, al ser considerada de menor calidad y prestigio, no permite continuar la trayectoria formativa en la universidad (CEPAL, 2017b). Además, los estudiantes de la región que optan por la educación y formación técnico-profesional ya presentan deficiencias de formación general que no son subsanadas en esta etapa de estudios. Ninguna iniciativa para crear itinerarios formativos entre la educación y formación técnico-profesional secundaria y la educación superior será útil si no revierte esa situación (Sevilla, 2017).

\section{Fortalecimiento de los sistemas de protección social y cuidado}

Para facilitar la transición hacia ocupaciones, actividades productivas y sectores que respondan al cambio estructural progresivo y sostenible desde el punto de vista ambiental, es preciso defender los derechos laborales adquiridos históricamente y forjar nuevos derechos que permitan acceder a un nivel mínimo de seguridad y bienestar independientemente de la inserción en el mercado laboral. Esto requiere avanzar en la articulación entre la protección social contributiva, basada en el empleo formal, y la protección social no contributiva. Es necesario contar con los mecanismos y la institucionalidad adecuados, entre los que se incluyen la provisión de niveles básicos y universales de bienestar y acceso a servicios de calidad; la protección frente al desempleo y la pérdida de ingresos; el acceso a pensiones contributivas; las políticas de salario mínimo; los derechos efectivos a la organización sindical y a la negociación colectiva, y los espacios de negociación y diálogo social entre el sector público y los actores del mundo del trabajo (empleadores y organizaciones sindicales) (CEPAL, 2017b).

Otro ámbito de acción es la creación o fortalecimiento de un sistema de cuidados, lo que, desde una perspectiva de derechos, requiere una nueva lógica de la reproducción social que impulse la debida provisión de bienes y servicios públicos para hacer visible y socializar el trabajo cotidiano no remunerado de las mujeres. Es especialmente urgente poner en marcha un sistema de cuidados para proporcionar a niñas y niños, personas mayores, enfermos crónicos y personas con discapacidad mejores entornos de vida, mayores posibilidades de desarrollo y de acceso a niveles más altos de bienestar; desfeminizar y socializar las tareas de reproducción social para liberar el tiempo de las mujeres y que puedan acceder al mercado de trabajo y llevar a cabo sus

Como la capacidad de buscar, discriminar, sintetizar, analizar y representar información en un ambiente digital, así como utilizar las herramientas digitales para compartir y colaborar con otros. 
proyectos de vida, y transformar los roles de género y lograr una distribución más equitativa entre hombres y mujeres de las labores de cuidado en los hogares.

El pilar de cuidados no solo se centra en la atención de carencias y la satisfacción de necesidades urgentes, sino que incluye también el propósito de desarrollar las capacidades de las personas y permitir que gocen de una vida digna. Contribuye a cerrar la brecha de participación económica entre hombres y mujeres y a superar la división sexual del trabajo que hace que recaiga sobre ellas gran parte de las labores de cuidado.

\section{El ingreso básico: ¿una opción?}

Tanto en los países desarrollados como en los países en desarrollo se discute, cada vez con más fuerza, la introducción de un ingreso básico —como complemento y refuerzo de los sistemas de protección social— para hacer frente a la persistencia de la pobreza y la desigualdad y el impacto incierto de los procesos de cambio tecnológico. El ingreso básico es un pago universal incondicional, en contante y regular, que el Estado entrega a los habitantes del país y que les permite satisfacer sus necesidades básicas. Si bien puede presentarse como una opción política de reciente aparición, el ingreso básico no es una idea nueva: fue debatida en el Reino Unido a comienzos del siglo XIX y en los Estados Unidos en las décadas de 1960 y 1970, y ya se ha aplicado como experiencia piloto en algunos países (Van Parijs y Vanderborght, 2017). En cambio, sí es nueva la amplitud del debate en torno a esta propuesta, en particular después de la crisis mundial del período 2008-2009. La CEPAL ha iniciado un proceso de análisis y reflexión sobre el ingreso básico en el marco de la formulación de propuestas sobre las características y pilares del nuevo régimen social de derechos o estados de bienestar que sería necesario debido a las transformaciones demográficas, laborales, tecnológicas y productivas en curso.

Al liberar a las personas de las más graves consecuencias de la dependencia material, el ingreso básico puede significar un proceso de reordenamiento de jerarquías sociales, aumentar el poder de negociación de las mujeres, los jóvenes y otros grupos en situación de discriminación y subordinación, y abrir espacios de mayor autonomía y libertad para todas las personas.

Es de particular importancia para los jóvenes - que experimentan altas tasas de desempleo o de empleo precario en condiciones de desconexión creciente entre educación, empleo e ingreso-, contar con un piso de seguridad económica básica para llevar a cabo sus proyectos de vida. De la misma manera, como se señaló en la Segunda Reunión de la Conferencia Regional sobre Desarrollo Social de América Latina y el Caribe, un ingreso básico sería un importante instrumento para desarrollar la autonomía económica de las mujeres. Por otra parte, este ingreso aumentaría la capacidad de negociación de los trabajadores, ya que no estarían obligados a aceptar cualquier trabajo, nivel de remuneración o condiciones de contratación. Es decir, el ingreso básico puede servir como herramienta no solo para erradicar la pobreza y disminuir la desigualdad, proporcionar seguridad económica y actuar como un estabilizador automático, sino también para detonar procesos de emancipación social y ampliación de libertades.

El ingreso básico se conceptualiza desde nociones diversas y en ocasiones contrapuestas de los principios que deben regir la sociedad y del papel del Estado y del mercado (CEPAL, 2017b). En algunos casos, se considera una herramienta que podría monetizar las prestaciones y servicios sociales y reducir el peso y el alcance de los regímenes del bienestar. También se debaten las repercusiones del ingreso básico en las negociaciones salariales. Mientras que, por un lado, se alerta sobre el riesgo de instituir un tipo de subsidio al capital, ya que una parte del ingreso del trabajador no dependería del monto de su salario, otras posiciones señalan lo contrario: como se mencionó anteriormente, un ingreso básico elevaría la capacidad de negociación de los trabajadores, particularmente de las mujeres y de aquellos con remuneración más baja u organización más débil.

Frente a quienes pudieran pensar en un ingreso básico para desmontar el estado de bienestar, la respuesta es que se trata exactamente de lo opuesto, esto es, el ingreso básico como una expansión y acumulación de derechos, no de sustitución de conquistas y prestaciones sociales. En estos casos, es considerado un pilar nuevo y adicional del estado de bienestar, que no reemplaza los servicios y prestaciones a los que por derecho acceden las personas. Es desde esta perspectiva que la CEPAL explora la pertinencia y viabilidad de esta propuesta. 
En América Latina y el Caribe, el debate sobre el ingreso básico se da a partir de la expansión relativamente reciente de la protección social no contributiva 7 . En particular, desde la perspectiva del enfoque de derechos, la implementación del ingreso básico sería una evolución de las transferencias monetarias condicionadas y focalizadas aplicadas en los últimos 20 años y que, a lo largo del tiempo, han legitimado las transferencias en efectivo y la posibilidad -o, en algunos casos, el derecho- de acceder al ingreso por una vía distinta a la de la propiedad de activos o el empleo.

En los países de la región el ingreso básico garantizado universal solo podría implementarse de manera gradual, progresiva y con una perspectiva de largo plazo. Las posibles modalidades para su implantación son muy variadas (por grupos de edad, por territorios, por niveles de ingreso) y dependerían de las condiciones de cada país, pero no es un objetivo imposible y puede convertirse en una herramienta para lograr el Objetivo de Desarrollo Sostenible de poner fin a la pobreza.

La implementación de un ingreso básico garantizado exige la conformación de una fiscalidad que lo haga posible. A diferencia de los programas de transferencias monetarias condicionadas, que implican recursos modestos en términos del PIB tanto por su focalización como por sus montos reducidos ${ }^{8}$, un ingreso básico garantizado implicaría una fuerte movilización de recursos. Esto no es inalcanzable para el grado de desarrollo de la región, pero sí requiere una fiscalidad con una capacidad mucho mayor de recaudación, progresividad y capacidad redistributiva.

Dado que los países de la región se encuentran en distintas situaciones económicas y demográficas, la CEPAL (2010) y Filgueira y Espíndola (2015) concluyen, al analizar los costos y beneficios de la universalización de las transferencias monetarias no contributivas del Estado para personas mayores y familias con hijos menores de edad, que no es posible proponer un modelo único de prestaciones para todos los países. Cada uno puede debatir y adoptar estrategias de ampliación de las garantías de ingresos básicos acordes a sus capacidades fiscales, necesidades sociales y posibilidades económicas ${ }^{9}$.

Más allá de las diferencias de ingresos, la desigual propiedad de activos físicos y financieros es una condición estructural que profundiza y perpetúa la desigualdad, ya que es más estable, intensa y rígida que las desigualdades derivadas de los mercados laborales. Por ello, merece atención la propuesta de que los nuevos regímenes de bienestar se sustenten en una distribución más equitativa de la posesión de activos, lo que puede lograrse fortaleciendo la propiedad pública, los bienes comunes y las políticas de fomento del acceso a la propiedad de activos por parte de los sectores de menores ingresos.

Las políticas para una mejor distribución de activos buscan fortalecer las economías social y solidaria. El asociacionismo, el cooperativismo, las iniciativas de comercio justo y, en general, las iniciativas productivas de organizaciones sociales y comunitarias no han contado con las políticas de fomento necesarias para su expansión, pese a que crean una parte importante de la ocupación y el empleo y cuentan con casos exitosos en términos de innovación, productividad y distribución equitativa de resultados y beneficios. El acceso al crédito y a los servicios financieros en condiciones de igualdad y con una lógica progresiva —es decir, la inclusión financiera - es también un instrumento importante para avanzar hacia un estilo de desarrollo en el que se cierren brechas económicas y de género ${ }^{10}$.

Existen modalidades de transferencias monetarias estrechamente emparentadas con los fundamentos filosóficos del ingreso básico garantizado (individualidad, universalidad, incondicionalidad), como la pensión ciudadana para personas mayores de Ciudad de México y, en buena medida, el programa Pensión para Adultos Mayores en México, la Renta Dignidad en el Estado Plurinacional de Bolivia y la Asignación Universal por Hijo en la Argentina.

8 Cecchini y Atuesta (2017) estiman que en 2015 el gasto en programas de transferencias condicionadas en América Latina y el Caribe alcanzó el 0,33\% del PIB regional, y el dirigido a las pensiones no contributivas, alrededor del $0,40 \%$.

9 Alrededor de 2011, el costo de universalizar una transferencia monetaria equivalente a una línea de pobreza a los hogares con niños y las personas mayores de 65 años variaba entre un mínimo del 1,5\% del PIB en la Argentina y Chile y un máximo del 13,7\% del PIB en Guatemala.

10 Dadas las barreras que las mujeres enfrentan para acceder al sistema financiero, las políticas de inclusión financiera pueden potenciar su autonomía y la igualdad de género (Rico, 2017; CEPAL, 2017b). 


\title{
C. Tres ejes de la descarbonización: digitalización, ciudades sostenibles y energías renovables
}

\author{
1. Un gran impulso ambiental para el cambio \\ estructural progresivo
}

Para avanzar hacia la sostenibilidad ambiental en los marcos de la Agenda 2030 para el Desarrollo Sostenible, el Acuerdo de París y la Nueva Agenda Urbana es preciso implementar políticas y crear y fortalecer instituciones que permitan un salto en el desarrollo económico orientado a diversificar la estructura productiva y gestionar de manera más eficiente el patrimonio natural sin vulnerar los límites ecológicos para la reproducción de la vida. Las políticas industriales y tecnológicas son fundamentales para alcanzar estos objetivos, pues de ellas depende el desarrollo de actividades y sectores basados en nuevas tecnologías, materiales y modelos de negocio. Esas políticas deben integrarse y coordinarse con acciones de los ámbitos impositivo y regulatorio, la inversión pública, el financiamiento, la infraestructura y la educación. La jerarquización e implementación coordinada de los instrumentos es una condición imprescindible para la eficaz aplicación de esas políticas.

El gran impulso (big push) propuesto por Rosenstein-Rodan (1960) es una estrategia de crecimiento económico que consiste en la coordinación de un gran número de inversiones que deben realizarse de manera simultánea en distintos sectores en un proceso coordinado e impulsado por la inversión pública ${ }^{11}$. Uno de sus argumentos es que existen aspectos indivisibles de las funciones de producción —ya sea en los insumos o en los productos- que hacen que la oferta eficiente de esos bienes solo pueda producirse a partir de una escala mínima. En un marco de múltiples inversiones que, para ser viables, deben ser realizadas simultáneamente y, debido a su escala, contar con amplios mercados, la rentabilidad del conjunto de acciones depende de su complementariedad.

Otra característica de esas inversiones es que se dan en mercados con información imperfecta, donde no hay precios o estos no proveen la información requerida para decidir de manera óptima. Al no informar, por ejemplo, sobre los beneficios o costos sociales que se derivan de las externalidades positivas o negativas, los precios de mercado no pueden ser la única base para los cálculos de las decisiones de inversión. Por ese motivo, resulta necesaria la función orientadora y coordinadora de las políticas públicas. Para desbloquear un escenario en el que es arriesgado dar el primer paso puede emplearse un paquete coordinado de inversiones que viabilice simultáneamente las distintas actividades. Ese impulso puede adoptar distintas formas y basarse en instrumentos de distinta índole, desde el financiamiento subsidiado y los incentivos impositivos hasta la regulación de los estándares tecnológicos y el fomento a la formación de capital.

Las inversiones que conforman el gran impulso y conducen al crecimiento del conjunto de la economía conllevan una fuerte actividad estatal en los procesos de innovación en tecnologías de propósito general12. Los beneficios de la innovación en esas tecnologías son difíciles de internalizar por el primer inversor, ya que pueden ser utilizadas de manera redituable en muchas otras actividades. Esto lleva a que las etapas de preinversión en esas tecnologías tiendan a recaer en el sector público, que históricamente las ha financiado y ha creado oportunidades en el mercado mediante la fijación de estándares, la creación de instituciones e

11 "Hay un nivel mínimo de recursos que debe ser dedicado a [...] un programa de desarrollo, si este ha de tener alguna probabilidad de éxito. Lanzar a un país a un crecimiento autosostenido es en cierto modo como hacer despegar a un avión. Hay una velocidad crítica sobre la pista que debe ser rebasada antes que el aparato se eleve [...] Procediendo paso a paso, no se logrará un efecto igual a la suma total de los pasos. Un quantum mínimo de inversión es condición necesaria (aunque no suficiente) para el éxito" (Rosenstein-Rodan, 1960, pág. 67).

12 Estas tecnologías se caracterizan por su impacto generalizado en productos y mercados y por su capacidad de reducir los costos de producción y facilitar el desarrollo de nuevos productos y procesos, que presuponen innovaciones con elevado riesgo en la medida en que requieren altos niveles de inversión inicial y largos plazos de maduración. 
incluso la coordinación y supervisión de su comercialización. Esta noción del gran impulso es aún más completa si se caracteriza la intervención estatal mediante el trinomio visión-misión-plan (Mazzucato, 2011 y 2015) ${ }^{13}$.

La propuesta de la CEPAL recoge estas ideas y las adapta a las particularidades de la región. Busca articular el cambio de los patrones de producción y consumo con la transformación productiva, poniendo a las políticas industrial y tecnológica en el centro de la agenda de desarrollo sobre la base de la sostenibilidad ambiental. Ello supone implementar políticas públicas coherentes y con continuidad; de no ser así, las inversiones, regulaciones, precios, impuestos y otros componentes de la acción estatal no darían lugar a una trayectoria de innovación, sino que quedarían como iniciativas aisladas.

Las nuevas oportunidades de transformación productiva pueden surgir de la aplicación de las tecnologías digitales a la producción, así como del aumento de la densidad del tejido industrial por efecto de la redefinición de las tecnologías en uso y de la matriz energética. Algunos ejemplos de ello son la gestión de ciudades inteligentes; la expansión del transporte masivo; el manejo de la biodiversidad; la recuperación de los territorios rurales; el manejo y aprovechamiento sostenible del agua dulce; el desarrollo de los biomateriales, y la producción de energías renovables y el consiguiente desarrollo de sus cadenas de valor. Cada una de estas actividades es una opción de diversificación productiva en una agenda transformadora que genere las condiciones materiales para la inclusión social al tiempo que oriente las inversiones en una trayectoria de crecimiento bajo en carbono.

\section{Políticas industriales y tecnológicas para la digitalización de la producción}

Promover el crecimiento económico y el empleo con sostenibilidad ambiental implica diseñar e implementar políticas industriales y tecnológicas que favorezcan la inversión en la elaboración de bienes y la provisión de servicios asociados a la producción y el consumo bajos en carbono y con una huella material que no atente contra el patrimonio natural. Para encauzar las inversiones en la dirección deseada y hacerlas viables, son necesarios instrumentos e instituciones que generen los incentivos adecuados, desde las políticas impositiva y regulatoria a las políticas de financiamiento e inversión pública, incluidos el desarrollo de infraestructura, la provisión de bienes públicos, el fomento a las MIPYMES y el estímulo a las asociaciones público-privadas. El objetivo es sustituir las actividades que tengan un alto impacto ambiental y un reducido dinamismo tecnológico, y que generen relativamente pocos eslabonamientos productivos y empleos, por una estructura productiva basada en actividades de elevado dinamismo tecnológico, fuertes encadenamientos productivos, empleos de calidad y baja huella ambiental. Es decir, un cambio estructural progresivo basado en un gran impulso ambiental. La experiencia internacional ofrece lecciones para conformar el marco en el que deberán operar ese tipo de políticas (Cimoli y otros, 2017):

- Se ha de responder a objetivos económicos y sociales: las políticas deben ser más que herramientas para aumentar la productividad, mejorar la competitividad y promover el cambio estructural. Deben formar parte de un proyecto social para alcanzar y equilibrar metas como la creación de empleo, el aumento de la igualdad y el combate del calentamiento global, como se postula en la Agenda 2030.

- Se requieren políticas activas de cambio estructural: las políticas deben concebirse en un contexto dinámico y focalizarse en trayectorias de aprendizaje y resultados en términos de productividad y competitividad. Estas trayectorias se apoyan en los mercados y la competencia, donde las políticas públicas orientan e incentivan la inversión privada.

13 La "visión" define la tecnología que se investiga y prevé sus aplicaciones y efectos en la producción y el consumo. Una visión que sea un pronunciamiento sociopolítico y defina una dirección permite la convergencia de actores, sectores e inversiones e impulsa innovaciones y procesos sinérgicos entre suministros, habilidades, equipamientos, servicios, distribuciones, redes y demandas (Mazzucato y Pérez, 2014). La noción de "misión" alude a la organización de una agenda acorde con la visión, la coordinación de los estamentos públicos que deben invertir en la creación de esa agenda y la articulación de los institutos y organismos que participarán en el proceso de investigación. Finalmente, el "plan" abarca la coordinación de las inversiones iniciales, la generación de condiciones para el mercado —incluida su articulación con los organismos públicos responsables de establecer estándares de producción y consumo-y la convocatoria al sector privado en el momento y las fases en que resulte más adecuado. 
- La política industrial y el mercado no se oponen: las buenas prácticas de política industrial deben coincidir con la defensa de la competencia y el dinamismo del sector privado. Existen abundantes ejemplos de cómo diseñar estrategias de políticas para desarrollar mecanismos competitivos. Por ejemplo, tarifas reguladas a partir de procesos de licitación pública, normas ambientales de productos y procesos con base en propuestas y prácticas óptimas del sector privado o la concesión de subsidios a la investigación y desarrollo solo después de haber recibido y evaluado licitaciones de conglomerados productivos o de regiones.

- Es necesario proveer una dirección a largo plazo: las políticas modernas trazan una trayectoria de desarrollo a largo plazo, se mantienen en el tiempo y simultáneamente ofrecen la necesaria flexibilidad. Es posible crear mercados para inversiones verdes (por ejemplo, mediante tarifas reguladas para favorecer las energías renovables) que generen aprendizajes tecnológicos, aprovechen economías de escala y produzcan con menores costos unitarios.

- Lo que distingue a los países es la capacidad de implementar políticas, no la de formularlas: las fallas de implementación debilitan o anulan las señales de política que buscan impulsar la inversión y la innovación. En la región, aún proliferan los programas que no se ejecutan por insuficiencia de recursos humanos y financieros o por falta de compromisos políticos para superar los problemas de gestión de políticas complejas que deben sostenerse a largo plazo.

- La implementación es compleja y arriesgada: se pueden reducir los costos de los posibles fracasos aumentando la transparencia del proceso, la participación y los pactos entre las partes interesadas, llevando a cabo un monitoreo continuo y evaluando el progreso hacia el logro del aprendizaje sistemático de políticas.

En resumen, cuando están bien formuladas, las políticas industriales y tecnológicas establecen un marco estratégico con indicadores para facilitar las decisiones de las empresas sobre las inversiones de largo plazo, en un proceso que estimula la competencia y ofrece garantías para la adopción de medidas correctivas. En la región, la atención debe centrarse en los arreglos institucionales necesarios para una efectiva implementación.

\section{a) Políticas e instrumentos para la transformación digital de la actividad productiva}

El principal desafío del cambio estructural ante la disrupción tecnológica analizada en el capítulo II es la incorporación de las tecnologías digitales y el paso de la Internet del consumo a la Internet de la producción (CEPAL, 2016). La digitalización de la producción es una poderosa fuerza en favor de la descarbonización y la sostenibilidad. Su expansión en la economía y la sociedad aumenta el peso de los servicios y los bienes intangibles (digitales), cuya huella material y de carbono es muy inferior a la de los bienes físicos, sobre todo en lo referente al uso de plásticos y a los costos de transporte. En este sentido, la virtualización de procesos —por ejemplo, en las fases de diseño, desarrollo de prototipos y pruebas_ reduce o elimina insumos físicos.

En relación con el funcionamiento de los mercados, la digitalización hace posible un notable proceso de desintermediación, mediante el cual se reduce el número de etapas o eslabones de las cadenas de valor $y$, por consiguiente, se ahorran energía e insumos. Por otra parte, la analítica de datos posibilita una mejor desagregación o segmentación de los mercados, dado que reduce las existencias invendibles y el desperdicio de materiales y esfuerzos. Finalmente, las empresas de la economía de ocupaciones transitorias (gig economy), desarrollada sobre la base de la digitalización, permiten un mejor aprovechamiento del capital fijo inmueble y móvil. Así, aumentan la oferta de servicios de hospedaje sin requerir más construcción hotelera e incrementan la oferta de servicios de movilidad urbana aprovechando el tiempo ocioso del capital en vehículos, sin aumentar la demanda de unidades, con el ahorro en materiales y energía que ello conlleva. Por su parte, las aplicaciones de navegación urbana (por ejemplo, Waze) reducen los tiempos de transporte y las emisiones. En este sentido, la digitalización es un poderoso instrumento para avanzar hacia ciudades sostenibles. 
Las empresas de banca virtual y tecnología financiera (fintech) ${ }^{14}$ extienden los servicios financieros sin costos ingentes de construcción, operación y desplazamiento, lo que facilita el acceso a dichos servicios por parte la población de menos recursos y las microempresas y pequeñas empresas, es decir, la inclusión financiera ${ }^{15}$. Para aprovechar todo el potencial de la irrupción de las empresas de alta tecnología es necesario que operen en una infraestructura flexible (lo que incluye el marco legal, la regulación y la fiscalidad) que responda a su dinámica empresarial y fortalezca su complementariedad con el sistema bancario. Asimismo, el mayor y más fluido acceso a los servicios financieros mediante las tecnologías digitales ha creado vínculos directos entre la inclusión financiera y los objetivos de los bancos centrales, en forma de sistemas de pago eficientes, mejoras en el funcionamiento del sistema financiero y protección de los consumidores y usuarios.

En el ámbito productivo, las actividades más avanzadas combinan tecnologías innovadoras, como la manufactura aditiva, los equipos de realidad aumentada y virtual, la Internet de las cosas, la analítica de datos, la robótica y la inteligencia artificial. Estas tecnologías permiten desarrollar nuevos procesos, sistemas de producción y productos inteligentes conectados. Asimismo, flexibilizan los procesos y facilitan el ajuste a diferentes escalas de producción, descentralizan la toma decisiones y permiten la fabricación de productos personalizados. Estos avances están presentes en diversas industrias manufactureras y actividades mineras y agrícolas, pero también en sectores como el financiero, el de la salud (algunos ejemplos son la tecnología emocional $^{16}$, la tecnología para el cuidado, las aplicaciones de monitoreo y la telemedicina) y en las ciudades (por ejemplo, la optimización de los procesos de compraventa de energía).

Esta nueva dinámica exige contar con un ecosistema que aproveche eficientemente las tecnologías digitales para impulsar nuevos emprendimientos y modelos de negocios que redunden en mayor crecimiento y competitividad. Debido al elevado nivel de acceso a las tecnologías digitales en los países de América Latina y el Caribe, la región tiene la posibilidad de utilizar dichas tecnologías en sus estrategias de desarrollo con menor rezago que en paradigmas tecnológicos anteriores. Para aprovechar ese potencial de transformación es necesario un ecosistema de innovación basado en datos que integre las nuevas tecnologías y las capacidades de procesamiento y de uso por parte de las personas y las organizaciones.

La integración entre tecnologías es necesaria también para reducir la huella ambiental de la digitalización y desarrollar fuentes renovables de energía. La demanda de electricidad de las tecnologías digitales, particularmente de los grandes centros de datos, tiene un peso significativo y creciente en el total de la demanda energética, y el alcance de sus efectos ambientales dependerá de con qué tipo de fuentes se satisfaga. Por otra parte, el desarrollo de fuentes renovables dependerá de los avances en la digitalización de sus sistemas productivos y redes de transmisión de corta y larga distancia.

El aprovechamiento del potencial de las tecnologías digitales en la producción requiere nuevos enfoques de política e incentivos públicos, así como estrategias para orientar las decisiones de inversión hacia actividades de alto valor agregado y que promuevan la difusión de las mejoras de productividad en el conjunto de la economía. Una política industrial digital en la región debe priorizar tres áreas de desarrollo:

- La infraestructura de banda ancha, fija y móvil, para alcanzar niveles de penetración cercanos a los países de ingreso medio de la OCDE y calidades cercanas a los estándares internacionales en términos de velocidad y latencia, así como servicios a precios competitivos.

14 La innovación en servicios financieros facilitada por la tecnología (fintech) puede "tener un impacto positivo en varios aspectos de la inclusión financiera, incluyendo los préstamos y las calificaciones crediticias de los hogares y empresas no bancarizados. (...) Los distributed ledgers son quizás la innovación más revolucionaria para los bancos centrales, los intercambios centralizados, y los mercados interbancarios (...) La regulación y la formulación de políticas deben adaptarse para superar los desafíos planteados por las tecnologías modernas" (Furche y otros, 2017).

15 La inclusión financiera incluye aspectos vinculados al uso y la calidad de estos servicios, la masificación de la educación financiera, la implementación de un adecuado marco regulatorio y la calidad de su infraestructura. La inclusión financiera suaviza la trayectoria del consumo, aumenta la efectividad de la tasa de interés y disminuye la volatilidad del producto con respecto a la inflación (Marcel, 2017).

16 La tecnología emocional se refiere a la medición de datos biométricos asociados con diferentes estados emocionales (como el pulso del corazón, la transpiración 0 la tensión muscular) y el uso de estos insumos en aplicaciones que asisten al usuario para lograr ciertos comportamientos o estados emocionales. Algunos ejemplos son las aplicaciones que responden a estados de estrés — y pueden calmar a un conductor alterado por el tránsito— 0 que colaboran en el cuidado de niños o personas mayores. 
- La industria de las tecnologías de la información - hardware, plataformas, aplicaciones o datos-, a fin de aumentar la oferta de calidad de proveedores de productos y servicios para la modernización digital de las empresas.

- Capacidades empresariales para la transformación digital de los modelos de negocios, productos y servicios.

Esta política industrial debe asegurar la sinergia entre los programas gubernamentales (nacionales, subnacionales y locales), promover las alianzas público-privadas y garantizar la transparencia y los mecanismos de evaluación y rendición de cuentas en los ámbitos de la inversión, la innovación y la regulación. El desafío institucional consiste en:

- Ampliar las estrategias de desarrollo digital —las agendas digitales-con políticas de transformación y especialización productiva, formación de recursos humanos e innovación tecnológica que presten atención a las MIPYMES.

- Transitar hacia modelos de regulación que generen incentivos para cubrir las nuevas necesidades de inversión en redes y consideren las características de la Internet de la producción en términos de nuevos modelos de despliegue, interoperabilidad, seguridad, protección de datos y privacidad.

- Desarrollar un mercado digital regional que permita aprovechar economías de escala y de red, mediante la armonización del espectro y de las regulaciones nacionales.

Las propuestas de políticas se sitúan en las esferas de la inserción internacional, la infraestructura y la regulación y las acciones de apoyo a la oferta y la demanda.

Las políticas de inserción internacional deben conectar a la región a las redes tecnológicas internacionales y apoyar la transferencia de conocimientos y capacidades en áreas como las de los dispositivos, las redes de alta velocidad, las plataformas digitales y la integración de mercados. Se busca atraer las nuevas capacidades tecnológicas y empresariales necesarias para llevar a cabo los programas de especialización prioritarios mediante instrumentos de cooperación internacional, formación de recursos humanos, transferencia tecnológica, atracción de inversiones y redes de emprendimiento.

El objetivo principal de la política de infraestructura y regulación es generar condiciones que aumenten la inversión en infraestructura para incrementar la penetración y la calidad de la banda ancha fija y móvil. El retraso en las inversiones en redes de nueva generación puede provocar una saturación de las redes ante el continuo crecimiento del tráfico de datos.

Esta política debe posibilitar, en un ambiente de creciente convergencia e hiperconectividad, la compatibilidad entre inversión, competencia e innovación. Es cada vez más necesario redefinir el alcance de las políticas de promoción de la competencia y precisar sus efectos sobre los nuevos mercados, cada vez más orientados a la oferta de intangibles. Deben reconsiderarse las categorías tradicionales, como el poder de mercado o el abuso de posición dominante, teniendo en cuenta dinámicas como la de los mercados en que el ganador se lleva todo (winner takes all), que se traduce en una tendencia hacia la concentración, o, por el contrario, la de los mercados en los que la entrada de nuevas empresas es muy significativa, debido a la disrupción tecnológica que elimina barreras y crea nuevos sectores. Esto implica reforzar los entes regulatorios y los instrumentos que aseguren marcos competitivos para la actividad empresarial en estas nuevas condiciones tecnológicas.

Ante los cambios en los marcos legales e institucionales, las empresas han adoptado dos enfoques. En uno, las empresas disruptivas construyen una masa crítica antes de participar en las discusiones regulatorias, lo que ejerce presión sobre el regulador y hace un llamado directo a la acción de todos los actores involucrados. En otro, participan con los reguladores en la formulación de la legislación, incluso en ambientes desregulados, como en el modelo de sandbox regulation o entorno de prueba ${ }^{17}$.

7 Este concepto de refiere a la creación de un espacio seguro y limitado temporalmente en el que las empresas pueden experimentar productos, servicios, modelos de negocio o mecanismos de distribución y probar, en diálogo con los reguladores, nuevos modelos e instrumentos regulatorios. 
Las políticas de oferta —creación de capacidades tecnológicas en materia de Internet para la producción-y las de demanda — desarrollo de capacidades digitales en las empresas— están estrechamente relacionadas. Una de las fallas recurrentes en la implementación de políticas en la región es la descoordinación entre los instrumentos de apoyo a la oferta y a la demanda. Las propuestas apuntan hacia dos direcciones. Por un lado, a fortalecer las capacidades tecnológicas mediante centros de investigación y la promoción de empresas de base tecnológica y, por otro, a desarrollar capacidades y promover la innovación digital en el ámbito productivo, principalmente en las MIPYMES, que son fundamentales para la demanda de capacidades y la generación de empleos.

La política industrial para la economía digital debe considerar como punto de partida el fortalecimiento de la industria del software y las aplicaciones, incluido el software libre, para crear nuevos sectores de alta productividad. Su relevancia radica en lo que aporta al desarrollo tecnológico mediante la transferencia y difusión de nuevas tecnologías, la generación de empleos calificados y la exportación de servicios. Aunque se han llevado a cabo experiencias exitosas de fomento a la industria en países como la Argentina, el Brasil, Chile, Colombia, México y el Uruguay, aún existen carencias relacionadas con la difusión del uso de sus productos y su apropiación en las actividades empresariales, particularmente en las MIPYMES.

\section{b) La transformación digital de las microempresas y pequeñas y medianas empresas}

La transformación digital de las MIPYMES requiere de su alfabetización digital y un cambio en sus modelos de gestión, sistemas de relaciones y capacidades internas. Para ello, es necesario reconfigurar la organización productiva para crear un modelo integrado y gestionado sobre la base de las nuevas plataformas tecnológicas. En este proceso, hay que tener en cuenta las economías de escala relacionadas con el desarrollo de capacidades y conocimientos clave que requieren respuestas colectivas y que configuran nuevas redes de servicios para las empresas, como los laboratorios de pruebas y certificación, los centros especializados de investigación y de desarrollo o las empresas de formación técnico-profesional.

Las estrategias y políticas de apoyo deben tener en cuenta dos elementos esenciales. En primer lugar, las medidas específicas de apoyo a las MIPYMES deben coordinarse con políticas habilitantes, cuyo propósito es crear las condiciones de base para competir en los mercados nacionales e internacionales. Esas medidas se refieren, por un lado, a acciones orientadas a potenciar la base tecnológica —como, por ejemplo, la ampliación de las redes de alta velocidad, el acceso y uso de la computación en la nube, la generación de estándares de interoperabilidad, la ciberseguridad o el acceso a instrumentos financieros- $y$, por otro, al fortalecimiento del capital social y las normas que apuntan a regular la competencia para evitar el abuso de posición dominante por parte de las grandes empresas.

En segundo lugar, debe considerarse que el impacto de la digitalización no es neutral en el universo de las MIPYMES. Las empresas que conforman este conjunto empresarial tienen capacidades estratégicas, capitales, conocimientos, vínculos y recursos económicos muy diferentes y, por lo tanto, reaccionan de formas heterogéneas a la transformación digital. Las empresas pueden mejorar o empeorar su posicionamiento competitivo por los efectos de las tecnologías digitales en los escenarios en los que operan. Las políticas de fomento deben tener en cuenta estas diferencias y desarrollar medidas específicas y diversificadas de apoyo a las MIPYMES, entre las que destacan las vinculadas al acceso y uso de la computación en la nube (véase el cuadro VII.1).

Cuadro VII.1

Medidas para apoyar la integración de las MIPYMES en la economía digital

\begin{tabular}{lll}
\hline Tipo de MIPYME & Medidas \\
\cline { 1 - 2 } $\begin{array}{l}\text { Empresas integradas en sistemas } \\
\text { productivos dinámicos (clústeres } \\
\text { o distritos) }\end{array}$ & $\begin{array}{l}\text { - Definición de estándares productivos para reforzar el posicionamiento estratégico de los clústeres dinámicos } \\
\text { - Fortalecimiento de la conexión con redes de centros tecnológicos especializados en tecnologías avanzadas } \\
\text { - Creación de bienes colectivos locales para pruebas (testing) }\end{array}$ \\
\hline $\begin{array}{l}\text { Empresas de alta gama no integradas } \\
\text { en clústeres o distritos }\end{array}$ & $\begin{array}{l}\text { - Facilitación de los procedimientos de exportación } \\
\text { - Apoyo a la formación empresarial para la gestión de las nuevas estrategias competitivas } \\
\text { - Impulso a la creación de empresas de servicios digitales }\end{array}$ \\
\hline $\begin{array}{l}\text { Proveedores no especializados } \\
\text { - Acompañamiento estratégico para identificar oportunidades competitivas } \\
\text { - Apoyos financieros y técnicos para la digitalización }\end{array}$ \\
\hline $\begin{array}{l}\text { Empresas no especializadas que } \\
\text { operan en mercados locales }\end{array}$ & - Alfabetización digital, incluido el acceso a la computación en la nube (aplicaciones, plataformas, hardware) y su uso \\
\hline
\end{tabular}

Fuente: Comisión Económica para América Latina y el Caribe (CEPAL). 
Las dos claves de esta estrategia son, por un lado, asegurar la convergencia de las políticas habilitantes y las medidas específicas y, por otro, identificar catalizadores que aceleren y refuercen el impacto de las medidas que se implementen, tales como:

- Grandes empresas integradas a cadenas productivas de MIPYMES: las políticas de apoyo pueden contemplar incentivos específicos para que las grandes empresas fomenten en sus proveedores la incorporación de tecnologías digitales a fin de desarrollar una relación de proveeduría más eficiente, transparente y duradera.

- Demanda del Estado y política de compras públicas: la contratación de bienes y servicios por parte del Estado también puede acelerar los procesos de incorporación de tecnologías digitales. Este debe calibrar sus requerimientos de acuerdo con las potencialidades y capacidades de las MIPYMES en cuestión —es decir, si ya cuentan con una base tecnológica y operacional o si están dando los primeros pasos en la producción y la organización digitales-.

- Centros tecnológicos y de desarrollo empresariales: los centros de apoyo a las empresas generan una oferta de servicios que va desde el apoyo a la gestión (centros de desarrollo empresariales) hasta la promoción de proyectos de innovación y aplicación de nuevas tecnologías (centros tecnológicos). Estos centros, en la medida en que se integren en los respectivos sistemas productivos y consoliden su capacidad de diálogo e interacción recíproca, pueden ser un catalizador de los procesos de difusión de las nuevas tecnologías.

- Ciudades sostenibles y nuevas asociaciones empresariales: el ecosistema productivo de las ciudades, con su capacidad de atraer conocimientos y capitales, es un crisol de oportunidades y emprendimientos. Un número creciente de ciudades medianas y grandes ha reconocido y empezado a valorar esta función, poniendo en marcha estrategias locales propias, con el propósito de orientar su senda de crecimiento hacia modelos de desarrollo más sostenibles e inclusivos. La recuperación de espacios físicos, la generación de nuevos servicios colectivos y la construcción de entramados locales con orientación hacia la innovación y la diversificación productiva se configuran como ecosistemas ideales para las MIPYMES.

- Desarrollar sinergias entre el aumento de la productividad de las MIPYMES, la producción y el consumo de energías renovables y la electrificación del transporte urbano: estos elementos facilitarán el avance hacia ciudades sostenibles con bajas emisiones; por ello, son componentes del gran impulso ambiental basado en la descarbonización.

\section{Ciudades sostenibles como motores del desarrollo}

Las ciudades son sistemas económicos abiertos con entradas de materiales y de energía y generación de entropía y residuos, que configuran metabolismos dependientes de la interacción entre los ciudadanos y las modalidades de gobernanza. La forma de interacción ciudadana, los mecanismos de participación y de definición de prioridades, el peso de los grupos sociales y el papel de la cultura del privilegio o de la convicción democrática determinan la exigencia de las normas, el direccionamiento de la inversión en infraestructura, la orientación de la política fiscal local y la calidad del medio ambiente y de vida.

La sostenibilidad urbana es uno de los ejes de las políticas de descarbonización y diversificación productiva, debido tanto a los patrones insostenibles de consumo energético y de contaminación vigentes como a las oportunidades de superar los problemas urbanos mediante la aplicación de las tecnologías e industrias emergentes ${ }^{18}$.

Las crecientes deseconomías en las ciudades, así como los retos en materia de calidad de vida, inclusión social y mejora radical de los servicios públicos, abren oportunidades de inversión en las que convergen la política urbana, la Nueva Agenda Urbana y los ODS. Las soluciones a problemas como la congestión y la

18 Las ciudades son responsables de entre el $60 \%$ y el $80 \%$ del consumo energético global y del $70 \%$ de las emisiones de $\mathrm{CO}_{2}$. También son el lugar donde se concentran las desigualdades y la contaminación (véase el capítulo V y ONU-Hábitat (2016) World Cities Report, Nairobi). 
contaminación exigen aportes de múltiples sectores y, para ello, según la propuesta de Rosenstein-Rodan analizada anteriormente, es preciso resolver importantes cuestiones de indivisibilidad mediante inversiones en infraestructuras habilitadoras (a las que denomina inversiones generales (overhead investments)) que dependen de decisiones de política pública. Así, la ciudad puede ser un locus de innovación e inversión para redireccionar el estilo de desarrollo hacia un cambio estructural progresivo basado en un gran impulso ambiental en sectores y territorios específicos.

La sostenibilidad urbana se puede beneficiar de los avances tecnológicos en el sector energético, la industria automotriz, la construcción y la digitalización. La política pública debe orientar y acelerar la innovación en estas actividades mediante normas de calidad y de desempeño de los bienes y servicios urbanos. La aplicación coordinada de normas, políticas públicas sectoriales, inversiones privadas e innovaciones tecnológicas puede cambiar los patrones de producción ${ }^{19}$. Más aún, las políticas de uso del suelo e inclusión urbana pueden reforzar los efectos positivos de las nuevas tecnologías.

\section{a) La movilidad sostenible como estrategia de descarbonización}

La movilidad urbana debe ser un foco de intervención, dada su alta contribución a las emisiones de $\mathrm{CO}_{2}$, la contaminación atmosférica y las brechas en materia de calidad y tiempos de viaje (véase el capítulo V). Es, asimismo, un área donde la política pública puede incentivar cambios productivos y fortalecer la innovación mediante regulaciones orientadas a la sostenibilidad.

Debido al aumento de la motorización y los viajes privados, las ganancias en eficiencia en el sector automotor y el cambio de la matriz energética no han sido suficientes para cumplir con las normas internacionales de salud referentes a la calidad del aire ni para avanzar hacia las metas climáticas. Algunas ciudades de la región, como Ciudad de México o Santiago, han introducido cambios normativos para definir límites a la capacidad de carga contaminante. Cuando se rebasa esta capacidad o los umbrales de concentración de contaminantes, se activan alarmas ambientales que llevan a la limitación de actividades. Esto amplía las capacidades de los Gobiernos para inducir el cambio técnico en los sistemas de monitoreo del territorio, de la combustión y de la movilidad. El cambio normativo no ha sido suficientemente dinámico y hay espacio para mayores exigencias dirigidas a posibilitar el cumplimiento de las normas de salud de calidad del aire y lograr procesos de innovación más rápidos. Varios países y ciudades han llevado a cabo cambios regulatorios para eliminar el uso del diésel en la mezcla urbana de combustibles fósiles mediante la restricción y futura eliminación de los vehículos que lo consumen, acciones que han sido impulsadas también por la revelación de escándalos industriales de manipulación de pruebas técnicas ${ }^{20}$. En este contexto, surge el interés en los vehículos eléctricos, que presentan beneficios asociados a la reducción de la contaminación, la diversificación energética y la mitigación del cambio climático, así como a menores costos de operación, en comparación con los vehículos con motores de combustión interna.

Mediante la regulación, la política urbana ha adquirido un papel más relevante en el cambio productivo y en la localización de empresas avanzadas desde el punto de vista tecnológico ${ }^{21}$. Las empresas más flexibles y dispuestas a acelerar el cambio técnico focalizan su esfuerzo innovador en áreas como el medio ambiente y la eficiencia energética. De esta manera, la electromovilidad y los nuevos materiales para vehículos ligeros adquieren mayor protagonismo, generan cambios importantes en la cadena de valor de la industria y mejoran sustancialmente los niveles de aceptación de esas tecnologías por parte del mercado (véase el recuadro VII.1).

19 En el Brasil, la norma de emisiones vehiculares redujo las emisiones de los vehículos ligeros y pesados cerca de diez veces entre 1989 y 2013 (CETESB, 2014).

20 En París y Ciudad de México se prevé la eliminación del diésel para 2025; en Alemania, la India y los Países Bajos, para 2030; en Londres y el estado de California (Estados Unidos), a partir de 2040. En China se plantea la restricción, sin fecha concreta aún, de todos los combustibles fósiles. En Noruega se ha manifestado la voluntad política de acelerar la transición, prohibiendo la venta de vehículos con motores de gasolina y diésel a partir de 2025. En 2017, las ciudades alemanas de Stuttgart, Múnich y Düsseldorf emitieron fallos contra la circulación de vehículos diésel (véase El país, "El diésel pone al límite a la industria más grande de Alemania", 28 de agosto de 2017 [en línea] https://elpais.com/economia/2017/08/25/actualidad/1503687596_501203.html).

21 Varias empresas han anunciado planes para lanzar modelos eléctricos, incluidas General Motors (20 modelos eléctricos hasta 2023, 2 de estos ya en 2018), Ford (13 modelos en los próximos años), Volvo, Nissan, Volkswagen, Daimler y Tesla (The New York Times, 2017). 


\section{Recuadro VII.1}

Regulación ambiental urbana y desarrollo tecnológico

Una iniciativa ambiciosa e integral es la de Copenhague, que, para alcanzar su objetivo de neutralidad carbónica en 2025. consensuó ocho líneas de acción hacia una economía verde para la transformación de la estructura productiva, la movilidad y la organización espacial. Puede considerarse que este esfuerzo va en la línea del gran impulso ambiental. Esta transformación va acompañada de una realineación de las políticas públicas de la ciudad -especialmente las de movilidad (transporte público y ciclismo) e infraestructura, para evitar el efecto cerrojo (lock-in) en una trayectoria alta en carbono- y del mantenimiento de un clúster tecnológico mediante el apoyo a la innovación y al crecimiento endógeno. El éxito de esta política radica en la eliminación acelerada del uso de combustibles fósiles. Una acción de este tipo podria ser un estímulo a su replicabilidad en la región.

En el universo empresarial, destaca la alianza entre la ciudad de Campinas (Brasil), BYD —una empresa china que incluye entre sus actividades la fabricación de vehículos eléctricos- y la industria de armadores locales, con el objetivo de producir vehículos para el transporte público, como respuesta a la decisión de la ciudad sobre la no homologación de vehículos de combustión interna destinados a ese tipo de transporte a partir de 2018. En São Paulo (Brasil), la empresa Eletra puso en funcionamiento el Dual Bus, un autobús hibrido, anticipándose asi a las restricciones al diésel. El sistema de transporte colectivo de Santiago incluirá, a partir de 2017, un 15\% de vehículos eléctricos. En Ciudad de México, por el contrario, a pesar del financiamiento disponible a través de la banca de desarrollo, se sigue optando por la compra de vehículos que funcionan con gas natural.

Fuente: Comisión Económica para América Latina y el Caribe (CEPAL), sobre la base de presentaciones realizadas en la Conferencia de las Ciudades: Implementando la Nueva Agenda Urbana en América Latina y el Caribe, Santiago, 2 a 6 de octubre de 2017, y el foro Bancos Nacionales de Desarrollo y Bancos Verdes: Instituciones Clave para Movilizar Financiamiento en las Contribuciones Nacionales Determinadas y los Objetivos de Desarrollo Sostenible, Ciudad de México, 26 y 27 de junio de 2017

Varias empresas han anunciado la futura eliminación del motor diésel de su línea de productos para concentrarse en los vehículos eléctricos e híbridos²2. Entre 2014 y 2017, las ventas mundiales anuales de vehículos eléctricos aumentaron de 320.713 unidades a cerca de 1.200.000, con lo que el número de unidades que circulan por el mundo podría superar con creces los 3 millones. En esto ha sido clave el notable descenso de los precios de las baterías - que representan cerca de un tercio del costo de producción de los vehículos-, el aumento de la autonomía y la rápida expansión de la infraestructura de recarga, especialmente en los países desarrollados.

Los avances tecnológicos, la reducción de costos y los cambios regulatorios son factores clave para el despliegue de la electromovilidad. En los países desarrollados, existen también generosos subsidios a la compra de vehículos eléctricos (por ahora, de elevada regresividad social). Se espera que los cambios se aceleren a mediados de la próxima década y que, en el largo plazo, los vehículos eléctricos se conviertan en la tecnología dominante. En 2040, los vehículos eléctricos de largo alcance tendrían un costo equivalente a unos 22.000 dólares actuales y el 35\% de los vehículos nuevos de todo el mundo contarían con enchufe. Asimismo, la posibilidad de que los vehículos almacenen o generen energía a escalas considerables y eficientes hará más difusa la frontera entre el sector automotor y el sector energético, que pasarían a ser parte de un mismo sistema de generación, almacenamiento y distribución.

Más allá de la innovación en los sistemas de propulsión, el panorama de la movilidad de personas y bienes cambia rápidamente como consecuencia de tendencias tecnológicas y socioculturales convergentes: la masificación de los vehículos conectados y, en última instancia, autónomos, y los cambios en los patrones de consumo expresados en el rápido crecimiento de la movilidad compartida (carsharing y ridesharing), donde la propiedad del automóvil comienza a disminuir. Aún existe una fuerte incertidumbre sobre la velocidad de esta transición, pero se está produciendo un cambio radical desde el paradigma del vehículo propio utilizado por una sola persona hacia un modelo de movilidad centrado —aunque no exclusivamente- en vehículos

22 El fabricante sueco-chino Volvo producirá solo automóviles con motor eléctrico o híbrido a partir de 2019 y el grupo francés PSA —propietario de las marcas Peugeot y Citroën— espera tener el 80\% de su producción electrificada en 2023. 
autónomos y en la movilidad compartida. Por ello, se puede anticipar cierta convergencia de la movilidad privada y la pública, sobre todo en algunos segmentos sociales.

Al adoptar una estrategia de descarbonización de la movilidad urbana, se debe priorizar la electrificación de los medios masivos y mejorar la articulación multimodal, campo en el que ha habido avances en los últimos 15 años $^{23}$. Para la innovación en esta área es importante acelerar la descarbonización, la descontaminación y la mejora del desempeño operativo. La electrificación de los vehículos y el incremento del uso de tecnologías digitales son oportunidades para mejorar el servicio ${ }^{24}$.

\section{b) Descarbonización y eficiencia energética en la industria de la construcción}

También en la industria de la construcción se anticipan cambios importantes y oportunidades para la política industrial, la digitalización y la articulación intersectorial. Los medidores eléctricos de entrada y salida y la aplicación de las tecnologías digitales en la administración de redes inteligentes de distribución borran las fronteras de la política industrial sectorial tradicional: la edificación, el desarrollo de materiales de construcción para la generación de electricidad ${ }^{25}$, la movilidad eléctrica individual, la electrificación de sistemas masivos de transporte urbano de superficie y la transmisión y generación eléctrica de gran escala van convirtiéndose gradualmente en componentes de un nuevo sector energético ampliado.

Aunque prevalece la visión de que la rentabilidad de la industria de la construcción y de la vivienda y la mejora normativa como motor de la innovación son factores que se oponen, los países y las ciudades tienen un margen de acción considerable para innovar en lo referente a la normativa de aplicación del etiquetado energético. Del mismo modo, estandarizar el financiamiento de estas nuevas actividades canalizado a través de la banca de desarrollo impulsaría la innovación en el ámbito de la construcción y la infraestructura de los servicios públicos. Al mismo tiempo, sería conveniente establecer requisitos mínimos de eficiencia energética y térmica para las construcciones y las viviendas y la operación de los sistemas de transporte masivo, de tratamiento de aguas o de manejo de residuos.

\section{c) Tecnologías digitales y ciudades sostenibles para impulsar la diversificación productiva}

Las tecnologías digitales pueden desempeñar un papel importante a la hora de racionalizar el uso de los recursos en las ciudades, mejorar la calidad de los servicios, fortalecer los procesos participativos y apoyar vínculos virtuosos entre las políticas urbanas y las iniciativas de transformación productiva.

La innovación tecnológica siempre ha sido un factor clave en la definición del tipo de desarrollo urbano, desde la electrificación, que facilitó la verticalización de la construcción a mayor altura, hasta la masificación del automóvil, que sigue teniendo efectos en las decisiones de inversión en infraestructura, tanto para fomentar su uso como —en ciudades innovadoras como Helsinki o Seúl— para reducirlo. La digitalización ha transformado los modos de producción, consumo y movilidad y ha generado oportunidades para el aprovechamiento más eficiente de los recursos en las ciudades, incluida la reducción de los tiempos de viaje urbanos. La digitalización es una oportunidad para vincular los retos de la transformación de la estructura productiva y de la sostenibilidad urbana.

A menudo, para referirse a la integración de las tecnologías digitales en la gestión urbana se utiliza el término "ciudades inteligentes". La definición de este concepto y los tipos de gestión urbana y modelos de

23 Las virtudes iniciales de algunos de estos sistemas de transporte masivo se han visto menoscabadas por el aumento de la motorización privada y el hecho de que algunas administraciones urbanas, con visiones cortoplacistas, han escatimado en inversión destinada a la expansión y modernización de los sistemas.

24 También se prioriza cada vez más la inversión en medios de transporte como los teleféricos o la infraestructura para la circulación de bicicletas, y la elaboración de la normativa correspondiente (CAF, 2016), y existe un amplio margen para mejorar la formulación de políticas y aumentar la inversión en ciclovías y en su articulación multimodal.

25 La República de Corea, durante la aplicación de su política de crecimiento verde, decidió fabricar celdas solares transparentes para su uso en ventanas y generadores de energía. Tesla ha avanzado en la misma dirección con la fabricación de techos para la generación fotovoltaica y baterías de escala doméstica, que podrían desplazar el liderazgo de Alemania en la instalación de paneles solares en edificaciones. 
gobernanza que supone son objeto de mucho debate ${ }^{26}$. Sin embargo, en el uso de este término se incorpora cada vez más la dimensión de utilización de las tecnologías digitales no solo en ámbitos materiales, como la construcción, las redes de energía, la gestión del agua, el manejo de los residuos, la movilidad y la logística, sino también en su integración con los problemas humanos, sociales, culturales y económicos de las ciudades (Hollands, 2015). Por el mismo motivo, el impacto de las tecnologías digitales depende de la calidad de la política, la gobernanza y la gestión urbana y de los objetivos que estas priorizan. El reto es integrar las soluciones tecnológicas en el funcionamiento de las ciudades, desde la infraestructura hasta los procesos participativos, y aprovechar las oportunidades para fomentar cambios productivos.

Como instrumento estratégico de innovación para promover la descarbonización, destacan las redes eléctricas inteligentes (smart grids), es decir, la integración de las redes de energía eléctrica mediante tecnologías digitales. Algunos elementos que constituyen estas redes son los medidores inteligentes, las aplicaciones móviles, las redes de flujos bidireccionales de energía, los sistemas de eficiencia energética y la disponibilidad de información sobre el uso de la energía, su precio y formas de optimizar el consumo. Ofrecen la posibilidad de crear redes de energía distribuida, en las que los consumidores pueden convertirse en "prosumidores", es decir, en usuarios que poseen pequeñas unidades de generación eléctrica —-potencialmente vinculadas a energías renovables no convencionales, como la eólica y la solar- y son, al mismo tiempo, consumidores y productores de energía, mediante el autoconsumo o alimentando a la red con el excedente de la energía que producen. La generación distribuida es la forma en que las tecnologías desarrolladas por las redes eléctricas inteligentes podrían tener mayor impacto en la potencia, la estabilidad y la eficiencia energéticas, así como en la eficiencia y el bienestar económicos (Bonetto y Rossi, 2017).

Además de las innovaciones en infraestructura, el aumento del acceso a Internet y el uso de dispositivos móviles inteligentes también generan oportunidades para facilitar los procesos deliberativos o democráticos. Ejemplos de ello son la votación virtual en proyectos financiados por los municipios o la participación en la formulación de los planes reguladores urbanos ${ }^{27}$. Además, los ciudadanos pueden proporcionar información sobre la calidad de la infraestructura y los servicios, la seguridad o las emergencias, entre otros aspectos de la vida urbana. Estas herramientas son especialmente útiles en contextos sobre los que no siempre hay información oficial, como los asentamientos informales.

Asimismo, la generación de grandes cantidades de datos a partir de las actividades de los usuarios ofrece tanto a las personas como a las empresas la posibilidad de proponer soluciones creativas para mejorar aspectos de la vida urbana, mediante el desarrollo de empresas de base tecnológica y basadas en el conocimiento (Perera y otros, 2013) 28 .

A través de la política pública es posible fomentar la aplicación de soluciones digitales para promover la sostenibilidad urbana e impulsar oportunidades de desarrollo productivo, y los gobiernos locales cuentan con un amplio margen de maniobra en este sentido. De hecho, un número cada vez más elevado de ciudades en la región comienza a involucrarse en mayor medida en el diseño y la ejecución de políticas locales para fomentar la innovación $(\mathrm{OCDE}, 2015)^{29}$. Para ello, es importante consolidar un sistema de instituciones educativas, de capacitación y de investigación.

Las alianzas público-privadas pueden promover un mejor aprovechamiento de las tecnologías digitales. Muchos gobiernos locales realizan esfuerzos para fortalecer la intermediación laboral, crear empleos e impulsar

26 La conceptualización de la ciudad inteligente, promovida principalmente por empresas de telecomunicaciones, se caracteriza por la utilización cada vez mayor de dispositivos conectados a Internet y entre sí, y la capacidad de recopilar grandes cantidades de información sobre el funcionamiento urbano para gestionar la ciudad de manera centralizada y eficiente (Greenfield, 2013). En esta formulación, se concibe la gestión urbana como un proceso apolítico, neutro y técnico. La experiencia, sin embargo, sugiere que la gestión digitalizada puede reforzar el control de ciertos grupos de interés, bajo el pretexto de esta supuesta neutralidad (Paschoal y Wegrich, 2017). Esta visión de arriba abajo supone que existe la posibilidad de ejercer un control centralizado de la gestión de las ciudades, lo que contrasta con el entendimiento de la ciudad como un sistema conformado por la interacción y los conflictos entre sus ciudadanos, es decir, un espacio fundamentalmente político y complejo, de donde provendría el potencial innovador y creativo que ha demostrado tener a lo largo de la historia.

27 Fue el caso del plan regulador estratégico de São Paulo, aprobado en 2014.

28 Patiño (2014) analiza casos de relación virtuosa entre datos abiertos y gobiernos municipales en Montevideo, Buenos Aires y Lima.

29 Entre ellas destaca Medellín (Colombia), que, mediante su Plan Estratégico de Ciencia, Tecnología e Innovación de Medellín 2011-2021 y bajo el liderazgo de Ruta N (organismo local de innovación y negocios creado en 2009), busca usar sus recursos para fortalecer la innovación y la creación de empresas (Pineda Serna y Scheel, 2011). Estas prácticas innovadoras han obtenido reconocimiento internacional. 
la educación y la capacitación de acuerdo con la estructura productiva de su territorio. Al estar en contacto directo con las empresas del sistema productivo local, pueden aprovechar esa cercanía para fortalecer los lazos entre los agentes productivos, la sostenibilidad urbana y la diversificación productiva.

La diversificación de los sistemas productivos locales pasa por el fortalecimiento de los encadenamientos productivos entre las grandes empresas y las MIPYMES, en el interior del universo de las MIPYMES y entre estas y las instituciones del sector público o instituciones de gran arraigo en la comunidad (anchor institutions) (CLES, 2017). Las compras públicas son otro instrumento para promover la diversificación del tejido productivo local. Para ello es necesario crear y fortalecer las redes públicas y privadas de empresarios y emprendedores en la ciudad, con visiones comunes y planes de acción de mediano y largo plazo.

\section{d) Fiscalidad urbana y racionalización del uso del territorio para una inversión más sostenible}

La implementación de nuevas tecnologías no garantiza resultados más sostenibles y debe enmarcarse en los objetivos de política pública. Las ciudades presentan especificidades territoriales relacionadas con los patrones de uso del suelo, la conectividad y las desigualdades que requieren políticas específicas. La planificación urbana y el ordenamiento territorial son importantes para canalizar los beneficios del cambio tecnológico, especialmente debido al efecto considerable que tienen la configuración física y los patrones de conectividad sobre la eficiencia en el uso de los recursos y la energía (Rode y otros 2017). Como se ha señalado en el capítulo $V$, una ciudad segregada que tiende a la expansión territorial desordenada exacerba el deterioro generado por los modos de movilidad motorizados. Por este motivo, la implementación de las nuevas tecnologías debe ir acompañada de políticas urbanas y territoriales sostenibles, respaldadas por una fiscalidad urbana que priorice la disminución de las desigualdades.

Salvo algunas excepciones, en la región se aprovechan poco los instrumentos de fiscalidad urbana que, además de generar recursos, racionalizan los usos del suelo y promueven la inclusión. El impuesto a la propiedad inmobiliaria es uno de los impuestos locales más comunes en los países en desarrollo (Bahl, Linn y Wetzel, 2013). Sin embargo, representa tan solo entre un 3\% y un $4 \%$ de los ingresos fiscales locales en la mayoría de los países en desarrollo, en comparación con valores de entre el $40 \%$ y el 50\% en ciudades de Australia, el Canadá, Francia, el Reino Unido y los Estados Unidos (ONU-Hábitat, 2016). Por su parte, en América Latina el impuesto sobre la propiedad inmobiliaria solo alcanzó el 0,33\% del PIB en 2012 (De Cesare, 2016), en comparación con el 1\% en los países de la OCDE en el mismo año (Blöchliger, 2015).

Fortalecer la fiscalidad urbana, incluida la aplicación de impuestos prediales, además de una manera de aumentar los ingresos locales, es un instrumento para enfrentar la desigualdad urbana mediante la reorientación de los patrones de uso del suelo, la captación de las plusvalías de la inversión pública y la lucha contra la especulación inmobiliaria (De Cesare, 2016). Asimismo, el uso de instrumentos de política urbana fundamentados en las funciones sociales de la ciudad puede generar recursos financieros importantes y financiar inversiones en infraestructura ${ }^{30}$.

Vincular los instrumentos fiscales con la política de suelo es, además, un mecanismo para luchar contra la cultura del privilegio. La poca e irregular recaudación de impuestos sobre la propiedad urbana y la privatización de las ganancias generadas por la inversión pública en un contexto de escasa captura de plusvalías son también síntomas de la lógica de esa cultura. En las ciudades, esta lógica se evidencia en la desigualdad y la segregación y se expresa físicamente en el carácter del desarrollo urbano.

En ese universo, las tecnologías emergentes, como la tecnología de cadenas de bloques (blockchain), pueden contribuir a mejorar los catastros urbanos, cuya administración adecuada es imprescindible para aplicar políticas y fiscalidades urbanas eficaces y aumentar la transparencia en la gestión. La digitalización

30 Algunos ejemplos son los certificados de potencial adicional de construcción (CEPAC) de São Paulo o la transferencia del derecho a construir en Porto Alegre. La contribución de mejoras se utiliza en algunas ciudades colombianas, incluidas Bogotá y Barranquilla (Smolka y Furtado, 2014). 
de los catastros mediante herramientas satelitales y de georreferenciación puede formar parte de una estrategia urbana de innovación tecnológica.

La normativa nacional sobre desarrollo urbano puede contribuir de manera significativa al empoderamiento de las ciudades y otros niveles de gobierno a la hora de aplicar instrumentos de fiscalidad e inclusión. Entre las experiencias de innovación referidas a esas políticas, destacan los países que cuentan con un marco normativo avanzado en materia de desarrollo urbano ${ }^{31}$. En este sentido, la integración de objetivos compatibles con el derecho a la ciudad en un marco coherente de legislación urbana es un reto estratégico para construir ciudades sostenibles y aprovechar mejor los beneficios de las nuevas tecnologías ${ }^{32}$. Una forma de impulsar avances legislativos en la materia es articular una política nacional urbana que considere la urbanización sostenible como parte de los objetivos nacionales de desarrollo.

\section{e) Condiciones habilitantes de la sostenibilidad urbana y el cambio productivo}

Las siguientes propuestas se articulan en torno a la descarbonización de los servicios públicos masivos y la apropiación del cambio tecnológico en los territorios urbanos:

1. Mejorar radicalmente la normativa sobre el desempeño ambiental de los servicios públicos y las emisiones de los vehículos urbanos para acelerar la innovación en el sector productivo, particularmente en materia de movilidad y construcción.

2. Fortalecer las finanzas locales sobre la base de la racionalización del uso del territorio urbano para descarbonizar la actividad productiva y reducir la desigualdad.

3. Fomentar la apropiación de las tecnologías digitales para mejorar la operación urbana mediante la virtualización y la consiguiente racionalización de la demanda de viajes, el mayor y más fácil acceso a todo tipo de servicios y la optimización de los servicios públicos —incluidos registros y catastros- y las finanzas locales. La digitalización también debe fortalecer y profundizar la participación informada y oportuna en las decisiones clave para orientar el estilo del desarrollo.

4. Desarrollar políticas nacionales urbanas —uno de los objetivos de la Nueva Agenda Urbana aprobada en la Conferencia de las Naciones Unidas sobre la Vivienda y el Desarrollo Urbano Sostenible (Hábitat III), puesto que constituye una oportunidad para alcanzar el desarrollo sostenible- y articularlas con las políticas industriales y tecnológicas en los distintos niveles de gobierno.

\section{El sector energético como motor del cambio}

La experiencia internacional muestra que el gran impulso ambiental es posible. Como ejemplos de fuera de la región pueden mencionarse el desarrollo de la energía fotovoltaica en China y el de la energía eólica en Alemania. En ambos, se trata de inversiones que requirieron procesos madurativos para poder desplegar todo su potencial y transformar los patrones de producción y consumo.

La estrategia de China se estructura en planes quinquenales que prevén inversiones equivalentes al $5 \%$ del PIB en sistemas de ahorro de energía y tecnologías respetuosas con el medio ambiente, biotecnología, tecnologías de la información de nueva generación, nuevos materiales, combustibles alternativos y automóviles eléctricos. En ese marco, se han realizado cuantiosas inversiones en tecnologías solares y eólicas. Para ello, se fomentó el aporte del financiamiento necesario por parte del Banco de Desarrollo de China a las empresas

31 El Estatuto de la Ciudad, del Brasil (2001), así como la Ley de Reforma Urbana (1989) y la Ley núm. 388, sobre ordenamiento territorial (1997), de Colombia, aseguran el marco normativo para numerosas iniciativas en esos países.

32 La participación de la sociedad civil en la articulación de la legislación urbana y la insistencia en su implementación es fundamental, más aún cuando se constatan la aplicación irregular de los instrumentos y deficiencias en la recaudación, incluso en contextos en que se cuenta con normativa avanzada. 
privadas $^{33}$ y se implementaron instrumentos tarifarios y regulatorios que redujeron la incertidumbre, como la fijación de tarifas regionales más favorables para la alimentación proveniente de la energía producida por proyectos solares (Liu, 2011). Estas iniciativas ubicaron rápidamente a sus fabricantes, sobre todo de paneles, entre los actores principales del mercado mundial ${ }^{34}$.

En Alemania, el Ministerio Federal de Investigación y Tecnología puso en marcha, en 1989, un programa para desarrollar la energía eólica, a partir de la combinación de un sistema de tarifa regulada ${ }^{35}$ y un crédito fiscal del 70\% para pequeños productores. Posteriormente, en 2011, el Banco Alemán de Desarrollo (KfW) anunció que aportaría 100.000 millones de euros (de 120.000 a 130.000 millones de dólares) durante los siguientes cinco años para promover las energías renovables y contribuir a la transición que busca conseguir el cierre de todas las centrales nucleares del país hacia 2022. Los horizontes de inversión a 20 años proporcionados por los incentivos del Gobierno alemán reducen la incertidumbre y aumentan la confianza de los inversores.

En contraste con las experiencias china y alemana, en América Latina y el Caribe solo se han empezado a combinar instrumentos para promover el desarrollo de estos sectores en los últimos años. Las fuentes de energía solar y eólica apenas superan el $1 \%$ de la oferta en algunos países; una situación incongruente con el gran potencial de la región ${ }^{36}$. En particular, el uso energético de los pequeños Estados insulares del Caribe sigue dependiendo de fuentes fósiles. Entre los Estados miembros de la Comunidad del Caribe (CARICOM), Dominica cuenta con la mayor participación (28\%) de fuentes renovables en la generación de electricidad, como resultado de una estrategia para lograr la autosuficiencia energética hacia 2020. En esta subregión se reconoce la necesidad de incrementar la coordinación para formular e implementar políticas energéticas sostenibles, y la CARICOM ha llevado a cabo diversas iniciativas en años recientes, incluida la formulación de estándares de eficiencia energética y la promoción de fuentes renovables en sus Estados miembros (CEPAL, 2016d).

Se estima que la demanda primaria de energía del conjunto de América Latina y el Caribe en 2040 será al menos un $80 \%$ mayor que la actual, y más de un $91 \%$ mayor en lo que respecta a la electricidad (Balza, Espinasa y Serebrisky, 2016). Ello implica planear, construir y mantener el equivalente a 18 nuevas plantas hidroeléctricas del tamaño de la de Itaipú (la más grande de la región y la tercera mayor del mundo). Este nivel de inversión sin precedente es una oportunidad para hacer de la diversificación de la matriz energética un motor endógeno y sostenible de desarrollo de actividades y creación de empleos bajos en carbono.

En la región, el avance en materia de energía eólica y solar ha tendido a realizarse en forma de contratos llave en mano con empresas transnacionales. De esta manera, si bien se diversifica la matriz energética y se reduce el impacto ambiental de la generación de energía, no se aprovechan las oportunidades de transformación productiva, ni se incorporan nuevas capacidades y conocimientos en la economía local, salvo en casos excepcionales en los que se implementan políticas industriales (véase el recuadro VII.2).

33 Las inversiones del Banco de Desarrollo de China (CDB) fueron clave en el éxito del desarrollo de la energía solar. Entre 2007 y 2012 , este banco destinó 78.000 millones de dólares a proyectos relacionados con la energía limpia. Después de 2010, concedió 47.000 millones de dólares a unos 15 fabricantes chinos líderes en paneles fotovoltaicos (Mazzucato y Penna, 2015).

34 Los objetivos de desarrollo de la energía solar en China se integraron con los de la energía eólica. El objetivo es alcanzar los 1.000 GW de energía eólica en 2050 (Liu, 2011).

35 En los sistemas de tarifa regulada (feed-in tariff(FiT)), la administración fija las tarifas según el tipo de energía renovable.

36 Algunos países, como Chile, Costa Rica, el Ecuador, México y Nicaragua, tienen planes de energía con perspectivas de mediano plazo y mayor penetración de energías renovables, pero han descuidado su papel como motor endógeno del desarrollo sobre la base de políticas industriales. 


\section{Recuadro VII.2}

Articulación de politicas para impulsar las energías renovables en el Brasil

Para impulsar las tecnologias vinculadas a las energias renovables, el Banco de Desarrollo del Brasil (BNDES), mediante su Programa Fondo Clima, ofreció préstamos de bajo costo ( $2 \%$ anual en términos reales) y a largo plazo de hasta el $70 \%$ del capital requerido a aproximadamente la mitad de los nuevos proyectos en esa área (BNDES, 2015). Aunque en 2016 redujo su aporte al Programa de Incentivo a las Fuentes Alternativas de Energía Eléctrica (PROINFA) debido a la recesión, el BNDES asignó 1.800 millones de dólares y participó con el 80\% de la inversión en proyectos con plazos de amortización de hasta 12 años y la creación de 150.000 puestos de trabajo directos e indirectos.

La arquitectura financiera adoptada para impulsar la energía eólica formó parte de la política industrial. El PROINFA fomentó este tipo de energía a gran escala, asi como la instalación de industrias afines y la prueba de nuevas tecnologias, y le asignó precios más atractivos. Las políticas tarifaria y fiscal se articularon para estimular la expansión del sector y reducir sus costos. En 2007, se iniciaron las subastas, que fijaron cuotas de mercado para la contratación de fuentes eólicas. En 2011 y 2012, los precios de este tipo de energía rivalizaban con los de la energía hídrica, la más competitiva del país. En el ámbito de la política fiscal, para aumentar la rentabilidad de las energías renovables, se recurrió a la exoneración de tributos federales sobre los ingresos de los proyectos, la reducción del impuesto sobre circulación de mercaderías y servicios (ICMS) sobre equipos y componentes producidos en algunos estados y los descuentos en las tarifas por el uso de los sistemas de transmisión y distribución (BNDES, 2016)a

Con respecto a la utilización de la regulación estatal como palanca para la innovación y la inversión, destaca la norma del BNDES para la acreditación de aerogeneradores, que facilitó el financiamiento de proyectos y componentes de producción nacional. En 2016, los seis fabricantes acreditados (Alstom, Vestas, Wobben Windpower, WEG, Acciona y Siemens Gamesa) tenían una capacidad anual de producción de equipos de más de 2 GW (BNDES, 2016). Según la Asociación Brasileña de Energía Eólica (ABEEólica, 2017a), el 80\% de su cadena productiva era nacional y sus inversiones ascendian a 5.400 millones de dólares. Como resultado del apoyo a la producción nacional, entre 2012 y 2015, al tiempo que crecía la oferta de energía eólica, disminuían las importaciones de equipos para la generación eólica. Esto desarrolló las capacidades tecnológicas nacionales y disminuyó la presión sobre el sector externo.

Aunque la pérdida de dinamismo de la economía brasileña en los últimos años redujo la contratación de energía eólica (en 2015 y 2016 no hubo licitaciones), a febrero de 2017 se habian alcanzado los 10,8 GW de capacidad instalada en 433 parques eólicos y una participación del 7\% en la matriz eléctrica (ABEEólica, 2017b).

Fuente: Comisión Económica para América Latina y el Caribe (CEPAL), sobre la base de Banco de Desarrollo del Brasil (BNDES), "0 desenrolar da energía eólica no Brasil", Río de Janeiro, 2016 [en línea] http://www.bndes.gov.br/wps/portal/site/home/conhecimento/noticias/noticia/energia-eolica-brasil; BNDES, "Fundo Clima - energias renovaveis", Río de Janeiro, 2015 [en línea] https://www.bndes.gov.br/wps/portal/site/home/financiamento/produto/ fundo-clima-energias-renovaveis; ABEEólica (Asociación Brasileña de Energía Eólica), "Brasil sobe no ranking mundial de capacidade instalada de energia eólica", São Paulo, febrero de 2017 [en línea] http://www.abeeolica.org.br/noticias/brasil-sobe-no-ranking-mundial-de-capacidade-instaladade-energia-eolica, y ABEEólica, "Dados mensais: fevereiro de 2017", São Paulo, febrero de 2017 [en línea] http://www.abeeolica.org.br/wp-content/ uploads/2017/02/Dados-Mensais-ABEEolica-02.2017.pdf.

a No obstante, aún existen en el Brasil subsidios a los combustibles fósiles, que deberían ser eliminados como parte de la política industrial en el sector energético y sustituidos por apoyos a las poblaciones objetivo. En promedio, entre 2011 y 2013, los subsidios a los combustibles en la región representaron un 1,4\% del PIB anual, mientras que los subsidios a la electricidad representaron un 0,8\% (Di Bella y otros, 2015).

\section{a) Lineamientos estratégicos para descarbonizar la matriz eléctrica}

Para diversificar la matriz energética se requieren políticas que combinen los cambios en la normativa con el estímulo a la producción local de equipamiento y servicios necesarios para desarrollar proyectos de inversión en energías renovables y en eficiencia energética. Esto puede incluir la creación de sistemas para almacenar grandes volúmenes de energía producidos de manera intermitente por las fuentes renovables, aprovechando los abundantes recursos naturales de los que dispone la región y generando encadenamientos productivos ligados a su producción y a sus aplicaciones tecnológicas. Estos sistemas de almacenamiento pueden expandirse a embalses, vehículos y edificios, desdibujando las fronteras sectoriales.

Para impulsar la descarbonización de la matriz eléctrica (diferente de la matriz energética, que incluye el consumo de combustibles fósiles líquidos para el transporte), es decir, para aumentar la penetración 
de las energías renovables en la generación de electricidad, es importante seguir los lineamientos que se enumeran a continuación:

- Armonizar en toda la región la normativa —aplicada hasta ahora solo en la Argentina, el Brasil, Chile y México- que permita licitar por bloques horarios y, por lo tanto, no exigir el suministro de energías renovables —en particular, la solar- durante las horas de oscuridad, lo que aumentaría su rentabilidad. Dicha armonización debe ser llevada a cabo por los Ministerios de Energía, en diálogo con el sector privado.

- Sustituir las importaciones en las cadenas productivas. Hasta ahora, la penetración de las energías renovables no convencionales se ha concretado mediante proyectos llave en mano. La experiencia brasileña analizada en el recuadro VII.2 ilustra el potencial de una política industrial orientada a este objetivo. Existe un gran espacio para la innovación en energía eólica y solar, así como para otras fuentes, como la energía geotérmica, el biodiésel y la energía mareomotriz, o la provisión de autobuses para los sistemas de transporte público, ámbito en que la región tiene experiencias de fabricación nacional. En este sentido, se puede analizar la posibilidad de apoyar a empresas translatinas del sector en la transición hacia la electrificación de la flota de transporte público. La responsabilidad de impulsar estas acciones corresponde a un esfuerzo colaborativo entre los Ministerios de Energía y de Ciencia y Tecnología y las universidades y empresas.

- Incorporar gradualmente los costos sociales reales a los costos económicos, lo que implica, entre otras acciones, retirar de manera paulatina los subsidios a los combustibles fósiles, tasar las emisiones, asignar un precio al $\mathrm{CO}_{2} \mathrm{O}$, por el contrario, premiar la inversión en energías renovables. Estas acciones deben ser impulsadas por los Ministerios de Hacienda y los gobiernos locales, sobre todo si se tasan los costos sociales de los automóviles y las emisiones locales asociadas al $\mathrm{CO}_{2}$.

- Reflejar paulatinamente el riesgo sistémico de las trayectorias altas en carbono —por sus efectos físicos, tecnológicos y sobre la reputación, entre otros-, que podrían transformar activos financieros en pasivos financieros (activos irrealizables o stranded assets). Estos activos podrían sufrir una dinámica caracterizada como "burbujas climáticas." Algunos ejemplos son los procesos de exceso de inversión en zonas que se verán afectadas adversamente por el cambio climático (donde, por ejemplo, la agricultura enfrenta riesgos de sequía) o en áreas en que el progreso técnico cambiará el patrón de producción o de consumo (si, por ejemplo, los automóviles o barcos eléctricos comienzan a reemplazar a los vehículos que utilizan combustibles fósiles y, por lo tanto, estos se vuelven invendibles o impagables). El papel central en el impulso de estas políticas corresponde a los bancos centrales, el sector bancario, las aseguradoras y las compras del sector público.

- Normalizar o estandarizar el financiamiento bancario a las energías renovables mediante la armonización de riesgos y oportunidades y tasas de retorno orientadas a aplanar la curva de aprendizaje. Los bancos de desarrollo, en alianza con los bancos privados y los Ministerios de Energía, son actores clave en este ámbito.

La complementariedad entre los países de la región puede impulsar las inversiones a gran escala. Los proyectos que usan las energías eólica y solar son de escala más reducida que los proyectos hidroeléctricos ${ }^{37}$ y que los basados en energías fósiles, que suelen estar geográficamente dispersos. Por otra parte, tienen un menor impacto ambiental, se autorizan con mayor facilidad y pueden llevarse a cabo con horizontes temporales más cortos. Esto aumenta la flexibilidad para la instalación de nueva capacidad renovable y es una solución atractiva para proporcionar acceso a la electricidad a comunidades aisladas.

La complementación entre los países y dentro de estos puede generar procesos técnicos y políticos virtuosos para la integración energética regional. Esto implica evaluar las tecnologías y normativas nacionales e internacionales para impulsar un cambio sostenible en la matriz energética de los países y de la región. Los países de la región pueden aprender de las experiencias en otros sistemas, donde al proporcionar soluciones

37 En comparación con grandes proyectos hidroeléctricos como Belo Monte (11.233 MW), en el Brasil, o Pescadero-ltuango (2.400 MW), en Colombia, y proyectos potenciales como HidroAysén (2.000 MW), en Chile. 
se anticipan desafíos y se adaptan los diseños regulatorios. Por ello, desde diversos ámbitos se plantea que la energía, recurso al que se le reconocen atributos de carácter estratégico y connotaciones de índole geopolítica, es un vector del nuevo impulso ambiental en favor de la integración regional, y el soporte de un desarrollo más inclusivo y sostenible. En resumen, una vez más destaca la necesidad de avanzar en la articulación de las políticas energéticas con las políticas industriales y las tecnológicas, tres componentes necesarios para generar un gran impulso ambiental.

\section{La transparencia y la confianza en las instituciones facilitan la implementación de políticas para promover el gran impulso ambiental}

Los cambios en las políticas públicas para promover el gran impulso ambiental necesitan de una base de apoyo y de legitimidad ciudadana. La transparencia, la rendición de cuentas, la evaluación del impacto de las políticas y los programas, la participación de las personas en las decisiones y el reconocimiento de las asimetrías de información y poder son elementos clave del gran impulso ambiental. Las iniciativas en América Latina y el Caribe para mejorar el acceso a la información, la participación y el acceso a la justicia en asuntos ambientales son parte del esfuerzo por avanzar en la implementación de la Agenda 2030 y los Objetivos de Desarrollo Sostenible.

En este sentido, el gran impulso ambiental puede contribuir a ampliar el papel y el sentido de la política social, que, hasta ahora, se ha focalizado en solo dos componentes del bienestar: el ingreso de las personas y el sistema de protección social. Con ello, tiende a soslayar la importancia del consumo colectivo basado en servicios públicos, que conforma una parte del ingreso indirecto de las familias y promueve la condición de ciudadanía y el sentido de pertenencia.

Se asiste, por el contrario, a una asignación de recursos que contribuye a la degradación de los servicios públicos, de la misma manera que aumenta la degradación ambiental, a medida que se asienta el patrón de consumo marcado por las élites. Se produce así una fuga masiva desde los servicios públicos de educación y salud hacia los privados. Este proceso se reproduce también en el abandono masivo del transporte público — dado que la baja calidad del servicio y la poca seguridad estimulan la movilidad en medios privados-, la sustitución del espacio público por los centros comerciales, el crecimiento de los servicios privados de seguridad, los barrios autosegregados e incluso la discriminación en el acceso al agua potable. El efecto acumulado de estos fenómenos corroe el sentido de pertenencia a una comunidad política y la igualación ciudadana en la esfera pública.

En suma, la provisión de servicios públicos de calidad, con normas de operación que atraigan a los sectores de mayores recursos y no discriminen a los más pobres, es clave para la reconstrucción de la convivencia ciudadana y la confianza democrática, la inclusión y el tránsito hacia un modelo de desarrollo con menor huella ambiental y mayor bienestar. Un país desarrollado es aquel en que los ricos utilizan el transporte público, se educan en escuelas públicas y beben agua del grifo, y donde las brechas sociales entre estos y los grupos de bajos ingresos no son abismales. La defensa del consumo colectivo sitúa el enfoque de derechos en el centro del debate acerca de los nuevos regímenes de bienestar y es parte esencial del gran impulso ambiental.

\section{E. A modo de cierre}

La calidad de la democracia depende tanto de las instituciones que promueven la igualdad de derechos como de los modos de convivencia que expresan el sentido de pertenencia a una sociedad. Las alternativas tecnológicas con menor huella de carbono y el cambio en la matriz energética deben procurar, al mismo tiempo, el fortalecimiento de esa pertenencia colectiva. De ahí la importancia de estrategias y políticas que 
permitan la transición hacia formas más sostenibles de producir, habitar y consumir y que, al mismo tiempo, potencien la provisión de bienes y servicios públicos de mejor calidad. De este modo, será posible transitar hacia un nuevo estilo de desarrollo, con menores brechas sociales y segregaciones espaciales, y conseguir un crecimiento basado en la innovación y la difusión de tecnologías limpias.

El ritmo de innovación y difusión de la revolución digital es exponencial y penetra todos los ámbitos de la vida, y América Latina y el Caribe no puede quedarse atrás. Es el momento de aprovechar los campos de innovación tecnológica que pueden constituir herramientas para el gran impulso ambiental. Estos campos incluyen esferas tan diversas como la gestión urbana y el transporte, el manejo de la biodiversidad, la conservación, el aprovechamiento y el reciclaje del agua, la calidad y oportunidad de los sistemas de protección social, la formación en capacidades estratégicas de las nuevas generaciones para el nuevo mundo del trabajo, el desarrollo de los biomateriales y la producción de energías renovables.

En este sentido, el gran impulso ambiental relaciona las opciones macroeconómicas, productivas, sociales y ambientales. Dada esta interdependencia, la región se encuentra ante el riesgo de perpetuar un círculo vicioso en que se refuerzan recíprocamente la baja productividad, el crecimiento volátil, la alta desigualdad y un grave costo ambiental, o bien, ante la oportunidad de avanzar hacia un círculo virtuoso con sinergias entre una macroeconomía proactiva, una matriz productiva y energética baja en carbono y una mejor calidad de vida.

En este documento, la CEPAL ha buscado dimensionar tanto la magnitud como la urgencia del desafío del gran impulso ambiental. Su magnitud se pone de manifiesto al reconocer la creciente interdependencia de los ámbitos del desarrollo. Su urgencia está dada por la espada de Damocles que supone el cambio climático y las oportunidades y riesgos derivados de la velocidad del cambio tecnológico. No se trata de postergar la hora de la igualdad, sino de reconocer la eficiencia del incremento de la igualdad para lograr un crecimiento más sólido, con mejor base productiva y que asegure un futuro sostenible para las generaciones venideras.

\section{Bibliografía}

ABEEólica (Asociación Brasileña de Energía Eólica) (2017a), "Brasil sobe no ranking mundial de capacidade instalada de energia eólica", São Paulo, febrero [en línea] http://www.abeeolica.org.br/noticias/brasil-sobe-no-ranking-mundial-decapacidade-instalada-de-energia-eolica/ [fecha de consulta: marzo de 2017].

(2017b) "Dados mensais: fevereiro de 2017", São Paulo, febrero [en línea] http://www.abeeolica.org.br/wp-content/ uploads/2017/02/Dados-Mensais-ABEEolica-02.2017.pdf.

Bahl, R., J. Linn y D. Wetzel (eds.) (2013), Financial Metropolitan Governments in Developing Countries, Cambridge, Lincoln Institute of Land Policy.

Balza, L., R. Espinasa y T. Serebrisky (2016), ¿Luces encendidas?: necesidades de energía para América Latina y el Caribe al 2040, Washington, D.C., Banco Interamericano de Desarrollo (BID).

Blanchard, O. y otros (2016), Progress and Confusion: The State of Macroeconomic Policy, Cambridge, MIT Press.

Blöchliger, H. (2015), "Reforming the tax on immovable property: taking care of the unloved," OECD Economics Department Working Papers, № 1205, OECD Publishing, París, abril [en línea] http://dx.doi.org/10.1787/5js30tw0n7kg-en.

BNDES (Banco de Desarrollo del Brasil) (2016), "O desenrolar da energía eólica no Brasil", Río de Janeiro [en línea] http:// www.bndes.gov.br/wps/portal/site/home/conhecimento/noticias/noticia/energia-eolica-brasil.

(2015), "Fundo Clima - energias renovaveis," Río de Janeiro [en línea] https://www.bndes.gov.br/wps/portal/site/home/ financiamento/produto/fundo-clima-energias-renovaveis.

Bonetto, R. y M. Rossi (2017), "Smart grid for the smart city," Designing, Developing, and Facilitating Smart Cities, $\checkmark$. Angelakis y otros (eds.), Cham, Springer.

CAF (Banco de Desarrollo de América Latina) (2016), Observatorio de Movilidad Urbana: informe 2015-2016, Caracas.

Cecchini, S. y B. Atuesta (2017), "Programas de transferencias condicionadas en América Latina y el Caribe: tendencias de cobertura e inversión", serie Políticas Sociales, № 224 (LC/TS.2017/40), Santiago, Comisión Económica para América Latina y el Caribe (CEPAL).

CEPAL (Comisión Económica para América Latina y el Caribe) (2017a), Financiamiento de la Agenda 2030 para el Desarrollo Sostenible en América Latina y el Caribe: desafíos para la movilización de recursos (LC/FDS.1/4), Santiago. (2017b), Brechas, ejes y desafíos en el vínculo entre lo social y lo productivo (LC/CDS.2/3), Santiago.

(2017c), Panorama Social de América Latina, 2016 (LC/PUB.2017/12-P), Santiago. 
(2016a), Horizontes 2030: la igualdad en el centro del desarrollo sostenible (LC/G.2660/Rev.1), Santiago.

(2016b), La matriz de desigualdad social en América Latina (LC/G.2690(MDS.1/2)), Santiago.

(2016c), La nueva revolución digital: de la Internet del consumo a la Internet de la producción (LC/L.4029/Rev.1), Santiago.

(2016d), Report of the Regional Dialogue and Training Workshop on Energy Efficiency and Renewable Energy Initiatives in the Caribbean (LC/CAR/L.505), Puerto España, sede subregional de la CEPAL para el Caribe, 15 de septiembre.

(2014), Pactos para la igualdad: hacia un futuro sostenible (LC/G.2586 (SES.35/3)), Santiago.

(2010), La hora de la igualdad: brechas por cerrar, caminos por abrir (LC/G.2432(SES.33/3)), Santiago.

CEPAL/ONU-Hábitat/MINURVI (Comisión Económica para América Latina y el Caribe/Programa de las Naciones Unidas para los Asentamientos Humanos/Asamblea General de Ministros y Autoridades Máximas de la Vivienda y el Urbanismo de América Latina y el Caribe) (2018), Plan de Acción Regional para la Implementación de la Nueva Agenda Urbana en América Latina y el Caribe, 2016-2036 (LC/TS.2017/77/Rev.2), Santiago, febrero.

CETESB (Compañía Ambiental del Estado de São Paulo) (2014), Plano de Controle de Poluição Veicular 2014-2016, São Paulo [en línea] http://cetesb.sp.gov.br/wp-content/uploads/2014/12/pcpv-2014.pdf.

Cimoli, M. y otros (eds.) (2017), Políticas industriales y tecnológicas en América Latina (LC/TS.2017/91), Santiago, Comisión Económica para América Latina y el Caribe (CEPAL).

CLES (Centre for Local Economic Strategies) (2017), Community Wealth Building through Anchor Institutions, Manchester, febrero.

De Cesare, C. M. (ed.) (2016), Sistemas del impuesto predial en América Latina y el Caribe, Cambridge, Lincoln Institute of Land Policy.

Di Bella, G. y otros (2015), "Energy subsidies in Latin America and the Caribbean: stocktaking and policy challenges", IMF Working Paper, NoWP/15/30, Washington, D.C., Fondo Monetario Internacional (FMI), febrero.

Dølvik, J. E. y otros (2015), The Nordic Model Towards 2030: A New Chapter?, Instituto de Estudios Internacionales Aplicados (FAFO) [en línea] http://www.fafo.no/images/pub/2015/20412.pdf.

Eichengreen, B. y P. Gupta (2015), "Tapering talk: the impact of expectations of reduced Federal Reserve security purchases on emerging markets", Emerging Markets Review, vol. 25.

Filgueira, F. (2015), "Modelos de desarrollo, matriz del Estado social y herramientas de las políticas sociales latinoamericanas", Instrumentos de protección social: caminos latinoamericanos hacia la universalización, Libros de la CEPAL, № 136 (LC/G.2644-P), S. Cecchini y otros (eds.), Santiago, Comisión Económica para América Latina y el Caribe (CEPAL).

Filgueira F. y E. Espíndola (2015), "Hacia un sistema de transferencias monetarias para la infancia y los adultos mayores: una estimación de impactos y posibilidades fiscales en América Latina", serie Políticas Sociales, № 216 (LC/L.3934), Santiago, Comisión Económica para América Latina y el Caribe (CEPAL).

Florida, R. (2017), The New Urban Crisis: How our Cities are Increasing Inequality, Deepening Segregation, and Failing the Middle Class-and What we Can do About it, Nueva York, Basic Books. Freeman, C. (2008), Systems of Innovation: Selected Essays in Evolutionary Economics, Cheltenham, Edward Elgar Publishing.

Furche, P. y otros (2017), "Fintech y el futuro de la banca central", Documentos de Política Económica, № 63, Santiago, Banco Central de Chile, agosto.

Greenfield, A. (2013), Against the Smart City, Nueva York, Do Projects.

Hanni, M., R. Martner, y A. Podestá (2015), "El potencial redistributivo de la fiscalidad en América Latina", Revista CEPAL, № 116 (LC/G.2643-P), Santiago, Comisión Económica para América Latina y el Caribe (CEPAL).

Harris, J. M. (2008), “Ecological macroeconomics: consumption, investment, and climate change," Working Paper, № 08-02, Medford, Global Development and Environment Institute, Tufts University.

Heckman, J. (2013), Giving Kids a Fair Chance, Cambridge, MIT Press.

Hollands, R. (2015), "Critical interventions into the corporate smart city", Cambridge Journal of Regions, Economy and Society, vol. 8, № 1, marzo.

IFC (Irving Fisher Committee on Central Bank Statistics) (2016), IFC Report. Measures of Financial Inclusion: A Central Bank Perspective, Banco de Pagos Internacionales (BPI), junio.

Innerarity, D. (2011), La democracia del conocimiento: por una sociedad inteligente, Barcelona, Paidós.

IRENA (Agencia Internacional de Energías Renovables) (2017), Renewable Energy Auctions: Analysing 2016, Abu Dhabi. (2016b), Renewable Energy Market Analysis: Latin America, Abu Dhabi.

Jacobs, J. (1986), Las ciudades y la riqueza de las naciones: principios de la vida económica, Barcelona, Editorial Ariel.

Jordán, R., L. Riffo y A. Prado (coords.) (2017), Desarrollo sostenible, urbanización y desigualdad en América Latina y el Caribe: dinámicas y desafíos para el cambio estructural (LC/PUB.2017/19), Santiago, Comisión Económica para América Latina y el Caribe (CEPAL), septiembre.

Lavarello, P. (2017), “¿De qué hablamos cuando hablamos de política industrial?", Manufactura y cambio estructural: aportes para pensar la política industrial en la Argentina, Libros de la CEPAL, No 149 (LC/PUB.2017/21-P), M. Abeles, M. Cimoli y P. Lavarello (eds.), Santiago, Comisión Económica para América Latina y el Caribe (CEPAL). 
Liu, C. (2011), "China uses feed-in tariff to build domestic solar market," New York Times, 14 de septiembre [en línea] http:// www.nytimes.com/cwire/2011/09/14/14climatewire-china-uses-feed-in-tariff-to-build-domestic-25559.html?pagewanted=all [fecha de consulta] 24 de junio de 2014.

Marcel, M. (2017), “Inclusión financiera, innovación tecnológica y estabilidad macroeconómica”, documento presentado en la Tercera Conferencia sobre Desarrollo, Estabilidad y Sustentabilidad de la Banca, Santiago, 3 de noviembre [en línea] http:// www.bcentral.cl/web/guest/consejeros?p_p_id=cl_bancocentral_buscador_anual_portlet_BuscadorFiltroAnualMVCPortlet_ INSTANCE_uyttqsfK65KE\&p_p_lifecycle=0\&p_p_state=normal\&p_p_mode=view\&_cl_bancocentral_buscador_anual_ portlet_BuscadorFiltroAnualMVCPortlet_INSTANCE_uyttqsfK65KE_anio=2017.

Marcus, G. (2016), "Remarks on the future of monetary policy", Progress and Confusion: The State of Macroeconomic Policy, O. Blanchard y otros (eds.), Cambridge, MIT Press.

Mazzucato, M. (2015), “The green entrepreneurial State", SPRU Working Paper series, N²015-28, Universidad de Sussex, octubre [en línea] www.sussex.ac.uk/spru/swps2015-28.

(2011), "The entrepreneurial State", Soundings, № 49, Londres, Lawrence and Wishart.

Mazzucato, M. y C. Penna (2015), “The rise of mission-oriented state investment banks: the cases of Germany's KfW and Brazil's BNDES", SPRU Working Paper series, N 2015-26, Universidad de Sussex, septiembre [en línea] http://www. sussex.ac.uk/spru/swps2015-26.

Mazzucato, M. y C. Pérez (2014), “Innovation as growth policy: the challenge for Europe”, SPRU Working Paper series, NN2014-13, Universidad de Sussex, julio [en línea] https://www.sussex.ac.uk/webteam/gateway/file.php?name=201413-swps-mazzucato-perez.pdf\&site=25.

Mercadante, A. (2017), "Educación y capacitación técnico-profesional en Brasil", inédito.

Moene, K. O. y M. Wallerstein (2006), "The Scandinavian model and economic development", Development Outreach, vol. 8, No 1, Instituto del Banco Mundial, febrero [en línea] http://documents.worldbank.org/curated/en/404591468165872122/ pdf/372500NEWSOREP10Box311126B01PUBLIC1.pdf.

Mora, L., R. Bolici y M. Deakin (2017), "The first two decades of smart-city research: a bibliometric analysis", Journal of Urban Technology, vol. 24, No 1.

Morin, E. (1992), El método 2: la vida de la vida, Madrid, Editorial Cátedra.

Naciones Unidas (2017), “Resolución aprobada por la Asamblea General el 23 de diciembre de 2016: 71/256. Nueva Agenda Urbana" (A/RES/71/256).

(2015), "Battle for sustainable development will be won or lost in cities, Deputy Secretary-General tells Mayor's Forum", 9 de junio [en línea] https://www.un.org/press/en/2015/dsgsm874.doc.htm.

(2013), A New Global Partnership: Eradicate Poverty and Transform Economies through Sustainable Development, Nueva York.

(2012), "'Our struggle for global sustainability will be won or lost in cities,' says Secretary-General, at New York event", 23 de abril [en línea] https://www.un.org/press/en/2012/sgsm14249.doc.htm.

OCDE (Organización de Cooperación y Desarrollo Económicos) (2016), Innovating Education and Educating for Innovation: The Power of Digital Technologies and Skills, París, OECD Publishing.

(2015), Promoviendo el desarrollo de sistemas locales de innovación: el caso de Medellín, Colombia, OECD Publishing, abril.

ONU-Hábitat (Programa de las Naciones Unidas para los Asentamientos Humanos) (2016), World Cities Report 2016. Urbanization and Development: Emerging Futures, Nairobi.

Paschoal, B. y K. Wegrich (2017), “Urban governance innovations in Rio de Janeiro: the political management of digital innovations", Journal of Urban Affairs http://dx.doi.org/10.1080/07352166.2017.1310561.

Patiño, J. A. (comp.) (2014). "Datos abiertos y ciudades inteligentes en América Latina: estudio de casos", Documentos de Proyectos (LCM.621), Santiago, Comisión Económica para América Latina y el Caribe, septiembre.

Patton, D. (2012), "Further huge boost to solar target "not on China's agenda"', Recharge News, 12 de septiembre [en línea] www.rechargenews.com/news/policy_market/article1298370.ece [fecha de consulta] 24 de junio de 2014.

Perera, C. y otros (2013), "Sensing as a service model for smart cities supported by Internet of Things", Transactions on Emerging Telecommunications Technologies, vol. 25, No 1.

Pérez Caldentey, E. (2017), "Quantitative easing (QE), changes in global liquidity, and financial instability", International Journal of Political Economy, vol. 46, N²-3.

Pineda Serna, L. y C. Scheel (2011), “Plan Estratégico de Ciencia, Tecnología e Innovación de Medellín 2011-2021", Medellín, Corporación Ruta N [en línea] https://www.rutanmedellin.org/images/programas/plan_cti/Documentos/Plan-de-CTi-deMedellin.pdf.

Polanyi, M. (1966), The Tacit Dimension, Londres, Routledge.

Pollin, R. (2012), Back to Full Employment, Cambridge, MIT Press. 
REN21 (Red de Políticas de Energía Renovable para el siglo XXI) (2016), Renewables 2016: Global Status Report, París [en línea] http://www.ren21.net/wp-content/uploads/2016/05/GSR_2016_Full_Report_lowres.pdf.

Rico, M. N. (2017), "Presentación del informe "Género en el sistema financiero," SBIF. Chile. CEPAL, 10 de julio de 2017" [en línea] http://www.cepal.org/sites/default/files/news/files/inclusion_financiera_para_las_mujeres.pdf.

Rode, P. y otros (2017), Resource Urbanisms: Asia's Divergent City Models of Kuwait, Abu Dhabi, Singapore and Hong Kong, Londres, LSE Cities, Escuela de Economía y Ciencias Políticas de Londres.

Rofman, R., V. Amarante e I. Apella (eds.) (2016), Cambio demográfico y desafíos económicos y sociales en el Uruguay del siglo XXI (LC/L.4121), Santiago, Comisión Económica para América Latina y el Caribe (CEPAL)/Banco Mundial.

Rosenstein-Rodan, P. (1960), “Notas sobre la teoría del 'gran impulso'," El desarrollo económico y América Latina, H. S. Ellis y H. C. Wallich (eds.), Ciudad de México, Fondo de Cultura Económica.

Sepúlveda, L. (2017), “La educación técnico-profesional en América Latina: retos y oportunidades para la igualdad de género", serie Asuntos de Género, N 144 (LC/TS.2017/13), Santiago, Comisión Económica para América Latina y el Caribe (CEPAL).

Sevilla, M. P. (2017), “Panorama de la educación técnica profesional en América Latina y el Caribe”, serie Políticas Sociales, Nº 222 (LC/L.4287), Santiago, Comisión Económica para América Latina y el Caribe (CEPAL).

Shin, H. S. (2016), "Global liquidity and procyclicality", ponencia realizada en la conferencia "The state of economics, the state of the world", Washington, D.C., Banco Mundial, 8 y 9 de junio.

Smolka, M. O. y F. Furtado (eds.) (2014), Instrumentos notables de políticas de suelo en América Latina, Cambridge, Lincoln Institute of Land Policy.

Summers, L. (2016), "Rethinking secular stagnation after seventeen months", Progress and Confusion: The State of Macroeconomic Policy, O. Blanchard y otros (eds.), Cambridge, MIT Press.

Sunkel, O. (2006), “En busca del desarrollo perdido", Problemas del Desarrollo, vol. 37, N 147, octubre-diciembre.

Ter-Minassian, T. (2016), Fiscal and Financial Issues for 21st Century Cities: Background and Overview, Brookings Institution, abril.

The New York Times (2017), "G.M. and Ford lay out plans to expand electric models", 2 de octubre [en línea] https://www. nytimes.com/2017/10/02/business/general-motors-electric-cars.html.

Tiebout, C. M. (1956), "A pure theory of local expenditures", The Journal of Political Economy, vol. 64, N 5, octubre.

Toynbee, A. (1971), Ciudades en marcha, Madrid, Alianza/Emecé.

Trajtenberg, L., S. Valdecantos y D. Vega (2015), “Los determinantes de la inflación en América Latina: un estudio empírico del período 1990-2013", Estructura productiva y política macroeconómica: enfoques heterodoxos desde América Latina, Libros de la CEPAL, No 138 (LC/G.2653-P), A. Bárcena, A. Prado y M. Abeles (eds.), Santiago, Comisión Económica para América Latina y el Caribe (CEPAL).

Van Parijs, P. eY. Vanderborght (2017), Basic Income: A Radical Proposal for a Free Society and a Sane Economy, Cambridge, Harvard University Press.

Vartiainen, J. (2014), To Create and Share - The Remarkable Success and Contested Future of the Nordic Social-Democratic Model, Instituto de Estudios Internacionales Aplicados (FAFO) [en línea] http://www.fafo.no/images/pub/2014/20372.pdf. 


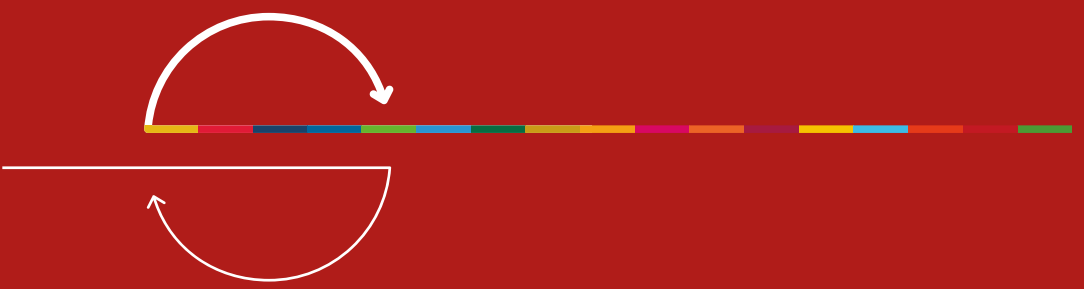

La desigualdad es ineficiente porque dificulta el aprendizaje, el aumento de la productividad, la innovación y el crecimiento. La igualdad no es entonces solo un principio ético inherente al desarrollo, sino también un instrumento clave para promoverlo.

Dando continuidad al énfasis que la Comisión Económica para América Latina y el Caribe (CEPAL) ha puesto en la igualdad desde 2010, y en concordancia con el propósito de no dejar a nadie atrás expresado en la Agenda 2030 para el Desarrollo Sostenible, en este documento se analizan mecanismos mediante los cuales la desigualdad reduce la eficiencia dinámica de las economías de América Latina y el Caribe. Se analizan y miden los efectos de la desigualdad de acceso a la salud y a la educación en la productividad y los ingresos, asi como las consecuencias de la desigualdad de oportunidades causada por la discriminación por razón de género o condición étnico-racial. También se examina cómo estas desigualdades se reflejan en el territorio, la infraestructura y la dinámica urbana, generando costos no solo en términos de productividad, sino también de ineficiencia energética y deterioro del medio ambiente, lo que compromete las posibilidades de desarrollo de las generaciones presentes y futuras.

Las restricciones impuestas por la desigualdad a la innovación y la creatividad son más intensas porque se internalizan en la cultura de los agentes, dando lugar a una cultura del privilegio en la que los muchos bienes públicos y derechos no son impersonales y parte importante de la población no accede a ellos. Esto debilita la confianza en las interacciones sociales y en las instituciones democráticas.

La CEPAL propone en este documento orientaciones estratégicas para aumentar la eficiencia dinámica de las economías latinoamericanas y caribeñas sobre la base de la igualdad. El desarrollo de capacidades y la construcción de Estados de bienestar son componentes centrales de un nuevo paradigma de desarrollo en el que la revolución tecnológica se ponga al servicio de un sendero de crecimiento bajo en carbono e intensivo en tecnología. En este contexto, aumentar la inversión pública y privada en torno a un gran impulso ambiental, mediante el que se diversifique la estructura productiva y se reduzca la heterogeneidad estructural, es una tarea urgente ante la velocidad los cambios que transforman la economía global y el aumento de la incertidumbre que los acompaña.

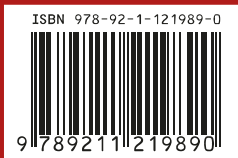

